\title{
Information Needs for
}

Characterization of High-Level

Waste Repository Sites in

Six Geologic Media

NUREG/CR--2663-Vol.I

Main Report

TI85 901691

Manuscript Completed: November 1981

Date Published: May 1985

Ertec Western, Inc.

3777. Long Beach Boulevard

Long Beach, CA 90807

\section{Prepared for}

Division of Health, Siting and Waste Management

Office of Nuclear Regulatory Research

U.S. Nuclear Regulatory Commission

Washington, D.C. 20555

NRC FIN B1019 


\section{DISCLAIMER}

This report was prepared as an account of work sponsored by an agency of the United States Government. Neither the United States Government nor any agency thereof, nor any of their employees, make any warranty, express or implied, or assumes any legal liability or responsibility for the accuracy, completeness, or usefulness of any information, apparatus, product, or process disclosed, or represents that its use would not infringe privately owned rights. Reference herein to any specific commercial product, process, or service by trade name, trademark, manufacturer, or otherwise does not necessarily constitute or imply its endorsement, recommendation, or favoring by the United States Government or any agency thereof. The views and opinions of authors expressed herein do not necessarily state or reflect those of the United States Government or any agency thereof. 


\section{DISCLAIMER}

Portions of this document may be illegible in electronic image products. Images are produced from the best available original document. 


\section{NOTICE}

This report was prepared as an account of work sponsored by an agency of the United States Government. Neither the United States Government nor any agency thereof. or any of their employees, makes any warranty, expressed or implied, or assumes any legal liability of responsibility for any third party's use, or the results of such use, of any information, apparatus, product or process disclosed in this report, or represents that its use by such third party would not infringe privately owned rights.

The views expressed in this report are not necessarily those of the U.S. Nuclear Regulatory Comission.

\section{NOTICE}

\section{Availability of Reference Materials Cited in NRC Publications}

Most documents cited in NRC publications will be available from one of the following sources:

1. The NRC Public Document Room, 1717 H Street, N.W. Washington, DC 20555

2. The Superintendent of Documents, U.S. Government Printing Office, Post Office Box 37082 , Washington, DC 20013-7982

3. The National Technical Information Service, Springfield, VA 22161

Although the listing that follows represents the majority of documents cited in NRC publications, it is not intended to be exhaustive.

Referenced documents available for inspection and copying for a fee from the NRC Public Document Room include NRC correspondence and internal NRC memoranda; NRC Office of Inspection and Enforcement bulletins, circulars, information notices, inspection and investigation notices; Licensee Event Reports; vendor reports and correspondence; Commission papers; and applicant and licensee documents and correspondence.

The following documents in the NUREG series are available for purchase from the NRC/GPO Sales Program: formal NRC staff and contractor reports, NRC-sponsored conference proceedings, and NRC booklets and brochures. Also available are Regulatory Guides, NRC regulations in the Code of Federal Regulations, and Nuclear Regulatory Commission Issuances.

Documents available from the National Technical Information Service include NUREG series reports and technical reports prepared by other federal agencies and reports prepared by the Atomic Energy Commission, forerunner agency to the Nuclear Regulatory Commission.

Documents available from public and special technical libraries include all open literature items, such as books, journal and periodical articles, and transactions. Federal Register notices, federal and state legislation, and congressional reports can usually be obtained from these libraries.

Documents such as theses, dissertations, foreign reports and translations, and non-NRC conference proceedings are available for purchase from the organization sponsoring the publication cited.

Single copies of NRC draft reports are available free, to the extent of supply, upon written request to the Division of Technical Information and Document Control, U.S. Nuclear Regulatory Commission, Washington, DC 20555.

Copies of industry codes and standards used in a substantive manner in the NRC regulatory process are maintained at the NRC Library, 7920 Norfolk Avenue, Bethesda, Maryland, and are available there for reference use by the public. Codes and standards are usually copyrighted and may be purchased from the originating organization or, if they are American National Standards, from the American National Standards Institute, 1430 Broadway, New York, NY 10018. 
Evaluation of the geologic isolation of radioactive materials from the biosphere requires an intimate knowledge of site geologic conditions, which is gained through precharacterization and site characterization studies. This report presents the results of an intensive literature review, analysis and compilation to delineate the information needs, applicable techniques and evaluation criteria for programs to adequately characterize a site, in six geologic media. These media, in order of presentation, are: granite, shale, basalt, tuff, bedded salt and dome salt.

Guidelines are presented to assess the efficacy (application, effectiveness, and resolution) of currently used exploratory and testing techniques for precharacterization or characterization of a site. These guidelines include the reliability, accuracy and resolution of techniques deemed acceptable, as well as cost estimates of various field and laboratory techniques used to obtain the necessary information. Guidelines presented do not assess the relative suitability of media. 
TABLE OF CONTENTS

Page

1.0 INTRODUCTION $. . \cdot \cdot \cdot \cdot \cdot \cdot \cdot \cdot \cdot \cdot \cdot \cdot \cdot \cdot \cdot \cdot \cdot \cdot \cdot \cdot \cdot . \cdot . \quad 1-1$

2.0 GRANITE . . . . . . . . . . . . . . . . . . . . . . 2-1

2.1 Previous Work in Granite . . . . . . . . . . 2-1

2.2 Precharacterization studies. . . . . . . . . 2-2

2.2.1 Geology of Granitic Rocks . . . . . . 2-2

2.2.2 Information Needs for Precharacterization

Studies in Granite. . . . . . . . . . 2-13

2.2.3 Technique Applications to Precharacterization Information Needs in Granite. . . . 2-16

2.2.4 Cost and Time Estimates for Precharaçterization Techniques. . . . . . . . . 2-29

2.2.5 Criteria for Evaluating Data Adequacy of Precharacterization Studies in Granite. - . 2-34

2.3 Site Characterization Studies 2-49

2.3.1 Geologic Features of Granite Important for Site Characterization . . . . . . 2-49

2.3.2 Information Needs for site Characterization Studies in Granite . . . . . . . 2-50

2.3.3. Technique Applications to Site Characterization Information Needs in Granite . . . 2-61

2.3.4 Cost and Time Estimates for Site Characterization Techniques . . . . . . 2-68

2.3.5 Criteria for Evaluating Data Adequacy of site Characterization studies in Granite .. . . . . . . . . . . 2-75

2.4 References . . . . . . . . . . . . . . 2-79

3.0 SHALE . . . . . . . . . . . . . . . . . . . . . . 3-1

3.1 Previous Work in Shale . . . . . . . . . . 3-1

3.2 Precharacterization studies. . . . . . . . . 3-1 
TABLE OF CONTENTS (Continued)

Page

3.2.1 Geology of Shale . . . . . . . .

3-1

3.2.2 Information Needs for Precharacterization

3.2.3 Technique Applications to Precharacteriza-

tion Information Needs in Shale . . . . . 3-16

3.2.4 Cost and Time Estimates for Precharacter-

3.2.5 Criteria for Evaluating Data Adequacy of Precharacterization Studies in Shale .. 3-33

3.3 Site Characterization Studies. ........ 3-44

3.3.1 Geologic Features of Shale Important for Site Characterization ........ 3-44

3.3.2 Information Needs for Site Characterization Studies in Shale......... 3-45

3.3.3 Technique Applications to Site Characterization Information Needs in Shale ...............

3.3.4 Cost and Time Estimates for Site Characterization Techniques. .......... 3-61

3.3.5 Criteria for Evaluating Data Adequacy of Site Characterization Studies in shale........... 3-70

3.4 References .............. 3-73

4.0 BAsalt. . . . . . . . . . . . . . . . 4-1

4.1 Previous Work in Basalt. ............ 4-1

4.2 Precharacterization Studies. . . . . . . 4-2

4.2.1 Geology of Basalt .......... 4-2

4.2.2 Information Needs for Precharacterization Studies Needs in Basalt ........ 4-8

4.2.3 Technique Applications to Precharacterization Information Needs in Basalt. ... 4-15 
TABLE OF CONTENTS (Continued)

Page

4.2.4 Cost and Time Estimates for Precharacterization Techniques. . . . . . . . 4-25

4.2.5 Criteria for Evaluating Data Adequacy of Precharacterization Studies in Basalt . . 4-39

4.3 Site Characterization Studies. ......... 4-44

4.3.1 Geologic Features of Basalt Important for Site Characterization ......... 4-44

4.3.2 Information Needs for Site Characterization Studies in Basalt. ......... 4-47

4.3.3 Technique Applications to Site Characterization Information Needs in Basalt ............ 4-... 48

4.3.4 Cost and Time Estimates for Site Characterization Techniques. ........... 4-66

4.3.5 Criteria for Evaluating Data Adequacy of Site Characterization Studies in Basalt. .............. 4-73

4.4 References ................ 4-79

5.1 Previous Work in Tuff. ........... 5-1

5.2 Precharacterization studies. . . . . . . 5-3

5.2.1 Geology of Tuff ........... 5-3

5.2.2 Information Needs for Precharacterization Studies in Tuff ........... 5-10

5.2.3 Technique Applications to Precharacterization Information Needs in Tuff. . . . . . 5-16

5.2.4 Cost and Time Estimates for Precharacterization Techniques in Tuff. . . . . . . 5-26

5.2.5 Criteria for Evaluating Data Adequacy of Precharacterization Studies in Tuff . . . 5-39

vii 
TABLE OF CONTENTS (Continued)

$\underline{\text { Page }}$

5.3 Site Characterization Studies. . . . . . . 5-45

5.3.1 Geologic Features of Tuff Important for

Site Characterization ......... . 5-45

5.3.2 Information Needs for Site Characteriza-

tion Studies in Tuff. .......... 5-48

5.3.3 Technique Applications to Site

Characterization Information Needs

in Tuff............. 5-62

5.3.4 Cost and Time Estimates for Site Characterization Techniques. ......... 5-71

5.3.5 Criteria for Evaluating Data Adequacy

of Site Characterization Studies in

Tuff. ............. 5-78

5.4 References ............... 5-84

6.0 BEDDED SALT ..................... 6-1

6.1 Previous Work in Bedded Salt ........... 6-1

6.2 Precharacterization Studies. . . . . . . 6-1

6.2.1 Geology of Bedded Salt. . . . . . . . 6-1

6.2.2 Information Needs for Precharacterization

Studies in Bedded Salt. . . . . . . . . 6-11

6.2.3 Technique Applications to Precharacteri-

zation Information Needs in Bedded Salt . . 6-22

6.2.4 Cost and Time Estimates for Precharacterization Techniques .......... 6-35

6.2.5 Criteria for Evaluating Data Adequacy of Precharacterization Studies in Bedded Salt. 6-49

6.3 Site Characterization Studies. . . . . . 6-57

6.3.1 Geologic Features of Tuff Important for Site Characterization . . . . . . . 6-57

6.3.2 Information Needs for Site Characterization Studies in Bedded Salt . . . . . . 6-62

\section{viii}


TABLE OF CONTENTS (Continued)

Page

6.3.3 Technique Applications to Site

Characterization Information Needs

in Bedded Salt. .............

6.3.4 Cost and Time Estimates for Site Character-

ization Techniques. . . . . . . . 6-86

6.3.5 Criteria for Evaluating Data Adequacy

of Site Characterization Studies in

Bedded Salt .......... 6-95

6.4 References ............... 6-102

7.0 DOME SALT ................. $7-1$

7.1 Previous Work in Dome Salt .......... 7-1

7.2 Precharacterization Studies. . . . . . . 7-2

7.2.1 Geology of Dome Salt. . . . . . . . 7-2

7.2.2 Information Needs for Precharacterization
Studies in Dome Salt. . . . . . . . $7-16$

7.2.3 Technique Applications to Precharacteri-
zation Information Needs in Dome Salt . . 7-26

7.2.4 Cost and Time Estimates for Precharacter-
ization Techniques . . . . . . . . 7-39

7.2.5 Criteria for Evaluating Data Adequacy of
Precharacterization Studies in Dome Salt. . $7-46$

7.3 Site Characterization Studies. . . . . . 7-59

7.3.1 Geologic Features of Dome Salt Important for Site Characterization . . . . . . . 7-59

7.3.2 Information Needs for Site Characterization Studies in Dome Salt....... 7-65

7.3.3 Technique Applications to site Characterization Information Needs in Dome Salt. .......... 7-73 
TABLE OF CONTENTS (Continued)

$\underline{\text { Page }}$

7.3.4 Cost and Time Estimates for Site Characterization Techniques. . . . . . . . . 7-84

7.3.5 Criteria for Evaluating Data Adequacy of Site Characterization Studies in Dome Salt . . . . . . . . 7-89

7.4 References ................ 7-101 

Ash-Flow Tuff Cooling Unit with Typical Bulk and Grain Densities 
Table No.

$2.2 \cdot 1-1$

$2 \cdot 2 \cdot 1-2$

$2 \cdot 2 \cdot 3-1$

$2.2 .4-1$

$2.2 .4-2$

$2 \cdot 2.4-3$

$2.2 .4-4$

$2.2 .4-5$

$2.2 .4-6$

$2.2 .4-7$

$2 \cdot 3 \cdot 1-1$

$2 \cdot 3 \cdot 2-2$

$2 \cdot 3 \cdot 2-3$

$2 \cdot 3 \cdot 2-4$

$2 \cdot 3 \cdot 3-1$
Title

Page

Representative Average Modes of Granitic Rocks by Region

Summary of Intact Rock Properties of Granite

$2-11$

$2-17$

Summary of Technique Applications in Granite

2-31

Sensing and Mapping

Cost and Time Summary for Drilling

$2-33$

and Coring

Cost and Time Summary for Borehole

Geophysical Logging

Cost an Time Summary for Geophysical

Exploration Techniques

Cost and Time Summary for Geomechanical

Techniques

Cost and Time Summary for Hydrology

Techniques

Cost and Time Summary for Seismotectonic Techniques

Geology Information Needs in Granite

Hydrology Information Needs in Granite

Geochemistry Information Needs in

Granite

Geomechanics Information Needs in

Granite

Site Characterization Technique

Applications
2-52

2-55

2-57

$2-35$

$2-37$

2-39

2-41

$2-43$ 
Table No.

Title

$\underline{\text { Page }}$

$2.3 .4-1$

Cost and Time Summary for Surface

$2-69$

Geologic Techniques in Site

Char acterization

$2.3 .4-2$

Cost and Time Summary for Subsurface

$2-70$

Geologic Mapping in Site Characterization

$2.3 .4-3$

Cost and Time Summary for Subsurface

$2-71$

Based Drilling and Coring in Site

Characterization

$2.3 .4-4$

Cost and Time Summary for Geophysical

Techniques in Site Characterization

$2 \cdot 3 \cdot 4-5$

Cost and Time Summary for Hydrologic

$2-74$

Techniques in Site Characterization

$2.3 .4-6$

Cost and Time Summary for Geomechanics

Techniques in Site Characterization

3.2.1-1

Summary of Properties of Clay Minerals

3-6

$3.2 .1-2$

Chemical Composition of Average Shales and Related Materials (in percent)

$3.2 \cdot 1-3$

Calculated Mineral Composition of

$2-73$ Average Shale

$2-76$

3-7

$3.2 .1-4$

Range of Intact Shale Properties

3-10

$3.2 \cdot 2-1$

Typical Shale stratigraphy

$3-13$

$3.2 \cdot 3-1$

Summary of Technique Applications in

$3.2 .4-1$

Shale

$3-8$

Cost and Time Summary for Remote Sensing

$3-25$

and Mapping

$3.2 .4-2$

Cost and Time Summary for Drilling and Coring

xiii 
Table No.

$3.2 .4-3$

$3.2 .4-4$

$3.2 .4-5$

$3.2 .4-6$

$3.2 .4-7$

$3 \cdot 3 \cdot 2-1$

$3.3 .2-2$

$3.3 .2-3$

$3.3 \cdot 2-4$

$3 \cdot 3 \cdot 3-1$

$3.3 .4-1$

$3.3 \cdot 4-2$

3.3.4-3

$3.3 .4-4$

$3.3 .4-5$

$3 \cdot 3 \cdot 4-6$
Title

$\underline{\text { Page }}$

Cost and Time Summary for Borehole

Geophysical Logging

Cost and Time Summary for Geophysical

Exploration Techniques

Cost and Time Summary for Geomechanical

Techniques

Cost and Time Summary for Hydrology Techniques

Cost and Time Summary for Seismotectonic Techniques

Geology Information Needs in Shale

$3-48$

Hydrology Information Needs in Shale

$3-50$

Geochemistry Information Needs in Shale

3-51

Geomechanics Information Needs in Shale

3-54

Site Characterization Technique

Applications

$3-56$

Cost and Time Summary for Surface

Geologic Techniques in Site

Characterization

Cost and Time Summary for Subsurface

Geologic Mapping in Site Characterization

$3-64$

$3-65$

Cost and Time Summary for Subsurface-

Based Drilling and Coring in site

Characterization

Cost and Time Summary for Geophysical

$3-66$

Techniques in Site Characterization

Cost and Time Summary for Hydrologic

$3-68$

Techniques in Site Characterization

Cost and Time Summary for Geomechanics

$3-69$

$$
\text { xiv }
$$


LIST OF TABLES (Continued)

Table No.

$$
\text { Title }
$$

Page

$4 \cdot 2 \cdot 1-1$

Properties of Intact Basalt

4-7

$4 \cdot 2 \cdot 3-1$

Summary of Technique Applications

4-17

in Basalt

$4-26$

Cost and Time Summary for Renote Sensing and Mapping

$4.2 .4-2$

Cost and Time Summary for Drilling

and Coring

$4.2 .4-3$

Cost and Time Summary for Borehole

Geophysical Logging

$4.2 .4-4$

Cost and Time Summary for Geophysical

Exploration Techniques

$4-28$

4-30

Cost and Time Summary for Geomechanical

Techniques

$4.2 .4-6$

Cost and Time Sumnary for Hydrology

Techniques

4-32

$4 \cdot 2 \cdot 4-5$

Cost and Time Summary for Seismotectonic Techniques

$4-38$

$4.2 .4-7$

Geology Information Needs in Basalt

4-49

Hydrology Information Needs in Basalt

4-52

$4 \cdot 3 \cdot 2-2$

Geochemistry Information Needs in Basalt

4-55

$4 \cdot 3 \cdot 2-3$

Geomechanics Information Needs in Basalt

4-57

$4 \cdot 3 \cdot 2-4$

Site Characterization Technique

4-59

$4.3 .3-1$

Applications

4-34

4-36

Cost and Time Summary for Surface

$4-67$

4.3.4-1

Geologic Techniques in Site

Characterization

$x v$ 
LIST OF TABLES (Continued)

Table No.

Title

$\underline{\text { Page }}$

$4 \cdot 3 \cdot 4-2$

Cost and Time Summary for Subsurface

$4-68$

Geologic Mapping in Site Characterization

$4.3 .4-3$

Cost and Time Summary for Subsurface

$4-70$

Based Drilling and Coring in Site

Characterization

$4 \cdot 3 \cdot 4-4$

Cost and Time Summary for Geophysical

$4-71$

Techniques in Site Characterization

$4 \cdot 3 \cdot 4-5$

Cost and Time Summary for Hyarologic

$4-72$

Techniques in Site Characterization

$4.3 \cdot 4-6$

Cost and Time Summary for Geomechanics

$4-74$

Techniques in Site Characterization

$5 \cdot 2 \cdot 3-1$

Summary of Technique Applications in Tuff

$5-17$

$5.2 .4-1$

Cost and Time Summary for Remote Sensing

$5-27$ and Mapping

$5.2 .4-2$

Cost and Time Summary for Drilling

$5-29$ and coring

$5.2 .4-3$

Cost and Time Summary for Borehole

$5-31$

Geophysical Logging

$5 \cdot 2 \cdot 4-4$

Cost and Time Summary for Geophysical

Exploration Techniques

$5-33$

Cost and Time Summary for Geomechanical

$5-35$ Techniques

$5.2 .4-6$

Cost and Time Summary for Hydrology

Techniques

5-37

Cost and Time Summary for Seismotectonic

5-40

Techniques

$5 \cdot 3 \cdot 2-1$

Geology Information Needs in Tuff

5-50

$5.3 \cdot 2-2$

Hydrology Information Needs in Tuff

$5-53$

xvi 
LIST OF TABLES (Continued)

Table No.

Title

Page

$5 \cdot 3 \cdot 2-3$

Geochemistry Information Needs in Tuff

5-56

$5 \cdot 3 \cdot 2-4$

Geomechanics Information Needs in Tuff

$5-59$

$5 \cdot 3 \cdot 3-1$

Site Characterization Technique

5-63

Applications

$5 \cdot 3 \cdot 3-2$

Ranges of Sorption Ratios (mL/g)

$5-70$

$5 \cdot 3 \cdot 4-1$

Cost and Time Summary for Surface

$5-72$

Geologic Techniques in Site

Characterization

$5.3 .4-2$

Cost and Time Summary for Subsurface

$5-74$

Geologic Mapping in Site Characterization

$5.3 .4-3$

Cost and Time Summary for Subsurface

$5-75$

Based Drilling and Coring in site

Characterization

$5 \cdot 3 \cdot 4-4$

Cost and Time Summary for Geophysical

Techniques in Site Characterization

$5 \cdot 3 \cdot 4-5$

Cost and Time Summary for Hydrologic

Techniques in Site Characterization

$5.3 .4-6$

Cost and Time Summary for Geomechanics

Techniques in Site Characterization

$6.2 .1-1$

Typical Evaporite Minerals

$6-3$

$6.2 \cdot 2-1$

Assumed Stratigraphy of a Typical

$6-13$

Site in Bedded Salt

$6.2 \cdot 2-2$

Summary of Criteria Used in Previous

$6-15$

Screening Studies for Repositories

in Bedded Salt

$6.2 \cdot 3-1$

Summary of Technique Applications in

$6-24$

Bedded Salt

xvii 

and Mapping and Coring Exploration Techniques

Cost and Time Summary for Geomechanical

$6-45$ Techniques

Cost and Time Summary for Hydrology

$6-47$ Techniques

Cost and Time Summary for Seismotectonic

$6-50$ Techniques

Issues for Field Testing in Salt, as

6-64 Identified by Department of Energy

$6.3 \cdot 2-2$

Geology Information Needs in Bedded

6-66 Salt

$6 \cdot 3 \cdot 2-3$

Hydrology Information Needs in Bedded

$6-68$ Salt

$6 \cdot 3 \cdot 2-4$

Geochemistry Information Needs in

$6-70$ Bedded Salt

$6 \cdot 3 \cdot 2-5$

Geomechanics Information Needs in Beđded Salt 
Table No.

Title

$\underline{\text { Page }}$

$6 \cdot 3 \cdot 3-2$

Representative Fluid Compositions used

$6-83$ for WIPP Experimentation

$6.3 \cdot 3-3$

Representative Compositions of Brines

$6-84$ from Some Bedded Salt Deposits

$6 \cdot 3 \cdot 4-1$

Cost and Time Summary for Surface

$6-88$

Geologic Techniques in Site

Characterization

$6.3 .4-2$

Cost and Time Summary for Subsurface.

$6-89$

Geologic Mapping in Site Characterization

$6.3 .4-3$

Cost and Time Summary for subsurface

$6-90$

Based Drilling and Coring in site

Characterization

$6 \cdot 3 \cdot 4-4$

Cost and Time Summary for Geophysical

$6-91$

Techniques in Site Characterization

$6.3 .4-5$

Cost and Time Summary for Hydrologic

6-93

Techniques in Site Characterization

$6.3 .4-6$

Cost and Time Summary for Geomechanics

Techniques in Site Characterization

$7 \cdot 2 \cdot 3-1$

Summary of Technique Applications in

7-27

Dome Salt

$7.2 .4-1$

Cost and Time Summary for Remote Sensing and Mapping

$7.2 .4-2$

Cost and Time Summary for Drilling

$7-43$

and Coring

$7.2 .4-3$

Cost and Time Summary for Borehole

$7-44$

Geophysical Logging

$7.2 .4-4$

Cost and Time Summary for Geophysical

Exploration Techniques 
Table No.

\section{$7.2 .4-5$}

$7.2 .4-6$

$7.2 .4-7$

$7 \cdot 3 \cdot 2-1$

$7 \cdot 3 \cdot 2-2$

$7.3 .2-3$

$7 \cdot 3 \cdot 2-4$

$7 \cdot 3 \cdot 3-1$

$7.3 .4-1$

$7.3 .4-2$

$7.3 .4-3$

$7.3 .4-4$

7.3.4-5
Title

$\underline{\text { Page }}$

Cost and Time Summary for Geomechanical Techniques

Cost and Time Summary for Hydrology Techniques

Cost and Time Summary for Seismotectonic Techniques

Geology Information Needs in Dome Salt

$7-67$

Hydrology Information Needs in Dome Salt

$7-68$

Geochemistry Information Needs in Dome Salt

7-70

7-74

Salt

Site Characterization Technique

7-76 Applications

Cost and Time Summary for Surface Geologic Techniques in Site Characterization

$7-86$

7-87

Geologic Mapping in Site Characterization

7-88

Cost and Time Summary for Subsurface Based Drilling and Coring in Site Characterization

Cost and Time Summary for Geophysical Techniques in Site Characterization

Cost and Time Summary for Hydrologic Techniques in Site Characterization 


\section{LIST OF TABLES (Continued)}

Table No.

Title

Page

$7.3 .4-6$

Cost and Time Summary for Geomechanics

7-92

Techniques in Site Characterization

$7 \cdot 3 \cdot 4-7$

Cost and Time Summary for Seismotectonic

7-93

Techniques in Site Characterization

$x \dot{x i}$ 


\title{
APPENDICES
}

(The Appendices are contained in Volume 2 of this report.)

\author{
APPENDIX A-1 Remote Sensing and Surface Mapping Techniques \\ APPENDIX A-2 Subsurface Mapping Methods for Site Character- \\ ization \\ APPENDIX B-1 Gravity Technique \\ APPENDIX B-2 Audio-Frequency Magnetotelluric Technique \\ APPENDIX B-3 Seismic Refraction Technique \\ APPENDIX B-4 Direct-Current Electrical Resistivity \\ Method \\ APPENDIX B-5 Magnetics Technique \\ APPENDIX B-6 Seismic Reflection Technique \\ APPENDIX B-7 The Seismic Crosshole Method \\ APPENDIX B-8 Mechanical Downhole Seismic Velocity Survey \\ Method \\ APPENDIX C Borehole Geophysical Logging Techniques \\ APPENDIX D-1 Drilling and Coring Methods for Prechracteri- \\ zation Studies \\ APPENDIX D-2 Subsurface Drilling Methods for Site Character- \\ ization \\ APPENDIX E-1 Geomechanical/Thermomechanical Techniques for \\ Precharacterization Studies \\ APPENDIX E-2 Geomechanical/Thermal Techniques for Site \\ Characterization studies \\ APPENDIX F-1 Exploratory Geochemical Techniques for \\ Precharacterization Studies \\ APPENDIX F-2 Geochemical Techniques for Site Characterization
}


APPENDICES (Continued)

APPENDIX G-1 Hydrologic Techniques for Precharacterization Studies

APPENDIX G-2 Hydrologic Techniques for Site Characterization

APPENDIX H Seismological Techniques

xxiii 

ACKNOWLEDGEMENTS

This report was prepared by the staff of Ertec Western Inc., Long Beach, California. The geologic media studies were performed under the direction of $\mathrm{Dr}$. Matthew Werner, Project Manager and Dr. J. Carl Stepp, Principal-in-charge and Technical Reviewer. Individual investigators included: Anthony Scacifero - Granite; Denise Pieratti - Shale; James Coss - Basalt; Gary Johnpeer - Tuff; Morris Balderman - Beđded Salt; and Dr. Hooshang Taraz - Dome Salt.

Contributions to the technique appendices were made by other Ertec personnel and outside consultants. The remote sensing and surface mapping was prepared by Charles Purcell, Ertec Western, Inc. The sequence of appendices on geophysical exploration techniques were done by the Ertec Western staff, under the direction of Fred Tahse and Reid McLamore, Borehole geophysical logging techniques were compiled by James Hallenberg, independent consultant, Tulsa, Oklahoma. The discussion of subsurface mapping techniques was supplied by Dr. Samuel Adams, Ertec Rocky Mountain, Inc. Precharacterization drilling and coring methods were prepared by George Payne, Southern Plains Energy Corp., Houston, Texas, and subsurface drilling and coring by Carl williams, Ertec Rocky Mountain. The discussions of geomechanical techniques for both precharacterization and site characterization were prepared by the staff of TerraTek, Salt Lake City, Utah, and both geochemical appenaices by $\mathrm{Dr}$. Donald Langmuir, Hydrochem Systems Corp., Golden, Colorado. The hydrology appendices were prepared by the staff of Ertec Western, under the direction of Dean Gregg and Dr. Richard Bateman. The seismotectonic techniques section was prepared by Dr. James Hileman, Ertec Western. 
The United States Nuclear Regulatory Commission has the licensing and related regulatory authority for facilities to store high-level radioactive waste materials. Such facilities will include underground geologic repositories. Conceptually, a geologic repository will consist of an excavated area beneath the earth's surface into which the radioactive waste would be placed. Several geologic media have been suggested as possibly suitable for emplacement of radioactive waste. These media are: granite, shale, basalt, tuff, bedded salt, and dome salt. Because the geologic environment will be relied on to isolate the wastes from the accessible environment, stability, level of understanding of the site and compatability of the host media with the radioactive materials are key factors in repository selection. Such understanding of the site would be developed through a characterization of site conditions relative to disposal of high-level wastes However, prior to site characterization, a determination is needed as to whether a site area is suitable to warrant further exploration (i.e., proceed with site characterization).

The objective of this report is to provide technical background information on the efficacy (application, effectiveness, and resolution) of currently used exploratory and testing techniques and associated costs which are appropriate for evaluating an area prior to site selection and characterization, and for site-specific characterization. The efficacy of these techniques are considered in terms of the six geologic media and information requirements of each media. The intent in evaluating these techniques is to aid the NRC in evaluating information on previous exploration and testing as may be presented in a site characterization report.

It should be cautioned that in any study, significant information may be obtained by compilation and analysis of results from previous work, as may be available in published literature and other sources. In spite of their value, such literature studies are not a technique in and of themselves but are a means of compiling results of work within the basic exploration and testing techniques. The application of literature data to the information needs at a prospective site, and the resolution and reliability of the data obtained from such sources, will depend on the techniques used in the original research that is reported in the source material. These discussions of techniques, therefore, will be applicable to evaluating literature sources as well as precharacterization and site characterization studies. 


\subsection{PRECHARACTERIZATION STUDIES}

Precharacterization studies were divided into two tasks: 1) technique studies and 2) media studies. Technique studies consist of evaluating the efficacy of various exploratory and testing techniques which would be appropriate at the precharacterization stage. Techniques were considered in the following disciplines:

- Remote Sensing

- Geologic Mapping

- Seismology/Tectonics

- Geophysical Exploration

- Drilling and Logging

- Hydrology

- Geochemistry

- Geomechanical/Thermal Studies

These studies, presented as appendices to this report, provide the basis for the evaluation of the information requirements in each of the geologic media.

The media studies discuss the medium geology (in the context of needs for waste isolation) and identify medium-specific information needs. From these needs the studies proceed to evaluate the available exploratory and testing techniques and the efficacy of these techniques in meeting the information needs for precharacterization studies of a site in the six media. Three levels or stages of exploration are considered for each medium:

1. No drilling at a site; data from surface-based exploration only,

2. Data available from drilling done prior to the siting study, in addition to that from surface-based work,

3. Drilling and appropriate logging performed during the siting study, in addition to the pre-existing borehole data and results of surface-based exploration. 
Also included in this evaluation for the six media is the identification of potential criteria or guidelines which might be considered in assessing the adequacy of preliminary exploration and testing data.

Ertec Western's staff conducted the two tasks which comprise the precharacterization study by compiling information based on their experience in conducting geologic, geotechnical, and hydrologic investigations under a variety of conditions. This experience is supplemented by a selected group of experts in the fields of geochemistry, geomechanics, deep drilling, and borehole geophysical techniques who have provided specific technique reports. The available results of previous government-sponsored work was a major source of information for the media studies. A number of these previous studies addressed various aspects of waste isolation issues and information needs, and compiled selected information on exploration techniques. Additional contacts were made with researchers and commercial contractors concerning state-of-the-art surveys, techniques or methods of exploration and testing.

\subsection{SITE CHARACTERIZATION STUDIES}

These sections describe the studies which would be appropriate in site characterization for a prospective radioactive waste repository. Site characterization, as defined in 10CFR60.2, involves the exploration and research undertaken to determine the range of geologic conditions and related parameters at a prospective repository site. Site characterization is distinguished by the excavation of pilot shafts, lateral drifts, and test rooms in the proposed host medium to allow detailed exploration and testing at the anticipated repository depth. The techniques involved in this detailed exploration and testing at depth are specific to site characterization and are emphasized in these sections.

Concurrent with the detailed work at depth, geosciences studies performed during site characterization employ a wide variety of techniques, including many of those used in precharacterization. These continued uses of the precharacterization techniques determine site conditions in greater detail or with greater reliability, thereby validating or confirming the previous findings. They also may be used to resolve specific information needs. Efficacy, applications, and criteria for evaluating results from the continued uses of these techniques would be generally as discussed for precharacterization.

The efficacy of the site characterization studies are considered in terms of the media and information requirements for each. For each geologic medium, appropriate tests and experiments (at the surface, 
or in boreholes or excavations) for site characterization are discussed. Included in the discussion is the rationale for use of the test or experiment, the degree of resolution and limitations of the tests and experiments, expected costs incurred in conducting the tests and experiments and the estimated time required. Also identified are precharacterization techniques which would be continued into site characterization studies or would also be appropriate in site characterization. Specialized technique reports emphasize only the information appropriate to site characterization from the disciplines of:

- Geologic mapping

- Drilling and logging

- Hyarology

- Geochemistry

- Geomechanical/thermal studies

For the other disciplines, the techniques described for precharacterization are also appropriate for site characterization and, therefore, incorporated by reference.

A few key assumptions made in the site characterization studies are:

(1) The site selected for characterization is deemed suitable for a radioactive waste repository; that is, precharacterization studies have been performed at the site and form the basis of site selection.

(2) Precharacterization studies have developed regional and area models for hydrology (surface and subsurface), geology (structure and lithology), seismology and tectonics and other parameters as needed to support the decision to undertake site characterization. Site characterization studies would provide verification of these precharacterization models and define more detailed site models.

(3) During site characterization, a shaft will be excavated to the proposed repository depth. The methodology, equipment, time and cost of this excavation are not considered in this report.

The site characterization techniques discussed generally are not influenced by the actual arrangement of the subsurface test facility.

$$
1-4
$$


The information needs at an individual site, as determined by the geologic conditions and the planned repository design, would dictate the testing and exploration to be performed at that site and the required layout of test excavations. In general, the NRC has indicated that a suitable facility for site characterization would comprise two shafts and about 1000 feet of tunnels (46FR13973). The requirements for each site, however, should be evaluated from the individual site characterization Reports. The discussions on information needs, applications and limitations of the available techniques, and criteria for evaluating the test results can aid in evaluating these requirements.

The remainder of this report is divided into the six media studies: Section 2.0 - Granite; Section 3.0 - Shale; Section 4.0 - Basalt; Section 5.0 - Tuff; Section 6.0 - Bedded Salt; and Section 7.0 - Dome Salt. Each section is divided into precharacterization and site characterization studies. Described within each section is the previous studies performed within the medium, geologic characteristics of the medium, information needs for each medium, the application of exploratory and testing techniques for resolving information needs, the time and cost requirements for performing these techniques, and the potential criteria or guidelines which might be used in the evaluation of the adequacy of data generated. All costs presented in this report are in 1981 dollars. 


\subsection{GRANITE}

\subsection{PREVIOUS WORK IN GRANITE}

The initial emphasis of the National Waste Terminal Storage Program was on salt deposits, however, in the mid 1970's, several studies were initiated to investigate the feasibility of isolating radioactive wastes in other geologic media. Prior to these studies, the data base on granite was limited chiefly to geologic research (Federal and state agencies, universities) and the mineral exploration industry. Studies were conducted mostly in areas of known or suspected mineralized belts.

The Swedish-American Cooperative Research Program began a joint study in 1977 between the Swedish Nuclear Fuel Supply Company (KBS) and the U.S. Department of Energy (DOE) through Lawrence Berkeley Laboratory, to evaluate an abandoned iron mine at stripa, Sweden. This study has focused primarily on assessing the thermomechanical behavior of granite by means of in situ heater tests and to evaluate the hydrology of fractured granite (0Ikiewicz and others, 1979).

Funding was approved in 1978, for Lawrence Livermore National Laboratory under a contract with DOE, to conduct spent fuel and heater tests in the Climax granite stock at the Nevada Test Site. Canisters of radioactive waste were buried and heater bays were installed 1378 feet below the ground surface to evaluate the effects of heat on the granite body (Carlson and others, 1980).

The U.S. Geological Survey has conducted geohydrologic studies for the DOE at Dupont's Savannah River Plant in South Carolina to determine the feasibility and safety of storing radioactive waste in crystalline rocks (Marine, 1979). Other similar studies have been condurted by Dupont in granites and related crystalline rocks throughout the southern Appalachian Region. The results of the various field and laboratory testing of granite has shown that it is a viable media for isolation of high-level radioactive wastes.

Dames and Moore (1979), under contract with Battelle Memorial Institute, Office of Nuclear Waste Isolation (ONWI), was tasked to study regions within the United States which may be suitable for siting potential repositories in crystalline igneous rocks, including granite. They identified eight regions in the conterminous 0.S. which are being considered for future study. Smedes (1980), utilizing a different methodology, also evaluated regional geologic characteristics of granite within the United States. The results of this study, as well 
as the Dames and Moore work indicated that there are large areas within the United States which offer the potential for siting a waste repository in granite.

\subsection{PRECHARACTERIZATION STUDIES}

\subsubsection{GEOLOGY OF GRANITE ROCKS}

\subsubsection{Origin and Emplacement}

Granites are intrusive igneous rocks that formed as plutons when magma crystallized beneath the surface of the earth. Granitic rocks make up the core of all continents and are the most extensively developed rocks of igneous origin found in shield areas and folded geosynclinal belts (Turner and Verhoogen, 1960; Carmichael and others, 1974).

Major occurrences of granite appear in several physiographic provinces throughout the United States (Dames and Moore, 1978):

- Northern Appalachian (Maritime) Granites

- Southern and Central Applachian Granites

- Precambrian Shield Granites

- Rocky Mountain Granites

- Pacific Mountain Range Granites

- Basin and Range Granites

- Adirondack Granites

- Mid-Continent Granites

Because of the wide variation in geographic regions, climatic and terrain conditions, major differences will exist between the structural and compositional characteristics of granite in the various regions.

Bodies of granitic rocks occur in many shapes and sizes. Plutons may be classified as "concordant" if their contacts are parallel to the bedding or foliation of the country rock or "discordant" if their contacts cut across the bedding planes or foliation (Badgley, 1965). Some types of granite plutons include sills, laccoliths, lopoliths, phacoliths, dikes, batholiths and stocks (Badgley, 1965; Billings, 1954). 
Cordant Plutons

Sills - are tabular plutons that are thin relative to their lateral extent. They are generally emplaced at shallow depths and may be up to several hundred feet thick.

Laccoliths - are intrusive plutons which have domed-up the overlying strata. The floor may be flat or bowed downward. They range in aerial extent from 1 to 5 miles and may be up to thousands of feet thick. They are implaced at relative shallow depths.

Lopoliths - are large lenticular bodies with convex tops. They may be tens to hundreds of miles in diameter and thousands of feet thick.

Phacoliths - are crescent-shaped plutons confined to crests of anticlines and troughs of synclines. They are generally small, rarely more than a few thousand feet across and hundreds of feet thick.

\section{Discordant Plutons}

Dikes - are tabular plutons which are generally oriented to joint directions and emplaced by injection along pre-existing joints. They are relatively thin, generally only tens of feet thick.

Batholiths - are large plutons generally emplaced in orogenic belts. They may be up to hundreds of square miles in diameter and generally increase in size with depth.

Stocks - are small batholiths ranging in size up to 40 square miles.

Data regarding the size of plutons is often insufficient or lacking. Therefore, the general term "pluton" is applied to any granite body whose geometry is unknown.

For the most part, the emplacement of granite plutons is associated with regional tectonic activity. However, plutonic intrusions also can be pre-tectonic or post-tectonic (Billings, 1954). Plutons associated with orogenic movements (syntectonic) and pretectonic intrusions are difficult to distinguish. Granites emplaced under these conditions are generally granulated, particularly along the margins. plutons will also be deformed by folds, broken by faults, and exhibit foliation. Post-tectonic intrusions, on the other hand, are primarily undeformed, unfolded and the rocks are not granulated or foliated (Billings, 1954). 
Most geologists agree that granitic rocks are the product of slow crystallization of siliceous magma ("magmatists") and have an intrusive relationship to the surrounding rocks. However, some workers ("transformists") favor a metamorphic or metasomatic origin of some granitic rocks. At depths of a few miles, igneous and metamorphic processes merge and may yield identical end products. Therefore, some granitic bodies may be entirely or in part metamorphic in origin (Turner and Venhoogen, 1960, Gilluly, 1948).

Many geologists now recognize three main mechanisms of emplacement (Badgley, 1954; Billings, 1965): 1) magmatic stoping, 2) forceful injection, and 3) metasomatic replacement. Each has significant implications regarding the relation of the granite to the surrounding rock, geologic structure, and nature of inclusions.

\section{Magmatic Stoping}

In magmatic stoping, a body of magma rises passively towards the surface of the earth. Blocks of the country rock are shattered due to thermal and mechanical stresses. These blocks sink into the molten magma and are assimilated. The magma gradually works its way upward expanding the dimensions of the granite body. The blocks of country rock may be as much as tens or hundreds of feet in size.

Cauldron subsidence is a variety of nagmatic stoping where the blocks of country rock are measured in thousands of feet or miles. Magmatic stoping generally produces jagged, irregular walls. Many large batholiths and stocks are emplaced by magmatic stoping, such as those found in New England and Norway (Billings, 1954).

\section{Forceful Injection}

In forceful injection emplacement of granite plutons, the magma pushes the country rock in an upward and sideways motion much the same way salt domes are emplaced (Billings, 1954). Most concordant plutons (silts, laccoliths and lopoliths) as well as dikes are emplaced by forceful injections. The mechanism of emplacement is due to the hydrostatic pressure of the magma being greater than the lithostatic pressure of the country rocks, thereby pushing the walls of rock apart. The Black Hills of South Dakota, Pikes Peak in Colorado, and the Sierra Nevada batholith of California are believed to be emplaced, in part, by forceful injection. 
Badgley (1965) described a mechanism of emplacement of plutons which shows evidence of magma rise without the forceful pushing aside of country rock as "permissive emplacement". Many geologists believe the Sierra Nevada Batholith was perhaps intruded by permissive emplacement along zones of shearing or weakness (Badgley, 1965).

Metasomatic Replacement

The process by which older consolidated rocks become more characteristic of granite (mineralogy, texture, and structure) is known as metasomatic replacement or "granitization". In order to convert existing rocks, for example sandstone or shale, to granite, it is necessary to add and remove certain minerals from the composition of the rock. There is still much controversy over how these minerals are transported. Some geologists believe that they are transported in solution. Others propose that the ions diffuse through the rock in a dry state (Billings, 1954).

Evidence for emplacement of plutons by granitization are:

1. Contacts between the pluton and country rock are gradational;

2. The structural pattern in the country rocks is the same as, and continues into, the granite mass; and

3. Textural and chemical similarities exist between the country rock and granite mass.

\subsubsection{Lithology and Stratigraphy}

Granite is a light-colored, coarse-grained, acidic, igneous rock composed chiefly of quartz and alkali feldspar. Most granites exhibit hypidiomorphic-granular texture with grains generally being a few milimeters in diameter or larger. Quartz is usually anhedral while the feldspars and accessory minerals vary from subhedral to euhedral. Phenocrysts in granite tend to be euhedral.

More than two thirds of the feldspar in granites is alkali feldspar. Quartz comprises about 10 to 30 percent of the rock. Biotite occurs in nearly all granites while muscovite and hornblende occur in most granites. Accessory minerals common in granites are: apatite, sphene, zircon, and magnetite (Spock, 1962; Williams and others, 1954).

The discussions in this report pertain to granite and related granitic rocks. "Granitic" and "granitoid" are adjectives describing other 
rocks in the granite suite with some characteristics relating to granite. Distinctions between granite and related granitic rocks depend on amounts of feldspars, quartz and accessory minerals present in the rock.

Figure 2.2.1-1 shows the classification of plutonic rocks recommended by the International Union of Geological Sciences (Geotimes, 1973). This classification was developed to meet the need for a workable system that geologists throughout the world could use.

Granite and related plutonic rocks may be grouped into three main families (Carmichael and others, 1974):

Diorite Family - includes intermediate plutonic rocks.

- Diorite - consists of andesine, hornblende and/or pyroxene.

- Quartz Diorite (tonalite) - contains quartz, biotite, hornblende, and andesine; it is transitional to the granodiorite-granite family.

Granodiorite-Granite Family - includes acidic oversaturated rocks.

- Granodiorite - contains dominant andesine-oligoclase and subordinate potash feldspar, biotite and/or hornblende.

- Quartz Monzonite (adamellite) - consists of equal amounts of potash feldspar and oligoclase-andesine, biotite and/or hornblende.

- Granite-contains dominant potash feldspar, subordinate oligoclase, biotite alone or with hornblende and/or muscovite.

Syenite Family - includes acid undersaturated plutonic rocks with intermediate silica content and high in alkali.

- Syenite - contains potash feldspar, subordinate albite-oligoclase, and one or more mafic minerals. Minor amounts of quartz or feldspathoid mark transitions to granites and nepheline syenite, respectively.

- Monzonite - similar to syenite but with equal amounts of potash feldspar and oligoclase-andesine.

- Nepheline syenite - contains feldspathoids (nepheline, sodalite, analcite, etc.) and potash feldspar with one or more mafic minerals. 


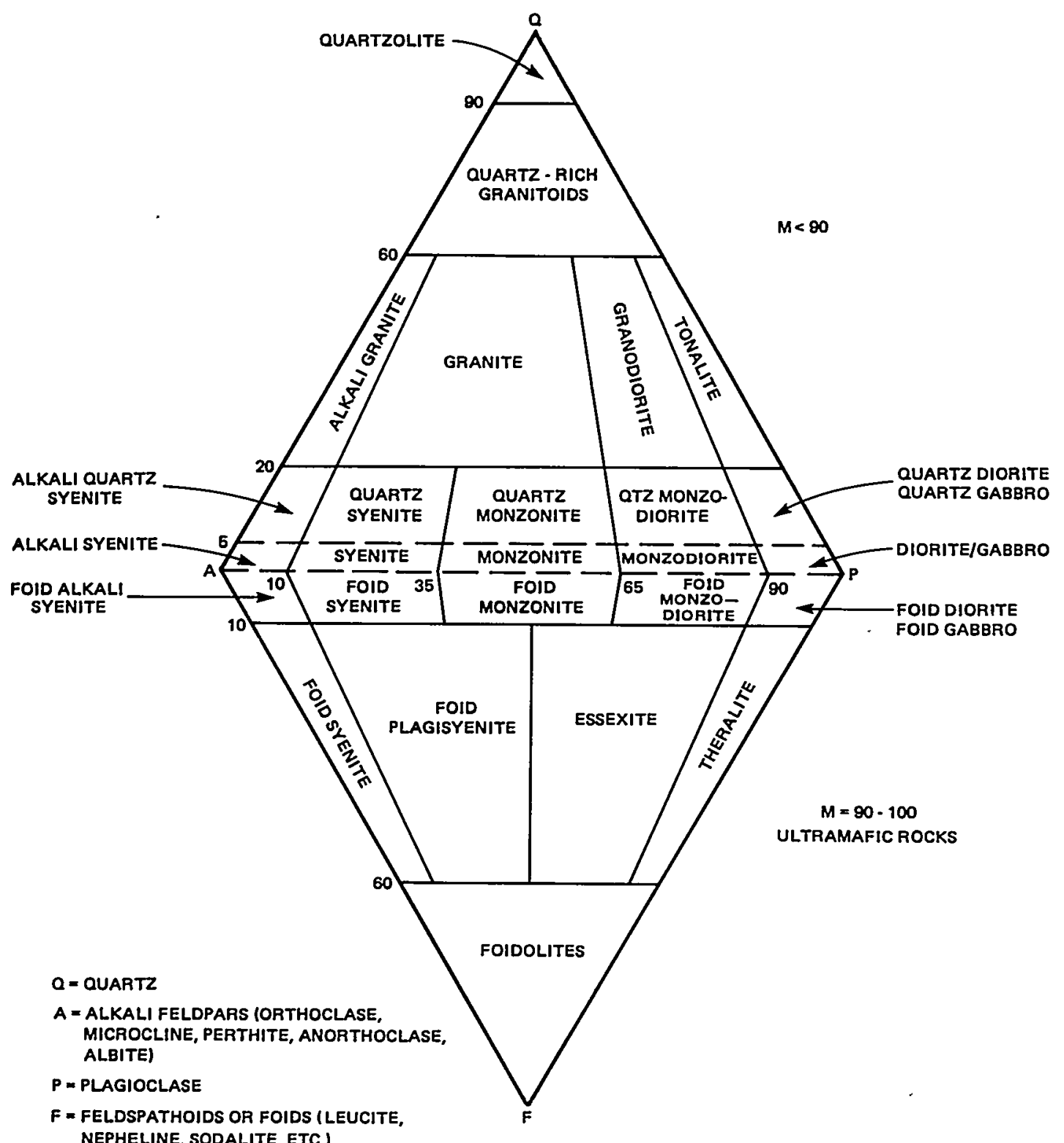
NEPHELINE, SODALITE, ETC.)

$M$ - MAFIC AND RELATED MINERALS IMICAS, AMPHIBOLES, PYROXENE, OLIVINE, ACCESSORY MINERALS)

MODIFIED FROM: GEOTIMES, 1973

FIGURE 2. 2. 1-1 CLASSIFICATION OF PLUTONIC ROCKS 
In general, discussions in this report will pertain to the more common rocks of the granodiorite-granite family. However., plutonic rocks of the other families should not be neglected when considering sites for precharacterization.

Table 2.2.1-1 shows representative average modes of generic granites from six regions in the United States (Dames and Moore, 1978; 1979).

In discussing the stratigraphy of granites, one cannot describe a stratigraphic column such as for sedimentary rocks since granites are not layered except where primary flow fabric or secondary metamorphic foliation occurs (Dames and Moore, 1978). A granite body, however, may have differences within its homogeneous mass such as a weathered zone, chilled zone, assimilated xenoliths or a secondary intrusion.

The thickness of the weathered zone is affected by such factors as climatic conditions, depth of the pluton, frequency of fractures, and hydrology. Gilluly (1948) indicates that granite bodies usually exhibit a progressive increase in grain size from the outer chilled zone to the interior of the pluton. The finer-grained chilled zone and possible zones of late-stage crystallization may tend to weather more readily than the interior of the pluton.

Other features which affect the stratigraphy of a granite mass are: fracture and shear zones, and joint systems. The frequency and orientation of these features are due to the tectonic and cooling history of the pluton. Secondary intrusions (dikes) and hydrothermal alteration along fractures and joints are inhomogenities which also occur within a granite body.

Many granites and granitic rocks are often intruded by light-colored rocks richer in quartz, alkali feldspar, and muscovite (Spock, 1954). These rocks (aplite, felsite and pegmatite) are composed of minerals that crystalized from the magma last. Aplite and felsite dikes are fine-grained and occur generally as small dikes only a few feet wide. Pegmatite dikes, on the other hand, are much coarser and may be up to several hundred feet across.

This overview of granite shows variations in lithology and stratigraphy based on differing modes of emplacement and mineralogy. Table 2.2.1-2 shows ranges in values of basic rock parameters that result from these variations. 
Table 2.2.1-1

REPRESENTATIVE AVERAGE MODES OF GRANITIC ROCKS BY REGION

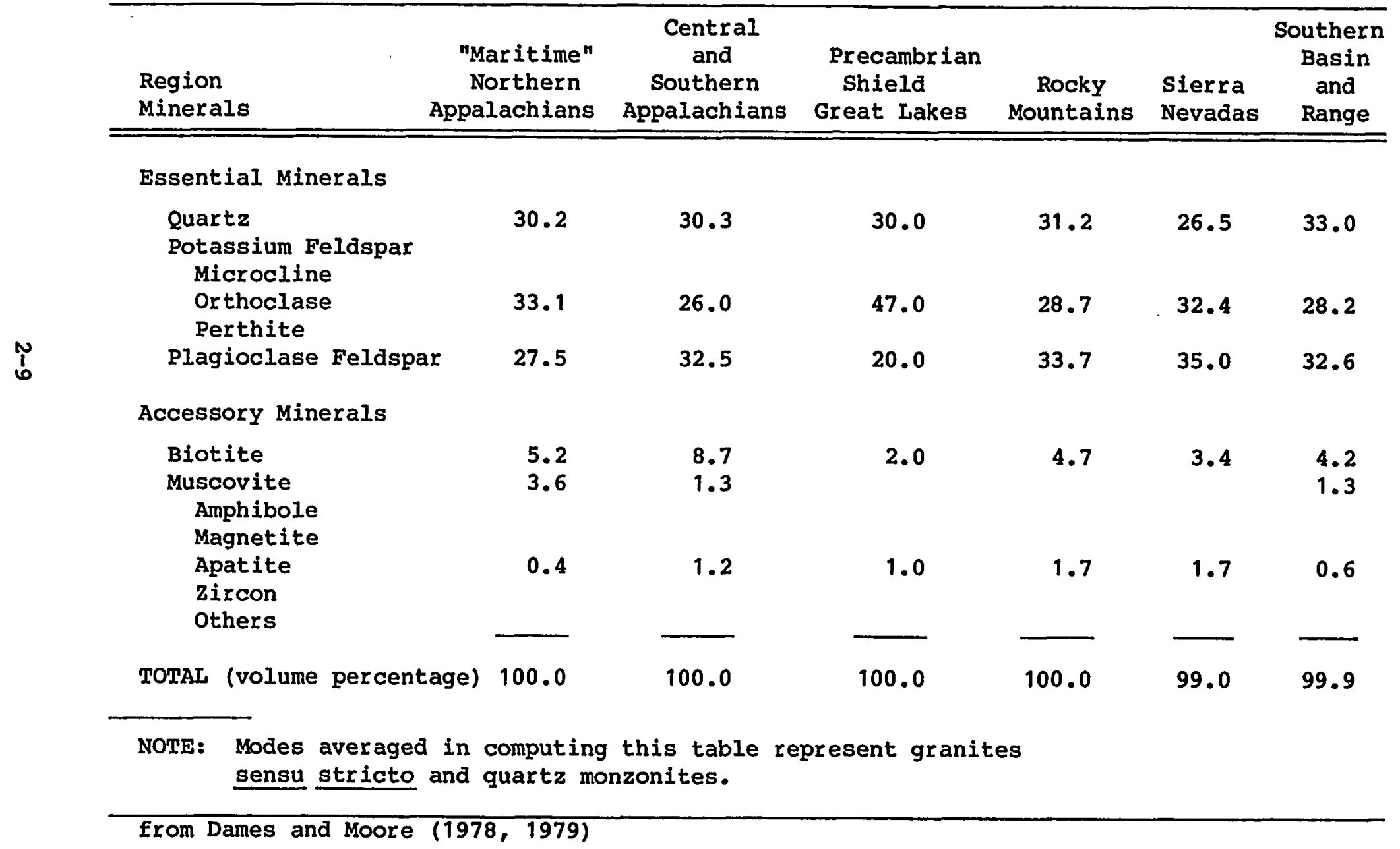




\subsubsection{Structure}

Structural features related to the intrusion of magma consist of foliation, lineation, joints, dikes, fractures, and faults (Billings, 1954). These features are a function of the cooling and tectonic history of the pluton. Plutons will be massive and void of any oriented structure (foliation or lineation) if movement of the magma ceases prior to crystallization. Simultaneous movement and crystallization of the magma will result in the development of structures.

As the outer and upper portions of the pluton cool and consolidate, the interior may still be molten. Continued movement of the interior magma will subject the outer shell to stresses which will fracture and rupture, not only the consoldiated shell of the pluton, but the country rock as well. This results in joints and faults developing in the pluton as well as extending into the country rock. Dikes may also form as secondary magma is intruded into these fractures.

Generally, fractures and joints which may be extensive at the surface or near the margins of a pluton, usually decrease in size, openness and number with depth, due to lithostatic pressure and histories or deformation or weathering. Joints and fractures found in granite are commonly filled with minerals such as hematite, gypsum, epidote, calcite, chlorite, fluorite, and sericite (Dames and Moore, 1978).

\subsubsection{Hydrology}

Hydrologic studies in granite would consider the following factors: fracture and matrix permeabilities, hydrologic gradients, ground water flow patterns, and relationships to aquifers and drainage basins (Dames and Moore, 1979).

Permeabilities in unfractured granite are generally very low. Fracture frequency tends to decrease with depth and fractures generally become closed by increased lithostatic pressure. Clark (1966) states that permeabilities of $10^{-6}$ to $10^{-7} \mathrm{~cm} / \mathrm{sec}$ at depths of 30 to 300 meters are found in granites in the United States. Precambrian granite at Stripa, Sweden has permeabilities of $10^{-7} \mathrm{~cm} / \mathrm{sec}$ or less (RBS, 1977).

Hydrologic data on granitic rocks generally are scarce and incomplete in most areas throughout the United States. Many areas of granite occurrence are remote and have limited published data. In addition, fracture zones which contain groundwater are not well known and must be identified individually. As a result, the evaluation of hydrologic 
Table 2.2.1-2

SUMMARY OF INTACT ROCK PROPERTIES OF GRANITE

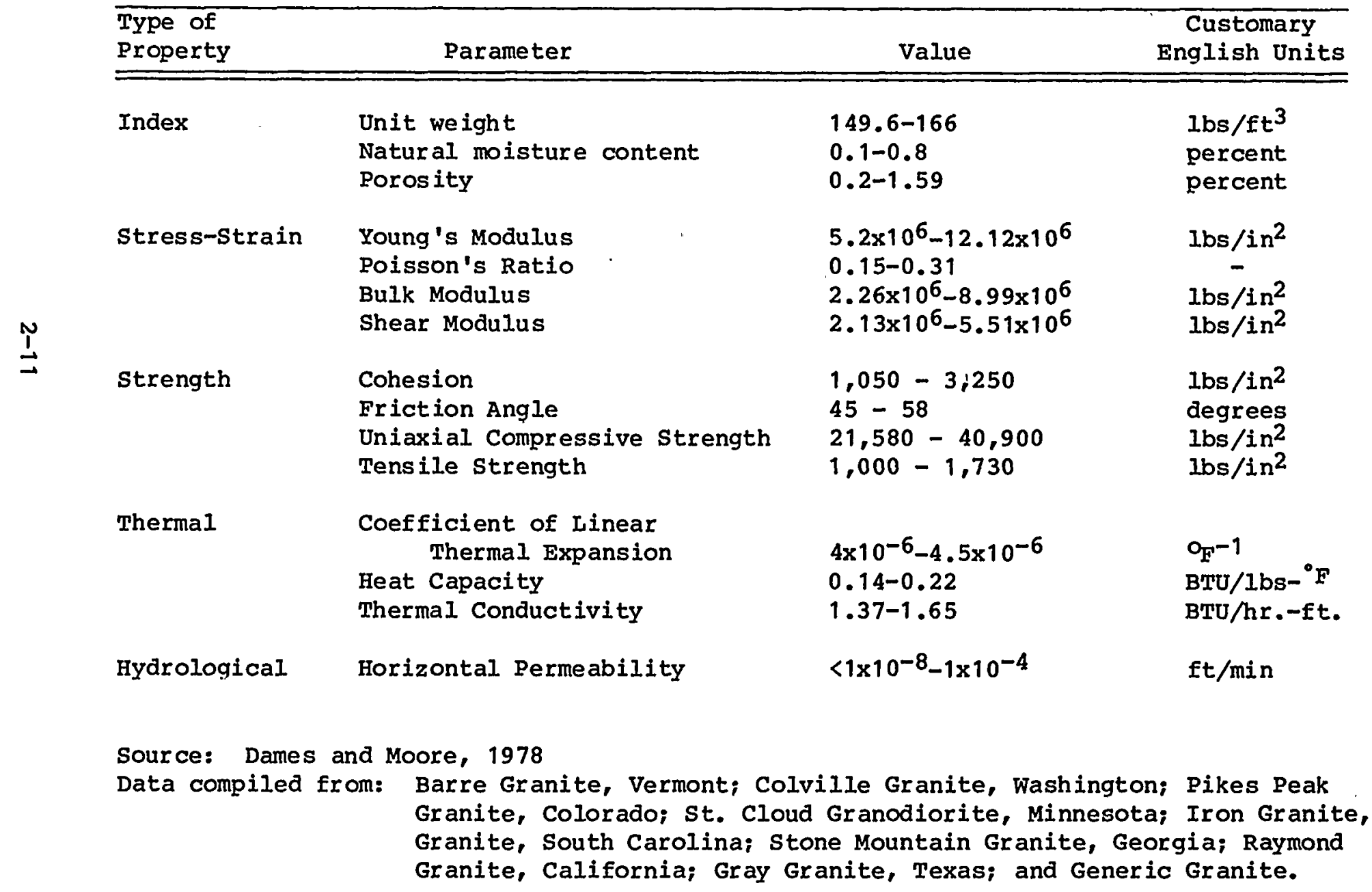


data is generally inferred from a few drill holes and from the presence of joints, fractures and faults.

\subsubsection{Resources}

A wide range of mineral and energy resources are associated with granitic rocks throughout the united States. These generally occur from secondary mineralization and are located in recognized mineral belts. Major occurrences of base and precious metal deposits are located in the western U.S., especially in the Rocky Mountain and Basin and Range regions. Many porphyry copper deposits occur throughout the Southwest. These deposits are associated with acid to intermediate igneous rocks (quartz monzonite, diorite, granodiorite, etc.) and contain primarily desseminated copper mineralization along with small amounts of molybdenum, gold, and silver (Stringham, 1966). The Rocky Mountain region contains numerous mining areas which produce gold, silver, copper, lead, zinc and molybdenum from granites such as in the Colorado Mineral Belt and the Idaho Batholith. Other regions in the U.S. have produced minor amounts of base and precious metals from granitic rocks. For example, the Southern Appalachians and the Pacific Northwest have produced iron, copper, lead, zinc, gold, tin and tungsten (Dames and Moore, 1979). Gold deposits in the Mother Lode of California are thought to be related to the emplacement of the sierra Nevada Batholith (Smith, 1981).

Pegmatites associated with granite batholiths have been producing strategic minerals since World War II. Beryllium and lithium, as well as other rare-earth metals, have been mined from granitic rocks in the Petaca District of northern New Mexico (Park and MacDiarmid, 1964) and locally in the New England states. Granites have been extensively quarried for dimension stone and monument stone throughout New England and the southern Appalachian Region for many years.

Energy resources are limited to uranium deposits found occasionally in granites as in the Rocky Mountain region. Geothermal resources are the primary energy resource found in granites of the Rocky Mountains and Pacific Northwest. Although these deposits are scarce, they have a large resource potential. These areas are critical not only for impacts of energy development but also because of the problems related to the dissipation of heat generated by these bodies. 


\subsubsection{INFORMATION NEEDS FOR PRECHARACTERIZATION STUDIES IN GRANITE}

\subsubsection{General}

Granite is being considered as a viable host rock for siting HLW repositories primarily because of its homogeneity and competency. Excavations made in granite can be expected to remain open for many years with minimal support (Dames and Moore, 1979). An advantage granite has over other geologic media is its homogeneous nature. Composition and structure will not vary significantly in a granite body. Although granites may be extensively jointed and fractured at the surface, the joints and fractures become generally tighter, and more widely spaced with depth.

The general geologic setting of a prospective repository site in granite may be anticipated from the occurrence of granite in various regions of the United States. A generic repository in granite would be typically 300 to 900 meters below the ground surface. The overburden will generally consist of unconsolidated deposits of alluvium and/or glacial materials as well as the upper portions of the granite body. Granites have adequate thickness and lateral extent for isolating radioactive waste materials and will generally extend well below repository levels.

Criteria for siting a repository in granite should consider informatior needs related to geology, hydrology, geochemistry, geomechanics, thermomechanics, tectonics, seismicity, and resources. The following discussions pertain to those information needs most critical to repository siting in granite.

\subsubsection{Geology}

With regard to geology, a major goal of precharacterization studies in granite would be to define the geometry of the granite body and to identify any structural discontinuities (fractures, joints, and faults) and lithologic variations. Evaluations should be made of the stratigraphy, lithology and structure of the host rock. The depth of the host rock should be deep enough to isolate the waste from the biosphere. Also, the host rock should have adequate thickness and lateral extent to isolate the waste for an extended period of time from surface phenomena, such as geomorphic processes, and from circulating ground water. 
The medium preferably should be homogeneous to aid in characterizing the entire rock mass. The composition of the rock and the pattern and distribution of fractures, joints, and faults must be evaluated to study the effects of ground-water flow and thermal conductivity. It must also be demonstrated that geomorphic processes (erosion, flooding, etc.) have not significantly affected the site since the beginning of the Quaternary (approximately the last 2 million years).

\subsubsection{Hyärology}

Intact, unfractured granite is characterized by extremely low permeability. However, most granite contains discontinuities such as fractures, joint sets, and faults which may allow transport of ground water through the rock mass. The nature and distribution of these discontinuities along with aquifer properties, permeability, porosity, ground-water flow and velocity are important information needs which must be addressed. Fracture flow models currently being used deal with homogeneous masses. However, models for fractured granite bodies are not generaly available, but are-being generated based on work done at Stripa Sweden.

Surface hydrology must be evaluated for its relation to ground-water conditions, flooding potential, water chemistry and the likelihood of water impoundment from extreme runoff or the possibility of failures of man-made structures. Past and potential climatic changes should be evaluated because they may have an effect on hydrologic conditions such as the amount of ground water in storage, recharge and discharge, and surface water conditions.

Ideally, repositories should be located in areas where hydraulic gradients are low and at a reasonable distance from ground-water discharge areas and surface water collection areas.

\subsubsection{Geochemistry}

Geochemical information needs for granite will include rock properties such as mineralogy, petrology, retardation, and alteration products of the host rock and the minerals along the joints and fractures where ground-water flow will occur.

Ground-water geochemistry should address items such as oxidation/ reduction potential, acidity, trace and bulk chemistry, and hydrologic evolution. In general, it should be demonstrated that the age of the ground water is sufficiently great that relatively closed hydrologic 
conditions can be assumed. These analyses would be performed in conjunction with hydrologic studies and would aid in understanding the hydrologic system. Conversely, information on hydrology would support the chemical sampling and testing program.

\subsubsection{Geomechanics}

Information needs in geomechanics include mechanical and thermal properties of the prospective host rock under in situ conditions. It also is necessary to determine geomechanical parameters significant for excavating shafts through the overlying materials. Specific factors to be determined for the rocks present include: rock engineering classifications, rock quality, strength, deformation moduli, specific heat, thermal conductivity, coefficient of thermal expansion, and potential for thermal alteration. In situ geomechanical performance also will depend on factors such as pore pressure and the distribution and character of discontinuities in the granite which will affect the rock quality and strength of the host rock.

An important consideration regarding granite is that fractures and joints generally decrease with depth. These changes should be quantified at a prospective site.

\subsubsection{Seismotectonics}

As in other media, a prospective site in granite should exhibit tectonic stability and low seismicity. Information needs in this regard include the histories of and potentials for: uplift or subsidence, faulting and other tectonic movements or deformations, igneous activity, and seismicity. Direct information on these factors may be obtained from geodetic surveys and the seismic record. However, much of the pertinent information typically is based on geologic interpretations. In addition, lineaments will need to be evaluated because they may express structural features such as faults and joints at depth.

\subsubsection{Resources}

Exploration history and distribution of potential or existing mineral and geothermal resources should be assessed before commencing characterization studies. Geothermal resources should be evaluated not only for their resource potential but because of their association with high thermal gradients. 


\subsubsection{TECHNIQUE APPLICATIONS TO PRECHARACTERIZATION INFORMATION} NEEDS IN GRANITE

\subsubsection{General}

This section is intended to provide detailed technical information on the applications, effectiveness and resolution of available exploration and testing techniques in precharacterization studies of prospective sites in granite.

Evaluations of exploratory and testing techniques have been applied to eight technical disciplines:
- Remote sensing/surface mapping
- Borehole logging
- Seismologic and tectonic studies
- Geophysical exploration
- Drilling
- Hydrologic studies
- Geochemical studies, and
- Geomechanical/thermomechanical studies

In this section, these techniques have been grouped according to the principal types of information obtained: geology, hydrology, geochemistry, geomechanics, seismotectonic framework, and resources. Generally, data from each of these groups is applicable to needs in the other groups and there is significant interchange between the groups.

Table 2.2.3-1 summarizes the relationship of various techniques to the information needs for granite host rocks.

Detailed information on theory, method, resolution, cost and time factors of these eight techniques is presented in Appendices A through H to this report.

Three stages of exploration prior to site characterization are considered:

1. No prior drilling at a. site; data from surface-based exploration only;

2. Data available from drilling done prior to the siting study, in addition to that from surface-based work; and 


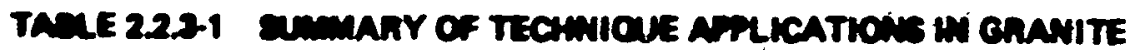

\begin{tabular}{|c|c|c|c|c|}
\hline \multirow{2}{*}{\multicolumn{2}{|c|}{ TECHNIQUE }} & STAGE 1 & STAGE 2 & STAGE 3 \\
\hline & & $\begin{array}{l}\text { NODRILLING SURFACE } \\
\text { EXPLORATION ONLY }\end{array}$ & EXISTING DRILLING & NEW DRILLING \\
\hline \multirow{2}{*}{ REMOTE SENSING } & SATELLITE & G h C S R & $G h \subset S R$ & G h C S R \\
\hline & AIRCRAFT & G h C S R & $G h \subset S R$ & $G h \subset S R$ \\
\hline \multirow{3}{*}{ SURFACE MAPPING } & LANDFORASS & G h S R & GHS & G H S r \\
\hline & LITHOLOGYMMATERIALS & G HC m $s R$ & $\underline{G} \underline{H} \underline{\mathbf{C}} \underline{\underline{\mathrm{S}}} \underline{\mathrm{R}}$ & $\underline{\underline{\mathbf{G}}} \underline{\underline{\underline{H}}} \underline{\underline{\mathbf{C}}} \underline{\underline{\underline{m}}} \underline{\underline{\mathrm{s}}} \underline{\underline{\mathrm{R}}}$ \\
\hline & PROCESSES/STRUCTURE & G H M S R & $\underline{G} \underline{H} \underline{M} \underline{\mathbf{S}} \underline{R}$ & $\underline{\underline{G}} \underline{\underline{\underline{M}}} \underline{\underline{\underline{M}}} \underline{\underline{\mathrm{S}}} \underline{\underline{R}}$ \\
\hline \multirow{4}{*}{$\begin{array}{l}\text { GEOPHYSICAL } \\
\text { LOGGING }\end{array}$} & ELECTRICAL & & GHCM S & $\underline{\underline{G}} \stackrel{\mathrm{H}}{=} \stackrel{\mathrm{M}}{=} \underline{\underline{S}}$ \\
\hline & RADIOACTIVE & & G HCMS R & 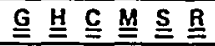 \\
\hline & MECHANICAL & & G HCMS R & $\underline{\underline{G}} \underline{\underline{H}} \underline{\underline{\mathbf{C}}} \underline{\underline{M}} \underline{\underline{\mathbf{S}}} . \underline{\underline{R}}$ \\
\hline & ACOUSTICAL & & GHMs & $\underline{\underline{G}} \underline{\underline{ }} \underline{\underline{M}} \underline{\underline{S}}$ \\
\hline \multirow{6}{*}{$\begin{array}{l}\text { GEOPHYSICAL } \\
\text { EXPLORATION }\end{array}$} & GRAVITY & G s r & $\underline{G} \underline{\mathbf{s}} \mathbf{I}$ & $\underline{G} \stackrel{s}{=} \underline{\underline{r}}$ \\
\hline & AUDIO-MAGNETOTELLUAICS & $G h \subset s R$ & $\underline{G} \underline{h} \underline{c} \underline{s} \underline{R}$ & $\underline{\underline{G}} \stackrel{\mathrm{h}}{=} \underline{\underline{\mathrm{S}}} \underline{\underline{\mathrm{S}}} \stackrel{\mathrm{R}}{=}$ \\
\hline & SEISMIC REFRACTION & G h $\mathrm{m} \mathrm{s}$ & $\underline{\mathbf{G}} \underline{\mathbf{h}} \underline{\underline{\mathrm{s}}}$ & $\underline{\underline{G}} \underline{\underline{h}} \underline{\underline{m}} \underline{\underline{s}}$ \\
\hline & RESISTIVITY & $g h s r$ & $\underline{g} \underline{\underline{s}} \underline{\underline{r}}$ & $\underline{\underline{g}} \stackrel{\mathrm{h}}{=} \stackrel{\mathrm{s}}{=}$ \\
\hline & MAGNETICS & $G \leq R$ & $\underline{G} \underline{R}$ & $\underline{\underline{\mathbf{G}}} \stackrel{\underline{\underline{s}}}{\underline{\mathbf{R}}}$ \\
\hline & SEISMIC REFLECTION & G $\leq R$ & $\underline{\mathbf{G}} \underline{\mathbf{R}} \underline{\mathrm{R}}$ & $\underline{\underline{G}} \underline{\underline{S}} \underline{\underline{R}}$ \\
\hline \multirow{4}{*}{$\begin{array}{c}\text { GEOMECHANICS/ } \\
\text { THERMOMECHANICS }\end{array}$} & ROCK MATERIAL/LAB TESTS & g h $M$ & $g \underline{h} \underline{M}$ & $\underline{\underline{g}} \stackrel{\mathrm{h}}{=} \stackrel{M}{=}$ \\
\hline & ROCK FIELD OBSERVATIONS & $g h \in M \leq r$ & $\underline{g} \underline{\mathrm{h}} \underline{\underline{M}} \underline{\mathrm{s}} \mathrm{r}$ & $\underline{\underline{g}} \stackrel{\mathrm{h}}{=} \stackrel{\mathrm{M}}{=} \stackrel{s}{=} \stackrel{r}{=}$ \\
\hline & DESIGN LAB TESTS & m & $\underline{M}$ & $\underline{\underline{M}}$ \\
\hline & DESIGN IN SITU TESTS & & & $h M$ \\
\hline \multirow{5}{*}{ GEOCHEMICAL. } & $\begin{array}{l}\text { GRAPHICAL } \\
\text { STATISTIC ANALYSES }\end{array}$ & $h \subset r$ & $\underline{h} \underline{c} \underline{r}$ & $\underline{\underline{H}} \underline{\underline{c}} \underline{\underline{\underline{r}}}$ \\
\hline & SAMPLING AND ANALYSES & $H \subset r$ & 보 $\subseteq \underline{E}$ & $\underline{\underline{\underline{H}}} \underline{\underline{\mathrm{g}}} \stackrel{\mathrm{r}}{\mathrm{n}}$ \\
\hline & YIATER-AOCK MODELING & & he & $\underline{\mathrm{H}} \stackrel{\mathrm{c}}{=}$ \\
\hline & STABLE ISOTOPE MODELING & & h c & $\underline{\underline{H}} \underline{\underline{\underline{c}}}$ \\
\hline & GROUNDWATER AGE DATING & & h c & $\underline{\underline{H}} \stackrel{c}{=}$ \\
\hline \multirow{6}{*}{ HYDROLOGY } & FLOOD FREQUENCY & $\mathrm{H}$ & H & $\mathbf{H}$ \\
\hline & RECHARGE/DISCHARGE & $\mathrm{H}$ & $\mathbf{H}$ & $\mathbf{H}$ \\
\hline & SURFACE WATER CHEMISTRY & $\mathrm{HCC}$ & 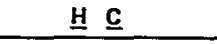 & $\underline{\underline{H}} \underline{\underline{C}}$ \\
\hline & NUMERICAL MOOELING & $\mathrm{H}$ & $\underline{\mathbf{H}}$ & $\underline{\underline{H}}$ \\
\hline & AQUIFER TESTS & & $\mathrm{H} \mathrm{m}$ & $\underline{\underline{H}} \underline{\underline{m}}$ \\
\hline & TRACER TESTS & & & H \\
\hline \multirow{6}{*}{$\begin{array}{l}\text { SEISMICITYI } \\
\text { TECTONICS }\end{array}$} & $\begin{array}{l}\text { HISTORICAL } \\
\text { EARTHOUAKE ANALYSIS }\end{array}$ & $\mathbf{s}$ & $\mathbf{s}$ & $\mathbf{s}$ \\
\hline & $\begin{array}{l}\text { INSTRUMENTAL } \\
\text { EARTHQUAKE ANALYSIS }\end{array}$ & $\mathbf{s}$ & $\mathbf{s}$ & $\mathbf{s}$ \\
\hline & MONITORING NETWORKS & $m s$ & $\mathrm{~ms}$ & $\mathrm{~ms}$ \\
\hline & VELOCITY STUDIES & gs & $\underline{g} \underline{s}$ & $\underline{\underline{S}}$ \\
\hline & FAULT STUDIES & g $s$ & $\underline{\underline{g}} \underline{\mathbf{S}}$ & $\underline{\underline{g}} \underline{\underline{S}}$ \\
\hline & $\begin{array}{l}\text { ATRENUATION AND } \\
\text { GROUND MOTION } \\
\end{array}$ & gS & $\mathrm{s}$ & $s$ \\
\hline \multicolumn{2}{|c|}{ DAILLING/LOGGING } & & $g h<m s r$ & 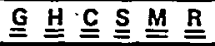 \\
\hline
\end{tabular}

EXPLANATION

CLASSES OF INFORMATION NEEDS

$G=$ GEOLOGY

$H=$ HYDROLOGY

C= GEOCHEMISTRY

$M=$ GEOMECHANICS/THERMOMECHANICS

$S=$ SEISMICITY/TECTONICS

$R=$ RESOURCES
NOTES:

1. CAPITAL LETTERS INDICATE MOST APPLICAGLE TEGHNIOUES.

LOWER CASE LETTERS INDICATE LESS APPLICABILITY. SINGLE UNDERLINE INDICATES ENHANCEMENT BY PREVIOUS DRILLING DATA DOUBLE UNDERLINE INDICATES ENHANCEMENT BY NEW DRILLING DATA.

2. LETTERS INDICATE INFORMATION NEED CLASSES WHOSE TECHNIQUES OBTAIN DATA THROUGH STAGES OF INVESTIGATION. LETTERS INDICATE APPLICABILITY WITHIN A STAGE, BUT DO NOT REPPESENT EQUIVALENCE BETHEEN TECHNIOUE. GESOLUTION, RELIABILTT, AND OTHER EVALUATION FACTORS ARE DISCUSSED IN TEXT. 
3. New drilling and appropriate logging performed during the siting study, in addition to the pre-existing borehole data and results of surface-based exploration.

In the first stage, it is assumed that no drilling has been done at the site; data is available from surficial techniques only. In addition, pertinent information may be obtained from the compilation and analysis of previous work available from published literature and maps, and other sources such as government agencies. Surface-based exploration will involve the compilation of data on geology of the overburden and host rock from surface exposures in the vicinity of the site. Regional structure and tectonic framework, surface hydrology, and resource evaluation may also be assessed by surface-based exploration.

The second stage of exploration assumes existing drill holes are available. Previous drilling in granite generally would have been performed for mineral and geothermal resource exploration. Water wells may be available in granite, however, these would typically be too shallow for evaluating hydrologic conditions at repository levels. Driller's or geologist's logs may be available for both exploratory holes and water wells. However, these logs usually provide general information only and, in the case of resource exploration, may be considered proprietary information by the mining companies. Borehole geophysical logs would be rare in these types of drill holes. It is also unlikely that these existing drill holes would be suitable for performing new geophysical logging, hydrologic testing or test monitoring.

New drilling and logging performed during the third stage of the exploration program would be designed to obtain the optimum information at depths suitable for repository siting. This would include the location of drill holes, coring, necessary samples for testing, and the selection of appropriate logging tools.

\subsubsection{Geology}

Information needs relating to geology include evaluating the lithology, stratigraphy, and structure of the overburden and host rock; depth to, thickness, and lateral extent of the host rock, and surface processes such as erosion and flooding. The following subsections will discuss the application of the most suitable techniques for the three phases of exploration described in section 2.2.3.1.

\subsection{Surface-based Exploration}

During this phase of exploration we are assuming no drilling will be

$$
2-18
$$


performed; only data from surface-based exploration will be collected and evaluated.

The techniques most suited for evaluating granite as a medium during precharacterization studies are geophysical exploration methods (Appendix $B$ ), and remote sensing and surface mapping (Appendix A). We assume that granite, unlike some other media, will be exposed at the surface in the vicinity of the proposed repository site. Because of granite's homogeneity, much data regarding the lithology, stratigraphy and structure can be obtained from surface mapping and remote sensing techniques. Mapping lithology and surface structures of granite will enable data to be extrapolated to repository levels with reasonable assurance, even though fractures and joints at the surface will usually decrease with depth.

Geometry of the host rock may best be identified using geophysical exploratory methods. Gravity and magnetic surveys and audio-magnetotelluric methods are most suited for identifying large igneous bodies at depth. Lateral extent may in part be identified using remote sensing, however, at depth, the geophysical methods will provide data on the boundaries of the granite mass. Thickness of the host rock will be difficult to assess by any surface-based technique. However, granite bodies typically have more than adequate thickness for repositories.

Structural features such as faults and joints and lithology may also be evaluated using geomechanical rock tests and field observations as part of the surface mapping effort.

Surface mapping and remote sensing techniques would provide information on overburden lithology, stratigraphy and structure. Results would provide interpretations of surface geologic processes such as flooding potential and erosional rates.

\subsection{Previous Drilling}

In the case of granites, existing drill holes, when available, would probably be limited to those drilled primarily for mineral exploration and would be confined to areas of granite which have been extensively mineralized, sheared, and altered. These may not be the best areas for repository siting, however.

If an existing drill hole can be found in an area for consideration, several geophysical logging techniques may be used to evaluate host rock lithology, stratigraphy and structure as well as depth to host rock. Mining exploration companies often use surface and downhole 
magnetic and resistivity surveys to evaluate ore deposits. In addition, radioactive tools such as natural gamma logs are often run for uranium exploration (L. Milliken, Ertec Rocky Mountain Inc., 1981, personal communication).

The availability of core is questionable because many mining companies do not often release this type of data. Core, when available, would be generally in adequate condition for visual inspection and rock mechanics laboratory testing even after several years in storage. Lithology logs including structure and alteration/mineralization may be available from mining companies.

Exploratory drilling in granite by mining companies is generally at depths ranging from 1,000 to 4,000 feet. Maximum drilling depths rarely exceed 6,000 feet (L. Milliken, Ertec Rocky Mountain Inc., 1981, personal communication). This is within the range of repository levels.

\subsection{New Drilling}

Drilling and logging along with surface and down-hole geophysical exploration are the principal techniques for evaluating geologic information needs during this phase of characterization.

As discussed in Appendix $\mathrm{D}-1$, diamond coring rigs have the capability of drilling $1-1 / 2$ to $4-3 / 4$ inch diameter holes to maximum depths of about 5,000 feet. However, because of the hardness and competence of granite, drilling costs are very high and bit wear is excessive. The type of data retrievable from drilling are oriented core for geomechanical testing and lithological analysis, determination of occurrence and orientation of fractures, joints, and faults, and depth to, and thickness of host rock.

Most information regarding geologic needs in granite can be obtained from borehole logging techniques (Appendix $\mathrm{C}-1$ ). These methods would be used to determine the geometry of the granite body and to identify discontinuities and rock properties of the host rock. Most logging techniques have been déveloped by the petroleum industry and are extensively used in sedimentary rocks. Many techniques have also been successfully applied to hard rock environments such as granite. Marine (1979) indicates that sonic logs which measure the acoustical velocity of the rock, work very well in correlating fractures and fracture zones.

The most effective tool for lithologic identification of the host rock is the gamma gamma density method which measures the rock's 
bulk density. This method is capable of better accuracy than any other logging method. Electric logs have limitations in hard rock environments due to lack of porosity. Mechanical logging tools such as the caliper and borehole deviation tools can detect fractured zones or dissolution in individual fractures and true depth and thickness, respectively. Multiple boreholes coupled with down-hole velocity tools may aid in the determination of lateral extent.

\subsubsection{Hydrology}

Hydrologic techniques (Appendix G-1) for granite would address important factors such as fracture flow and the relationship of the granite body to aquifers overlying the repository zone. Granite generally has low porosity and low primary permeability. However, because granite is usually fractured and jointed, it is very important to assess the nature, distribution, and orientation of the fractures, joints, and faults where ground-water flow could occur.

\subsection{Surface-based Exploration}

During this stage of exploration, hydrologic techniques would evaluate information needs involving climate, surface hydrology, and shallow ground-water hydrology. Remote sensing and surface mapping may be used to identify hydrologic factors including: recharge/discharge areas, and surface hydrology parameters such as drainage patterns and basins, and flood-prone areas. Published data on climate, stream-flow records, and precipitation would help to evaluate the regional hydrologic regime.

Flood frequency analysis is needed to evaluate the impacts of potential adverse flooding on repository sites. This technique would utilize surface hydrology data such as stream-flow records and drainage geometry along with climatic data. Potential climatic changes can be determined from historical rainfall and flood information, and from geomorphic, paleobiologic and archaeological evidence.

Evaluation of recharge/discharge areas is important to estimate groundwater flow and gradient parameters. This evaluation is best suited for shallow aquifer studies and may not be applicable to the host rock depths.

Surface water chemistry may be used as a tool to evaluate the potential for surface-water/ground-water interaction which would bear on the suitability of a repository site. Other surface-based techniques which 
provide data regarding aquifer properties and permeability are geomechanical field observations and rock sample laboratory tests. Description of discontinuities at the surface will include observations of fracture openness and seepage.

\subsection{Previous Drilling}

Data from previously drilled holes is unlikely to provide useful information on ground-water conditions because existing water wells are usually of insufficient depth to reach repository levels. Data obtained from existing drill holes such as water quality are not very reliable without knowing such parameters as the aquifer in question and the conditions under which the well was drilled. Water level measurements and temperature data can however be obtained from existing drill holes which may provide useful information on hydrostratigraphy. Previously drilled holes will increase the reliability and resolution of hydrologic data, especially near-surface hydrostratigraphy, when used in conjunction with surface-based exploration and evaluations.

\subsection{New Drilling}

Drilling and logging would provide useful data regarding the hydrostratigraphy in that aquifers, aquicludes, and fracture patterns would be identified. It also would allow aquifer testing, laboratory permeability and water quality testing, and analyses by numerical modeling.

Aquifer tests measure aquifer properties such as transmissivity, storage coefficient, anisotropy, and inhomogeneity. Since flow in granites is chiefly through fractures, the flow is generally anisotropic. Consequently, aquifer tests in fractured granite must take into consideration fracture geometry. Resolution of such tests will be largely influenced by knowledge of geology, but will also be affected by the well construction method, and accurate calibration of pumps, valves and gauges.

Numerical modeling may be used to solve complex ground-water flow problems using a variety of hydrologic parameters obtained from field tests. However, these tests are state-of-the-art and because granite fracture patterns may be complex, fracture flow models are generally unavailable. Forecasting can be used to predict transit time for water flowing thorugh the repository to the biosphere and changes in flow caused by excavations in the repository or by catastrophic events such as flooding, tectonics, and erosion. 


\subsubsection{Geochemistry}

Geochemical techniques (Appendix $F-1$ ) in granite would address information needs dealing with the differences between properties of the host rock, the materials along joints and fractures where ground-water flow would occur, and the ground water itself. These techniques would also address other water/rock interactions such as retardation, leaching and complexing. Geochemical age dating of ground water is very important to site characterization to assure long ground-water residence times and long flow path rates.

\subsection{Surface-based Exploration}

Geochemical techniques applied during this phase of site characterization would utilize available data on ground-water quality and mineralogy of granite. Without the benefit of existing or new drilling, most geochemical data would be from surface water and rock outcrop sources. Because granite bodies typically have relatively uniform lithology, outcrops may provide cursory information on geochemistry at repository levels. Analysis of granite mineralogy and alteration products may be performed using combined remote sensing and surface mapping techniques. Audio-magnetotelluric and magnetic surveys may provide data on the location and extent of mineralized zones. Water quality analysis may utilize stream (surface water) and spring (ground water) sampling. Graphical and statistical analyses can be applied to produce water quality maps.

\subsection{Previous Drilling}

Ground-water quality data and rock mineralogy data can be obtained from existing water wells and cores, when available. Various sources are available for ground-water quality data. These include federal, state and municipal agencies such as the U.S. Geological Survey, Environmental Protection Agency, state geological surveys, and private water companies to name a few. Sources of rock geochemical data from core and rock samples include the USGS, published reports, and universities.

Statistical computer analysis and graphical techniques may be used to evaluate ground-water quality data to produce isochemical and ground-water facies maps as tools for interpreting ground-water regimes.

Water/rock modeling utilizing existing data may be used to determine what minerals found in granite control ground-water chemistry, what 
minerals are dissolving or precipitating in the ground-water flow direction, and to predict the solubility of radionuclides in the ground water. Data needed to perform these techniques are $\mathrm{Eh}, \mathrm{pH}$, and temperature.

Stable isotope modeling can be used to reconstruct the history and evolution of ground water. Noble gases can be used to compute the temperature of ground-water recharge from precipitation. Radioactive isotope age dating of ground water is important to determine the rate of flow of ground water.

\subsection{New Drilling}

The techniques applied to newly drilled holes for water sampling and core analysis are identical to those described in section 2.2.3.4.2. The purpose of drilling additional boreholes would be to increase data points where information is insufficient or unavailable.

\subsubsection{Geomechanics}

Geomechanical and thermomechanical techniques (Appendix E-1) are used to determine the properties of the granite host rock to assure stability of underground openings and to predict.the influence of the repository on the surrounding volume of rock with regard to thermal effects of waste storage.

\subsection{Surface-based Exploration}

During this stage of exploration, rock quality and the nature of discontinuities can be assessed using surface mapping of lithology and structure. In order to accomplish this, one must assume that the lithology and structure which are exposed in surface outcrops are indicative of conditions at depth.

In situ stress state and unconfined compressive strength are important geomechanical parameters which can be assessed prior to drilling. Rnowledge of in situ stress state is important for design of the repository. The in situ stress state effects the selection of excavation dimensions and orientation of the repository with respect to the stress field. An unfavorable stress field may result in spalling of the rock, and shearing along joints and fractures. 
Unconfined compressive strength laboratory tests can be used to estimate the value of Young's modulus which can be applied for excavation design and correlation purposes.

Although fractures attenuate with depth, field observations of discontinuities at the surface will help to determine the mechanical behavior of the rock mass for stability analysis. The tensile strength of intact basalt is high, producing elasto-brittle behavior, but may be significantly lowered by discontinuity spacing and orientation, which provide ready-made slip, or failure, planes. Parameters relating to jointing and fracturing which can be evaluated in the field are: orientation, spacing, roughness, length, strength, aperture filling, seepage, and block size.

Surface-based seismic refraction surveys may be used to determine the strength of the host rock by its high seismic velocity. Velocities of granite typically range from 15,000 to 18,000 feet per second (R. McLamore, Ertec Western Inc., 1981 personal communication).

\subsection{Previous Drilling}

Existing boreholes, when available, can provide much useful data assuming adequate logging was performed at the time of drilling and suitable core is available. Most of the tests described in this section would have been performed during the original logging program.

Rock Quality Designation (RQD) is a measure of fracture frequency and general quality of the rock for engineering purposes. The RQD may be determined on existing core if the core has been properly stored and not mishandled. Porosity and density parameters can be determined from laboratory tests on existing core. Samples of rock tested in the laboratory will determine water content and absorption. Water content of granite affects rock strength, sonic velocity and flow characteristics. Absorption measures the void index of rock which indicates whether pore space is interconnected. Permeability tests measure the ease with which fluids flow through a rock sample. Sonic velocity tests on rock samples can determine elastic moduli and Possion's ratio. Uniaxial unconfined compressive strength test is primarily for strength classification.

Triaxial compression tests measure the strength of rock samples under confined conditions; this would be more typical of in situ conditions at repository depths. Thermal conductivity measures the rate at which heat flows through a rock mass under a temperature gradient. 
Table 2.2.1-2 contains selected mechanical and thermal properties of intact granite. It will be important to distinguish between intact properties of small samples of granite and larger rock mass properties. In general, the rock mass properties will be less than the intact properties due to the presence of discontinuities in the rock (Dames and Moore, 1978).

\subsection{New Drilling}

All of the tests used for rock characterization and classification during the two preceding stages of exploration can be applied in the case of new drilling also. There is no assurance that the tests performed on existing core from previous drilling will be representative of the in situ conditions. The selection and drilling of new holes and appropriate in situ testing will provide useful information for rock classification at repository depths.

Recently, in situ heater and spent fuel tests performed in granite at Stripa, Sweden and the Nevada Test Site have been done to provide data regarding effects of thermal conductivity of radioactive wastes on the hos rock. Similarly, in situ geomechanics tests on the Climax Granite at the Nevada Test site have determined stress and rock deformation parameters (Heuze, and others, 1981.

Borehole modulus tests (Goodman Jack and CSM cel1), which apply loads to the rock may be used to asess rock mass modulii. In situ stress state tests determine the stability of openings in the rock. This data is useful for comparison of strength properties of the rock mass. It can also be used to estimate the maximum shear stress in the rock mass which is of particular importance if the mass is jointed.

\subsubsection{Seismotectonics}

Seismological techniques (Appendix H) and the evaluation of the tectonic framework as applied to site characterization are concerned with the potential source of earthquakes that could affect a repository and the levels of strong ground motion that might occur at a repository site. Seismological techniques along with supporting geological and geophysical techniques will provide information to evaluate the following information needs: areas of Quaternary faulting, areas of high seismicity, Quaternary volcanism, and structural deformation (uplift and subsidence). 


\subsection{Surface-based Exploration}

The primary techniques for evaluating tectonics involve remote sensing and surface mapping. Areas of structural deformation and igneous activity can be assessed by detailed airphoto and satellite imagery analysis followed by field mapping and verification of surface features. The nature, orientation, and distribution of faults can also be studied using these two techniques. Faulting can be detected through the presence of scarps, lineations, and offsets in recent landforms.

In the evaluation of seismicity and tectonic data, previous records of earthquake occurrences from both historic and instrumental sources can be analyzed. Because of the regional nature of seismic information and the tectonic framework, these techniques are not media specific.

Monitoring networks may be set up in regions being considered for site characterization to also assess the current seismotectonic setting in addition to past seismic hazards. Field experiments may be implemented to determine crustal velocities, bulk elastic parameters, and seismic wave attenuation measurements.

Seismic velocity profiles may provide useful information regarding velocity, structure, and earthquake hypocenters. This technique is similar to geophysical seismic refraction methods, only in this case, deeper information may be obtained. The technique may provide additional data on the structure and geometry of the host rock as well as geomechanical stress conditions.

Surface based geophysical exploration techniques in combination with fault assessment studies may provide data regarding the nature of faulting and igneous activity. Gravity, audio-magnetotellurics, seismic refraction, magnetics, and resistivity surveys would provide data on tectonic features.

\subsection{Previous Drilling and New Drilling}

Techniques applied during these two stages of exploration (using existing drill holes and new drilling during site studies) are combined because the techniques used during both stages are identical. Drilling and logging may indicate the presence of concealed faults and shear zones by the analysis of geologists logs and visual observations.

Borehole logging methods such as electrical and acoustical techniques may provide data on seismic velocity structure and the location of faults. Radioactive logging may indicate the location of igneous 
intrusions such as dikes which may confirm the presence of previous igneous activity. Temperature logs may provide data on the geothermal gradient and thermal conductivity of the host rock which may also indicate potential for igneous activity.

\subsubsection{Resources}

Resource evaluations in granitic host rocks are concerned primarily with mineral and geothermal resources. Information needs which must be addressed pertain to the location and extent of existing resources and the potential for future resources or expansion of existing resource areas.

\subsection{Surface-based Exploration}

Prior to any drilling at a potential repository site, data regarding known resources and potential resource areas may be obtained from published literature and existing geologic maps. Remote sensing techniques and surface mapping may not provide additional data on a regional scale. Computer enhancement of satellite imagery has been applied to the detection of hydrothermal alteration but this technique is not yet widely applied and is considered speculative (C. Purcell, Ertec Western Inc., 1981, personal communication). Surface-based geophysical exploration, such as gravity and magnetics, have been used to detect massive sulfide deposits in granite. Radon detection has seen limited use in uranium exploration. Because of the high mobility of radon atoms and the unpredictability of migration, this is not seen as a viable technique for structure contouring or mineral detection depths greater than $30 \mathrm{~m}$. Release of radon from ground water is also unreliable because the high solubility of uranium permits the production of radon at a great distance from the source of uranium ( $L$. Milliken, Ertec Rocky Mountain Inc., 1981, personal communication).

Areas of potential geothermal resources also may be known from the literature.

\subsection{Previous Drilling}

In areas of known mineral and geothermal resources, extensive exploration must have occurred. Logs, core, and assays may be available from mining and exploration companies. However, as stated earlier, these data are usually proprietary information and may not be accessible to others. Borehole logging tools are used only occasionaly in the 
mineral industry. Radioactive and mechanical tools (gamma ray and caliper) may provide data on structure-controlled mineralized veins within the host rock. Data from existing drill holes would refine information needs on the lithology, structure, mineralogy of the host rock and fracture filling, and stratigraphy.

\subsection{New Drilling}

New drilling would increase the reliability and resolution of resource evaluation in granitic host rocks. Data obtained from new drill holes would improve geologic interpretations on the lithology, stratigraphy and structure of the host rock with respect to resource potential. Drill holes placed in zones of suspected alteration and mineralization would be used to evaluate and define the limits of potential resource areas. The best data would be provided from borehole logging in selected drill holes. Nuclear-detection tools such as natural gamma ray and mechanical tools (caliper, borehole deviation) would define any mineralization and alteration products in the fractures and joints. Geochemical sampling of ground water may provide data on trace elements dissolved in the ground water.

\subsubsection{COST AND TIME ESTIMATES FOR PRECHARACTERIZATION TECHNIQUES}

Cost and time estimates for the techniques that would be used in the investigation of a prospective site in granite are summarized in the accompanying Tables $(2.2 .4-1$ to 2.2.4-7). Many of these techniques are essentially similar to those used in other media and for other types of studies and, as a result, cost and time estimates also will not vary.

In general, the cost and time requirements outlined on the tables are for typical exploration and testing procedures. They represent, for the most part, average values. Exploratory and testing techniques may generally be higher for granite than some other media because of rugged terrain conditions, inaccessability to some areas, and extra equipment and manpower which may be needed. Generally, granite areas have insufficient data in terms of previous work done. Therefore, exploration and testing techniques will be more extensive in these areas. The costs presented in the tables will likely increase yearly with the inflation rate. Parameters that are unique to granite are emphasized in the following discussion. 


\subsubsection{Remote Sensing and Mapping}

Costs and times involved in remote sensing analyses and surface geologic mapping are discussed in Appendix $A$ and summarized in Table 2.2.4-1. Although there would be specific objectives in this work for a site in granite, the techniques used would be essentially the same as for sites in other media; cost and time estimates similarly would not differ. The main factors influencing costs and times for this work would be accessibility and trafficability of terrain at a site and the complexity of geologic conditions. These differ significantly at known occurrences of granite and cannot be accounted for on a generic basis.

\subsubsection{Drilling and Coring}

Costs and times for drilling and coring and for geologic logging of cuttings and core are discussed in Appendix $D$ and summarized in Table 2.2.4-2. Because of the hardness of granite, the cost of drilling may be significantly higher than other media. This increase in cost is primarily due to the rapid deterioration of drill bits.

Additional problems may arise because of drill rig accessability and availability. Most large areas of granite are located in remote, mountaineous areas and far removed from petroleum industry drill rigs active in the Midwest and Gulf coast regions. Lead time for $r i g$ availability may be excessive from petroleum industry sources ( 6 to 18 months) while mining exploration equipment typically can be obtained on shorter notice ( 6 weeks to 6 months). Water well drilling equipment may not be suited for reaching repository levels. In addition, most water well rigs are not equipped for the types of sampling tools needed for site characterization.

\subsubsection{Borehole Geophysical Logging}

Costs for various borehold geophysical logs are discussed in Appendix $C$ and summarized in Table .2.4-3. Per foot costs typically would depend on factors such as mobilization distance, standby time, and calibration requirements, in addition to the total footage logged and the number of tools run concurrently.

\subsubsection{Geophysical Exploration}

Geophysical survey granite costs are summarized in Table 2.2.4-4, and discussed in Appendix B. Granite areas may have rugged terrain 
TABLE $2.2 .4-1$

COST AND TIME SUMMARY FOR REMOTE SENSING AND MAPPING

Acquiring Imagery or Photography

\begin{tabular}{|c|c|c|c|}
\hline & Approximate Cost Range & $\begin{array}{l}\text { Delivery } \\
\text { Time (1) } \\
\end{array}$ & $\begin{array}{l}\text { Approximate } \\
\text { Area Covered }\end{array}$ \\
\hline $\begin{array}{l}\text { LANDSAT } \\
\text { Enhancement }\end{array}$ & $\begin{array}{c}\$ 8-150 \text { per image }(2) \\
\$ 200-1000 \text { per scene }(3)\end{array}$ & $\begin{array}{l}1-4 \text { weeks } \\
4-16 \text { weeks (3) }\end{array}$ & $13,500 \mathrm{mi}^{2}$ \\
\hline \multicolumn{4}{|l|}{ SKYLAB } \\
\hline $\begin{array}{l}\text { Multispectral } \\
\text { Earth Terrain }\end{array}$ & $\begin{array}{l}\$ 8-150 \text { per image }(2) \\
\$ 8-150 \text { per image }(2)\end{array}$ & $\begin{array}{l}1-4 \text { weeks } \\
1-4 \text { weeks }\end{array}$ & $\begin{array}{l}2,000 \mathrm{mi}^{2} \\
4,600 \mathrm{mi}^{2}\end{array}$ \\
\hline $\begin{array}{l}\text { Stereo Aerial Photogr } \\
\text { Purchase existing } \\
\text { New flight }\end{array}$ & $\begin{array}{l}\text { aphy } \\
\$ 3-60 \text { per frame (2) } \\
\$ 25-40 \text { per frame (4) }\end{array}$ & $\begin{array}{l}1-4 \text { weeks } \\
2-6 \text { weeks }\end{array}$ & $3-80 \mathrm{mi}^{2}$ \\
\hline $\begin{array}{l}\text { Low Sun Angle Photogr } \\
\text { Purchase existing } \\
\text { New flight }\end{array}$ & $\begin{array}{l}\text { phy } \\
\$ 3-60 \text { per frame (2) } \\
\$ 25-75 \text { per frame }(4)\end{array}$ & $\begin{array}{l}1-4 \text { weeks } \\
2-6 \text { weeks }\end{array}$ & $3-12 \mathrm{mi}^{2}$ \\
\hline $\begin{array}{l}\text { Radar Imagery } \\
\text { Purchase existing } \\
\text { New flight }\end{array}$ & $\$ 125 \underset{(7)}{\text { per strip }}$ & $\begin{array}{l}1-3 \text { weeks } \\
3-10 \text { weeks }\end{array}$ & $\begin{array}{l}100-2500 \mathrm{mi}^{2} \\
\text { Per survey } \\
\text { design }\end{array}$ \\
\hline
\end{tabular}

Interpreting Imagery or Photography

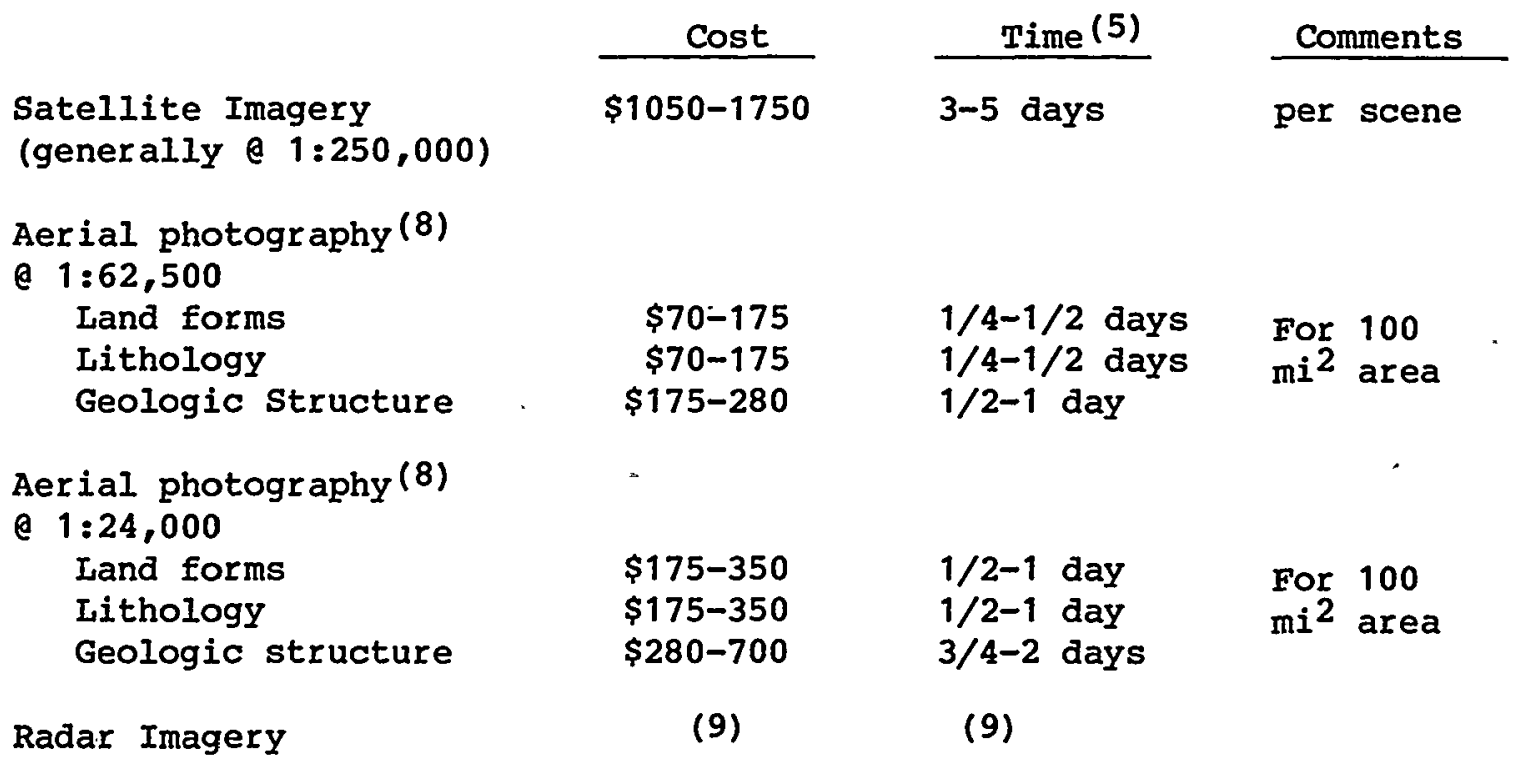


TABLE 2.2.4-1 (Cont.) - NOTES

Field Mapping (6)

Reconnaissance
$1: 62,500$ scale
$1: 24,000$ scale

Relatively complete mapping

$1: 62,500$ scale

$1: 24,000$ scale

\begin{tabular}{|c|c|c|}
\hline Cost & Time (5) & Comments \\
\hline $\begin{array}{l}\$ 1800 \\
\$ 3000\end{array}$ & $\begin{array}{l}3 \text { days } \\
5 \text { days }\end{array}$ & $\begin{array}{ll}\text { For } & 100 \\
\mathrm{mi}^{2} & \text { area }\end{array}$ \\
\hline $\begin{array}{l}\$ 4200 \\
\$ 6600\end{array}$ & $\begin{array}{r}7 \text { days } \\
11 \text { days }\end{array}$ & $\begin{array}{ll}\text { For } & 100 \\
\mathrm{mi}^{2} & \text { area }\end{array}$ \\
\hline
\end{tabular}

NOTES

(1) Delivery times generally do not depend on quantity ordered.

(2) Cost of photos or imagery is determined by size of print ordered, whether in color or black and white, and extra charges for shorter delivery time.

(3) Cost and delivery time for enhancements depends on source and on availability of previous processing for scene desired.

(4) Flight costs in addition to costs of photo reproduction indicated above.

(5) Approximate man-days to complete work; delivery time may be longer. Time required for interpretations can depend on complexity of geologic conditions at a site.

(6) Cost and time estimates assume interpretation of imagery and photography completed previously. Actual times and costs in an area would be influenced by access, trafficability, and complexity.

(7) Obtaining radar imagery from a new flight costs several thousand dollars. Actual costs depend on mobilization (radar equipment is not widely available), altitude requirements, and other flight parameters.

(8) Estimated times and costs are applicable to all $9^{\prime \prime} \times 9^{\prime \prime}$ stereo aerial photographs: black and white, color and infrared (both black and white and color).

(9) Time and cost for interpreting radar imagery depends on resolution and scale of the imagery, purpose of the interpretation, and other factors. See Appendix A for discussion. 
TABLE 2.2.4-2

COST AND TIME SUMMARY FOR

DRILLING AND CORING(1)

Drilling

Type

Equipment

Production

$\begin{array}{ccc}\text { Production } & \text { Cost (2) } & \text { Production } \\ \text { Rate } & \text { Cost } & \text { Rate }\end{array}$

(per foot) (feet per day) (per foot) (feet per day)

Petroleum (3)

Using Mud

Using Air

$\$ 400$

100

200

$\$ 840(4)$

40

$\$ 100$

-

Mining

Using Mud

Using Air

$\$ 270$

100

200

$\$ 710(4)$

45

70

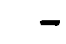

Water Well

NOTES :

(1) Adapted from Appendix D

(2) Including all drilling supplies, support personnel and ancillary equipment.

(3) Add approximately $\$ 350,000$ to total cost for mobilizing petroleum drill rig to typical granite site.

(4) Includes $\$ 450$ per foot for core bits and coring services. 
and associated difficulties in access. In such an event, it may become necessary to provide four-wheel-drive or helicopter support to supply and more the crews rapidly, and ground-based surveys (gravity, seismic reflection and refraction) may experience increased costs.

\subsubsection{Geomechanics}

Geomechanical and thermomechanical testing costs are summarized in Table 2.2.4-5 and discussed in Appendix $\mathrm{E}$. No unique costs are anticipated for conducting the geochemical and thermomechanical tests on granite samples.

\subsubsection{Hydrology}

Hydrological testing costs are presented in Table 2.2.4-6 and discussed in Appendix G. No unique costs are anticipated while conducting these tests on granite. Costs of drilling and well construction are not included in these estimates.

\subsubsection{Geochemistry}

Estimates of costs and times for typical laboratory and analytical techniques in geochemistry are summarized in Appendix F-1. Costs for obtaining and transporting samples are not included.

\subsubsection{Seismotectonics}

Cost and time estimates for seismological monitoring and analyses are presented in Table 2.2.4-7 and discussed in Appendix $\mathrm{H}$. Estimates for tectonic analyses and related fault and structural mapping are shown in Table 2.2.4-1. No unique costs are anticipated while conducting the seismological studies in granite.

2.2.5 CRITERIA FOR EVALUATING DATA ADEQUACY OF PRECHARACTERIZATION STUDIES IN GRANITE

\subsubsection{General}

The purpose of this section is to discuss criteria (guidelines) which may be used by the NRC in assessing the adequacy of preliminary exploration and testing and to aid in determining whether or not a site should be characterized. The application of a specific technique to 
TABLE $2.2 .4-3$

COST AND TIME ESTIMATES FOR

BOREHOLE GEOPHYSICAL LOGGING

Techniques

Approximate

Cost Range

Time (3)

Typical Log Package (1)

Borehole Caliper

Focused Resistivity

Single-point Resistivity

Spontaneous Potential

Gross-count Gamma Ray

Density

Neutron Porosity

Deviation

$\$ 1300$

to

$\$ 6500$ (2)

$1 / 2$ day

Additional Logs(4)

Electrical

Radioactive

Acoustic

$\left.\begin{array}{l}\$ 350-900(5) \\ \$ 300-1000(5) \\ \$ 800-2700(5)\end{array}\right\}$

Add approximately one hour per sonde

Specialized logs requiring separate mobilization: (not practical for single hole)

Radar Log

$\$ 6000(6)$

$1 / 2$ day

Gravity Log

$\$ 4000(6)$

1/2 day 
TABLE 2.2.4-3 (Cont.) - NOTES

(1) Assumes:

a. single 1000-foot hole

b. 400 miles (round trip) travel charge to well site

c. holes ready to log upon arrival (i.e., no standby time)

d. logging speed of 50 feet per minute

e. non-logging (entering hole) at 60 feet per minute

f. log package combined in two sondes

(2) Low cost for minerals logging contractor; high end cost for oilfield logging contractor. Cost per hole would be reduced if travel charge can be applied to additional holes.

(3) Approximate time on site, not including travel

(4) Assumed to be added to package described in note (1)

(5) Actual costs will depend on services desired, available combinations in single sondes, and minimum charges imposed by some contractors. Ranges are as in note (2), above.

(6) Estimated cost for single 1000-foot hole logged as part of larger program. Includes interpretation. 
TABLE $2.2 .4-4$

COST AND TIME SUMMARY FOR

GEOPHYSICAL EXPLORATION TECHNIQUES

Technique

Gravity

Audio-Magnetotelluric

Seismic Refraction

Resistivity Profile

Resistivity Sounding

Airborne Magnetic

Ground Magnetic

$$
\begin{aligned}
& \text { Approximate } \\
& \text { Cost (1) }
\end{aligned}
$$

\section{$\$ 60-75$ per} station (2)

$\$ 900$ per station

$\$ 3,000-15,000$

per mile (3)

$\$ 1000$ per station(4)

$\$ 2500$ per sounding ( 6$)$

$\$ 20$ per mile plus mobilization cost (see Appendix B-5)
Typical Production Ratès (1)

2 to 4 stations per hour

2 stations per crew per day

(3)

3 stations per crew per day in field (5)

2 soundings per crew per day in field(5)

2 to 6 week delivery (depending on equipment availability) 
TABLE 2.2.4-4 (Cont.) - NOTES

(1) All estimates assume average to good access, terrain, and weather conditions. Costs and times for all ground-based techniques will be higher in areas of rugged terrain or otherwise difficult access or trafficability.

(2) For 100 to 200 station survey under good field conditions (see Figure 4 in Appendix $B-1)$. Widely spaced stations require increased travel times, affecting costs and production rates. Costs for surveys requiring helicopter access could be on the order of $\$ 250$ per station.

(3) Cost and production rate determined by (1) spacing between geophones, (2) number of shots recorded in each layout, and (3) shot size. Single large shots may require several days of prparation, while small surveys may be completed in a few hours. See Appendix B-3 for discussion.

(4) Based on typical survey consisting of six profiles, each $1 \mathrm{~km}$ long. See Table $4 \mathrm{~A}$ in Appendix B-4.

(5) See Table 5 in Appendix B-4 for estimates of times for additional related activities.

(6) Based on typical soundings with five separate measurements and maximum 300-meter pole separation. See Table 4B in Appendix B-4.

(7) When run along with gravity survey, ground magnetic measurements may be done at additional cost of about $\$ 400$ per day, representing one man and magnetometer rental. Survey would cover area at approximately same rate as the gravity survey (discussed above) although measurements may be taken at more stations. 
TABLE 2.2.4-5

COST AND TIME SUMMARY FOR

GEOMECHANICAL TECHNIQUES

\section{Technique}

Regional Stress State

Unconfined Compressive strength

Description of discontinuities

Rock Quality

Designation

Porosity/Density

Water Content

Absorption

Sonic Velocity

Uniaxial Compressive Stress

Permeability

Triaxial Compressive Strength

Thermal Conductivity

Borehole Modulus

In Situ Stress State
Approximate

Cost Range

$$
\begin{gathered}
\$ 4,440 \\
\text { (estimate) }
\end{gathered}
$$

$\$ 25-300$

$$
\$ 14,400
$$$$
\text { (estimate) }
$$

(2)

$\$ 50$

$\$ 10$

$\$ 50$

$\$ 50-500(3)$

$\$ 250(4)$

$\$ 250-1,000$

$\$ 2,000-10,000(5)$

$\$ 1,000-2,000(6)$

$\$ 10,000-15,000(7)$

$\$ 40,000-\$ 60,000(7)$

$\$ 50,000-\$ 70,000(7)$
Approximate

Turn-Around Time (1)

$\begin{array}{cc}3 \text { wks } & \text { per region - } \\ \text { (estimate) } & \begin{array}{l}\text { based on liter- } \\ \text { ature review }\end{array}\end{array}$

5 minutes (9) per test

1 man month per site

$$
2 \text { weeks }
$$

per test

2 weeks

per test

2 weeks

per test

3 weeks

per test

3-6 weeks

per test

3 weeks

per test

3-6 weeks

per test

8 weeks

per test

1 week (8)

per test

5 hours $(8)$

per test

1-10 days $(8)$

per test 
TABLE 2.2.4-5 (Cont.) - NOTES

(1) Turn-around time for delivery of laboratory results, unless otherwise stated.

(2) Done by well-site geologist in conjunction with normal core logging at no measurable increase in cost or change in drilling rate.

(3) Higher costs are for tests at elevated temperature and pressure.

(4) Includes measurement of deformation. Can obtain strength data only for less than $\$ 50$.

(5) Test program would be designed to meet project needs. Further cost increases would result from requirements for additional measurements or testing at elevated temperature or pressure.

(6) Higher cost for tests at elevated pressure.

(7) Excluding drilling costs.

(8) Actual working time on test.

(9) Field tests using portable point load apparatus or schmidt hammer. See Pages 8 and 9, Appendix E-1. 
COST AND TIME SUMMARY FOR HYDROLOGY TECHNIQUES

Technique

\section{Surface Hyarology}

Singular Flood Frequency Regional Flood Frequency Rainfall-Runoff 100-year flood plain Flooding from dam failure Discharge measurements

Field surveys of recharge/discharge

Surface-water sampling

Borehole Testing (5)

Head measurement
a. Manual
b. Winch
c. Recorder

Drill stem test

Pump test

Injection test Straddle packer test

Tracer tests

\section{Permeability Tests}

on core samples

Numerical Modeling

$\begin{array}{cl}\$ 300 & 1-2 \text { days } \\ \$ 5500 & 2 \text { weeks } \\ \$ 1000-2300 & 2-5 \text { days } \\ \$ 5400 & 2 \text { weeks } \\ \$ 1800-3100 & 4-7 \text { days } \\ \$ 50 & 1 \text { hour (2) } \\ \$ 60-100 & 1 \\ \$ 50-75 & (3)\end{array}$

Approximate

Cost Range

\section{Comments}

Approximate

Time
(1)

per square mile (3) per square mile (4)

$$
\begin{aligned}
& \$ 25-100(6) \\
& \$ 100-500(7) \\
& \$ 3000-10,000
\end{aligned}
$$
to $\$ 25,000(10)$ to $\$ 25,000(10)$ $\$ 200$ or more $(11)$

$$
\begin{aligned}
& 1-2 \text { hour (6) } \\
& 1-4 \text { hour (7) } \\
& 1 / 2-3 \text { days }
\end{aligned}
$$

$2 \mathrm{hr}-7$ days $2 \mathrm{hr}-7$ days (11) per measurement per measurement installation of recording system

per test per test

$$
\begin{aligned}
& \$ 250-1000(12) \quad 3 \text { weeks }(12) \\
& \$ 400-4000 \text { (13) } 1-10 \text { days (13) }
\end{aligned}
$$

per test

per model 
TABLE 2.2.4-6 (Cont.) - NOTES

(1) Cost and time for specific analysis, after compiling basic field data.

(2) Cost and time for single field measurement, using simple plywood wier, portable flume, or existing structure. Does not include travel to measurement site.

(3) Assumes 2-man field party working at rate of 10 to 15 square miles per day. Actual costs and rates of progress would vary with field conditions.

(4) Assumes 2-man field party working at rate of 25 to 50 square miles per day, including cost of expendible sampling equipment. Costs for typical water-quality tests are in Table 1 of Appendix $G$.

(5) Not incluaing arilling or completion costs. See Appendix D.

(6) Manual measurement using tape or probe to about 750 ' depth - not including travel to well site.

(7) Measurement at greater depth, requiring winch to handle probe not including travel to well site.

(8) Costs and time requirements for testing vary according to depth, duration of test, and size or type of drilling equipment used. See Appendix G.

(9) Pump test costs depend on equipment in place at a well and duration of the test. Can be done for about $\$ 200$ at existing water-supply well with pump in place. Cost can be thousands of dollars for complex testing systems requiring installation of pump, power supply, and equipment for monitoring water levels.

(10) Cost and time estimate for high-technology testing in tight formation at repository depths. Includes mobilization of specialized equipment and preliminary analyses of results.

(11) For long-duration tests, as may be needed in formations with low permeability, costs are likely to be determined by need for continued monitoring, involving pumping or bailing to detect tracers in deep aquifer. Such tests could cost several thousand dollars.

(12) Does not include cost or time for obtaining core.

(13) Cost and time for numerical analyses only, after basic field and lab data are compiled. 
TABLE 2.2.4-7

COST AND TIME SUMMARY FOR

SEISMOTECTONIC TECHNIQUES

Technique

Historical Data

Instrumental Data

Fixed Network

Installation
Operation

Portable Network

Crustal Refraction - Profile
Approximate Cost Range

Time

Comments

$\$ 2,900-5,900$

2 weeks

per basic analysis

$\$ 5,800-8,800$

1-2 months

per basic analysis

$\begin{array}{lcl}\$ 8,000-10,000 & 12-28 \text { weeks } & \text { per station } \\ \$ 7,300-14,600 & -- & \begin{array}{l}\text { cost per } \\ \text { station } / \text { year }\end{array}\end{array}$

$\$ 3,250-5,700$

2 days

cost per (to install)

station/month

$\$ 2,000-\$ 5,400 \quad 1-4$ weeks

per station 
the various information needs for $\mathrm{HWW}$ repository siting in granite requires that the resultant data be adequate to fulfill the information needs and of sufficient resolution and reliability. The previous sections of this report have addressed techniques which are likely to be applied in precharacterization studies in granite. The following subsections will describe the exploration and testing program which will generally be adequate to fulfill the information needs of each major technical discipline (i.e., geology, hydrology, geochemistry, geomechanics/thermomechanics, seismotectonics, and resources). Limitations or problems which may exist in applying the various techniques to the information needs at the precharacterization stage of work in granitic rocks will also be discussed.

\subsubsection{Geology}

To adequately meet the information needs relating to geology, the following exploration and testing techniques should be applied:

- Overburden Iithology/stratigraphy/structure - remote sensing, surface mapping, borehole logging, seismic refraction, drilling.

- Host rock thickness/lateral extent - remote sensing, surface mapping, borehole logging, gravity, audio-magnetotellurics, magnetics, drilling.

- Host rock lithology/stratigraphy structure - remote sensing, surface mapping, borehole logging, gravity, audio-magnetotellurics, seismic refraction, resistivity, magnetics, geomechanics, seismology, drilling.

- Surface erosion - remote sensing, surface mapping.

As in any medium, surface geology and geologic processes should be well understood from the precharacterization studies at a site in granite. Information on Quaternary paleoclimates is needed for analyses of the geologic processes and should be developed in the course of this work. similarly, these surface studies should identify faults or other discontinuities that may be expressed at the surface.

The investigations should encompass the prospective site and include information from off-site as needed to confidently satisfy the information needs. For a prospective site in granite, surface expressions of fractures, joints and faults are a particular concern and should be emphasized in this effort. However, for the most part, approach and 
scope of the surface geologic studies will be determined by the conditions at a prospective site and cannot be predicted on a generic basis for granite.

Criteria for evaluating the techniques used in surface geology will depend on site conditions. In general, the validity of results from these techniques is determined by the quality of geology information in relation to the complexity of the geologic record. Factors that should be considered regarding completeness of surface geologic information include: (1) types of geologic materials exposed at the surface, (2) extent and continuity of structural features, (3) nature of vegetation and other cover, and (4) seasonal effects on remote sensing data.

Substantial information on subsurface stratigraphy, lithology, and geologic structure is needed to select a prospective site in granite and to confidently plan the characterization program. Data obtained in this regard should include thickness, lateral extent, and lithology of the prospective host rock as well as information on the overburden and host rock below the repository level that may be needed for hydrology and other analyses. Although off-site preliminary information may be available, these investigations require new drilling and logging with supplemental geophysical exploration surveys to extrapolate information from the borehole locations.

\subsubsection{Hydrology}

A program of hydrologic exploration and testing should apply the following techniques to the information needs:

- Hydrostratigraphy - drilling, borehole logging, aquifer testing.

- Recharge/Discharge - remote sensing, surface mapping.

- Porosity-Permeability - drilling, borehole logging.

- Aquifer Properties - arilling, borehole logging, aquifer tests.

- Heads and Gradients - aquifer tests, drilling.

- Flow direction/velocity/travel time - ground-water age-dating, numerical modeling, aquifer tests.

- Ground-water age - numerical modeling, age-dating techniques.

- Surface hydrology - remote sensing, surface mapping, flood frequency analyses, water chemistry. 
Surface hydrology, as related to both present and past (Quaternary) climate conditions, should be well established by the precharacterization work. As in the case for surface geology, the approach and scope of this work and the criteria for evaluating the techniques used are essentially independent of the prospective host medium. These will be determined by the surface conditions at a prospective site.

Investigations of subsurface hydrology prior to site characterization should include determining hydrostratigraphy of the overburden and identifying aquifer properties of fractures and potential fracture-flow paths above, within, and below the prospective host rock. Aquifer properties and dynamics of ground-water movement should be determined with considerable confidence, although additional, more detailed analyses will be performed during site characterization.

\subsubsection{Geochemistry}

In order to adequately evaluate the geochemical aspects of a site, exploration and testing should include the following:

- Rock mineralogy and alteration - surface mapping, borehole logging, geomechanical field observations, drilling.

- Retardation properties - drilling, borehole logging, water-rock modeling.

- Geochemical age dating - sampling and graphical and statistical analyses.

Geochemical findings at the precharacterization stage in granite should be reviewed in the context of their relationship to the overall geologic framework. Information needs to be evaluated will consider the interaction between ground water and mineralogy along existing joints and fractures to determine replacement or alteration products. Dissolution along these discontinuities which are potential pathways for radionuclide migration will also need to be assessed. These techniques will aid in evaluating the flow rate of ground water within the host rock at repository levels. 


\subsubsection{Geomechanics}

A generally adequate exploration and testing program for assessing geomechanical/thermomechanical properties would include the following:

- Rock quality/discontinuities - surface mapping, remote sensing, borehole logging, field observations, laboratory testing, drilling.

- In-situ stresses - drilling, borehole logging, laboratory testing.

- Strength parameters - drilling, borehole logging, laboratory testing.

- Specific heat - drilling, borehole logging, laboratory and in situ testing.

- Thermal conductivity/expansion/alteration - drilling, borehole logging, laboratory and in situ testing.

It should be demonstrated that the host rock be of sufficient strength to adequately support openings and have adequate thermal conductivity to absorb or dissipate the heat generated by the radioactive waste. knowledge of the mineralogy of the host rock and fractures is important since there is some correlation between quartz content and thermal conductivity (Birch and Clark, 1940).

The proper selection of rock samples for laboratory testing is an important criteria. As stated previously, large representative samples or samples smaller than the fracture spacing are needed to obtain accurate results in granite. Many laboratory tests will give erratic results if fractures present in the rock are not taken into consideration when selecting samples for testing. It will be important to obtain oriented core to adequately evaluate the geometry of the fracture patterns in the rock.

\subsubsection{Seismotectonics}

Evaluating the adequacy of regional seismological and tectonic data for a prospective site in granite is essentially similar to evaluations in other media or for other types of critical facilities. An adequate exploration and testing program for confirming the seismic stability of the region should include the following:

- Faulting - remote sensing, surface mapping, borehole logging, geophysical exploration, fault studies, earthquake analyses. 
- Igneous Activity - remote sensing, surface mapping, drilling and logging, geophysical exploration.

- Earthquakes - historical and instrumental earthquake analyses, monitoring networks, velocity and fault studies.

- Uplift and Subsidence - remote sensing, surface mapping, earthquake analyses, fault studies.

A problem associated with evaluating the seismicity and tectonic framework of a region is the deterministic evaluation of the maximum credible earthquake. Sites within low seismic risk zones may have large intensity events which must be considered on an individual basis when evaluating the maximum credible earthquake such as in the midcontinent region of the U.S. To adequately evaluate the recency of faulting, trenches may need to be excavated to confirm relative age relationships of Quaternary deposits and to find suitable material for absolute age dating. Surface mapping and remote sensing of faults can lead to inaccurate interpretation of the regional structure. Subsurface geophysical testing is needed to identify undetected faults or faults at depth.

\subsubsection{Resources}

In order to evaluate the mineral and geothermal resources, an adequate exploration and testing program should include the following techniques:

- Mineral resources - remote sensing, surface mapping, drilling, borehole logging, geophysical exploration, geochemical sampling.

- Geothermal resources - remote sensing, surface mapping, arilling, borehole logging, geophysical exploration, geochemical analỵsis, temperature gradients.

Resource potential and existing resource evaluation of a prospective site can be determined by the precharacterization studies and should be well established before undertaking the commitment of time and expense involved in site characterization.

Areas of existing or known resources should be identified from general geologic investigations; however, resource evaluation using exploratory and testing techniques must be conducted to avoid the utilization of potentially valuable resource areas. Regional evaluation of mineral and geothermal resources generally cannot be applied to site-specific areas. Many areas of granite contain few mining operations but still may contain undeveloped, potentially valuable resources. 


\subsection{SITE CHARACTERIZATION STUDIES}

\subsubsection{GEOLOGIC FEATURES OF GRANITE IMPORTANT FOR SITE CHARACTERIZATION}

The preceding section on precharacterization studies (Section 2.2) presented a detailed description of the geology of granitic rocks; specifically origin, emplacement, lithology, stratigraphy, and structure. That discussion emphasized properties which could be determined by surface and subsurface exploratory techniques. During site characterization, these geologic properties will be studied in greater detail by direct observation and in situ testing. The purpose of this section is to summarize the important geologic aspects as they apply to site characterization.

With regard to geology, the most pertinent issues for site characterization are the presence of fractures and discontinuities (joints, faults, dikes), and the mineralogy of the host rock and fracture fillings. Granitic rocks suitable for waste repository siting occur as large plutonic bodies which may be up to tens of miles across and thousands of feet thick. Plutons form by magma injection or intrusion into the surrounding rocks or by the replacement of the surrounding rock. During the process of emplacement and cooling of the granitic magma, joints, fractures, and secondary intrusions such as dikes cause inhomogeneities which affect the properties of the rock mass as a whole. These discontinuities are important to characterize as they represent potential ground-water flow paths and mechanisms for possible radionuclide migration to the biosphere.

The composition of granitic rocks depends primarily on the amounts of quartz, feldspar, and mafic minerals present in the rock (Figure 2.2.2-1). Common granitic rocks will range from "classic" granite which contains predominantly quartz and alkali feldspar to gabbro and diorite which contain little or no quartz, but do contain plagioclase feldspar and abundant mafic minerals. The mineralogy of the host rock will be important to repository siting for assessing thermal and strength parameters of the host rock. The occurrence of secondary mineralization along joints and fractures is also an important consideration when discussing the geology of granitic rocks because of the reaction potential between the minerals along the fractures, ground water, and possible radionuclides.

Generally, large, homogenous granitic plutons contain numerous joint sets, fractures, and other discontinuities. However, fractures, and joints which may be extensive at the surface or along the margins of the pluton typically decrease in size, openness, and number with depth due primarily to lithostatic pressures. 


\subsubsection{General}

Precharacterization information needs for a prospective repository in granite have been presented in Section 2.2.2, with emphasis on studies performed for selecting a potentially suitable site. The information needs specific to site characterization however, are those that require the detailed exploration and testing techniques available at this stage. While many of the techniques used in precharacterization continue to be applicable, the important difference involves the excavation of a pilot shaft and development of a test room within the repository interval. This allows much more detailed examination and in situ testing of the rocks at depth as well as providing a base for intensive exploratory drilling (horizontal and/or inclined) in granite without creating a connection between the prospective repository and the biosphere. As a result, it is possible to obtain a very large amount of detailed information on the proposed host rock during site characterization. However, this exploration and testing involves considerable expense and significant schedule commitment, beginning with design and construction of the pilot shaft and test room.

Because of the time and expense involved in the site characterization effort, there must be a high level of confidence in the ultimate suitability of a candidate site, based on results of precharacterization. In general, precharacterization is expected to resolve those issues that may be addressed without the detailed exploration and testing at depth. Issues that may be essentially resolved in precharacterization include surface geology, surface hydrology, climate, tectonics, seismicity, and potential for igneous activity. Exploration history and resource potential at the site are also precharacterization issues that may be determined by investigations that are of a reconnaissance level, and therefore can be resolved in advance of site characterization.

Following suitable completion of the precharacterization studies, the main issues to be emphasized in site characterization are: (1) verifying site suitability with regard to containment and isolation of radionuclides and (2) providing the detailed site-specific parameters for design and construction of a repository. In addition, there would

be continued exploration and testing to better quantify or increase reliability of information in other areas as well as continued monitoring of precharacterization results to confirm the previous findings of potential site suitability. 
The following subsections discuss the information needs specific to site characterization of a prospective repository site in granite under the categories of: geology, hydrology, geochemistry, geomechanics, seismotectonics, and resources. For each category there is a brief description of the information that is assumed to have been obtained from precharacterization.

\subsubsection{Geology}

Information needs at the site characterization level will result in obtaining more detailed information on geologic conditions at the repository site, as they relate to design, construction, and performance of the repository. The geologic issues summarized in Section 2.2.2 are common to both levels of investigation but would be evaluated in more detail during the site characterization studies.

Precharacterization studies should be adequate to define surface geologic conditions and processes, and generally define the stratigraphy, lithology, and structures present at the surface and at depth. Subsurface geologic information at the precharacterization level should have included depth, thickness, and lateral extent of the granite pluton. Structural features and discontinuities such as faults, fractures, joints, and dikes should be identified during precharacterization and serve to define the limits of the repository. Table 2.3.2-1 lists the geologic issues that would be emphasized in precharacterization and those stressed in site characterization.

Intensive site characterization studies at repository depths will be required to verify and refine fracture density and orientation; depth, thickness and lateral extent of the host rock; lithology, texture, stratigraphy and structure of the host rock; and overburden conditions.

Fluid-flow effects of discontinuities on hydrology, geochemistry and geomechanics are probably the most important geologic information needs for site characterization studies in granite. Fracture geometry, including spacing, orientation, continuity, infilling and aperture greatly influence hydrologic parameters, such as:

- fracture permeability

- ground-water circulation

- ground-water flow rates and directions 
TABLE $2 \cdot 3 \cdot 2-1$

GEOLOGY INEORMATION NEEDS IN GRANITE

Emphasized in Precharacterization

1. Geologic processes.

2. Lithology, stratigraphy, and structure of the overburden and host rock above the repository level.

3. Depth to, and thickness of the host rock.

4. Discontinuities (fractures, joints, faults, dikes, etc.)

\section{Emphasized in Site Characterization}

1. Detailed mineralogy and lithology of the host rock.

2. Detailed mineralogy and lithology of fracture in-fillings.

3. Lateral variations in the host rock.

4. Fracture geometry.

5. Any other geologic anomalies. 
- ground-water convection (induced by radioactive heating of the host)

- ground-water residence time

Geomechanical/thermal parameters affected by fracture characteristics include:

- rock strength

- creep

- spallation, and

- $\quad$ stress variations

Geochemical fracture effects include:

- radionuclide sorption

- radionuclide migration

- alteration (natural or induced)

- waste/media and waste/joint filling interactions

- reaction rates (dependent on exposed area)

The geometry of the host rock (depth, thickness and lateral extent) bears heavily on the issues of construction design and retrievability performance. Host medium geometry, particularly thickness and lateral extent, sets bounding criteria on repository location and configuration, and repository depth is a factor affecting rock creep (geomechanical). Repository and water table depth (hydrology) will, in part, determine the hydraulic head and gradient present, and thus will affect water control. 
Lithology and stratigraphy is important to construction design for the evaluation of drillability and water control. The presence, pervasiveness and extent of fractures (including joints and faults) during excavation may affect the strength and stability of openings. Iithologic information also supports the hydrologic information needs for flow rates in aquifers or host rock and permeability measurements, and may also identify whether sorptive minerals, such as zeolites, are present in either the host rock or the overburden.

Petrography can be used to assist in establishing the lateral extent and thickness of suitable host rocks, the effects of heat and water on fracture infillings and rock alterations, and determine the host rock mineralogy and texture. The latter is important because mechanical strength is partially dependent upon mineral assemblage (Ghosh, 1980). Petrography can also be an adjunct to geochemical testing and for possible mineral resource evaluations.

\subsubsection{Hydrology}

The hydrological information needs specific to site characterization relate to fluids and flow paths within the granite and more importantly to fracture flow. The general hydrologic information needs discussed for precharacterization (Section 2.2.2.3) would continue to be addressed by exploration and testing at a greater detail and by continued monitoring. The information needs in hydrology that would be emphasized before and during site characterization are summarized in Table 2.3.2-2.

Climate history (present and past) and surface hydrology are surface investigations which should be resolved before detailed site characterization subsurface investigations are begun. Hydrology of the aquifers above and ground water occurrences within the proposed repository level should generally be well known from the subsurface precharacterization work, but continued evaluations and monitoring should be performed concurrently with site characterization.

Because the primary transport mechanism of radionuclides from repository to biosphere will be ground water, an accurate assessment of the hydrologic and hydrogeologic regimes is critical to site characterization. The information needs of hydrology for site characterization do not differ significantly from those defined in precharacterization, but do differ in the level of detail required.

Important information needs for site characterization will include both regional and local characteristics and include verification of the following (Appendix G-2): 
TABLE $2 \cdot 3 \cdot 2-2$

HYDROLOGY INFORMATION NEEDS IN GRANITE

\section{Emphasized in Precharacterization}

1. Climate.

2. Surface hydrology.

3. Aquifers.

4. Dissolution.

5. Water Chemistry.

Emphasized in Site Characterization

1. Fracture flow.

2. Quantification of aquifer properties.

3. Sorption properties.

4. Quantification of dissolution rates. 
- the occurrence, magnitude, and rate of ground water flow at the repository level

- the age and residence time of ground water within the repository

- the interrelationships between ground water and the proposed storage media (sorption)

- the thermal effects on the hydrologic regime

\subsubsection{Geochemistry}

Site characterization information needs in geochemistry are essentially as described in section 2.2.2.4 for precharacterization, but will emphasize rock and water chemistry at proposed repository levels and their influence on repository safety and performance. Table 2.3.2-3 compares the information needs for precharacterization with site characterization. Assessment of chemical properties along flow paths to the accessible environment is also necessary to evaluate radionuclide migration potential. Chemical conditions in shaft and borehole areas will be needed to provide repository sealing design parameters.

Waste/rock/water interactions, including waste/host rock and waste/ joint-filling reactions are important in radionuclide migration evaluations. Data are required on chemical reactions and rates, ion processes and nuclide solubility. Because radioactive material decay produces high canister temperatures, $845^{\circ} \mathrm{F}$ (Kaser, 1979), it is critical that all these parameters be evaluated as a function of heat, pressure and moisture content.

Prior to and during repository construction, a systematic program of geochemical sampling should be performed to assess any spatial (horizontal and vertical) geochemical variations, which will be used for:

- evaluating lateral extent and thickness of host rock

- predicting rock/water geochemical variations

- monitoring rock alterations for possible presence of previously undetermined mineral resources 
TABLE $2 \cdot 3 \cdot 2-3$

GEOCHEMISTRY INFORMATION NEEDS IN GRANITE

Emphasized in Precharacterization

1. Water chemistry.

2. Host rock chemistry.

3. Fracture filling chemistry.

4. Preliminary dating of rocks and fluids.

Emphasized in Site Characterization

1. Detailed chemistry of host rock and fractures.

2. Detailed fluid chemistry.

3. Reactions with canisters, waste and other engineering materials.

4. Ion exchange and radionuclide solubility.

5. Dating of rocks and fluids. 
Whole rock and fluid chemistry is valuable for the verification of:

o effects of heat and water on rock geochemistry

- geochemical changes due to existing or induced alterations

- radionuclide solubility and sorption

- ground water residence time

- natural radionuclide background levels

- mineralogy

- monitoring for possible mineral resources

\subsubsection{Geomechanics}

The precharacterization studies (Section 2.2.2.5) should have adequateIy established that geomechanical and thermomechanical conditions were potentially suitable for the proposed repository. They should also have included identifying discontinuities in the prospective repository zone and laboratory testing to identify the geomechanical/thermal properties of the fracture fillings present. The in situ stress and temperature fields also should be reasonably well determined by precharacterization. Geomechanical conditions in the overburden also should be determined by precharacterization, as these conditions must be known to design and excavate the pilot shaft. After these parameters have been evaluated and found to be within acceptable ranges, they should be confirmed and quantified in sufficient detail by continued laboratory testing during the site characterization program. Table 2.3.2-4 lists the geomechanical issues that would be emphasized in both precharacterization and site characterization.

One of the most critical information needs during site characterization consists of determining moduli and strength parameters of the host rock and related joints and fractures.

As summarized by Heuze (1981), critical issues for the Climax Granite can be applied to any granitic host rock. These issues are interrelated with the geological and hydrological needs as described in the preceding sections:

- fracture geometry 
TABLE $2 \cdot 3 \cdot 2-4$

GEOMECHANICS INFORMATION NEEDS IN GRANITE

Emphasized in Precharacterization

1. Temperature field.

2. In situ stress field.

3. Thermal conductivity and specific heat.

4. Deformation moduli of host rock.

5. Geometry of discontinuities and inhomogeneities of the host rock.

Emphasized in Site Characterization

1. Detailed survey of discontinuities and inhomogeneities in the repository zone.

2. Mechanical behavior of the host rock at elevated temperatures.'

3. Radiation effects.

4. Structural stability of the repository. 
- influence of discontinuities as a function of stress, temperature, aperture, and normal and shear deformations

- permeability of discontinuities as a function of stress, temperature, aperture, and normal and shear deformations

- thermomechanical and hydrological scale effects from laboratory to field

- determination of in situ stress state

- modeling for the prediction of discontinuous rock masses with regard to thermal field, induced stresses, displacement and hydraulic behavior

- influence of moisture content on the strength and deformation of the rock mass

- mechanical behavior of the rock mass at sustained elevated temperatures

- predictions for non-elastic rock mass behavior (creep, fracturing, etc)

- limiting conditions for thermal decrepitation, disintegration, and induced fracturing in the near field

- structural stability of rooms and pillars under sustained thermal loading

- influence of thermal perturbation on background microseismicity levels

\subsubsection{Seismotectonics}

The precharacterization information needs for a prospective repository in granite are essentially the same as in other media and are summarized in section 2'2.2.6. It is expected that these conditions would be demonstrated to be favorable at a site before selection for characterization. This would be particularly true for granitic rocks in areas having a past history of seismicity or tectonic movement. Seismic monitoring should be continued throughout site characterization and results should be incorporated into the repository design as appropriate. 


\subsubsection{Resources}

Resource potential of a site should be well established by precharacterization (Section 2.2.2.7) as it would seem inappropriate to conduct detailed testing at depth and then have a site found unacceptable because of pre-existing resources. Because the incidence of resource occurrence in granite is typically low, precharacterization results should be adequate for evaluating the presence of mineral and geothermal resources, but the resource potential of the site should be verified during site characterization by continued monitoring of the geologic, geomechanical and geochemical exploration results.

\subsubsection{TECHNIQUE APPLICATIONS TO SITE CHARACTERIZATION INFORMATION NEEDS IN GRANITE}

\subsubsection{General}

This section is intended to provide detailed technical information on the applications, effectiveness and resolution of pertinent exploration and testing techniques which would be conducted during site characterization studies at candidate repository sites in granite. Techniques applicable to precharacterization studies in granite are presented in Section 2.2.3. Most of the techniques described in the precharacterization section will continue to be important during the site characterization phase. These techniques would be used to continue to verify and update the data base and provide more detailed, site-specific information needed to characterize conditions at, and within the candidate repository. Table 2.3.3-1 summarizes the relationship of the applicable techniques to the information needs for site characterization in granite.

\subsubsection{Geology}

Preliminary data regarding surface and subsurface geology was obtained during precharacterization studies using remote sensing and geologic mapping techniques along with borings and associated geophysical loging tools. The results of the precharacterization studies provided data on the geometry of the host rock and lithology, structure and stratigraphy of the overburden and host rock. Site characterization studies will provide more detailed, site-specific information at the proposed repository level and serve to verify data obtained from precharacterization. 
TABLE 2.3.3-1 SITE CHARACTERIZATION TECHNIQUE APPLICATION

\begin{tabular}{|c|c|c|c|c|c|c|c|c|}
\hline $\begin{array}{l}\text { APPLICATIONS OF TECHNIQUES } \\
\text { TO INFORMATION NEEDS } \\
\text { FOR SITE CHARACTERIZATION } \\
\text { - MAJOR CONTRIBUTION } \\
\text { O SUPPORTING CONTRIBUTION }\end{array}$ & 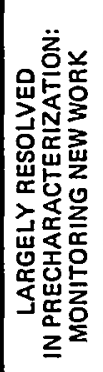 & 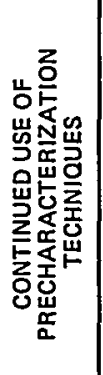 & 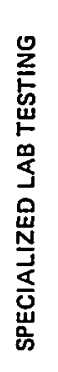 & 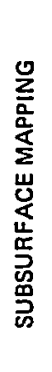 & 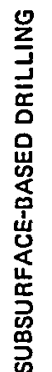 & 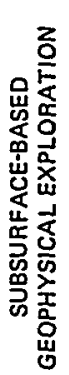 & 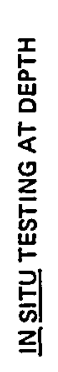 & 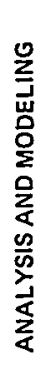 \\
\hline \multicolumn{9}{|l|}{ GEOLOGY } \\
\hline OVERBURDEN STRATIGRAPHY & $\bullet$ & 0 & & o & & & & \\
\hline DEPTH TO/LATERAL EXTENT/THICKNESS & $\bullet$ & 0 & & 0 & 0 & 0 & & \\
\hline FRACTURES/JOINTS/FAULTS & o & 0 & 0 & $\bullet$ & 0 & 0 & 0 & 0 \\
\hline LITHOLOGY/MINERALOGY/TEXTURE & 0 & 0 & 0 & $\bullet$ & 0 & o & & \\
\hline SEISMOTECTONICS/RESOURCES & - & o & & 0 & o & 0 & & \\
\hline SURFACE GEOLOGY & - & 0 & & 0 & & & & \\
\hline \multicolumn{9}{|l|}{ HYDROLOGY } \\
\hline FRACTURE FLOW & 0 & 0 & & & 0 & & $\bullet$ & 0 \\
\hline PERMEABILITIT & 0 & ○ & & & o & o & - & \\
\hline HYDRAULIC CONDUCTIVITY & 0 & 0 & 0 & & 0 & & $\bullet$ & 0 \\
\hline FLOW RATES & 0 & o & & & 0 & & $\bullet$ & 0 \\
\hline RESIDENCE TIMES & 0 & 0 & - & & & & 0 & 0 \\
\hline INFILTAATION & 0 & 0 & & & & & $\bullet$ & \\
\hline GROUNDWIATER CIRCULATION & 0 & 0 & & & 0 & & 0 & - \\
\hline HYOROTHERMAL & 0 & 0 & & & & & 0 & 0 \\
\hline FLOODING/SURFACE HYDROLOGY & $\bullet$ & 0 & & & & & & 0 \\
\hline
\end{tabular}


TABLE 2.3.3-1 (CONT'D) SITE CHARACTERIZATION TECHNIQUE APPLICATION

\begin{tabular}{|c|c|c|c|c|c|c|c|c|}
\hline $\begin{array}{l}\text { APPLICATIONS OF TECHNIQUES } \\
\text { TO INFORMATION NEEDS } \\
\text { FOR SITE CHARACTERIZATION } \\
\text { - MAJOR CONTRIBUTION } \\
\text { O SUPPORTING CONTRIBUTION }\end{array}$ & 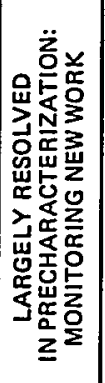 & 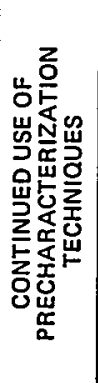 & 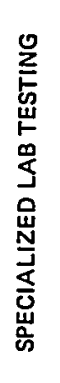 & 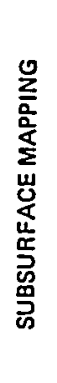 & 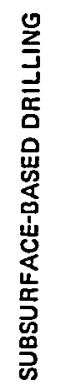 & 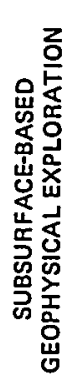 & 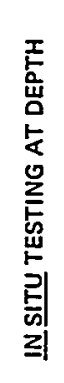 & 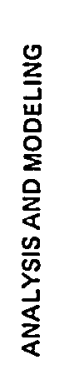 \\
\hline \multicolumn{9}{|l|}{ GEOCHEMISTRY } \\
\hline WASTE/ROCK INTERACTIONS & $\circ$ & $\bullet$ & $\bullet$ & & $\circ$ & & & $\circ$ \\
\hline WHOLE ROCK AND FLUID CHEMISTRY & o & $\bullet$ & $\bullet$ & & $\circ$ & & & $\circ$ \\
\hline \multicolumn{9}{|l|}{ GEOMECHANICS } \\
\hline MODULI AND STRENGTH TEST & 0 & - & $\circ$ & & $\circ$ & & $\bullet$ & \\
\hline STRESS VARIATION & $\circ$ & $\bullet$ & & & $\circ$ & & $\bullet$ & \\
\hline EXPOSURE EFFECTS & $\circ$ & - & & & $\circ$ & & $\circ$ & \\
\hline THERMAL PARAMETERS & $\circ$ & $\bullet$ & 0 & & $\circ$ & & $\bullet$ & \\
\hline SEISMOTECTONICS & $\circ$ & $\bullet$ & & & & o & & 0 \\
\hline RESOURCES & 0 & $\bullet$ & & & 0 & 0 & & \\
\hline & & & & & & & & \\
\hline & & & & & & & & \\
\hline & & & & & & & & \\
\hline & & & & & & & & \\
\hline & & & & & & & & \\
\hline & & & & & & & & \\
\hline & & & & & & & & \\
\hline
\end{tabular}


The regional geology would have been interpreted after completion of the precharacterization studies utilizing small-scale aerial photographs and satellite imagery in conjunction with regional geologic mapping. During the site characterization studies, large-scale aerial photographs $(1: 12,000$ to $1: 24,000)$ would be used to interpret in detail the geology at the repository site. The aerial photography would also be used to determine locations for drill sites and trench locations which may be needed for filling data gaps.

Detailed geologic mapping at the repository site would concentrate on the structural features of the granite. Mapping of discontinuities at this detailed scale would be important to determine the joint patterns, fracture geometry and any other discontinuities which may affect the construction and design of the repository.

Some additional drilling and associated geophysical logging would be conducted to proposed repository depths at all the shaft locations.. The same techniques would apply as in the precharacterization studies for drilling and logging. In addition, two geophysical methods not previously described during precharacterization studies (seismic crosshole method and mechanical downhole seismic velocity survey), would be conducted in existing and new drill holes to verify seismic wave velocities, and geomechanical strength moduli. An advantage downhole seismic velocity surveys have over surface refraction surveys is that lower velocity material can be detected underlying higher velocity material (Appendix B-8). Previous applications of these two techniques have been confined to shallow depths (a few hundred feet) but would provide important strength parameters to pilot shaft design.

During the construction of the pilot shaft, test room, and exploratory drifts, detailed geologic mapping and logging of the structural features and lithology of the host rock and overburden will be performed. In addition, inclined and/or horizontal holes will be drilled from within the excavations for the purpose of characterizing mineralogy, fracture patterns, and any other discontinuities at the repository level.

\subsubsection{Hydrology}

Hydrologic techniques used in site characterization include laboratory determinations of permeability and in situ tests at depth. Sophisticated ground-water modeling techniques would be important for evaluating fluid movement and dissolution (Appendix G-2). Dissolution residues and discontinuities that control potential flow paths would have been identified during precharacterization and verified from the 
geologic techniques discussed in the previous section. Applications of standard borehole and laboratory hydrologic tests would continue from precharacterization, as described in section 2.2.3.3. These tests would continue to refine and verify the gross hydrologic parameters.

Verification of ground water transport models generated in precharacterization studies is critical in understanding radionuclide migration. Site characterization will require the development of a three dimensional model of ground-water movement around and through the repository. This model can then be coupled with a radionuclide/host rock geochemical model to evaluate the activity level and rate of radionuclide migration. Aquifer and tracer tests will be performed to acquire hydrologic parameters for use as input data to the models described above. Modeling of the hydrologic regime under extremely low-flow conditions may exceed present state-of-the-art models.

Fracture flow data needed for input into the ground-water models for radionuclide migration evaluation may be obtained from: core analysis, excavation logging, down-hole geophysical logging, surfacebased geophysical exploration, aquifer and geochemical tests, core logging of both inclined and horizontal boreholes within the test room and detailed excavation logging. These techniques will aid in the identification of discontinuities (fractures, joints, and faults) which are potential pathways for ground-water flow.

Site characterization will utilize standard aquifer tests such as step-drawdown and constant discharge where flows are measurable. Additional head and gradient measurements along with water-level measurements, will be used in modeling the flow regime in local aquifers and establish water control needs for shaft excavation.

Packer tests will be performed to evaluate fracture flow. Parameters which influence the rate of ground-water flow through a fractured medium are: fracture spacing, aperture size, orientation, continuity, roughness, wall coatings, fracture filling, and uniformity of the openings (Isherwood, 1981).

\subsubsection{Geochemistry}

Geochemical techniques for site characterization in granite will be essentially similar to those in other media as described in Appendix F-2. In general, these techniques will fall into the areas of descriptive geochemistry and evaluations of geochemical reactions. 
Descriptive geochemistry will involve the application of standard laboratory techniques to assess fluid and rock compositions which are needed to evaluate lateral and vertical variations and radionuclide interactions with ground water and host rocks. Rock geochemistry will be analyzed from samples obtained in cores and in excavations.

Fritz and others (1979) describe the aqueous geochemical sampling and analyses which was conducted at Stripa, Sweden. The analyses included:

- field measurements of alkalinity (Eh, $\mathrm{pH}$, conductance, temperature, and dissolved oxygen)

- complete major ion analysis on samples from all ground water types

- determination of composition of dissolved gases on a selected number of samples, with special emphasis on noble gases

- deuterium and oxygen-18 analyses of the host rock

- carbon-13 and oxygen-18 analyses of fracture fillings

- analyses of carbon-13 in dissolved aqueous carbon

- determination of ground-water ages through analyses of tritium, carbon-14, uranium isotopes, and uranium daughter products

Evaluations of geochemical reactions would be based on the descriptive geochemical information and the anticipated thermal and fluid flow conditions in the repository as determined from results of the geomechanical and hydrological studies. These analyses would utilize the modeling techniques discussed in Appendix F-1.

\subsubsection{Geomechanics}

Geomechanical techniques applied to the information needs for site characterization in granite consist of laboratory testing, in situ testing, and analyses using appropriate models. Additional pertinent information to identify and describe discontinuities and inhomogeneities in the granite host rock will be obtained from the subsurface exploration techniques described in Section 2.3.3.2.

The applications of laboratory testing for site characterization are essentially identical as in precharacterization and will not 
be described here. Appendix E-2 provides a detailed discussion of techniques for in situ geomechanical testing in granite for site characterization. The tests described are generally applicable to granite, however, it is important to note that tests of this scale actually are specially developed programs which would be designed to meet the requirements of a specific site. Because all of the thermal, elastic, and mechanical properties of granite are a function of temperature (Isherwood, 1981), it is essential that the tests be performed over the anticipated temperature range.

Numerical or computer modeling of repository conditions and responses is also an important application for meeting the geomechanical information needs. The applications of specific modeling programs are discussed in Appendix $\mathrm{E}-2$ for site characterization and a comprehensive listing of computer codes applicable to various aspects of waste isolation has been prepared by Nuclear Safety Associates (1980).

\subsubsection{Seismotectonics}

Seismicity and tectonics techniques applicable for site characterization would largely consist of the continuation of monitoring the seismograph network established during precharacterization. Prospective repositories in granite will occur in regions of varied seismic activity from relatively stable areas (Great Lakes region) to areas of historically active earthquakes (Rocky Mountain region). It is expected that monitoring networks will determine the level of seismic activity at a prospective repository site during precharacterization. However, in the event a significant or anomalous seismic event occurs during site characterization, additional specific investigations may be required using the techniques discussed, in Appendix $\mathrm{H}$.

\subsubsection{Resources}

Evaluation of resource potential during site characterization should be limited to ongoing monitoring of the exploration programs and hydrology and geochemistry studies to confirm the findings of precharacterization. The techniques applied in this evaluation would be identical to those applied in precharacterization, and are discussed in section 2.2 .3 .7 . 
Estimates for the cost and time that would be required for the techniques used in characterizing a site in granite are summarized in Tables 2.3.4-1 through 2.3.4-6. Additionally, the work in site characterization would involve continued use of the techniques for precharacterization; the cost and time estimates summarized in Tables 2.2.4-1 to 2.2.4-7 would remain applicable for site characterization. In evaluating cost and time estimates for site characterization, an important consideration is that many of the tests are specially designed for site conditions and particular information needs. Durations of geomechanical and hydrologic tests, in particular, may be a design factor and can be important in determining costs.

\subsubsection{Geologic Mapping and Supporting Activities}

Typical cost and time estimates for detailed surface mapping that would be conducted at a prospective site during characterization, and the supporting work in remote sensing, excavation logging, and age dating are summarized in Table 2.3.4-1. This work would be performed during site characterization but chiefly would involve verifying previous findings. It would not be reasonable to undertake characterization at a site if there were significant outstanding questions regarding surface geology. For these estimates, it is assumed that access and trafficability would not be problems at a site chosen for characterization.

Table 2.3.4-2 summarizes typical cost and time estimates for mapping geologic conditions in the pilot excavations. Costs for the geochemical analyses that may be used in support of this mapping are provided in Appendix F-1. For subsurface mapping done in coordination with the excavation, cost and schedule are likely to be controlled by the need to avoid interference with the excavation process.

\subsubsection{Subsurface Based Drilling and Coring}

Appendix $D$ includes a comprehensive summary of the costs and penetration rates for various techniques used in drilling and coring from pilot excavations. Information applicable to granite is summarized in Table 2.3.4-3, with some revisions to the Appendix costs for increased compatibility with the costs for other techniques. Costs for mobilization and delays for availability of suitable equipment are not included on the assumption that the site characterization program should be of sufficient magnitude to maintain the required equipment on site for a significant period. 
COST AND TIME SUMMARY FOR SURFACE GEOLOGIC TECHNIQUES

IN SITE CHARACTERIZATION

\begin{tabular}{cc}
$\begin{array}{c}\text { Approximate } \\
\text { Cost }\end{array}$ & $\begin{array}{c}\text { Approximate } \\
\text { Time }\end{array}$ \\
\hline
\end{tabular}

REMOTE SENSING INTERPRETATION

1:4800 photo analysis

( 100 photos for $12 \mathrm{mi}^{2}$ site)

$\$ 1,750-3,500(1) \quad 5-10$ man days

DETAILED SURFACE MAPPING

(for $12 \mathrm{mi}^{2}$ site area)

General Mapping

$\$ 12,000-18,000$

20-30 man days (10-15 field days for 2-man crew)

Detailed structure analysis (2)

$\$ 6,000$

10 man days (5 field days for 2-man crew)

EXCAVATION LOGGING (3)

Reconnaissance

$\$ 1,200 /$ day $(4)$

$10,000 \mathrm{ft}^{2} / \mathrm{day}(4)$

Detailed logging at $1^{n}=10^{\prime}$

$\$ 1,200 /$ day $(4)$

$1,500 \mathrm{ft}^{2} /$ day (4)

NOTES:

(1)

Does not include cost of large scale stereographic aerial photos, assumed to be available in site characterization.

(2)

Only applicable where bedrock (overlying the salt) is exposed at the surface. Cost and time is in addition to general mapping.

(3)

For surface excavations such as exploratory trenches or quarry cuts. Also for natural exposures such as bluffs or stream banks.

Typical production rate and daily cost for 2-man field crew. Rates will vary according to access, difficulty of cleaning off the excavation, and, particularly, complexity of geologic conditions. Mapping of critical relationships at larger scale would require additional time. 
TABLE $2.3 \cdot 4-2$

COST AND TIME SUMMARY FOR SUBSURFACE GEOLOGIC MAPPING IN SITE CHARACTERIZATION (1)

\section{Cost Per Day}

\section{Typical Mapping}

Rate

Detailed Mapping

$\$ 650.00$

$1200 \mathrm{ft}^{2} / \mathrm{day}(3)$

of Shaft or Drift

at $1^{n}=5 \cdot(2)$

NOTES :

(1) Based on Appendix A-2.

(2) Typical scale for geologic mapping in drift 8 feet wide and 8 feet high, after completion of engineering survey and preparation of base maps.

(3) Actual rates depend on complexity of geologic conditions at the place mapped. 
TABLE 2.3.4-3

COST AND TIME SUMMARY FOR

SUBSURFACE-BASED DRILLING AND CORING

IN SITE CHARACTERIZATION (1)

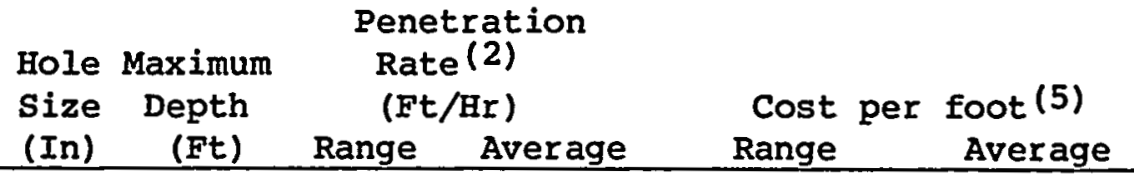

PERCUSSION DRILLS

Track arill

$2-5 \quad 200 \quad 400-500(3) 450(3) \$ 0.30-0.40(6) \$ 0.35(6)$

Core

Size

CORE DRILLS

$\begin{array}{ccccccc}\begin{array}{c}\text { Longyear } \\ \text { EHS 38 }\end{array} & \text { NQ }(1-7 / 8) & 1900 & 10-15(4) & 12(4) & \$ 9-13 & \$ 11 \\ \text { Longyear } 65 & \text { BQ }(1-3 / 8) & 500 & 3-5(4) & 4(4) & \$ 17-27 & \$ 23\end{array}$

NOTES:

(1) Adapted from Appendix D-2

(2) Not including move-in or set-up time. Rates calculated for representative drill or core sizes and would differ for other sizes.

(3) At 678 efficiency.

(4) At 508 efficiency.

(5) Direct operating costs $\times 1.75$ to account for administration, insurance, interest, contractor's profit margin and other typical cost factors. Does not include cost of on-site geologic inspection or subsequent core logging. Does not include allowance for standby time.

(6) Compressor costs calculated assuming two drills per compressor 
Techniques for geologic logging of the cuttings and core, as discussed in Appendices $\mathrm{D}-1$ and $\mathrm{E}-1$ would continue to apply in site characterization. Geophysical logging techniques discussed in Appendix $C$ also would remain applicable for vertical and near vertical holes; costs generally would be as summarized in Table 2.2.4-3.

\subsubsection{Geophysics}

In general, the geophysical techniques techniques discussed in Appendices B-1 to B-8 would remain applicable in site characterization and costs would continue to follow the parameters outlined in Table 2.2.4-4. Costs and time estimates for the techniques used in site characterization for detailed evaluation of near surface engineering parameters and for exploring the rock surrounding the pilot excavations are summarized in Table 2.3.4-4.

The radar and sonar techniques used for subsurface exploration in geologic media are specifically designed systems and therefore can differ significantly in costs and capabilities. Moreover, new techniques are continually under development, making it difficult to forecast costs and capabilities for work that would be performed in future years.

\subsubsection{Hydrology}

Costs and times for the hydrologic techniques most important in site characterization are summarized in Table 2.2.4-5, based on the information in Appendix G-2. All of the techniques in the table involve testing programs that vary in cost and duration according to their design, in addition to the properties of the medium. Costs of drilling and well completion are not included in the estimates for the hydrologic techniques.

\subsubsection{Geochemistry}

Cost estimates for typical geochemical analyses are summarized in Appendix F-1. The specific tests and the number of analyses needed would be determined by site conditions and cannot be quantified reliably on a generic basis. The main factors determining turn-around time for results of the geochemical analyses are capabilities of the available laboratories, their work load, and the priority of the specific project. It is expected that most individual analyses 
COST AND TIME SUMMARY FOR

GEOPHYSICAL TECHNIQUES

IN SITE CHARACTERIZATION

\begin{abstract}
Approximate
Cost

Approximate

cost

SEISMIC CROSSHOLE

(typical survey to about

$\$ 34,000-39,000(1)$

4-5 weeks (2)

500 feet)

DOWNHOLE SEISMIC VELOCITY

(typical survey to about

$\$ 7,500-16,000(1)$

2-3 weeks (2)

500 feet)

RADAR OR SONAR

(from pilot excavation)

$\$ 5,500(3)$

3 days (3)

NOTES:

(1)

Includes drilling costs.

(2) Turn around time for results from beginning field work. Does not include mobilization.

(3) Typical cost and field time for set of radial probings from single test room. Only a few sources provide radar or sonar services commercially. Both services are available from Rock Probers, Inc. (c/o Dr. R. R. Unterberger, Texas A \& M Univ.). Xadar Corporation, formerly Ensco, Inc. (Springfield, Virginia) provides radar. Typical daily rates are $\$ 1,500$ (Rock Probers, 2 or 3 man crew) to $\$ 1,750$ (Ensco, 2 man crew) for a minimum of three days, not including travel. Following initial setup and calibration numerous probes can be done in a day. Ensco estimates that lateral probes can be done along a tunnel at 1000 to 2000 feet per day. Actual duration of work in pilot excavations would depend on their layout and extent, and on the need to recalibrate radar velocities due to variations in the medium. (J. Fowler, 1981, personal communication, and R. R. Unterberger, 1981, personal. communication).
\end{abstract}


TABLE 2.3.4-5

COST AND TIME SUMMARY FOR

HYDROLOGIC TECHNIQUES

IN SITE CHARACTERIZATION

\begin{tabular}{lcc}
$\begin{array}{c}\text { Tests and } \\
\text { Analyses }(1)\end{array}$ & $\begin{array}{c}\text { Approximate } \\
\text { Cost Range (2) }\end{array}$ & $\begin{array}{c}\text { Approximate } \\
\text { Turn around } \\
\text { Time }(3)\end{array}$ \\
\hline INJECTION TESTS & $\begin{array}{c}\$ 20,000-50,000 \\
\text { per test }\end{array}$ & $5-15$ days \\
STRADDLE PACKER TESTING & $\begin{array}{c}\$ 10,000-25,000 \\
\text { per test }\end{array}$ & $5-15$ days \\
TRACER TESTS & $\begin{array}{l}\$ 20,000 \text { or more } \\
\text { per test interval }\end{array}$ & $\begin{array}{l}\text { Time until } \\
\text { detection } \\
\text { depends on } \\
\text { site conditions }\end{array}$ \\
& &
\end{tabular}

FLOW SYSTEM MODELING

Without fracture flow

2 dimensional

$\$ 20,000$

2-4 weeks

3 dimensional

$\$ 30,000$

3-6 weeks

With fracture flow

2 dimensional

$\$ 50,000$

5-10 weeks

3 dimensional

$\$ 75,000$

7-15 weeks

NOTES:

(1) Described in Appendix G

(2) These tests are typically designed for particular site conditions in characterization. Costs are determined by test design and duration.

(3) Times for hydrologic tests are determined by site conditions and may vary significantly. 
for site characterization could be performed within a few weeks but longer times may be required for specialized analyses or for work on large numbers of samples.

\subsubsection{Geomechanics}

The work in geomechanics and thermomechanics for site characterization involves specialized laboratory testing and in situ tests designed individually for each program. Representative costs and times are provided in Table 2.3.4-6 but these can differ significantly according to design of a specific program. In particular, the number of tests required to characterize a site would be determined by the variability of site conditions and the proposed repository layout. Instrumentation life span is a notable problem for long duration tests and the development of new or unique systems could be costly.

\subsubsection{CRITERIA FOR EVALUATING DATA ADEQUACY OF SITE CHARACTERIZATION STUDIES IN GRANITE}

\subsubsection{General}

The previous discussions of geologic features (Section 2.3.1), information needs (Section 2.3.2) and technique applications (Section 2.3.3) pertinent to site characterization can be used to develop criteria for evaluating a site characterization study in granite. This study should include an evaluation of the precharacterization data, its applicability and degree of refinement resulting from site-specific studies. It is assumed that precharacterization studies have satisfactorily answered the information needs of the task. Based on this assumption, the following subsections will discuss the criteria of techniques which are relatively unique to site characterization. Following the organization of previous chapters, the criteria are grouped by discipline, i.e., geology, hydrology, geochemistry, and geomechanics. No criteria are presented for seismotectonics and resources in this section because information needs and applications in these categories are completely discussed previously.

\subsubsection{Geology}

Geologic information needs and applicable techniques have been previously discussed and it is assumed that site characterization studies will be used to verify and refine precharacterization data. However, 
TABLE $2.3 \cdot 4-6$

COST AND TIME SUMMARY FOR GEOMECHANICS TECHNIQUES

IN SITE CHARACTERIZATION (1)

Tests $^{(2)}$

HYDROTHERMOMECHANICAL

IN SITU BLOCR TEST

SCHMIDT HAMMER CHARACTERIZATION OF JOINTS IN TEST ADIT

CORE TILT TESTING Apparatus (purchase or fabrication costs)

Typical set of tests

JOINT TILT TESTING (program)

SELF WEIGHT SLIDING TEST

(on large jointed blocks)

\section{Approximate} Cost
Approximate

Duration

$$
\$ 600,000-700,000(3) \quad 9-12 \text { months (3) }
$$

$$
\$ 1,000(4) \quad 1-2 \text { days }
$$

$\$ 500$

$$
\mathrm{N} / \mathrm{A}
$$

$\$ 500$

one day

$$
\$ 10,000
$$

2 weeks

$$
\$ 2500-4500 / \text { sample }
$$

NOTES:

(1) Geomechanical testing for site characterization involves test programs designed for particular information needs and site specific conditions. Costs and durations will vary according to test design.

Descriptions in Appendix E-2.

(3) Not including excavation of test room.

(4) Including cost of schmidt hammer. 
pilot shaft and test room excavation and associated inclined or horizontal drilling introduce additional techniques for direct examination of the host rock at repository depths. The following information needs and the applicability of new techniques for studies in granite are:

- Lithology, stratigraphy and structure - downhole T.V. or radar viewing (in borehole); excavation logging (pilot shaft and test room); radar ranging

- Thickness and lateral extent - excavation logging; radar ranging

Accurate pilot shaft excavation logging will provide good correlation of downhole geophysical loggging and surface exploration techniques, permitting further refinement and verification of previous data. Application of these new techniques, combined with data from other techniques, should adequately characterize some of the unique features of granite such as: fracture geometry and density, and lithologic and mineralogic variations.

\subsubsection{Hydrology}

Testing during this phase will largely be used to verify previous data, and precharacterization and site characterization data used as an input data base for two important modeling studies. The initial study will model the hydrologic conditions in and around the repository and be primarily concerned with fracture flow. This model and additional data will be input for a second program to model radionuclide migration. With the exception of extensive use of numerical modeling techniques, other applicable hydrologic criteria have been previously discussed (Section 2.2.5.3). Utilization of pre- and site characterization data should be oriented toward consideration of unique features in granite which will affect hydrologic conditions, including:

- host rock flow anisotropies

- host and fracture permeabilities

- increased horizontal flow rates due to structural features (joints, faults, dikes, etc.) 


\subsubsection{Geochemistry}

Geochemical criteria for precharacterization have been summarized in Section 2.2.5.4, and it is anticipated the information from site characterization will be used to verify previous data. In addition to the previously described techniques, the rock and water geochemical properties must be determined over the range of temperature, moisture content and pressure anticipated in the repository. These data will be used to determine radionuclide sorption and reaction rates, as well as provide input to the radionuclide migration modeling program.

Unique geochemical features of granite which must be considered include:

- Reaction of host rock and fracture infilling materials with water and waste

- Extent, pervasiveness, and surface area of fractures available for interaction with wastes and water

- Possible lateral or vertical rock chemistry variations in repository volume

- Long term elevated temperatures and steep temperature gradients due to low heat conductivity

\subsubsection{Geomechanics}

Precharacterization geomechanical criteria have been previously discussed (Section 2.2.5.5). The primary difference between pre- and site characterization data is that the boreholes, pilot shaft, and test room(s) allow in situ testing of the host rock. In addition to standard laboratory tests previously discussed, this phase should be heavily biased toward in situ testings of the host rock. Information needs and applicable in situ tests are shown below.

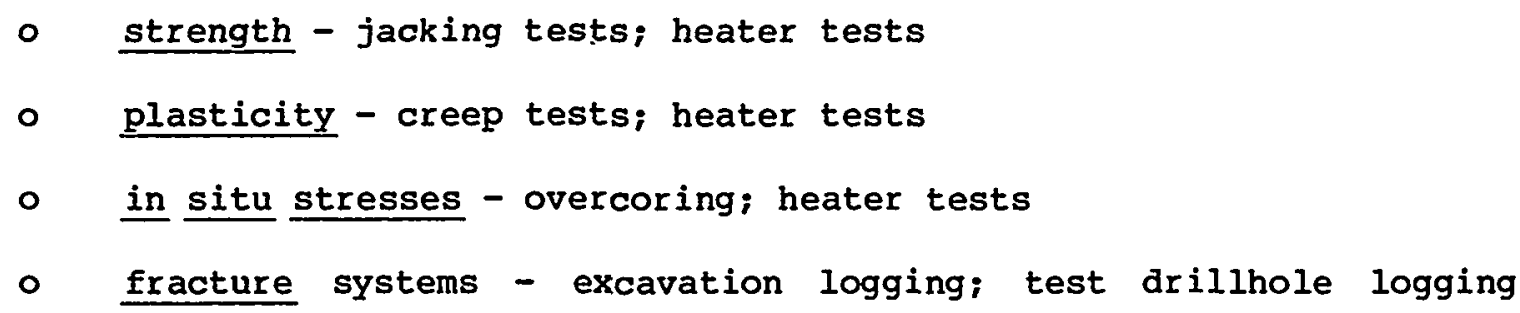


Because granite has a low thermal conductivity, it can be assumed that temperature gradients from waste canister heating will be steep and persist for a long time period. The increased stress due to these temperature gradients requires in situ heater tests to establish the geomechanical parameters.

In addition to the temperature variation of geomechanical parameters is the problem of thermal parameter variation with temperature. Because basic thermal property measurements in the laboratory do not duplicate natural conditions, it is essential that in situ values of these parameters be determined whenever possible.

Unique features of granite which should be addressed during geomechanical and thermal testing are:

- existence of conversion factor between laboratory and in situ tests

- intraflow parameter variations

- wet/dry strengths

\subsection{REFERENCES}

Badgley, P.C., 1965, Structural and Tectonic Principles: Harper and Row, New York, 521 p.

Billings, M.P., 1954, Structural Geology (Second Ed): Prentice-Hall, Inc., New Jersey, 514 p.

Birch, F., and Clark, H., 1940, The Thermal Conductivity of Rocks and its Dependence on Temperature and Composition: American Journal of Science, Vol. 238, 11 p.

Carlson, R. C., and others, 1980, Spent Fuel Test - Climax: Technical Measurements Interim Report, FY 1980: Lawrence Livermore National Laboratory Rpt. No. UCRL - 53064, 104 p.

Carmichael, I.S., Turner, F.J., and Verhoogen, J., 1974, Igneous Petrology: McGraw-Hill Book Company, New York, 739 p.

Chan, T., and others, 1980, Thermal and Thermomechanical Data from In Situ Heater Experiments at Stripa, Sweden, Technical Information Report No. 29: Swedish Nuclear Fuel Supply Co. and Lawrence Berkeley Laboratory, Rpt. No. LBL-11477, 102 p.

$$
2-79 \text {. }
$$


Clark, S. P., Sr., 1966, Handbook of Physical Constants: Geological Society of America Memoir 97, 587 p.

Dames and Moore, 1978, Technical Support for GEIS: Radioactive Waste Isolation in Geologic Formations, Vol. 3, Stratigraphies of Salt, Granite, Shale, and Basalt: Union Carbide, Office of Waste Isolation Rpt. No. Y/OWI/TM-36/3.

- 1979, Crystalline Intrusives in the United States and Regional Geologic Characteristics Important for Storage of Radioactive Waste: Battelle, office of Nuclear Waste Isolation, Draft Rpt. No. ONWI-50.

Fritz, P., Barker, J. F., and Gale, J. E., 1979, Geochemistry and Isotope Hydrology of Groundwaters in the Stripa Granite, Results and Preliminary Interpretation: Lawrence Berkeley Laboratory, Tech. Info. Rpt. No. 12, LBL-8285, 135 p.

Geotimes, 1973, Plutonic Rocks, Classification and Nomenclature Recommended by the IUGS Subcommission on the Systematics of Igneous Rocks: Vol. 18, No. 10, October 1973, pp. 26-30.

Ghosh, D. K., 1980, Relationship between Petrological, Chemical and Geomechanical Properties of Deccan Basalt, India: Bulletin of the International Assoc. of Engineering. Geology, No. 22, pp. 287-292.

Gilluly, J. (chairman), 1948, Origin of Granite: Geological Society of America Memoir 28, 139 p.

Heuze, F. E., 1981, The Climax Granite, Nevada Test Site, as a Host for a Rock Mechanics Test Facility Related to the Geologic Disposal of High Level Nuclear Wastes: Lawrence Livermore Laboratory Rpt. UCID-18946, 44 p.

Heuze, F. E., Patrick, W. C., De la Cruz, R. V., and Voss, C. F., 1981, In Situ Geomechanics, Climax Granite, Nevada Test Site: Lawrence Livermore National Laboratory Rpt. No. UCRL-53076, 63 p.

Isherwood, D., 1981, Geoscience Data Base Handbook for Modeling a Nuclear Waste Repository, Vol. 2: Lawrence Livermore Laboratory Rpt. UCRL -52719 , 331 p.

Karnbranslesakerhet (KBS), 1977, Handling of spent Nuclear Fuel and Final Storage of Vitrified High Level Reprocessing Waste, Vol. II, Geology: Swedish Government (PRAVO), 81 p. 
Raser, J. D., 1979, Thermal Analysis of Hanford Defense Waste, Strontium and Cesium Capsules Isolated in Basalt: Atomics International Div. Rockwell Hanford Operation, U8001, 33 p.

Marine, I.W., 1979, Hydrology of Buried Crystalline Rock at Savannah River Plant near Aiken, South Carolina: U.S. Dept. of Energy, Savannah River Operations Office Rept. No. DOE/SR-WM-79-2, 220 p.

Nuclear Safety Associates, 1980, Post-closure monitoring and prediction of long-term repository performance; Section III-G in Document 2 of 4, Statement of Position of the Utility Nuclear Waste Management Group-Edison Electric Institute In the Matter of Proposed Rulemaking on the Storage and Disposal of Nuclear Waste, PR-50, -51 .

Olkiewicz, A., Gale, J. E., Thorpe, R., and Paulson, B., 1979, Geology and Fracture System at Stripa; Technical Information Report No. 21: Swedish Nuclear Fuel Supply Co. and Lawrence Berkeley Laboratory, Rpt. No. LBL-8907, 164 p.

Park, C. F., Jr. and MacDiarmid, R. A., 1964, Ore Deposits (Second Ed.): W. H. Freeman and Company, San Francisco, 522 p.

Smedes, H. W., 1980, Rationale for Geologic Containment of High-Level Radioactive waste, and Assessment of the Suitability of Crystalline Rocks: U.S. Geol. Survey Open File Rpt. 80-1065.

Smith, R. M., 1981, Source of Mother Lode Gold, in California Geology, May 1981: California Divison of Mines and Geology, pp. 99-103.

Spock, L. E., 1962, Guide to the Study of Rocks (Second Ed.): Harper and Row, New York, 298 p.

Stringham, B., 1966, Igneous Rock Types and Host Rocks Associated with Porphyry Copper Deposits, in Titley, S. R. and Hicks, C. L., Geology of the Porphyry Copper Deposits, Southwestern North America: The University of Arizona Press, Tucson, pp. 35-40.

Turner, F.J. and Verhoogen, J., 1960, Igneous and Metamorphic Petrology, (Second Ed.): McGraw-Hill Book Company, Inc., New York, 694 p.

Williams, H., Turner, F. J., and Gilbert, C. M., 1954, Petrography: W. H. Freeman and Co., San Francisco, 406 p.

Witherspoon, P. A., Cook, N.G.W., and Gale, J. E., 1981, Geologic Storage of Radioactive Waste: Field Studies in Sweden: Science, Vol. 211, pp. 894-900. 


\subsection{SHALE}

\subsection{PREVIOUS WORR IN SHALE}

Although data on shale is generated from general geologic research, petroleum exploration, mineral exploration and siting for HLW repositories, little information on shale as a generic rock type is available. Some information from general geologic research can be found in discussions of various geologic terrains. Data generated for resource exploration may still be considered proprietary information. The Atomic Energy Commission began looking at shale for potential repository sites in 1971. Initial work consisted of surveying the literature to identify shale beds and to describe their properties (Merewether and others, 1973). Later work concentrated on specific shale formations within the conterminous United States, notably the Pierre Shale of the Northern Great Plains (Shurr, 1977), but primarily utilized literature and exploration data.

Baseline studies conducted in 1978 identified six different areas within the conterminous United States that were used to develop a generic stratigraphic section of shale that could be suitable for HLW storage studies (Dames and Moore, 1978). The information used to derive the section again relied on published data and prior exploration regarding rock properties of shale and similar argillaceous rock. A set of expected and typical properties from consolidated illitic shales was compiled and used in generic analyses. Studies of the Triassic basins have begun but little information is available on findings of the studies.

\subsection{PRECHARACTERIZATION STUDIES}

\subsubsection{GEOLOGY OF SHALE}

\subsubsection{General}

A number of terms have been used to describe sediments that make up fine-grained rocks, including argillite, lutite, siltstone, mudstone, claystone, marlstone and shale. Differences in terminology are based on the mineralogy and size of the constituent particles, and degree of induration and foliation. Claystones and siltstones are composed primarily of clay and silt-sized particles, respectively. The term marlstone implies a mixture of clay and calcium carbonate. Lutite is generally used as a generic term for fine grained sedimentary rock, although it can have the connotation of being principally clay. Use of 
the term shale normally implies a degree of fissility, while argillite implies a higher degree of induration than in the other fine grained rocks. Mudstone was initially used to describe a rock that rapidly decomposed and converted to mud (clay and/or silt) after exposure to the atmosphere. The term can also be used for fine grained sedimentary rocks of an indefinite composition, including all of the above terms. For the purposes of this discussion, shale will be used as a generic term, because of their dominance in the sedimentary rock sequences, and their frequent association with the other rock types mentioned above.

The wide range of composition and physical properties that shale exhibits contributes to several factors which are of concern, including origin, mineralogy of clays, diagentic history, deformation and structure.

\subsubsection{Origin and Depositional History}

Shales are the most abundant rock type of sedimentary origin, and are represented in approximately half of the measured stratigraphic section. Pettijohn (1957) calculated that shales comprise 70 percent of all sediments produced throughout geologic time.

Shales are made up of silt and clay sized particles that are derived from abrasion and degradation of older rocks (yielding mainly silt), weathering (residual clays) and chemical and biochemical additions (Pettijohn, 1957). The amount of mechanically derived sediment available for redeposition is dependent on the relief and climate of the source area. Chemically derived sediments are either precipitated along with deposition of the sediment, or form by reactions with the surrounding sediment. The majority of shales are deposited by running water and accumulate in a wide variety of environments. Terrigenous shales are deposited in lakes, floodplains, and in swamps in humid terrains or playa margins in arid terrains. Generally, they show abrupt lateral and vertical gradations into other sedimentary rock types, representing fluctuating depositional conditions. Appreciable amounts of organic material can be present. Marine shales comprise the bulk of shales found in the geologic record. They tend to be more widespread, massive and laterally continuous. Marine shales accumulate in shallow lagoons, interdistributary channels of large deltas and protected bays, and in large epeiric seas and shelves (Dunbar and Rodgers, 1957). Residual shales are produced by in situ weathering and degradation. These deposits are generally not widespread and are not represented in older strata. Their significance to siting a HLW repository is minimal and they are not further discussed. 
The depositional environment can influence the chemistry and mineralogy of shales. The chemistry is dependent on constituent minerals, conditions of deposition, age of the sediments and post-depositional diagenesis or alteration.

Silica is a dominant constituent, contained in detrital feldspars, clay minerals, detrital quartz and siliceous organisms (Garrels and Mackenzie, 1971). Highly siliceous shales appear to be derived from amorphous silica or volcanic ash. These kinds of rock are hard and resist disintegration. Generally, a coarser grain size can be correlated with a high silica content.

Alumina in shales is derived from detrital feldspars and clay minerals. Approximately 5 percent of shales are classified as high alumina (greater than 22 percent $\mathrm{Al}_{2} \mathrm{O}_{3}$ ). High alumina shale is indicative of a hot, humid climate, dominance of chemical weathering and a source area of felsic igneous rocks (Ernst, 1969). High alumina shale also may result if the source is another clay mineral, or if the residual materials forming the shales were bauxitic (Pettijohn, 1957).

The remaining chemical constituents are present mainly in feldspars or clay minerals. Higher than average contents of iron oxides, calcium carbonate or potassium forms clay ironstones, calcareous shales (mar1stones) or potassic shales.

Shales can also be characterized by a high content of a particular mineral, and these generally are indicative of the depositional environment (Krumbein and Sloss, 1963). Quartzose shale is characterized by rounded quartz grains and represents the reworking of sedimentary strata as transgressive seas onlap older, stable land masses. Their common association with quartzose sandstone and marine limestone suggests deposition under relatively stable conditions with low subsidence rates. Feldspathic shales are characterized by a high percentage of feldspar in the silt sized fraction and a finer matrix of kaolinitic clay minerals. These shales represent winnowing out of coarse arkosic sediments, and are characteristic of quiet sedimentation following rapid erosion.

Chloritic shale exhibits a wide range in grain size and variety of minerals. It is generally associated with greywacke and reflects rapid deposition of relatively fine detrital sediments. Chloritic shales are generally typical of a rapidly eroding orogenic source area.

Micaceous shale also exhibits a wide range of textures and grain size, with abundant muscovite flakes along cleavage planes and a fine grained sericite matrix. It results from deposition of detrital material under moderately unstable conditions in the sedimentary basin. 


\subsubsection{Stratigraphy/Lithology}

Shales represent deposition in many different kinds of depositional environments and have varying stratigraphic associations. The most important settings for deposition of fine grained sediments are deltas and geosynclines (including flysh and turbidite deposits). Deltaic deposits can occur at a continental margin or into a lake. Common features are lateral and vertical gradations of sediment size and structure whereby sandier material occurs interbedded with clay or silt sized deposits.

Marine basins are a common setting for shale deposition. Periods of transgression will be marked by thick accumulation of fine grained silts and clays on wide, alluvial plains near the coast (Reineck and Singh, 1980) while thick deltaic sequences are built up and deposited over vast areas of the shelf. Deposition during maximum regression takes place directly onto the steep continental slope. Lateral drifting of the sediment does not occur. Deposition is extremely rapid, resulting in thick piles of underconsolidated, unstable sediments. Frequent slumping, leading to turbidity currents, occurs which transports sediment to the continental rise and ocean basins. Thick deposits of shale and sandstone are also found in association with thick sequences of limestones that frormed in a platform-geosyncline couple. (Dunbar and Rodgers, 1957).

Clay minerals comprise a large part of the total minerals in shales. The properties of clay minerals are the most varied, and will have the most effect on shale properties. The constituent clay minerals of shales fall into three groups: kaolinites, illites and montmorillonites. Each group has a distinct type of crystal structure and certain distinctive physical characteristics, but exhibit a wide range of chemical composition (Dunbar and Rodgers, 1957). The chemical composition and physical properties of the clay mineral groups are shown on Table 3.2.1-1 and discussed in Deer, Howie and Zussman (1966).

The chemical composition of kaolinite is subject to little variation. Some ion substitution ( $\mathrm{Mg}, \mathrm{Fe}$ ) for $\mathrm{Al}$ may occur, but it is negligible. Kaolinite has a low capacity for cation exchange, little or no surface adsorbed water is present and dehydration of the mineral takes place at elevated temperatures. Hydrothermal synthesis occurs between $250^{\circ} \mathrm{C}$ and $400^{\circ} \mathrm{C}$, while decomposition of kaolinite occurs at approximately $400^{\circ} \mathrm{C}$.

Illites generally contain little or no interlayer water and if pure, are not subject to swelling. Some chemical variations occur, generally substitution of $\mathrm{Mg}$ and $\mathrm{Fe}$ for $\mathrm{Al}$ ions. The presence of a large number 
of inter-layer potassium ions prevents the entry of water and other cations, so that illites have a low cation exchange capacity. Dehydration takes place in a number of stages. Adsorbed water is rapidly released at $110^{\circ} \mathrm{C}$, and more slowly between $110^{\circ} \mathrm{C}$ and $350^{\circ} \mathrm{C}$. Water from the expulsion of hydroxide ions occurs between $350^{\circ} \mathrm{C}$ and $600^{\circ} \mathrm{C}$.

Montmorillonites are considered "swelling" clay minerals in that they take up water between their structural layers and all show marked cation exchange properties. They lose the interlayer water on heating between $100^{\circ} \mathrm{C}$ and $250^{\circ} \mathrm{C}$, and as water is driven from the latice, the basal spacing decreases. Slow loss of constituent water begins at $300^{\circ} \mathrm{C}$, accelerates at $500^{\circ} \mathrm{C}$ and is complete at $750^{\circ} \mathrm{C}$. Dehydration is reversible up to approximately $600^{\circ} \mathrm{C}$. The montmorillonite group is chemically varied, with tetrahedral positions occupied by ferric iron or titanium. Octahedral sites may contain $\mathrm{Fe}^{+2}, \mathrm{Mn}$ and $\mathrm{Ni}$. $\mathrm{Ca}$ and $\mathrm{Na}$ are the most commonly occurring exchangeable cations. The cation exchange capacity ranges from $80-150 \mathrm{~m} . \mathrm{eq} / 100 \mathrm{gm}$, but varies with particle size and the nature of the cation.

The constituent minerals of shale exhibit a wide variety of compositions depending on depositional environment, source area and postdepositional processes; therefore the composition and rock properties can vary. Table $3 \cdot 2.1-2$ shows ranges in the chemistry of shales, and Table 3.2.1-3 modal mineral components. Because of the wide variation in chemistry and modal minerals of shales, it is not possible to discuss an "average" or "generic" shale with predictable properties.

Induration by compaction can affect the physical properties of shales. Argillaceous muds have an initial porosity of 80 percent which decreases continuously with increasing depth of burial, to approximately 500 meters. The total volume of the sediment can decrease by up to $50 \%$ due to compaction (Rieke and Chilingarean, 1974). The physical strength of clays is basically a function of decreased pore space, which is a consequence of overburden pressure exerted by the sediment itself (Greensmith, 1971). Diagenesis of the clay minerals occurs after deposition, which can affect the resultant rock properties.

Humid conditions accompanied by extensive leaching will tend to produce kaolinitic clays or silica and aluminum hydrates. The end product is dependent on the $\mathrm{pH}$ of the downward moving water and the prevalence of oxidizing or reducing conditions (Grim, 1958). Neutral or acid conditions will tend to promote kaolinite, while an alkaline environment will favor montmorillonite or chloritic micas. Montmorillonite will form if evaporation is dominant and leaching processes are negligible. Non-acid, potassium rich conditions favor illite creation. Illite can also be converted from potassium-poor conditions upon transport to an 
TABLE $3.2 \cdot 1-1$

SUMMARY OF PROPERTIES OF CLAY MINERALS

\begin{tabular}{|c|c|c|c|}
\hline & KAOLINITE & ILLITE & MONTMORILONITE \\
\hline composition & $\mathrm{Al}_{4} \mathrm{Si}_{4} \mathrm{O}_{10}(\mathrm{OH})_{8}$ & $\mathrm{KAl}_{4}(\mathrm{Si}, \mathrm{Al})_{8} \mathrm{O}_{20}(\mathrm{OH})_{4}$ & 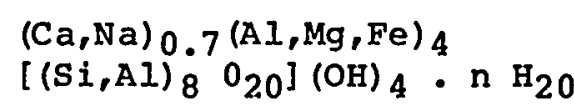 \\
\hline $\begin{array}{l}\text { cation exchange } \\
\text { capacity }\end{array}$ & $10 \mathrm{~m} \cdot \mathrm{eg} / 100 \mathrm{gm}$ & $10-40 \mathrm{~m} \cdot \mathrm{eq} / 100 \mathrm{gm}$ & $80-150 \mathrm{~m} \cdot \mathrm{eg} / 100 \mathrm{gm}$ \\
\hline $\begin{array}{l}\text { dehydration step } \\
\text { temperatures }\end{array}$ & $400^{\circ} \mathrm{C}-525^{\circ} \mathrm{C}$ & $\begin{array}{l}110^{\circ} \mathrm{C}, \quad 110^{\circ} \mathrm{C}-350^{\circ} \mathrm{C}, \\
600^{\circ} \mathrm{C}\end{array}$ & $\begin{array}{l}100^{\circ} \mathrm{C}-250^{\circ} \mathrm{C}, 300^{\circ} \mathrm{C}, \\
300^{\circ} \mathrm{C}-700^{\circ} \mathrm{C}\end{array}$ \\
\hline density & $2.0-2.55 \mathrm{gm} / \mathrm{cm} 3$ & & $2.0-2.7 \mathrm{gm} / \mathrm{cm}^{3}$ \\
\hline $\begin{array}{l}\text { principal interlayer } \\
\text { cations }\end{array}$ & None & $\mathbf{K}$ & $\mathrm{Ca}, \mathrm{Na}$ \\
\hline paragenesis & acidic conditions & $\begin{array}{l}\text { alkaline conditions, } \\
\text { high } \mathrm{Al} \text { and } \mathrm{K} \\
\text { concentrations } \\
\text { favorable }\end{array}$ & $\begin{array}{l}\text { alkaline conditions, } \\
\text { availability of } \mathrm{Mg}, \mathrm{Ca} \\
\text { deficiency of } \mathrm{K}\end{array}$ \\
\hline & & & $\begin{array}{ll}\text { Source: } & \text { Deer, Howie and } \\
& \text { Zussman, } 1966\end{array}$ \\
\hline
\end{tabular}


TABLE $3 \cdot 2 \cdot 1-2$

CHEMICAL COMPOSITION OF AVERAGE SHALES

AND RELATED MATERIALS

(in per cent)

\begin{tabular}{|c|c|c|c|c|c|c|}
\hline Constituent & A & B. & C & D & $\mathbf{E}$ & $\underline{F}$ \\
\hline $\mathrm{SiO}_{2}$ & 58.10 & 55.43 & 60.15 & 60.64 & 56.30 & 69.96 \\
\hline $\mathrm{TiO}_{2}$ & 0.65 & 0.46 & 0.76 & 0.73 & 0.77 & 0.59 \\
\hline $\mathrm{Al}_{2} \mathrm{O}_{3}$ & 15.40 & 13.84 & 16.45 & 17.32 & 17.24 & 10.52 \\
\hline $\mathrm{Fe}_{2} \mathrm{O}_{3}$ & 4.02 & 4.00 & 4.04 & 2.25 & 3.83 & 3.47 \\
\hline FeO & 2.45 & 1.74 & 2.90 & 3.66 & 5.09 & \\
\hline Mno & -- & $\mathbf{T}$ & $\mathbf{T}$ & --- & 0.10 & 0.06 \\
\hline MgO & 2.44 & 2.67 & 2.32 & 2.60 & 2.54 & 1.41 \\
\hline $\mathrm{CaO}$ & 3.11 & 5.96 & 1.41 & 1.54 & 1.00 & 2.17 \\
\hline $\mathrm{Na}_{2} \mathrm{O}$ & 1.30 & 1.80 & 1.01 & 1.19 & 1.23 & 1.51 \\
\hline $\mathrm{K}_{2} \mathrm{O}$ & 3.24 & 2.67 & 3.60 & 3.69 & 3.79 & 2.30 \\
\hline $\mathrm{H}_{2} \mathrm{O}+$ & 5.00 & 3.45 & 3.82 & 3.51 & 3.31 & 1.96 \\
\hline $\mathrm{H}_{2} \mathrm{O}-$ & & 2.11 & 0.89 & 0.62 & 0.38 & 3.78 \\
\hline $\mathrm{P}_{2} \mathrm{O}_{5}$ & 0.17 & 0.20 & 0.15 & --- & 0.14 & 0.18 \\
\hline $\mathrm{CO}_{2}$ & 2.63 & 4.62 & 1.46 & 1.47 & 0.84 & 1.40 \\
\hline $\mathrm{SO}_{3}$ & 0.64 & 0.78 & 0.58 & --- & 0.28 & 0.03 \\
\hline CI & $-\infty$ & -- & -- & -- & -- & 0.30 \\
\hline Organic & $0.80^{a}$ & $0.69 a$ & $0.88^{a}$ & -- & $1.18^{a}$ & 0.66 \\
\hline Misc. & --- & $0.06^{b}$ & $0.04^{b}$ & $0.38 \mathrm{C}$ & $1.98 \mathrm{C}$ & 0.32 \\
\hline Total & 99.95 & $\overline{100.48}$ & $\overline{100.46}$ & $\overline{99.60}$ & $\overline{100.00}$ & $\overline{100.62}$ \\
\hline
\end{tabular}

A. Average shale (Clarke, 1924, p.24) (based on cols. B and C).

B. Composite sample of 27 Mesozoic and Cenozoic shales, H. N. Stokes, analyst (Clarke, 1924, p. 552).

C. Composite sample of 51 Paleozoic shales, H. N. Stokes, analyst (Clarke, 1924, p. 552).

D. Unweighted average of 36 analyses of slate (29 Paleozoic, 1 Mesozoic, 6 early Paleozoic or Precambrian) (Eckel, 1904).

E. Unweighted average of 33 analyses of Precambrian slates (Nanz, 1953).

F. Composite analysis of 235 samples of Mississippi delta, Geo. Steiger, analyst (Clarke, 1924, p. 509).

a Carbon.

b BaO.

c $\mathrm{FeS}_{2}$

Source: Pettijohn, 1957 
TABLE $3.2 .1-3$

CALCULATED MINERAL COMPOSITION OF AVERAGE SHALE

(in percent)

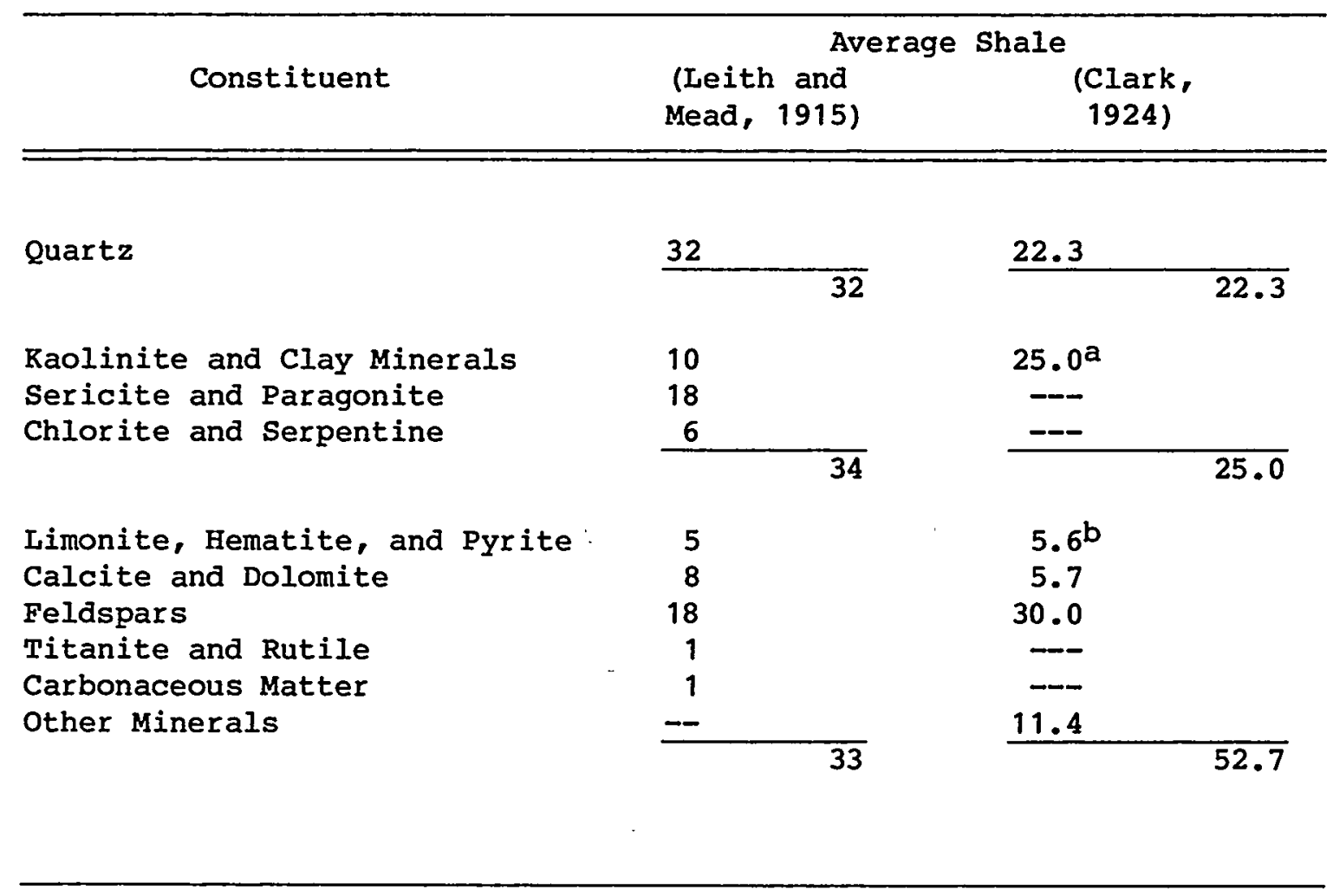

a probably sericite in part. In that case the feldspar figure becomes lower.

b Limonite only. 
alkaline marine basin (Greensmith, 1971). Grim (1958) suggests large changes in composition occur if clays are deposited in highly saline waters, with preferential formation of montmorillonite, illite and chlorite and the loss of kaolinite. The degree of transformation is dependent on chemistry of circulating waters and rate of burial. Some work has been done on distribution of clay minerals that are deposited near shore and in an offshore basin to suggest that kaolinite is being converted to illite as the distance from the shore increases (Greensmith, 1971). Illite and kaolinite-rich shales can therefore be correlated with fresh and brackish marginal deltaic zones and montmorillonite-rich zones with more open marine areas (Greensmith, 1971).

This brief overview. of shales shows variations in stratigraphy, and lithology that result from differing depositional environment and post-depositional processes. Ranges exist in the basic rock parameters that result from these variations (Table $3.2 .1-4)$. It is not practical to describe properties inherent to a generic shale nor to extrapolate rock behavior without knowledge of the clay mineralogy, alteration and depositional environment.

\subsubsection{Structure}

Depositional structures include bedding planes, laminations, and mudcracks. The thickness of beds will depend on clay mineralogy, and depositional conditions. Laminations reflect changing composition (alternating fine and coarse layers), varying organic content, or alternating layers of calcareous material and silt. Most laminations result from the annual cycle and reflect varying temperature, salinity and silt contents.

Fissility is due to compaction and recrystallization or alignment of micas along preferred planes after deposition. Fissility can also be caused by parallel orientation of micas at the time of deposition. An increased amount of siliceous or calcareous material in shales will decrease the fissility, while a high proportion of organic material tends to increase the fissility. Fissility is more pronounced in older deposits and in steeply dipping beds. Joints occur parallel to or along bedding planes. The joints are generally closed at depth and may be healed with calcite or silica cement, or clay infillings. Shale sequences are generally warped or gently folded due to deposition in a basin and subsequent compaction and basin downwarping. Plastic beds generally will flow during folding while stiffer, less plastic beds will tend to be highly fractured. 
TABLE $3.2 .1-4$

RANGE OF INTACT SHALE PROPERTIES

BASIC PARAMETERS

Type of Property

Parameter

Customary

Index

- Unit Weight

Units

- Natural moisture

content (intact)

- Porosity (rock mass)

$1.87-3.01 \mathrm{gm} / \mathrm{cm}^{3}$

$0-388$ (weight)

0-458 (volume)

Stress-strain

- Young's Modulus

$0.01-44.1 \mathrm{GPa}$

- Poisson's Ratio

$0.03-0.50$ *

Strength

- Cohesion**

- Friction Angle**

$0-4250 \mathrm{lbs} / \mathrm{in}^{2}$

- Dilation Angle

4.2-56 degrees

+5 degrees

- Uniaxial Compressive Strength

0.48-255 MPa

- Tensile Strenth

0-10.6 MPa

Thermal

- Coefficient of Linear Thermal Expansion

$4 \times 10^{-6} \cdot \mathrm{F}^{-1}$

- Heat Capacity

Variable, more study required

- Thermal Conductivity

1.94, parallel to bedding

1.42, perpendicular to bedding

Hydrological Horizontal permeability $\left(R_{h}\right) 10^{-4}-10^{3} \mathrm{ft} / \mathrm{yr}$

- Vertical permeability $\left(\mathrm{K}_{\mathrm{V}}\right) \quad 1 / 2-1 / 10$ times $\mathrm{K}_{\mathrm{h}}$

*Values greater than 0.5 have been recorded, indicating volumetric expansion due to dilatant shearing. **1500-3500 psi range.

Sources:

Dames and Moore, 1978b, Johnston and Palmer, 1981

$3-10$ 


\subsubsection{Hydrology}

Most fine grained shales, especially those with closely spaced joints, will have relatively high porosities but very low permeabilities. While open fractures at depth can contribute to the water bearing capabilities of a shale, more commonly the fractures act as barriers to water movement (Davis and Dewiest, 1966). Large pore space will provide storage for vast amounts of groundwater. Porosity in shales, however, decreases with depth of burial and to some degree, age. Initial porosities in shales may be greater than 50 percent, which decreases to 10 to 25 percent as pore fluids are expelled during compaction (Ernst, 1969). Porosity and ability for groundwater flow will be higher in sandy interbeds than in the shale. If the shale is overconsolidated, or if the sediments which make up the shale were buried rapidly, so that the interstitial fluid could not escape, fluid pressure and porosity will be abnormally high (Rieke and Chilingarian, 1974).

\subsubsection{Resources}

Shales are known to contain oil and gas resources. These resources are formed from organic material within the shale during compaction of the sediment. As compaction continues, the petroleum resources migrate out of shale into more permeable units. Shale beds, if deformed, may form an impermeable cap which traps oil and gas in sandy interbeds or permeable layers below the shale layers.

Shales can also contain significant amounts of oil trapped within the pore space (oil shale). Distillation can yield variable amounts of oil. Extensive oil shale deposits are found in the Colorado Plateau region of the U.S. Petroleum source rocks (mainly shales) represent diverse origins and are present throughout the geologic record.

Thick sequences of shales, sandstones, thin marine limestones and coal beds are present in Pennsylvanian rocks of the Allegheny Plateau. Shale and siltstone make up approximately 60 percent of the sequence. The coal beds range from thin, lenticular discontinuous beds to thick, massive beds covering hundreds of square miles. Coal is also found in association with shales in the Illinois and Michigan basins, and the Mid-Continent Region.

Reciently, the association of uranium and shales has been investigated, although no literature is available on results. Uranium is a mobile ion and can be present in deposits accumulated under continental oxidizing and leaching conditions (Greensmith, 1971). 


\subsubsection{INFORMATION NEEDS FOR PRECHARACTERIZATION STUDIES IN SHALE}

The information needed to evaluate a potential site for a HLW repository can be based on the stratigraphy and depositional history of shales. Criteria used as a basis for regional screening studies can also provide insight to pertinent factors.

The general geologic setting of a repository in shales can be determined from shale occurrences in the continental United States. Shales occur throughout the United states, with thick, continuous sequences along the Gulf coast, in the mid continent region and several basins in the Appalachians and in the Eastern states. These areas are tectonically stable, although post depositional warping, folding and faulting may have occurred.

Although it is not possible to describe a generic shale from which physical properties can be extrapolated, a generalized stratigraphic column can be described, which is a composite of thick shale sequences that occur throughout the United States (Table 3.2.2-1). Beds are assumed to be flat lying or gently warped. Interlayers of sandier material may occur, but massive sequences of shale can be expected.

To date, no exploratory work relative to HLW repositories has been carried out in shales. Generalized overviews and information compiled from the literature has been used to describe known shale occurrences that are suitable for HLW repositories.

\subsubsection{Geology}

The general category of geology includes information needs relating to past geologic processes, and the geometry and lithology of the host rock. Information needs specific to shales are the composition of clay minerals, depositional environment, and post-depositional processes including diagenesis and induration. Shales tend to slake upon weathering and exposure to the atmosphere. The clay minerals in shales are subject to lattice destruction upon heating and dehydration, which will affect the strength and stability of the host rock. It is assumed that the shale sequence will extend to the surface, but conditions and properties at the surface will not be characteristic of those at depth.

As at any prospective repository site, it is important to determine climatic fluctuations and surface hydrologic conditions over Quaternary time, which are expressed by geomorphology and surface geology.

Stratigraphy, lithology and structure within the shale sequence will be of particular concern for identifying potentially suitable host rock. 
TABLE $3.2,2-1$

TYPICAL SHALE STRATIGRAPHY

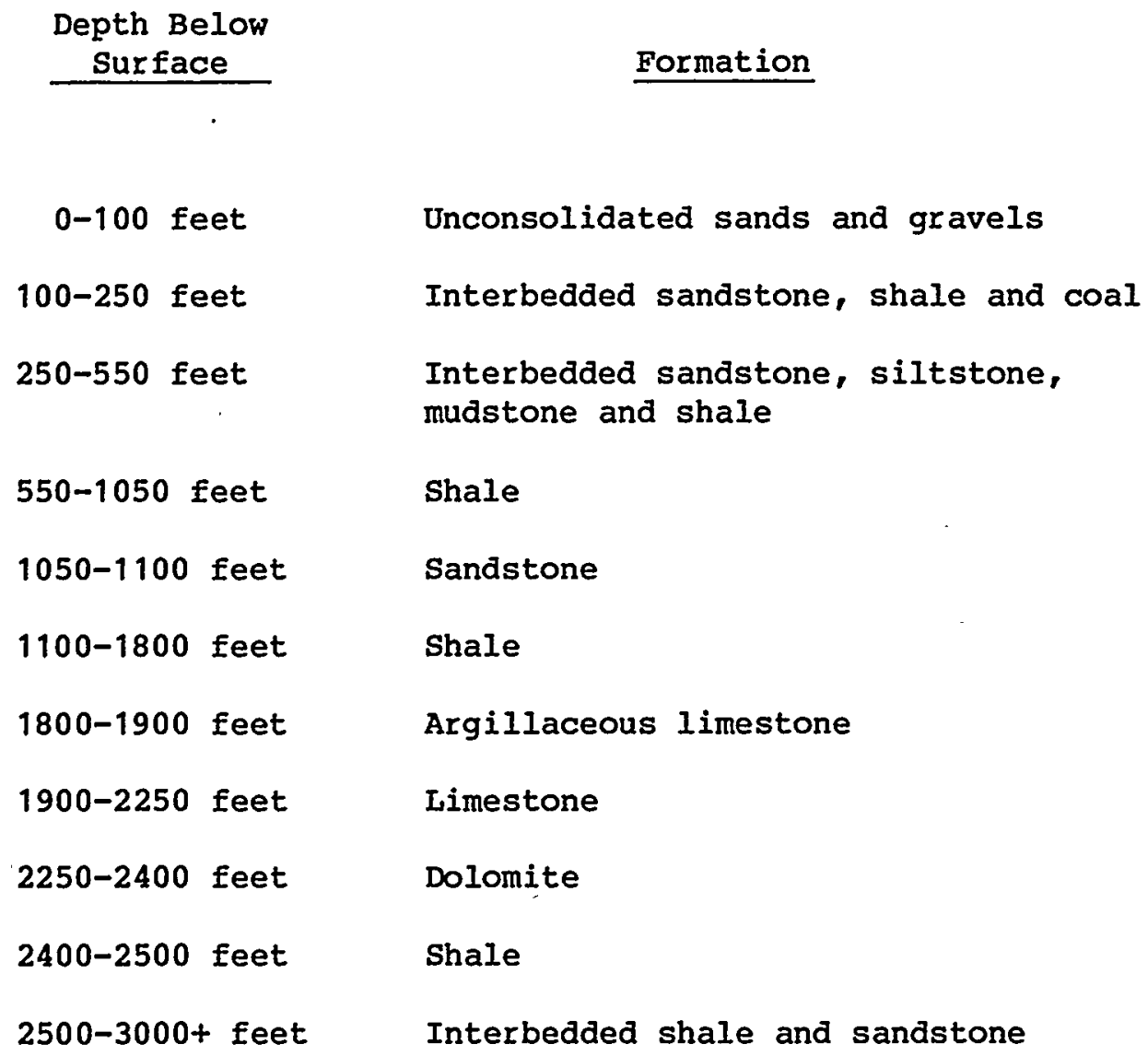


Shales contain clay minerals which, in general have good sorptive characteristics, high ion-exchange capacity and good retardation potential (Weaver, 1980; Merewether, and others, 1973).

Many argillaceous rocks, however, include mineral constituents or properties that may be unacceptable. Relatively undeformed shales with relatively high plasticity contain montmorillonite which may release water when heated, while shales with little montmorillonite are older, less plastic and tend to be more permeable as the result of tectonic deformation. Montmorillonite also tends to contribute to the structural instability of the rock because of its ability to absorb or release hydroxide ions from its lattice. Reaction of clay minerals to heating will have a significant impact on the suitability of a shale for HLW disposal. Other shales may contain carbonaceous matter that may yield combustible carbon compounds when heated or contribute to swelling and disintegration (Merewether and others, 1973).

Investigation of structure and stratigraphy will identify shale partings, sandy interbeds or layers, and faults or open fractures. These features may contain water which would make identification of these features important to the hydrologic analysis.

Structural data on fractures and faults should be collected and used during evaluations for geomechanical and hydrological analyses.

\subsubsection{Hydrology}

Hydrologic information needs include surface processes, climate and ground water regimes. These are essentially the same for any medium.

Information on surface hydrology is needed as it would relate to ground water hydrology and inundation potential. Specific information on surface hydrology includes rainfall-runoff relationships, flood potentials, effects of impoundment failures, stream flow data and surface water quality.

Hydrostratigraphy will be similar throughout the shale body. The most important factor to determine at a particular site is the number, distribution and character of water bearing units. Shales are generally characterized by variable porosity and low permeability. Factors which would influence the porosity and permeability of shales would be open fractures or faults, porous sandstone, clay or fractured limestone interbeds. Other factors, such as low groundwater content, flow velocity and gradients, and host rock isolated from surrounding 
hydrologic regime are important properties that need to be determined for a shale site to be considered suitable for HLW disposal.

\subsubsection{Geochemistry}

Information needs in geochemistry include geochemical dating of rocks and water, water chemistry and geochemical characterization of the constituent minerals of the prospective repository.

Geochemical dating is used to determine age of groundwater, and by extrapolation, residence time.

Water-chemistry information needs include determining $\mathrm{pH}, \mathrm{Eh}$, and mineral content of the waters from various sources at and near the prospective site. Determining the effect of circulating water on composition and properties of constituent minerals is important. Information needs regarding rock geochemistry include mineralogy, organic content, alteration, and retardation properties of the various rock types.

\subsubsection{Geomechanics}

Information needs in geomechanics include mechanical and thermal properties of the prospective host rocks under in situ conditions. It also is necessary to determine geomechanical parameters significant for excavating shafts through the overlying materials. Specific factors to be determined for the rocks present include: engineering classification, rock quality, compressive and tensile strengths, deformation moduli, plasticity, specific heat, thermal conductivity, coefficient of thermal expansion, and potential for thermal alteration. Changes in shale due to increased temperature which will affect strength, water content and stability need to be investigated. Time dependent deformation (creep or flow) is not anticipated to be a problem in shale, although loss of strength may occur due to other mechanical processes, such as stress relief after excavation or slaking. In situ geomechanical performance also will depend on factors such as pore pressure and the distribution and character of discontinuities in the rock.

Since shale units that would be suitable for radioactive waste disposal tend to be massive, they will tend to have the same, or similar geomechanical properties throughout their thickness. However, the presence of interbeds or layers of variable composition could affect these properties and their ranges. 


\subsubsection{Seismotectonics}

As discussed previously, significant occurrences of shales in the United states generally are in regions that are tectonically stable and have low levels of seismicity. Even so, it would be desirable to establish that seismic/tectonic conditions are favorable at the precharacterization stage. Information needs in this regard include the histories of and potentials for: uplift or subsidence, faulting and other tectonic movements or deformations, igneous activity, and seismicity. Direct information on these factors may be obtained from geodetic surveys and the seismic record. However, much of the pertinent information typically is based on geologic interpretations.

\subsubsection{Resources}

Resources present in shale include oil and gas, coal, possible uranium and oil trapped in pore spaces (oil shale). The resource potential and history of exploration and exploitation at a potential site should be established prior to characterization. Information on hydrocarbons and mineralization can be obtained from the deep stratigraphy and structure and laboratory samples.

\subsubsection{TECHNIQUE APPLICATIONS TO PRECHARACTERIZATION INFORMATION NEEDS IN SHALE}

Specific information needs to be answered in order to characterize the potential of a shale body for storage of HLW were discussed in the previous section. Specific techniques used to define the physical extent, and evaluate the properties, of the medium are discussed in this section. Established exploration and testing techniques are described in the Appendices. The techniques have been grouped according to principal type of information obtained: geology, hydrology, geochemistry, geomechanics, seismotectonics and resources. Information obtained in each group may be applicable to needs in the other groups and significant interchange between groups should occur. Table 3.2.3-1 summarizes general applications.

Three stages of exploration of the shale body can be described:

First stage: No drilling completed or planned at the site; data is from surface-based exploration only. 
TABLE 3.2.3-1 SUMMARY OF TECHNIQUE APPLICATIONS IN SHALE

\begin{tabular}{|c|c|c|c|c|}
\hline \multirow{2}{*}{\multicolumn{2}{|c|}{ TECHNIOUE }} & STAGE 1 & STAGE 2 & STAGE 3 \\
\hline & & $\begin{array}{l}\text { NO DRILLING SURFACE } \\
\text { EXPLORATION ONLY }\end{array}$ & EXISTING DRILLING & NEW DRILLING \\
\hline \multirow{2}{*}{ REMOTE SENSING } & SATELLITE & G h $S R$ & & \\
\hline & AIRCRAFT & $G h S R$ & & \\
\hline \multirow{3}{*}{ SURFACE MAPPING } & LANDFORMS & $G S R$ & & \\
\hline & LITHOLOGY/MATERIALS & G $H$ m & G & G \\
\hline & PROCESSES/STRUCTURE & $G H S R$ & g & $\mathbf{g}$ \\
\hline \multirow{4}{*}{$\begin{array}{l}\text { GEOPHYSICAL } \\
\text { LOGGING }\end{array}$} & ELECTRICAL & & G H C m s & $\underline{\underline{G}} \stackrel{\underline{H}}{=} \underline{\underline{C}} \underline{\underline{m}} \underline{\underline{\underline{s}}} \underline{\underline{R}}$ \\
\hline & RADIOACTIVE & & $\mathrm{GHC \textrm {m } \mathrm { S }}$ & $\underline{\underline{\mathbf{G}}} \underline{\underline{\underline{H}}} \underline{\underline{\mathbf{C}}} \underline{\underline{\mathrm{m}}} \underline{\underline{\mathbf{s}}} \underline{\underline{\mathbf{R}}}$ \\
\hline & MECHANICAL & & GHCm S & $\underline{\underline{G}} \stackrel{h}{=} \underline{\underline{m}} \underline{\underline{\underline{s}}}$ \\
\hline & ACOUSTICAL & & G H C m S & $\underline{\underline{G}} \underline{\underline{h}} \underline{\underline{c}} \underline{\underline{M}} \underline{\underline{s}}$ \\
\hline \multirow{6}{*}{$\begin{array}{l}\text { GEOPHYSICAL, } \\
\text { EXPLORATION }\end{array}$} & GRAVITY & G $s$ r & $\underline{G} s \mathrm{r}$ & $\underline{\underline{G}} \mathbf{s}$ \\
\hline & AUDIO-MAGNETOTELLURICS & $G \leqslant r$ & $\underline{G} s \mathrm{r}$ & $\underline{\underline{G}} s \mathrm{r}$ \\
\hline & SEISMIC REFRACTION & Q h 5 s & $\underline{G} s \mathrm{r}$ & $\underline{G} s \mathbf{r}$ \\
\hline & RESISTIVITY & $G h \leq r$ & $\underline{G} h \mathbf{S} r$ & $\underline{G} \mathbf{h} s \mathbf{r}$ \\
\hline & MAGNETICS & $G s r$ & $\underline{G} s \mathbf{r}$ & $\underline{\underline{G}} \mathbf{s} \mathbf{r}$ \\
\hline & SEISMIC REFLECTION & 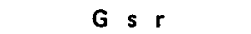 & $G \leq r$ & $G \leqslant r$ \\
\hline \multirow{4}{*}{$\begin{array}{l}\text { GEOMECHANICS/ } \\
\text { THERMOMECHANICS }\end{array}$} & ROCK MATERIALLAAB TESTS & $g \subset M s$ & g h $M$ & g h $\underline{M}$ \\
\hline & ROCK FIELD OBSERVATIONS & g c $M s$ & gc $M s$ & \\
\hline & DESIGN LAB TESTS & $g h^{\prime} M$ & g $\underline{M}$ & $g \underline{h} \underline{\underline{M}}$ \\
\hline & DESIGN IN SITU TESTS & & & M \\
\hline \multirow{5}{*}{ GEOCHEMICAL } & $\begin{array}{l}\text { GRAPHICAL } \\
\text { STATISTIC ANALYSES }\end{array}$ & $h<r$ & $h<r$ & $\stackrel{H}{=} \times r$ \\
\hline & SAMPLING AND ANALYSES & $g h \subset r$ & g h $c r$ & $\mathrm{gHCr}$ \\
\hline & WIATER-ROCK MODELING & & h c & $\underline{\underline{H}} \mathrm{C}$ \\
\hline & STABLE ISOTOPE MODELING & & h c & $\underline{\underline{H}} \mathrm{c}$ \\
\hline & GROUNDWATER AGE OATING & & h c & $\underline{\underline{H}} \mathrm{C}$ \\
\hline \multirow{6}{*}{ HYDROLOGY } & FLOOD FREQUENCY & $H$ & & \\
\hline & RECHARGE/DISCHARGE & H & H & $\underline{\underline{H}}$ \\
\hline & SURFACE WATER CHEMISTRY & g H & & \\
\hline & NUMERICAL MODELING & H & $H$ & $\underline{H} \underline{\underline{C}}$ \\
\hline & AQUIFER TESTS & & $H$ & $\mathrm{~g} \stackrel{\mathrm{H}}{=} \mathrm{m}$ \\
\hline & TRACER TESTS & & & H C \\
\hline \multirow{6}{*}{$\begin{array}{l}\text { SEISMICITYI } \\
\text { TECTONICS }\end{array}$} & $\begin{array}{l}\text { MISTORICAL } \\
\text { EARTHOUAKE ANALYSIS }\end{array}$ & s & & \\
\hline & $\begin{array}{l}\text { INSTRUMENTAL } \\
\text { EARTHOUAKE ANALYSIS }\end{array}$ & $\mathbf{s}$ & & \\
\hline & MONITORING NETWORKS & $\mathbf{s}$ & & \\
\hline & VELOCITY STUDIES & g $s$ & $\underline{\mathbf{s}}$ & $\underline{\underline{\mathbf{S}}}$ \\
\hline & FAULT STUDIES & G S & & \\
\hline & $\begin{array}{l}\text { ATTENUATIONAND } \\
\text { GROUNDMOTION }\end{array}$ & g S & $\underline{\mathbf{s}}$ & $\underline{\underline{\mathbf{S}}}$ \\
\hline \multicolumn{2}{|c|}{ DRILLING/LOGGING } & & $G h \subset m s r$ & $\underline{\underline{G}} \stackrel{\underline{H}}{\underline{C}} \underline{\underline{M}} \underline{\underline{S}} \stackrel{R}{=}$ \\
\hline
\end{tabular}

EXPLANATION

CLASSES OF INFORMATION NEEDS

G. GEOLOGY

$\mathrm{H}=$ HYDROLOGY

C= GEOCHEMISTRY

$M=$ GEOMECHANICS/THERMOMECHANICS

$S=$ SEISMICITYITECTONICS

$R=$ RESOURCES
NOTES:

1. CAPITAL LETTERS INDICATE MOST APPLICABLE TECHNIOUES.

LOWER CASE LET

SINGLE UNDERLINE INDICATES ENHANCEMENT BY PREVIOUS DRILLING DATA. DOUBLE UNDERLINE INDICATES ENHANCEMENT BY NEW DRILLING DATA.

2. LETTERS INDICATE INFORMATION NEED CLASSES WHOSE TECHNIQUES OBTAIN DATA THROUGH STAGES OF INVESTIGATION. LETTERS INDICATE APPLICABILITY WITHIN A STAGE, BUT DO NOT REPRESENT EQUIVALENCE BETWEEN TECHNIQUE. RESOLUTION, RELIABILITY, AND OTHER EVALUATION FACTORS ARE DISCUSSED IN TEXT. 
Second stage: Data is available from drilling already completed at the site for other purposes; data may be obtained from additional surface exploration.

Third State: Drilling and appropriate downhole tests and logging is performed; additional data from pre-existing drill holes and surface exploration can be obtained where needed.

In the first stage, it is assumed that no drilling was done at the site; data is available from surficial techniques only. Pertinent data may be obtained from the compilation and analysis of previous work, published literature and maps and unpublished data.

The second stage of exploration assumes data is available from existing boreholes. Previous drilling in shale would have been performed for hydrocarbon exploration. Shallow water wells may exist, although potable water is not common in shales. Drillers and/or geologists logs will probably be available, but would provide only general, descriptive information. Borehole geophysical logs (Spontaneous Potential, resistivity, natural gamma) may be available. It is unlikely that any existing boreholes will be suitable for performing new geophysical logging, hydrologic testing or monitoring. Core samples, while probably available, will not be suitable for testing or analysis.

New drilling and logging during the third stage of the exploration program would be designed to obtain optimum information at depths suitable for repository siting. The program should consider and specify location of drill holes, coring, logging and sampling of the shale body, test intervals and specimens and appropriate downhole logging techniques.

\subsubsection{Geology}

Information needs relating to geology include evaluating the lithology, stratigraphy and structure of the shale body and host layer; depth to, thickness and lateral extent of the host rock; and surface processes such as flooding and erosion.

\subsection{No Drilling at a Site}

The host rock and associated units of a prospective repository site would not typically be exposed at the surface, although shales are generally uniform laterally and vertically. Where exposed, alteration 
in the composition of clay minerals and degradation of the rock mass by weathering will not allow direct extrapolation to conditions at depth. Little direct information, therefore, can be obtained without drilling. Techniques that can be used before drilling a site are remote sensing, surface mapping, and to a lesser degree, geophysical exploration.

The information needs relating to geomorphology, Quaternary geology, paleoclimate, history of erosion and deposition, and similar topics can be addressed before drilling is undertaken at a site. These typically utilize techniques in remote sensing and surfacing mapping, supplemented by shallow drilling and trenching as required. As discussed previously, these information needs are unrelated to the medium involved but instead are determined by the other geologic conditions at a prospective site. Resolution and reliability of these geologic observations and the resulting interpretations also would depend on site conditions, particularly on the amount of information available and the complexity of the geologic record.

Geophysical techniques, particularly seismic reflection, may be used to identify such features and to recognize termination of suitable beds by sedimentary facies changes. Reliability and resolution of these determinations could vary significantly, according to local conditions in relation to the nature of the features involved. Thickness and composition of the overburden at a site would be particularly important in determining how reliably sedimentary facies changes. Reliability and resolution of these determinations could vary significantly, according to local conditions in relation to the nature of the features involved. Thickness and composition of the overburden at a site would be particularly important in determining how reliably features of a given size may be detected.

General information on stratigraphy, lithology, and geologic structure at a prospective site may be extrapolated from off-site boreholes and interpreted from seismic reflection data.

Satellite imagery is used to obtain a regional overview and interpretation of the regional geologic structure (faults, folds, orientation of fracture sets); general stratigraphy; and for discrimination of rock types. Aircraft imagery can be used to interpret structural features, rock types, soil moisture and ground water features.

\subsection{Previous Drilling}

As previously stated, existing core, logs and boreholes will have limited application in repository siting. Downhole logs which can be 
correlated with geophysical exploration techniques can increase the reliability and accuracy of interpretation.

\subsection{New Drilling}

New drilling at a potential repository site will allow optimum location of boreholes, detailed core logging and selection of the most suitable borehole geophysical logging techniques. The combined effect of these techniques is to increase resolution and reliability of the stratigraphic, lithologic and structural data. Data available from drilling includes core for laboratory testing (geomechanical and thermomechanical); lithologic analysis; depth to and thickness of host rock; and occurrences of discontinuities (fractures, joints and faults).

Shale is extensively drilled for petroleum investigations, and as a result, downhole logging techniques for use in shale formations are reasonably accurate. The Gross Count Gamma Ray (GCGR) log can be used to determine the amount of clay or shale in sedimentary sequences. Gamma Ray (GR) logs are useful to identify specific types of clays, and may be used to determine depositional history. The Spontaneous Potential (SP) $\log$ is especially useful in shales. The relative component amounts of shale can be determined by a density-acoustic travel time cross plot.

\subsubsection{Hydrology}

Hydrology techniques for shale would provide information on surface processes, and ground water chemistry and flow. Shales generally have variable porosity and low permeability which tend to inhibit ground water movement and ion migration.

\subsection{No Drilling at a site}

Hydrologic techniques that can be used at a site without drilling are limited to climate, surface hydrology and shallow water hydrology. Remote sensing and mapping identifies recharge/discharge areas, drainage patterns and basins, and flood prone areas. Regional hydrologic regimes and flood frequency, may be evaluated from published data.

Surface water chemistry must be determined so that predictions can be made for ion migration potential and ion exchange capacity of the various clay minerals that make up the major portion of shale beds. 


\subsection{Previous Drilling}

Data from previous drilling is unlikely to yield useable data. Boreholes drilled for petroleum exploration will reach depths suitable for HLW disposal. However, samples taken from them for water quality analysis may not be reliable, as the drilling fluids probably were not flushed from the hole after completion. Casing was probably placed in the hole, which would limit the sampling interval or depth. Existing holes will probably not be open due to shale's tendency to slake, and degrade. Water level measurements may not be accurate if material has fallen into the hole and artificially influenced its depth. Downhole logs may be used in conjunction with hydrologic data for correlation and resolution of hydrostratigraphy.

\subsection{New Drilling}

Drilling and logging at a potential HLW repository site will yield information on aquifers, aquicludes and fractures that will determine the hydrostratigraphy. It would also allow the use of aquifer testing, laboratory permeability and water quality testing and analysis by numerical modeling. Specific concerns relating to shales include the difficulties of measuring hydrologic parameters in materials of low permeability. Pump tests are useful in shales if the stratigraphy is well enough known that specific horizons can be tested. Values for porosity and permability of aquifers can vary widely depending on the mineral composition, post depositional history (diagenesis and induration) and origin of the shales. Flow may occur in limey or sandy interbeds or along open fractures, and give unreliable results for the tests. Laboratory porosity and permeability tests of selected horizons obtained during arilling may contribute more information to site hydrology.

Techniques for modeling and analysis may be used to evaluate hydrologic conditions, using data previously obtained from borehole lab testing, geologic data and geochemical analyses. Results of the modeling will provide information on locations and mechanisms of recharge and discharge, heads and gradients, and direction, rate and velocity of flow. Reliability is based on a good understanding of the hydrologic system. As the repository model consists of simple layering, extrapolation may be readily made.

\subsubsection{Geochemistry}

Geochemical data and analyses will address information needs dealing with interactions of the host rock and its constituent minerals with 
groundwater flow. Age dating of groundwater will establish residence time and flow velocity.

\subsection{No Drilling}

Techniques available at this stage are limited to testing of surfacewater quality, which will support the hydrologic and geologic efforts. Geochemical conditions, rock interactions and alterations and chemistry of constituents at depth can only be inferred.

\subsection{Previous Drilling}

Previous drilling will provide general information on geochemical conditions at depth by interpretation of lithology and stratigraphy from downhole geophysical logs. Direct sampling and testing at this stage will be unreliable.

\subsection{New Drilling}

New drilling will allow application of laboratory techniques for geochemical analyses of rock and water with a high degree of reliability. Geochemical interpretations can be made from selected downhole geophysical logs. These data can provide the basis for geochemical descriptions of the prospective repository, as described in the technique report on geochemistry (Appendix $\mathrm{F}-1$ ).

Although properties of specific samples can be determined with a high degree of certainty, extrapolation to the host rock may be tenuous if the clay mineralogy is highly variable throughout the shale body.

\subsubsection{Geomechanics}

These techniques, described in Appendix E-1, are used to evaluate the properties of the shale host rock to assure stability of the repository and to predict the effect of the repository on surrounding rocks.

\subsection{No Drilling}

As shale beds which would house a potential repository may crop out miles from the site, and shale properties cannot be extrapolated with confidence, drilling is necessary to obtain information on host rock characteristics. Surface exposures would be heavily weathered and 
fractured, and not typical of shales at depth. Therefore, geomechanical and thermomechanical information on a shale body would be restricted to extrapolation from conditions offsite, general interpretations based on available geologic information and general interpretations of tectonic stress.

\subsection{Previous Drilling}

Data from previous drilling could provide useful data by defining stratigraphy and lithology. Rock mass properties are dependent on constituent minerals and post depositional processes so that much information can be extrapolated if the distribution of rock types is known.

\subsection{New Drilling}

New drilling will allow direct extrapolation of geomechanical parameters by use of the techniques in Appendix E-1. Detailed logging and borehole geophysics will better define geologic conditions (stratigraphy, lithology and structure). Important parameters to determine during testing would include compressive and tensile strengths, elastic moduli, plasticity, specific heat, coefficients of thermal conductivity and expansion, and potential for thermal.alteration.

\subsubsection{Seismotectonics}

Seismicity and tectonics information needs are independent of the medium and the stage of site investigation. Regional seismicity studies are conducted to determine potential sources of earthquakes and to predict levels of strong ground motion that could affect the site. Seismological studies are media independent, and progress from regional to site specific. A complete analysis of a seismological program, including order of investigation, is provided in Appendix $\mathrm{H}$.

Tectonic studies (uplift, subsidence and faulting) utilize remote sensing and surface mapping techniques.

\subsubsection{Resources}

\subsection{No Drilling}

Before drilling is begun at a site, resource potential will probably be well known from extrapolation of off site data and interpretation of 
geophysical surveys. Hydrocarbon resources may occur in sandstones capped by impermeable shales, or in stratigraphic or structural traps in shales. Hydrocarbon potential could be correlated with similar conditions off site and verified by geophysical surveys. Potential for exploitable uranium, coal or oil shales could be postulated by surface outcrop sampling and testing.

\subsection{Previous Drilling}

Regionally, previous drilling was probably carried out for petroleum or coal exploration. Existing logs and driller's reports, unless propriety, can generally suggest the existence of resources.

\subsection{New Drilling}

New drilling at a prospective site would increase the reliability and resolution of resource evaluation by proving or disproving geologic interpretations relating to hydrocarbon or resource potential. Generally, however, exploitable resources at proposed repository depths would have been found before this stage of exploration.

\subsubsection{COST AND TIME ESTIMATES FOR PRECHARACTERIZATION TECHNIQUES}

Cost and time estimates for the techniques that would be used in investigation of a prospective site in shale are summarized in the accompanying Tables $(3.2 .4-1$ to 3.2.4-7). Many of these techniques are essentially similar to those used in other media and for other types of studies and, as a result, cost and time estimates also will not vary. Parameters that are unique to shale are emphasized in the following discussion.

\subsubsection{Remote Sensing and Mapping}

Costs and times involved in remote sensing analyses and surface geologic mapping are discussed in Appendix $A$ and summarized in Table 3.2.4-1. Although there would be specific objectives in this work for a site in shale, the techniques used would be essentially the same as for sites in other media; cost and time estimates similarly would not differ. The main factors influencing costs and times for this work would be accessibility and trafficability of terrain at a site and the complexity of geologic conditions. These differ significantly at known occurrences of shale and cannot be accounted for on a generic basis. 
COST AND TIME SUMMARY FOR REMOTE SENSING AND MAPPING

Acquiring Imagery or Photography

\begin{tabular}{|c|c|c|c|}
\hline & Approximate Cost Range & $\begin{array}{c}\text { Delivery } \\
\text { Time (1) }\end{array}$ & $\begin{array}{l}\text { Approximate } \\
\text { Area Covered }\end{array}$ \\
\hline $\begin{array}{l}\text { LANDSAT } \\
\text { Enhancement }\end{array}$ & $\begin{array}{c}\$ 8-150 \text { per image }{ }^{(2)} \\
\$ 200-1000 \text { per scene }(3)\end{array}$ & $\begin{array}{l}1-4 \text { weeks } \\
4-16 \text { weeks }(3)\end{array}$ & $13,500 \mathrm{mi}^{2}$ \\
\hline $\begin{array}{l}\text { SKYLAB } \\
\text { Multispectral } \\
\text { Earth Terrain }\end{array}$ & $\begin{array}{l}\$ 8-150 \text { per image }(2) \\
\$ 8-150 \text { per image }(2)\end{array}$ & $\begin{array}{l}1-4 \text { weeks } \\
1-4 \text { weeks }\end{array}$ & $\begin{array}{l}2,000 \mathrm{mi}^{2} \\
4,600 \mathrm{mi}^{2}\end{array}$ \\
\hline $\begin{array}{l}\text { Stereo Aerial Photogr } \\
\text { Purchase existing } \\
\text { New flight }\end{array}$ & $\begin{array}{l}\text { aphy } \\
\$ 3-60 \text { per frame }(2) \\
\$ 25-40 \text { per frame }(4)\end{array}$ & $\begin{array}{l}1-4 \text { weeks } \\
2-6 \text { weeks }\end{array}$ & $3-80 \mathrm{mi}^{2}$ \\
\hline $\begin{array}{l}\text { Low Sun Angle Photogr } \\
\text { Purchase existing } \\
\text { New flight }\end{array}$ & $\begin{array}{l}\text { aphy } \\
\$ 3-60 \text { per frame (2) } \\
\$ 25-75 \text { per frame (4) }\end{array}$ & $\begin{array}{l}1-4 \text { weeks } \\
2-6 \text { weeks }\end{array}$ & $3-12 \mathrm{mi}^{2}$ \\
\hline $\begin{array}{l}\text { Radar Imagery } \\
\text { Purchase existing } \\
\text { New flight }\end{array}$ & $\$ 125 \underset{(7)}{\text { per strip }}$ & $\begin{array}{l}1-3 \text { weeks } \\
3-10 \text { weeks }\end{array}$ & $\begin{array}{l}100-2500 \mathrm{mi}^{2} \\
\text { Per survey } \\
\text { design }\end{array}$ \\
\hline
\end{tabular}

Interpreting Imagery or Photography

Satellite Imagery (generally \& 1:250,000)

Aerial photography ( 8$)$

e $1: 62,500$

Land forms

Lithology

Geologic structure

Aerial photography (8)

e $1: 24,000$

Land forms

Lithology

Geologic structure

Radar Imagery

$\frac{\text { Cost }}{\$ 1050-1750} \quad \frac{\text { Time }(5)}{3-5 \text { days }} \quad \frac{\text { Comments }}{\text { per scene }}$

$\$ 70-175$

$\$ 70-175$

\$175-280

$1 / 4-1 / 2$ days

$1 / 4-1 / 2$ days

$1 / 2-1$ day

For 100

$\mathrm{mi}^{2}$ area

$\$ 175-350$

$\$ 175-350$

$\$ 280-700$

1/2-1 day

$1 / 2-1$ day

$3 / 4-2$ days

For 100

$\mathrm{mi}^{2}$ area
(9) 
TABLE 3.2.4-1 (Cont.) - NOTES

Field Mapping (6)

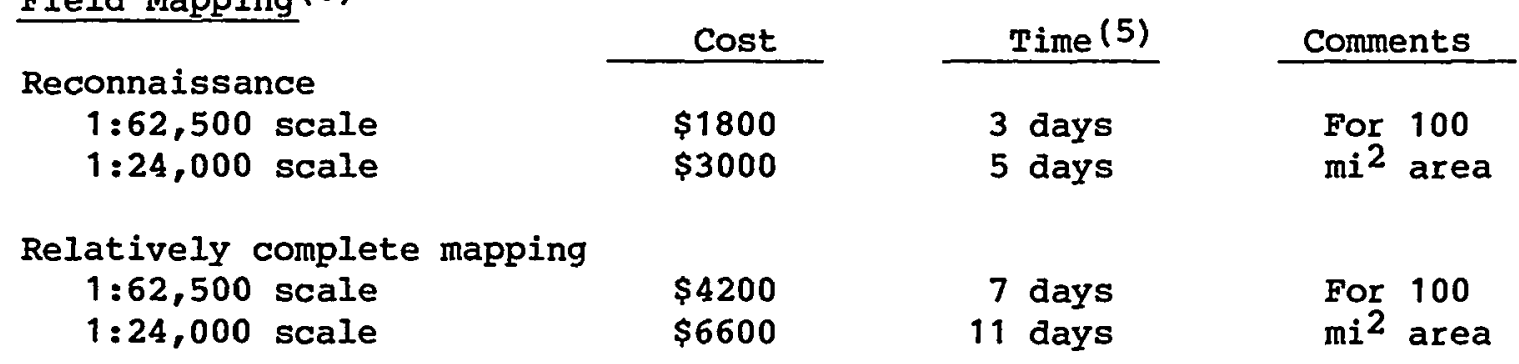

NOTES

(1) Delivery times generally do not depend on quantity ordered.

(2) Cost of photos or imagery is determined by size of print ordered, whether in color or black and white, and extra charges for shorter delivery time.

(3) Cost and delivery time for enhancements depends on source and on availability of previous processing for scene desired.

(4) Flight costs in addition to costs of photo reproduction indicated above.

(5) Approximate man-days to complete work; delivery time may be longer. Time required for interpretations can depend on complexity of geologic conditions at a site.

(6) Cost and time estimates assume interpretation of imagery and photography completed previously. Actual times and costs in an area would be influenced by access, trafficability, and complexity.

(7) Obtaining radar imagery from a new flight costs several thousand dollars. Actual costs depend on mobilization (radar equipment is not widely available), altitude requirements, and other flight parameters.

(8) Estimated times and costs are applicable to all $9^{n} \times 9^{n}$ stereo aerial photographs: black and white, color and infrared (both black and white and color).

(9) Time and cost for interpreting radar imagery depends on resolution and scale of the imagery, purpose of the interpretation, and other factors. See Appendix A for discussion. 


\subsubsection{Drilling and Coring}

Costs and times for drilling or coring and for geologic logging of cuttings and core are discussed in Appendix D-1. Drilling techniques and equipment used in the petroleum industry are judged most effective for work in shale. As for other techniques, the validity of estimates presented in Table 3.2.4-2 may vary according to site conditions such as terrain, accessibility, and nature of overburden materials.

\subsubsection{Borehole Geophysical Logging}

Costs for various borehole geophysical logs are discussed in Appendix $C$ and summarized in Table 3.2.4-3. Per foot costs are indicated but total expenses typically would depend on factors such as mobilization distance, standby time, and calibration requirements, in addition to the total footage logged.

Times required for running individual logs depend on trolling speed and setup requirements (i.e., changing probes, calibration, etc.). In general, however, several logs can be run per day (eight logs per day are assumed in Table 3.2.4-3) and the most extensive logging program at a single well can be completed within a couple of days once the contractor is on the site. These times are nearly insignificant in comparison to the duration of drilling and associated testing.

\subsubsection{Geophysical Exploration}

Costs and times for various techniques of geophysical exploration are discussed in Appendix $B$ and summarized in Table 3.2.4-4. Seismic reflection surveys are most applicable in shale while resistivity and seismic refraction also may be used for specific information needs. Gravity and airborne magnetic surveys also may be applicable to reconnaissance investigations of specific information needs. Additional techniques, discussed in Appendix B, may not be applicable in shale and are not included in Table 3.2.4-4.

The ranges of costs and times reflect to a large extent the differences between reconnaissance-level surveys in the early part of an investigation and the detailed, high-resolution surveys needed as precharacterization studies focus on a site. This is particularly evident for seismic reflection surveys, as the lower costs are for reconnaissance surveys to determine general structure and resource potential at moderate depths. The smaller detector spacing and higher resolution needed for reliable investigation at the proposed repository levels would result in corresponding increases in costs and time requirements. 
TABLE 3.2.4-2

COST AND TIME SUMMARY FOR DRILLING \& CORING (1)

$\begin{array}{lcccc}\begin{array}{c}\text { Type } \\ \text { Equipment }\end{array} & \begin{array}{c}\text { Cost (2) } \\ \text { (per foot) }\end{array} & \begin{array}{c}\text { Drilling } \\ \text { Production } \\ \text { Rate }\end{array} & \begin{array}{c}\text { (feet per day) } \\ \text { Cost (2) } \\ \text { (per foot) }\end{array} & \begin{array}{c}\text { Coring } \\ \text { Production } \\ \text { Rate }\end{array} \\ \text { (feet per day) } \\ \text { Mining } & \$ 32 & 500 & \$ 135 & 120 \\ \text { Water Well } & \$ 60 & 200 & \$ 150 & 80 \\ & \$ 40 & 200 & \$ 135 & 60\end{array}$

NOTES:

(1) Adapted from Appendix D

(2) Includes personnel, supplies, mud, and all other support equipment. 
TABLE $3.2 .4-3$

COST AND TIME ESTIMATES FOR

BOREHOLE GEOPHYSICAL LOGGING

Techniques

Approximate

Cost Range

Time (3)

Typical Log Package (1)

Borehole Caliper

Focused Resistivity

Single-point Resistivity

Spontaneous Potential

Gross-count Gamma Ray

Density

Neutron Porosity

Deviation

$\$ 1300$

to

$\$ 6500(2)$

$1 / 2$ day

Additional Logs (4)

Electrical

Radioactive

$\$ 350-900(5)$

$\$ 300-1000$ (5)

Acoustic $\$ 800-2700(5)$

Add approximately one hour per sonde

Specialized logs requiring separate mobilization: (not practical for single hole)

Radar Log

$\$ 6000(6)$

$1 / 2$ day

Gravity Log

$\$ 4000(6)$

$1 / 2$ day 
TABLE 3.2.4-3 (cont.) - NOTES

(1) Assumes:

a. Single 1000-foot hole

b. 400 miles (round trip) travel charge to well site

c. holes ready to $l o g$ upon arrival (i.e., no standby time)

d. logging speed of 50 feet per minute

e. non-logging (entering hole) at 60 feet per minute

f. log package combined in two sondes

(2) Low cost for minerals logging contractor; high end cost for oilfield logging contractor. Cost per hole would be reduced if travel charge can be applied to additional holes.

(3) Approximate time on site, not including travel

(4) Assumed to be added to package described in note (1)

(5) Actual costs will depend on services desired, available combinations in single sondes, and minimum charges imposed by some contractors. Ranges are as in note (2), above. 
TABLE $3.2 .4-4$

COST AND TIME SUMMARY FOR

GEOPHYSICAL EXPLORATION TECHNIQUES

Technique

Seismic Refraction

Resistivity Profile

Resistivity Sounding

Seismic Reflection

- Typical survey

- High resolution

Gravity

Audio-magnetotellurics
Approximate Cost Range (1)

$\$ 3,000-15,000$ per mile(2)

$\$ 1000$ per station(3)

$\$ 2500$ per sounding (5)

$\$ 4000$ per

line mile(6)

$\$ 10,000$ per

line mile(6)

\$60-75 per station (7)

$\$ 900$ per station
Typical Production Rates (1)

(2)

3 stations per crew per day in field (4)

2 soundings per crew per day in field(4)

Field rate of 100 line miles per month per crew (6)

Field rate of 40 line miles per month per crew $(\sigma)$

2 to 4 stations per hour

2 stations per crew per day 
TABLE 3.2.4-4 (cont.) - NOTES

(1) All estimates assume average to good access, terrain, and weather conditions. Costs and times for all ground-based techniques will be higher in areas of rugged terrain or otherwise difficult access or trafficability.

(2) Cost and production rate determined by (1) spacing between geophones, (2) number of shots recorded in each layout, and (3) shot size. Single large shots may require several days of preparation, while small surveys may be completed in a few hours. See Appendix B-3 for discussion.

(3) Based on typical survey consisting of six profiles, each $1 \mathrm{~km}$ long. See Table $4 A$ in Appendix B-4.

(4) See Table 5 in Appendix B-4 for estimates of times for additional related activities.

(5) Based on typical soundings with five separate measurements and maximum 300-meter pole separation. See Table 4B in Appendix B-4.

(6) Based on typical land-based crew working on medium-term contract, using dynamite source, 96-trace, 1-millisecond, 12-fold sampling and 50-meter detector spacing. Assumes no adverse conditions of access or trafficability. Data processing adds $\$ 200$ to $\$ 300$ per mile for "typical" survey and $\$ 800$ to $\$ 1200$ per mile for highresolution. Specialized processing would incur additional costs. See Appendix B-6 for discussion.

(7) For a 100-200 station survey under good field conditions (see Fig. 4, Appendix B-1). Widely spaced stations require increased travel times, affecting costs and production rates. Survey costs where helicopter access is required could be on the order of $\$ 250$ per station. 


\subsubsection{Geochemistry}

Estimates of costs and times for typical laboratory and analytical techniques in geochemistry are summarized in Appendix $\mathrm{F}-1$. Costs for obtaining and transporting samples are not included.

\subsubsection{Geomechanics}

Costs and times for typical laboratory and field techniques in geomechanics are provided in Table 3.2.4-5. Creep testing which is likely to be very important in shale, is not included in this table as it is expected that sufficient data for precharacterization would be obtained from long-duration triaxial compression tests. Additional data on creep testing will be provided in Section 3.3.4.5 for site Characterization.

\subsubsection{Hydrology}

Costs and times for typical techniques used in hydrologic studies are summarized in Table 3.2.4-6. As discussed previously, these investigations at a prospective site in shale will address several different hydrologic systems, above, within and below the shale bed. In general, the potential range of costs indicated reflects the differences between testing of shallow, relatively productive aquifers above the shale and work in the deeper, relatively unproductive zones within and below the shale. Costs of drilling and well completion are not included in these estimates.

\subsubsection{Seismotectonics}

Costs and time estimates for seismological monitoring and analyses are summarized in Table 3.2.4-7. Estimates for the relating faulting and geologic studies are in Table 3.2.4-1.

3.2.5 CRITERIA FOR EVALUATING DATA ADEQUACY OF PRECHARACTERIZATION STUDIES IN SHALE

The information discussed previously on geology of shale (3.2.1), information needs $(3.2 .2)$ and applications of techniques $(3.2 .3)$ can be applied to develop general criteria or guidelines for evaluating the information on exploration and testing expected to be presented in a site Characterization Report for a prospective repository site in 
TABLE $3.2 .4-5$

COST AND TIME SUMMARY FOR

GEOMECHANICAL TECHNIQUES

Technique

Regional Stress State

Unconfined Compressive Strength

Description of discontinuities

Rock Quality

Designation

Porosity/Density

Water Content

Absorption

Swelling and Slake Durability

Sonic Velocity

Uniaxial Compressive Stress

Permeability

Triaxial Compressive Strength

Thermal Conductivity

Borehole Modulus

In Situ Stress State
Approximate

Cost Range

$\$ 4,440$

(estimate)

$\$ 25-300$

$\$ 14,400$

(estimate)

(2)

$\$ 50$

$\$ 10$

$\$ 50$

$\$ 350-1,250$

$\$ 50-500(3)$

$\$ 250(4)$

$\$ 250-1,000$

$\$ 2,000-10,000(5)$

$\$ 1,000-2,000(6)$

$\$ 10,000-15,000(7)$
Approximate Turn-Around Time (1)

Comments

3 wks (estimate)

$$
\begin{aligned}
& \text { per region - } \\
& \text { based on liter- } \\
& \text { ature review }
\end{aligned}
$$

5 minutes (9)

per test

1 man month

per site (estimate)

(2)

$\begin{array}{ll}2 \text { weeks } & \text { per test } \\ 2 \text { weeks } & \text { per test } \\ 2 \text { weeks } & \text { per test }\end{array}$

2 weeks

per test

3 weeks

per test

3-6 weeks

per test

3 weeks

per test

3-6 weeks per test

8 weeks per test

1 week (8) per test

$$
\begin{array}{llll}
\text { overcoring } & \$ 40,000-\$ 60,000(7) & 5 \text { hours }(8) & \text { per test } \\
\text { hydrofracture } & \$ 50,000-\$ 70,000(7) & 1-10 \text { days }(8) & \text { per test }
\end{array}
$$


TABLE 3.2.4-5 (cont.) - NOTES

(1) Turn-around time for delivery of laboratory results, unless otherwise stated.

(2) Done by well-site geologist in conjunction with normal core logging at no measurable increase in cost or change in arilling rate.

(3) Higher costs are for tests at elevated temperature and pressure.

(4) Includes measurement of deformation. Can obtain strength data only for less than $\$ 50$.

(5) Test program would be designed to meet project needs. Further cost increases would result from requirements for additional measurements or testing at elevated temperature or pressure.

(6) Higher cost for tests at elevated pressure.

(7) Excluding drilling costs.

(8) Actual working time on test.

(9) Field tests using portable point load apparatus or Schmidt Hammer. See pages 8 and 9, Appendix E-1. 
TABLE 3.2.4-6

COST AND TIME SUMMARY FOR HYDROLOGY TECHNIQUES

Technique

Surface Hydrology

Singular Flood Frequency

Regional Flood Frequency

Rainfall-Runoff

100-year flood plain

Flooding from dam failure

Discharge measurements

Field surveys of recharge/discharge

Surface-water sampling

Borehole Testing (5)

Head measurement
a. Manual
b. Winch
c. Recorder

Drill stem test

Pump test

Injection test

Straddle packer test

Tracer tests

\section{Permeability Tests}

on core samples

Numerical Modeling
Approximate

Approximate Turn-Around

Cost Range

Time

Comments
(1)

(1)

(1)

(1)

(3)

(4)

$\$ 50-75$ per square mile (3)

per square mile ${ }^{(4)}$

$$
\begin{aligned}
& \$ 25-100(6) \\
& \$ 100-500(7) \\
& \$ 3000-10,000
\end{aligned}
$$

to $\$ 25,000(10)$

to $\$ 25,000(10)$

$\$ 200$ or more (11)

$$
\begin{aligned}
& 1-2 \text { hour }(6) \\
& 1-4 \text { hour }(7) \\
& 1 / 2-3 \text { days }
\end{aligned}
$$

per measurement

$$
\text { per }
$$

measurement installa-

tion of recording system

per test per test

$$
\begin{array}{ccc}
\$ 250-1000(12) & 3 \text { weeks }(12) & \text { per test } \\
\$ 400-4000(13) & 1-10 \text { days }(13) & \text { per model }
\end{array}
$$


TABLE 3.2.4-6 (Cont.) - NOTES

(1) Cost and time for specific analysis, after compiling basic field data.

(2) Cost and time for single field measurement, using simple plywood wier, portable flume, or existing structure. Does not include travel to measurement site.

(3) Assumes 2-man field party working at rate of 10 to 15 square miles per day. Actual costs and rates of progress would vary with field conditions.

(4) Assumes 2-man field party working at rate of 25 to 50 square miles per day, including cost of expendible sampling equipment. Costs for typical water-quality tests are in Table 1 of Appendix G.

(5) Not including arilling or completion costs. See Appendix D.

(6) Manual measurement using tape or probe to about 750 ' depth - not including travel to well site.

(7) Measurement at greater depth, requiring winch to handle probe not including travel to well site.

(8) Costs and time requirements for testing vary according to depth, duration of test, and size or type of drilling equipment used. See Appendix G.

(9) Pump test costs depend on equipment in place at a well and duration of the test. Can be done for about $\$ 200$ at existing water-supply well with pump in place. Cost can be thousands of dollars for complex testing systems requiring installation of pump, power supply, and equipment for monitoring water levels.

(10) Cost and time estimate for high-technology testing in tight formation at repository depths. Includes mobilization of specialized equipment and preliminary analyses of results.

(11) For long-duration tests, as may be needed in formations with low permeability, costs are likely to be determined by need for continued monitoring, involving pumping or bailing to detect tracers in deep aquifer. Such tests could cost several thousand dollars.

(12) Does not include cost or time for obtaining core.

(13) Cost and time for numerical analyses only, after basic field and lab data are compiled. 
TABLE $3.2 .4-7$

COST AND TIME SUMMARY FOR

SEISMOTECTONIC TECHNIQUES

Technique

Approximate

Cost Range

Time

Comments

Historical Data

$\$ 2,900-5,900$

2 weeks

per basic analysis

Instrumental Data

$\$ 5,800-8,800$

1-2 months

per basic analysis

Fixed Network

Installation

$\$ 8,000-10,000$

12-28 weeks

per station

Operation

$\$ 7,300-14,600$

per station/

year

Portable Network

$\$ 3,250-5,700$

2 days per station/ (to install) month

Crustal Refracton Profile

$\$ 2,000-5,400$

1-4 weeks

per station 
shale. As described in 10CFR60.11 (Federal Register v46, p13681, Feb. 25 , 1981) the Site Characterization Report is to include results of the exploration and testing supporting site selection in addition to the planned site characterization work. Discussions in this section emphasize guidelines for evaluating previous exploration; evaluation of the work performed in site characterization is to be the topic of Section 3.3

\subsubsection{Geology}

Basic information needs relating to geology are covered in section 3.2.2. A generally adequate exploration program would include:

- Iithology, Stratigraphy, Structure of the overburden - remote sensing, surface mapping, borehole logging, geophysical exploration, drilling and sample logging

- Depth to host rock - drilling and sample logging, borehole logging, geophysical exploration (except resistivity), seismological velocity studies

- Lateral extent and thickness of the host rock - remote sensing (aircraft imagery), surface mapping, drilling and logging, borehole logging, geophysical exploration (except resistivity), geomechanical and thermomechanicai (later stages only), fault studies

- Lithology, stratigraphy, structure of the host rock - remote sensing, surface mapping, drilling and sample logging, borehole logging, geophysical exploration (seismic reflection)

- Erosion - remote sensing, surface mapping

Sufficient surface outcrops and confidence in being able to extrapolate surface conditions to depth are important elements in an exploration program. In a shale terrain the subsurface rock mass is generally in better condition than surface rock. Therefore, only surface exploration must be reinforced and substantiated with an extensive subsurface program. Due to the potential variability of shale beds, core drilling will provide better information than rotary drilling, where indications of small interbeds may be lost. Borehole geophysical tests require correlation using borehole data. Geophysical exploration techniques, such as seismic reflection surveys, may record poor data or no record in the shale body because of weak energy return, but could still prove valuable in demonstrating the shale body is uniform and horizontal. 


\subsubsection{Hydrology}

A basic program to determine hydrologic information needs should include:

- Hydrostratigraphy - drilling, borehole logging (electrical, radioactive, acoustic), geophysical exploration (audio-magnetotellurics (AMT), seismic refraction, resistivity), hydrology (recharge/ discharge, numerical modeling, aquifer and tracer tests),

- Recharge/Discharge - remote sensing (aircraft imagery), surface mapping, geochemistry sampling and analysis, hydrology (recharge/ discharge, surface water sampling and analysis)

- Porosity/Permeability - borehole logging, geophysical exploration (AMT, resistivity), geomechanics and thermomechanics lab tests, geochemistry sampling and analysis, hydrology (recharge/discharge, aquifer and tracer tests).

- Aquifer properties - borehole logging (electrical, radioactive, accoustic), geomechanical and thermomechanical (rock mass lab tests, in situ tests), geochemistry sampling and analysis, hydrology (recharge/discharge, aquifer and tracer tests)

- Heads and gradients of groundwater - hydrology (recharge/discharge, aquifer and tracer tests)

- Groundwater flow direction, velocity and travel time - geochemistry (sampling and analysis), stable isotope modeling, groundwater age dating, hydrology (recharge/discharge, numerical modeling, and tracer tests)

- Surface hydrology - remote sensing, surface mapping, (Paleo) flood frequency, recharge/discharge, and surface water chemistry

- Climate - surface mapping of landforms.

Surface hydrology and its relation to present and Quaternary climate conditions, should be well established during pre-characterization studies. The approach, scope of work and criteria for evaluating the techniques used are independent of the host medium. These factors will be determined by conditions prevalent at a prospective site. The principal result of surface hydrology studies coupled with paleoclimate studies is a prediction of future erosion rates above the repository. surface hydrology will also provide input into characterizing the hydrologic regime. 
Prior to site characterization, hydrostratigraphy and aquifer properties for water-bearing zones should be investigated. Potential for flow paths above, within and below the host rock should be determined. Flow paths within shale will probably be restricted to sandy interbeds or highly fractured zones, and will contain only small amounts of fluid. The permeability and porosity of the shale will be important in determining the strength and behavior after it has been exposed to elevated temperatures.

Hydrological techniques are limited by the adequacy of the samples and data collected during studies without borings or with only previous borings. Since most tests will be conducted on boreholes drilled specifically for the project, sufficient confidence can be placed in the quality of samples and test results. Variations in subsurface stratigraphy require that selected zones must be chosen for aquifer testing, or erroneous results may occur. Packer tests may produce values that are higher than in situ values, as fissile layers are forced apart by water pressure.

\subsubsection{Geochemistry}

Rock and water chemistry parameters can generally be adequately described with the following techniques:

- Rock mineralogy and alteration - remote sensing, surface mapping drilling and logging (electrical, radioactive)

- Organic content - surface mapping, borehole logging (radioactive), geochemical sampling and analysis

- Retardation properties - borehole logging (electrical, radioactive), geochemical analysis and water-rock modeling, stable isotope modeling

- Geochemical dating - surface mapping, geochemical sampling and analysis, stable isotope modeling, standard age dating techniques

- Water chemistry - borehole logging (electrical), geochemical sampling and analysis, water-rock modeling, stable isotope modeling, hydrology (surface water chemistry)

The geochemistry of shale may be well defined from preliminary studies of depositional environment and lithology. Mineralogic differences in shales, and the relative abundances of these minerals may affect the 
repository. Composition of ground water may inhibit or accelerate ion exchange and absorption. Precharacterization studies should be performed with changes to the overall rock chemistry in mind.

\subsubsection{Geomechanics}

A basic program for geomechanics and thermomechanics will include:

- Rock classification, rock quality and discontinuities - surface mapping (lithology/materials), borehole logging, geophysical exploration (seismic refraction, resistivity); geomechanical and thermomechanical, drilling and logging

- In situ stress - geomechanical and thermomechanical in situ tests, instrumental earthquake analysis

- Strength, moduli plasticity - borehole logging (acoustic); geomechanical and thermomechanical, drilling and logging.

- Pore pressure - borehole logging (electrical), geomechanical and thermomechanical in situ and lab tests.

- Specific Heat - borehole logging (electrical, radioactive) geomechanics and thermomechanical in situ tests.

- Thermal conductivity, expansion, alteration - borehole logging (electrical, radioactive), geomechanical and thermomechanical in situ tests

The most important factor to consider for shale is the thermal related reactions of constituent clay minerals. The minerals in shale have significantly different mechanical and thermal properties. Their distribution and relative proportions will greatly influence the geomechanical conditions at a repository level. Some clay minerals in shales dehydrate upon heating, which can affect the basic structural lattice, resulting in loss of strength and accelerated degradation. Core from old boreholes will be unsuitable for testing; in many cases boreholes will be blocked and cannot be used. Therefore, the greatest contribution to geomechanical and thermomechanical information needs at the precharacterization stage is detailed logging, and in situ testing in new drill holes. 


\subsubsection{Seismotectonics}

A program to adequately characterize the seismologic and tectonic setting of the siting region should generally include the following:

- Uplift/subsidence - remote sensing, surface mapping, fault studies

- Faulting - remote sensing, surface mapping, borehole logging (electrical), geophysical exploration, earthquake analysis

- Igneous activity - remote sensing, surface mapping

- Earthquakes - analysis of historic and instrumentally recorded earthquakes

Seismotectonic programs basically are not media specific and the same types of studies must be done for every siting region. Iimitations in data adequacy and applications of techniques include a lack of historical data, lack of events in a seismically quiescent area from which to evaluate maximum credible earthquakes and seismic potential, and conflicting instrument readings. Surface mapping and remote sensing of faults can lead to ambiguous results, which may require subsurface examination to resolve. Fault studies may not yield unambiguous results even with detailed examination, especially if there are no datable materials or offset beds.

\subsubsection{Resources}

A basic program for resource evaluation should include the following techniques:

- Minerals - remote sensing, surface mapping, geophysical exploration (gravity, AMT, magnetic, resistivity), drilling and borehole logging (all but acoustic)

- Hydrocarbon - remote sensing, drilling and borehole logging (all but acoustic), geophysical exploration (seismic reflection)

- Geothermal - remote sensing, surface mapping (except landforms), drilling and borehole logging (except acoustic)

Surface exploration and remote sensing can be extrapolated with care to assess subsurface conditions. Most of the surface based techniques need to be correlated with subsurface exploration. 


\subsubsection{GEOLOGIC FEATURES OF SHALE IMPORTANT FOR SITE CHARACTERIZATION}

General geologic properties of shale, discussed in section 3.2.1, emphasized factors that contribute to the identification of potentially suitable sites during precharacterization. These factors can be determined by use of existing or new drilling, geophysical exploration, and remote and surficial mapping. Site characterization requires that the geologic properties of shale be determined by direct observation and in situ testing. Factors of importance for shale for site characterization include hydrology, geomechanics, and geochemistry. Geologic properties of shale that influence these factors include:

1. Mineralogy and Lithology - Variance in mineralogy and lateral and vertical gradations directly influence geochemistry and thermomechanical properties and may have an effect on the geomechanical properties; and

2. Structure - Laminations, fractures, sandy interlayers, and fissile layers influence the geomechanical properties and may provide hydrologic pathways.

These geologic properties and how they are related to site response and characterization needs are discussed in the following sections.

\subsubsection{Mineralogy and Lithology}

The mineralogy and lithology of shale can be gradational laterally and vertically, reflecting differences in source rock, depositional environment and post-depositional processes. Freshwater deltaic shales generally show abrupt or lateral and vertical gradations into sandier material, representing fluctuating depositional conditions. Marine shales are generally thick, continuous sequences, sometimes associated with sandstone and limestone reflecting more stable depositional conditions. Clay minerals, which have the most effect on shale properties, can vary due to post-depositional processes, circulation of groundwater, changes in the salinity and $\mathrm{pH}$ of the circulating water, rate of burial, elapsed time since burial, and temperature changes, as 
well as depositional environment. Determinations of the percent and type of clay minerals, and possible variations are important because each group (kaolinite, illite, montmorillonite) will react differently to heat and pressure variations, as well as in complex chemical reactions.

The location, extent and thickness of sandy interlayers is important to define at the characterization stage, because they can act as conduits for groundwater movement, and detract from the strength and stability of a repository. These may have been identified to a large degree during stage III drilling and downhole logging performed during precharacterization.

Post-depositonal processes, such as compaction and diagenesis, can create very fissile shale, made up of fine layers. Generally, highly fissile shale has low strength, and tends to slake and break easily.

\subsubsection{Structure}

The most important factors at this stage of site study are lateral extent of sandy interbeds and fractures, both of which would decrease strength, and act as pathways for ground water flow. It is expected that at repository depths all fractures would be tightly sealed. However, in certain hydrologic regimes, the fractures may still be conduits for ground water flow.

The internal structure would influence the geomechanical properties of the shale being considered for a waste respository. Prior exploration would have noted any large structural anomalies. Site characterization would require determination of features on a smaller scale.

\subsubsection{INFORMATION NEEDS FOR SITE CHARACTERIZATION STUDIES IN SHALE}

\subsubsection{General}

The general information needs for a prospective repository in shale have been summarized in section 3.2.2 with emphasis on precharacterization studies performed for selecting a potentially suitable site. The information needs specific to site characterization are, to a large extent, those that require detailed exploration within the host rock. Many of the techniques used during precharacterization continue to be applicable during testing and development of a pilot shaft and test room near the repository level. This allows more detailed examination and testing of the rocks at depth as well as providing a base 
for intensive drilling (horizontal or inclined) in the shale without creating a connection between a prospective repository and the surrounding rock. While the site characterization stage, allows an extensive amount of geotechnical data to be collected in the host rock, this exploration and testing involves a considerable expense. Therefore, there must be a high level of confidence in the site selected during the precharacterization stage.

Precharacterization is expected to delineate and resolve issues that may be addressed without detailed exploration and testing at depth. Issues that may be essentially resolved during precharacterization include surface geology, surface hydrology, climate, tectonics, seismicity, and potential for igneous activity. The latter three factors will generally not be major considerations in precharacterization studies as most suitable shale deposits are located within the stable continent regions of the U.S. All of these issues, however, are evaluated on the basis of regional areas, rather than site-specific testing at depth. The exploration history and resource potential at a site can be based on reconnaissance-level investigation and will be resolved prior to site selection.

After precharacterization studies have identified a suitable site, the main issues that must be resolved are (1) determining site-suitability with respect to containment and isolation of radionuclides and (2) providing detailed site-specific parameters for design and construction of a repository. In addition, continued exploration and testing would quantify and increase reliability of information in other areas. Continued monitoring of data and conditions determined during precharacterization will confirm the previous findings as to potential site suitability. The following subsections summarize the information needs specific to site characterization of a prospective repository site in shale. For each subsection, geology, hydrology, geochemistry, geomechanics, seismotectonics, and resources, there is a brief decription of the information that would have been obtained during precharacterization (for a more complete summary see Section 3.2.2); additional needs are extrapolated from these initial concerns.

\subsubsection{Geology}

The information needs regarding geology at the site characterization stage involve obtaining detailed information on the geologic conditions in the host rock; specifically relating to design, construction and performance of the repository. Many of the issues addressed during precharacterization (Section 3.2.2.2) are still applicable at this 
stage of site investigation, but would be addressed in greater depth and at a finer scale. Table 3.3.2-1 summarizes the information needs for geology.

The precharacterization study results should be sufficient to define surface geologic conditions and processes and generally describe stratigraphy, lithology, and geologic structures at depth. Surface geology should have been studied in enough detail to interpret nature and rates of relevant processes including erosion, deposition, and Quaternary climate and hydrology. Subsurface geologic information obtained from precharacterization would include depth, thickness and locations should be known, and the potential for jointing at depth should have been evaluated. Stratigraphy of the entire shale sequence should be known so that suitable beds, interbeds, existing and potential aquifers, and confining beds are delineated. Analyses of the rock should have been done so that the clay mineralogy is known. Areas of, and potential for, resource exploitation (oil, gas, oil shale, coal, etc.) would be known prior to the site characterization phase. It is expected that areas of high potential for future exploitation would not be proposed for a HLW repository.

The detailed and more intensive studies conducted within or close to the host rock during site characterization should provide a refined description of the lithology and structure within the host bed of the shale sequence. These studies should include determining the percentage and type of clay minerals that constitute the shale, variations in bed thickness, thickness and composition of sandy interbeds, and areas of fissile, under- or overcompacted layers. Lateral variations in mineralogy may adversely affect the repository and should be determined during site characterization.

Faults should have been identified during the precharacterization study. Fractures may be present, although they will probably be closed at depth, site characterization studies should identify any fractures at depth because they can be potential gorund water flow paths. Fracture fillings are not expected to be present due to the limited movement of ground water.

\subsubsection{Hydrology}

The information needs in hydrology that are specific to site characterization in shale relate to flow paths along sandier interbeds, and the porosity of the host bed. General information required for precharacterization needs, such as hydraulic conductivity, residence 
TABLE $3 \cdot 3 \cdot 2-1$

GEOLOGY INFORMATION NEEDS IN SHALE

Emphasized in Precharacterization

1. Stratigraphy.

2. Iithology.

3. Geologic structures and faults.

4. Surface geology.

5. Surface processes.

6. Quaternary climate.

7. Resource evaluation.

8. Seismotectonics.

Emphasized in Site Characterization

1. Clay mineralogy.

2. Interbeds and discontinuities. 
times of ground water, flow rates, and permeability, would continue to be addressed by investigations at greater detail, and by continued monitoring. The information needs pertinent to hydrology are summarized on Table 3.3.2-2.

Climate history and surface hydrology involve investigations that do not require subsurface exploration. They should be resolved before undertaking the detailed subsurface work of site characterization. Hydrostratigraphy above and below the host bed should be generally known from the precharacterization, although refinement of data will continue concurrently with site characterizaiton.

Shale can exhibit a porosity of up to 45 percent, although it generally exhibits low permeability at depth. The limited information obtained from new or existing drilling during precharacterization should be suitable to define sandy interbeds along which flow can occur and recognize the general distribution of highly porous zones. Detailed observations at depth contribute to direct observation of potential flow paths and an evaluation of their nature and variability. Site characterization studies should also evaluate the presence of fluids with in the shale and potential effects on repository, construction and the thermal loading on their migration or other behavior.

\subsubsection{Geochemistry}

Table 3.3.2-3 is a summary of information needs in shale pertaining to geochemistry. Information needs of geochemistry for site characterization involve detailed determinations of reactions between the whole rock, circulating or in situ fluids, constituent clay minerals and variations in temperatures due to waste emplacement. The behavior of the shale and its clay mineral constituents will influence the repository performance, and the geochemical properties of rocks and fluids must be established in order to quantify potential for radionuclide transport into the accessible environment. Chemical conditions in the areas of the shaft and boreholes need to be determined to provide design parameters for sealing the repository after emplacement of waste.

The results of precharacterization should be adequate to define the general geochemistry of the site, particularly the clay mineralogy, and establish chemistry of any water in over- and underlying aquifers. Mineralogical variations that would contribute to retardation or complexing, or require special considerations when selecting sealant material need to be delineated. Previous dating of rocks and water should have established the geologic history of the site and demonstrated the residence time and isolation of fluids. 
TABLE $3 \cdot 3 \cdot 2-2$

HYDROLOGY INFORMATION NEEDS IN SHALE

Emphasized in Precharacterization

1. Hydraulic conductivity.

2. Residence time of ground water.

3. Flow rates.

4. Permeability.

5. Surface geology.

6. Climate history.

7. Hydrostratigraphy.

Emphasized in Site Characterization

1. Flow paths.

2. Porosity.

3. Permeability. 
TABLE 3.3.2-3

GEOCHEMISTRY INFORMATION NEEDS IN SHALE

Emphasized in Precharacterization

1. Gross clay mineralogy.

2. Ground water or fluid chemistry.

3. Water/rock age dating.

\section{Emphasized in Site Characterization}

1. Rock/ground water interactions.

2. Chemical reaction of clay minerals.

3. Geochemical variations within host rock.

4. Chemical reactions pertinent to radionuclide transport.

5. Temperature gradient.

3-51 
Detailed, intensive subsurface work in site characterization should provide a detailed understanding of geochemical variations within the host shale bed, including stratigraphically controlled changes in mineralogy and possible lateral variations resulting from post depositional alteration. Depending on specific site conditions and the level of information obtained during precharacterization, additional work would address uncertainties or specific needs outside the repository zone. An important part of site characterization would involve investigating geochemical reactions relating to repository performance, including reactions of pore water and clay minerals with materials required for engineered barriers and contained waste. An important concern would be chemical reactions to radionuclide transport such as retardation, complexing, diffusion, precipitation and filtration. These reactions would require evaluation in the prospective host bed as well as along flow paths to the accessible environment. The temperature gradient and ambient temperature need to be determined as the chemical reactions of clay minerals are highly temperature dependent.

\subsubsection{Geomechanics}

A main objective of site characterization in shale is to determine geomechanical and thermal conditions near the repository level through in situ testing. Geomechanics are a major concern in shale because the potential for plastic flow would pose problems in maintaining underground openings, and for retrieval. Shale also can be unstable and exhibit total loss of strength upon loading which may occur during seismic shaking. The thermal conditions are necessary to define as some clay minerals in shale dehydrate and can lose strength at different temperatures. It is important to determine the baseline temperature conditions as well as those expected to be present during waste emplacement.

Precharacterization studies should have established that geomechanical conditions are potentially suitable for a repository, and should have identified interbeds, open fractures, and other discontinuities. In situ stress and temperature fields should be reasonably well determined. Geomechanical conditions in the overburden should be known so the test shaft can be designed and excavated. Site characterization tests should be used to confirm and revise the boundaries and bounds defined by precharacterization.

Detailed in situ testing at depth for site characterization will determine the response of shale to anticipated repository conditions. The information provided by these tests include distribution of stresses from mechanical and thermal loading or unloading, strain, 
temperature variations and gradients and potential for temperature induced slaking, fracturing or alteration.

The information needs for pre- and site characterization are summarized in Table $3.3 .2-4$.

\subsubsection{Seismotectonics}

The information needs for a repository in shale are essentially the same as those discussed in section 3.2.2.5. It is expected that these conditions would be deemed favorable prior to site selection. Seismic monitoring should be continued through site characterization and results incorporated into the design basis for the repository.

\subsubsection{Resources}

Resource potential of a site should be evaluated by precharacterization to eliminate conflicts that would arise if a repository were planned for an area that had pre-existing resources. Because the resources found in shale (oil, gas, coal, oil shale deposits, uranium) usually occur at a large scale, precharacterization studies should be adequate to define their extent and potential.

\subsubsection{TECHNIQUE APPLICATIONS TO SITE CHARACTERIZATION INFORMATION NEEDS IN SHALE}

Site characterization studies are not initiated unless the precharacterization studies indicate a high confidence level in final site acceptance. As noted previously, site characterization information needs, while similar to those required for precharacterization are used differently. Precharacterization information is used to document the geologic conditions present, while site characterization data is used to verify precharacterization models and conclusions and document repository conditions. Data collection techniques for site characterization do not differ greatly from those used in precharacterization, but not all techniques have sufficient reliability or resolution to provide the level of detail required in this phase. The mechanics, reliability and resolution of techniques referenced in the following subsections have been previously discussed either in the precharacterization studies or the technique reports in the appendix. 
TABLE $3 \cdot 3 \cdot 2-4$

GEOMECHANICS INFORMATION NEEDS IN SHALE

Emphasized in Precharacterization

1. Identification of interbeds, open fractures and other discontinuities.

2. In situ stress and temperature

3. Geomechanical condition in the overburden

Emphasized in Site Characterization

1. Stability of open excavation.

2. Thermal conditions.

3. Stress distribution.

4. Strain. 
For discussion of applicable techniques, it is assumed that the pilot shaft will be logged continuously, and one, or more, new boreholes will be drilled for state-of-the-art downhole logging, hydrologic testing and correlation of pre- and site characterization data. Following the format of previous sections, the technique applications best suited for satisfying an information need are discussed by discipline. Table 3.3.3-1 summarizes site characterization information needs for shale and shows the techniques applicable for satisfying these needs. Detailed breakdowns of information needs are found in appropriate sections, but may not be specifically referenced in the table.

\subsubsection{Geology}

Site surficial geology and long term geologic stability should be verified by detailed surface mapping, excavation logging, and use of large (1:8000 or larger) scale aerial photographs. The subsurface characteristics of the prospective host should be confirmed by core studies, drilling, surface and subsurface-based geophysical surveys, and detailed mapping of subsurface excavations. Subsurface mapping of the pilot shaft, test room(s) and exploratory drifts should be very detailed ( 1 inch equals 5 feet is considered an appropriate scale), and emphasize identification of mineralogic and structural variations required for geochemical, geomechanical and hydrology analyses.

Because of possible effects on geomechanical strength, radionuclide migration and hydrology, a thorough understanding of host lithology is important. Although clay minerals contained in shale generally have desirable radionuclide migration properties (good sorption, high ion-exchange capacity and good retardation), the overall acceptability of a shale medium is largely dependent upon the type and percentage of clay minerals present.

Refinement and verification of precharacterization lithology are necessary adjuncts to the detailed assessment of hydrologic parameters and radionuclide migration rates. Applicable techniques for verifying these parameters are:

- core studies

- geophysical logging

A high density of core samples is required to insure that the clay mineral content accurately characterizes the host rock, and clay mineralogy should be further verified by petrographic and $X-R a y$ techniques. The lithology and stratigraphy developed from these core 
TABLE 3.3.3-1 SITE CHARACTERIZATION TECHNIQUE APPLICATION

\begin{tabular}{|c|c|c|c|c|c|c|c|c|}
\hline $\begin{array}{l}\text { APPLICATIONS OF TECHNIQUES } \\
\text { TO INFORMATION NEEDS } \\
\text { FOR SITE CHARACTERIZATION } \\
\text { O MAJOR CONTRIBUTION } \\
\text { O SUPPORTING CONTRIBUTION }\end{array}$ & 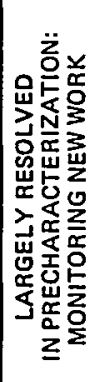 & 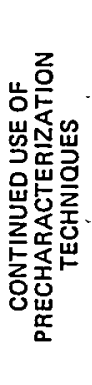 & 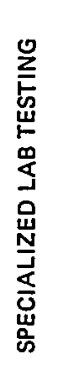 & 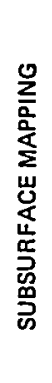 & 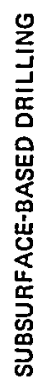 & 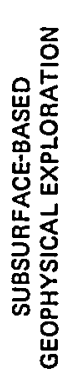 & 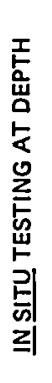 & 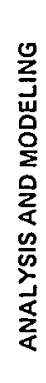 \\
\hline \multicolumn{9}{|l|}{ GEOLOGY } \\
\hline \multicolumn{9}{|l|}{ LITHOLOGY } \\
\hline PERCENT AND TYPE OF CLAY MINERALS & 0 & 0 & & $\bullet$ & 0 & & 0 & \\
\hline CLAY MINERALS CHANGES FROM HEAT & 0 & $\bullet$ & - & o & & & 0 & \\
\hline THICKNESS AND TYPE OF INTERBEDS & $\bullet$ & 0 & & 0 & 0 & 0 & & \\
\hline FISSILITY & 0 & 0 & & 0 & & & $\bullet$ & \\
\hline LATERAL EXTENT & $\bullet$ & 0 & & & & 0 & & \\
\hline STRUCTURE & $\bullet$ & 0 & & 0 & 0 & 0 & & \\
\hline \multicolumn{9}{|l|}{ HYDROLOGY } \\
\hline POROSITY VS PERMEABILITY & 0 & 0 & & 0 & & & $\bullet$ & $\circ$ \\
\hline INTERBED FLOW PATHS & 0 & - & & & & 0 & & 0 \\
\hline HYDRAULIC CONDUCTIVITY ANISOTROPIES & 0 & 0 & & & 0 & & - & 0 \\
\hline FLOW RATES & o & 0 & & & $\circ$ & & $\bullet$ & o \\
\hline RESIDENCE TIMES & 0 & $\bullet$ & & & & & 0 & o \\
\hline \multicolumn{9}{|l|}{ GEOCHEMISTRY } \\
\hline WASTE/ROCK INTERACTIONS & 0 & • & & & 0 & & & o \\
\hline LATERAL/VERTICAL VARIATIONS & 0 & $\bullet$ & & & 0 & & & 0 \\
\hline
\end{tabular}


TABLE 3.3.3-1 (CONT'D) SITE CHARACTERIZATION TECHNIQUE APPLICATION

\begin{tabular}{|c|c|c|c|c|c|c|c|c|}
\hline $\begin{array}{l}\text { APPLICATIONS OF TECHNIQUES } \\
\text { TO INFORMATION NEEDS } \\
\text { FOR SITE CHARACTERIZATION } \\
\text { - MAJOR CONTRIBUTION } \\
\text { O SUPPORTING CONTRIBUTION }\end{array}$ & 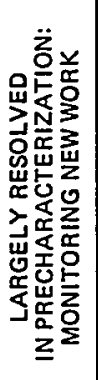 & 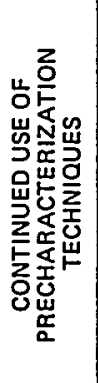 & 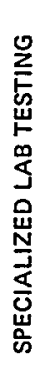 & 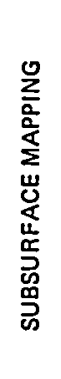 & 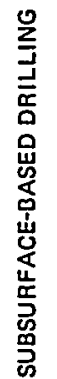 & 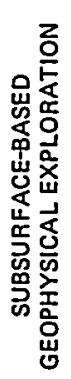 & 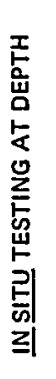 & 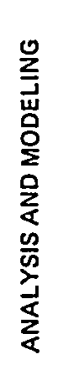 \\
\hline WHOLE ROCK AND FLUID CHEMISTRY & o & $\bullet$ & & & o & & & $\circ$ \\
\hline TEMPERATURE DEPENDENCE & $\circ$ & - & & & & & o & $\circ$ \\
\hline - COMPOSITION AND REACTION OF CLAY MINERALS & 0 & $\bullet$ & - & & $\circ$ & & $\circ$ & \\
\hline \multicolumn{9}{|l|}{ GEOMECHANICS } \\
\hline MODULI AND STRENGTH TESTS (INCL. CREEP) & 0 & - & & & o & & - & \\
\hline $\begin{array}{l}\text { IN SITU TEMPERATURES AND PRESSURES } \\
\text { (EASE TIME) }\end{array}$ & o & 0 & & & $\circ$ & & $\bullet$ & \\
\hline SLAKING & $\circ$ & 0 & & & $\circ$ & & $\bullet$ & \\
\hline SEISMIC EFFECTS & 0 & o & & & & 0 & o & - \\
\hline THERMAL PARAMETERS & 0 & $\bullet$ & & & o & & - & \\
\hline SEISMOTECTONICS & $\circ$ & - & & & & $\circ$ & & o \\
\hline RESOURCES & o & - & & & o & o & & \\
\hline & & & & & & & & \\
\hline & & & & & & & & \\
\hline & & & & & & & & \\
\hline & & & & & & & & \\
\hline & & & & & & & & \\
\hline & & & & & & & & \\
\hline
\end{tabular}


samples should be correlated with downhole geophysical log information to refine and verify models developed by surface-based geophysical surveys. The downhole logging techniques used to indirectly, or directly, assess the percentage of clay minerals by measurement of permeability and/or porosity include acoustic (sonic), gravity and resistivity.

Hydrostratigraphy verification is also needed as input to numerical modeling programs to evaluate radionuclide migration and interbed flow paths and can best be obtained during the geologic studies. Techniques applicable to this information need are the same required for verification of geologic needs, as follows:

- core studies

- subsurface mapping

- downhole geophysical logging

- high-resolution, surface-based geophysical surveys

- aquifer tests

Accurate core logging is needed to establish the stratigraphic location of permeable interbeds and establish correlation points for downhole geophysical logging and high-resolution, surface-based geophysical surveys. Aquifer tests such as injection and tracer tests are needed to verify precharacterization permeability and flow rate data. Additional correlation, particularly for overburden stratigraphy, may be obtained from resistivity and crosshole seismic surveys (see Appendices B-4 and B-7). Although resistivity surveys are not commonly used at present for surveys at repository depths, it is not precluded by the state-of-the-art.

Other lithologic concerns are fissibility, clay mineral changes resulting from elevated repository temperatures and the expansive nature of the clay minerals. Fissibility evaluations must be made in situ measurements at depth. Although in situ measurements of temperature induced mineralogy changes can be done, laboratory experiments will probably remain the most cost effective technique for this information need. The expansive nature of some clay minerals is well known, and while not expected to present a problem at repository depths, expansive experiments like alternating saturation and desiccation of the host rock may be necessary. This potential problem area must be addressed, but appropriate tests are not known at this time. 
The thickness and type of interbeds, lateral extent of host rock and structure within the repository volume should have been determined during precharacterization, but must be verified during this phase. The technique most applicable for verifying these parameters will be logging of subsurface based drillings or excavations. Core samples from inclined or horizontal boreholes drilled from the test room(s) and subsurface excavation logging will assist in identifying lateral or vertical mineralogy or lithology variations.

\subsubsection{Hydrology}

Site characterization hydrologic techniques include laboratory, aquifer and in situ hydrologic tests. Data from these, and other, tests will be used as input to numerical modeling programs to assess and verify hydrologic models. The hydrology information needs can be broken down into the broad categories of ground-water transport and hydrostratigraphy. Analysis of groundwater transport is primarily a numerical modeling problem, but the hydrostratigraphy can be assessed with standard testing methods.

Verification of precharacterization groundwater transport models is critical to evaluate radionuclide migration to the biosphere. Techniques applicable for generating input data parameters include aquifer and tracer tests.

Groundwater transport characterization will be the first of two numerical models necessary to assess possible biosphere contamination by migrating radionuclides. This model will use measured parameters as input for a three-dimensional groundwater movement model to assess flow around and through the repository. The results of this transport model will be used as input for a model of radionuclide/host rock geochemical interactions to evaluate the activity level and rate of radionuclide migration. Chemical or radioactive tracer tests to measure flow rates and residence times, and standard aquifer tests, such as step-drawdown, constant discharge, recovery and transmissivities to measure flow rates and hydraulic conductivity anisotropies, will all be used as input to these programs.

\subsubsection{Geochemistry}

Geochemical techniques for site characterization of a shale medium will be essentially identical to those for other media, and are described in Appendix F-2. In general, these techniques will fall into the general 
areas of descriptive geochemistry and evaluation of geochemical reactions. Descriptive geochemistry will use standard laboratory techniques to assess fluid and rock chemistries in great detail, which are needed to evaluate:

- lateral or vertical variations in geochemistry and mineralogy

- radionuclide interactions with ground water and the host rock, particularly with clay minerals

- composition of clay minerals

Chemical reaction assessment will be made from descriptive geochemical information and the inferred temperature and fluid flow conditions. Because of drastic changes in the water content of clay minerals produced by elevated temperatures, it is important that both descriptive and chemical reaction tests be performed over the fluid content and temperature ranges inferred from thermal modeling studies (see Section 3.3.3.4).

\subsubsection{Geomechanics}

Geomechanical techniques that are applicable during site characterization include laboratory or in situ testing programs and computer assisted numerical modeling of heat flow. Laboratory testing techniques for site characterization are essentially the same as those described for precharacterization (Appendix E-1), and are not described separately. Appendix E-2 provides a specific discussion of in situ geomechanical testing techniques which can be used for site characterization. Although generally applicable, it is important to note that these tests are part of specially developed programs designed to verify previous test results. Because of possible mechanical property variations caused by elevated temperatures and chemical alterations, it is essential that the mechanical parameters described previously (Section 3.2.3.4). be performed over the temperature ranges anticipated to occur within and proximal to the repository.

Numerical and computer modeling of repository conditions and responses is an important application for meeting the geochemical information needs. The applications of specific modeling programs are discussed in Appendix E-2. An additional important study required is the modeling of the host rock response to seismic shaking. Underground excavations in shale may not withstand seismic shaking. Despite the typical occurrence of shale in seismically "quiet" areas, this possibility must be fully investigated by scale model and numerical modeling techniques. 
Additional temperature-dependent testing must be done to evaluate changes in thermal parameters as a function of temperature. These primarily laboratory based studies are important to evaluate the thermal gradient produced by heating from waste decay. The elevated temperatures produced in the repository will alter thermal parameters, such as conductivity, mechanical properties, such as strength, and stress fields. Alteration of stress fields may produce spallation or, when combined with water driven out of the clay minerals, decrepitation (steam spallation).

\subsubsection{Seismotectonics}

Seismotectonic techniques applicable to site characterization will largely be limited to monitoring of the precharacterization emplaced seismograph network(s). Because shales of suitable thickness for a repository area are found in areas with little tectonic, volcanic or seismic history, it is expected that this monitoring will verify precharacterization assessments. However, in the event there is a notable or anamalous seismic occurrence during the characterization period, additional specific investigations, using the techniques of Appendix $\mathrm{H}$, may be required.

\subsubsection{Resources}

Because shale sequences contain hydrocarbon, coal, gas and mineral resources, it is presumed that the economic potential of a site area will have been explored in detail during precharacterization. Therefore, a site characterization will consist solely of an ongoing monitoring program to verify previous exploration findings.

\subsubsection{COST AND TIME ESTIMATES FOR TECHNIQUES IN SITE CHARACTERIZATION}

Estimates for the costs and times that would be required for the techniques used in characterizing a site in shale are summarized in Tables 3.3.4-1 through 3.3.4-6. The work in site characterization would involve continued use of the techniques of precharacterization; the cost and time estimates summarized in Tables 3.2.4-1 to 3.2.4-7 would remain applicable for these. An important consideration in evaluating cost and time estimates for site characterization is that many of the tests are specially designed for site conditions and particular information needs. Durations of geomechanical and hydrologic tests, in particular, may be a design factor and can be important in determining costs. 


\subsubsection{Geologic Mapping and Supporting Activities}

Typical costs and times for detailed surface mapping required at a prospective site during characterization, and the supporting work in remote sensing, trenching, and age dating are summarized in Table 3.3.4-1. This work would be performed during site characterization but chiefly involves validating previous findings. It would not be reasonable to undertake characterization at a site if there were significant outstanding questions regarding surface geology. For these estimates, it is assumed that access and trafficability would not be problems at a site chosen for characterization.

Table 3.3.4-2 summarizes typical costs and times for mapping geologic conditions in the pilot excavations. Costs for the geochemical analyses that may be used in support of this mapping are provided in Appendix F-2. For subsurface mapping done in coordination with the excavation, costs and schedule are likely to be controlled by the need to avoid interference with the excavation process.

\subsubsection{Subsurface Based Drilling and Coring}

Appendix D-2 includes a comprehensive summary of the costs and penetration rates for various techniques used in drilling and coring from pilot excavations. Applicable information for shale is summarized in Table 3.3.4-3. Some revisions were made to the costs in Appendix D-2 for increased compatibility with the costs for other techniques. Costs for mobilization delays for availability of suitable equipment are not included on the assumption that the site characterization program should be of sufficient magnitude to maintain the required equipment on site for a significant period.

Techniques for geologic logging of the drill return or core, as discussed in the Appendices $\mathrm{D}-1$ and $\mathrm{E}-1$ would continue to apply in site characterization. Geophysical logging techniques discussed in Appendix $C$ also would remain applicable for vertical and near vertical holes; costs generally would be as summarized in Table 3.3.4-3.

\subsubsection{Geophysical Techniques in Site Characterization}

In general, the geophysical techniques discussed in Appendix B would remain applicable in site characterization. Costs would continue to follow the parameters outlined in Table 3.2.4-4. Costs for the techniques used in site characterization for detailed evaluation of near surface engineering parameters and for exploring the shale surrounding the pilot excavations are summarized in Table 3.3.4-4. 
COST AND TIME SUMMARY FOR SURFACE GEOLOGIC TECHNIQUES

IN SITE CHARACTERIZATION

\begin{tabular}{cc}
$\begin{array}{c}\text { Approximate } \\
\text { Cost }\end{array}$ & $\begin{array}{c}\text { Approximate } \\
\text { Time }\end{array}$ \\
\hline
\end{tabular}

REMOTE SENSING INTERPRETATION

$1: 4800$ photo analysis

( 100 photos for $12 \mathrm{mi}^{2}$ site)

$\$ 1,750-3,500(1) \quad 5-10$ man days

DETAILED SURFACE MAPPING

(for $12 \mathrm{mi}^{2}$ site area)

General Mapping

$\$ 12,000-18,000$

20-30 man days (10-15 field days for 2-man crew)

Detailed structure analysis(2) $\$ 6,000$

10 man days (5 field days for 2-man crew)

EXCAVATION LOGGING (3)

Reconnaissance

$\$ 1,200 /$ day ${ }^{(4)} \quad 10,000 \mathrm{ft}^{2} / \mathrm{day}^{(4)}$

Detailed logging at $1^{n}=10^{\prime}$

$\$ 1,200 /$ day $(4) \quad 1,500 \mathrm{ft}^{2} /$ day $(4)$

NOTES:

(1) Does not include cost of large scale stereographic aerial photos, assumed to be available in site characterization.

(2)

Only applicable where bedrock (overlying the salt) is exposed at the surface. Cost and time is in addition to general mapping.

(3) For surface excavations such as exploratory trenches or quarry cuts. Also for natural exposures such as bluffs or stream banks.

(4)

Typical production rate and daily cost for 2-man field crew. Rates will vary according to access, difficulty of cleaning off the excavation, and, particularly, complexity of geologic conditions. Mapping of critical relationships at larger scale would require additional time. 
TABLE $3 \cdot 3 \cdot 4-2$

COST AND TIME SUMMARY FOR SUBSURFACE GEOLOGIC MAPPING IN SITE CHARACTERIZATION (1)

Cost Per Day

Typical Mapping Rate

Detailed Mapping

$\$ 650.00$

$1200 \mathrm{ft}^{2} /$ day (3)

of Shaft or Drift

at $1^{n=}=5^{\prime}(2)$

NOTES:

(1) Based on Appendix A-2.

(2) Typical scale for geologic mapping in drift 8 feet wide and 8 feet high, after completion of engineering survey and preparation of base maps.

(3) Actual rates depend on complexity of geologic conditions at the place mapped. 
TABLE $3 \cdot 3 \cdot 4-3$

COST AND TIME SUMMARY FOR

SUBSURFACE-BASED-DRILLING AND CORING

IN SITE CHARACTERIZATION (1)

$$
\begin{array}{lc}
\text { Hole Maximum } & \begin{array}{c}
\text { Penetration } \\
\text { Rate(2) }
\end{array} \\
\text { Size Depth } & \text { (Ft/Hr) }
\end{array}
$$

Cost per foot (5)

\begin{tabular}{|c|c|c|c|c|c|c|}
\hline $\begin{array}{l}\text { Jackleg } \\
\text { (hand held) }\end{array}$ & $1-1 / 4-$ & 20 & $12-28(3)$ & $20(3)$ & $\$ 2-4(6)$ & $\$ 2(6)$ \\
\hline Drifter & $\begin{array}{l}1-1 / 2- \\
3-1 / 2\end{array}$ & 50 & $20-60(3)$ & $40(3)$ & $\$ 2-5(6)$ & $\$ 2(6)$ \\
\hline Track drill & $\begin{array}{c}2-5 \\
\text { Core } \\
\text { Size }\end{array}$ & 200 & $30-100(3)$ & $65(3)$ & $\$ 2-5(6)$ & $\$ 2^{(6)}$ \\
\hline
\end{tabular}

(In) (Ft) Range Average Range Average

CORE DRILLS

$\begin{array}{ccccccc}\text { Longyear } & \text { HQ }(2-1 / 2) & 1200 & & & & \\ \text { EHS 38 } & \text { NQ }(1-7 / 8) & 1900 & 4-8(4) & 6(4) & \$ 17-34 & \$ 23 \\ & \text { BQ }(1-3 / 8) & 2400 & & & & \\ \text { Longyear 65 } & \text { BQ }(1-3 / 8) & 500 & 3-5(4) & 4(4) & \$ 28-47 & \$ 35\end{array}$

NOTES:

(1) Adapted from Appendix D-2

(2) Not including move-in or set-up time. Rates calculated for representative drill or core sizes and would differ for other sizes.

(3) At 678 efficiency.

(4) At 508 efficiency.

(5) Direct operating costs $\times 1.75$ to account for administration, insurance, interest, contractor's profit margin and other typical cost factors. Does not include cost of on-site geologic inspection or subsequent core logging. Does not include allowance for standby time.

(6) Compressor costs calculated assuming two drills per compressor $3-65$ 
TABLE $3 \cdot 3 \cdot 4-4$

COST AND TIME SUMMARY FOR GEOPHYSICAL TECHNIQUES

IN SITE CAARACTERIZATION

$\frac{\begin{array}{c}\text { Approximate } \\ \text { Cost }\end{array}}{\frac{\text { Approximate }}{\text { Time }}}$
$\begin{aligned} & \text { SEISMIC CROSSHOLE } \\ & \text { (typical survey to about } \\ & 500 \text { feet) }\end{aligned}$
$\begin{aligned} & \$ 34,000-39,000(1) \\ & 4-5 \text { weeks (2) }\end{aligned}$
$\begin{aligned} & \text { DOWNHOLE SEISMIC VELOCITY } \\ & \text { (typical survey to about } \\ & 500 \text { feet) }\end{aligned}$

NOTES:

(1) Includes drilling costs.

(2) Turn around time for results from beginning field work. Does not include mobilization. 
The radar and sonar techniques used for subsurface exploration in geological media are specially designed systems and therefore can differ significantly in costs and capabilities. Moreover, new techniques are continually under development, making it difficult to forecast costs and capabilities for work that would be performed in future years.

\subsubsection{Hydrology}

Costs and times for hydrologic techniques most important in site characterization are summarized in Table 3.3.4-5, based on the information in Appendix G-2. All of the techniques in Table 3.3.4-5 involve testing programs that vary in cost and duration according to their design and the properties of the tests medium. Costs of drilling and well completion are not included in the estimates for the hydrologic techniques.

\subsubsection{Geochemistry}

Cost estimates for typical geochemical analyses are summarized in Tables 6 through 8 of Appendix F-1. The specific tests and the number of analyses needed would be determined by site conditions and cannot be quantified reliably on a generic basis. The main factors determining. turn around time for results of the geochemical analyses are capabilities of the available laboratories, their work load, and the priority of the specific project.

It is expected that most individual analyses for site characterization could be performed within a few weeks, but longer times may be required for specialized analyses or for work on large numbers of samples.

\subsubsection{Geomechanics}

The work in geomechanics for site characterization involves specialized laboratory testing and in situ tests designed individually for each program. Representative costs and times are provided in Table 3.3.4-6 but these can differ significantly according to design of a specific program. In particular, the number of tests required to characterize a site would be determined by the variability of site conditions and the proposed repository layout. Instrumentation is a notable problem for long duration tests and needs to develop new or unique systems could be costly. 
TABLE $3 \cdot 3 \cdot 4-5$

COST AND TIME SUMMARY FOR

HYDROLOGIC TECHNIQUES

IN SITE CHARACTERIZATION

\begin{tabular}{|c|c|c|}
\hline $\begin{array}{l}\text { Tests and } \\
\text { Analyses }(1)\end{array}$ & $\begin{array}{l}\text { Approximate } \\
\text { Cost Range }(2)\end{array}$ & $\begin{array}{c}\text { Approximate } \\
\text { Turn around } \\
\text { Time }(3)\end{array}$ \\
\hline INJECTION TESTS & $\begin{array}{c}\$ 20,000-50,000 \\
\text { per test }\end{array}$ & $5-15$ days \\
\hline STRADDLE PACKER TESTING & $\begin{array}{c}\$ 10,000-25,000 \\
\text { per test }\end{array}$ & 5-15 days \\
\hline TRACER TESTS & $\begin{array}{l}\$ 20,000 \text { or more } \\
\text { per test interval }\end{array}$ & $\begin{array}{l}\text { Time until } \\
\text { detection } \\
\text { depends on } \\
\text { site conditions }\end{array}$ \\
\hline FLOW SYSTEM MODELING & & $\cdot$ \\
\hline Without fracture flow & & \\
\hline 2 dimensional & $\$ 20,000$ & 2-4 weeks \\
\hline 3 dimensional & $\$ 30,000$ & 3-6 weeks \\
\hline With fracture flow & & \\
\hline 2 dimensional & $\$ 50,000$ & 5-10 weeks \\
\hline 3 dimensional & $\$ 75,000$ & $7-15$ weeks \\
\hline
\end{tabular}

NOTES :

(1)

Described in Appendix G

(2) These tests are typically designed for particular site conditions in characterization. Costs are determined by test design and duration.

(3) Times for hydrologic tests are determined by site conditions and may vary significantly. 
TABLE 3.3.4-6

COST AND TIME SUMMARY FOR

GEOMECHANICS TECHNIQUES

IN SITE CHARACTERIZATION (1)

Tests (2)

HYDROTHERMOMECHANICAL

IN SITU BLOCK TEST

SCHMIDT HAMMER CHARACTERIZATION

OF JOINTS IN TEST ADIT

CORE TILT TESTING

Apparatus (purchase

or fabrication costs)

Typical set of tests

JOINT TILT TESTING

(program)

SELF WEIGHT SLIDING TEST

(on large jointed blocks)
Approximate

Cost

$\$ 600,000-700,000$

$\$ 1,000(4)$

$\$ 500$

N/A

$\$ 500$

one day

$\$ 10,000$

2 weeks

$\$ 2500-4500 /$ sample $\$ 50,000 /$ program
Approximate

Duration 
3.3.5 CRITERIA FOR EVALUATING DATA ADEQUACY OF SITE CHARACTERIZATION STUDIES IN SHALE

Previous discussion of the unique geologic features of shale (Section 3.3.1), information needs (Section 3.3.2) and technique applications (Section 3.3 .3 ) pertinent to site characterization can be used to develop criteria for evaluation of a site characterization study. This study should evaluate precharacterization data, how it was applied, and the degree of refinement resulting from site specific studies, and assumes that precharacterization studies have satisfactorily answered the information needs of the task. Based on this assumption, the following sections discuss the technique criteria which are relatively unique to site sharacterization. No criteria are presented for seismicity/ tectonics and resources in this section because information needs and applications in these categories are completely discussed previously.

\subsubsection{Geology}

Geologic information needs and applicable techniques have been previously discussed (section 3.3.5.1), and it is assumed that site characterization studies will be used to verify and refine precharacterization data. However, pilot shaft and test room(s) excavation, and associated inclined or horizontal drilling introduces additional techniques for direct examination of the host rock at repository depths. Information needs and the applicability of new techniques for host study are shown below.

- Lithology, Stratigraphy and Structure - downhole T.V. or radar viewing (in corehole); subsurface mapping (pilot shaft and test room); radar ranging

- Thickness and lateral extent - subsurface mapping; radar ranging

Accurate pilot shaft mapping will provide excellent reference points for correlaton of downhole geophysical logging and surface exploration techniques, permitting further refinement and verification of previous lithology and stratigraphy models. Application of these new techniques should adequately characterize some of the unique features of shale such as:

- percent and type of clay minerals 


- thickness and type of interbeds
- stratigraphic location of beds of varying clay contents
- lithologic variations
- fissility
- mineralogic variations
- clay mineral changes due to heat

\subsubsection{Hydrology}

Testing during this phase will largely be used to verify previous data, with precharacterization and site characterization data used as an input data base for two important modeling studies. The initial study will model the hydrologic conditions in and around the repository and be primarily concerned with flow rate assessment. This model and additional data will be used for a second program to model radionuclide transport, or migration rates. With the exception of extensive use of numerical modeling techniques, other applicable hydrologic techniques have been previously discussed (Section 3.2.5.2). Utilization of pre- and site characterization data should be oriented toward consideration of unique features in shale which will affect hyorologic conditions, including:

- interbed flow rates and paths

- permeability and porosity

- hydraulic conductivity anisotropies

\subsubsection{Geochemistry}

Major information needs and applicable techniques have been summarized in Section 3.2.5.3, and it is anticipated the information from site characterization will be used to verify previous data. In addition to the previously described techniques, the rock and water geochemical properties must be determined over the range of temperature, moisture content and pressure anticipated in the repository. These data will be used to determine radionuclide sorption and reaction rates, as well as providing input to the radionuclide migration modeling program. 
Unique geochemical features of shale which must be considered include:

- differences in chemical reactions between different clay minerals

- lateral and vertical chemistry variations within the repository volume.

- changes in clay mineralogy due to heat

- temperature-dependent variation of reactions and reaction rates

\subsubsection{Geomechanics}

Fundamental geomechanical parameters have been previously discussed (Section 3.6.4). The primary difference in pre- and site characterization studies is that the subsurface boreholes, pilot shaft, and test room(s) allow direct testing of fresh host rock. In addition to standard laboratory tests, described in section 3.2.5.4, this phase should be heavily biased toward in situ testings of the host medium. Information needs and applicable in situ tests are shown below.

- $\quad$ strength - jacking tests; heater tests

- plasticity - creep tests; heater tests

- in situ stresses - overcoring; heater tests

Because of the low thermal conductivity of shale it can be assumed that temperature gradients from waste canister heating will be steep and persist for a long time period. The increased stress due to these temperature gradients requires in situ heater tests to establish the geomechanical parameters.

In addition to temperature-dependent geomechanical parameters, shales also experience thermal parameter variations with temperature. Because basic thermal property (Section 3.2.5.4) measurements in the laboratory do not duplicate natural conditions, it is essential that in situ values of these paramenters be determined whenever possible.

Uniques features of shale which should be addressed during geochemical and thermal testing are:

- effect of water on strength and creep

- parameter variations between beds

- effect of clay mineralogy on geochemical and thermal parameters 


\subsection{REFERENCES}

Dames and Moore, 1978a, Stratigraphies of Salt, Granite, Shale and Basalt: Office of Waste Isolation, Rpt. No. Y/OWI/TM-36/3.

, 1978b, Baseline Rock Properties - Shale: Office of Waste

Isolation, Rpt. No. Y/OWI/TM-36/6.

Deer, W. A., Howie, R. A., Zussman, J., 1966, An Introduction to the Rock Forming Minerals: John Wiley and Sons, New York, 528 p.

Dunbar, C. O., and Rodgers, J., 1957, Principles of Stratigraphy: John Wiley and Sons, New York, 356 p.

Ernst, W. G., 1969, Earth Materials: Prentice-Hall, Inc., Englewood Cliffs, New Jersey, 149 p.

Garrels, R. M. and Mackenzie, F. T., 1971, Evolution of Sedimentary Rocks: W. W. Norton and Co., New York, 397 p.

Greensmith, J. T., 1971, Petrology of the Sedimentary Rocks: Thomas Murby and Co., London, 502 p.

Grim, R. E., 1958, Concept of Diagenesis in Argillaceous Rocks: AAPG Bull, v. 42, pp. 246-253.

Johnston, R.G. and Palmer, R.A., 1981, Characteristics of Candidate Geologies for Nuclear Waste Isolation: A Review: Rockwell International, Rpt. No. DOE/ET/41900-6.

Krumbein, W. C., and Sloss, L. L., 1963, Stratigraphy and Sedimentation: W. H. Freeman and Co., San Francisco, 660 p.

Merewhether, E. A., Sharps, J. A., Gill, J. R., and Cooley, M. E., 1973, Shale, Mudstone and Claystone as potential host rocks for Underground Emplacement of Waste: U.S. Geol. Survey Open File Rpt. 4339-5.

Pettijohn, F. J., 1957, Sedimentary Rocks: Harper and Rowe, New York, 718 p.

Rieke, H. H. III, and Chilingorian, G. V., 1974, Compaction of Argillaceous Sediments: Elsevier Scientific Publishing Co., Amsterdam, 424 p.

Reineck. H.E. and Singh, I. B., 1980, Depositional Sedimentary Environments: Springer-Verlag, Berlin, 549 p. 
Shurr, G. W., 1977, The Pierre Shale, Northern Great Plains; A Potential Isolation Medium for Radioactive Waste: U.S. Geol. Survey Open File Rpt. 77-776.

Weaver, C. E., 1980, Use of R-Ar Dating and Oxygen Isotopes for Determining the Thermal History of Shales: Office of Nuclear Waste Isolation, Rpt. No. ONWI-107. 


\subsection{BASALT}

\subsection{PREVIOUS WORK IN BASALT}

The presence of thick flows of basalt with an areal extent of thousands of square miles have attracted the attention of numerous workers through the years. These massive deposits are interchangeably termed "flood" or "plateau" deposits to distinguish them from volcanic cones.

Plateau basalts are found on every continent and range in age from Precambrian to Holocene. Major basalt areas in the United States are the mid-continent Precambrian (Goldrich, 1968) Keweenawan basalts, Triassic (Dunbar, 1968) Newark Series on the eastern seaboard, late Miocene to Pliocene (Waters, 1952, 1961, 1962) Columbia, and Quaternary (Prinz, 1970) Snake River Plateaus in the Northwest. The geology of all these areas has been studied extensively, but the major emphasis has been on economic geology.

While these economic geology studies have produced large amounts of data, unfortunately little of it is applicable for repository site evaluation. The area of the United States which has seen the most extensive work relative to waste repository siting is the Columbia plateau basalts in the northwestern United States.

Early studies of the Columbia Plateau provided a general description of the structural elements and stratigraphy. A concise review of this early work was done by Waters (1961), and the reader is referred to his work for additional information. The 1970's saw an increased interest in the Columbia Plateau as possible nuclear power plant sites (Washington Public Power and Supply System, 1973, 1977), and more recently as possible nuclear waste repository sites. It is from these latter projects that the bulk of data applicable for site precharacterization or characterization has come.

In the last few years extensive amounts of work on stratigraphy, structure, lithology and hydrology have been done in and around the Hanford Nuclear Site (Rockwell Hanford Staff, 1977, 1979; Gephart, 1979; Myers and Price, 1979). The deep stratigraphy of the Columbia Plateau basalts has been assessed by drilling operations, (Summers and others, 1978) and gross intraflow structures determined by petrographic analysis (Long, 1978). The regional geology for the Pasco Basin, in which the Hanford site is located, has had extensive amounts of work (Summers and others; 1978; Rockwell 1977, 1978, 1979; Fugro, 1980) and the regional structure, geology and seismicity has been well defined (Rockwell, 1979; Fugro 1980). From this data base, general geologic 
knowledge and considerations of basalt, it is possible to outline: the positive and negative aspects of basalt as a repository medium; the information required to characterize the medium as a repository waste site; and the applicable techniques for characterization.

\subsection{PRECHARACTERIZATION STUDIES}

\subsubsection{GEOLOGY OF BASALT}

Basalt is a generic term for typically aphanitic to fine-grained, well indurated volcanic deposits extruded onto the surface, although examples of intrusive rocks, in the form of dikes and sills, are well known. Basalts are commonly divided into two major groupings, tholeiitic and alkaline (olivine), on the basis of $\mathrm{sio}_{2}$ content, although the boundary between the two types is fully transitional. Oceanic basalts are typically alkaline, while the preponderance of basalt deposits on land are of the tholeiitic type, (Verhoogen and others, 1970; MacDonald, 1972). Basalts are also found worldwide as volcanic cones (e.g. Hawaiian Islands) or extensive continental sheet flows (e.g. Columbia Plateau) covering thousands of square kilometers. It is the geology of these massive continental deposits which will be considered here.

Because plateau basalts are the most voluminous, $>1.5 \times 10^{6} \mathrm{~km}^{3}$, volcanic rocks exposed on the surface (Verhoogen and others, 1970), and typically have a high mechanical strength, low permeability and high sorption, they are an attractive possibility for a waste repository. A suitable geologic setting for a repository would be a thick $(>300 \mathrm{~m})$ sequence of aphanitic flows, with only minor fracturing as a result of cooling.

\subsubsection{Origin and Emplacement}

Emplacement of basalt is by volcanic activity, either from single vents or linear fissures. Single vents form shield volcanoes, which may coalesce to form multivent volcanic areas, of which the Hawaiian Islands are the archetype. - Linear fissure eruptions produce large plateau basalts, such as formed by the 1783 Laki eruption in Iceland (Tyrell, 1937; MacDonald, 1972). Areally large plateau basalts, such as the Deccan Plains in India or the Columbia River Plateau, are probably the result of a combination of multiple fissure and single vent eruptions (Washington, 1922; Rutten, 1964; Kuno, 1969).

Basaltic magma typically has a low viscosity because of high temperatures produced by entrained gases, resulting in a very fluid flow 
(Wentworth, 1954; MacDonald, 1972). These flows tend to overtop topography and form broad, virtually featureless plains with very low dips $\left(0.5-2^{\circ}\right)$, or shield volcanoes with slightly steeper slopes $\left(5-10^{\circ}\right)$.

\subsubsection{Typical Stratigraphy and Lithology}

Basalt deposits of sufficient thickness to be considered for repository sites are typically made up of very gently dipping $\left(<10^{\circ}\right)$ multiple flows, 10-60m (30-200 ft) thick. Dependent upon the time interval between flows and the geologic setting, some deposits are made up of a sequence of basalt. intercalated with sedimentary or weathered materials. Typical of these intercalations are sedimentary units found in the Deccan Plains or Columbia River basalts. Sandstone is the most prevalent interbed material, but paleosols, gravel, clay, diatomaceous earth and, rarely, ash and tuff have been noted.

Data from the Columbia Plateau basalts (Swanson, D. A., 1979c; Goles, 1980) and Deccan Plains (Washington, 1922) indicates that earlier stages of volcanism may produce more frequent and voluminous flows than later. This is indicated by the fact the lower portions of thick flow sequences typically have fewer intercalations and thicknesses of $300 \mathrm{~m}$ $(1000 \mathrm{ft})$.

Lithologically, basalt is typically medium- to high-density, aphanitic to crystalline with some olivine and/or feldspar phenocrysts in a glassy groundmass. The exact mineral assemblages vary according to the chemical mix of the magma, but most plateau basalts are a saturated to slightly oversaturated in silica content. Geochemical comparisons of plateau basalts from all over the world has shown their geochemistries to be amazingly similar (Washington, 1922). The geochemistry of an individual flow is typically very uniform, a characteristic which will assist in lateral correlation of stratigraphy.

The final density of a basalt flow is somewhat dependent upon the cooling history. As the lava cools, entrained gases come out of solution to form small pockets of gas, which rise toward the flow surface. If the cooling is rapid enough these gas pockets are "frozen" as spherical or teardrop shaped vesicles, typically concentrated in the upper third of the flow. Because the individual vesicles are frozen in place, they usually form a closed cellular system, although extensive fracturing may provide leakage paths through the vesiculated area.

A second lithologic anomaly of basalt is the occurrence of pillow lavas, which are formed by rapid cooling of the flow by water. While 
these features are not common in plateau basalts, their presence may be detrimental because of possible fluid paths around the pillows and anisotropies in mechanical strength and geochemical reactions. The occurrence of pillow lavas would indicate eruption of lava into standing water or over a marshy area, information which can be of use in evaluating paleogeography and paleoclimates.

\subsubsection{Structure}

Gibson (1969) compared the fissure eruption, basin subsidence characteristics and geochemical variations between Icelandic and Columbia plateau basalts and reached the conclusion that plateau basalts simply occur in regions under strong tensional stresses regardless of how the stress is generated. This implies that the original structure of the basalt would be expected to be flat-lying and that of the underlying country rock to have characteristics of a tensional environment. Kuno (1969) analyzed the difference in extrusion rates between plateau and island volcanism concluding that the rates of extrusion are not significantly different. From this he inferred that the essential condition for production of large volume flows is not an unusually high concentration of heat, but a concentration of heat over an extensive area of the mantle for long periods of time. This extensive concentration of heat may act as a convection cell, and the lateral spreading beneath the crust could provide the driving force for crustal tension.

With the exception of the Precambrian Reweenawan basalts associated with a mid-continent gravity anomaly, basalts in the United states are of Triassic or younger age, and tend to be structurally simple areas, which are easily delineated by surface mapping and geophysical survey techniques. The more important problem in determining suitability as a host rock may be the smaller scale intraflow structure.

The most prevalent intraflow structure within undeformed basalt flows is the extensive fracture system resulting from cooling. The type section of these fractures is: a basal member of regularly spaced, vertically jointed, polygonal slabs (lower colonnade), resulting from rapid cooling by contact with underlying strata; a middle member of smaller and less regularly oriented jointing (entablature), oftentimes fan shaped; and an upper vesiculated member (Figure 4.2.1-1). In some instances the vesicular member is replaced by an upper colonnade, resulting from rapid subaerial cooling exposure. Dependent on the cooling and erosion histories of a flow, one or more of these members may be missing. In addition to the vertical columnar joints described above, many flows have additional horizontal joint sets, attributed to differential cooling stresses, all of which are typically 


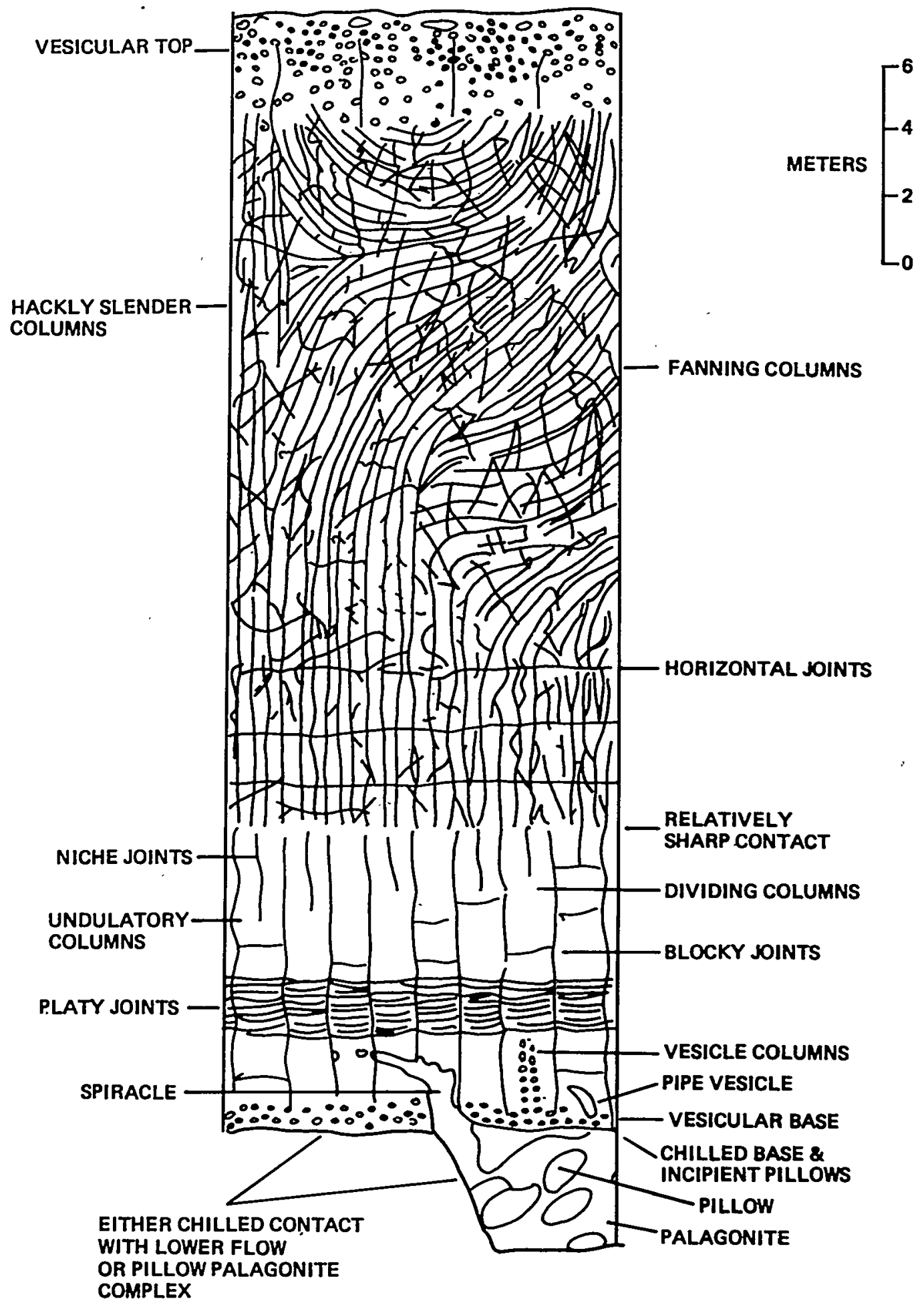

FIGURE 4. 2. 1-1

GENERALIZED BASALT FLOW STRUCTURE

FROM AGAPITO AND OTHERS, 1977 
filled with clay or other materials at depth. This intraflow fracture network, when combined with mineralogic variations, will result in thermal and mechanical property variations. Typical values of properties of interest to repository siting are summarized in Table 4.2.1-1.

Additional structural features associated with emplacement include vesicles, dikes, vents, lava tubes and fumaroles. Vesicles commonly occur as a zone of closed cells, typically in the upper third of the flow, although basal vesicle layers have been identified. Because of their small size and spherical to teardrop shape, they are commonly preserved regardless of burial depth. Dikes are forcibily emplaced across stratification so they may be flanked by breccia zones, which will affect both the hydrologic and mechanical properties of the medium. Buried eruptive vents may appear as breccia pipes, with the same effects described above. The presence of buried lava tubes has been inferred in drilling operations by a sudden drop of the drill tool. Although there is no definitive evidence, the larger tubes might collapse or close up with deep burial. Fumaroles, or non-eruptive vents, provide vertical discontinuities which have the same deleterious effects as above. Although none of the above items have been positively identified in subsurface data, it should be presumed that they may exist because of their occurrence in modern flows.

\subsubsection{Hydrology}

In basaltic terranes, ground water movement is predominantly in permeable interbeds (sandstones, etc.) between basalt flows, or in basalt interflows brecciated by emplacement, cooling or tectonism. The dense flow interiors typically have low permeability and porosity, implying low hydraulic conductivities. It is felt (Summers and others, 1978) that the vertical conductivity, $k_{V}$, is typically $h$ igher in these dense interiors than the horizontal conductivity, $k_{h}$. This difference in conductivity may be due in part to the vertical joint sets, i.e., the colonnade and entabulature, mentioned previously. These filled sets provide an upward path for groundwater movement but the discontinuity of the joint, and perhaps the presence of clay or mineralization fillings in the joints limits horizontal conduction. However, other investigators (Ledgerwood and Deju, 1979) feel that $k_{V}$ is typically an order of magnitude lower than $k_{h}$. In either case, vertical movement is enhanced by the presence of tectonic fracture zones, i.e., fault breccia, or upward conduction along the margins of cross-cutting feeder dikes. In interbeds or interflows, $k_{h}$ is typically higher than $k_{v}$ (Summers and others, 1978), due to the higher porosity and more permeable nature of these strata. 
TABLE $4.2 \cdot 1-1$

SUMMARY OF BASALT THERMAL

AND MECHANICAL PROPERTIES

\begin{tabular}{|c|c|c|c|}
\hline Property & $\begin{array}{c}\text { Estimated } \\
\text { Value } \\
\end{array}$ & Range & $\begin{array}{c}\text { Major } \\
\text { Influence } \\
\end{array}$ \\
\hline Density, $g / \mathrm{m}^{3}$ & $2.9 \times 10^{6}$ & $\begin{array}{l}2.4 \times 10^{6} \\
\text { to } 3.1 \times 10^{6}\end{array}$ & Porosity \\
\hline Diffusivity, $\mathrm{m}^{2} / \mathrm{s}$ & $6.5 \times 10^{-7}$ & $\begin{array}{l}5.2 \times 10^{-7} \\
\text { to } 8.0 \times 10^{-7}\end{array}$ & Porosity \\
\hline $\begin{array}{l}\text { Thermal } \\
\text { conductivity, } \mathrm{W} / \mathrm{m}-{ }^{\circ} \mathrm{C}\end{array}$ & 1.5 & $1.4-4.28$ & \\
\hline Specific heat, $\mathrm{kJ} / \mathrm{kg}-{ }^{\circ} \mathrm{C}$ & 1.0 & $0.95-1.05$ & \\
\hline $\begin{array}{l}\text { Thermal expansion } \\
\text { coefficient, }{ }^{\circ} \mathrm{C}^{-1}\end{array}$ & $5.4 \times 10^{-6}$ & $\begin{array}{l}2.9 \times 10^{-6} \\
\text { to } 11.6 \times 10^{-6}\end{array}$ & Temperature \\
\hline Young's modulus, GPa & 70 & $61-112$ & \\
\hline Poisson's ratio & 0.26 & $0.22-0.28$ & \\
\hline $\begin{array}{l}\text { Uniaxial compressive } \\
\text { strength, } \mathrm{MPa}\end{array}$ & 200 & $0-400$ & $\begin{array}{l}\text { Porosity, } \\
\text { jointing }\end{array}$ \\
\hline $\begin{array}{l}\text { Angle of internal } \\
\text { friction, degrees }\end{array}$ & 55 & $45-60$ & Jointing \\
\hline Tensile strength, MPa & 14 & $0-23.0$ & Jointing \\
\hline
\end{tabular}

Source: Agapito and others, 1977 


\subsubsection{Resources}

Basalt typically has no primary mineralization of economic value, any recoverable resources are the result of secondary mineralization. This process typically requires significant amounts of time to allow for deposition, and throughgoing fracture patterns to allow hydrothermal fluid circulation. Previous work in United States plateau basalts has shown the relatively undeformed flows, even as old as Triassic age, seldom have recoverable mineral resources. The exceptions to this generalization are anygdaloidal copper deposits in the Precambrian Keweenawan basalts in Michigan, and some mercury production from possible early Quaternary andesitic basalts at Steamboat springs, Nevada (Ridge, 1970), both of which have been tectonically deformed. Thus, it is seen that age and amount of deformation may be an indicator of the probable amounts of economically recoverable minerals in a thick basalt deposit.

The occurrence of other resources (geothermal, hydrocarbon and ground water) are briefly discussed below. Although geothermal resources have been recognized in plateau basalt terranes (NOAA, 1980), the incidence of occurence is not high. Hydrocarbon resources, while not unknown, are uncommon, because plateau basalts typically do not occur in areas favorable for petroleum formation, and associations of hydrocarbon resources and basalt are fortuitous. Ground water has been withdrawn from basalt terranes, but the production is typically limited to permeable interbeds and interflows.

\subsubsection{INFORMATION NEEDS FOR PRECHARACTERIZATION STUDIES IN BASALT}

For evaluation of information needs and applicability of testing techniques, it is helpful to have a repository model. For the purposes of the following discussions the repository is assumed to be approximately $2 \times 3 \mathrm{~km}(1.2 \times 1.8 \mathrm{mi})$ and located in massive flow basalts at a depth of $600-900 \mathrm{~m}(2000-3000 \mathrm{ft})$, with an overburaen sequence of interbedded basalt, sedimentary units and scorious or brecciated basalt interflows. This model defines some of the gross requirements which would have to be satisfied in precharacterization studies before detailed site evaluation is undertaken. The information needs addressed in this report are concerned solely with the geologic suitability of medium, and do not consider other facets, such as proximity to population centers, recognized by the Department of Energy (DOE, 1980a). Specific information needs for evaluating whether a proposed site may be suitable for characterization are outlined below. 


\subsubsection{Geology}

Information needs for geology include geologic processes, such as erosion and deposition, geomorphology, Quaternary geology, stratigraphy, lithology and structure. $\dot{A}$ knowledge of erosional or depositional rates, geomorphology and Quaternary geology, is necessary for assessing the long term integrity of the repository. Establishment of stratigraphy, lithology and structure is central to evaluation of acceptability, because unless certain geometric and integrity considerations are met, further evaluation is not meaningful. The following sections address the specific information needs of these three areas.

\subsection{Stratigraphy}

The importance of stratigraphy is in evaluation of the structural and hydrogeologic regime of the site area, and must consider the overburden as well as the host rock. Because of the typically dense, fine grained character of basaltic rocks they have high mechanical strength and low permeability, but the stratigraphy above and below the host rock often contains sedimentary interbeds, or brecciated basalt interflows, which have a lower mechanical strength, and can be efficient groundwater conduits.

At a minimum, the thickness and lateral extent of flows, interbeds and interflows should be determined. Lateral continuity may be constrained by faults, dikes, vents, breccia pipes or folding. Particular attention should be paid to the presence, thickness and stratigraphic position of units above and below the anticipated repository level. Accurate stratigraphy will then assist in the optimum choice of depth, consistant with cost.

\subsection{Lithology}

The lithology of basalt flows and interbeds exposed by local relief can be determined by standard techniques (geochemistry, thin section analysis, etc), and geophysical techniques can give an indication of lithology present in the subsurface. Utilization of geochemical testing techniques will probably also be required, because the mineralogy of aphantic rocks often cannot be identified with hand samples or thin sections.

An important portion of the lithologic study will be classification of host rock and overburden mineralogy. This classification is necessary because of possible significant effects, adverse or favorable, on the 
interaction of repository materials with radionuclide contaminated fluids.

Coincident with lithologic and mineralogic descriptions is analysis of fracture and joint patterns. Because basalt flows exposed on the surface generally present a common pattern of original jointing related to cooling (colonnade and entablature), it is reasonable to assume that buried flows would have a similar pattern. Previous studies have indicated that this is so and the change between the regular, vertical, polygonal fracturing in the colonnade and the more random pattern in the entablature can be identified by petrographic differences (Long, 1978). Because the minerals assemblages are similar, these petrographic differences are textural and related to the flow cooling history. The fracture pattern is also controlled by the cooling history; therefore, petrographic examination may be a viable tool to extend the usefulness of fracture logging beyond the immediate area of a drillhole. These petrographic studies may also be useful to correlate geochemistry, lateral extent, and vertical position in a flow.

\subsection{Structure}

The term structure embraces both the small scale structures resulting from fracturing during cooling, and regional structure (folding and faulting). Although core sample studies have shown that basalt flows have a ubiquitous fracture system (Long, 1978) these fractures may not form a through-going system. Indeed, there is some evidence that the fractures in both the basalt and interbeds close with depth (Summers and others, 1978). Whether this apparent closure is due to overburden pressure or clay and secondary mineralization infilling is not fully understood, but the evidence suggests a low permeability or hydraulic conductivity.

Additional information useful in characterizing the medium is: interbed fractures, stratification within flows, presence of other volcanic features (dikes, vents, fumaroles, etc) and tectonic features such as folds and faults. Some large area basalt flows may retain their original dip, which implies that they have seen little deformation since emplacement. However, folding and faulting in the Keweenawen basalts in Michigan and in the Columbia Plateau show that this generalization may only hold true over small areas. 


\subsubsection{Hydrology}

Groundwater circulation will be the prevalent method of radionuclide dispersal from the repository, and a thorough understanding of the site hydrology and hydrogeologic parameters is critical, because of the requirement for non-contamination of the biosphere within a given time frame. Possible effects and changes in the surface hydrology, including those arising from catastrophic flooding or long term climatic changes, must be evaluated, as well as ground water basin and aquifer hydrogeologic parameters. These parameters can be divided into two general categories: 1) hydrostratigraphy and basin recharge/ discharge; and 2) aquifer characteristics. The first category includes deduction of structural control of ground-water flow, location and lateral dimensions of water-bearing strata, vertical (stratigraphic) position of water-bearing strata, recharge/discharge characteristics of the basin and flow paths from the repository to the biosphere. In the second category are the hydraulic conductivities and porosity, all of which control water movement through the subsurface.

of particular importance to these hydraulic studies is the stratigraphic position and differentiation of flow properties between basalt flows and interbed/interflow units. Because of higher permeabilities, these interbed/interflow units will conduct the bulk of the ground water flow. The presence of minor structural features, such as breccia pipes or lava tubes, may also result in anomalously high flow rates. This differentiated information is vital to determine the time, rate and levels of possible radionuclide contamination of over- and underlying aquifers, and may be augmented by additional data on groundwater age.

\subsubsection{Geochemistry}

Geochemical data from both flows and interbed/interflow units are needed to support lithology/stratigraphy studies and hydrologic modeling. Because of the geochemical and lithologic uniformity of flows, whole rock chemistry and petrographic examinations may be of use to infer fracture patterns, lateral extent and continuity. Age dating can assist in inferring lateral extent and continuity as well as providing subsidiary information on the probabilities of recoverable mineral deposits (see section 4.2.1.5). Further refinements of these information needs may be possible by use of trace element analysis.

Because the nature of radionuclide reactions with ground water, interbeds/interflows and host rock are critical, a major information need 
will be determination of equilibruim concentrations for the reactants and products in all media. To support these studies, information on the following chemical conditions and reaction rates are needed (Erdal and others, 1981):

- Relative solubility of nuclides

- Effects of hydrolysis

- Polymerization reactions

- Formation of complexes

- Oxidation/reduction potentials and conditions

- Radiation/radiolysis conditions

$\circ \quad \mathrm{pH}$

Additional data is also required on ion processes (Erdal and others, 1981) such as:

- Ion exchange/exclusion processes

- Replacement reactions

- Aqueous/pore diffusion

- Physical transport and filtration

- Precipitation processes

Because a main objective of these studies is evaluation of sorption and travel time of radionuclides, additional information on sorption and desorption rates, bedrock surface area in contact with the ground water, effect of fracture geometry and mineralization on geochemical processes, and the effects of temperature and pressure is needed.

\subsubsection{Geomechanical}

Geomechanical information needs embrace both rock mechanics and thermal properties of the host rock and both parameter sets are necessary to establish the capability of basalt to absorb and dissipate the heat produced by radionuclide decay, while maintaining site integrity. The physical properties required are: 
- Discontinuities

- Rock density

- Young's modulus

- Poisson's ratio

- Compressive strength

o Tensile strength

- Cohesion

The presence and attitude of discontinuities in both the host rock and overburden is important because they will lower the tensile strengths of the rock and provide ready-made preferred slip planes. Because the properties of interbeds and host rock may vary significantly, samples of both must be tested. There is evidence that a wide disparity may exist between wet and dry sample strengths (Grosh, 1980), therefore engineering tests should be performed under both conditions.

To evaluate the effects of heat on host rock strength and geochemical reactions, values for several different thermal properties are required. At a minimum, these properties are:

- Coefficients of thermal expansion

- Thermal conductivity

- Specific heat

- Heat flow in the repository vicinity

Because of the possibility of laboratory tests giving erroneously high values for elastic properties, a site characterization program of in situ testing to verify laboratory results, or determine a useful ratio between laboratory and field tests, may be necessary to adequately evaluate geomechanical and thermal properties. Additional in situ testing should be planned to measure parameters such as temperature, pressure, stress state and pore pressure, which can be of significant value in evaluation of seismotectonics and hydrology. 


\subsubsection{Seismotectonics}

Evaluation of the seismotectonic regime in the repository area is another critical need, and should include the inferred past, present and future regimes. The processes which could affect the integrity of a repository are:

- Seismic activity and faulting

- Uplift/subsidence

- Igneous activity

- Natural stress state alterations

These studies should include analysis and synthesis of both local and regional regimes, and will largely be dependent upon existing data and data from other information needs. Specific concerns which should be addressed by these studies include:

- possibility of renewed volcanism

- more recent history of tectonism than some of the other media

- possible higher seismic activity than present in other media

\subsubsection{Resources}

Although basaltic terranes typically have minimal resources, the potential of each site must be quantified. Resources can be divided into four broad categories:

- Mineral (metallic and non-metallic)

- Hydrocarbon

- Geothermal

- Water supplies

Evaluation of these resources should also address itself to the possibility that resources presently considered uneconomical to extract may not be so in the future. 
Other concerns regarding resources which should be considered when evaluating a repository site (DOE, 1980b) are:

- The repository location should not preclude the extraction of mineral resources.

- Mineralization at, or below, the repository depth should be sufficiently low to preclude the chance of repository breach by future generations.

4.2.3 TECHNIQUE APPLICATIONS TO PRECHARACTERIZATION INFORMATION NEEDS IN BASALT

A study to evaluate a lithologic medium as a potential repository site must satisfy the information needs outlined in section 4.2 .2 , and is dependent on available exploration techniques. The reliability and resolution of the techniques are adequately discussed in the technique reports (Appendices $A-H$ ), and, unless affected by a unique condition in basalt, will not be addressed further in this section.

Applicability of some techniques is limited by the stage of characterization. In this discussion three characterization stages are considered:

1. No drilling at site; i.e. all data from surface-based exploration (mapping and geophysics).

2. Data available from previous drilling at the site (plus surface exploration information).

3. Drilling and appropriate logging/testing done during the siting study (plus previous boring and surface exploration data).

For evaluating applicability of techniques in the case of previous drilling, the following assumptions are made about the types of well and information available:

- Type - water and mineral

- Cores - available

- Logs - driller's, geologist's, Spontaneous Potential, resistivity and natural gamma (gross count gamma ray). 
It should be noted that the availability of these data may enhance the applicabilities of other techniques, as shown in Table 4.2.3-1, but it is not considered likely that pre-existing holes will be in suitable condition for new logging or hydrologic testing.

It is recognized that the applicability ratings in Table 4.2.3-1 may be affected by subjective bias, and the value of any technique could be argued. The ratings below, as well as any cautions about reliability or resolution in the following discussions, are based on data compilation from various sources, and are thought to represent any special problems for adequately characterizing basalt as a host medium.

\subsubsection{Geology}

\subsection{No Drilling at Site}

The information needs relating to geomorphology, Quaternary geology, paleoclimate, history of erosion and deposition, and similar topics can be addressed before drilling is undertaken at a site. These typically utilize techniques in remote sensing and surfacing mapping, supplemented by shallow drilling and trenching as required. These information needs are unrelated to the medium involved and determined by geologic conditions. Resolution and reliability of these observations and the resulting interpretations also would depend on site conditions, particularly on the amount of information available and the complexity of the geologic record.

Basalt has several unique features which could affect the applicability, reliability or resolution of surface-based exploration for determining site geology. Among these are:

- Typically exposed at surface, so a first approximation of host rock lateral extent can be made.

- Near horizontal attitudes will assist in tracing lateral continuity of flows.

- Colonnade and entabulature joint patterns can assist in determining small scale structure of the host rock.

- Intercalated basalt flows and sedimentary units will provide stratigraphic information. 
TABLE 4.2.3-1 SUMMARY OF TECHNIOUE APPLICATIONS IN BASALT

\begin{tabular}{|c|c|c|c|c|}
\hline \multirow{2}{*}{\multicolumn{2}{|c|}{ TECHNIQUE }} & STAGE 1 & STAGE 2 & STAGE 3 \\
\hline & & $\begin{array}{l}\text { NO DRILLING SURFACE } \\
\text { EXPLORATION ONLY }\end{array}$ & EXISTING DRILLING & NEW DRILLING \\
\hline \multirow{2}{*}{ REMOTE SENSING } & SATELLITE & $G h S r$ & G h $S \mathbf{r}$ & G h S r \\
\hline & AIRCRAFT & G h $S \mathrm{r}$ & G h $\mathbf{S} \mathbf{r}$ & $G \mathbf{h} \mathbf{S}$ \\
\hline \multirow{3}{*}{ SURFACE MAPPING } & LANDFORMIS & G h $S r$ & G $h \mathbf{S} r$ & G $h S \mathrm{r}$ \\
\hline & LITHOLOGYIMATERIALS & G h c m s r & $\mathrm{G} \underline{\mathrm{H}} \underline{\mathrm{c}} \underline{\mathrm{m}} \underline{\mathrm{s}} \underline{\mathbf{r}}$ & 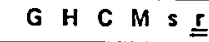 \\
\hline & PROCESSES/STRUCTURE & G $h s \mathbf{r}$ & G h $s \mathbf{r}$ & $G h s r$ \\
\hline \multirow{4}{*}{$\begin{array}{l}\text { GEOPHYSICAL } \\
\text { LOGGING }\end{array}$} & ELECTRICAL & & $g h r$ & G $H \mathbf{R}$ \\
\hline & RADIOACTIVE & & $\mathrm{ghr}$ & G H R \\
\hline & MECHANICAL & & gh $\mathrm{m} \mathrm{s}$ & G $H \mathbf{m}$ s \\
\hline & ACOUSTICAL & & $\mathrm{gh} \mathrm{h} \mathrm{s}$ & $\mathbf{G} \mathbf{H} \mathbf{m}$ \\
\hline \multirow{6}{*}{$\begin{array}{l}\text { GEOPHYSICAL } \\
\text { EXPLORATION }\end{array}$} & GRAVITY & $g \leqslant r$ & g $s r$ & $\stackrel{g}{=} \mathbf{s}$ \\
\hline & AUDIO-MAGNETOTELLURICS & g h c S R & $\underline{\mathrm{g}} \underline{\mathrm{h}} \underline{\mathrm{c}} \mathrm{s} \underline{\mathrm{R}}$ & $\underline{\underline{g}} \stackrel{h}{=} \stackrel{\mathrm{c}}{=} \stackrel{R}{=}$ \\
\hline & SEISMIC REFRACTION & ghs & $\underline{\underline{g}} \underline{h} \mathbf{s}$ & $\underline{\underline{g}} \stackrel{h}{=} s$ \\
\hline & RESISTIVITY & g h $s \quad r$ & $\underline{g} \underline{h} s \underline{r}$ & $\underline{\underline{g}} H s \underline{r}$ \\
\hline & MAGNETICS & G s $R$ & $\underline{G} \mathbf{s} \underline{R}$ & $\underline{\mathbf{G}} \mathbf{s} \stackrel{\mathbf{R}}{=}$ \\
\hline & SEISMIC REFLECTION & $\mathbf{G} \mathbf{s} \mathbf{R}$ & $\underline{\mathbf{G}} \mathbf{s} \underline{\mathrm{R}}$ & $\underline{\underline{G}} \mathbf{s} \underline{\underline{R}}$ \\
\hline \multirow{4}{*}{$\begin{array}{l}\text { GEOMECHANICS } \\
\text { THERMOMECHANICS }\end{array}$} & ROCK MATERIALILAB TESTS & $\mathrm{g} h \mathbf{m}$ & $\underline{\underline{g}} \underline{\mathrm{h}}$ & $\underline{\underline{g}} \mathrm{HM}$ \\
\hline & ROCK FIELD OBSERVATIONS & $g h c m s r$ & $\underline{g} \underline{h} \underline{m} \mathbf{s}$ & $\underline{\mathbf{g}} \stackrel{\mathrm{h}}{\underline{\mathrm{m}} \mathrm{s} r}$ \\
\hline & DESIGN LAB TESTS & & m & $\mathbf{M}$ \\
\hline & DESIGN IN SITU TESTS & & & $M$ \\
\hline \multirow{5}{*}{ GEOCHEMICAL. } & $\begin{array}{l}\text { GRAPHICAL } \\
\text { STATISTIC ANALYSES }\end{array}$ & $g h<r$ & $\mathbf{g} \underline{h} \underline{c} \underline{r}$ & $\mathbf{g} \stackrel{h}{=} \underline{\underline{r}}$ \\
\hline & SAMPLING AND ANALYSES & g h $\mathbf{h} \mathbf{r}$ & $\underline{g} \mathrm{H} \underline{\mathrm{c}}$ & $\underline{\underline{\underline{g}}} \stackrel{\mathrm{H}}{=} \mathbf{C} R$ \\
\hline & VIATER-ROCK MOOELING & & h $\mathbf{c}$ & H c \\
\hline & STABLE ISOTOPE MODELING & & h c & H c \\
\hline & GROUNDWATER AGE DATING & h c & $\underline{h} \underline{c}$ & H c \\
\hline \multirow{6}{*}{ HYOROLOGY } & FLOOD FREOUENCY & H & $\mathrm{H}$ & $\mathbf{H}$ \\
\hline & RECHARGE/DISCHARGE & & $\mathbf{h}$ & H \\
\hline & SURFACE WATER CHEMISTRY & HC & $\underline{H} \underline{\mathbf{C}}$ & $\underline{\mathrm{H}} \underline{\underline{\underline{C}}}$ \\
\hline & NUMERICAL MODELING & $\mathbf{h}$ & $\underline{\mathbf{h}}$ & $\underline{\mathbf{h}}$ \\
\hline & AQUIFER TESTS & & $\mathbf{h}$ & H \\
\hline & TRACER TESTS & & & $\mathbf{H}$ \\
\hline \multirow{6}{*}{$\begin{array}{l}\text { SEISMICITY/ } \\
\text { TECTONICS }\end{array}$} & $\begin{array}{l}\text { HISTORICAL } \\
\text { EARTHOUAKE ANALYYSIS }\end{array}$ & $\mathbf{s}$ & $\mathbf{s}$ & $\mathbf{s}$ \\
\hline & $\begin{array}{l}\text { INSTRUMENTAL } \\
\text { EARTHQUAKE ANALYSIS }\end{array}$ & $\mathbf{s}$ & $\mathbf{s}$ & S \\
\hline & MONITORING NETWORKS & $\mathbf{s}$ & $\mathbf{s}$ & $\mathbf{s}$ \\
\hline & VELOCITY STUDIES & g s & 95 & $9 \underline{s}$ \\
\hline & FAULT STUDIES & g s & $9 \underline{s}$ & $9 \underline{s}$ \\
\hline & $\begin{array}{l}\text { ATTENUATION AND } \\
\text { GROUND MOTION }\end{array}$ & g $s$ & $\underline{\mathbf{g}} \underline{\mathbf{s}}$ & $\underline{\underline{g}} \stackrel{\underline{s}}{=}$ \\
\hline \multicolumn{2}{|c|}{ DRILLING/LOGGING } & & gh $\mathrm{cm}$ s r & G H C M $S R$ \\
\hline
\end{tabular}

EXPLANATION

CLASSES OF INFORMATION NEEDS

G F GEOLOGY

$H=$ HYDROLOGY

C= GEOCHEMISTRY

$M=$ GEOMECHANICS/THERMOMECHANICS

S. SEISMICITY/TECTONICS

$\mathrm{R}=\mathrm{RESOURCES}$
NOTES:

1. CAPITAL LETTERS INDICATE MOST APPLICABLE TECHNIQUES. LOWER CASE LETIERS INDICATE LESS APPLICABILITY. DOUBLE UNDERLINE INDICATES ENHANCEMENT BY NEW DRILLING DATA.

2. LETTERS INDICATE INFORMATION NEED CLASSES WHOSE TECHNIQUES OBTAIN DATA THROUGH STAGES OF INVESTIGATION. LETTERS INDICATE APPLICABILITY WITHIN A STAGE, BUT DO NOT REPRESENT EQUIVALENCE BETWEEN TECHNIQUE. RESOLUTION, RELIABILITY, AND OTHER EVALUATION 
Presence of exposed and buried dikes, vents, fumaroles and lava tubes will complicate the structure and lithology.

- Low density, resistivity or susceptibility contrasts between basalt flows and intercalations may complicate the data interpretation for gravity, magnetic, audio-magnetotelluric and resistivity techniques, i.e., it may be difficult to differentiate between flows.

0

Inverted density contrasts, i.e., a low velocity layer under a high velocity layer, could limit the usefulness of seismic refraction techniques in detecting low density interbeds intercalated between basalt flows.

- Low density contrasts may severely limit interpretation of structures such as vents, dikes and fumeroles.

- Presence of interbeds of scoria or highly vesicular portions of basalt flows may serve as marker beds and assist in stratigraphic interpretation.

Because plateau basalts are typically noted for lateral continuity of flows, other general information on stratigraphy, lithology and structure can be extrapolated from off-site boreholes or interpreted from seismic data.

\subsection{Previous Drilling}

Results of previous drilling in basalts can greatly aid evaluations of stratigraphy lithology, and geologic structure. The typical borehole geophysical logs assumed to be available can be useful for stratigraphic interpretation because they can detect interbeds less than a meter thick, and may greatly increase the reliability and accuracy of geophysical interpretations. In particular, the borehole data would provide depth control for geophysical interpretations and allow lithologic correlations with seismic stratigraphy, and may significantly reduce the minimum thickness stratigraphic unit that can be confidently mapped through a site area from a few tens of meters (based on seismic reflection alone) to perhaps less than a meter. 


\subsection{New Drilling}

New drilling at a prospective site would allow detailed core logging and selection of the most suitable borehole geophysical logging techniques. The combined effect of these techniques will greatly increase the resolution and reliability of the stratigraphic, lithologic, and structural information. Although the borehole geophysical logs can be interpreted with considerable confidence, direct observation of core samples is valuable to confirm lithology and analyze structural features.

Mud logging and selected geophysical logging in new boreholes can provide data for uncored zones, and aid or supplement core logging. Natural gamma logs are particulary useful for confirming depths of the core return. In addition to the basic logs assumed available for the pre-existing holes, logs that may be useful include spectral gamma, density, porosity, and acoustic logs to aid lithology determinations. State-of-the-art tools such as borehole radar and gravity also may be used to aid identification of structural features, breccia pipes and other anomalies. As noted previously, standard borehole logs can typically resolve layers less than a meter thick and by use of other logging techniques, layers to 0.1 meter may be detected with significant confidence. Resolution and reliability of the radar and gravity tools has not been established.

\subsubsection{Hydrology}

\subsection{No Drilling at Site}

Basalt has several unique intra- and interflow features which may affect hydrologic measurements. Intraflow features are the lithologic differences and distinctive joint set patterns between the colonnade and entabulature. Interflow features such as permeable interbeds, scoria beds, fractured flow surfaces and lava tubes occur along flow contacts, and breccia pipes, vents, or dikes cross-cut flows. The effects of these features include:

- intraflow hydraulic conductivity anisotropies

- increased horizontal hyaraulic conductivity along flow contacts

- local areas of high vertical hydraulic conductivity at vents, breccia pipes and dike contacts. 
Techniques in the precharacterization stage are independent of medium and limited to those involving climate, surface hydrology, and hydrology of ground water at shallow depths. Resolution and reliability of these techniques are also independent of the medium, but dependent on local conditions and factors, such as length and quality of climate and streamflow records.

Without drilling at a site, some information on hydrology in and below the host rock level may be inferred from extrapolation of lithologic and stratigraphic data, but drilling and aquifer testing are needed to obtain reliable hydrologic data.

\subsection{Previous Drilling}

Previous drilling at a prospective repository site in basalt is unlikely to include water wells to depths of concern and existing holes are unlikely to be suitable for hydrologic testing or monitoring at or below the repository level. As a result, the main benefits to hydrologic studies from the previous drilling would be definition of hydrostatigraphy and water table depths with much greater reliability, using techniques discussed in section 4.2.3.1.

\subsection{New Drilling}

New drilling at a prospective repository site is needed for implementation of hydrologic testing techniques. Examples of hydrologic testing in this stage would be obtaining water samples by pumping or bailing (testing of these samples is discussed under "Geochemistry"), aquifer test performance, and well completion for monitoring water levels in selected aquifers. Specific concerns for this work in basalt include the difficulties of measuring hydrologic parameters in materials of low permeability.

Laboratory porosity and permeability tests performed on core samples obtained from this drilling may contribute to understanding of aquifer properties. As discussed in the technique report on hydrology (Appendix G-1), there typically is some uncertainty in these tests because of possible disturbance of the core samples. In basalt, however, a more important concern is how representative are the samples of the condition in the repository zone. The reliability of these tests therefore must be evaluated on the basis of detailed core logging and geologic analyses of site conditions.

Numerical modeling and analysis techniques can be used to evaluate hydrologic conditions, based on borehole logging and laboratory test 
data. Geologic structure and geochemical data about water quality and age in various zones can also aid these analyses. Results of this data can provide information on:

- recharge/discharge

- heads and gradients

- direction and rate of flow

- travel time

Reliability and resolution of modeling and analysis techniques are highly dependent on the level of understanding of the hydrologic system. Although the generally horizontal layering of flood basalts is a simple hydrologic system, the variable hydraulic conductivities may make the system very complicated in detail. It is important in these analyses not to select the most adverse parameters because they may result from very localized conditions.

\subsubsection{Geochemistry}

\subsection{No Drilling}

With no drilling at a site, the geochemical techniques available are limited to testing of surface-water quality and isotope dating of surface samples, which-will support the hydrologic and geologic efforts, respectively. At this stage of investigation, the geochemical conditions directly relevant to a prospective repository can only be inferred from general information on lithology and stratigraphy.

\subsection{Previous Drilling}

Data from previous drilling can provide general information on geochemical conditions at repository depths by interpretation of stratigraphy and lithology from borehole geophysical logs. This general information would be useful because of the typically homogeneous chemistry of a given flow. However, due to alterations in core samples during surface storage, the reliability of the geochemical information would be uncertain, and probably able to resolve general stratigraphic units only. 


\subsection{New Drilling}

New drilling would provide fresh rock and water samples for geochemical laboratory analyses and geochemical interpretations of selected borehole geophysical logs. This testing and analysis will provide the basic geochemical description of the host rock, with particular emphasis on radionuclide reactions, and rock and water age dating. Specific techniques that may be used are described in the topical report on geochemistry.

Geochemical properties of individual samples can be determined with a high degree of accuracy and reliability. However, the more important question of how well the geochemical environment, i.e., radionuclide interactions of the host rock can be defined depends on how well the geologic and hydrologic framework is understood, in addition to accuracy of testing and density of sampling. These factors cannot be quantified with any confidence on a generic basis.

\subsubsection{Geomechanics}

\subsection{No Drilling}

Information needs in geomechanics are the mechanical and thermal properties of the rock units present and a description of in situ stress conditions. Fracture and joint patterns extrapolated from surface outcrops should be received with caution because stress changes resulting from overburden removal and weathering may have a significant affect. In view of these factors, geomechanical information obtained without drilling would typically be limited to:

- extrapolation of offsite conditions,

- general interpretations based on available lithologic, stratigraphic, and structural information

$\circ$

general tectonic stress interpretations.

\subsection{Previous Drilling}

Previous borehole data would be useful for defining lithologic units with a higher accuracy and reliability. Because of significant geomechanical differences in rock types (i.e., massive flows, interbeds and interflows), the distribution and characteristics of these units will be important to obtain during the pre-characterization stage. The 
resolution and reliability of geomechanics information from previous drilling will depend on:

\author{
- data quality \\ - density of core sampling program \\ - representativeness of core samples \\ - length of storage time under surface conditions
}

\title{
4.2.3.4.3 New Drilling
}

New drilling will allow direct determination of geomechanical parameters by use of the techniques described in the accompanying technique report on Geomechanics (Appendix E-1). In addition to this data, detailed core logging and borehole geophysics would be available to better define stratigrapbhy, lithology, and geologic structure. Additional in situ tests for determining temperature, pressure, stress conditions (overcoring or hydrofracturing) and pore pressures can be performed to obtain reliable information on conditions at repository depth. As mentioned previously (Section 4.2.2.4), there may be significant differences in geomechanical properties between wet and dry samples, which must be determined.

The variation in geomechanical properties between host rock, interbeds and interflows is much greater than the uncertainty in geomechanical measurement techniques. Accordingly, the reliability and resolution of the geomechanical analyses would be determined to a large extent by the quality of the site geologic model.

\subsubsection{Seismotectonics}

Seismotectonic information needs are independent of medium and stage of investigation (i.e, no drilling, etc.), although basalts are unique in that they are typically relatively young (Miocene to Holocene) in age. These relatively young ages, and emplacement by volcanism, suggest the possibility of higher than usual seismic activity, compared to other media. This possibility must be fully explored during the precharacterization study.

Techniques used to obtain seismotectonics information include the seismic techniques described in the Appendix reports combined with geologic techniques of remote sensing, surface mapping, and subsurface 
exploration. Reliability and resolution of technique interpretations cannot be quantified on a generic basis because they depend on complex factors such as length and quality of the local seismic record and level of understanding of local and regional geologic regimes. It is expected, however, that seismotectonic activity in and around the prospective site can be sufficiently quantified to show that no significant hazard will be present.

\subsubsection{Resources}

The unique feature of basalt affecting techniques for resource evaluation is the relatively young age of many plateau basalts. Because mineralization in basalt is typically of a secondary nature, deposits of this type will be minimal because there has been so little time (geologically) for secondary mineralization to occur.

\subsection{No Drilling}

With no drilling at a site, resource potentials must be evaluated by extrapolation of off-site data and geophysical survey interpretation. Because mineralization in basalt is typically minimal and localized, and hydrocarbon occurrences are fortuitous, these extrapolations should be accepted cautiously.

\subsection{Previous Drilling}

Data from previous drilling would enhance the resolution and reliability of resource determinations by additional direct evidence of stratigraphy, lithology, structure and, to some extent, geochemistry. The types of borehole geophysical logs assumed to be available would be valuable for reliable identification of stratigraphy.

\subsection{New Drilling}

New drilling would increase the reliability and resolution of resource evaluations by generally improving the confidence in geologic interpretations. It may also be assumed that this new drilling would include holes placed to evaluate any potential resources identified in the site area. Because pre-characterization exploration would involve a detailed study of general geology, the resource potential of the site would be defined with a high level of confidence, and it is unlikely that resources of present or potential economic value would be overlooked. 


\subsubsection{COST AND TIME ESTIMATES FOR PRECHARACTERIZATION TECHNIQUES}

The various techniques available to meet the information needs in basalt have a wide range of "base costs", reflecting time, materials and unit costs (e.g., cost per foot, per hole, etc.), to which must be added the base interpretation time. To minimize verbose, and possibly confusing, text and and render technique costs comparable, a tabular format is used for cost-data presentation (Tables 4.2.4-1 to 4.2.4-7). The costs in these tables are generally independent of media but a few techniques deviate significantly in cost when used in a basalt medium as compared to tuff, shale, granite and dome or bedded salt. Those techniques with additional costs, due to unique features of the medium are summarized by a short explanatory text.

\subsubsection{Remote Sensing and Mapping}

The basic costs for these techniques are presented in Table 4.2.4-1 and discussed in Appendix A. Costs for photo acquisition and interpretation are largely independent of medium, but field mapping in a basalt terrane may be higher than in some of the media because of anticipated rugged or remote terrain, which may require support equipment to facilitate field personnel movement in a cost-effective manner.

\subsubsection{Drilling and Coring}

Drilling and coring costs are presented in Table 4.2.4-2 and discussed in Appendix $D-1$. Because of the hardness of basalt, the cost of arilling may be significantly higher than in some of the other media. The increased cost is primarily due to:

- Rapid deterioration of drill bits due to rock hardness

- Possible accessability problems for drilling rigs

Additional problems may arise in drill rig availability. Because most large area basalt deposits are located in the northwestern United States, the intensive petroleum drilling activity in the Midwest and Gulf Coast areas may impose a long lead time (6-18 mos.) for acquiring suitable drilling equipment. However, the use of mining exploration rigs, may alleviate this problem, because they typically can be obtained on a shorter lead time ( 6 wks. -6 mos.). 
TABLE $4 \cdot 2 \cdot 4-1$

COST AND TIME SUMMARY FOR

REMOTE SENSING AND MAPPING

Acquiring Imagery or Photography

$\begin{array}{lll}\text { Approximate Cost Range } & \begin{array}{c}\text { Delivery } \\ \text { Time }(1)\end{array} & \begin{array}{c}\text { Approximate } \\ \text { Area Covered }\end{array} \\ \begin{array}{c}\$ 8-150 \text { per image (2) } \\ \text { LANDSAT } \\ \text { Enhancement }\end{array} & \begin{array}{l}1-4 \text { weeks } \\ \$ 200-1000 \text { per scene (3) }\end{array} \text { 4-16 weeks (3) } & 13,500 \mathrm{mi}^{2}\end{array}$

SKYLAB

Mult ispectral

\$8-150 per image (2) 1-4 weeks

$2,000 \mathrm{mi}^{2}$

Earth Terrain

$$
\$ 8-150 \text { per image (2) } 1-4 \text { weeks }
$$$$
4,600 \mathrm{mi}^{2}
$$

Stereo Aerial Photography

Purchase existing

New flight

$\$ 3-60$ per frame (2)
$\$ 25-40$ per frame $(4)$

$3-80 \mathrm{mi}^{2}$

Low Sun Angle Photography

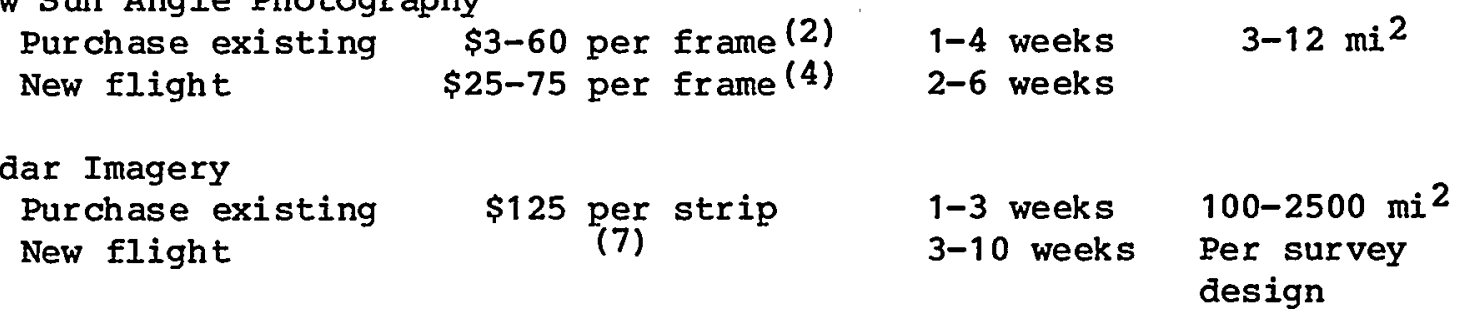

Interpreting Imagery or Photography

\begin{tabular}{|c|c|c|c|}
\hline & Cost & Time (5) & Comments \\
\hline $\begin{array}{l}\text { Satellite Imagery } \\
\text { (generally a } 1: 250,000 \text { ) }\end{array}$ & $\$ 1050-1750$ & 3-5 days & per scene \\
\hline \multicolumn{4}{|l|}{$\begin{array}{l}\text { Aerial photography (8) } \\
\text { e } 1: 62,500\end{array}$} \\
\hline $\begin{array}{l}\text { Land forms } \\
\text { Lithology } \\
\text { Geologic Structure }\end{array}$ & $\begin{array}{r}\$ 70-175 \\
\$ 70-175 \\
\$ 175-280\end{array}$ & $\begin{array}{l}1 / 4-1 / 2 \text { days } \\
1 / 4-1 / 2 \text { days } \\
1 / 2-1 \text { day }\end{array}$ & $\begin{array}{ll}\text { For } & 100 \\
\mathrm{mi}^{2} & \text { area }\end{array}$ \\
\hline \multicolumn{4}{|l|}{$\begin{array}{l}\text { Aerial photography ( } 8) \\
\text { e } 1: 24,000\end{array}$} \\
\hline $\begin{array}{l}\text { Land forms } \\
\text { Lithology } \\
\text { Geologic structure }\end{array}$ & $\begin{array}{l}\$ 175-350 \\
\$ 175-350 \\
\$ 280-700\end{array}$ & $\begin{array}{l}1 / 2-1 \text { day } \\
1 / 2-1 \text { day } \\
3 / 4-2 \text { days }\end{array}$ & $\begin{array}{ll}\text { For } & 100 \\
\mathrm{mi}^{2} & \text { area }\end{array}$ \\
\hline Radar Imagery & (9) & (9) & \\
\hline
\end{tabular}


TABLE 4.2.4-1 (Continued)

Field Mapping ${ }^{(6)}$

Reconnaissance

$1: 62,500$ scale

Cost
$\begin{gathered}\$ 1800 \\ \$ 3000\end{gathered}$

Time $(5)$
3 days
5 days

Comments

$1: 24,000$ scale

Relatively complete mapping

$1: 62,500$ scale

$1: 24,000$ scale

$\$ 4200$

$\$ 6600$

7 days
11 days

For 100

$\mathrm{mi}^{2}$ area

NOTES

(1) Delivery times generally do not depend on quantity ordered.

(2) Cost of photos or imagery is determined by size of print ordered, whether in color or black and white, and extra charges for shorter delivery time.

(3) Cost and delivery time for enhancements depends on source and on availability of previous processing for scene desired.

(4) Flight costs in addition to costs of photo reproduction indicated above.

(5) Approximate man-days to complete work; delivery time may be longer. Time required for interpretations can depend on complexity of geologic conditions at a site.

(6) Cost and time estimates assume interpretation of imagery and photography completed previously. Actual times and costs in an area would be influenced by access, trafficability, and complexity.

(7) Obtaining radar imagery from a new flight costs several thousand dollars. Actual costs depend on mobilization (radar equipment is not widely available), altitude requirements, and other flight parameters.

(8) Estimated times and costs are applicable to all $9^{n} \times 9^{n}$ stereo aerial photographs: black and white, color and infrared (both black and white and color).

(9) Time and cost for interpreting radar imagery depends on resolution and scale of the imagery, purpose of the interpretation, and other factors. See Appendix A for discussion. 


\begin{tabular}{lcccc}
\multicolumn{2}{c}{ TABLE $4.2 .4-2$} \\
COST AND TIME SUMMARY FOR \\
DRILLING AND CORING (1)
\end{tabular}

NOTES

(1) Adopted from Appendix D.

(2) Including all drilling supplies, support personnel and ancillary equipment.

(3) For mobilizing petroleum drill rig to typical basalt site, add about $\$ 86,000$ for rig suitable for drilling only or $\$ 185,000$ to obtain rig suitable for coring.

(4) Includes $\$ 285$ per foot for core bits and related coring services. 


\subsubsection{Borehole Geophysical Logging}

Geophysical logging costs are summarized in Table 4.2.4-3 and discussed in Appendix C-1. No unique costs are anticipated while performing borehole logging techniques that would greatly increase costs above those in other media.

\subsubsection{Geophysical Exploration}

Geophysical survey costs are summarized in Table 4.2.4-4, and discussed in Appendix B. Basalt areas may have rugged terrain and associated difficulties in access. In such an event, it may become necessary to provide four-wheel drive or helicopter support to supply and move the crews rapidly, and ground-based surveys (gravity, seismic reflection and refraction) may experience increased costs.

\subsubsection{Geomechanics}

Geomechanical and thermal testing costs are summarized in Table 4.2.4-5 and discussed in Appendix E-1. No unique costs are anticipated for conducting the geomechanical and thermal tests on basalt samples.

\subsubsection{Geomechanical}

Geomechanical testing costs are summarized in Appendix $\mathrm{F}-1$. No unique costs are anticipated for conducting the geochemical analysis on basalt samples.

\subsubsection{Hydrology}

Hydrologic testing costs are summarized in Table 4.5-6 and discussed in Appendix G-1. No unique costs beyond those previously discussed in section 4.2.4.2 are anticipated for conducting hydrologic tests in basalt.

\subsubsection{Seismotectonics}

Seismologic costs are summarized in Table 4.2.4-7 and discussed in Appendix $\mathrm{H}$. No unique costs are anticipated to conduct seismologic studies on basalt. 
TABLE $4.2 .4-3$

COST AND TIME ESTIMATES FOR

BOREHOLE GEOPHYSICAL IOGGING

Approximate

Techniques

Cost Range

Time (3)

Typical Log Package (1)

Borehole Caliper

Focused Resistivity

Single-point Resistivity

Spontaneous Potential

$\$ 1300$

Gross-count Gamma Ray

Density

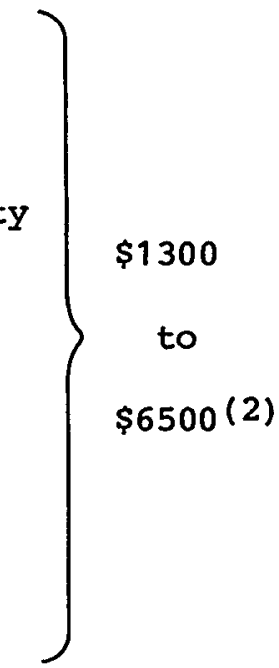

$1 / 2$ day

Neutron Porosity

Deviation

Additional Logs (4)

Electrical

Radioactive

Acoustic

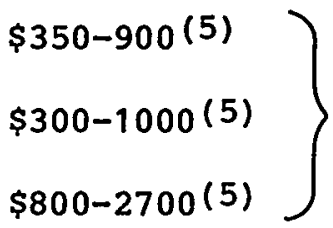

Add approximately

one hour per sonde

Specialized logs requiring separate mobilization: (not practical for single hole)

Radar Log

$\$ 6000(6)$

$1 / 2$ day

Gravity Log

$\$ 4000(6)$

$1 / 2$ day 
TABLE 4.2.4-3 (Continued) - NOTES

\section{(1) Assumes:}
a. Single 1000-foot hole
b. 400 miles (round trip) travel charge to well site
c. Holes ready to log upon arrival (i.e. no standby time)
d. Logging speed of 50 feet per minute
e. Non-logging (entering hole) at 60 feet per minute
f. Log package combined on two sondes

(2) Low cost for minerals logging contractor; high end cost for oilfield logging contractor. Cost per hole would be reduced if travel charge can be applied to additional holes.

(3) Approximate time on site, not including travel.

(4) Assumed to be added to package described in note (1)

(5) Actual costs will depend on services desired, available combinations in single sondes, and minimum charges imposed by some contractors. Ranges are as in note (2) above.

(6) Estimated cost for single 1000-foot hole logged as part of larger program. Includes interpretation. 
TABLE $4.2 .4-4$

COST AND TIME SUMMARY FOR

GEOPHYSICAL EXPLORATION TECHNIQUES

\begin{tabular}{|c|c|c|}
\hline Technique & $\begin{array}{c}\text { Approximate } \\
\text { Costs Range (1) }\end{array}$ & $\begin{array}{c}\text { Typical Production } \\
\text { Rates (1) }\end{array}$ \\
\hline Gravity & $\$ 60-75$ per station $(2)$ & $\begin{array}{l}2 \text { to } 4 \text { stations } \\
\text { per hour }\end{array}$ \\
\hline Audio magnetotelluric & $\$ 900$ per station & $\begin{array}{l}2 \text { stations per } \\
\text { crew per day }\end{array}$ \\
\hline Seismic refraction & $\begin{array}{c}\$ 3000-15,000 \text { per } \\
\text { mile (3) }\end{array}$ & (3) \\
\hline Resistivity profile & $\$ 1000$ per station $(4)$ & $\begin{array}{l}3 \text { stations per crew } \\
\text { per day in field (5) }\end{array}$ \\
\hline Resistivity sounding & $\$ 2500$ per sounding $(6)$ & $\begin{array}{l}2 \text { soundings per crew } \\
\text { per day in field (5) }\end{array}$ \\
\hline Airborne magnetic & $\begin{array}{l}\$ 20 \text { per mile plus } \\
\text { mobilization cost } \\
\text { (See Appendix B-5) }\end{array}$ & $\begin{array}{l}2 \text { to } 6 \text { week delivery } \\
\text { time (depending on } \\
\text { equipment avail- } \\
\text { ability) }\end{array}$ \\
\hline Ground magnetic & (7) & (7) \\
\hline \multicolumn{3}{|l|}{ Seismic reflection } \\
\hline -Typical survey & $\$ 4,000$ per line mile $(8)$ & $\begin{array}{l}\text { Field rate of } \\
100 \text { line miles per } \\
\text { month per crew }(8)\end{array}$ \\
\hline -High resolution & $\$ 10,000$ per line mile $(8)$ & $\begin{array}{l}\text { Field rate of } \\
40 \text { line miles per } \\
\text { month per crew }(8)\end{array}$ \\
\hline
\end{tabular}


TABLE 4.2.4-4 (cont.) - NOTES

(1) All estimates assume average good access, terrain, and weather conditions. Costs and.time for all ground-based techniques will be higher in areas of rugged terrain or otherwise difficult access or trafficability.

(2) For 100 to 200 station survey under good field conditions (see Figure 4 in Appendix $B-1$ ). Widely spaced stations require increased travel times, affecting costs and production rates. Costs for surveys requiring helicopter access could be on the order of $\$ 250$ per station.

(3) Cost and production rate determined by (1) spacing between geophones, (2) number of shots recorded in each layout, and (3) shot size. Single large shots may require several days of preparation, while small surveys may be completed in a few hours. See Appendix B-3 for discussion.

(4) Based on typical survey consisting of six profiles, each $1 \mathrm{~km}$ long. See Table $4 \mathrm{~A}$ in Appendix $\mathrm{B}-4$.

(5) See Table 5 in Appendix B-4 for estimates of times for additional related activities.

(6) Based on typical soundings with five separate measurements and maximum 300-meter pole separation. See Table 4B in Appendix B-4.

(7) When run along with gravity survey, ground magnetic measurements may be done at additional cost of about $\$ 400$ per day, representing one man and magnetometer rental. Survey would cover area at approximately same rate as the gravity survey (discussed above), although measurements may be taken at more stations.

(8) Based on typical land-based crew working on medium-term contract, using dynamite source, 96-trace, 1-millisecond, 12-fold sampling and 50-meter detection spacing. Assumes no adverse conditions of access or trafficability. Data processing adds $\$ 200$ to $\$ 300$ per mile for typical survey and $\$ 800$ to $\$ 1,200$ per mile for highresolution. Specialized processing would incur additional costs. See Appendix B-6 for discussion. 
TABLE $4.2 .4-5$

COST AND TIME SUMMARY FOR

GEOMECHANICAL TECHNIQUES

Technique

Regional Stress State

Unconfined Compressive Strength

Description of discontinuities

Rock Quality

Designation

Porosity/Density

Water Content

Absorption

Swelling and slake Durability

Sonic Velocity

Uniaxial Compressive Stress

Permeability

Triaxial Compressive Strength

Thermal Conductivity

Borehole Modulus

In Situ Stress State
Approximate Cost Range

\author{
$\$ 4,440$ \\ (estimate)
}

$\$ 25-300$

$$
\begin{gathered}
\$ 14,400 \\
\text { (estimate) }
\end{gathered}
$$

$$
\$ 50
$$$$
\$ 10
$$

$\$ 50$

$$
\$ 350-1,250
$$

$\$ 50-500(3)$

$$
\$ 250 \text { (4) }
$$

$\$ 250-1,000$

$\$ 2,000-10,000(5)$

$\$ 1,000-2,000(6)$

$\$ 10,000-15,000(7)$
Approximate Turn-Around Time (1)

3 wks (estimate)

5 minutes

1 man month (estimate)

(2)

$\begin{array}{ll}2 \text { weeks } & \text { per test } \\ 2 \text { weeks } & \text { per test } \\ 2 \text { weeks } & \text { per test }\end{array}$

2 weeks

3 weeks

per test

per test

3-6 weeks

per test

3 weeks

per test

\section{3-6 weeks}

per test

8 weeks

per test

per test

overcoring

$\$ 40,000-\$ 60,000(7)$

5 hours (8)

per test

hydrofracture

$\$ 50,000-\$ 70,000(7)$

1-10 days $(8)$

per test 
TABLE 4.2.4-5 (cont.) - NOTES

(1) Turn-around time for delivery of laboratory results, unless otherwise stated.

(2) Done by well-site geologist, in conjunction with normal core logging at no measurable increase in cost or change in drilling rate.

(3) Higher costs are for tests at elevated temperature and pressure.

(4) Includes measurement of deformation. Can obtain strength data only for less than $\$ 50$.

(5) Test program would be designed to meet project needs. Further cost increases would result from requirements for additional measurements or testing at elevated temperature or pressure.

(6) Higher cost for tests at elevated pressure.

(7) Excluding drilling costs.

(8) Actual working time on test.

(9) Field tests using portable point Ioad apparatus or Schmidt Hammer. See page 8 and 9 , Appendix E-1. 
TABLE $4.2 .4-6$

COST AND TIME SUMMARY FOR

HYDROLOGY TECHNIQUES

Technique

Surface Hydrology

Singular Flood Frequency

Regional Flood Frequency

Rainfall-Runoff

100-year flood plain

Flooding from dam failure

Discharge measurements

Field surveys of

recharge/discharge

Surface-water sampling

Borehole Testing (5)

Head measurement
a. Manual
b. Winch
c. Recorder

Drill stem test

Pump test

Injection test

straddle packer test

Tracer tests

Permeability Tests

on core samples

Numerical Modeling
Approximate

Cost Range
Approximate

Turn-Around

Time

Comments

(3)

(4)

per square mile (3) per square mile(4)

$$
\begin{array}{ll}
\$ 25-100(6) & 1-2 \text { hour }(6) \\
\$ 100-500(7) & 1-4 \text { hour }(7) \\
\$ 3000-10,000 & 1 / 2-3 \text { days }
\end{array}
$$

(8)

(9)

(8)

to $\$ 25,000(10) \quad 2 \mathrm{hr}-7$ days to $\$ 25,000(10)$ $\$ 200$ or more (11)

$2 \mathrm{hr}-7$ days (11)

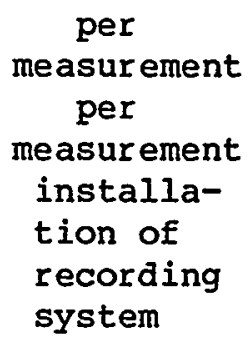

per measurement per measurement installation of recording system

per test per test
$\$ 250-1000(12) \quad 3$ weeks $(12)$
per test
$\$ 400-4000(13) \quad 1-10$ days $(13)$ 
TABLE 4.2.4-6 (cont.) - NOTES

(1) Cost and time for specific analysis, after compiling basic field data.

(2) Cost and time for single field measurement, using simple plywood wier, portable flume, or existing structure. Does not include travel to measurement site.

(3) Assumes 2-man field party working at rate of 10 to 15 square miles per day. Actual costs and rates of progress would vary with field conditions.

(4) Assumes 2-man field party working at rate of 25 to 50 square miles per day, including cost of expendible sampling equipment. Costs for typical water-quality tests are in Table 1 of Appendix $G$.

(5) Not including drilling or completion costs. 'See Appendix D.

(6) Manual measurement using tape or probe to about $750^{\prime}$ depth - not including travel to well site.

(7) Measurement at greater depth, requiring winch to handle probe not including travel to well site.

(8) Cost and time requirements for testing vary according to depth, duration of test, and size or type of drilling equipment used. See Appendix G.

(9) Pump test costs depend on equipment in place of a well and duration of the test. Can be done for about $\$ 200$ at existing water-supply well with pump in place. Cost can be thousands of dollars for complex testing systems requiring installation of pump, power supply, and equipment for monitoring water levels.

(10) Cost and time estimate for high-technology testing in tight formation at repository depths. Includes mobilization of specialized equipment and preliminary analyses of results.

(11) For long-duration tests, as may be needed in formations with low permeability, costs are likely to be determined by need for continued monitoring, involving pumping or bailing to detect tracer in deep aquifer. Such tests could cost several thousand dollars.

(12) Does not include cost or time for obtaining core.

(13) Cost and time for numerical analyses only, after basic field and lab data are compiled. 
TABLE $4.2 .4-7$

COST AND TIME SUMMARY FOR

SEISMOTECTONIC TECHNIQUES

Technique
Historical Data
Instrumental Data
Fixed Network
Installation
Operation
Portable Network
Crustal Refraction
Profile

Approximate

Cost Range

Time Comments

$\$ 2,900-5,900 \quad 2$ weeks per basic

analysis

$\$ 5,800-8,800 \quad 1-2$ months per basic analysis

$\begin{array}{rcl}\$ 8,000-10,000 & 12-28 \text { weeks } & \text { per station } \\ 7,300-14,600 & - & \begin{array}{l}\text { per station/ } \\ \text { year }\end{array}\end{array}$

$\$ 3,250-5,700 \quad 2$ days cost per

(to install) station/month

$\$ 2,000-5,400 \quad 1-4$ weeks per station 


\subsubsection{CRITERIA FOR EVALUATING DATA ADEQUACY OF PRECHARACTERIZATION STUDIES IN BASALT}

The previously discussed information on geology (Section 4.2.1), information needs (Section 4.2.2) and applications of techniques (Section 4.2.3) in basalt can be used to develop general criteria or guidelines for evaluating the information on exploration and testing likely to be presented in a Site Characterization Report for a prospective repository site in basalt. The Site Characterization Report should include results of the previous exploration and testing used to select the site (precharacterization) and descriptions of the planned exploration during site characterization. Identification of information needs and techniques for site specific characterization will be the topic of section 4.3. Following the organization of the preceding chapters, the criteria discussed in this section are grouped according to the disciplines addressed: geology, hydrology, geochemistry, geomechanics, seismotectonics, and resources.

\subsubsection{Geology}

The information required to adequately characterize a medium for a waste repository site, and the most applicable techniques for gathering this data, are shown below.

- Erosional and depositional processes - remote sensing; surface mapping

- Lithology, stratigraphy and structure of overburden - drilling and logging; geophysical logging; seismic reflection

- Depth to host rock - geophysical logging; arilling and logging

- Thickness and lateral extent of host rock - geophysical logging, drilling and logging; seismic reflection

- Lithology, stratigraphy and structure of host rock - geophysical logging; drilling and logging; seismic reflection.

Accurate determination of subsurface conditions (stratigraphy, Iithology, structure, etc.) will be strongly dependent on cross-correlation with other techniques, such as remote sensing, surface mapping, geophysical surveys, drilling and geophysical logging. An adequate evaluation program should make maximum use of all available techniques. 


\subsubsection{Hydrology}

The minimum data and most applicable techniques to adequately characterize the needs of hydrology should include the following:

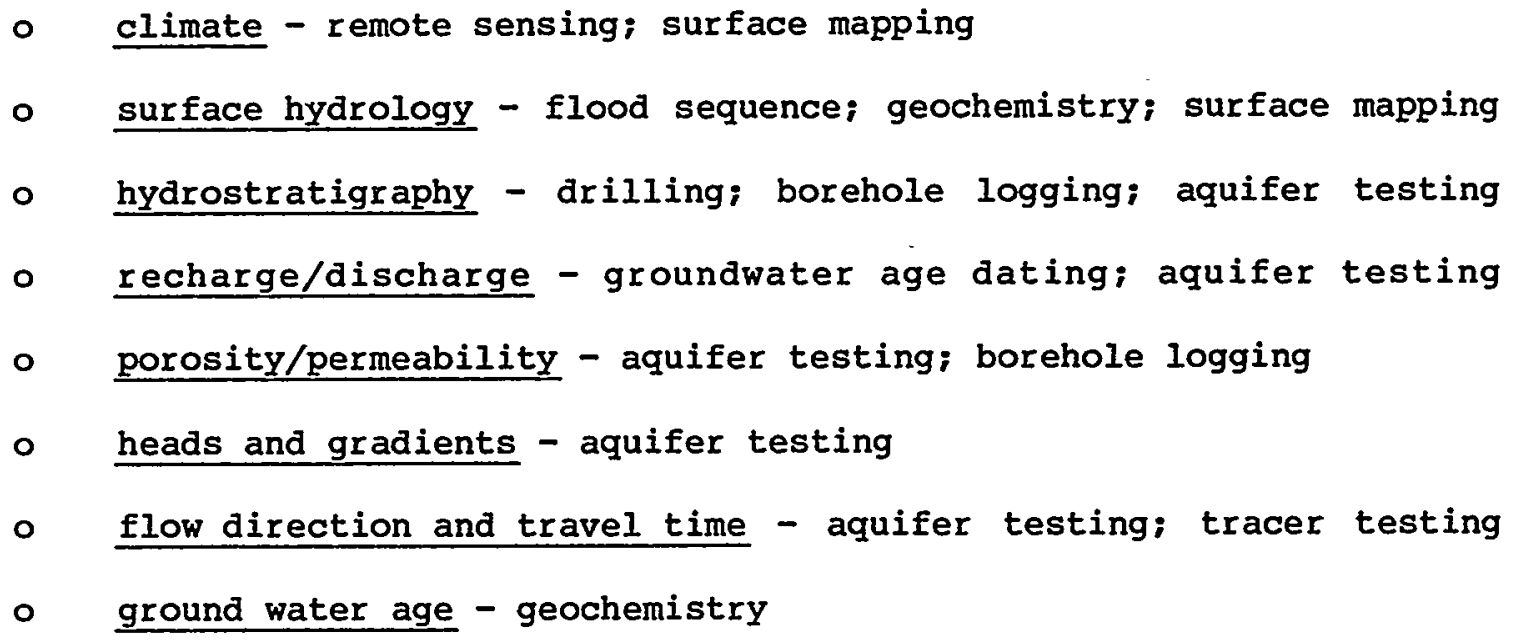

Accurate determination of surface hydrology should be well established by the precharacterization work. The results of both the surface and subsurface hydrologic studies are used in meeting the needs of the hydrology discipline and provide data that may be required to fill needs of other disciplines.

Unique features of basalt which must be considered are:
- flow anisotropies within a unit
- permeability of interbeds
- permeability of flow contacts
- fracture flow
- anisotropic flow due to cross-cutting
- structures (dikes, vents, etc.)

\subsubsection{Geochemistry}

The minimum data and most applicable techniques to adequately characterize the geochemistry information needs should include the following:

- rock mineralogy and alteration - remote sensing; surface mapping; petrography; sampling and analysis; borehole logging

- retardation properties - petrology; sampling and analysis 
- water chemistry - sampling and analysis; resistivity; borehole logging

- sorption - sampling and analysis

Some of these information needs are closely related to those of the hydrology and resource disciplines, and the exploration program should provide for integration of geochemical data with other disciplines.

Because of the characteristic interbedded nature of many flood basalts, some unique problems which must be addressed are:

- insure that samples are representative of both the host rock and interbeds

- differences in host rock and interflow/interbed geochemistries, in particular retardation and sorption properties.

\subsubsection{Geomechanics}

The minimum geomechanical and thermal properties to adequately characterize basalt as a host rock, and the most applicable techniques to determine them are broken into two categories.

\section{Geomechanical Parameters}

- Rock classification, quality and discontinuities - surface mapping; laboratory testing (core samples)

- Strength - laboratory testing (core samples)

- Moduli - laboratory testing (core samples)

- $\quad$ lasticity - laboratory testing (core samples)

- In situ stresses - in situ testing

- Pore pressure - in situ testing

Thermal Parameters

- Specific heat - laboratory testing (core samples)

- Conductivity - laboratory testing (core samples) 

samples)

- Thermal alteration - laboratory testing (core samples)

- Natural temperature and gradients - in situ testing

The actual laboratory techniques for measuring these parameters vary, so the actual test to be used need not necessarily be called out. The important criteria are that the aforementioned parameters be measured.

Unique features of basalt which will require particular attention are:

- possible differences in mechanical properties between wet and dry samples

- continuity of fracture and joint patterns

- parameter differences between the host rock and interbeds or interflows

- intraflow variations of parameters

o ratio of laboratory and in situ parameter values

\subsubsection{Seismotectonics}

Because of the sporadic nature of tectonic movement and seismic activity, it may be difficult to define what amount of data will be "adequate" to answer the information needs. At a minimum, a study should include the items discussed below.

- Uplift and subsidence - surface mapping; fault studies

- Faulting - remote sensing; monitor network; fault studies; surface mapping; seismic reflection

- Igneous activity - monitor networks; gravity surveys

- Seismic activity - monitor networks; historical seismic analysis; instrumental seismic analysis (includes fault plane solutions)

- Natural stress variations - in situ testing. 
With the exception of natural stress variation testing, none of the techniques above are "hands on" tests, and therefore subject to errors of interpretation.

The worth of these studies is highly dependent on data from other information needs, and subject to limitations discussed previously. Additional sources of error which must be considered are:

- non-occurrence of an earthquake during the monitor network lifespan

- anisotropies in the natural stress fields

- relatively high incidence of seismicity compared to other media.

\subsubsection{Resources}

The minimum data and most applicable techniques to adequately characterize the needs of the resource disciplines must include the following:

- Mineral resources - remote sensing; surface mapping; geophysical exploration; drilling and logging; petrography; geochemical analysis

- Hydrocarbon resources - surface mapping; geophysical exploration; drilling and logging

- Geothermal resources - remote sensing; surface mapping; geophysical exploration; drilling and sampling; temperature gradients; geochemical analysis

- Water resources - remote sensing; surface mapping; geophysical exploration; arilling and logging, geochemical analysis

Those needs are closely related to those of both hydrology and geochemistry, and the exploration program should provide for integration of this data with that from other disciplines.

The primarily secondary nature of mineralization in basalt, and rare, fortuitous occurrence of hydrocarbon resources, indicate that there should be no unique or significant problems in evaluating resource potential. 


\subsection{SITE CHARACTERIZATION STUDIES}

\subsubsection{GEOLOGIC FEATURES OF BASALT IMPORTANT FOR SITE CHARACTERIZATION}

The previous discussion of the general geology of basalt (Section 4.2) emphasized properties which could be determined by surface and drill hole exploration techniques. During site characterization these geologic properties will be studied in greater detail by direct observation and in situ testing. It seems appropriate to reiterate some salient features of plateau, or flood, basalts which bear directly on site characterization.

The lower (early) flows of thick basalt sequences are apparently more voluminous and may be more acceptable for repository sites. The upper, or more recent, flows are frequently thinner and intercalated with permeable interbeds, thus less desirable for repository siting. Although basalt typically has high inherent mechanical strength, low permeability and high sorption, other factors present potential problems which must be fully verified and assessed during site characterization. These factors include:

- Intraflow fractures: Directly affect geomechanical and hydrologic properties and may influence geochemical reactions;

- Mineralogy, texture and lithology: Directly affect geomechanical and geochemical properties and may affect hydrology;

- Small scale structures and discontinuities: May affect geomechanical and hydrologic properties;

- Alteration zones: Directly affect geochemical and geomechanical properties and may affect hydrology.

Each specific problem area is discussed in detail in the following sections.

\subsubsection{Intraflow Fractures}

Probably the most important property of basalt in site characterization is the presence and understanding of microstructure joint sets resulting from cooling. The lower portions of a flow (colonnade) typically have vertical, regular, polygonal joints, whereas joints in the upper 
portion of a flow (entabulature) are shorter and more randomly oriented (Fig. 4.2.2-1). Because of possible effects on geomechanical strength, thermal properties, ground-water flow and geochemical reactions, the delineation of joint density, extent, orientation and roughness is critical to assessing a candidate flow for suitability. The extent, often one-half of the total flow thickness, and linearity of colonnade joints may favor the more irregularly jointed entabulature as a choice for repository placement.

The effect of jointing on geomechanical strength and thermal properties is significant because of induced anisotropies in rock strength and stiffness, particularly if joints are regularly spaced and of consistent orientation, leading to failure along built-in planes of weakness (joints). Although it is expected that joints at repository depths will be closed or filled (Deju, 1977), possible drastic alterations in the heat flow would occur across open (air filled) or mineral infilled joints. Parameters such as joint infilling materials, joint orientation and variation of thermal parameters can only be demonstrated by in situ testing of undisturbed joints.

Joint width, extent and infilling will largely govern the direction and rate of ground-water movement through the repository volume. The joint dimensions (width, extent) and roughness determine the surface area available for chemical reactions, such as sorption. The available surface area and joint infilling mineralogy combine to affect the final radionuclide migration rate.

\subsubsection{Mineralogy, Texture and Lithology}

As discussed previously (Section 4.2.1.2), plateau basalts are typically saturated to slightly oversaturated in $\mathrm{SiO}_{2}$, with varying accessory mineral assemblages and phenocryst/groundmass ratios. Although vertical or lateral variations within a flow are typically minimal, the possible effect on geomechanics, geochemistry and hydrology requires a detailed evaluation.

Although the quantity and disposition of mafic minerals appear to have little effect on strength, the presence of feldspar can produce either detrimental or favorable effects on the geomechanical strength. The presence of feldspar may indicate a susceptibility to weathering or disintegration. A high percentage of microcrystalline feldspar and glass may decrease the compressive strength; although a tabular or granular orientation may enhance the compressive strength (Ghosh, 1980). 
Variations in mineralogy, and thus geochemistry, would affect the reaction of the host rock with radionuclides. Additional geochemical variations from joint infillings will further influence chemical reactions and radionuclide migration.

Both small (intraflow) and large (interflow) textural differences influence the host rock strength, geochemistry and hydrology. The term texture includes phenocryst/groundmass crystal size and density as well as vesicular or spiracle zones. Large crystal size and high phenocryst/groundmass ratios tend to increase the mechanical strength. Increasing the phenocryst/groundmass ratio 5-10\% in a hard dense basalt will typically result in a similar increase in compressive strength. Conversely, voids created by vesicles and spiracles will decrease and vary strength. An accurate textural assessment, particularly location, size and density of voids, will assist in extrapolation of mechanical properties through the repository volume.

An additional gross textural feature which may influence these properties is pillow basalts and associated palagonite. While rare, these features could have significant deleterious effects on waste/host chemical reactions and radionuclide migration because of differing geochemistries and an internally varying pillow chemical composition due to water alteration. Radionuclide migration may possibly be enhanced by ground water flow around the pillow edges, and palagonite filled interstices between pillows and/or discontinuities across pillow boundaries will also alter the geomechanical and thermal properties of the host. Although pillow basalts and palagonite typically are at the base of a flow, the potential problem makes. it important to verify their absence in the repository volume.

\subsubsection{Small Scale Structures and Discontinuities}

Included in this category are features such as intraflow folding and some primary volcanic features such as dikes, vents or lava tubes. Intraflow folding may affect geomechanical strength by introducing local fractures from stress variations during cooling.

Primary volcanic features can affect both the hydrologic regime and geomechanical strength. Vertical, crosscutting features, such as dikes, fumaroles or vents, are typically bordered by, or composed of, a breccia zone which may produce significant vertical hydraulic conductivity anistropies. Horizontal features, such as lava tubes, fractured vesicle zones and brecciated flow boundaries, will produce significantly higher horizontal hydraulic conductivities. A hard dense basalt, open lava tube, or brecciated zone will have obvious mechanical 


\subsubsection{Alteration Zones}

Alteration products will typically occur along discontinuities, such as fractures or flow boundaries, and affect local geochemistry, geomechanics and hydrology. Because the chemistry of these altered materials is different from that of the host rock, their reactions with radionuclides will most probably also differ. Low temperature $\left(\left\langle 250 \mathrm{C}^{\circ}\right)\right.$ alterations produce zeolites, such as laumontite and heulandite (Robinson and others, 1981), which have desirable sorption properties, and will affect radionuclide migration.

Alteration materials along fractures will typically increase the mechanical strength by bonding the fracture together, but the presence of a discontinuity and altered infilling materials may produce significant changes in heat flow properties. An open (air-filled) joint has a thermal conductivity approximately $1 / 1200$ th of that of intact basalt (Agapito and others, 1977) which will significantly reduce heat flow and steepen the thermal gradient. Filling of a discontinuity will increase the joint's thermal conductivity and tend to flatten the thermal gradient, reducing thermal-induced stresses on the rock. Conversely, if the fracture is assumed to be tightly closed at depth, the presence of alteration materials may result in a steepened gradient. The presence of alteration products filling fractures will also aid in reducing ground-water flow by decreasing, or eliminating, travel paths.

\subsubsection{INFORMATION NEEDS FOR SITE CHARACTERIZATION IN BASALT}

General information needs emphasizing precharacterization studies to select a potentially suitable repository site have been summarized in Section 4.2.2. Site characterization information needs are basically the same, but require more detailed use of available exploration techniques. Many precharacterization techniques will be applicable, but pilot shaft excavation and test room development near the proposed repository level will allow detailed examination and testing of the host rock at depth, and allow intensive horizontal or inclined drilling without connecting the prospective repository and accessible environment. It is possible to obtain detailed geosciences information on the proposed host rock during site characterization, but significant expense and schedule commitment, beginning with design and construction of the pilot shaft and test room, is required.

The main emphasis in site characterization is verification of site suitability with regard to radionuclide containment and isolation, and 
obtaining detailed site-specific parameters needed for repository design and construction.

Topics of concern relating to these issues include:

- construction design

- retrievability performance

- radionuclide migration

- thermal performance

In addition, continued exploration and testing to refine or increase information reliability, and continued monitoring of precharacterization assessment of resource and seismotectonic potentials, will be needed.

Because of the time and expense of site characterization requires that precharacterization results give a high confidence level to ultimate site suitability. In general, precharacterization data would resolve issues that may be addressed without detailed subsurface exploration and testing, and include: surface geology, surface hydrology, climate, seismotectonics, and potential for igneous activity. These issues are typically addressed by regional investigations around a site, rather than by detailed exploration and testing at depth. Similarly, exploration history and resource potential at a site may be determined by reconnaissance level investigations, and therefore should be resolved in advance.

The following subsections summarize specific site characterization information needs of a prospective repository site under the categories of: geology, hydrology, geochemistry, geomechanics, seismotectonics, and resources. Each category has a brief description of information assumed to be available from precharacterization, and site characterization information needs are discussed from this basis.

\subsubsection{Geology}

Geology information needs at the site characterization level are largely constrained to obtaining detailed information on the candidate host rock geologic conditions as related to repository design, construction, and performance. The geologic issues summarized in section 4.2.2.1 are common to both levels of site investigation, but must be addressed at a finer scale in site characterization. Table 4.3.2-1 
TABLE $4 \cdot 3 \cdot 2-1$

GEOLOGY INEORMATION NEEDS IN BASALT

Emphasized in Precharacterization:

1. Geologic processes.

2. Lithology, stratigraphy and structure of over - and underlying rocks.

3. Depth and thickness of basalt.

4. Large scale structural features (faults, folds, dikes, etc.).

5. Interbeds and fracture zones.

Emphasized in Site Characterization:

1. Intraflow fractures;

2. Mineralogy and' texture variations;

3. Small scale structures or discontinuities;

4. Detailed mineralogy and lithology;

5. Alteration zones. 
compares the items emphasized in precharacterization and those that should be stressed during site characterization.

Precharacterization should adequately define surface geologic conditions and processes, and generally describe the stratigraphy, lithology, and geologic structure at depth. Surface mapping should have provided sufficient data to interpret the nature and rates of relevant processes including: erosion, deposition, previous Quaternary climate and hydrologic conditions. Subsurface information should have provided depth and thickness information and delineate features such as faults, folds, breccia pipes, vents, dikes or fumaroles which might limit the lateral extent of a suitable flow. Stratigraphy of the host rock and the over- and underlying units should be adequate to define existing or potential aquifers and confining units.

Because of their effect of intraflow fractures on hydrology, geomechanics and geochemistry, data on these fractures is probably the most important geologic need. Detailed in situ investigation of fracture density, orientation, extent, infilling material, exposed area (roughness) and pervasiveness are required to evaluate the effects of these fractures. These properties, particularly density and extent, will affect hydrologic parameters such as fracture permeability, and ground water movement and residence time. Density, orientation, extent, in-filling material, roughness and pervasiveness will affect geomechanical/thermal parameters such as host rock strength, excavation stability, and heat flow and gradients. The exposed area and infilling materials will be important factors controlling radionuclide sorption, natural or induced alterations, waste/host rock and waste/infilling reactions, and reaction rates.

The next most important information need is detailed knowledge of the host rock mineralogy, texture and lithology, including lateral and vertical variations. Detailed mineral analysis is needed to assess possible variations in mechanical strength or chemical reaction potential. Critical in situ assessment of small or large scale textural variations is needed to evaluate potential strength or excavation stability problems. Careful in situ and laboratory analysis of host rock lithology, particularly porosity and permeability, is necessary to evaluate areas of possible decreased mechanical strength or increased fracture flow. Lithologic differences can also be used to correlate the lateral extent and thickness of a prospective host basaltic flow (Long, 1978).

Small scale structures and discontinuities, as described in section 4.3.1.3, may be important to evaluate repository geomechanical conditions. In situ evaluation of these features is needed for studies of geomechanical conditions. 
The importance of alteration zones, as discussed in section 4.3.1.4, is the possible alteration of heat flow geochemical reactions. Although these zones need to be examined in situ, detailed analyses of their thermal and chemical properties must also be studied in the laboratory.

\subsubsection{Hyarology}

Present and paleoclimate history and surface hydrology should be resolved before detailed subsurface work is undertaken. Aquifer hydrology above and below the repository level should be generally well known from subsurface precharacterization work, but quantification of aquifer properties should be performed concurrently with site characterization. Table 4.3.2-2 compares the items emphasized in precharacterization and site characterization.

Because the primary radionuclide transport mechanism from repository to biosphere will be groundwater, an accurate assessment of hydrologic and hydrogeologic regimes at the repository level is critical. Hydrology information needs for site characterization do not differ significantly from those required for precharacterization, but will require a significantly higher level of detail. The following sections address hydrology information needs, their uses, and correlation with information needs of other disciplines.

Because radionuclide migration into the biosphere is primarily dependent on ground water, ground-water transport is the most critical hydrology information need. Specific precharacterization parameters for this information need are ground-water circulation and movement, ground-water infiltration, residence time and ground-water convection (induced hydrothermal effects).

Ground-water circulation, movement and infiltration parameters are necessary to model radionuclide migration out of the repository, and parameter evaluation will be based largely on theoretical and computer models. Measurements of ground-water residence times are a necessary adjunct to modeling ground-water movement.

Ground water convection assumes the possibility of establishing single or multiple convection cells in connate water contained in the repository by heat transfer from waste containers. These convection cells would enhance any natural hydrothermal circulation and/or establish a new induced hydrothermal regime, radically altering geochemical reactions and rates, ground water flow rates and directions, and changing the radionuclide migration rate. 
TABLE $4 \cdot 3 \cdot 2-2$

HYDROLOGY INFORMATION NEEDS IN BASALT

Emphasized in Precharacterization:

- Climate

- Surface hydrology

- Aquifers above and below repository

- Preliminary water ages

- Aquifer discharge/recharge

- Preliminary ground-water flow model

Emphasized in Site Characterization:

- Ground-water transport

- Fluid residence time in host rock

- Host rock permeability

- Interstratal and fracture flow

- Head and gradient measurements

- Hydraulic conductivity anistropies

- Detailed ground-water flow models

- Detailed raionuclide migration models 
Host rock and interbed permeabilities must be measured to adequately characterize and verify the hydrostratigraphic model inferred from precharacterization data. Interstratal and fracture flow refers to ground water movement along scorious, fractured or brecciated flow boundaries, created by weathering, flow emplacement or tectonic movement, and does not include flow in discrete interbeds. Interstratal flow and ground water infiltration data is needed to evaluate water control and retrievability performance.

Head and gradient measurements will provide additional information on overburden water control measures required during and after construction. Assessment of hydraulic gradient values, i.e., positive or negative, is important to radionuclide migration evaluation because a negative gradient will tend to enhance upward movement of contaminated ground water.

Hydraulic conductivity measurements are needed to assess horizontal and vertical anisotropy and refine ground water movement models. Because of wide variations in horizontal, $k_{h}$, and vertical, $k_{v}$, conductivities in basalt, an understanding of these anisotropies is critical for effective ground water transport modeling. In particular the ratios of $k_{h}$ and $k_{v}$ must be addressed because different investigators are diametrically opposed as to these ratios. For instance, Ledgerwood and Deju (1976) estimated $k_{h}$ to be an order of magnitude higher than $k_{v}$; whereas, summers and others (1978) felt that $k_{v}$ is typically higher than $k_{h}$. In addition to differences caused by jointing, features such as buried vents, fumaroles, breccia pipes, lava tubes and vesicles can produce significant vertical or horizontal hydraulic conductivity anisotropies.

All these information needs are oriented toward providing input data for sophisticated computer modeling programs initially used to generate a detailed three-dimensional model of ground water transport at repository levels. Once the transport model is available, it can be integrated with geochemical data to build up a detailed model of radionuclide migration out of the repository.

\subsubsection{Geochemistry}

Geochemistry information needs in site characterization are essentially those described for precharacterization (Section 4.2.2.3), but will emphasize rock/fluid/waste chemistry reactions at repository depth. The infuence of these reactions on repository safety and performance can be divided into two generic areas:

- waste/rock interactions 
Table 4.3.2-3 compares information emphasized in precharacterization and site characterization and gives a more complete listing of items to be addressed for the two generic areas.

Assessment of rock/fluid/waste chemical properties along flow paths to the biosphere is critical for assessment of radionuclide migration, and potential reactions around the shaft and borehole are needed to delineate seal design parameters.

Analysis of waste/rock interaction includes detailed information on waste/host rock, waste/joint filling or waste/interbed reactions, and is paramount to radionuclide migration evaluation. During shaft and test room excavation, and repository construction a systematic program of geochemical sampling should be performed to assess spatial (horizontal and vertical) geochemical variations in the candidate host flow and verify overburden chemistry. Information is required not only on chemical reactions and rates, and ion processes, but the effects of alteration products on these processes. The specific types of information required are enumerated in the precharacterization discussion (Section 4.2.2.3), and will not be repeated here. Because radioactive material decay produces high $\left(845^{\circ} \mathrm{F}\right)$ canister temperatures (Raser, 1979), it is critical that these reactions and processes be evaluated as a function of temperature, pressure and moisture content. Additional information on natural radionuclide levels is needed to evaluate possible chemical reaction saturation levels.

Because the radionuclide transport will typically be by ground water fluids, a detailed understanding of rock/fluid chemistry is essential to evaluate nuclide migration. Detailed information on the rock and fluid chemistries will allow a prediction of possible interactions, and data on fluid residence times will be needed to evaluate how complete these reactions may be. Basic information on nuclide solubility and sorption, and the effcts of temperature is required to assess the efficiency and rates of processes described in Section 4.2.2.3.

\subsubsection{Geomechanical}

Geomechanical and thermal properties bear on all topics of concern (construction design, etc.), therefore, reliable data on these properties is necessary for proper design and safety assessment. Preliminary values of many geomechanical parameters should have been gathered during precharacterization, but must be refined for the repository per 
TABLE $4 \cdot 3 \cdot 2-3$

GEOCHEMISTRY INFORMATION NEEDS IN BASALT

Emphasized in Precharacterization:

- Host rock and interbed chemistry

- Aquifer fluid chemistry

- Overburden chemistry

Emphasized in Site Characterization:

Waste/Rock Interactions:

- Detailed chemistry of host flow including spatial variations

- Effect of alteration products

- Natural radionuclide level

Whole Rock and Fluid Chemistry:

- Detailed rock and fluid chemistries

- Prediction of rock/fluid interactions

- Fluid residence time

- Nuclide solubility and sorption

- Effect of temprature and fluid content on chemical reactions 
se and extensive in situ testing at repository levels performed. Table 4.3.2-4 shows the parameters emphasized in each stage.

Like the information needs for geology, a detailed analysis of discontinuities and their effect on mechanical and thermal properties is the most critical data required. The potential for discontinuities to act as built-in planes of weakness, and their known effects on heat flow and conduction, requires a detailed analysis of discontinuity extent and geometry. Coincident with this study should be a similar program to delineate the effects of joint filling materials on mechanical stress and thermal properties.

Because of the elevated temperatures produced by waste decay, a detailed knowledge of the temperature-dependence of thermal and geomechanical properties, such as thermal conductivity and moduli is required. To adequately understand these temperature-dependencies, extensive in situ and laboratory testing must be done. In addition to the parameters previously discussed (Section 4.2.2.4), information on creep, angle of internal friction and post-failure characteristics is needed. Post-failure characteristics include plastic or brittle failure behavior under varying conditions of temperature and confining pressure. Basalt will typically fail rapidly with little warning, indicating little, if any, plastic behavior. Because of this tendency toward brittle failure, and the high inherent mechanical strength, creep is not anticipated to be a problem. However this inference must be supported by time-scaled in situ testing.

The temperature gradient produced by waste decay will necessitate additional studies on induced stress fields and the possibility of steam induced spallation (decrepitation). Prior to, or coincident with, these studies should be a program to determine the probabilities of stress relief induced spallation.

Because basalt mechanical strength is dependent upon the water content, use of hydrologic data will be required to fully characterize the host rock. There appears to be significant differences, perhaps as much as 308 , in the strength of wet vs. dry basalt (Sharp, 1972; Ghosh, 1980), which requires that this parameter be quantified across the moisture contents expected in the repository.

\subsubsection{Seismotectonics}

The information needs for a prospective site in any media are essentially the same as summarized for precharacterization (Section 4.2.2.5), and it is expected that favorable conditions would be demonstrated at a site before selection for characterization. This is particularly true 
TABLE $4.3 \cdot 2-4$

GEOMECHANICS INFORMATION NEEDS IN BASALT

Emphasized in Precharacterization:
- Natural thermal gradient and temperature
- Thermal parameters of host rock and overburden
- Deformation moduli and strength of host rock and overburden
- Preliminary survey of discontinuities

Emphasized in Site Characterization:

- Detailed analysis of discontinuities and their effects

- Temperature-dependence of thermal properties

- Temperature-dependence of deformation moduli and strength

- Stress relief (spallation) and steam-induced (decrepitation) failures

- Induced temperature gradient and related stress field effects

- Wet/dry strength 
for basalt, because flows of sufficient thickness to be considered as a host medium typically occur in areas with a history of seismicity, tectonic movement and volcanism. Seismic monitoring should be continued throughout the site characterization period and results incorporated into the repository design basis as appropriate.

\subsubsection{Resources}

The resource potential of a site should be well established by precharacterization as it would seem inappropriate to conduct detailed testing at depth and then find a site unacceptable because of preexisting resources. Because resource occurrence in basalt is typically low, precharacterization results should be adequate for evaluating the presence of resources. However, this conclusion should be verified during site characterization by continued monitoring of geologic and geochemical exploration results.

\subsubsection{TECHNIQUE APPLICATIONS TO SITE CHARACTERIZATION INFORMATION NEEDS IN BASALT}

Initiation of a site characterization study presupposes, based on precharacterization studies, a high confidence level on final site acceptance. As noted previously, site characterization information needs are similar to those for precharacterization, but differ in level of detail. Precharacterization studies will define the bounds of site geologic conditions, and site characterization data will be used to refine and document the bounds. Techniques used in site characterization do not differ greatly from those of in precharacterization, except for host rock detailed testing and in situ testing at depth.

It is assumed that the pilot shaft will be logged continuously, and one, or more, new boreholes drilled for state-of-the-art downhole logging, hydrologic testing and correlation of precharacterization data with site characterization data. Following the format of previous sections, the technique applications best suited for satisfying an information need are discussed by discipline (geology, hydrology, etc.). Table 4.3.3-1 summarizes the major site characterization information needs and applicable techniques. Some information needs are described in more detail in the appropriate sections, and not specifically referenced in the table. 
TABLE 4.3.3-1 SITE CHARACTERIZATION TECHNIQUE APPLICATION

\begin{tabular}{|c|c|c|c|c|c|c|c|c|}
\hline $\begin{array}{l}\text { APPLICATIONS OF TECHNIOUES } \\
\text { TO INFORMATION NEEDS } \\
\text { FOR SITE CHARACTERIZATION } \\
\text { - MAJOR CONTRIBUTION } \\
\text { O SUPPORTING CONTRIBUTION }\end{array}$ & 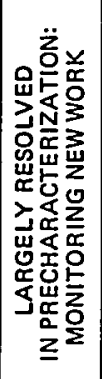 & 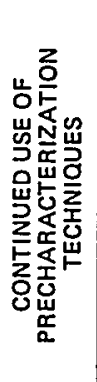 & 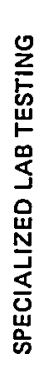 & 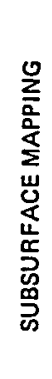 & 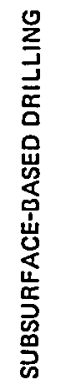 & 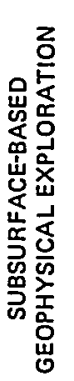 & 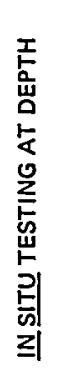 & 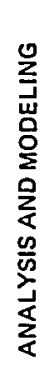 \\
\hline \multicolumn{9}{|l|}{ GEOLOGY } \\
\hline SURFACE GEOLOGY & • & o & & 0 & & & & \\
\hline OVERBURDEN STRATIGRAPHY & - & 0 & & 0 & & & & \\
\hline DEPTH, LATERAL EXTENT AND THICKNESS & $\bullet$ & o & & o & 0 & 0 & & \\
\hline INTERFLOW FRACTURES & 0 & 0 & o & $\bullet$ & o & 0 & 0 & 0 \\
\hline PRIMARY VOLCANIC FEATURES & 0 & 0 & & $\circ$ & 0 & - & & \\
\hline MINERALOGY AND LITHOLOGY & 0 & 0 & o & - & 0 & 0 & & \\
\hline TEXTURE & 0 & 0 & 0 & $\bullet$ & 0 & & & \\
\hline SEISMOTECTONICS AND RESOURCES & - & 0 & & $\circ$ & & 0 & & 0 \\
\hline FAULTS AND FOLDS & - & 0 & & 0 & 0 & 0 & & \\
\hline \multicolumn{9}{|l|}{ HYDROLOGY } \\
\hline FLOODING AND SURFACE HYOROLOGY & $\bullet$ & 0 & & & & & & o \\
\hline \multicolumn{9}{|l|}{ GROUNDWATER TRANSPORT } \\
\hline CIRCULATION AND MOVEMENT & 0 & 0 & & & c & & 0 & - \\
\hline INFILTRATION & 0 & 0 & & & & & $\bullet$ & 0 \\
\hline CONVECTION & & & & & & & 0 & - \\
\hline RESIDENCE TIME & 0 & 0 & $\bullet$ & & & & & 0 \\
\hline
\end{tabular}


TABLE 4.3.3-1 (CONT'D) SITE CHARACTERIZATION TECHNIQUE APPLICATION

\begin{tabular}{|c|c|c|c|c|c|c|c|c|}
\hline $\begin{array}{l}\text { APPLICATIONS OF TECHNIQUES } \\
\text { TO INFORMATION NEEDS } \\
\text { FOR SITE CHARACTERIZATION } \\
\text { - MAJOR CONTRIEUTION } \\
\text { O SUPPORTING CONTRIBUTION }\end{array}$ & 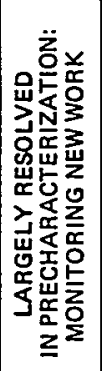 & 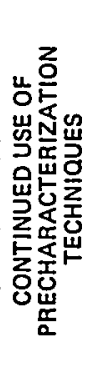 & 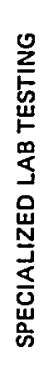 & 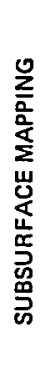 & 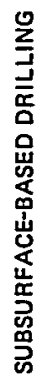 & 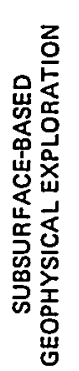 & 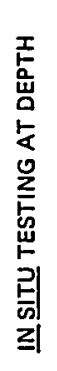 & 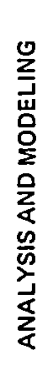 \\
\hline \multicolumn{9}{|l|}{ HYDROSTRATIGRAPHY } \\
\hline INTERSTRATAL AND FRACTURE FLOW & 0 & 0 & & & o & & $\bullet$ & $\circ$ \\
\hline AQUIFER TESTS & 0 & 0 & & & 0 & & $\bullet$ & 0 \\
\hline HYDRAULIC CONDUCTIVITIES & 0 & 0 & ० & & & & $\bullet$ & o \\
\hline CAVITIES & o & o & & o & o & - & 0 & \\
\hline \multicolumn{9}{|l|}{ GEOCHEMISTRY } \\
\hline WASTE/ROCK INTERACTIONS & $\circ$ & $\circ$ & $\bullet$ & & 0 & & & 0 \\
\hline WHOLE ROCK AND FLUID CHEMISTRY & $\circ$ & 0 & $\bullet$ & & $\mathbf{0}$ & & & 0 \\
\hline \multicolumn{9}{|l|}{ GEOMECHANICAL } \\
\hline MODULI AND STRENGTH & 0 & 0 & 0 & & $\circ$ & & $\bullet$ & \\
\hline STRESS VARIATION & $\circ$ & 0 & & & o & & $\bullet$ & \\
\hline EXPOSURE EFFECTS & $\circ$ & $\bullet$ & & & 0 & & $\circ$ & \\
\hline THERMAL PARAMETERS & 0 & 0 & 0 & & 0 & & $\bullet$ & \\
\hline SEISMOTECTONICS & 0 & - & & & & 0 & & 0 \\
\hline RESOURCES & 0 & $\bullet$ & & & 0 & 0 & & \\
\hline & & & & & & & & \\
\hline & & & & & & & & \\
\hline
\end{tabular}




\subsubsection{Geology}

Verification of site surficial geology and long term geologic stability should be accomplished by detailed surface mapping and large $(1: 8,000$ of larger) scale aerial photographs. The subsurface characteristics of the prospective host should be verified by drilling, core studies, subsurface-based geophysical surveys and subsurface mapping. Subsurface mapping of the pilot shaft, test room(s) and exploratory drifts should be very detailed, and emphasize identification of mineralogic and structural variations needed in geochemical, geomechanical and hydrologic analyses.

Direct observation of excavation surfaces will allow detailed analysis of critical fracture parameters, such as geometry, spacing, pervasiveness and extent, which are important because of their effects on geochemistry (possible alterations), geomechanics (planes of weakness) and hydrology (fracture flow). Techniques to refine and verify precharacterization fracture assessment include:

- core studies

- subsurface mapping

- in situ geomechanical testing

- geophysical logging

- downhole T.V. and/or cameras

- geochemical testing

- subsurface geophysi'cal techniques

The drilling and core logging techniques would be essentially as discussed for precharacterization (Section 4.2.3.1). Fractures exposed in the pilot shaft and test room(s) excavations can be inspected and measured directly during subsurface mapping. In situ geomechanical studies should include overcoring and jacking tests to verify stress fields and host medium strength. Geophysical logging should include acoustic, resistivity, self-potential, croshole shear wave and resistivity, and, if available, radar. Use of downhole photography and/or television viewing will enable close range critical examination of fractures exposed in boreholes. Geochemical testing will assess the degree and type of fracture infilling and allow extrapolation of fracture extent. Subsurface mining techniques include seismic refraction, electrical resistivity, and ranging radar. The 
reader is referred to the various technique reports for comprehensive discussions of the mechanics and resolution of these various techniques.

Horizontal or inclined drilling from the test room allows more intensive exploration of the proposed repository zone than feasible from the surface, and can be evaluated over a much larger area, although in less detail. Horizontal boreholes would be particularly useful for evaluating lateral mineralogy, or other, changes.

Applicable techniques for detailed characterization of host rock mineralogy, texture, lithology, and small scale structures and discontinuities are:

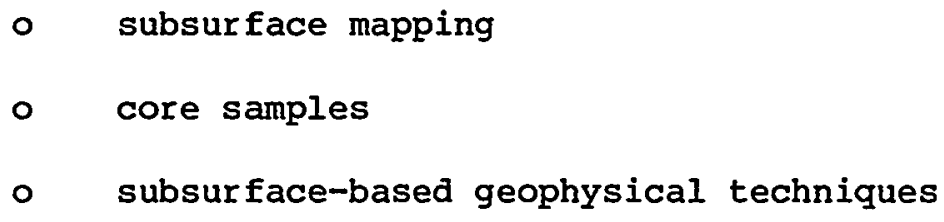

Because of the unique opportunity for in situ inspection of these parameters, subsurface mapping will be an important technique, and should emphasize lateral or vertical changes in mineralogy and lithology.

A high density of core samples is necessary to accurately evaluate host rock mineralogy which should be further verified by petrographic techniques, described in section 4.3.3.1.4. Lithologic correlation of core samples with downhole geophysical logging data is needed to refine and verify surface-based geophysical survey correlation points from precharacterization studies. Lithology and stratigraphy can be assessed directly with several different downhole logging techniques including acoustic (sonic), downhole gravity, Spontaneous Potential, resistivity, natural gamma and neutron, or indirectly by measuring permeability and porosity. Additonal correlation between holes, particularly for overburden stratigraphy, may also be obtained from crosshole seismic surveys. Although crosshole surveys at repository depths are not common (see Appendix B-7), the state-of-the-art does not preclude the use of this technique. Establishment of seismic velocities through a prospective basalt flow, would also aid in evaluating fracture density.

Subsurface geophysical techniques include radar ranging and wide array resistivity measurements from shafts and adits. Because of the presence of numerous discontinuities, these techniques will probably only be useful for extrapolating known trends. 
Alteration zones in the repository can be identified by geochemical methods and direct in situ inspection. Of the two techniques, laboratory based geochemical techniques will be the most useful, because the role of alteration zones will be mainly dependent on chemistry.

\subsubsection{Hydrology}

Site characterization hydrologic techniques include laboratory testing of permeability, aquifer tests and in situ hydrologic tests at repository depths. Data from these and other tests will be used as input to numerical modeling programs to assess and verify hydrologic models.

Verification of groundwater transport models is critical to evaluate radionuclide migration to the biosphere. Techniques applicable for verifying these models are:

- numerical modeling

- aquifer tests

- tracer tests (residence time)

Complete characterization will require two numerical models to assess possible biosphere contamination by radionuclide migration. The first model will use measured parameters to produce a three-dimensional model of groundwater movement around and through the repository. This transport model can then be coupled with a model of radionuclide/host rock geochemical interactions to evaluate the activity level and rate of radionuclide migration. Aquifer and tracer tests will be performed to obtain definitive parameter values for use in the modeling programs described above.

Verification of hydrostratigraphy, particularly interstratal flow, is needed as input to numerical modeling programs to evaluate radionuclide migration. Techniques applicable to this information need are:
- core studies
- subsurface mapping
- downhole geophysical logging
- aquifer tests
- geochemistry 
Accurate core logging is needed to establish the stratigraphic location of aquifers and intraflow structures and provide correlation points for downhole geophysical logging. Standard aquifer tests such as step-drawdown, constant discharge, recovery and transmissivities will be needed to verify precharacterization permeability and flow rate data. Inherent in transmissivity tests are measurements of permeability and specific capacity, whose major need is in modeling of hydrologic and flow regimes above, in and below the repository. Head and gradient measurements, along with water levels, will be used in modeling the flow regime and establish water control needs. Geochemical testing of water samples is required to verify groundwater age, thus refining groundflow flow rates and directions models.

Core logging of horizontal or inclined drill holes off the test room(s) and detailed subsurface mapping will assist in identifying vertical discontinuities (dikes, breccia pipes, etc.) which might act as vertical conduits for groundwater flow. Because of the low density contrast between these vertical discontinuities and the basalt flows themselves, and the probability of being missed by boreholes, their presence may be difficult to evaluate from surface-based data.

Ground-water convection can be determined from modeling of anticipated ground-water flow rates and temperature rises produced by waste decay. Because there is little empirical data available for a basis of this model, it is important that as many data inputs as possible be used.

Cavities, unless fortuitously discovered by drilling or excavation, must be assessed from geophysical methods. The methods most applicable to this assessment are:

- subsurface-based geophysical surveys

- downhole geophysical logging

The best techniques are downhole and/or subsurface radar probing. Although the density of basalt will somewhat limit the effective range of radar, the penetration may still be several hundreds of meters for the case of subsurface probing.

\subsubsection{Geochemistry}

Geochemical techniques for site characterization in basalt will be essentially identical to those for other media, and are described in Appendix F-2. In general, the techniques will fall into the generic areas of descriptive geochemistry and geochemical reaction evaluation. 
Descriptive geochemistry will use standard laboratory techniques to assess fluid and rock chemistries in great detail, which are needed to evaluate lateral or vertical geochemistry variations, and radionuclide interations with ground water and the host rock Assessment of geochemical reactions will be made from descriptive geochemical information and inferred temperature and fluid flow conditions. Because of possible reaction rate dependence on temperature and chemical composition of ground water, it is important that tests be performed over the temperature and fluid content ranges inferred from thermal modeling (see Section 4.3.3.4) and descriptive evaluations of ground-water chemistry.

\subsubsection{Geomechanias}

Applicable geomechanical techniques include laboratory or in situ testing programs and computer assisted numerical modeling. Adaitional relevant information to identify and describe discontinuities and variations will be obtained from subsurface exploration techniques.

Laboratory testing techniques for site characterization are essentially the same as those described for precharacterization (Appendix E-1) and do not require a separate description. Appendix E-2 provides a specific discussion of in situ geomechanical testing techniques which can be used for site characterization. Although generally applicable, it is important to note that these tests are part of specially developed programs designed for individual applications. Because of possible mechanical property variations caused by elevated temperatures and chemical alterations, it is essential that the mechanical parameters described previously (Section 4.2 .3 .4 ) be tested over the anticipated temperature range.

Numerical, or computer, modeling of repository conditions and responses is an important application for meeting the geomechanical information needs. The applications of specific modeling programs are discussed in Appendix E-2, and a comprehensive listing of applicable computer codes has been compiled (Nuclear Safety Associates, 1980).

\subsubsection{Seismotectonics}

Seismotectonic techniques applicable to site characterization will largely be limited to monitoring of the seismographic network emplaced during precharacterization. Although basalt flows of suitable thickness for a repository are in areas with a history of tectonism, volcanism and seismicity, it is expected that this monitoring will verify 
precharacterization assessment that these processes present no potentially adverse effects to the repository. However, in the event there is a notable seismic occurrence during the characterization period, additional specific investigations, using the techniques of Appendix $\mathrm{H}$, may be required.

\subsubsection{Resources}

Evaluation of resource potential during site characterization should be limited to ongoing hydrology and geochemistry monitoring programs. Because the purpose of this monitoring is to verify the resource evaluation in the precharacterization stage, the techniques discussed in Section 4.3.3.6 will be applicable.

\subsubsection{COST AND TIME ESTIMATES FOR TECHNIQUES IN SITE CHARACTERIZATION}

Estimates for the costs and times required for the techniques used in characterizing a site in basalt are summarized in Tables 4.3.4-1 through 4.3.4-6. Additional site characterization work would involve continued use of precharacterization techniques and the cost and time estimates summarized in Tables $4.2 .4-1$ to $4.2 .4-7$ would remain applicable for these. In evaluating cost and time estimates for site characterization, an important consideration is that many of the tests are specially designed for site conditions and particular information needs. Durations of geomechanical and hydrologic tests, in particular, may be a design factor and can be important in determining costs.

\subsubsection{Geologic Mapping and Supporting Activities}

Typical costs and times for detailed surface mapping, as would be done at a prospective site during characterization, and the supporting work in remote sensing, trenching, and age dating are summarized in Table 4.3.4-1. This work would be performed during site characterization but would chiefly involve validating previous findings because initiation of site characterization would not be reasonable if there were significant outstanding questions on surface geology. For these estimates, it is assumed that access and trafficability would not be problems at a site.

Table 4.3.4-2 summarizes typical costs and times for mapping geologic conditions in the pilot excavations and costs for supporting geochemical analyses are provided in Appendix F-2. For subsurface mapping done in coordination with the excavation, cost and schedule are 
COST AND TIME SUMMARY FOR SURFACE GEOLOGIC TECHNIQUES

IN SITE CHARACTERIZATION

\begin{tabular}{cc}
$\begin{array}{c}\text { Approximate } \\
\text { Cost }\end{array}$ & $\begin{array}{c}\text { Approximate } \\
\text { Time }\end{array}$ \\
\hline
\end{tabular}

REMOTE SENSING INTERPRETATION

$1: 4800$ photo analysis

( 100 photos for $12 \mathrm{mi}^{2}$ site)

$\$ 1,750-3,500(1) \quad 5-10$ man days

DETAILED SURFACE MAPPING

(for $12 \mathrm{mi}^{2}$ site area)

General Mapping

$\$ 12,000-18,000$

20-30 man days (10-15 field days for 2-man crew)

Detailed structure analysis (2)

$\$ 6,000$

10 man days

( 5 field days

for 2-man crew)

EXCAVATION LOGGING (3)

Reconnaissance

$\$ 1,200 /$ day (4)

$10,000 \mathrm{ft}^{2} /$ day (4)

Detailed logging at $1^{n}=10^{\prime}$

$\$ 1,200 /$ day (4)

$1,500 \mathrm{ft}^{2} / \mathrm{day}^{(4)}$

\section{NOTES:}

(1)

Does not include cost of large scale stereographic aerial photos, assumed to be available in site characterization.

(2)

Only applicable where bedrock (overlying the salt) is exposed at the surface. Cost and time is in addition to general mapping.

(3)

For surface excavations such as exploratory trenches or quarry cuts. Also for natural exposures such as bluffs or stream banks.

(4)

Typical production rate and daily cost for 2-man field crew. Rates will vary according to access, difficulty of cleaning off the excavation, and, particularly, complexity of geologic conditions. Mapping of critical relationships at larger scale would require additional time. 
TABLE $4.3 .4-2$

COST AND TIME SUMMARY FOR SUBSURFACE GEOLOGIC MAPPING IN SITE CHARACTERIZATION (1)

Cost Per Day

Typical Mapping Rate

Detailed Mapping

$\$ 650.00$

$1200 \mathrm{ft}^{2} /$ day $(3)$

of Shaft or Drift

at $1^{n}=5^{\prime}(2)$

NOTES :

(1)

Based on Appendix A-2.

(2) Typical scale for geologic mapping in drift 8 feet wide and 8 feet high, after completion of engineering survey and preparation of base maps.

(3) Actual rates depend on complexity of geologic conditions at the place mapped. 
likely to be controlled by the need to avoid interference with the excavation process.

\subsubsection{Subsurface Based Drilling and Coring}

Appendix D-2 includes a comprehensive summary of the costs and penetration rates for various drilling and coring techniques from pilot excavations. Information applicable to basalt is summarized in Table 4.3.4-3, with some revisions to the costs in Appendix D-2 for increased compatibility with the costs for other techniques. Costs for mobilization and delays in availability of suitable equipment are not included on the assumption that the site characterization program should be of sufficient magnitude to maintain the required equipment at the site.

Techniques for geologic logging of the drill return or core, as discussed in Appendices $D-1$ and $E-1$ would continue to apply in site characterization. Geophysical logging techniques discussed in Appendix C would also remain applicable for vertical and near vertical holes and costs would generally be as summarized in Table 4.2.4-3.

\subsubsection{Geophysical Techniques in Site Characterization}

In general, the geophysical techniques discussed in Appendix B would remain applicable and costs would follow those outlined in Table 4.2.4-4. Costs of site characterization techniques for detailed evaluation of near surface engineering parameters and for exploring the host surrounding the pilot excavations are summarized in Table 4.3.4-4.

As discussed previously, the radar and sonar techniques used for subsurface exploration in geologic media are specially designed systems and therefore can differ significantly in costs and capabilities. Moreover, new techniques are continually under development, making it difficult to forecast costs and capabilities for techniques that might be applicable in a few years.

\subsubsection{Hydrology}

Costs and times for hydrologic techniques most important in site characterization are summarized in Table 4.3.-5, based on information in Appendix G-2. All of these techniques involve testing programs that vary in cost and duration according to their design, and properties of the test medium. Costs of drilling and well completion are not included in the estimates for the hydrologic techniques. 
TABLE $4.3 .4-3$

COST AND TIME SUMMARY FOR SUBSURFACE BASED DRILLING AND CORING IN SITE CHARACTERIZATION (1)

\begin{tabular}{lcc} 
Penetration & \\
Hole Maximum & Rate(2) & \\
Size Depth & (Ft/Hr) & Cost per foot (5) \\
(In) (Ft) & Range Average & Range Average \\
\hline
\end{tabular}

PERCUSSION DRILLS

$\begin{array}{lcccccc}\begin{array}{l}\text { Jackleg } \\ \text { (hand held) }\end{array} & \begin{array}{c}1-1 / 4- \\ 1-1 / 2\end{array} & 20 & 2-16(3) & 8(3) & \$ 4-24(6) & \$ 7(6) \\ \text { Drifter } & \begin{array}{l}1-1 / 2- \\ 3-1 / 2\end{array} & 50 & 4-30(3) & 15((3) & \$ 4-\$ 31(6) & \$ 8(6) \\ & 2-5 & 200 & 8-50(3) & 25(3) & \$ 4-\$ 24(6) & \$ 7(6) \\ \text { Track drill } & \begin{array}{l}\text { Core } \\ \text { Size }\end{array} & & & & & \\ & \end{array}$

CORE DRILLS

Longyear EHS 38

NQ $(1-7 / 8) 1900$

$2-4(4)$

$3^{(4)}$

$\$ 40-\$ 81$

$\$ 54$

Longyear 65

BQ $(1-3 / 8) \quad 500 \quad 2-4(4)$

$\$ 40-\$ 80$

$\$ 54$

NOTES:

(1)

Adapted from Appendix $\mathrm{D}-2$

(2) Not including move-in or set-up time. Rates calculated for representative drill or core sizes and would differ for other sizes.

(3) At 678 efficiency.

(4) At 508 efficiency.

(5) Direct operating costs $\times 1.75$ to account for administration, insurance, interest, contractor's profit margin and other typical cost factors. Does not include cost of on-site geologic inspection or subsequent core logging. Does not include allowance for standby time.

(6)

Compressor costs calculated assuming two drills per compressor

$$
4-70
$$


COST AND TIME SUMMARY FOR

GEOPHYSICAL TECHNIQUES

IN SITE CHARACTERIZATION

Approximate

Cost

SEISMIC CROSSHOLE

(typical survey to about

500 feet)

DOWNHOLE SEISMIC VELOCITY

(typical survey to about

500 feet)

RADAR OR SONAR

(from pilot excavation)
$\$ 34,000-39,000(1)$

4-5 weeks (2)
Approximate

Time
$\$ 7,500-16,000(1)$

$2-3$ weeks (2)

\section{NOTES :}

Includes arilling costs.

(2) Turn around time for results from beginning field work. Does not include mobilization.

(3) Typical cost and field time for set of radial probings from single test room. Only a few sources provide radar or sonar services commercially. Both services are available from Rock Probers, Inc. (c/o Dr. R. R. Unterberger, Texas A \& M Univ.). Xadar Corporation, formerly Ensco, Inc. (Springfield, Virginia) provides radar. Typical daily rates are $\$ 1,500$ (Rock Probers, 2 or 3 man crew) to $\$ 1,750$ (Ensco, 2 man crew) for a minimum of three days, not including travel. Following initial setup and calibration numerous probes can be done in a day. Ensco estimates that lateral probes can be done along a tunnel at 1000 to 2000 feet per day. Actual duration of work in pilot excavations would depend on their layout and extent, and on the need to recalibrate radar velocities due to variations in the medium. (J. Fowler, 1981, personal communication, and R. R. Unterberger, 1981, personal communication). 
TABLE $4.3 \cdot 4-5$

COST AND TIME SUMMARY FOR

HYDROLOGIC TECHNIQUES

IN SITE CHARACTERIZATION

\begin{tabular}{lcc}
$\begin{array}{c}\text { Tests and } \\
\text { Analyses }(1)\end{array}$ & $\begin{array}{c}\text { Approximate } \\
\text { Cost Range (2) }\end{array}$ & $\begin{array}{c}\text { Approximate } \\
\text { Turound } \\
\text { Time }(3)\end{array}$ \\
\hline INJECTION TESTS & $\begin{array}{c}\$ 20,000-50,000 \\
\text { per test }\end{array}$ & $5-15$ days \\
STRADDLE PACKER TESTING & $\begin{array}{c}\$ 10,000-25,000 \\
\text { per test }\end{array}$ & $5-15$ days \\
TRACER TESTS & $\begin{array}{l}\$ 20,000 \text { or more } \\
\text { per test interval }\end{array}$ & $\begin{array}{l}\text { Time until } \\
\text { detection } \\
\text { depends on } \\
\text { site conditions }\end{array}$ \\
& &
\end{tabular}

FLOW SYSTEM MODELING

Without fracture flow

2 dimensional

$\$ 20,000$

2-4 weeks

3 dimensional

$\$ 30,000$

3-6 weeks

With fracture flow

2 dimensional

$\$ 50,000$

5-10 weeks

3 dimensional

$\$ 75,000$

7-15 weeks

NOTES:

(1) Described in Appendix G

(2) These tests are typically designed for particular site conditions in characterization. Costs are determined by test design and duration.

(3) Times for hydrologic tests are determined by site conditions and may vary significantly. 


\subsubsection{Geochemistry}

Cost estimates for typical geochemical analyses are summarized in Tables 6 through 8 of Appendix F-1. The specific tests and number of analyses needed will depend on site conditions and cannot be reliably quantified on a generic basis. The main factors determining turnaround time for geochemical analyses results are the available laboratory capabilities their work load, and priority of the specific project. It is expected that most individual analyses could be performed within a few weeks but longer times may be required for specialized analyses or large numbers of samples.

\subsubsection{Geomechanics}

Geomechanics for site characterization involves specialized laboratory testing and in situ tests designed individually for each program. Representative costs and times are provided in Table 4.3.4-6 but may differ significantly according to specific program design. In particular, the number of tests required to characterize a site would be determined by site condition variability and the proposed repository layout. Instrumentation stability and life span is a major problem in long duration tests and development of new or unique systems could be costly.

\subsubsection{CRITERIA FOR EVALUATING DATA ADEQUACY OF SITE CHARACTERIZATION STUDIES IN BASALT}

Previous discussion of the unique geologic features of basalt (Section 4.3.1), information needs (Section 4.3.2) and technique applications (Section 4.3.3) can be used to develop criteria for evaluating a site characterization study. This study should include an evaluation of the precharacterization data, how applied, and degree of refinement resulting from site specific studies. It is assumed that precharacterization studies have satisfactorily answered the information needs of the task. Based on this assumption, the following sections will discuss techniques criteria which are relatively unique to site characterization. To evaluate the adequacy of the data developed for each discipline, the following items should be addressed in the site characterization report:

- technique used to perform the studies; 
COST AND TIME SUMMARY FOR

GEOMECHANICS TECHNIQUES

IN SITE CHARACTERIZATION (1)

Tests (2)

HYDROTHERMOMECHANICAL

IN SITU BLOCK TEST

SCHMIDT HAMMER CHARACTERIZATION

OF JOINTS IN TEST ADIT

CORE TILT TESTING

Apparatus (purchase

or fabrication costs)

Typical set of tests.

JOINT TILT TESTING

(program)

SELF WEIGHT SLIDING TEST

(on large jointed blocks)
Approximate Cost

$$
\$ 600,000-700,000(3)
$$

$\$ 1,000(4)$

$\$ 500$

N/A

$\$ 500$

one day

$\$ 10,000$

2 weeks

$\$ 2500-4500 /$ sample $\$ 50,000 /$ program
Approximate

Duration

9-12 months (3)

NOTES :

(1) Geomechanical testing for site characterization involves test programs designed for particular information needs and site specific conditions. Costs and durations will vary according to test design.

(2)

Descriptions in Appendix $\mathrm{E}-2$.

(3) Not including excavation of test room.

(4) Including cost of Schmidt hammer. 
technique resolution, reliability and precision should be given, and described in sufficient detail to allow an independent evaluation of applicability

specifications and limitations of test equipment should be provided

0

test results and/or all data developed should be interpreted among or between major disciplines

o

analyses and tests should be performed by qualified personnel and duplicated and repeated to reduce the probability of analytical or human error.

\subsubsection{Geology}

Site characterization geologic investigations are largely concentrated in hydrology, geochemistry, and geomechanics, and chiefly intended to describe the proposed repository volume and identify variations or anomalies that may influence site suitability or repository performance. These activities include detailed subsurface mapping, subsurface-based drilling and geophysical exploration, and supporting laboratory analyses. Criteria for the information obtained are concerned with: (1) capabilities of available techniques and (2) geologic properties of basalt that affect the ability to understand site conditions.

Capabilities of available techniques are reflected in confidence levels placed on geologic information in different parts of the proposed host flow. Subsurface mapping has very high resolution and reliability but is limited to the extent of the pilot excavations, and drilling and geophysical techniques must be used to characterize the host rock beyond this extent. As discussed in section 4.2.2.1.3, drill core may be logged in great detail and features on the order of $1 \mathrm{~mm}$ or smaller may be detected with confidence. Although representative of a large host rock volume, core sample interpretations are not as reliable because of their small size.

Geophysical techniques are also used to characterize the repository volume outside the pilot excavations and boreholes. Radar, sonar, and techniques discussed under precharacterization may be used to identify variations in mineralogy, texture or lithology, as well as small scale structure and discontinuities. In general, technique resolution and confidence in interpretation decreases with increasing depth of penetration. Low frequency, long wave length radar systems are effective at greater distances but cannot resolve small features detectable by 
high-resolution, low-penetration systems. The resolution and penetration of a radar system is determined by the design of the individual system used and cannot be quantified reliably on a generic basis.

The geologic information must be evaluated on how well it forms a coherent model with the known conditions, and whether it adequately characterizes important unique features of basalt such as:

- fracture geometry and density

- inter- and intraflow boundaries

- mineralogy, texture and lithology variations

- small scale structure and discontinuities

\subsubsection{Hydrology}

Standard hydrologic techniques in dense basalt are handicapped by low permeability and long travel times, thus necessitating long term testing. The general criteria for evaluating hydrologic testing must be how well these results tests are integrated with related geology and geochemistry testing. The critical item is whether, and how well, the problems cited below are addressed.

- host rock flow anisotropies

o host, interbed and flow contact permeabilities

- anomalous vertical flow due to cross-cutting structures

- increased horizontal flow rates due to primary structural features (lava tubes, fractured vesicular zone, etc.)

\subsubsection{Geochemistry}

Geochemistry is important in site characterization because of contributions to repository environment description, hydrologic condition evaluation, and predicting performance of the repository under anticipated waste emplacement conditions. There are two main aspects of geochemical work: (1) describe the geochemical properties of rocks and fluids, mainly by laboratory analyses, and (2) interpret past and 
potential geochemical reactions with fluids and waste. Criteria for evaluating the geochemical test results of site characterization are concerned with the interpretations as well as the laboratory analyses. Sample collection and field or laboratory geochemical analyses procedures are found in Appendix F-2, which should be generally followed, although equivalent alternates may be evaluated individually.

Criteria for evaluating geochemical interpretations of ground water age or alteration history should recognize the complexity of such interpretations and the uncertainties involved. As discussed in Appendix F-2, a single set of stable isotope data normally is subject to several possible interpretations, so multiple analyses should be made to reduce these uncertainties. Hydrologic and geologic history interpretations from the geochemical analyses should similarly be evaluated against the other types of available evidence.

Geochemical reactions relating to anticipated repository performance would be interpreted from the geochemical framework determined during site characterization, and expected repository conditions. Because each of these has some uncertainty, criteria for evaluating these interpretations should consider the degree of uncertainty and sensitivity to possible input parameter variations. These considerations should make it possible to establish confidence that aticipated reactions are within desired bounding conditions, even though significant numerical uncertainties exist.

The final criteria is to ensure that several unique geochemical features of basalt have been adaressed. These unique features include:

- Reaction of host rock and joint infilling materials with water and waste

- Extent, pervasiveness and surface area of fractures available for interaction with waste and water

- Possible lateral or vertical rock chemistry variations in repository volume; and

- Long term elevated temperatures and steep temperature gradients due to low heat conductivity.

\subsubsection{Geomechanics}

A program for evaluating basalt response to anticipated thermal and mechanical stresses is a critical part of site characterization, and 
incorporates geologic description of the flow(s) proposed for a repository, results of laboratory testing, and specific in situ testing. This information then is applied in numerical models to evaluate repository performance. The criteria for the geologic work are discussed in section 4.3.5.1 and those for commonly used laboratory testing are discussed under precharacterization (Section 4.1 .5 and Appendix E-1).

Site characterization geomechanical testing programs are described in Appendix E-2 and generally represent the level of work required, but testing must be designed for site conditions and evaluated on that basis. Notable concerns in the design and operation of such tests include in situ stress measurements testing and creep test loading rates, as discussed in Appendix E-2. Instrumentation systems will require particular attention for long duration tests because long term reliability may be uncertain.

Important considerations for test result analysis and repository performance modeling include: (1) reliable geologic descriptions of discontinuities and mineralogic variations and (2) accurate prediction of temperature conditions. Detailed information on discontinuities and textural variations (i.e., grain size, texture, etc.) of a test sample is necessary for proper interpretation of laboratory or in situ results. Temperature conditions are a particular concern for predicting heat transfer, thermal gradients and mechanical strength, because laboratory testing has indicated that those parameters can vary significantly over the anticipated repository temperature range.

As discussed previously under geochemistry, geomechanical evaluations of a prospective repository are based on a number of measurements and interpretations, each having some level of uncertainty. Criteria for evaluating these analyses requires consideration of the uncertainty in each input parameter and the resulting effects on repository performance prediction. This analysis will be important in establishing that expected repository performance is within desired bounds. 
Agapito, J.F.T., and others, 1977, Geo-engineering review and proposed program outline for the structural design of a radioactive waste repository in Columbia Plateau basalt; Rockwell Hanford Operations, Rpt. RHO-ST-6

Barker, R.A., 1979, Computer simulation and geohydrology of a basalt aquifer basin in the Pullman-Moscow Basin, Washington and Idaho; Wash. Dept. Ecol., Water-Supply Bull., no. 48, 119 p.

Barnes, M.W. and Scheetz, B.E., 1979, Laboratory alteration of a Columbia River Basalt by hot groundwater; an application to deep geological disposal of radioactive waste [abstr]; Geol. Soc. Am. Abstr. Prog. Vol. 11, no. 7, 384 p.

Barney, G.S. and Wood, B.J., 1980, Identification of key radionuclides in a nuclear waste repository in basalt; Rockwell Hanford Operations Rpt. RHO-SWI-ST-9

Benson, L.V., 1980, A tabulation of ion exchange data on smectites, certain zeolites and basalt; Lawrence Berkley Laboratory Rpt. LBL-10541

Benson, L.V., and others, 1980, A study of rock-water-waste interactions in the Pasco Basin, Washington, Part II, Preliminary equilibrium-step simulations of basalt diagenesis; Lawrence Berkeley Laboratory Rpt. LBL-9677

Brown, J.C., 1979, Definition of the basalt groundwater flow system, Horse Heaven Plateau, Washington [abstr.]; Geol. Soc. Amer. Abstr. Prog., Vol. 11, no. 7, 395 p.

Bultitude, R. J., 1976, Flood basalts of probable early Cambrian age in northern Australia, in Volcanism in Australia: Elsevier Scientific Publ. Co., Amsterdam, pp. 1-20.

Calkins, F. C., 1905, Geology and water resources of a portion of east-central Washington: U.S. Geol. Survey Water Supply Paper 118.

Chapman, N.A., 1978, Application of laboratory hydrothermal studies to heating experiments: in Seminar on in situ heating experiments in geological formations (Anon.), OECD Publ., Paris, France, pp. 229-235 
Dames and Moore, 1978, Stratigraphies of salt, granite, shale, and basalt; volume 3, in Technical support for GEIS: Radioactive waste isolation in geologic formations: U.S. Department of Energy, contract no. W-7405 eng 26, 64 p.

Department of Energy, 1980a, Report on Geologic Exploration Activities; DOE Rpt. DOE-R-C-14

, $1980 \mathrm{~b}$, In the matter of proposed rulemaking on the storage and disposal of nuclear waste (Waste confidence rulemaking); DOE Rpt. DOE/NE-0007.

Deju, R.A., and others, 1977, Environmental factors needed to establish the geotechnical feasibility of storing radioactive waste in Columbia River Basalt; Rockwell Hanford Operations Rpt. RHO-ST-8

Dunbar, C. O., and Waage, K. M., 1969, Historical Geology: New York, John Wiley and Sons, Inc., Third Edition, 556 p.

Einarsson, T., 1949, The eruption of Hekla 1947-1948; IV.3 The flowing lava. Studies of its main physical and chemical properties: Soc. Scientiarum Islandica, Reykjavik, 70 p.

Erdal, B.R. and others, 1979, Sorption and migration of radionuclides in geologic media; in Scientific basis for nuclear waste management Vol. I, McCarthy, G.J., ed, Plenum Press, New York, New York, pp. 423-426

Erdal, B. R., and others, 1981, Nuclide migration field experiments program plan: Los Alamos Laboratory report LA-8487-MS, NC-70, 71 p.

Erikson, R.L. and Krupka, R.M., 1980, Thermal property measurements of Pomona Member Basalt from coreholes DB-5 and DB-15, Hanford Site, Washington; Rockwell Hanford Operations Rpt. RHO-BWI-C-76

Fugro Inc., 1980, Assessment of volcanic and geothermal activity in the Pasco Basin and vicinity: Rockwell Hanford Operations, Project No. 79-265, $191 \mathrm{p}$.

Gephart, R. E., and others, 1979, Hydrologic studies within the Columbia Plateau, Washington; an intergration of current knowledge: Rockwell Hanford Operations Report RHO-BWI-ST-5,

545 p. 
Gibson, I. L., 1969, A comparative account of the flood basalt volcanism of the Columbia Plateau and eastern Iceland: Bull. Volcanology, ser. 2, Vol. 33, pp. 419-437.

Goldrich, S.S., 1968, Geochronology in the Lake superior region: Canadian Jour. Earth Science, Vol. 5, p. 715-724.

Goles, G. G., 1980, Columbia River Basalts: Unpublished report, Univ. of Oregon, $42 \mathrm{p}$.

Green, D. H., and Ringwood, A. E., 1967, Genesis of Basaltic Magmas: Contributions to Mineralogy and Petrology, Vol. 15, p. 103-190.

Green, J., and Poldervaart, A., 1955, Some basalt provinces: Geochimica et Cosmochimica Acta, Vol. 7, pp. 177-188.

Grosh, D. K., 1980, Relationship between petrological, chemical and geomechanical properties of Deccan basalt, India; Bull. International Assoc. Eng. Geology, no. 22, pp. 287-292.

Heard, H.C. and others, 1979, Simultaneous measurements of permeability, electrical conductivity and ultrasonic velocity in igneous and metamorphic rocks [abstr.]; EOS (Am. Geophys. Un. Trans.), Vol. 60 , no. 18 , p. 381

Hodgkinson, D.P. and Bourke, B.J., 1978, The far field heating effects of a radioactive waste depository in hard rock: in Seminar on in situ heating experiments in geological formations (Anon.), OECD Publ., Paris, France, pp. 237-249

Houghton, D., 1841, [Fourth] annual report of the State Geologist: Mich., House of Representatives [Doc.] no. 27, 184 p.

Isherwood, D., 1981, Geoscience data base handbook for modeling a nuclear waste repository; Lawrence Livermore Lab. Rpt. UCRL-52719, vol. 2

Kaser, J.D., 1979, Thermal analysis of Hanford defense waste strontium and cesium capsules isolated in basalt; Rockwell Hanford Operations, Rpt. RHO-LD-78

Kline, A.I. and Shade, J., 1979, Theoretical and experimental study of diffusion of nuclear waste material in basaltic rocks [abstr.]; EOS (Am. Geophys. Union, Trans.) Vol. 60, no. 46, p. 974 
Krishnan, M.S., 1968, Geology of India and Burma: Higginbothams, Ltd., Madras, 536 p.

Kuno, н., 1969, Plateau basalts: EOS, Monograph Series 13, pp. 495-501.

Lawrence Livermore Laboratory, 1979, Review of geotechnical measurement techniques for a nuclear waste repository in bedded salt; Lawrence Livermore Lab. Rpt. UCRL 15141

Lomenicka, T.F., 1976, Terminal storage of radioactive waste in geologic formations; Union Carbide, Off. Waste Isolation Rep. No. Y/OWI/TM-6

, 1977, Geologic and hydrologic factors for locating repositories of radioactive wastes; Union Carbide, Off. Waste Isolation, Rep. No. Y/OWI/TM-14

- 1979, Geologic and hydrologic factors for locating repositories of radioactive wastes; Southeast Geol., v.21, no. 1, pp. 75-82

Long, P. E., 1978, Characterization and recognition of intraflow structures, Grande Ronde Basalt: Rockwell Hanford Operations Report RHO-BWI-LD-10, 74 p.

Macdonald, G. A., 1972, Volcanoes: New Jersey, Prentice-Hall, Inc., 510 p.

Merriam, J. C., 1901, A contribution to the geology of the John Day Basin: Univ. California Dept. Geol. Sci. Bull., Vol. 2, p. 268-314.

McKee, E. H., Swanson, D. A., and Wright, T. L., 1977, Duration and volume of Columbia River Basalt volcanics, Washington, Oregon, and Idaho (abs.): Geol. Soc. Amer. Abstr. Prog., v. 9, no. 4, pp. 463-464.

Miller, R. J., 1979a, Determination of basalt physical and thermal properties at varying temperatures, pressures and moisture contents. First Progress Report, Fiscal year 1979; Rockwell Hanford Operations Rpt. RHO-BWI-C-50

- 1979b, Determination of basalt physical and thermal properties at varying temperatures, pressures and moisture contents. Second Progress Report, Fiscal year 1979; Rockwell Hanford Operations Rpt. RHO-BWI-C-54 
Miller, R.J., 1979c, Determination of basalt physical and thermal properties at varying temperatures, pressures and moisture contents. Third Progress Report, Fiscal year 1979; Rockwell Hanford Operations Rpt. RHO-BWI-C-55

Morgan, M.T. and West, G.A., 1980, Thermal conductivity of the rocks in the Bureau of Mines Standard Rock Suite; Oak Ridge Nat'1 Lab. Rpt. ORNL/TM-7052

Myers, C. W., and Price, S. M., 1979, Geologic studies of the Columbia Plateau, a status report: Rockwell Hanford Operations Rpt. RHO-BWI-ST-4, 196 p.

National Oceanic and Atmospheric Administration, 1980, Thermal Springs List for the United States: NOAA Map 1, scale 1:5,000,000.

Noe-Nygaard, A., 1968, On extrusion forms in plateau basalts; shield volcanoes of "scutulum" type: Scientia Islandica, Ann. Vol., pp. 10-13.

Pardee, J. T., and Bryan, K., 1926, Geology of the Latah Formation in relation to the lavas of the Columbia Plateau near spokane, Washington: U.S. Geol. Surv. Prof. Paper 140-A, p. 1-16.

Park, C.F., Jr., and MacDiarmid, R. A., 1970, Ore Deposits: San Francisco, W. H. Freeman and Company, second edition, 522 p.

Parsons, Brinckerhoff, Quade and Douglas, 1976, Thermal guidelines for a repository in bedrock: Union Carbide, Off. Waste Isolation Rpt. No. Y/OWI/SUB-7 16504

Piper, A.M., 1974, Rock types, also geologic and hydrologic settings favorable to deep placement of high-level radioactive wastes; Union Carbide, Off. Waste Isolation Rpt. No. Y/OWI/SUB-3745/4

, 1975, Hypothetical prototype sites of repositories for radioactive wastes; flood basalts; Union Carbide, Off. Waste Isolation Rpt. No. Y/OWI/SUB-3745/6

Price, S. M., 1978, An evaluation of dike-flow correlations indicated by geochemistry, Chief Joseph swarm, Columbia River Basalt: Rockwell Hanford Operations Rpt. RHO-SA-59, 322 p.

Prinz, M., 1970, Idaho rift system, Snake River Plain, Idaho: Geol. Soc. Amer. Bull., Vol. 81, pp. 941-948. 
Raymond, J. R., and Tillson, D. D., 1968, Evaluation of a thick basalt sequence in south-central washington, geophysical and hydrological exploration of the Rattlesnake Hills deep stratigraphic test well: Battelle Northwest Lab. Rept. 776, 120 p.

Reidel, S.P., and others, 1980, Rate of deformation in the Pasco Basin during the Miocene as determined by distribution of Columbia River Basalt flows [abstr.]; Geol. Soc. Amer. Abstr. Prog., Vol. 12, no. 3, p. 149

Releya, J.F., and others, Interaction of waste radionuclides with geomedia: Program approach and progress: in Scientific basis for nuclear waste management, Vol. I, McCarthy, G.J., ed, Plenum Press, New York, pp. 379-394

Ridge, J.D., ed., 1970, Ore deposits of the United States, 1933-1967: New York, The Maple Press Company, Volumes one and two, pp. 992-1880.

Robinson, G.R., and others, 1981, Feasibility study of data for nuclear-waste disposal-Thermodynamic properties of basalt, granite, shale and tuff: U.S. Geol. Surv., Open-File Rpt. 81-470 (Prelim.).

Rockwell Hanford Staff, Department of Waste Isolation Research and Engineering, 1977, The basalt storage program: Rockwell Hanford Operations Rpt. RHO-SA-11, 34 p.

Basalt Waste Isolation Project, 1979, Basalt waste isolation project, Annual report - fiscal year 1979: Rockwell Hanford Operations Rpt. RHO-BWI-79-100, $190 \mathrm{p}$.

- Dept. of Water Isolation, 1978, Basalt waste isolation program, annual report, fiscal year 1978: Rockwell Hanford Operations Rpt. RHO-BWI-78-100, 180 p.

Runchal, A.R. and Maini, T., 1979, Regional groundwater flow near a high-level radioactive waste repository; Eng. Bull., no. 50, pp. $11-20$

Russell, I.C., 1893, Geologic reconnaissance in central Washington: U.S. Geol. Surv. Bull. 108, pp. 5-108

r 1902, Geology and water resources of the Snake River plains of Idaho: U.S. Geological Surv. Bull. 199, 192 p.

Rutten, M.G., 1964, Formation of a plateau basalt series (From the example of Iceland): Bull. Volcanol., ser. 2, Vol. 27, pp. 93-111. 
Ryan, M.P., 1974, Fracture mechanics and columnar basalts in Rock Mechanics, the American Northwest, Voight, B. and Voight, M.A., ed., Pa. State Univ., University Park, Pa., pp. 247-251

Sharp, R.R., 1972, A geological engineering evaluation of an underground nuclear test site; University of Arizona (unpub.), PhD dissertation.

Schultz, D. (ed.) 1980, Disposal of hazardous waste; proceedings of the Sixth Ann. research symp.; NTIS Rpt. No. EDA-600/9-80-010

Smith, G.O., 1901a, Geology and water resources of a portion of Yakima County, Washington: U.S. Geol. Survey Water-Supply Paper 55, 68 p.

- 1901b, Geology and physiography of central Washington: U.S. Geol. Surv. Prof. Paper 19, pp. 1-39

1903a, Description of the Ellensburg quadrangle, Washington: U.S. Geol. Surv. Geol. Atlas, Ellensburg Folio, no. 86.

Stearns, H.T., Crandall, L., and Steward, W.G., 1938, Geology and groundwater resources of the Snake River Plain in southeastern Idaho: U.S. Geological Surv. Water Supply Paper 774, 268 p.

Summers, W.K., Weber, P.A., and Schwab, G.E., 1978, A survey of the Ground-water geology and hydrology of the Pasco Basin, Washington: Rockwell Hanford Operations Rpt. RHO-BWI-C-41, 221 p.

Swanson, D.A., and others, 1972, Feeder dikes for Yakima basalt near Pasco, Washington [abs.]: Geol. Soc. Amer. Abstr. Prog., Vol. 4, no. 3 , p. 245.

Swanson, D.A., and Wright, T.L., 1976, Guide to field trip between Pasco and Pullman, Washington emphasizing stratigraphy, vent areas, and intercanyon-flows of Yakima basalt: Geol. Soc. Amer. (Cordilleran Section) 72nd Annual Meeting, Field Guide No. 1, 33 p.

Swanson, D.A., and Helz, R.T., 1979a, Bedrock geologic map of the vent system for the Ice Harbor Member of the Saddle Mountains Basalt, Ice Harbor Dam-Basin City area, southeast Washington: U.S. Geol. Surv. Open-File Rpt. 79-292. 
Swanson, D.A., Wright, T.L., and Zeitz, I., 1979b, Aeromagnetic map and geologic interpretation of the west-central Columbia Plateau, Washington and adjacent Idaho: U.S. Geol. Surv. Geophys. Invest. Map GP-917.

Swanson, D.A., and others, 1979c, Reconnaissance geologic map of the Columbia River Basalt Group in eastern Washington and northern Idaho; U.S. Geol. Surv., Open-File Rpt. No. 79-1363

1979d, Preliminary structure contour maps on the top of the Grande Ronde and Wanapum basalts, eastern Washington and northern Idaho; U.S. Geol. Surv. Open-File Rpt. 79-1364

Swanson, D.A., Wright, T.L., and Helz, R.T., 1975, Linear vent systems and estimated rates of magma production and eruption for the Yakima Basalt on the Columbia Plateau, Amer. Jour. Sci., Vol. 275, no. 8, pp. 877-905.

Tyrell, G.W., 1937, Flood basalts and fissure eruption: Bull. Volcanology., ser. 2, vol. 1, pp. 89-111.

United States Geological Survey, 1980, Plan for identification and geological characterization of sites for mined radioactive waste repositories: U.S. Geological Survey, Water Resources Investigation Open-file Rpt. 80-686, 72 p.

Verhoogen, J., and others, 1970, The Earth - An introduction to physical geology: New York, Holt, Rinehart and winston, Inc., 748 p.

Waite, D.A., Shipler, D.B., and McPherson, R.B., 1980, Environmental characterization for the siting of deep geologic nuclear waste repositories: Health Phys., Vol. 39, no. 6, p. 1031

Waring, G.A., 1913, Geology and water resources of a portion of southcentral Washington: U.S. Geol. Surv. Water-Supply Paper 316, 46 p.

White, W.S., 1913, Geology and water resources of a portion of southcentral Washington: U.S. Geol. Surv. Water-Supply Paper 316, 46 p.

Washington, H.S., 1922, Deccan traps and other plateau basalts: Geol. Soc. Amer. Bull., Vol. 33, pp. 765-803. 
Washington Public Power Supply System, 1973, Preliminary safety analYsis report (Amendment 9): WPPSS Nuclear Project No. 1, Richland, Washington, Vol. 1 and 2, Docket 50-397.

1977, Preliminary safety analysis report (Amendment 23): WPPSS Nuclear Project No. 1 and 4, Richland, Washington, Vol. 2A and 2B, Docket 50-460 and 50-513.

Waters, A. C., 1955, Volcanic rocks and the tectonic cycle: Geol. Soc. Amer. Spec. Paper 62, pp. 703-722.

1961, Stratigraphic and lithologic variations in the Columbia River Basalt: Amer. Jour. Science, Vol. 259, pp. 583-611.

1962, Basalt magma types and their tectonic associations, Pacific Northwest of the United States, in The crust of the Pacific Basin: Amer. Geophys. Union, Geophys. Monograph 6, pp. 158-170.

Wentworth, C. R., 1954, The physical behavior of basaltic lava flows: Journal of Geology, Vol. 62, No. 5, pp. 425-438.

White, W. S., 1960, The native copper deposits of Northern Michigan in Ore Deposits in the United States, 1963/1967, Ridge, J. D., ed.; Amer. Inst. Mining, Metallurgical and Petroleum Eng.

White, W. S., 1970, The Reweenawan lavas of Lake Superior, an example of flood basalts; Amer. Jour. Sci., v. 258A (Bradley Volume) pp. 367-374. 


\subsection{TUFF}

\subsection{PREVIOUS WORR IN TUFF}

One of the most comprehensive summaries of the historical development of the concepts of ash flow tuff eruption and deposition is by Chapin and Elston (1979). The following is from their summary and is meant to provide a framework for the sequence of theories that has resulted in the modern concept of the origin of tuff presented in section 5.2.

The concept of pyroclastic rock formation began in 1868 when Fritsch and Reiss coined the term "eutaxite" for rocks they described as being composed of ejected fragments of various colors and textures. In 1879, Wolf described "flowing lava" in a volcanic center in Ecuador and was thus perhaps one of the first to report the pyroclastic origin of tuff Later, in 1892, Dell'Erba interpreted lavas in Italy as tuffs which had been hot at the time of deposition.

During early exploration of the western United States, Turner (1894) and Ransome (1898) theorized over the origin of rhyolites which had characteristics of both tuff and lava. Iddings $(1885-1886,1889)$ was the first to introduce the concept of welding of glassy fragments in tuff at the Yellowstone National Park.

Anderson and Flett (1903) and Lacroix (1903, 1904) made the first detailed observations of flows that formed during the 1902 eruptions in Martinique (Pelee) and in the West Indies (Soufriere). Lacroix was the first to use the term "nuee ardente" to describe this previously unrecognized type of volcanism. Perret (1935) published the best documented accounts of nuee ardente eruptions during his close-up observations of the 1929-1932 eruptions of Mt. Pelee.

The reports of Anderson, Flett and Lacroix inspired new thought on the interpretation of volcanic rock. In 1905, Dakyns and Greenly reported that so-called slates in wales were in fact Pelian type deposits. In 1919, Zambonini agreed with Dell'Erbas' 1892 conclusion of the Pelean origin of "lavas" in Italy. Discovery of the Valley of Ten Thousand Smokes and subsequent publication of a series of papers by Griggs (1918), 1922), Fenner $(1920,1923)$ and Zeis (1929) further stimulated this new thought. Marshall (1935) was the first to use the term "ignimbrite" for rocks be observed in New Zealand. Marshall also recognized the importance of devitrification in observing the fragmental character of pyroclastic rock. At this point in time, enough was known about the origin and emplacement of tuff that workers began to recognize tuff deposits on a more frequent basis and several important papers appeared in the next few years. Gilbert (1938) reported on his 
field and petrographic study of the Bishop Tuff in California. Anderson and Russell (1939) were the first to utilize tuff as a datum for regional stratigraphic correlation, and Kuno (1941) distinguished "pumice flows" from "ejected pumice" in eruptions in Japan. Williams $(1941,1942)$ helped fill out the basic framework of ash flow magmatism with his reports on "Calderas and Their Origin" and "The Geology of Crater Lake National Park...". Also in 1942, Westerveld described tuffs in Sumatra and was able to compare them with deposits on other continents. Thus, by 1942, the basic features of tuffs were known and much of the work had been documented in leading journals worldwide.

Between 1942 and 1960, the geologic community as a whole was slow to adopt these concepts. Finally, in 1960, two papers by Smith (1960a and $1960 \mathrm{~b})$ and one by Ross and Smith (1961) again accelerated the concepts of tuff formation. These three papers have become classic papers on tuff formation. Since 1960, exceptional progress has been made in the field of tuff and caldera formation. Many of these are alluded to or referenced in the 1980 special publication of the Geological society of America on "Ash-Flow Tuffs" (Chapin and Elston, 1979). This document also presents a series of papers representing the most modern concepts of tuff origin and emplacement.

Tuffs at the Nevada Test Site (NTS) are currently being evaluated by Sandia National Laboratories, Argonne National Laboratories, and the USGS. Like the Basalt Waste Isolation Project (BWIP) at the Hanford Site in the Washington (Johnstone and Wolfsberg, 1980; Wolfsberg and others, 1980; Vine and others, 1980), the Nevada Nuclear Waste Storage Investigation (NNWSI) was initiated in 1977 to determine specifically if a site for a repository could be found within the boundaries of the test site. A main difference between these two sites is that the NTS has a specific mission -- the testing of nuclear weapons. Therefore, the search for and potential location of a repository site at NTS must be compatible with an active program of testing nuclear weapons.

In the evaluation of the NTS, a number of sites characterized by numerous geologic media (alluvium, argillite, tuff and granite) have been considered. Work on all but tuff (at Yucca Mountain) has been discontinued because questions concerning structural features indicated high probability for rejection (ONWI, 1980). 


\subsection{PRECHARACTERIZATION STUDIES}

\subsubsection{GEOLOGY OF TUFF}

An ideal geologic setting for a nuclear waste repository is a thermally stable, mechanically strong medium enveloped by low permeability, highly sorptive materials. Welded tuff sheets having a basal nonwelded zeolitized portion may meet these conditions and in addition, provide multiple barriers to radionuclide escape. The following description, therefore, is meant to set the stage for the geology of a tuff sheet. It is not meant to be a detailed description of tuff formation. For this, the reader is referred to the references listed in section 5.4 .

Tuff is a general term for pyroclastic deposits of volcanic dust, ash, pumice and scoria produced by explosive disintegration of viscous lava from a crater or, less commonly, a fissure. It is a consolidated but not necessarily a welded deposit.

Nonwelded tuff, ash falls, and many interbedded deposits, owing to their high permeability, have a ground-water flow system that will not afford the long residence time desired for a host medium. For this reason, the geology of welded tuff sheets associated with basal zeolite zones will be considered further.

Two varieties of welded tuff can be distinguished based mainly on texture, geometry, and field relationships. The first is formed by pyroclastic flows, defined by Sheridan (1979) as all denser than air avalanches, streams, and flows that receive their initial energy from volcanic eruptions. Examples of pyroclastic ash flow tuff deposits in the U.S. are the Apache Leap Tuff in the Superstition Mountains in Arizona, the Bandelier Tuff in the Jemez Mountains of New Mexico, the Crater Lake Caldera, Oregon, the Yellowstone Plateau Volcanic Field, northwest Wyoming and those at NTS in Nevada.

The second variety is formed by air fall, defined by sheridan as deposits formed by ballistic transport of volcanic ejecta carried in gas streaming from a vent. In the United States, air fall welded tuffs are less common than welded pyroclastic flows. Curtis (1968) describes welded air-fall deposits in the crater wall of Katamai Crater, Alaska. Other welded air-fall deposits have been described in Italy, Greece, Iceland, New Zealand, and Japan (Sparks, 1975; Walker, 1973; and Healy, 1973).

Zeolitized tuff is also of interest in repository siting. This is nonwelded tuff that contains zeolite, a hydrous silicate of open molecular 
structure which has a low density, high porosity, very low permeability, high water content, extremely high sorptive properties, moderate compressive strength, and moderate thermal conductivity. An inherent problem of zeolilic tuff is that dehydration of some zeolite minerals begins at about $100^{\circ} \mathrm{C}$, and unless the water release is able to escape through the rock, it could contribute to changes in stress that could result in fracture. An increase in temperature could also cause some zeolites to decompose to new minerals of lower sorptive properties.

\subsubsection{Origin and Emplacement}

A comprehensive summary of tuff and caldera formation has been published by Johnstone and Wolfsberg (1980) and provides much of the background for this discussion. Tuff may be deposited either directly by explosive volcanic events, or they may be reworked and redeposited by surface processes. Because silicic (e.g., rhyolitic) volcanism tends to be more explosive than the eruption of more mafic magmas, silicic tuff tends to be much more voluminous and widespread than basaltic tuff despite the much greater volumes of basaltic volcanic rocks. In the western United States, particularly in the Basin-andRange physiographic province, accumulations of tuff locally exceed 3000 meters in thickness, and individual units may be tens of kilometers in lateral extent.

Eruptions of silicic magmas vary in volume from a few cubic meters to a massive catastrophic event depositing hundreds of cubic meters of ash and lava in a single eruption. Upon eruption, silicic magmas most commonly contain about 108 primary crystals (phenocrysts) and incorporate about $10 \%$ lithic fragments, so that generally $80 \%$ of the material deposited is glass. In large eruptions the great majority of material is ejected explosively as fine ash, shards, and pumice because of the high viscosity and high volatile content of silicic magmas.

As shown in Figure 5.2.1-1, this main part of the eruptive cycle is characterized by Plinian eruption (Sheridan, 1980). The eruptive column can be divided into a gas-thrust region and a convective-thrust region. The energy line traces the potential flow head from the top of the gas thrust region to the distal toe of the flow. Pyroclastic flows could surpass topographic barriers that do not extend above the energy line.

Large explosive eruptions commonly begin with ejection of pumice, shards, and ash that are deposited downwind of the vent as a cool unsorted layer of low-density material (termed an air-fall or ash-fall deposit). This nonwelded layer may eventually become zeolitized. As 


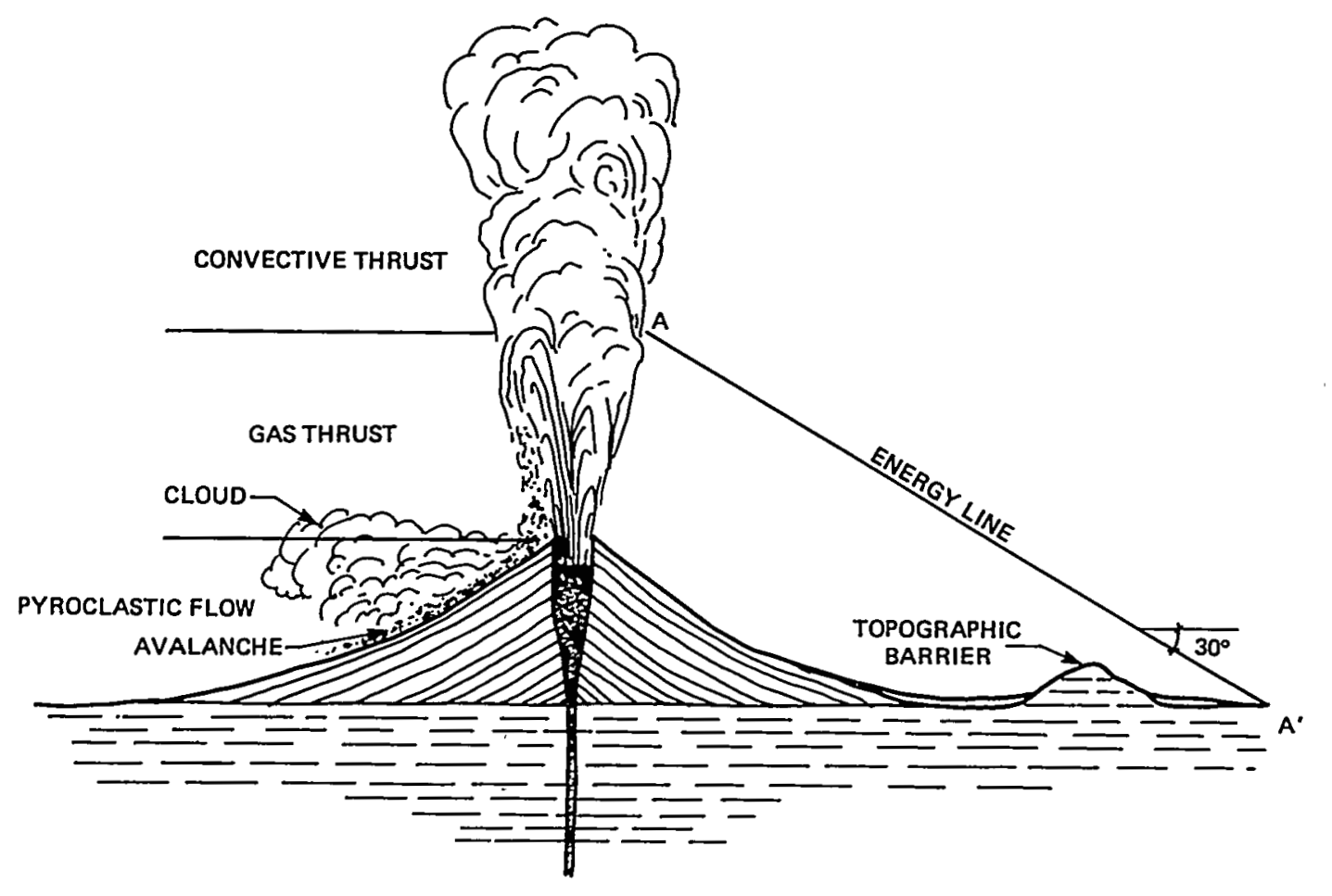

FIGURE 5.2.1-1 SCHEMATIC DIAGRAM OF A PLINIAN

ERUPTION FROM A COMPOSITE VOLCANO 
eruption proceeds and increases in intensity, clouds of incandescent ash propelled by evolving gases are formed over the vent and collapse downslope, depositing heated material in thick blankets. This latter type of deposit is volumetrically most significant. As eruption then proceeds, the rocks overlying the magma chamber may collapse to form a caldera, which may subsequently fill with thick sequences of volcaniclastic deposits. Materials deposited above about $500^{\circ} \mathrm{C}$ will compact and weld by viscous deformation of the glass. Compacted material that cools rapidly (i.e., weeks to months) may remain glassy, while that which cools more slowly will crystallize to cristobalite, quartz, and a mixture of feldspars.

The net result is a complex deposit up to several hundred meters thick which has cooled as a single unit, and is commonly referred to as a cooling unit. A schematic cross section through such a deposit is given in Figure 5.2.1-2. These deposits commonly have a core of welded material, most of which may have devitrified (i.e., crystallized) to quartz and feldspar with or without cristobalite. At the base of the welded zone is a layer of densely welded material that has not crystallized but remains a dense glass called a vitrophyre. Welding decreases outward from the core so that the welded zone is surrounded by zones of material decreasing in density, thermal conductivity, coherence, and strength. Commonly at the base of the ash-flow deposit there is an unsorted, nonwelded zeolized horizon of loosely aggregated pumice and ash called the air-fall unit. Because the surface material is also loosely aggregated, it is readily reworked by surface processes and may be redeposited by streams and ponds or by volcaniclastic mudflows (lahars). Such processes give rise to sorted, bedded deposits called bedded tuff.

Because glass is thermodynamically unstable, it commonly alters to various crystalline phases. At elevated temperatures, quartz, cristobalite, and feldspars crystallize, as occurs in welded zones. If the porosity is high and water saturation occurs, glass may alter completeIy to zeolites in a little as 10,000 years even at a temperature below $100^{\circ} \mathrm{C}$. If saturation is not achieved, or if the porosity is low as in vitrophyres, alteration will not occur and the material may remain glassy for millions of years. There is no evidence that material once crystallized to quartz and feldspar will later alter to zeolites under conditions common in these rocks, although feldspars may alter slowly to clays, particularly in the presence of acid groundwaters.

\subsubsection{Typical stratigraphy}

Both external and internal relationships are of importance when interpreting stratigraphic relationships in tuff. External relationships 


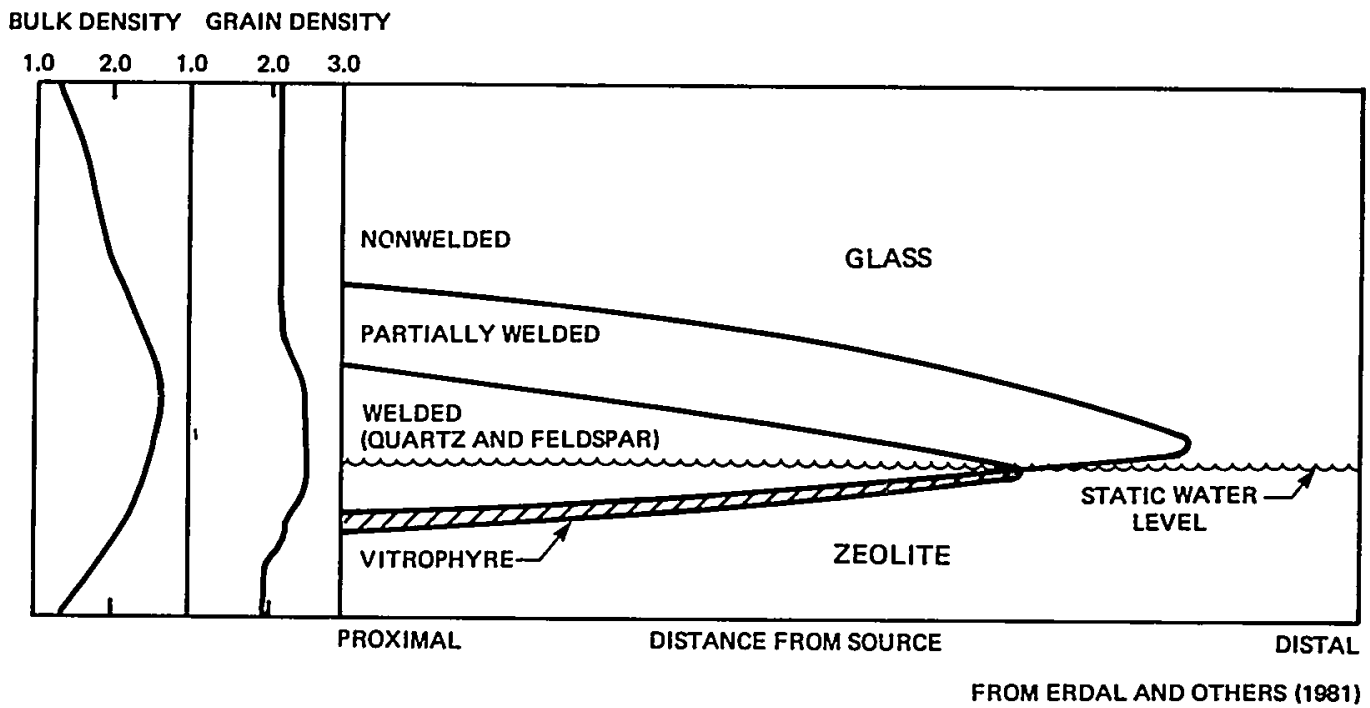

FIGURE 5.2.1-2 SCHEMATIC CROSS SECTION THROUGH AN ASH-FLOW TUFF COOLING UNIT WITH TYPICAL BULK AND GRAIN DENSITIES 
include gross stratigraphic and lithologic relationships. Internal relationships include degree of welding, strain relationships, alteration structures and minor compositional changes. In the absence of clear cut geologic relationships, the final distinction may require laboratory and petrographic study of rock specimens. In most cases, however, knowledge of the mode of eruption and emplacement, and careful study of the geologic field relationships will enable interpretation of the overall stratigraphic relationships as well as internal stratigraphic relationships (degree of welding, strain relationships, alteration, structures) that may have a bearing on a repository.

Tuff sheets typically vary in both vertically and laterally (Figure 5.2.1-2). A complete eruptive episode may result in numerous pyroclastic flows as well as pyroclastic air-falls and lava flows. Careful examination of the age, textural and chemical characteristics may enable correlation of units from place to place. Actual thicknesses and the areal extent of tuff sheets can vary widely but large sheets are typically on the order of thousands of meters thick and a few thousand square kilometers in area. For example, the Apache Leap Tuff of central Arizona, a tuff sheet not unlike many of the welded tuffs throughout the western U.S. was emplaced over an area of $1000 \mathrm{~km}^{2}$. It is part of an ash flow field that may have originally covered as much as $4000 \mathrm{~km}^{2}$. The sheet reaches a maximum thickness of 600 meters. Its original thickness probably averaged about 150 meters throughout the region (Peterson, 1980). The internal stratigraphy of the Apache Leap tuff was determined by utilizing zones of secondary crystallization and interpreting systematic flattening of pumice fragments, (Peterson, 1979).

\subsubsection{Structures}

After eruption, tuff sheets typically come to rest at very low angles of repose (less than about 7 degrees). Therefore, in their primary stage, tuff sheets can be conceived of as a bedded media much like shale, bedded salt or flood basalt. The upper surface is typically planar perhaps with the tops of pre-existing topography exposed. The base is unconformable with the pre-existing topography. Structures associated with tuff sheets are generally those relating to the ring fracture zone surrounding the vent area, columnar jointing relating to cooling of the sheet after emplacement and fumaroles formed around areas of degassing of the sheet after placement.

The ring fracture faults relate to regional tumescence and fracture around the caldera structure. They are steep and may extend in a curvilinear manner for several kilometers to a depth well within the crust. In many cases they may be completely buried by subsequent

$$
5-8
$$


eruption of tuff. If renewed activity occurs, the ring fractures may be present at the surface.

Columnar joints are conspicuous features of many tuff sheets and are particularly well developed in the lower and middle parts. While similar to columnar joints in lava flows, they tend to be coarser and less regular. Fumaroles are vents on the surface of the tuff sheet through which gases and vapors were emitted. They are characteristic of late stage volcanic activity.

\subsubsection{Hydrology}

Although welded and zeolitized tuffs are widespread and occur in thick sections in the western states, their homogeneity and hydrologic properties have not been characterized. Perhaps one of the best studied welded tuff sheets from the standpoint of hydrology is the Nevada Test Site (NTS) in Nevada. As this area has most of the textural and structural characteristics that would be expected in a "typical" tuff, its hydrologic factors of most importance to a repository will be summarized.

The water table at NTS is between 390 and 600 meters deep and the local relief is such that in places it intersects the potentiometric surface. However, the depth to the water table in other tuff sheets may differ significantly, depending upon climate, geology, and elevation. Estimates based on radiocarbon ages indicate an average groundwater velocity of about 30 meters/year in an area of suspected fracturing of the tuffaceous rocks. This estimate is therefore probably somewhat higher than it would be in unfractured tuff but additional data are needed to quantify the difference.

The sorption capacities of tuffaceous rocks along flow paths from the NTS are very high. However, it can be expected that both travel times and sorption capacities will be greater in interbeds of less welded or nonwelded zeolitized zones.

\subsubsection{Resources}

The potential for metal deposits in near surface and surface volcanotectonic structures such as calderas and in rocks erupted from these centers was evaluated by Mckee (1979). The following is summarized from his report.

Major ore deposits are commonly associated with late-stage intrusive phases of a magma systems. Ash flows erupt from the top of magma 
chambers at shallow depths, and tend to be silicic and enriched in lithophile elements only. Therefore, ash flows, especially thick accumulations of them such as exist in collapse calderas may have ore potential for uranium, lithium, and barium. Base and precious metals, however are not associated with primary silicic differentiates. They tend to be dispersed by eruption and are not common in tuffs. Shallow-fracture systems such as calderas may be mineralized by later (secondary) igneous activity, but most metals are concentrated in rocks emplaced at greater depth. Except where mineralized by younger hydrothermal systems, faults formed by cauldron collapse are also typically barren of metals. Mineralization is generally unrelated to the magma system that caused the caldera (McRee, 1979).

Interbeds of more porous tuff may contain potable water, a geologic resource of importance in some areas. Potable water may also occur along fractures and joints. However, the occurrence of potable water depends on site characteristics and cannot be predicted on a generic basis.

Glass in the tuff is unstable and tends to crystallize with time, aided by ground water and other fluids which may circulate through the rock. Most typically, the resulting minerals are zeolites; such as clinoptilolite (MacDonald, 1972). Where highly developed, such mineralization may be an economic mineral deposit.

Energy resources also occur in association with tuff. Geothermal resources may occur above or below repository levels in areas of voluminous, young (less than 10 million years) silicic tuffs. In Nevada, highly fractured tuff is a reservoir rock for oil (Fugro National Inc., 1980).

\subsubsection{INFORMATION NEEDS FOR PRECHARACTERIZATION STUDIES IN TUFF}

The information needs which must be satisfied prior to site characterization include a variety of needs from six disciplines. These disciplines are geology, hydrology, geochemistry, geomechanics, tectonics/ seismicity, and resources. It is important to note that these needs cover more than the surface area (and buffer zone) and more than the subsurface volume excavated for waste emplacement. The best example is the need to characterize possible ground water flow systems leading from the site to the surrounding region.

Techniques which may be employed to meet the needs of the six disciplines (Section 5.2.3) are not all in routine use today, but may 
become routine in the near future (e.g. gravity logging and radar logging).

In the remainder of this section, the information needs for each discipline are outlined. All information needs outlined are deemed appropriate to precharacterization, and many needs will also be common to site characterization. The main difference being in the actual number of tests or analyses that should be performed to fill the need. For example, in the geochemistry discipline, one of the information needs is for data on redox conditions. In precharacterization the data are of general interest to determine approximate redox conditions in tuff, but site characterization will require much more data to fully characterize redox conditions at a site.

\subsubsection{Geology}

The geologic needs of stratigraphy, lithology and structure are fundamental to understanding the repository setting because they provide a framework for describing, delineating and correlating rock types from scattered outcrops or subsurface borings. The application of stratigraphic principles allows the development of a three-dimensional model of the repository.

The needs of the geology discipline can be broken down into the needs for stratigraphy and Iithology and the needs for structure. The factors needed to characterize stratigraphy and lithology of tuff sheets are as follows:

- Chemical and mineralogical composition

- Textural characteristics

- Geometric relationships of various tuff units

- Geophysical properties that may facilitate correlation

- Visual observations of rock samples or outcrops that may facilitate correlation.

The factors needed to characterize structure of tuff sheets include:

- Distribution of rock lithologies

- Condition of rock samples (cooling cracks, faults, fractures, breccia zones) 


\subsubsection{Hydrology}

The knowledge of the groundwater regime of a repository in tuff is perhaps the most important category because hydraulic transport from the region of the repository represents the most likely mechanism for radionuclides to reach the accessible environments.

The following characteristics of hydrology should be well understood before undertaking studies at a prospective site in tuff:

- Location and dimension of aquifers and aquitards and ground water

- Hydraulic gradient, porosity, permeability, and transmissivity

- Rates and locations of discharge and recharge (including distribution of surface drainage)

- Flow paths and travel time for nuclide travel from the proposed repository zone to the biosphere

- Ground water age, temperature, and chemistry (organic and inorganic)

- Postulated effects of future processes (uplift, subsidence, climate) on groundwater conditions

The principal hydrologic issue for siting a repository in tuff is confirmation that the ground water systems are capable of providing the required long term isolation. Because most ground water calculations assume isotropic intergranular flow rather than anisotropic fracture flow (Grove, 1978; Dagan, 1979), the effects of fracture systems in tuff must be evaluated specifically. The hydrology of fractured systems is a relatively new field for which a considerable amount of research is needed before it is well understood. It is postulated, however, that many fractures become closed at depth. Therefore, knowledge of fluid velocity, hydrodynamic dispersion, and fracture characteristics (size, length, roughness) is also needed (Erdal and others, 1981) to help characterize flow in fractured systems which may be present in tuff.

\subsubsection{Geochemistry}

Several geochemical needs must be filled to gain an understanding of the ability of the rock and water mass to enhance, impede, or prevent the movement of radionuclides through the tuff as well as to provide 
data on waste/rock interaction. Detailed whole rock geochemical analyses and age dating will be required to identify the lateral and vertical variations in lithology that are expected in a tuff medium. Because the nature of the interactions of radionuclides with the rock is of primary importance, values are needed for the equilibrium concentrations of the reactants and products both in solution and on the tuff.

Accordingly, values for the following conditions and processes are also needed in tuff:
- Effects of hydrolysis
- Polymerization reactions
- Formation of complexes
- Oxidizing-reducing conditions
- Radiation-radiolysis conditions
- Mechanisms and kinetics of the following interactions:
- ion exchange processes
- ion exclusion processes
- aqueous/pore diffusion
- replacement reactions
- physical transport and filtration
- precipitation processes
$\circ \quad \mathrm{pH}$
- Oxidation and reduction potential

The main objective of the above data is to determine the sorption characteristics of tuff. Other factors which are needed to access the sorption properties and characteristics of waste/rock interaction of tuff are:

- Surface area of rock in contact with groundwater 
- Effect of fracture geometry on geochemical processes

- Effects of minerals along fractures

- Temperature and pressure

It is important to note that geomechanical and geochemical properties may couple to cause changes in the ability of the tuff to contain emplaced radionuclides. For example, temperature may affect the rate of some chemical reactions, which may retard or enhance the movement of radioisotopes in the groundwater.

\subsubsection{Geomechanics}

Geomechanical and thermal properties are needed chiefly to determine the capability of the tuff to absorb and dissipate the heat emitted by the radioactive waste. Although welded tuffs typically have adequate strength for stability of underground excavations, significant discontinuities and disturbed zones should be identified. These features can be identified in boreholes and from observations of surface exposures. Mechanical and thermal properties can also be measured on rock samples collected from boreholes. Knowledge of the geomechanical properties will enable an understanding of possible changes that may be induced by excavation, waste emplacement, dewatering, backfilling and sealing. The specific geomechanical and thermal parameters needed in tuff include:
- Rock density
- Coefficient of thermal expansion
- Thermal conductivity
- Specific heat
- Heat flow from the tuff in the vicinity of the repository
- Young's modulus
- Poisson's ratio
- Cohesion
- Compressive strength
- Tensile strength 
A particular concern in tuff is variation in these properties between welded and unwelded zones and between tuff and overlying or underlying rock units. In situ stresses in the tuff at depth should also be determined.

\subsubsection{Seismotectonics}

Tectonic processes that could affect the repository by inducing regional or local deformations in the earth's crust need to be evaluated. Such processes for tuff many include:
- Faulting
- Seismic activity
- Igneous activity
- Uplift/subsidence

Hazards from these processes can be estimated for a tuff medium by analyzing their probable likelihood and consequences. For example, potential hazards from possible renewed igneous activity have been assessed for some igneous systems (Crowe, 1978; Crowe and Carr, 1980; Fugro Inc., 1980). These studies have shown that over most of the United States, igneous activity is not of significant concern. In areas of Quaternary volcanism, it is generally possible to quantify (with adequate reliability) the level of risk at a site. Similar studies have been conducted for several nuclear power plants in the United States to evaluate the risk probabilities from seismic activity.

\subsubsection{Resources}

In a tuff medium, natural resources may include minerals, energy resources, or water resources that are sufficiently concentrated for commercial exploitation. Their occurrences have been summarized in Section 5.2.5.1. It is important to note that economic resources are based mainly on demand and technology and that economic or political conditions can change the classification of a resource material from one that is uneconomical to extract to one very economical to extract. They are important because their presence may affect land use, and, more importantly, exploration for such deposits by future generations might result in an inadvertent intrusion of the containment system. 
In regards to repository siting in tuff, two concerns about resource potential are important:

1. The repository should not preclude extraction of mineral resources,

2. Mineralization should be low enough to minimize the chance that future generations will breach the repository.

These concerns can be addressed by obtaining and evaluating geochemical data on the tuff to determine the concentration of individual elements or compounds. The possible resources of interest in tuff include:

- Mineral commodity occurrences (e.g., precious, base, and ferrous metals; uranium)

- Non-metallic and industrial minerals (e.g., ore grade zeolite)

- Hydrocarbons (present below the tuff or in fracture fillings within tuff)

- Geothermal resources

- Potable water

Other potential resources may also be identified, based largely on economic and political criteria.

\subsubsection{TECHNIQUE APPLICATIONS TO PRECHARACTERIZATION INFORMATION NEEDS IN TUFF}

Established techniques of exploration and testing can be used to satisfy the information needs for a prospective repository site in tuff. For this discussion, techniques are grouped according to the principal types of information obtained: geology, hydrology, geochemistry, geomechanics, seismotectonics, and resources. However, information obtained in each of the groups typically is applicable to needs in the others and in practice there is significant interchange between groups. General applications are summarized in Table 5.2.3-1.

Applications of techniques are considered at three stages of exploration: (1) no drilling at the prospective site, (2) results of previous drilling available for the site, and (3) drilling performed at the site specifically for this work. The types of information available at each of these stages have been assumed for this discussion, based on typical characteristics of a prospective site in tuff.

$$
\text { 5-16 }
$$


TABLE 5.2.3-1 SUMMARY OF TECHNIOUE APPLICATIONS IN TUFF

\begin{tabular}{|c|c|c|c|c|}
\hline \multirow{2}{*}{\multicolumn{2}{|c|}{ TECHNIQUE }} & STAGE 1 & STAGE 2 & STAGE 3 \\
\hline & & $\begin{array}{l}\text { NO DRILLLING SURFACE } \\
\text { EXPLORATION ONLY }\end{array}$ & EXISTING DRILLING & NEW DRILLLING \\
\hline \multirow{2}{*}{ REMOTE SENSING } & SATELLITE & G H S r & G H S r & G $H \mathbf{S} r$ \\
\hline & AIRCRAFT & G H S r & G H S r & G H S r \\
\hline \multirow{3}{*}{ SURFACE MAPPING } & LANDFORMSS & G H S r & G H S r & G H S r \\
\hline & LITHOLOGY/MATERIALS & G H S R c m & G $H S R$ c m & G H $S$ B $c m$ \\
\hline & PROCESSES/STRUCTURE & G H S R & G H S R & G H S R \\
\hline \multirow{4}{*}{$\begin{array}{l}\text { GEOPHYSICAL } \\
\text { LOGGING }\end{array}$} & ELECTRICAL & & $g h c m$ & G H C M \\
\hline & FADIOACTIVE & & $g h r c m$ & $G H \sim C M$ \\
\hline & MECHANICAL & & $g h r m$ & $G h \subset M$ \\
\hline & ACOUSTICAL & & $\mathrm{g} \mathbf{h} \mathbf{m}$ & $G h M$ \\
\hline \multirow{6}{*}{$\begin{array}{l}\text { GEOPHYSICAL } \\
\text { EXPLORATION }\end{array}$} & GRAVITY & g $5 \mathrm{r}$ & $g \leq \underline{r}$ & $\underline{\underline{g}} s \stackrel{r}{=}$ \\
\hline & AUDIO-MAGNETOTELLUUICS & $g$ h $s$ r c & $\underline{g} \underline{h} \underline{\mathbf{r}} \underline{\mathbf{c}}$ & $\underline{\underline{g}} \stackrel{\mathrm{h}}{=} \stackrel{\mathrm{r}}{=} \underline{\mathrm{c}}$ \\
\hline & SEISMIC REFRACTION & g h s & $\underline{g} \underline{h} \mathbf{s}$ & $\underline{\underline{g}} \underline{\underline{h}} \mathbf{s}$ \\
\hline & RESISTIVITY & g h $5 \mathrm{r}$ & $\underline{\underline{g}} \underline{\underline{h}} \mathbf{s} \underline{\mathbf{r}}$ & $\underline{\underline{g}} H s \underline{\underline{r}}$ \\
\hline & MAGNETICS & G $s \quad R$ & $\underline{\mathbf{G}} \mathbf{s} \underline{\mathrm{R}}$ & $\underline{\underline{G}} \mathbf{s} \underline{\underline{R}}$ \\
\hline & SEISMIC REFLECTION & G $\mathbf{s} R$ & $\underline{\mathbf{G}} \mathbf{S} \underline{\underline{R}}$ & G 5 R \\
\hline \multirow{4}{*}{$\begin{array}{l}\text { GEOMECHANICS/ } \\
\text { THERMOMECHANICS }\end{array}$} & ROCK MATERIALLLAB TESTS & $\mathrm{gh} \mathrm{m}$ & $\underline{g} \underline{h} \underline{m}$ & g $\mathrm{H} \mathrm{M}$ \\
\hline & ROCK FIELD OBSERVATIONS & $\mathrm{ghs} \mathrm{h} \mathrm{m}$ & $g \underline{h} s \mathbf{r} \underline{\mathbf{m}}$ & $g h s R \leq \underline{M}$ \\
\hline & DESIGN LAB TESTS & & $M$ & M \\
\hline & DESIGN IN SITU TESTS & & & $\mathbf{M}$ \\
\hline \multirow{5}{*}{ GEOCHEMICAL } & $\begin{array}{l}\text { GRAPHICAL } \\
\text { STATISTIC ANALYSES }\end{array}$ & $g h r c$ & $g \underline{h} \underline{\mathbf{c}}$ & $g h \leq c$ \\
\hline & SAMPLING AND ANALYSES & $g h r c$ & $\underline{g} \mathrm{H} \underline{\mathbf{c}}$ & $\underline{G} \mathbf{H} \mathrm{C}$ \\
\hline & VIATER-ROCK MOOELING & & h c & H C \\
\hline & STABLE ISOTOPE MODELING & & h c & HC \\
\hline & GROUNDWATER AGE DATING & h $\mathrm{C}$ & $\underline{\mathbf{h}} \underline{\mathbf{c}}$ & $H C$ \\
\hline \multirow{6}{*}{ HYDROLOGY } & FLOOD FREOUENCY & H & $\mathrm{H}$ & $H$ \\
\hline & RECHARGE/DISCHARGE & & $\mathbf{h}$ & H \\
\hline & SURFACE WAYER CHEMISTRY & H C & $\underline{H} \underline{\mathrm{C}}$ & H C \\
\hline & NUMERICAL MODELING & h & $\underline{\mathbf{h}}$ & h \\
\hline & AOUIFER TESTS & & h $\underline{m}$ & $H$ m \\
\hline & TRACEA TESTS & & & H \\
\hline \multirow{6}{*}{$\begin{array}{l}\text { SEISMICITYI } \\
\text { TECTONICS }\end{array}$} & $\begin{array}{l}\text { HISTORICAL } \\
\text { EARTHQUAKE ANALYSIS }\end{array}$ & g $\mathbf{S}$ & g s & g $S$ \\
\hline & $\begin{array}{l}\text { INSTRUMENTAL } \\
\text { EARTHQUAKE ANALYSIS }\end{array}$ & 95 & 9 S & 95 \\
\hline & MONITORING NETWORKS & $\mathbf{S}$ & $\mathbf{s}$ & $\mathbf{S}$ \\
\hline & VELOCITY STUDIES & g s & g $\underline{s}$ & g $\underline{s}$ \\
\hline & FAULT STUDIES & gs & $9 \underline{s}$ & g $S$ \\
\hline & $\begin{array}{l}\text { ATTENUATION AND } \\
\text { GROUND MOTION }\end{array}$ & $\mathbf{s}$ & s & $\mathbf{s}$ \\
\hline \multicolumn{2}{|c|}{ DRILLING/LOGGING } & & $g h s r c m$ & $G H=R C M$ \\
\hline
\end{tabular}

EXPLANATION

CLASSES OF INFORMATION NEEDS

G - GEOLOGY

H= HYDROLOGY

C = GEOCHEMISTRY

$M=$ GEOMECHANICS/THERMOMECHANICS

$S=$ SEISMICITY/TECTONICS

$R=$ RESOURCES
NOTES:

1. CAPITAL LeTters indicate MOST APPLICABLE TECHNIOUES

LOWER CASE LEYTERS INDICATE LESS APPLICABILITY.

N DOUBLE UNDERLINE INDICATES ENHANCEMENT BY NEW ORILLING DATA.

2. LETTERS INDICATE INFORMATION NEED CLASSES WHOSE TECHNIOUES OBTAIN DATA THROUGH STAGES OF INVESTIGATION. LETTERS INDICATE OBTAIN DATA THROUGH STAGES OF INVESTIGATION. LETTERS INDICATE APPLICABILLTY WITHIN A STAGE, BUT DONOT REPRESENT EOUIVALENCE
BETNIEEN TECHNIOUE. RESOLUTION, RELIAEILITY, AND OTHER EVALUATION FACTORS ARE DISCUSSED IN TEXY. 
In the first case, where no drilling has been done at the site, information is assumed to be available from surface techniques only. It the near-surface aquifers only. It is expected that borehole data will be available from the surrounding (off-site) vicinity. Through extrapolation, surrounding data may provide a general knowledge of the subsurface stratigraphy and aid interpretations of geophysical data.

Previous drilling in tuff typically would have been for mineral exploration and to a lesser extent for water and oil exploration. Drillers' logs or geologists' logs are likely to be available for these holes but may provide general information only as exploration companies commonly consider the detailed logs to be proprietary. Core samples are likely to be available but tuff cores will generally be of poor quality. The most valuable information from the pre-existing boreholes typically will be any borehole geophysical logs that may exist. Based on typical industry practice, it is assumed that spontaneous potential logs would be available. It is considered unlikely that the pre-existing boreholes would be in suitable condition for running new logs or for hydrologic testing or monitoring.

In new drilling specifically for the exploration program, coring, sampling, and logging would be designed to best obtain the desired information. These would include detailed core logging, obtaining core for testing, and the use of selected borehole geophysical logs.

\subsubsection{Geology}

\subsection{No Drilling at a Site}

The tuff at a prospective repository site would typically be exposed at the surface or perhaps within a few kilometers of the site. Where exposed, it may be somewhat altered by weathering although its gross characteristics would remain the same. As a result, useable information on a prospective host rock can be obtained without drilling. The techniques that may be used before drilling at a site are remote sensing, surface mapping, and geophysical exploration. These can be applied to some significant information needs at a site.

The information needs relating to geomorphology, Quaternary geology, paleoclimate, history of erosion and deposition, and similar topics can be addressed before drilling is undertaken at a site. These typically utilize techniques in remote sensing and surface mapping, supplemented by trenching as required. These information needs are unrelated to the medium involved but instead are determined by the other geologic conditions at a prospective site. Resolution and reliability of these geologic observations and the resulting interpretations also would 
depend on site conditions, particularly on the amount of information available and the complexity of the geologic record.

Lateral extent of the suitable host rock surrounding a prospective site may be addressed by identifying tectonic features or anomalous structures, that may be expressed at the surface. Geophysical techniques, particularly seismic reflection, also may be used to identify such features and to recognize termination of suitable tuff beds. Reliability and resolution of these determinations could vary significantly, according to local conditions in relation to the nature of the features involved. Thickness and composition of the overburden at a site would be particularly important in determining how reliably features of a given size may be detected.

General information on stratigraphy, lithology, and geologic structure at a prospective site may be extrapolated from off-site boreholes and interpreted from seismic reflection data. Unless disrupted by tectonic features, tuff sheets are generally laterally continuous (Figure 5.2.1-2), allowing such extrapolations to be made with considerable confidence. Thin interbeds of other lithologic character typically can be recognized on borehole geophysical logs but beds to be correlated by seismic reflection generally must be at least several meters thick.

The degree of welding can be determined from density analyses of exposed rock specimens. This technique will allow preliminary estimates of permeability to be determined. It will also facilitate correlation of tuff units and assist in identification of any major lateral discontinuities which may exist.

\subsection{Previous Drilling}

Results of previous drilling at a site in tuff can greatly aid evaluations of stratigraphy, lithology, and geologic structure. The typical borehole geophysical logs assumed to be available can be very useful for interpreting stratigraphy and can detect interbeds less than 0.5 meters thick. Moreover, the data from previous boreholes can greatly increase the reliability and accuracy of geophysical interpretations.

In particular, the borehole data would provide depth control for the geophysical interpretations and would confirm lithologic correlations. The minimum thickness stratigraphic unit that could be mapped confidently through the site area would be reduced from a few meters (based on seismic reflection alone) to less than a meter. 


\subsection{New Drilling}

New drilling at a prospective site in tuff would allow detailed core logging and selection of the most suitable borehole geophysical logging techniques. The combined effect of these techniques is to greatly increase the resolution and reliability of the stratigraphic, lithologic, and structural information. Although the borehole geophysical logs can be interpreted with considerable confidence, direct observation of the core is valuable to confirm lithology and to analyze structural features. Detailed core logging can detect features on the order of 0.3 centimeters or less. This level of detail is desired in tuff because of the importance of identifying non-welded beds that may represent pathways for migration of radionuclides.

Selected geophysical logs run in the new boreholes can be used to provide data for zones that are not cored and to aid or supplement the core logging. Natural gamma logs are particularly useful for confirming depths of the core return. In addition to the basic logs assumed available for the pre-existing holes, logs that may be useful include spectral gamma, density, porosity, and accoustic logs to aid lithology determinations. State-of-the-art tools such as borehole radar and borehole gravity also may be used to aid identification of structural features or anomalies. As noted previously, standard borehole logs typically can detect layers less than 0.5 meters. By using combinations of logs under relatively controlled conditions, layers to three centimeters may be detected with significant confidence. Resolution and reliability of the radar and gravity tools has not been established.

\subsubsection{Hydrology}

Remarkably little is known about the hydrologic regimes in tuff. Therefore, the "no drilling" and "previous drilling" stages are considered of limited utility in a tuff media.

\subsection{No Drilling At a Site}

Hydrologic techniques that may be used at a site with no drilling are limited to those involving climate, surface hydrology, and hydrology of groundwater at shallow depths, well above the tuff. These techniques are independent of the prospective host medium and would be applied at any site as described in the technique report on hydrology (Appendix G-1). Resolution and reliability of these techniques also are independent of the host medium and depend on local conditions and 
factors such as the length and quality of climate and streamflow records.

Without drilling at a site, some information on hydrology in and below the tuff may be developed from inference and extrapolation of lithologic and stratigraphic data. However, drilling and aquifer testing are needed to obtain reliable hydrologic data.

\subsection{Previous Drilling}

Previous drilling at a prospective repository site in tuff is unlikely to include holes to the repository and the depths are not likely to be suitable for hydrologic testing or monitoring. As a result, the main benefits to the hydrologic studies from the previous drilling would be that hydrostratigraphy could be defined with somewhat greater reliability, using techniques discussed in the preceding section (5.2.3.1).

\subsection{New Drilling}

New drilling at a prospective repository site in tuff is needed for application of hydrologic testing techniques. At this stage of exploration, water samples may be obtained by pumping or bailing, aquifer tests may be performed, and the well may be completed for monitoring water levels. Specific concerns for this work in tuff include the difficulties of measuring hydrologic parameters in materials of low fracture permeability.

Laboratory porosity and permeability tests may be performed on core samples obtained from the new drilling and may contribute to understanding of aquifer properties. As discussed in the technique report on hydrology (Appendix G-1), there typically is some uncertainty in these tests because of possible disturbance of the core samples. The reliability of these tests therefore must be evaluated on the basis of detailed core logging and comprehensive geologic analyses of conditions at the prospective site.

Techniques for modeling and analysis may be used to evaluate hydrologic conditions at a prospective site, based on the results of the borehole and laboratory testing. Geologic determinations of the site configuration and geochemical data regarding quality and age of the water in the various zones also contribute to these analyses. Results provide information on hydrologic flow in the prospective repository area, 
including: locations and mechanisms of recharge and discharge, hydrologic heads and gradients, directions and rates of flow, and travel times through the hydrologic system.

Reliability and resolution of the modeling and analysis techniques is determined chiefly by how well the geohydrologic system is understood. On a conceptual basis, tuff is a simple hydrologic system with generally horizontal and continuous layering. However, the variability of aquifer properties discussed above suggests that these systems may be much more complicated in detail and may be difficult to quantify accurately, even though conditions may be well within an acceptable range for repository performance. Professional judgement will be very important in these analyses.

Dissolution is of concern in tuff especially when considering long-term stability of excavated chambers. It may be evaluated using techniques of hydrologic analysis combined with interpretations of dissolution history and rates based on geologic techniques. The geologic techniques contributing information regarding dissolution include remote sensing analyses and surface mapping to recognize surface expressions of dissolution as well as drilling and geophysical exploration to identify the subsurface zones where dissolution has occurred. The resolution and reliability of such analyses is essentially that of the geohydrologic model combined with the level of understanding of the dissolution mechanisms involved. As a result, dissolution potential is likely to be difficult to quantify accurately. However, the typically low rates of dissolution for tuff are such that dissolution potential is likely to be well within an acceptable range for repository performance, even considering the uncertainty involved.

\subsubsection{Geochemistry}

\subsection{No Drilling}

Techniques available in geochemistry before drilling is done at a site are limited to testing of surface-water quality and isotope dating of surface samples, supporting the hydrologic and geologic efforts, respectively. At this stage of investigation, geochemical conditions directly relevant to a prospective repository may only be inferred from general information on lithology and stratigraphy.

\subsection{Previous Drilling}

Previous drilling will provide general information on geochemical conditions at prospective repository depths by interpretation of 
stratigraphy and lithology from borehole geophysical logs. This general information would be very useful to document the level of variability of associated lithologies within the tuff. However, the geochemical information available at this stage would be of uncertain reliability.

\subsection{New Drilling}

New drilling at a prospective site would include application of laboratory techniques for geochemical analyses of rock and water samples and would allow geochemical interpretations to be made from selected borehole geophysical logs. This testing and analysis provides the basis for geochemical description of the prospective repository environment, assessment of sorption characteristics, and for age dating of rock and water samples. The specific techniques that may be used are described in the technique report on geochemistry (Appendix F-1).

Geochemical properties of individual samples can be determined with a high degree of accuracy and reliability. However, the more important question of how well the geochemical environment of the prospective repository can be defined depends on how well the geologic and hydrologic framework is understood in addition to accuracy of testing and density of sampling. These factors cannot be quantified with any confidence on a generic basis.

\subsubsection{Geoméchanics}

\subsection{No Drilling At a site}

Information needs in geomechanics comprise the mechanical and thermal properties of the rocks influencing the repository and description of in situ stress conditions. For a prospective site in tuff, drilling is needed to obtain information on host rock characteristics at or near repository depths. As tuff may crop out at or near the site, samples of this material may provide approximate data about conditions at reporting depths, providing it is not heavily weathered. It should be noted, however, that patterns of fractures and joints cannot be extrapolated confidently from surface exposures to repository depth. In view of these factors, geomechanical information that may be obtained at a site in tuff without drilling typically would be limited to: (1) limited extrapolations of surface conditions, (2) general interpretations based on available lithologic, stratigraphic, and structural information from rocks that may crop out and (3) general interpretations of tectonic stresses in the region. 


\subsection{Previous Drilling}

Data from previous boreholes at a site could provide useful information in geomechanics by defining lithologic zones with increased accuracy and reliability. As there are typically only minor variations in lithology throughout a tuff sheet, any significant anomolous situations (such as interbeds of nonwelded tuff or dense lava) may be apparent from arillers or geologists logs. The reliability and resolution of geomechanics information from previous drilling would depend heavily on the quality of the available geologic information.

\subsection{New Drilling}

New drilling at a prospective site would allow direct determination of geomechanical parameters by use of the techniques described in the accompanying technique report on geomechanics (Appendix E-1). In addition to these tests, detailed core logging and borehole geophysics would be available to better define stratigraphy, lithology, and geologic structure, and particularly to identify the interbeds that could be a concern for the stability of proposed underground openings. Important parameters to be determined in testing would include: density, strength, elastic moduli, plasticity, specific heat, coefficients of thermal conductivity and expansion, and potential for thermal alteration of associated zeolitized minerals.

The variation in geomechanical properties between the rock types associated with a tuff sheet (Figure 5.2.1-2) is much greater than the uncertainty in geomechanical measurement techniques. Accordingly, the reliability and resolution of the geomechanical analyses would be determined to a large extent by the quality of the geologic model of the site.

\subsubsection{Seismotectonics}

Information needs in seismicity and tectonics are resolved in programs that are independent of the potential host medium involved and of the stage of site investigation (as detailed by the availability of borehole data). As discussed in section 5.2.1, tuff typically is found in parts of the United States that are characterized by tectonic instability and low to moderate levels of seismic activity. It would be beneficial to confirm and quantify these conditions before undertaking drilling at a site, although final analyses commonly would be delayed to allow additional time for monitoring of seismicity. 
Techniques used to obtain information on seismicity and tectonics include the seismic techniques described in Appendix $\mathrm{H}$ combined with geologic techniques for recognizing faults and tectonic movements from remote sensing, surface mapping, and subsurface exploration. Reliability and resolution of the interpretations from these techniques cannot be quantified on a generic basis because they depend on complex factors such as length and quality of the local seismic record and level of understanding of the associated geologic setting. In spite of these possible uncertainties, seismotectonic conditions at a prospective site in tuff are expected to be well within the acceptable range for a repository.

\subsubsection{Resources}

\subsection{No Drilling at a Site}

Before drilling is commenced at a site in tuff, resource potential may be well known or suspected from extrapolation of off-site data or from interpretation of geophysical data. In a tuff sheet (Figure 5.2.1-2) zeolite may be a recoverable resource that would occur at the base of a flow. If more than one tuff sheet is present, several zeolite zones may occur. This general condition should be revealed by various surface based geophysical techniques such as seismic reflection or seismic refraction. The typically bedded nature of tuff sheets may also allow extrapolation of resource bearing beds from off-site boreholes. While all these techniques are approximate, they should be reliable enough to reveal those situations where resources are compatible with the site geology.

\subsection{Previous Drilling}

Information from previous drilling at a prospective site would improve the resolution and reliabiity of resource determinations by allowing direct identification of ore zones and refining interpretations of stratigraphy, lithology, and geologic structure. The borehole geophysical logs assumed to be available would be the most valuable information in this regard as they can allow reliable identification of ore zones.

\subsection{New Drilling}

New drilling at a prospective site would increase the reliability and resolution of resource evaluations by generally improving the confidence in geologic interpretations. It also may be assumed that this new 
drilling would include holes placed to evaluate any potential resources identified or suspected in the site area. In view of the expectation that precharacterization exploration of a prospective site would involve a detailed study of general geology, resource potential of the site could be defined with a high level of confidence. It is unlikely that resources of present or potential economic value would be overlooked.

\subsubsection{COST AND TIME ESTIMATES FOR PRECHARACTERIZATION TECHNIQUES}

The various techniques available to meet the information needs in tuff have a wide range of costs, reflecting time and materials as well as per test (e.g., linear cost per mile, cost per hole, etc.). In addition to the "base cost" one can consider interpretation or analysis time. To keep the technique costs comparable, they are presented largely exclusive of interpretation time. This is because some techniques require a large amount of time to interpret (e.g., gravity data), while other techniques require little interpretation time.

To render the technique costs comparable, a tabular format is used for cost data presentation (Tables 5.2.4-1 to 5.2.4-7). The costs in these tables are generally independent of media. A few techniques however, deviate significantly in cost when used in a tuff medium (as compared to basalt, shale, granite, dome salt and bedded salt). In the following sections those techniques having unique costs are summarized by $a$ short explanatory text.

\subsubsection{Remote Sensing and Mapping}

The costs for remote sensing and surface mapping are presented in Table 5.2.4-1. The costs for photo acquisition and photo interpretation are largely independent of medium. However, the field mapping procedures in tuff may be impacted because of anticipated rugged and remote terrain conditions. This problem may require support equipment such as four-wheel-drive vehicles or helicopters to facilitate deployment of field personnel in a timely cost effective manner.

\subsubsection{Drilling and Coring}

The costs for drilling and coring are presented in Table 5.2.4-2 and discussed in Appendix $\mathrm{D}-1$. Because of the relative softness of tuff, it should be noted that drilling time and costs for tuff are relatively 
COST AND TIME SUMMARY FOR REMOTE SENSING AND MAPPING

Acquiring Imagery or Photography

\begin{tabular}{|c|c|c|c|}
\hline & Approximate Cost Range & $\begin{array}{c}\text { Delivery } \\
\text { Time (1) } \\
\end{array}$ & $\begin{array}{l}\text { Approximate } \\
\text { Area Covered }\end{array}$ \\
\hline $\begin{array}{l}\text { LANDSAT } \\
\text { Enhancement }\end{array}$ & $\begin{array}{c}\$ 8-150 \text { per image }(2) \\
\$ 200-1000 \text { per scene }(3)\end{array}$ & $\begin{array}{l}1-4 \text { weeks } \\
4-16 \text { weeks }(3)\end{array}$ & $13,500 \mathrm{mi}^{2}$ \\
\hline $\begin{array}{l}\text { SKYLAB } \\
\text { Multispectral } \\
\text { Earth Terrain }\end{array}$ & $\begin{array}{l}\$ 8-150 \text { per image }(2) \\
\$ 8-150 \text { per image }(2)\end{array}$ & $\begin{array}{l}1-4 \text { weeks } \\
1-4 \text { weeks }\end{array}$ & $\begin{array}{l}2,000 \mathrm{mi}^{2} \\
4,600 \mathrm{mi}^{2}\end{array}$ \\
\hline $\begin{array}{l}\text { Stereo Aerial Photogr } \\
\text { Purchase existing } \\
\text { New flight }\end{array}$ & $\begin{array}{l}\text { aphy } \\
\$ 3-60 \text { per frame (2) } \\
\$ 25-40 \text { per frame }(4)\end{array}$ & $\begin{array}{l}1-4 \text { weeks } \\
2-6 \text { weeks }\end{array}$ & $3-80 \mathrm{mi}^{2}$ \\
\hline $\begin{array}{l}\text { Low Sun Angle Photogr } \\
\text { Purchase existing } \\
\text { New flight }\end{array}$ & $\begin{array}{l}\text { aphy } \\
\$ 3-60 \text { per frame (2) } \\
\$ 25-75 \text { per frame }(4)\end{array}$ & $\begin{array}{l}1-4 \text { weeks } \\
2-6 \text { weeks }\end{array}$ & $3-12 \mathrm{mi}^{2}$ \\
\hline $\begin{array}{l}\text { Radar Imagery } \\
\text { Purchase existing } \\
\text { New flight }\end{array}$ & $\$ 125 \underset{(7)}{\text { per strip }}$ & $\begin{array}{l}1-3 \text { weeks } \\
3-10 \text { weeks }\end{array}$ & $\begin{array}{l}100-2500 \mathrm{mi}^{2} \\
\text { Per survey } \\
\text { design }\end{array}$ \\
\hline
\end{tabular}

Interpreting Imagery or Photography

\begin{tabular}{|c|c|c|c|}
\hline & Cost & Time (5) & Comments \\
\hline $\begin{array}{l}\text { Satellite Imagery } \\
\text { (generally e } 1: 250,000 \text { ) }\end{array}$ & $\$ 1050-1750$ & 3-5 days & per scene \\
\hline \multicolumn{4}{|l|}{$\begin{array}{l}\text { Aerial photography (8). } \\
\text { e } 1: 62,500\end{array}$} \\
\hline $\begin{array}{l}\text { Land forms } \\
\text { Lithology } \\
\text { Geologic Structure }\end{array}$ & $\begin{array}{r}\$ 70-175 \\
\$ 70-175 \\
\$ 175-280\end{array}$ & $\begin{array}{l}1 / 4-1 / 2 \text { days } \\
1 / 4-1 / 2 \text { days } \\
1 / 2-1 \text { day }\end{array}$ & $\begin{array}{ll}\text { For } & 100 \\
\mathrm{mi}^{2} & \text { area }\end{array}$ \\
\hline \multicolumn{4}{|l|}{$\begin{array}{l}\text { Aerial photography (8) } \\
\text { e } 1: 24,000\end{array}$} \\
\hline $\begin{array}{l}\text { Land forms } \\
\text { Lithology } \\
\text { Geologic structure }\end{array}$ & $\begin{array}{l}\$ 175-350 \\
\$ 175-350 \\
\$ 280-700\end{array}$ & $\begin{array}{l}1 / 2-1 \text { day } \\
1 / 2-1 \text { day } \\
3 / 4-2 \text { days }\end{array}$ & $\begin{array}{ll}\text { For } & 100 \\
\mathrm{mi}^{2} & \text { area }\end{array}$ \\
\hline Radar Imagery & (9) & (9) & \\
\hline
\end{tabular}


TABLE 5.2.4-1 (cont.)

Field Mapping $^{(6)}$

Reconnaissance

$1: 62,500$ scale

$1: 24,000$ scale

Relatively complete mapping

$1: 62,500$ scale

$1: 24,000$ scale

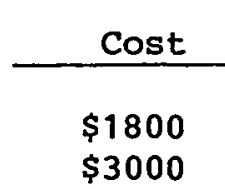

$\$ 4200$

$\$ 6600$

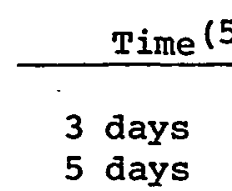

7 days

11 days
Comments

For 100

$\mathrm{mi}^{2}$ area

For 100

$\mathrm{mi}^{2}$ area

NOTES

(1) Delivery times generally do not depend on quantity ordered.

(2) Cost of photos or imagery is determined by size of print ordered, whether in color or black and white, and extra charges for shorter delivery time.

(3) Cost and delivery time for enhancements depends on source and on availability of previous processing for scene desired.

(4) Flight costs in addition to costs of photo reproduction indicated above.

(5) Approximate man-days to complete work; delivery time may be longer. Time required for interpretations can depend on complexity of geologic conditions at a site.

(6) Cost and time estimates assume interpretation of imagery and photography completed previously. Actual times and costs in an area would be influenced by access, trafficability, and complexity.

(7) Obtaining radar imagery from a new flight costs several thousand dollars. Actual costs depend on mobilization (radar equipment is not widely available), altitude requirements, and other flight parameters.

(8) Estimated times and costs are applicable to all $9^{\prime \prime} \times 9^{n}$ stereo aerial photographs: black and white, color and infrared (both black and white and color).

(9) Time and cost for interpreting radar imagery depends on resolution and scale of the imagery, purpose of the interpretation, and other factors. See Appendix A for discussion. 
TABLE $5 \cdot 2.4-2$

COST AND TIME SUMMARY FOR

DRILLING AND CORING(1)

Drilling

Type

Equipment

\begin{tabular}{|c|c|c|c|}
\hline & illing & & oring \\
\hline $\begin{array}{c}\text { Cost }(2) \\
\text { (per foot) }\end{array}$ & $\begin{array}{c}\text { Production } \\
\text { Rate } \\
\text { (feet per day) }\end{array}$ & $\begin{array}{c}\text { Cost }(2) \\
\text { (per foot) }\end{array}$ & $\begin{array}{c}\text { Production } \\
\text { Rate } \\
\text { (feet per day) }\end{array}$ \\
\hline
\end{tabular}

100

$\$ 600(4)$

40

200

$-$

-

$\$ 80$

100

$\$ 560(4)$

45

Using Air

$\$ 60$

200

$\$ 270$

$\$ 70$

30

60
15
Using Air
$\$ 530(4)$

NOTES:

(1) Adapted from Appendix D.

(2) Including all arilling supplies, support personnel and ancillary equipment.

(3) For mobilizing petroleum drill rig to typical tuff site add about $\$ 71,500$ for rig suitable for arilling only or $\$ 183,000$ to obtain rig suitable for coring.

(4) Includes $\$ 285$ per foot for core bits and coring services. 
low (as compared to other igneous rock media such as granite and basalt). However, because most large tuff sheets are located in the western United States, availability of suitable drill rigs may be limited. If large rigs are required, they may require a long lead time to acquire because of the intense drilling activity in specific areas in the midwest and Texas gulf coast. However, in many cases slim-hole rigs which are more readily available may be used.

\subsubsection{Borehole Geophysical Logging}

Geophysical logging costs are summarized in Table 5.2.4-3 and discussed in Appendix $\mathrm{c}-1$. No unique costs are anticipated while performing borehole logging techniques that would greatly inflate costs beyond those of other media.

\subsubsection{Geophysical Surveys}

Geophysical survey costs are summarized in Table 5.2.4-4 and discussed in Appendix B. In a tuff media where terrain conditions are commonly rugged and access is difficult, ground based surveys (such as gravity, seismic refraction, and seismic reflection), may experience increased costs for deployment. In some cases, it may be necessary to supply the crews with four-wheel-drive vehicles or. helicopter support, which may signifcantly increase th total geophysical survey program costs.

\subsubsection{Geomechanical}

Geomechanical and thermal costs are summarized in Table 5.2.4-5 and discussed in Appendix E-1. No unique costs are anticipated while conducting the geomechanical and thermal tests on tuff.

\subsubsection{Geochemical}

Geochemical costs are summarized in Appendix $F-1$. No unique costs are anticipated while conducting the geochemical analysis on tuff.

\subsubsection{Hydrologic}

Hydrologic costs are summarized in Table 5.2.4-6 and discussed in Appendix G-1. No unique costs are anticipated while conducting the hydrologic tests on tuff. 
TABLE $5 \cdot 2 \cdot 4-3$

COST AND TIME ESTIMATES FOR BOREHOLE GEOPHYSICAL LOGGING

Techniques

Approximate

Cost Range

Time (3)

Typical Log Package (1)

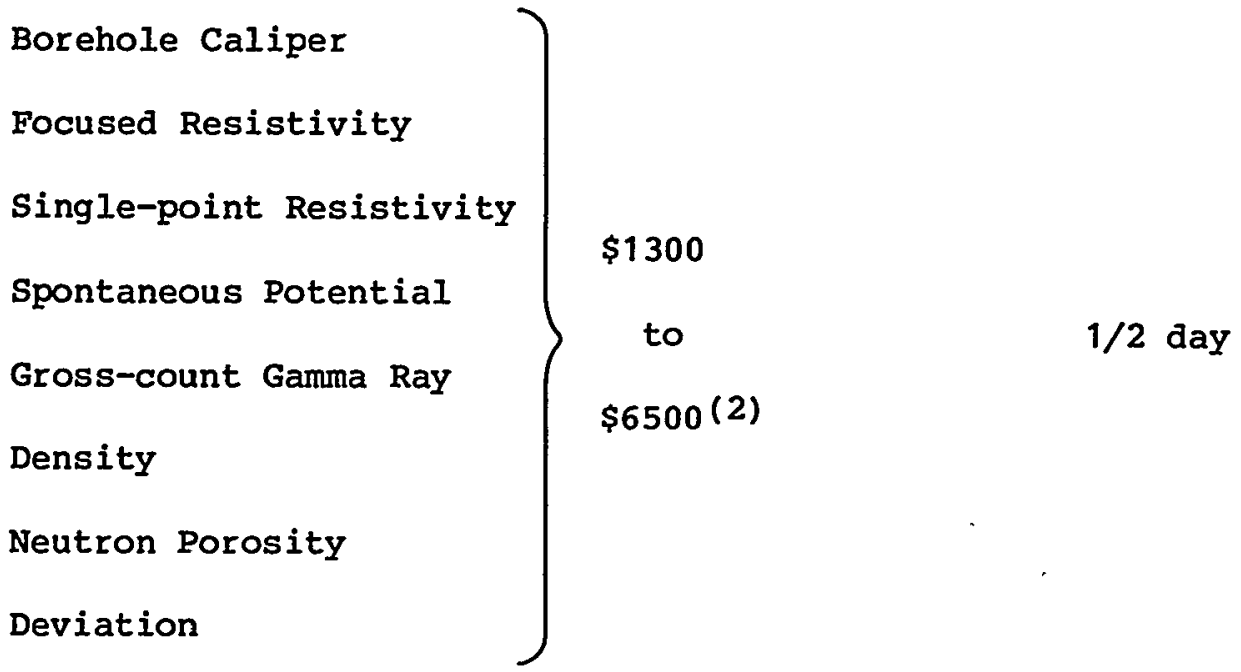

Additional Logs (4)

Electrical

Radioactive

$\$ 350-900(5)$

$\$ 300-1000(5)$

Acoustic

$\$ 800-2700$ (5)

Add approximately

one hour per sonde

Specialized logs requiring separate mobilization: (not practical for single hole)
Radar Log
$\$ 6000(6)$
$1 / 2$ day
Gravity Log
$\$ 4000(6)$
$1 / 2$ day

$5-31$ 
TABLE 5.2.4-3 (cont.) - NOTES

\section{(1) Assumes:}

a. Single 1000-foot hole

b. 400 miles (round trip) travel charge to well site

c. Holes ready to log upon arrival (i.e. no standby time)

d. Logging speed of 50 feet per minute

e. Non-logging (entering hole) at 60 feet per minute

f. Log package combined on two sondes

(2) Low cost for minerals logging contractor; high end cost for oilfield logging contractor. Cost per hole would be reduced if travel charge can be applied to additional holes.

(3) Approximate time on site, not including travel.

(4) Assumed to be added to package described in note (1)

(5) Actual costs will depend on services desired, available combinations in single sondes, and minimum charges imposed by some contractors. Ranges are as in note (2) above.

(6) Estimated cost for single 1000-foot hole logged as part of larger program. Includes interpretation. 
TABLE $5 \cdot 2 \cdot 4-4$

COST AND TIME SUMMARY FOR

GEOPHYSTCAL EXPLORATION TECHNIQUES

Technique

Gravity

Audio-Magnetotelluric

Seismic Refraction

Resistivity Profile

Resistivity Sounding

Airborne Magnetic

Ground Magnetic

Seismic reflection

-Typical survey

-High resolution
Approximate Cost (1)

\$60-75 per

station (2)

$\$ 900$ per station

$\$ 3,000-15,000$

per mile (3)

$\$ 1000$ per station(4)

$\$ 2500$ per sounding $(6)$

$\$ 20$ per mile plus mobilization cost (see Appenđix B-5)

(7)

$\$ 4,000$ per line mile $(8)$

$\$ 10,000$ per line mile( $(8)$
Typical Production Rates (1)
Field rate at

100 line miles

per month

per crew (8)

2 to 4 stations

per hour

2 stations per crew per day

(3)

3 stations per crew per day in field(5)

2 soundings per crew per day in field(5)

2 to 6 week delivery (depending on equipment availability)

(7)

Field rate of

40 line miles

per month

per crew (8) 
TABLE 5.2.4-4 (cont.) - NOTES

(1) All estimates assume average to good access, terrain, and weather conditions. Costs and times for all ground-based techniques will be higher in areas of rugged terrain or otherwise difficult access or trafficability.

(2) For 100 to 200 station survey under good field conditions (see Figure 4 in Appendix $B-1$ ). Widely spaced stations require increased travel times, affecting costs and production rates. Costs for surveys requiring helicopter access could be on the order of $\$ 250$ per station.

(3) Cost and production rate determined by (1) spacing between geophones, (2) number of shots recorded in each layout, and (3) shot size. Single large shots may require several days of preparation, while small surveys may be completed in a few hours. See Appendix $B-3$ for discussion.

(4) Based on typical survey consisting of six profiles, each $1 \mathrm{~km}$ long. See Table $4 \mathrm{~A}$ in Appendix $\mathrm{B}-4$.

(5) See Table 5 in Appendix B-4 for estimates of times for additional related activities.

(6) Based on typical soundings with five separate measurements and maximum 300-meter pole separation. See Table 4B in Appendix B-4.

(7) When run along with gravity survey, ground magnetic measurements may be done at additional cost of about $\$ 400$ per day, representing one man and magnetometer rental. Survey would cover area at approximately same rate as the gravity survey (discussed above) although measurements may be taken at more stations.

(8) Based on typical land-based crew working on medium-term contract, using dynamite source, 96-trace, 1-millisecond, 12-fold sampling and 50-meter detector spacing. Assumes no adverse conditions of access or trafficability. Data processing adds $\$ 200$ to $\$ 300$ per mile for typical survey and $\$ 800$ to $\$ 1200$ per mile for highresolution. Specialized processing would incur additional costs. See Appendix B-6 for discussion. 
COST AND TIME SUMMARY FOR

GEOMECHANICAI, TECHNIQUES

Technique

Regional stress State

Unconfined Compressive Strength

Description of discontinuities

Rock Quality

Designation

Porosity/Density

Water Content

Absorption

Swelling and slake Durability

Sonic Velocity

Uniaxial Compressive Stress

Permeability

Triaxial Compressive Strength

Thermal Conductivity

Borehole Modulus

In Situ Stress State

$$
\begin{array}{lr}
\text { overcoring } & \$ 40,000-\$ 60,000(7) \\
\text { hydrofracture } & \$ 50,000-\$ 70,000(7) \\
5-35
\end{array}
$$

$$
\begin{gathered}
\$ 14,400 \\
\text { (estimate) }
\end{gathered}
$$

$\$ 50$

$\$ 10$

$\$ 50$

$\$ 350-1,250$

$\$ 50-500(3)$

$\$ 250$ (4)

$\$ 250-1,000$

$\$ 2,000-10,000(5)$

$\$ 1,000-2,000(6)$

$\$ 10,000-15,000(7)$

$\begin{array}{lc}\frac{\text { Time (1) }}{3 \text { wks }} \begin{array}{c}\text { pomments } \\ \text { (estimate) } \\ \text { based on liter- } \\ \text { ature review }\end{array} \\ 5 \text { minutes (9) } & \text { per test } \\ \begin{array}{l}1 \text { man month } \\ \text { (estimate) }\end{array} & \text { per site }\end{array}$

(2)

2 weeks

2 weeks

2 weeks

2 weeks

3 weeks

3-6 weeks

3 weeks

3-6 weeks per test

8 weeks per test

1 week (8) per test 
TABLE 5.2.4-5 (cont.) - NOTES

(1) Turn-around time for delivery of laboratory results, unless otherwise stated.

(2) Done by well-site geologist in conjnction with normal core logging at no measurable increase in cost or change in drilling rate.

(3) Higher costs are for tests at elevated temperature and pressure.

(4) Includes measurement of deformation, can obtain strength data only for less than $\$ 50$.

(5) Test program would be designed to meet project needs. Further cost increases would result from requirements for additional measurements or testing at elevated temperature or pressure.

(6) Higher cost for tests at elevated pressure.

(7) Excluding drilling costs.

(8) Actual working time on test.

(9) Field tests using portable point load apparatus or Schmidt Hammer. See page 8 and 9, Appendix E-1. 
COST AND TIME SUMMARY FOR HYDROLOGY TECHNIQUES

Technique

Surface Hydrology

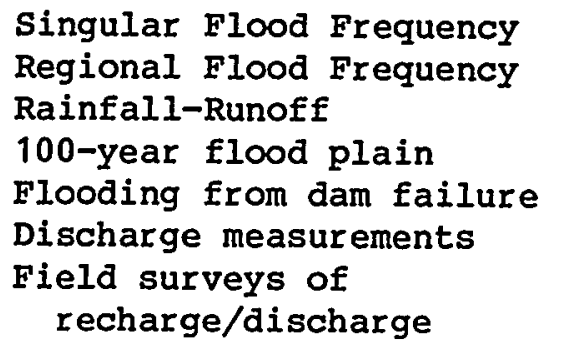

Surface-water sampling

Borehole Testing (5)

Head measurement
a. Manual
b. Winch
c. Recorder

Drill stem test

Pump test

Injection test

Straddle packer test

Tracer tests

\section{Permeability Tests}

on core samples

Numerical Modeling

\begin{tabular}{lcc} 
Approximate & $\begin{array}{c}\text { Approximate } \\
\text { Turn-Around } \\
\text { Cost Range }\end{array}$ & Time \\
\hline
\end{tabular}

Approximate

Time

Comments
(1)

(1)

(1)

(1)

(1)

(2)

(3)

(4)

$\$ 50-75$

$$
\begin{array}{lcc}
\$ 25-100(6) & 1-2 \text { hour (6) } & \begin{array}{c}
\text { per } \\
\text { measurement } \\
\text { per }
\end{array} \\
\$ 100-500(7) & 1-4 \text { hour (7) } & \begin{array}{c}
\text { measurement } \\
\text { installa- } \\
\text { tion of } \\
\text { recording } \\
\text { system }
\end{array}
\end{array}
$$

per square mile (3) per square mile (4) $\begin{array}{lll}\text { to } \$ 25,000(10) & 2 \mathrm{hr}-7 \text { days } & \text { per test } \\ \text { to } \$ 25,000(10) & 2 \mathrm{hr}-7 \text { days } & \text { per test }\end{array}$ $\begin{array}{lll}\text { to } \$ 25,000(10) & 2 \mathrm{hr}-7 \text { days } & \text { per test } \\ \text { to } \$ 25,000(10) & 2 \mathrm{hr}-7 \text { days } & \text { per test }\end{array}$ $\$ 200$ or more (11) (11)

$$
\begin{array}{lll}
\$ 250-1000(12) & 3 \text { weeks }(12) & \text { per test } \\
\$ 400-4000(13) & 1-10 \text { days }(13) & \text { per model }
\end{array}
$$


TABLE 5.2.4-6 (cont.) - NOTES

(1) Cost and time for specific analysis, after compiling basic field data.

(2) Cost and time for single field measurement, using simple plywood wier, portable flume, or existing structure. Does not include travel to measurement site.

(3) Assumes 2-man field party working at rate of 10 to 15 square miles per day. Actual costs and rates of progress would vary with field conditions.

(4) Assumes 2-man field party working at rate of 25 to 50 square miles per day, including cost of expendible sampling equipment. Costs for typical water-quality tests are in Table 1 of Appendix G.

(5) Not including drilling or completion costs. See Appendix D.

(6) Manual measurement using tape or probe to about $750^{\prime}$ depth - not including travel to well site.

(7) Measurement at greater depth, requiring winch to handle probe not including travel to well site.

(8) Cost and time requirements for testing vary according to depth, duration of test, and size or type of drilling equipment used. See Appendix G.

(9) Pump test costs depend on equipment in place of a well and duration of the test. Can be done for about $\$ 200$ at existing water-supply well with pump in place. Cost can be thousands of dollars for complex testing systems requiring installation of pump, power supply, and equipment for monitoring water levels.

(10) Cost and time estimate for high-technology testing in tight formation at repository depths. Includes mobilization of specialized equipment and preliminary analyses of results.

(11) For long-duration tests, as may be needed in formations with low permeability, costs are likely to be determined by need for continued monitoring, involving pumping or bailing to detect tracer in deep aquifer. Such tests could cost several thousand dollars.

(12) Does not include cost or time for obtaining core.

(13) Cost and time for numerical analyses only, after basic field and lab data are compiled. 


\subsubsection{Seismotectonics}

Seismology costs are summarized in Table 5.2.4-7 and discussed in Appendix $\mathrm{H}$. No unique costs are anticipated while conducting the seismologic studies on tuff.

\subsubsection{CRITERIA FOR EVALUATING DATA ADEQUACY OF PRECHARACTERIZATION STUDIES IN TUFF}

The previously discussed information needs (Section 5.2.2), and applications of techniques (Section 5.2.3) can be used to develop general criteria or guidelines for evaluating the information on exploration and testing likely to be presented in a site characterization Report for a prospective repository site in tuff. Such a Site Characterization Report would include results of the previous exploration and testing used to select the site (precharacterization studies) and descriptions of the planned exploration effort for site characeterization. The discussions in this section emphasize guidelines for evaluating precharacterization exploration and testing. Evaluation of the work performed for site characterization will be the topic of Section 5.3. Following the organization of the preceeding sections, these criteria are grouped according to disciplines: geology, hydrology, geochemistry, geomechanics, seismotectonics, and resources.

\subsubsection{Geology}

The information generally required to adequately characterize a medium for a waste repository site, and the most applicable techniques for gathering these data are presented below.

- Erosional and depositional processes - remote sensing, surface mapping

- Lithology, stratigraphy and structure of overburden - drilling and geophysical logging, seismic reflection, petrology;

- Lithology, stratigraphy and structure of host rock - drilling and logging, seismic reflection;

- Depth to host rock - drilling and logging, seismic refraction, seismic reflection; 
TABLE $5.2 .4-7$

COST AND TIME SUMMARY FOR

SEISMOTECTONIC TECHNIQUES

Technique

Historical Data

Instrumental Data

Fixed Network

Installation

Operation

Portable Network

Crustal Refraction Profile
Approximate

Cost Range

Time

Comments

$\$ 2,900-5,900$

2 weeks

per basic

analysis

$\$ 5,800-8,800 \quad 1-2$ months

per basic analysis

$\begin{array}{ccl}\$ 8,000-10,000 & 12-28 \text { weeks } & \text { per station } \\ \$ 7,300-14,600 & -- & \begin{array}{l}\text { cost per } \\ \text { station/year }\end{array}\end{array}$

$\$ 3,250-5,700 \quad 2$ days cost per (to install) station/month

$\$ 2,000-\$ 5,400 \quad 1-4$ weeks per station 
Accurate determination of subsurface conditions (stratigraphy, litho1ogy, structure, etc.) is strongly dependent on cross-correlation of several techniques, such as remote sensing, surface mapping, geophysical surveys, drilling, and geophysical logging. An adequate precharacterization program should make maximum use of all available techniques.

A more complete discussion of the geology needs, techniques, and possible sources of error is presented in section 5.2.3.

\subsubsection{Hydrology}

The data and most applicable techniques to adequately characterize the hydrology of a site should generally include the following: - Hydrostratigraphy - drilling, borehole logging, aquifer testing,

- Recharge/discharge - groundwater age dating, aquifer testing, surface mapping, remote sensing

- Porosity/permeability - aquifer testing, borehole logging, petrography, rock density testing

- Heads and gradients - aquifer testing

- Flow direction/travel time - aquifer testing, tracer tests

- Groundwater age - geochemistry; groundwater age dating

- Dissolution - geochemistry, borehole logging, petrography

- Surface hydrology - flood frequency, geochemistry, surface mapping

Surface hydrology should be well evaluated by the precharacterization work. The results of both the surface and subsurface hydrology studies are used in meeting the needs of the hydrology discipline and to provide data that may be required to fill needs of other disciplines. 
A more complete discussion of the geochemistry needs, techniques and possible sources of error is presented in Section 5.2.3.

\subsubsection{Geochemistry}

The data needs and most applicable techniques to adequately characterize the needs of geochemistry should generally include the following:

- Sorption - sampline and analysis;

- Rock mineralogy and alteration - remote sensing, surface mapping, petrography, sampling and analysis, borehole logging;

- Organic content - Petrography and geochemical analyses,

- Retardation properties - petrography and geochemical analyses;

- Water chemistry - sampling and analysis, resistivity, borehole logging.

Some of these needs are closely related to these of the hydrology and resource disciplines. The exploration program should provide for integration of geochemical data with other disciplines.

A primary objective of the geochemistry discipline should be determination of sorption characteristics of the welded and zeolotized portions of the tuff sheet. This will require integration of data from other disciplines (geology and geomechanics).

A more complete discussion of the geochemistry needs, techniques and possible sources of error is presented in Section 5.2.3. 


\subsubsection{Geomechanics}

Adequate characterization of the geomechanical and thermal properties of a host rock requires the measurement of certain parameters. The minimum parameters required and the best techniques to measure them fall into the two categories shown below:

\section{Geomechanical Parameters}

- Density - laboratory testing, in situ testing

- Rock classification, quality and discontinuities - surface mapping, laboratory testing

- Strength - laboratory testing

- Moduli - laboratory testing

- Plasticity - laboratory testing

- In situ stresses - in situ testing

- Pore pressure - in situ testing

\section{Thermal Parameters}

- Specific heat - laboratory testing

- $\quad$ Conductivity - laboratory testing

- Coefficient of thermal expansion - laboratory testing

- Thermal alteration - laboratory testing

The actual laboratory techniques for measuring these parameters vary. The important criteria are that the aforementioned parameters be measured. 
A more complete discussion of the effects of these items are found in Section 5.2.3.

\subsubsection{Seismotectonics}

The seismic and tectonic parameters needed and the best techniques to measure them are as follows:

- Uplift and subsidence - surface mapping, fault studies

- Faulting - remote sensing, monitor networks, fault studies, surface mapping, seismic reflection

- Igneous activity - monitoring networks, gravity surveys

- Seismic activity - monitoring networks, historical seismic analyses, instrumental seismic analyses (includes fault plane solutions)

- Natural stress variations - in situ testing

With the exception of testing for natural stress variations, none of the techniques above are "hands on" tests, and are therefore subject to errors of interpretation. The value of these studies is highly dependent upon integration of data from other disciplines and subject to limitations discussed previously. A further discussion of these problem areas is found in section 5.2.3.

\subsubsection{Resources}

The minimum data and most applicable techniques to adequately characterize the needs of the resource discipline should include the following:

- Mineral resources - surface mapping, petrography, geophysical exploration remote sensing, drilling and logging, geochemical analyses

- Hydrocarbon resources - surface mapping, geophysical exploration, remote sensing, drilling and logging, geochemical analyses petrography 
Geothermal resources - surface mapping, geophysical exploration, remote sensing, drilling and logging, geochemical analyses, temperature gradients

- Water resources - surface mapping, geophysical exploration, remote sensing, arilling and logging, geochemical analyses

These needs are closely related to those of the hydrology and geochemistry disciplines. Therefore, the exploration program should provide for careful integration of resource data with these disciplines.

In addition, careful analysis of existing resources that may be known off-site should be made to determine if they may be extrapolated to the site. A more complete discussion of the needs, techniques, and possible sources of error is presented in section 5.2.3.

\subsection{SITE CHARACTERIZATION STUDIES}

\subsection{GEOLOGIC FEATURES OF TUFF IMPORTANT FOR SITE CHARACTERIZATION}

The geology of tuff was summarized in section 5.2.1. Included was a brief discussion of its origin and emplacement, stratigraphy, structure, hydrology, and resources. The salient points of that discussion relating to site characterization are presented again here to provide a reference framework for the description of appropriate techniques, tests and experiments that follow.

A nuclear waste repository will require a thermally stable, mechanically strong geologic medium enveloped by low permeability and highly sorptive materials. Welded tuff sheets having a basal non-welded zeolitized portion may meet the conditions required for nuclear waste storage while providing multiple barriers to radionuclide migration.

Tuff is a general term for pyroclastic deposits of volcanic dust, ash, pumice, and scoria produced by explosive disintegration of viscous lava from a crater or, less commonly, a fissure. It is a consolidated but not necessarily a welded deposit. Tuff may be deposited either directly by explosive volcanic events, or it may be reworked and redeposited by surface processes, in which case it takes on the character of a sedimentary rock. Only the former is considered suitable for a repository. Two varieties of welded tuff can be distinguished based mainly on texture, geometry, and field relationships. The first 
is formed by pyroclastic flows, defined by Sheridan (1979) as "all denser-than-air avalanches, streams, and flows that receive their initial energy from volcanic eruptions."; the second is formed by pyroclastic air-fall material, defined as deposits formed by "... ballistic transport of...ejecta carried in gas streaming from a vent, ejecta settling...from a convective plume..., and/or deposition from convective clouds...".

zeolitized tuff is also of interest in repository siting. This is non-welded tuff that contains zeolite, a hydrous silicate of open molecular structure which has a low density, high porosity, very low permeability, high water content, extremely high sorptive properties, moderate compressive strength, and moderate thermal conductivity. The low permeability and high sorptive properties are attractive as barriers to radionuclide migration.

Eruptions of silicic volcanism vary in volume from a few cubic meters to a massive catastrophic event depositing hundreds of cubic meters of ash and lava in a single eruption. Upon eruption, silicic magmas most commonly contain about 108 primary crystals (phenocrysts) and incorporate about $10 \%$ lithic fragments, so that generally 808 of the material deposited is glass. Because of the high viscosity and high volatile content of silicic magmas the great majority of material is ejected explosively as pumice, shards and fine ash.

Large explosive eruptions commonly begin with ejection of tephra that is deposited downwind of the vent as a cool unsorted layer of low-density material (termed an air-fall or ash-fall deposit). This nonwelded layer may subsequently become zeolitized. As eruptions proceed and increase in intensity, clouds of incandescent ash propelled by evolving gases are formed over the vent and collapse downslope, depositing heated material in thick blankets. This latter type of deposit is volumetrically more significant with regard to repository siting because large volumes of laterally extensive, relatively homogeneous rock is produced. The rocks overlying the magma chamber may collapse to form a caldera, which may subsequently fill with thick sequences of volcaniclastic deposits. Materials deposited above about $500^{\circ} \mathrm{C}$ will compact and weld by viscous deformation of the glass. Compacted material that cools rapidly (i.e., weeks to months) may remain glassy, while that which cools more slowly may crystallize to a mixture of cristobalite, quartz, and feldspar.

The net result is a complex deposit up to several hundred meters thick which has cooled as a single unit (commonly referred to as a cooling unit). These deposits have a core of welded material, most of which may have devitrified (i.e., crystallized) to quartz and feldspar with or without cristobalite. At the base of the welded zone is a layer of 
densely welded material that has not crystallized but remains a dense glass (vitrophyre). Welding decreases outward from the core so that the welded zone is surrounded by zones of material decreasing in density, thermal conductivity, coherence, and strength. Commonly at the base of ash-flow deposit there is an unsorted, nonwelded zeolized ai-fall unit horizon of loosly aggregated pumice and ash.

Both external and internal relationships are important when interpreting stratigraphic and structural relationships that are important to repository siting. External relationships include gross stratigraphic and lithologic relationships. Internal relationships such as degree of welding, strain relationships, alteration structures, and minor compositional changes all impart unique features on the tuff sheet which ultimately may affect sorption, flow rates, residence time of ground water or geomechanical parameters. Careful examination of the age, textural and chemical characteristics may enable correlation of units. Actual thicknesses and areal extent of tuff sheets can vary widely but large sheets may be thousands of meters thick and a few thousand square kilometers in area.

After eruption, tuff sheets typically come to rest at very low angles of repose (less than about 7 degrees). Therefore, in their primary stage, tuff sheets can be conceived of as a bedded or layered media much like shale, bedded salt or flood basalt. The upper surface is typically planar, perhaps with the tops of pre-existing topography exposed and the base is unconformable with the pre-existing topography. Structures associated with tuff sheets are generally those relating to the ring fracture zone surrounding the vent area, columnar jointing relating to cooling of the sheet after emplacement, and fumaroles formed around areas of degassing of the sheet after placement. Columnar joints are conspicuous features of many tuff sheets and are particularly well developed in the lower and middle parts. While similar to columnar joints in basaltic lava flows, they tend to be coarser and less regular.

Although welded and zeolitized tuffs are widespread and occur in thick sections in the western states, their homogeneity and hydrologic properties have not been characterized in detail. One of the best studied welded tuff sheets from the standpoint of hydrology is at the Nevada Test Site (NTS) in Nevada. The water table at NTS is between 390 and 600 meters deep, but the surface relief is such that in places it intersects the potentiometric surface. Estimates based on radiocarbon ages at NTS indicate an average groundwater velocity of about 30 meters/year in an area of suspected fracturing. This estimate is therefore probably somewhat higher than it would be in unfractured tuff. The sorption capacities of tuffaceous rocks along flow paths are indicated to be very high. However, it can be expected that sorption 
capacities will be greater in interbeds of less welded or nonwelded zeolitized zones.

\subsubsection{INFORMATION NEEDS FOR SITE CHARACTERIZATION IN TUFF}

Site characterization information needs are largely those requiring detailed exploration techniques. Many of the precharacterization techniques continue to be applicable, but an important difference is pilot shaft excavation and a test room development at the proposed repository level. These operations allow detailed examination, in situ testing of the host rock at depth, and a base for intensive (horizontal or inclined) drilling and coring without connecting the prospective repository with the surface environment. It is possible to obtain a large amount of detailed information on the proposed host rock during site characterization. This exploration and testing involves considerable expense and significant schedule commitment, beginning with design and excavation of the pilot shaft and test room.

Following suitable completion of the precharacterization studies, the main issues to be emphasized in site characterization are: (1) verification of site suitability with regard to containment and isolation of radionuclides; and (2) providing detailed site parameters for repository design and construction. Topics of concern regarding these issues include:
- construction design
- retrievability performance
- radionuclide migration
- thermal performance

In addition, there would be continued exploration and testing to refine or increase information reliability. Monitoring of precharacterization results for resource and seismotectonic studies to verify previous findings would continue.

Because of the time and expense of site characterization, precharacterization resuts must produce a high confidence level in the ultimate suitability of a candidate site. In general, precharacterization data should resolve issues that may be addressed without detailed exploration and testing at depth. Issues that should be essentially resolved 
in precharacterization include: surface geology, surface hydrology, climate, tectonics, seismicity, and potential for igneous activity. All of these issues are typically addressed by regional investigations around a site, rather than by detailed exploration and testing at depth. Similarly, the resource potential at a site can be resolved in advance since the potential may be determined by reconnaissance level investigations, in comparison to the detailed site characterization studies.

The following subsections summarize information needs specific to the site characterization of a prospective repository. The needs are discussed under the categories of: geology, hydrology, geochemistry, geomechanics, seismotectonics, and resources. Each category has a brief description of information assumed to have been obtained from precharacterization.

\subsubsection{Geology}

Geologic information needs at the site characterization level mainly involve obtaining more detailed information on geologic conditions of the candidate host bed as they relate to design, construction, and performance of the repository. These geologic issues are summarized in Section 5.2.2.1 and Table 5.3.2-1.

Precharacterization results should be adequate to define surface geologic conditions and processes, and generally describe stratigraphy, lithology, and geologic structure at depth. Surface geology should have been determined as needed to interpret the nature and rates of relevant processes including: erosions deposition, climate, and hydrologic conditions. Precharacterization subsurface geologic information should include depth, thickness, and lateral extent of potential host beds. Features such as faults, vents, dikes or fumaroles would limit the lateral extent of suitable tuff units and should have been defined previously. The stratigraphy of the host and the overlying and underlying units should be adequately known to allow definition of existing or potential aquifers and confining units. Intensive programs at depth will be required to verify and refine fracture density and orientation, depth, thickness and lateral extent of the host rocks, lithology, stratigraphy, and structure of host rock and overburden, and petrography. The bearing of these information needs on characterization issues, and interrelationships with other formation needs are described in the following sections. 
TABLE $5 \cdot 3 \cdot 2-1$

GEOLOGY INFORMATION NEEDS IN TUFF

Emphasized in Precharacterization:

1. Geologic processes.

2. Lithology, stratigraphy, and structure of rocks above and below the tuff.

3. Depth, thickness and lateral extent of the tuff.

4. Large scale structures (faults, folds, vents, etc.).

5. Interbeds.

Emphasized in Site Characterization:

1. Detailed mineralogy and lithology of the tuff.

2. Fracture density and orientation.

3. Lateral variations.

4. Smaller scale structures.

5. Texture.

6. Any other geologic anomalies (e.g., Iithic inclusions, permeability, density, etc.). 


\subsection{Fracture Density and Orientation}

Because of the far reaching effects of fractures on hydrology, geochemistry and geomechanics, this is one of the most important geologic information needs. Fracture density, orientation, extent, fillings, exposed area, roughness, and pervasiveness greatly influence such hydrologic parameters as:

- fracture permeability

- ground-water circulation

- ground-water flow rates and directions

- ground-water convection (induced by radioactive heating of the host rock)

- ground-water residence time

Geomechanical/thermal parameters possibly affected by fracture characteristics include:

- rock strength

- creep

- spallation

- stress variations

Geochemical fracture effects include:

- radionuclide sorption

- radionuclide migration

- alteration (natural or induced)

- waste/rock/water and waste/joint filling interactions

- reaction rates (dependent on exposed area) 


\subsection{Lithology, Stratigraphy, and Structure}

Lithology, stratigraphy, and structure are important to construction design as well as shaft design. The presence, pervasiveness, and extent of fractures (including joints and faults), and inclination of tuff layers or fractures exposed during excavation may affect the strength and stability of the host medium. Lithologic information also supports the hydrologic information needs of flow rates in aquifers or host rock and permeability measurements. Lithologic data may also identify whether highly sorptive minerals, such as zeolites, are present in either the host rock or in the rock mass surrounding the proposed repository.

\subsection{Mineralogy and Texture}

Definition of the host rock mineralogy and texture and any lateral or vertical variations is very important. Any alteration or secondary mineralization such as zeolites is also important. The latter is important because mechanical strength and sorption are partially dependent upon mineral assemblage. Petrographic studies can be an adjunct to geochemical analyses for verification of mineral resources.

\subsubsection{Hydrology}

The information needs for both pre- and site characterization are sumarized in Table 5.3.2-2. Climate (present and past) and surface hydrology are surface-based investigations that should be completed before site characterization is commenced. The hydrology of aquifers above and below the tuff also should be generally well known from the subsurface precharacterization work, although continued evaluations may be performed concurrently with site characterization to verify initial findings.

Because the primary transport mechanism of radionuclides from repository to biosphere will be groundwater, an accurate assessment of the hydrologic and hydrogeologic regimes is critical to site characterization. The information needs of hydrology for site characterization do not differ significantly in the level of detail required for precharacterization. The following sections address hydrology information needs, the uses of these needs, and their correlation with information needs of other disciplines. 
TABLE $5 \cdot 3 \cdot 2-2$

HYDROLOGY INEORMATION NEEDS IN TUFF

Emphasized in Precharacterization:

1. Climate.

2. Surface hydrology.

3. Aquifer characteristics above and below the proposed repository horizon.

Emphasized in Site Characterization:

1. Fluid-bearing zones and flow paths within the tuff.

2. Hydrated or molecular water.

3. Aquifer properties. 


\subsection{Hydrostratigraphy}

The hydrostratigraphy information need primarily includes verification of precharacterization data on interstratal flow and permeability. Ground-water infiltration and flow rates in aquifers will be needed in construction design to determine type and amount of water control (e.g., dewatering of overburden) required during construction or repository operation. Information on ground-water circulation, movement, and flow rates (in aquifers and in natural or induced hydrothermal regimes) is required to assess radionuclide migration.

The term interstratal flow, as used here, refers to ground-water movement along brecciated tuff unit contacts, and does not include flow within descrete interbedded aquifers. Parameter elements which will assist in assessment of required water control are fracture flow, ground-water infiltration, and ground-water movement. Data on radionuclide migration will be derived from evaluation of fracture flow, hydraulic conductivity anisotropies, and ground-water infiltration. Ground-water infiltration and fracture flow data will also be used in evaluation of retrievability performance, because the possibility of natural or induced hydrothermal conditions may have a bearing on geochemical reactions and rates.

The primary use of permeability data is to support assessment of: flow rates in aquifers, interstratal flow rates, and ground-water infiltration, circulation, movement, and residence time.

\subsection{Quantification of Aquifer Properties}

A further quantification of aquifer properties will verify and refine precharacterization models of recharge/discharge, fluid transport, and hydraulic heads and gradients. These models will provide input for numerical models to evaluate the possible effects of thermally induced ground-water convection or circulation. Refinement of aquifer models would be accomplished by more detailed investigations and by continued monitoring from precharacterization.

Ground-water convection assumes the possibility of establishing single or multiple convection cells in the ground water regime by heat transfer from waste containers. The source for such water could likely be molecular water released from the tuff subsequent to heating by the waste. Such convection cells would enhance any natural hydrothermal circulation and/or establish an induced hydrothermal regime. Establishment of convection cells could radically alter geochemical reactions and rates (sorption), as well as ground-water flow rates and 
directions. The end result of these alterations might change the radionuclide migration rate.

\subsection{Identification of Voids or Other Cavities}

Voids in tuff are typically of both primary and secondary origin and include features such as buried vents and fumaroles. These features can produce hydraulic conductivity anisotropies, which will affect ground-water movement, construction design, and radionuclide migration. Fortunately, the geomechanical stability and relatively low solubility of tuff do not favor formation of significant voids.

\subsubsection{Geochemistry}

Site characterization information needs in geochemistry are essentially as summarized in Section 5.2.2.3 and Table 5.3.2-3. However, in this section rock/water/waste interactions at repository conditions, and their influence on repository safety and performance are emphasized. Assessment of these chemical properties along flow paths to the environment is also necessary to evaluate radionuclide migration potential. Chemical conditions in shaft and borehole areas will be needed to provide repository sealing design parameters.

\subsection{Waste/Rock/Water Interactions (Sorption)}

This information need is generic, including waste/host, waste/jointfilling or waste/interbed reactions and is paramount in radionuclide migration evaluation or sorption. Information required includes determination of possible chemical reactions and rates, ion processes, and nuclide solubility. The specific types of information required are enumerated in Section 5.2.2.3.

Because radioactive material decay produces high canister temperatures, it is critical that all of these parameters be evaluated as a function of heat, pressure and moisture content.

Host rock geochemical sampling should be performed to assess any spatial (horizontal and vertical) geochemical variations, which will be used for:

- evaluation of lateral extent and thickness of host rock

- documentation of the presence of anomalous interbeds 
TABLE $5 \cdot 3 \cdot 2-3$

GEOCHEMISTRY INFORMATION NEEDS IN TUFF

Emphasized in Precharacterization:

1. Chemical composition of tuff.

2. Composition of fluids in aquifers.

3. Composition of rocks along potential flow paths.

4. Preliminary dating of rocks and fluids.

5. Sorption characteristics.

Emphasized in Site Characterization:

1. Tuff composition.

2. Reactions with canisters, wasteforms, and other engineered materials.

3. Sorption.

4. Complexing and polymerization of radionuclides in repository fluids.

5. Ion exchange and exclusion.

6. Precipitation.

7. Filtration.

8. Age of rocks and fluids. 
- prediction of rock/water geochemical variations

- monitoring alterations for possible presence of previously undetermined mineral resources

\subsection{Rock and Water Composition}

The two main sources of water in tuffs are pore water and molecular water such as that contained in zeolites, hydrated glass, and clay. Two studies have been undertaken to characterize the behavior of water under different stimuli (Johnstone and Wolfsberg, 1980). The two studies that have been undertaken to date include:

- water loss upon drying

- in situ tuff water-migration/heater experiment

Studies of this type are also need on tuff at the proposed repository volume.

The first study has only recently become of great interest because expected conditions in a waste-disposal scenario make evaporative drying an important mechanism that needs to be considered. Results of the water loss experiment are reported in Hadley and Turner (1980) and Johnstone and Wolfsberg (1980).

The in situ water-migration/heater experiment at NTS is the initial assessment of water behavior in deep underground environments $(2400 \mathrm{~m})$ in response to a thermal source. Similar tests are needed on samples within the actual proposed repository volume. The status of this test is summarized in Johnstone and Wolfsberg (1980).

Data from this information need to be integrated with data derived from other major disciplines to assess:

- effects of heat and water on geochemistry

- geochemical changes due to existing or induced thermal alterations

- nuclide solubility and sorption 


\subsubsection{Geomechanical Needs}

Information needs in geomechanics are essentially as summarized in Section 5.2.2.4 and Table 5.3.2-4. Reliable information on geomechanical and thermal conditions is important input for construction design, radionuclide migration and thermal performance. Many geomechanical parameters have been established through study of NTS tuffs. However, the information required to extrapolate the results to repository levels is generally not available.

\subsection{Strength Parameters}

The effects of water and temperature on strength parameter values must be considered. These data should be integrated to aid in the verification of:

- fracture and fracture in-filling effects on geomechanical properties

- wet/dry strength

- mineralogy vs. strength

- stability of test rooms subsequent to excavation

Examples of parameters which need to be examined from this information category include:

- density

- moduli

- compressive and tensile strength

- elastic properties

- creep

- post-failure characteristics 
TABLE $5 \cdot 3 \cdot 2-4$

GEOMECHANICS INFORMATION NEEDS IN TUFF

Emphasized in Precharacterization:

1. Temperature field.

2. In situ stress field.

3. Thermal conductivity and specific heat of overburden and proposed repository level.

Emphasized in Site Characterization:

1. Thermal expansion data.

2. Creep properties of tuff at anticipated repository temperatures.

3. Decrepitation and other temperature effects.

4. Radiation effects.

5. Anticipated temperature field.

6. Detailed survey of discontinuities and inhomogeneities in the repository zone. 
Post-failure characteristics include the plastic or brittle nature of deformation under varying conditions of temperature, confining stress, and moisture. All of the above parameters need to be evaluated as a function of the temperature range expected within proposed repository materials.

\subsection{Stress Variation}

In situ testing, such as over-coring or jacking tests, are needed to establish the stress regime present in the repository. These tests will be used to assess the possibility of spallation due to stress relief by excavation. When combined with information on groundwater heating and heat transfer, these data can be used to predict decrepitation (steam-induced spallation). Spallation and decrepitation data bear both on construction design and retrievability performance (Section 5.3.2). Additional parameters which may be deduced from these data include creep of the tuff and residual stress.

\subsection{Effects of Exposure}

This information need is concerned with the possible effects on mechanical or thermal properties resulting in formation of alteration products by exposure to the atmosphere. It is known that water plays a significant role on the strength of tuff (Johnstone and Wolfsberg, 1980). Dry welded tuff has a compressive strength about 258 greater than for saturated samples. A complete evaluation of these processes must include verification of temperature and moisture effects.

\subsection{Thermal Parameters}

The thermal parameters which need to be verified for site characterization include:

- heat capacity and thermal diffusivity

- thermal expansion coefficient

- conductivity

- specific heat

- effect on rock alteration processes and rates 
Because many of these parameters are known to vary with temperature, they must be characterized at temperatures above $100^{\circ} \mathrm{C}$; the temperature which might result after waste emplacement (Johnstone and Wolfsberg, 1980; Raines and others, 1980).

These data are needed to assess the overall thermal performance of the repository, as well as the effect of temperature on:

- geochemistry

- geomechanics

- alteration

- water

\subsection{Radiation Effects}

The radiation effects on various geomechanical parameters must be studied to determine the degree to which repository parameters will change after waste emplacement. The geomechanical parameters which are of concern include:

- density

- thermal expansion

- thermal conductivity

- mechanical properties (especially unconfined, uni- and triaxial compression)

- mineralogical alterations

\subsubsection{Seismotectonics}

The information needs for a prospective site in tuff are summarized in section 5.2.2.5. These conditions should be demonstrated to be favorable at a site before site characterization commences. As tuffs typically occur in areas with a past history of seismicity, tectonism, and volcanism seismic monitoring should be continued through the period of site characterization and the results incorporated into seismotectonic models repository design. During site characterization studies, microseismicity studies should be carried out to monitor 
possible stress changes within underground chambers excavated for test rooms.

\subsubsection{Resources}

Resource potential of a site should be known from precharacterization studies. Because of the incidence of resource occurrence in tuff is typically low (see sections 5.2.1.5 and 5.3.1) precharacterization results should be adequate for evaluating the presence of resources. However the resource potential of the site should be verified during site characterization by continued monitoring of the geologic and geochemical exploration results.

\subsubsection{TECHNIQUE APPLICATIONS TO SITE CHARACTERIZATION INFORMATION NEEDS IN TUFF}

The techniques to be discussed in this section are those involved in the detailed testing of the host rock and in situ testing at depth. It is assumed that a significant portion of the work during the site characterization program involves continued application of the techniques used in precharacterization, as discussed in section 5.2.3. These techniques would be applied essentially as in precharacterization and are not discussed further here.

There is much less precedent and experience for site characterization work than for precharacterization studies. Precharacterization generally utilizes techniques that were developed by the oil, mineral and engineering industries. However, only a few programs used by mining or underground construction industry achieve the level of detail and reliability desired for site characterization and only a few tests have been specifically designed for waste isolation applications. Some of these tests are summarized in a recent report on evaluation of tuff as a medium for a nuclear waste repository (Johnstone and Wolfsberg, 1980). As with. work on other geologic media being considered for nuclear waste repository siting, significant in situ testing and subsurface geologic mapping at depth have not been done. The techniques that are considered appropriate for each of the information needs at a site in tuff are summarized generally in Table $5 \cdot 3 \cdot 3-1$.

\subsubsection{Geology}

During site characterization, geologic properties of the tuff would be determined in the field from detailed subsurface-based excavation 
TABLE 5.3.3-1 SITE CHARACTERIZATION TECHNIQUE APPLICATION

\begin{tabular}{|c|c|c|c|c|c|c|c|c|}
\hline $\begin{array}{l}\text { APPLICATIONS OF TECHNIQUES } \\
\text { TO INFORMATION NEEDS } \\
\text { FOR SITE CHARACTERIZATION } \\
\text { - MAJOR CONTRIBUTION } \\
\text { O SUPPORTING CONTRIBUTION }\end{array}$ & 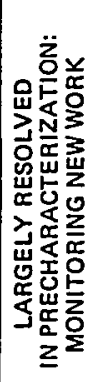 & 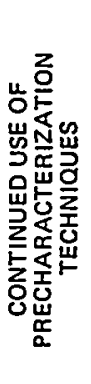 & 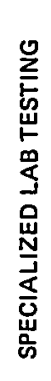 & 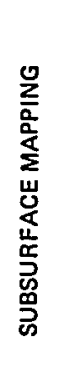 & 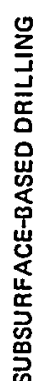 & 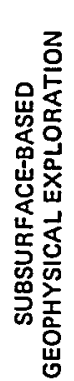 & 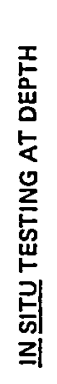 & 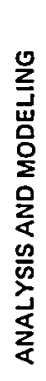 \\
\hline \multicolumn{9}{|l|}{ GEOLOGY } \\
\hline \multicolumn{9}{|l|}{$\begin{array}{l}\text { SURFICIAL GEOLOGY AND } \\
\text { OVERBURDEN STRATIGRAPHY }\end{array}$} \\
\hline $\begin{array}{l}\text { OEPTH/THICKNESS/LATERAL EXTENT } \\
\text { OF SUITAGLE REPOSITORY HORIZONS }\end{array}$ & 0 & $\bullet$ & & $\bullet$ & $\bullet$ & o & & o \\
\hline LOCATION OF ANOMALOUSLY WELDED ZONES & 0 & $\bullet$ & & $\bullet$ & 0 & o & & 0 \\
\hline LOCATION OF ZEOLITIZED ZONES & 0 & $\bullet$ & & - & 0 & & & o \\
\hline LITHOLOGY & 0 & $\bullet$ & 0 & $\bullet$ & 0 & $\mathbf{0}$ & & o \\
\hline $\begin{array}{l}\text { FRACTURES-ORIENTATION, DENSITY, } \\
\text { SEPARATION, FILLING, ETC. }\end{array}$ & 0 & 0 & 0 & $\bullet$ & 0 & o & 0 & 0 \\
\hline \multicolumn{9}{|l|}{ GEOCHEMISTRY } \\
\hline ROCK CHEMISTRY & $\circ$ & $\bullet$ & $\bullet$ & & 0 & & & 0 \\
\hline WATER CHEMISTRY & $\circ$ & $\bullet$ & $\bullet$ & & o & & & 0 \\
\hline ROCKNWATER INTERACTIONS & $\bullet$ & $\bullet$ & & & & & & 0 \\
\hline WASTE/ROCK/WATER INTERACTIONS (SORPTION) & $\circ$ & - & $\bullet$ & & & & & 0 \\
\hline \multicolumn{9}{|l|}{ GEOMECHANICS } \\
\hline PETROFABRICS & o & $\bullet$ & & $\bullet$ & 0 & o & & 0 \\
\hline THERMAL PARAMETERS & 0 & - & o & & o & & • & 0 \\
\hline CREEP & 0 & $\bullet$ & 0 & & & & - & 0 \\
\hline EXPOSURE EFFECTS (DRYING) & o & $\bullet$ & 0 & 0 & & & $\bullet$ & 0 \\
\hline
\end{tabular}


TABLE 5.3.3-1 (CONT'D) SITE CHARACTERIZATION TECHNIQUE APPLICATION

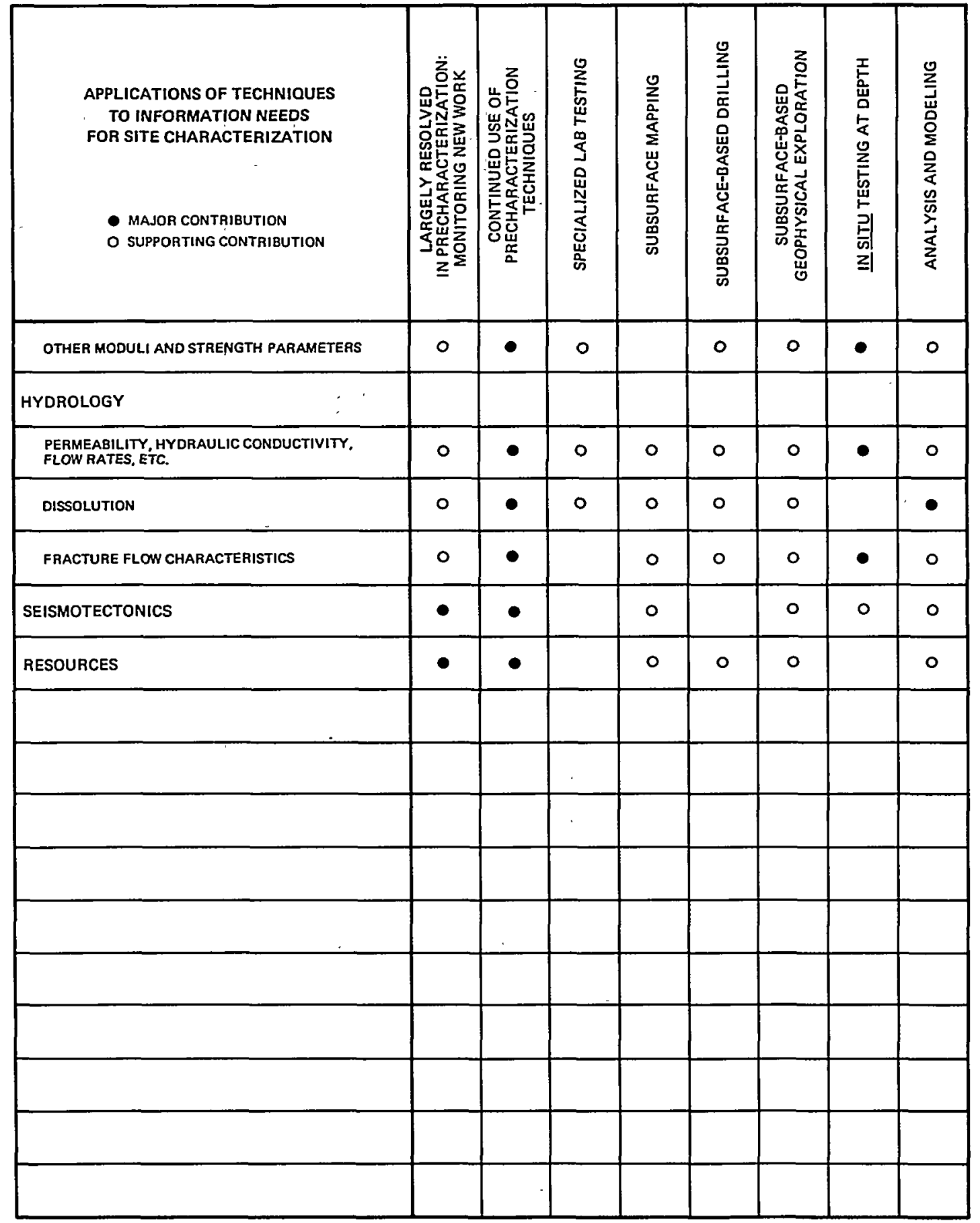


mapping, subsurface-based drilling, and subsurface based geophysical exploration. These would be supported by laboratory analyses of mineralogy and petrology. The main objectives of these investigations would be evaluating geologic factors necessary for design, construction, and performance of the proposed repository.

Detailed excavation mapping and in situ testing would be done in the pilot shaft, test room(s), and exploratory drifts using established techniques common to mining and engineering geology. A primary logging technique for positively identifying tuff unit variations is total intensity magnetometer logging. This technique has been successfully used at NTS (Douglas and Millett, 1978). This logging would emphasize identifying mineralogic, textural, and structural variations in the tuff and systematically describing them to aid analyses in geomechanics, geochemistry, and hydrology. Additionally, logging in the pilot shaft would provide significant information regarding the overburden. Direct observation of the excavation surfaces would allow detailed analyses of discontinuities such as vents, fumaroles, fractures, or faults. The contacts between the tuff layers may be examined to evaluate features that may influence mechanical or hydraulic behavior of the rock mass (such as corrosion surfaces, permeability, or cooling cracks). Other anomalous features such as nonwelded zones, sedimentary interbeds, density changes, or zeolitized zones could also be observed. Logging in shafts, rooms, or drifts would allow identification of anomalous vertical features (such as faults and cooling cracks) that may be missed in widely-spaced boreholes. These features would be important for evaluating potential migration flow paths within the tuff as well as for geomechanical considerations.

Variations of significant parameters within the tuff (such as anomalous lithic inclusions, texture, grain size, and density) that may occur laterally or vertically can be evaluated by detailed logging of the test excavations.

Geomechanical parameters have been found to be particularly influenced by density (Johnstone and Wolfsberg, 1980). These parameters could be similarly quantified, perhaps supplemented by laboratory and in situ tests.

Drilling (based from a test room within the tuff) would allow more intensive exploration of the proposed repository zone than would be feasible from the surface. The significant conditions and features addressed in excavation logging may be evaluated over a much larger area by using horizontal, inclined, or vertical boreholes. Horizontal boreholes would be particularly useful for evaluating lateral changes in mineralogy or other factors. The drilling and logging techniques 
would be applied essentially as discussed for precharacterization (Section 5.2.3).

State-of-the-art techniques for subsurface based geophysical surveys using radar, sonar, or resistivity devices are applicable for identifying anomalous features within the tuff. Although borehole radar has not yet been widely accepted, it may prove exceedingly valuable as a tool for locating features such as voids, faults, fracture zones, lithologic or mineralogic changes, and pre-existing boreholes that may be present at significant distances from the pilot shaft, test room(s), or test drifts. Applications of radar in tuff have not been summarized in the literature, however, Stewart and Unterberger (1974) and more recently, Unterberger (1979), summarize its application for use in bedded salt. They report that the resolution and range of this technique are determined by the frequency (and associated wavelength) of the radar signal. The maximum effective range is reduced with greater moisture content or larger amounts of impurities. A high resolution radar system, suitable for detecting small fractures or impurities, has a wavelength of about $3 \mathrm{~cm}$ and an effective range of about 20 meters. In a tuff medium, this distance would be somewhat less. A low frequency-long range radar system has a wavelength of about four meters and is effective to ranges of almost 2000 meters (or about 500 meters in wet salt). The minimum size feature that could be detected by this low frequency system in salt would be about two orders of magnitude larger than that detectable by the high resolution system. In tuff this relationship would probably generally hold true.

Sonar probing systems that have been developed for exploration of other media (for example dome salt) will also be applicable in tuff. While these studies have not yet been applied to characterization of tuff, it is expected that resolution of the sonar technique will be somewhat less in a tuff medium.

Resistivity surveys (required for verification of stratigraphy and lithology) may be conducted at depth in subsurface excavations in much the same manner as at the surface. Reliability, resolution, and other aspects of the applicable techniques are discussed in Appendix B-2.

\subsubsection{Hydrology}

Hydrologic techniques used in site characterization include laboratory determinations of permeability and in situ hydrologic tests in the host rock at depth. Sophisticated modeling would be important for evaluating fluid movements and dissolution. Fractures and other discontinuities that may control or reveal potential flow paths would 
be identified by the geologic techniques discussed in section 5.2.3. Applications of standard borehole and laboratory hydrologic tests would continue from precharacterization studies.

The water content and its effect on rock strength is a concern specific to tuff and would be evaluated in site characterization. Techniques for evaluating these phenomena have been discussed in the literature (Johnstone and Wolfsberg, 1980). They include:

- compressive and tensile tests

- vapor diffusion tests

- heater tests

These techniques would be applied to verify water content data of the tuff.

A major aspect of the hydrologic work in site characterization would involve modeling of factors such as fluid movements and dissolution rates. The applicable hydrologic modeling techniques for tuff are similar to those in other bedded media and are discussed in Appendix G-2. Models specifically designed to evaluate dissolution, water loss, in situ water-migration, and joint flow are currently being developed by Sandia National Laboratories (Johnstone and Wolfsberg, 1980). These models use both in situ and disturbed samples to assess the water response to a thermal source and identify important parameters controlling radionuclide transport. These parameters include:

- intergranular porosity and penetration depth

- fracture aperture

- fracture length

- fluid velocity

- sorption distribution coefficient

\subsubsection{Geochemistry}

The geochemical techniques used for site characterizaiton in tuff would be essentially similar to those in other media, as described in Appendix F-2. In general, techniques will be applied in two areas: descriptive geochemistry and evaluations of geochemical reactions. Both areas are designed to evaluate the sorptive properties, or more 
specifically, sorption ratios of tuffs using both batch and dynamic techniques.

Sorption ratio ( $R d$ ) is a unit used at NTS to express the distribution of activity between phases in tuff. It is defined as:

$$
\text { Rd }=\frac{\text { activity in solid phase per unit mass of solid }}{\text { activity in solution per unit volume of solution }}
$$

The descriptive geochemical work will involve applications of standard laboratory techniques to determine compositions of the tuff at the prospective repository zone with considerable detail. The chemical compositions of a tuff at NTS are summarized in Heiken and Bevier (1979), whose report indicates that the tuffs are variable in composition and degree of alteration/devitrification. This variability needs to be better quantified.

Evaluations of geochemical reactions would be based on the descriptive geochemical information and the anticipated thermal and fluid-flow conditions in the repository, as determined from results of the geomechanical and hydrologic work. These analyses would utilize the modeling techniques discussed in Appendix F-2.

A particular emphasis during site characterization will be on verifying sorptive properties of tuff. It is known that sorption varies with the lithology of the tuff due mainly to variation in zeolite and silica content and degree of devitrification of the tuff (Johnstone and Wolfsberg, 1980). These variations will be determined using standard geochemical techniques discussed in detail in Wolfsberg and others, 1979; Vine and others, 1980; and Wolfsberg and others, 1981.

The techniques include:

- X-Ray diffraction and fluorescence

- microprobe

- atomic absorption spectroscopy

- emission spectroscopy

- radioactivity detectors

- radiochemistry 
Table 5.3.3-2 summarizes the ranges of sorption ratios obtained for tuffs containing significant percentages (>208) of zeolite and for devitrified tuffs that are high in silica and feldspars and contain $<58$ clays or zeolites.

\subsubsection{Geomechanics}

Techniques applied to the information needs in geomechanics for characterizing a site in tuff comprise laboratory testing, in situ field test programs and analyses using models. Additional information relevant to geomechanics studies will be obtained from the exploration techniques in subsurface geology utilized to identify and describe discontinuities and variations in tuff. To date, the geomechanical property studies in tuff have concentrated on ambient temperature properties on samples obtained from the Nevada Test Site. Particular emphasis during site characterization will be quantifying the in situ values for these properties. As discussed by Helzer and Ramspott (1979), large scale heater experiments should be conducted. The applications of laboratory testing during site characterization are essentially the same as in precharacterization. Appendix E-2 provides a specific discussion of techniques for in situ geomechanical testing in tuff for site characterization.

An important part of the work in geomechanics is for site characterization modeling and verifying repository behavior. Applications of selected models are discussed in Appendix E-2. Currently, studies are under way at NTS to evaluate creep behavior in tuff (Johnstone and Wolfsberg, 1980). These studies suggest that creep may be a factor in mine opening stability during the operating phase of a repository. The findings of such studies should be verified during site characterization.

\subsubsection{Seismotectonics}

Techniques in seismicity and tectonics for site characterization would largely consist of continuing to monitor the seismograph networks emplaced during precharacterization. The main occurrences of tuff in the United states are in areas that are typically not tectonically stable and demonstrate a low-to-moderate level of seismicity. It is expected that significant questions regarding seismicity and tectonics be resolved during precharacterization. However, any notable or anomalous events recorded during the characterization period may require additional specific investigations using the techniques discussed in Appendix $H$. 
TABLE 5.3.3-2

Ranges of Sorption Ratios (mL/g)*

Element

Cs, Sorption

Cs, Desorption

Sr, Sorption

Sr, Desorption

$B a$, Sorption

$\mathrm{Ba}$, Desorption

Ce, Sorption

$\mathrm{Ce}$, Desorption

Eu, Sorption

Eu, Desorption

Am, Sorption

Am, Desorption

$\mathrm{Pu}$, Sorption

$\mathrm{Pu}$, Desorption

Tc (air), Sorption

TC (air), Desorption

TC $\left(\mathrm{N}_{2}\right)$, Sorption

TC $\left(\mathrm{N}_{2}\right)$ Desorption

U (air), Sorption

U (air), Desorption

$\mathrm{U}\left(\mathrm{N}_{2}\right)$, Sorption

$\mathrm{U}\left(\mathrm{N}_{2}\right)$, Desorption
Devitrified Tuff

150 to 870

310 to 630

53 to 190

56 to 200

430 to 1500

440 to 1300

80 to 15000

400 to 15000

90 to 7500

800 to 7300

130

2200

110

1100

0.3

1.2

8 to 26

18 to 79

1.6 to 2.2

6 to 13

0.5 to 1.5

2 to 14
Zeolitized Tuff

8600 to 29000

13000 to 33000

1800 to 20000

2700 to 20000

15000 to 130000

34000 to 190000

550 to 2000

1200 to 13000

1200 to 2500

2100 to 8700

180

1100

120

340

0.2

2.0

13

118

2.3 to 5.1

15

15

57

I, Sorption

0

0

* Given are average values for times ranging from 1 to 12 weeks. Determinations were made under ambient atmosphere and room temperature conditions except where $\mathrm{N}_{2}$ is noted. Data from Johnstone and Wolfsberg (1980). 


\subsubsection{Resources}

Resource evaluations during site characterization should be limited to continued monitoring of the ongoing exploration programs to confirm the finding of precharacterization regarding resource potential. The techniques applied in this work would be identical to those applied in precharacterization studies discussed in section 5.2.3.5.

\subsubsection{COST AND TIME ESTIMATES FOR TECHNIQUES IN SITE CHARACTERIZATION}

Estimates for the costs and time that would be required for the techniques used in characterizing a site in tuff are summarized in Tables-5.3.4-1 through 5.3.4-6. Additionally, site characterization work would involve continued use of the techniques described in precharacterization; the cost and time estimates summarized in Tables 5.2.4-1 to 5.2.4-7 would remain applicable for these precharacterization techniques. In evaluating cost and time estimates for site characterization, an important consideration is that many of the tests are specially designed for site conditions and particular information needs. Durations of geomechanical and hydrologic tests may be important in determining total costs.

\subsubsection{Geologic Mapping and Supporting Activities}

Typical costs and time required for detailed surface mapping, as would be done at a prospective site during characterization, and the supporting work in remote sensing, trenching, and age dating are summarized in Table 5.3.4-1. This work would be performed during site characterization but would chiefly involve validating previous findings. It would not be reasonable to undertake characterization at a site if there were significant outstanding questions regarding surface geology. For these estimates, it is assumed that access and trafficability would not pose severe problems at a site chosen for characterization.

Table 5.3.4-2 summarizes typical costs and times for mapping geologic conditions in the pilot excavations. Costs for the geochemical analyses that may be used in support of this mapping are provided in Appendix F-2. Subsurface mapping done in coordination with the excavation, the cost and schedule are likely to be controlled by the need to avoid interference with the excavation process.

\subsubsection{Subsurface Based Drilling and Coring}

Appendix D-2 includes a comprehensive summary of the costs and penetration rates for various techniques used in drilling and coring 
COST AND TIME SUMMARY FOR

SURFACE GEOLOGIC TECHNIQUES

IN SITE CHARACTERIZATION

\begin{tabular}{|c|c|c|}
\hline & $\begin{array}{l}\text { Approximate } \\
\text { Cost } \\
\end{array}$ & $\begin{array}{l}\text { Approximate } \\
\text { Time } \\
\end{array}$ \\
\hline \multicolumn{3}{|l|}{ REMOTE SENSING INTERPRETATION } \\
\hline $\begin{array}{l}1: 4800 \text { photo analysis } \\
\left(100 \text { photos for } 12 \mathrm{mi}^{2} \text { site }\right)\end{array}$ & $\$ 1,750-3,500(1)$ & $5-10$ man days \\
\hline \multicolumn{3}{|l|}{$\begin{array}{l}\text { DETAILED SURFACE MAPPING } \\
\text { (for } 12 \mathrm{mi}^{2} \text { site area) }\end{array}$} \\
\hline General Mapping & $\$ 12,000-18,000$ & $\begin{array}{l}20-30 \text { man days } \\
(10-15 \text { field days } \\
\text { for } 2-\text { man crew) }\end{array}$ \\
\hline Detailed structure analysis (2) & $\$ 6,000$ & $\begin{array}{l}10 \text { man days } \\
(5 \text { field days } \\
\text { for } 2-\text { man crew) }\end{array}$ \\
\hline \multicolumn{3}{|l|}{ EXCAVATION LOGGING (3) } \\
\hline Reconnaissance & $\$ 1,200 /$ day $(4)$ & $10,000 \mathrm{ft}^{2} / \mathrm{day}^{(4)}$ \\
\hline Detailed logging at $1^{n}=10^{\prime}$ & $\$ 1,200 /$ day $(4)$ & $1,500 \mathrm{ft}^{2} / \mathrm{day}(4)$ \\
\hline
\end{tabular}

NOTES :

(1)

Does not include cost of large scale stereographic aerial photos, assumed to be available in site characterization.

(2)

Only applicable where bedrock (overlying the salt) is exposed at the surface. Cost and time is in addition to general mapping.

For surface excavations such as exploratory trenches or quarry cuts. Also for natural exposures such as bluffs or stream banks.

Typical production rate and daily cost for 2-man field crew. Rates will vary according to access, difficulty of cleaning off the excavation, and, particularly, complexity of geologic conditions. Mapping of critical relationships at larger scale would require additional time. 
from pilot excavations. Information applicable to tuff is summarized in Table 5.3.4-3, with some revisions to the Appendix D-2 costs for increased compatibility with the costs for other techniques. Costs for mobilization and delays for availability of suitable equipment are not included on the assumption that the site characterization program should be of sufficient magnitude to maintain the required equipment on site for a significant period.

Techniques for geologic logging of the arill cuttings or core, as discussed in Appendices $\mathrm{D}-1$ and $\mathrm{E}-1$ would continue to apply in site characterization. Geophysical logging techniques discussed in Appendix $C$ also would remain applicable for vertical and near vertical holes; costs would generally be as summarized in Table 5.2.4-3.

\subsubsection{Geophysical Techniques in Site Characterization}

In general, the geophysical techniques discussed in Appendix B would remain applicable in site characterization and costs would continue to follow the parameters outlined in Table 5.2.4-4. Costs for the techniques used in site characterization for detailed evaluation of near surface engineering parameters and for exploring the tuff surrounding the pilot excavations are summarized in Table 5.3.4-4.

As discussed previously, the radar and sonar techniques used for subsurface exploration in geologic media are specially designed systems and therefore can differ significantly in costs and capabilities. Moreover, new techniques are continually under development, making it difficult to forecast costs and capabilities for work that would be performed in future years.

\subsubsection{Hydrology}

Costs and times for the hydrologic techniques most important in site characterization are summarized in Table 5.3.4-5, based on the information in Appendix G-2. All of the techniques in Table 5.3.4-5 involve testing programs that vary in cost and duration according to their design, in addition to the properties of the test medium. Costs of drilling and well completion are not included in the estimates for the hydrologic techniques.

\subsubsection{Geochemistry}

Cost estimates for typical geochemical analyses are summarized in Appendix F-1. The specific tests and the number of analyses needed 
TABLE $5 \cdot 3 \cdot 4-2$

COST AND TIME SUMMARY FOR SUBSURFACE GEOLOGIC MAPPING IN SITE CHARACTERIZATION (1)

Cost Per Day

Typical Mapping Rate

Detailed Mapping

$\$ 650.00$

$600 f t^{2} /$ day (3)

of Shaft or Drift

at $1^{n=5} \cdot(2)$

NOTES :

(1)

Based on Appendix A-2.

(2)

Typical scale for geologic mapping in drift 8 feet wide and 8 feet high, after completion of engineering survey and preparation of base maps.

(3)

Actual rates depend on complexity of geologic conditions at the place mapped. 
TABLE $5 \cdot 3 \cdot 4-3$

COST AND TIME SUMMARY FOR

SUBSURFACE BASED DRILLING AND CORING

IN SITE CHARACTERIZATION (1)

\begin{tabular}{|c|c|c|c|c|c|c|}
\hline & \multirow{2}{*}{$\begin{array}{c}\text { Hole } \\
\text { Size } \\
\text { (inches) }\end{array}$} & \multirow{2}{*}{$\begin{array}{c}\text { Maximum } \\
\text { Depth } \\
\text { (ft) }\end{array}$} & \multicolumn{2}{|c|}{$\begin{array}{r}\text { Penetration } \\
\text { Rate (2) }\end{array}$} & \multirow{2}{*}{$\begin{array}{l}\text { Cost per } \\
\text { Range }\end{array}$} & \multirow{2}{*}{$\begin{array}{l}\text { foot (5) } \\
\text { Average }\end{array}$} \\
\hline & & & Range A & verage & & \\
\hline \multicolumn{7}{|l|}{ PERCUSSION DRILLS } \\
\hline $\begin{array}{l}\text { Jackleg } \\
\text { (hand held) }\end{array}$ & $\begin{array}{l}1-1 / 4- \\
1-1 / 2\end{array}$ & 20 & $12-28(3)$ & $20(3)$ & $\$ 2-5(6)$ & $\$ 3(6)$ \\
\hline Drifter & $\begin{array}{l}1-1 / 2- \\
3-1 / 2\end{array}$ & 50 & $20-60(3)$ & $40(3)$ & $\$ 2-7(6)$ & $\$ 4(6)$ \\
\hline Track drill & $2-5$ & 200 & $30-100(3)$ & $65(3)$ & $\$ 2-7(6)$ & $\$ 3(6)$ \\
\hline \multicolumn{7}{|l|}{ CORE DRILLS } \\
\hline $\begin{array}{l}\text { Longyear } \\
\text { EHS } 38\end{array}$ & $\begin{array}{l}\mathrm{HQ}(2-1 / 2) \\
\mathrm{NQ}(1-7 / 8) \\
\mathrm{BQ}(1-3 / 8)\end{array}$ & $\begin{array}{l}1200 \\
1900 \\
2400\end{array}$ & $4-8(4)$ & $6(4)$ & $\$ 20-40$ & $\$ 26$ \\
\hline Longyear 65 & $\mathrm{BQ}(1-3 / 8)$ & 500 & $3-5(4)$ & $4(4)$ & $\$ 32-54$ & $\$ 40$ \\
\hline
\end{tabular}

NOTES :

(1) Adapted from Appendix D-2.

(2) Not including move-in or set-up time. Rates calculated for representative drill or core sizes and would differ for other sizes.

(3) At $67 \%$ efficiency.

(4) At $50 \%$ efficiency.

(5) Direct operating costs $\times 2.0$ to account for administration, insurance, interest, contractor's profit margin and other typical cost factors. Does not include cost of on-site geologic inspection or subsequent core logging. Does not include allowance for standby time.

(6) Compressor costs calculated assuming two arills per compressor. 
TABLE $5 \cdot 3 \cdot 4-4$

COST AND TIME SUMMARY FOR

GEOPHYSICAL TECHNIQUES

IN SITE CHARACTERIZATION

\begin{tabular}{|c|c|c|}
\hline & $\begin{array}{l}\text { Approximate } \\
\text { Cost } \\
\end{array}$ & $\begin{array}{l}\text { Approximate } \\
\text { Time } \\
\end{array}$ \\
\hline $\begin{array}{l}\text { SEISMIC CROSSHOLE } \\
\text { (typical survey to about } \\
500 \text { feet) }\end{array}$ & $\$ 34,000-39,000(1)$ & $4-5$ weeks $(2)$ \\
\hline $\begin{array}{l}\text { DOWNHOLE SEISMIC VELOCITY } \\
\text { (typical survey to about } \\
500 \text { feet) }\end{array}$ & $\$ 7,500-16,000(1)$ & $2-3$ weeks $(2)$ \\
\hline $\begin{array}{l}\text { RADAR OR SONAR } \\
\text { (from pilot excavation) }\end{array}$ & $\$ 5,500(3)$ & 3 days $(3)$ \\
\hline
\end{tabular}

NOTES:

(1)

Includes drilling costs.

(2) Turn around time for results from beginning field work. Does not include mobilization.

(3) Typical cost and field time for set of radial probings from single test room. Only a few sources provide radar or sonar services commercially. Both services are available from Rock Probers, Inc. (c/O Dr. R. R. Unterberger, Texas A \& M Univ.). Xadar Corporation, formerly Ensco, Inc. (Springfield, Virginia) provides radar. Typical daily rates are $\$ 1,500$ (Rock Probers, 2 or 3 man crew) to $\$ 1,750$ (Ensco, 2 man crew) for a minimum of three days, not including travel. Following initial setup and calibration numerous probes can be done in a day. Ensco estimates that lateral probes can be done along a tunnel at 1000 to 2000 feet per day. Actual duration of work in pilot excavations would depend on their layout and extent, and on the need to recalibrate radar velocities due to variations in the medium. (J. Fowler, 1981, personal communication, and R. R. Unterberger, 1981, personal communication). 
COST AND TIME SUMMARY FOR

HYDROLOGIC TECHNIQUES

IN SITE CHARACTERIZATION

$\begin{array}{llc} & & \text { Approximate } \\ \text { Tests and } & \text { Approximate } & \text { Turn around } \\ \text { Analyses (1) } & \text { Cost Range (2) } & \text { Time (3) }\end{array}$

INJECTION TESTS

STRADDLE PACKER TESTING

TRACER TESTS

FLOW SYSTEM MODELING

Without fracture flow

2 dimensional

3 dimensional

With fracture flow

2 dimensional

3 dimensional

$$
\begin{gathered}
\$ 20,000-50,000 \\
\text { per test } \\
\$ 10,000-25,000 \\
\text { per test }
\end{gathered}
$$

$$
\$ 20,000 \text { or more }
$$$$
\text { per test interval }
$$

5-15 days

$5-15$ days

Time until

detection

depenas on

site conditions

NOTES:

(1)

Described in Appendix G

(2)

These tests are typically designed for particular site conditions in characterization. Costs are determined by test design and duration.

(3)

Times for hydrologic tests are determined by site conditions and may vary significantly. 
tests and the number of analyses needed would be determined by site conditions and cannot be quantified reliably on a generic basis. The main factors determining turn-around-time for results of the geochemical analyses are capabilities of the available laboratories, their work load, and the priority of the specific project. It is expected that most individual analyses for site characterization could be performed within a few weeks but longer times may be required for specialized analyses or for work on large numbers of samples.

\subsubsection{Geomechanics}

The work in geomechanics for site characterization involves specialized laboratory testing and in situ tests designed individually for each program. Representative costs and times are provided in Table 5.3.4-6 but these can differ significantly according to design of a specific program. In particular, the number of tests required to characterize a site would be determined by the variability of site conditions and the proposed repository layout. Reliability of present. instrumentation is a notable problem for long duration tests; development of new or unique systems would be costly.

\subsubsection{CRITERIA FOR EVALUATING DATA ADEQUACY OF SITE CHARACTERIZATION STUDIES IN TUFF}

Previous discussions of unique geologic features of tuff (Section 5.3.1), the information needs for repository siting (Section 5.3.2), and the technique applications pertinent to site characterization (Section 5.3.3) form the basis for development of criteria for data adequacy.

These criteria include an evaluation of data developed from precharacterization studies and the degree to which site characterization increases the level of knowledge about repository conditions. A basic assumption herein is that precharacterization data have largely fulfilled information needs of some disciplines.

The following subsections, grouped by major discipline, will present criteria for data evaluation unique to site characterization (precharacterization data are evaluated in Section 5.2.5). To evaluate the adequacy of the data developed for each discipline, the following items should be addressed in the site characterization report:

- techniques used to perform the site characterization studies should be identified 
TABLE $5.3 \cdot 4-6$

COST AND TIME SUMMARY FOR

GEOMECHANICS TECHNIQUES

IN SITE CHARACTERIZATION (1)

Tests (2)

Approximate

Approximate

Cost

Duration

HYDROTHERMOMECHANICAL

IN SITU BLOCK TEST

$\$ 600,000-700,000(3) \quad 9-12$ months $(3)$

SCHMIDT HAMMER CHARACTERIZATION

OF JOINTS IN TEST ADIT

$\$ 1,000(4)$

1-2 days

CORE TILT TESTING

Apparatus (purchase

$\$ 500$

$\mathrm{N} / \mathrm{A}$

or fabrication costs)

Typical set of tests

$\$ 500$

one day

JOINT TILT TESTING

$\$ 10,000$

2 weeks

(program)

SELF WEIGHT SLIDING TEST

(on large jointed blocks)

$\$ 2500-4500 /$ sample $\$ 50,000 /$ program

3-4 weeks

NOTES:

(1)

Geomechanical testing for site characterization involves test programs designed for particular information needs and site specific conditions. Costs and durations will vary according to test design.

(2)

Descriptions in Appendix E-2.

(3)

Not including excavation of test room.

(4)

Including cost of Schmidt hammer.

$5-79$ 
- purported resolution, reliability, and precision of the techniques should be given

- techniques should be described in sufficient detail to allow an independent evaluation of their resolution and reliability

- all analyses and tests should be duplicated and repeated to reduce the probability of analytical or human error;

- all tests and analyses should be performed by qualified personnel

- results of all tests and analyses should be made available to the scientific community for independent evaluation of data adequacy

$\circ$ specifications and limitations of test equipment should be provided test results and/or all data developed should be integrated among or between major disciplines

\subsubsection{Geology}

The information needs and applicable techniques pertinent to precharacterization have been previously summarized in section 5.2.4. It is assumed that geologic studies during site characterization will adequately verify and refine data such that all required geologic information needs are adequately fulfilled.

The chief concern will be the identification of anomalous conditions in the proposed repository volume. To meet this end major underground excavations such as test rooms or in situ rock mechanics laboratories will be established. Horizontal, vertical, or inclined drilling from the subsurface excavations will allow direct examination of the tuff at proposed repository depths. However, while these excavations will enable collection of data having a very high degree of resolution and reliability, it only covers a limited area. This will necessitate application of other techniques (see below) to further verify geologic conditions which exist elsewhere within the proposed repository volume.

The additional data and studies required to verify repository conditions in a tuff medium and the most applicable techniques for gathering these data are presented below:

- lithology, stratigraphy, and structure - detailed surficial mapping, downhole T.V. and radar viewing, excavation logging, radar ranging, seismic crosshole and density measurement techniques 
thickness and lateral extent of suitable rock volume - excavation logging, radar ranging, seismic crosshole techniques, density measurement techniques

Accurate pilot shaft and excavation logging will provide excellent reference points for correlation of downhole logging and surface exploration techniques. This will permit further refinement and verification of various study data. Application of these new techniques combined with data from other ongoing techniques should adequately characterize and/or verify many of the important geologic features of tuff repository and its environs such as:

- overburden stratigraphy

- depth and thickness of suitable horizons

- location of nonwelded zones

- lateral extent of suitable horizons

- petrography/petrology/petrofabrics

- cooling unit thicknesses

- fracture characteristics (e.g., orientation, spacing, density)

- density anomalies

\subsubsection{Hydrology}

Testing during this phase will largely be used to provide data for two important modeling studies. The main objective of the hydrology studies during site characterization will be to verify suspected flow paths in the tuff. Other objectives include verification of parameters such as ground-water velocity, groundwater age, water/rock interactions, etc. The initial modeling study will be on hydrologic conditions in and around the proposed repository volume and will be primarily concerned with flow path and flow rate assessment. This model and additional data will provide input for other programs to model radionuclide transport. With the exception of extensive numerical modeling techniques, other applicable hydrologic techniques have been previously discussed in section 5.3.4.2. It should be noted that many of the standard hydrologic tests have limited applicability 
in low-permeability media such as tuff. Because of this it will be important to integrate data from the geology and geochemistry disciplines. Use of pre- and site characterization data should be oriented toward consideration of unique features in tuff which will affect or reflect hydrologic conditions, including:

- overburden hydrology

- repository hydrology

- dissolution

- fracture flow

- variations in the degree of welding and its affect on water transport

- $18 \mathrm{O} /{ }^{16} \mathrm{O}$ and $\mathrm{D} / \mathrm{H}$ ratios for use in solving water transport problems

\subsubsection{Geochemistry}

The major information needs and applicable techniques have been summarized in section 5.2.4.3. It is anticipated that the data developed from site characterization will be used to verify previous data and support such disciplines as hydrology and geology. An important aspect of the geochemical discipline will be to verify sorption parameters established during precharacterization. In addition to the previously described techniques, the geochemical properties of both the tuff and its contained water must be determined over the range of temperature, moisture, and pressure conditions anticipated in the proposed repository volume. These data will be used to determine radionuclide sorption, reaction rates, groundwater age, etc., as well as to provide input to the radionuclide migration modeling program (Section 5.3.4.2).

Unique geochemical features of tuff which must be considered include:

- sorption ratios for various radionuclides

o reaction of host rock and joint infilling materials with water and waste

- extent, pervasiveness and surface area of fractures available for interaction with waste water 
- detailed water and rock composition in proposed repository volume

- possible lateral or vertical rock chemistry changes

\subsubsection{Geomechanics}

Fundamental geomechanical technique parameters affecting the response of the tuff to the expected thermal and mechanical stresses have been previously discussed in Appendix E-2 and in Section 5.2.3. The primary difference between pre- and site characterization data is that the boreholes, pilot shafts and test room(s) allow visual inspection and in many cases in situ testing of fresh host rock of the repository volume. In addition to standard laboratory tests, described in sections 5.2.5.4, this phase would be heavily biased toward in situ testing of the host and special laboratory tests and experiments of host rock samples. Information needs and applicable in situ tests are shown below.

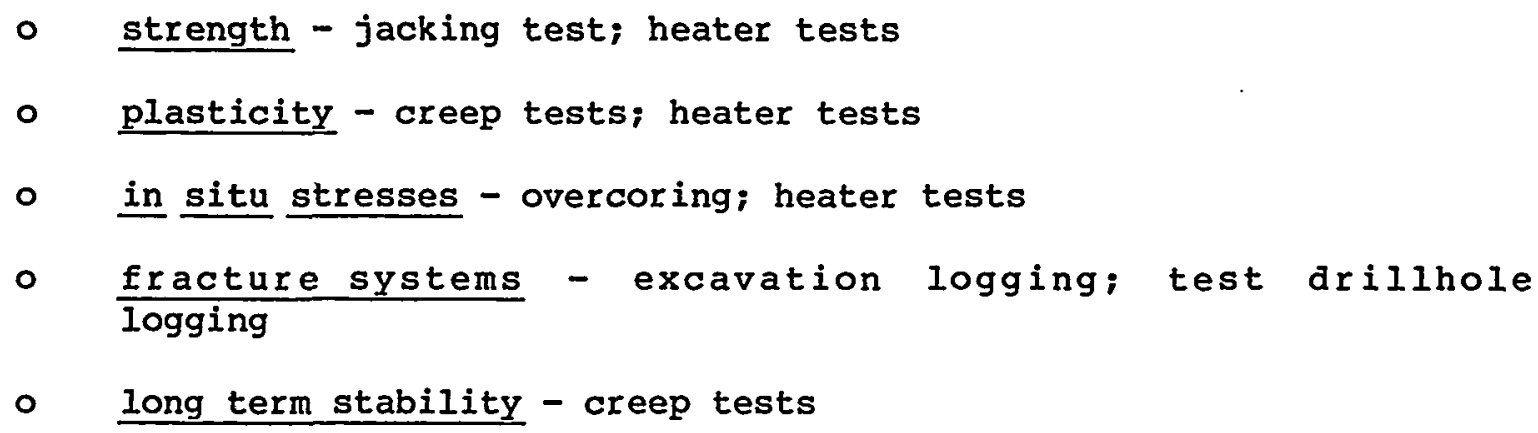

Because tuff has a low thermal conductivity, it is assumed that temperature gradients from waste canister heating will be steep and persist for a long period of time. The increased stress due to these temperature radients can be adequately approximated by long term in situ heater tests.

In addition to the temperature variation of geomechanical parameters there is the problem of variation of thermal parameters with temperature. Because basic thermal property (see section 5.2.5.4) measurements in the laboratory typically do not duplicate natural conditions, it is essential that in situ values of these parameters be determined whenever possible.

Unique features of tuff which should be addressed during geomechanical and thermal testing are:

- degree of variance between laboratory and in situ tests 


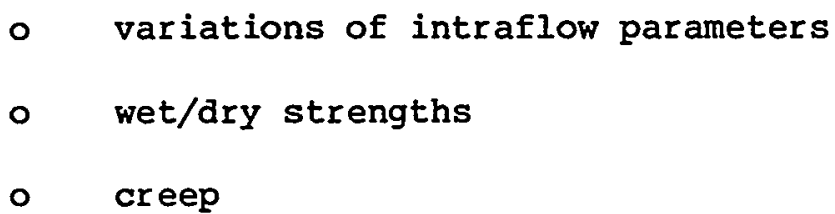

\subsection{REFERENCES}

Anderson, C. A., and Russell, R. D., 1939, Tertiary formations of northern Sacramento Valley California: California Journal of Mines and Geology, Vol. 35, pp. 219-253.

Anderson, T., and Flett, J. S., 1903, Report on the eruptions of the Soufriere in st. Vincent in 1902, and on a visit to Montagne Pelee, in Martinique, Part I: Royal Society of London Philosophical Transactions, ser. A, Vol. 200, pp. 353-553.

Chapin, C. E., and Elston, W. E., 1979, eds, Ash-flow tuffs: Geol. Soc. of Amer. Spec. Paper $180,211 \mathrm{p}$.

Crowe, B. M.r 1978, Disruptive event analysis; Volcanism: Prepared for Waste Isolation Safety Assessment Program, Battelle Pacific Northwest Laboratories, Richland, WA.

Crowe, B. M., and Carr, W. J., 1980, Preliminary assessment of volcanism at a proposed nuclear waste repository in the southern Great Basin: U.S. Geological survey Open-File Rpt. 80-357, $15 \mathrm{p}$.

Curtis, G. H., 1968, The stratigraphy of the ejecta from the 1912 eruption of Mount Katmai and Novarupta, Alaska: Geological Society of America Memoir 116, pp. 153-210.

Dagan, G., 1979, Models of groundwater flow in statistically homogeneous porous formations: Water Resources Research, Vol. 15, No. 1, pp. 47-63.

Dakyns, J. R., and Greenly, E., 1905, On the probable Pelean origin of the felsitic slates of Snowdon, and their metamorphism: Geological Magazine (Great Britain), 5th serv., Vol. 2, pp. 541-549.

Dell'Erba, L., 1892, Considerazioni sulla genesi del piperno: Giornale Mineralogia, Cristallografia and Petrografia, Vol. 3, pp. 23-53. 
Douglas, A.C., and Millet, M.R., 1978, Total intensity magnetometer logging as a stratigraphic tool in Tertiary volcanic rock: Lawrence Livermore Laboratory Rpt. UCRL-52617, 11 p.

Erdal, B. 'R., and others, 1981, Nuclide migration field experiments program plan: Los Alamos Laboratory report LA-8487-MS, NC-70, $71 \mathrm{p}$.

Fenner, C. N., 1920, The Katmai region, Alaska, and the great eruption of 1912: Journal of Geology, Vol. 28, pp. 569-606.

, 1923, The origin and mode of emplacement of the great tuff deposit in the Valley of Ten Thousand Smokes: National Geographic Society Contributed Technical Papers, Katmai Series, no. $1,74 \mathrm{p}$.

Fritsch, K. von, and Reiss, W., 1868, Geologische Beschreibung der Insel Tenerife: Winterthus, Wurster and Co., $494 \mathrm{p}$.

Fugro, Inc., 1980, Assessment of volcanic and geothermal activity in the Pasco Basin and vicinity: Rockwell Hanford operations, Project Number 79-265, 115 p.

Fugro National, Inc., 1980, MX mineral resources survey, Nevada/Utah siting area: U.S. Air Force Report FN-TR-41D, 311 p.

Gilbert, C. M., 1938, Welded tuff in eastern California: Geological Society of America Bulletin, Vol. 49, pp. 1829-1862.

Griggs, R. F., 1918, The great hot and flow of the Valley of Ten Thousand Smokes (Ratmai district, Alaska): Ohio Journal of Science, Vol. 19, pp. 117-142.

, 1922, The Valley of Ten Thousand Smokes (Alaska): Washington, D. C., National Geographic Society, 341 p.

Grove, D. B., 1978, The use of Galerkin finite-element methods to solve mass-transport equations: U.S. Geological Survey, Water Resources Rpt. PB-227, 532 p.

Hadley, J.R., and Turner, J.E.R., 1980, Evaporative water loss from welded tuff: Sandia National Laboratories Rpt. SAND80-0201, 21 p.

Healey, J., 1973, Welded pyroclastic rock at Tongariro: New zealand Journal of Geology and Geophysics, Vol. 6, pp. 712-714. 
Hieken, G.H., and Bevier, M.L., 1979, Petrology of tuff units from the J-13 drill site, Jackass Flats, Nevada: Los Angeles Scientific Laboratory Rpt. I,A-7563-MS, 55 p.

Helzer, F., and Ramspott, L., eds., 1979, Proceedings of a workshop on thermomechanical modeling for a hard rock waste repository: Lawrence Livermore Laboratory Rpt. ONWI-98, UCAR-10043, 135 p.

Iddings, J. P., 1885-1886, Obsidian Cliff, Yellowstone National Park: U.S. Geological Survey 7th Annual Rpt., pp. 249-295.

- Geology of the Yellowstone National Park: U.S. Geological Survey Monograph 32, pt. 2, chap. 10, pp. 356-430.

Johnston, J. K., and Wolfsberg, K., eds, 1980, Evaluation of tuff as a medium for a nuclear waste repository: Intern status Report on the Properties of Tuff: Sandia National Laboratories Rpt. SAND80-1464 (1980), $142 \mathrm{p}$.

Kuno, H., 1941, Characteristics of deposits formed by pumice flows and those by ejected pumice: Tokyo University Earthquake Research Institute Bulletin, Vol. 9, pp. 144-149.

Lacroix, A., 1903, L'eruption de la Montagne Pel'ee en Janvier 1903: Acade'mie des Sciences (Paris), Comptes Rendus, Vol 136, pp. $442-445$.

, 1904, La Montagne Pel'ee et ses eruptions: Paris, Masson et Cie, 662 p.

Macdonald, G. A., 1972, Volcanoes: New Jersey, Prentice-Hall, Inc., 510 p.

Marshall, P., 1935, Acid rocks of Taupo-Rotorua volcanic district: Royal Society of New Zealand Transactions, Vol. 64, pt. 3, pp. 323-366.

McKee, E. H., 1979, Ash-flow sheets and calderas; their genetic relationship to ore deposits in Nevada: Geological Society of America Special Paper 180, pp. 205-211.

ONWI, 1980, Report on geologic exploration activities: Office of Nuclear Waste Isolation, Rpt. DOE-RL-C-14, 66 p. 
Perret, F. A., 1935, The eruption of Mt. Pel'ee 1929-1932: Carnegie Institution of Washington Publication 458, $126 \mathrm{p}$.

Peterson, D. W., 1979, Significance of the flattening of pumice fragments in ash-flow tuffs: Geological Society of America, Special Paper 180, pp. 195-204.

Raines, G.E., and others, 1980, Development of reference conditions for geologic repositories for nuclear waste in the U.S.A.: Sandia National Laboratories, Rpt. SAND-80-2416C (Dr), 27 p.

Ransome, F. L., 1898, Some lava flows of the western slope of the Sierra Nevada, California: U.S. Geological Survey Bulletin 89, 74 p.

Ross, C. S., and Smith, R. L., 1961, Ash-flow tuffs; their origin, geologic relations, and identification: U.S. Geological survey Professional Paper 366, 81 p.

Sheridan, M. F., 1979, Emplacement of pyroclastic flows: A review: Geological Society of America Special Paper of the ignimbrites of Vulsini volcano, central Italy: Geologisches Rundschau, Vol. 64, pp. 497-523.

Stewart, R.D., and Uterberger, R.R., 1976, Seeing through rock salt with radar: Geophysics, Vol. 41, pp. 123-132.

Turner, H W., 1894, The rocks of the Sierra Nevada: U.S. Geological Survey 14th Annual Report, pt. 2, pp. 435-495.

Unterberger, R. R., 1979, radar and sonar probing of salt: Northern Ohio geological Society fifth Symp. on Salt, Vol.1, pp. 423-437.

U.S. Nuclear Regulatory Commission, 1981, Disposal of high-level radioactive wastes in geologic Repositories; Technical criteria: U.S. Nuclear Regulatory Commission, 10CFR, Part 60, 62 p.

Vine, E. W., and others, 1980, Sorption-desorption studies on tuff, II. a continuation of studies with samples from Jackass Flats, Nevada, and initial studies with samples from Yucca Mountain, Nevada: Los Alamos Scientific Laboratory Rpt. LA-8110-MS, 70p.

Walker, G.P.I., 1973, Explosive volcanic eruptions-A new classification scheme: Geologisches Rundschau, Vol. 62, pp. 431-446. 
Westerveld, J., 1942, Welded rhyolitic tuffs or "ignimbrites" in the Pasoemah region, West Palembang, South Sumatra: Leidsche Geologische Mededeelingen, Vol. 13, pp. 202-217.

Williams, H., 1941, Calderas and their origin: University of California Publications in Geological Sciences, Vol. 25, pp. 239-346.

Williams, H., 1942, The geology of Crater Lake, National Park, Oregon, with a reconnaissance of the Cascade Range southward to Mount Shasta: Carnegie Institute of Washington Publications 540 , 162 p.

Wolf, T., 1878, Der Cotopaxi und seineletzte Eruption am 26 Juni 1877: Neues Jahrbuch fur Mineralogie, Geologie und Paleontologie, pp. 113-167.

Wolfsberg, K., and others, 1979, Sorption-desorption studies on tuff, I. Initial studies with samples from J-13 drill site, Jackass Flats, Nevada: Los Alamos Scientific Laboratory Report LA-7480MS, $56 \mathrm{p}$.

Zambonini, F., 1919, II tufo pipernoide della campania e i suoi minerali: Italy, R. Comitato Geologico Memoir, Vol. 7, pt. 2, pp. $1-130$.

Zies, E. G., 1929, The Valley of Ten Thousand Smokes: 1, The fumarolic incrustations and their bearing on ore deposition; 2, The acid gases contribute to the sea during volcanic activity: National Geographic Society Contributed Technical Papers (Katmai Series), Vol. 1, no. 4, 79 p. 


\subsection{BEDDED SALT}

\subsection{PREVIOUS WORK IN BEDDED SALT}

Origin, occurrence, and properties of bedded salt have received significant attention in the geologic sciences. Interest. related to mining of the halite and associated potash ores began in the last century and has continued to the present. More recently, petroleum geologists have observed that hydrocarbon resources commonly occur in association with evaporite sequences. This has generated additional interest in the depositional environments of bedded salt and the associated sediments and reefs (e.g., Buzzalini, 1969; Fisher, 1977). The resulting work in economic and petroleum geology has provided significant information on bedded salt, much of which is available in published literature.

There has been particular emphasis on bedded salt as a potential host rock for isolation of radioactive materials. Early studies of waste isolation identified bedded salt as a candidate medium (e.g., NAS/NRC, 1957). Subsequent programs in bedded salt have included Project Salt Vault (Empson and others, 1970), exploration and testing for the waste Isolation Pilot Plant (WIPP) and the preceding Bedded Salt Pilot Plant (Powers and others, 1978). Programs to select potential repository sites have continued to address bedded salt in various regions (DOE, 1980). Results of this specialized work are presented in various project reports and provide the basis for several articles in the general literature. Investigations specifically for isolation of radioactive materials provide particular information on the requirements for a repository site in bedded salt and on topics of concern for waste isolation. Moreover, significant information on dissolution, detailed stratigraphy and structure, and mechanical properties has originated in these studies.

\subsection{PRECHARACTERIZATION STUDIES}

\subsubsection{GEOLOGY OF BEDDED SALT}

\subsubsection{Origin and Depositional Environment}

Bedded salt is a sedimentary rock consisting mainly of halite. These rocks are chemical precipitates from brines that become concentrated under conditions where evaporation exceeds inflow. These conditions can 
occur in restricted marine basins, desert playa lakes, or supratidal coastal salt flats. The halite is but one of a sequence of evaporite minerals and is found in association with other evaporites (Table 6.2.1-1) and with fine grained clastic sediments. Although significant salt bodies have formed from evaporation in closed continental basins, such as those in the Basin and Range Province of the southwestern United states (e.g., Pierce, 1973), bedded salt deposits of marine origin are most significant as candidates for waste isolation and will be discussed chiefly in this report. While deposition in closed continental basins generally is well understood, there are several complexities involving origin of marine evaporites. It has long been thought that marine evaporites formed in "barred basins"; that is basins with a narrow and shallow connection to the open ocean. However, significant refinements and modifications to this model have resulted from continued investigations of existing evaporite deposits and from observations of present day saline environments and oceanographic processes.

From studies of the Castile Formation in southeastern New Mexico and west Texas, Ring (1947) determined that the gross mineral composition of the evaporite sequence differed significantly from the mineral composition in normal sea water. Specifically, the Castile Formation is largely anhydrite with little halite while the ratio of sodium chloride to calcium sulfate in sea water is about 30:1. Moreover, the thickness of anhydrite in the Castile Formation could not have evaporated from a "static" basin of reasonable.size. From this, King (1947) theorized a two layer flow model whereby normal ocean water flows into the basin near the surface and dense brine, from which anhydrite has precipitated but containing much of the sodium chloride, flows out as a counter current at depth. Observations of ocean currents later were found to support this model (Scruton, 1953). Aside from its academic interest, this model of brine flow is important for explaining the origin of thick monomineralic evaporite deposits and its dynamic aspect helps to explain lateral facies of evaporite minerals (e.g., Mear, 1962). Without going into additional detail, it seems generally applicable to deep and shallow evaporite basins.

Observations of modern saline environments in the Gulf of California and the Persian Gulf have combined with additional stratigraphic studies of salt deposits to support theories that significant salt deposition occurs on shallow marine shelves and on supratidal coastal salt flats, termed sabkhas (Kinsman, 1969). Some proponents of sabkha deposition suggest that all evaporites originate in this manner and that thick deposits typically attributed to deeper basins result from tectonic downwarping of the shelf area during evaporite deposition (e.g., Treesh and Friedman, 1973). However, several critical analyses 
CARBONATES

Calcite
Dolomite
Magnesite

SULFATES
$20 \mathrm{ppm}(2)$

$7 \mathrm{ppm}(2)$

$4 \mathrm{ppm}(2)$

$\mathrm{MgCO}_{3}$

$3022 \mathrm{ppm}(3)$

2000 ppm (3)

(4)

\section{CHLORIDES}

$\begin{array}{llc}\text { Halite } & \mathrm{NaCl} & 264,000 \mathrm{ppm}(3) \\ \text { Sylvite (1) } & \mathrm{KCl} & 256,000 \mathrm{ppm}(3) \\ \text { Carnalite } & \mathrm{KMgCl}_{3} \cdot 6 \mathrm{H}_{2} \mathrm{O} & \text { (5) }\end{array}$

\section{Notes:}

(1) Economically important as potash ores (Jones and others, 1960)

(2) In $\mathrm{CO}_{2}$-free water at pressure of 200 bars e $25^{\circ} \mathrm{C}$ (Clark, 1966, p. 436

(3) In water at $20^{\circ} \mathrm{C}$ (Braitsch, 1971, Table 3)

(4) Precipitates in complex system from seawater concentrated to about 28 of original weight, following precipitation of about 978 of original NaCl (Braitsch, 1971, Table 8)

(5) Precipitates in complex system from seawater concentrated to about 1.28 of original weight following precipitation of about 998 of original NaCl (Braitsch, 1971, Table 8)

(6) Precipitates from concentrated brine in complex systems at temperatures above $40^{\circ} \mathrm{C}$.

(7) Precipitates in complex system from concentrated brine. 
of such proposals have discounted them because: (1) rates of tectonic movement typically are too slow to account for the observed sedimentary relationships, and (2) sedimentary features found in the supposed deeper basin evaporite deposits could not have developed on shallow shelves or on supratidal flats. Sabkha deposition does appear to be important as basins become filled and has been shown to be the source of several significant evaporite units (e.g., Presley, 1979; Huh and others, 1977, Nurmi and Friedman, 1977).

Diagenesis, or postdepositional alteration, can be an important factor in the origin of bedded salt. There is abundant petrographic and isotopic evidence that most large evaporite bodies have undergone such alteration (Kirkland and Evans, 1973, p. 248). Proponents of sabkha origin for evaporites consider diagenesis to be an essential step in development of the deposit, including dolomitization of calcareous skeletal remains, alteration of gypsum to anyhdrite, and recrystallization of halite (Kinsman, 1969). Others theorize that some marine evaporites are completely diagenetic in origin. It has been suggested that the deposits originated as sabkha sediments in which anhydrite, gypsum, and dolomite form by reactions with marine-derived groundwater while the halite and potash salts develop much later in reactions involving connate brines (Shearman, 1966). Alteration is thought to be particularly important in regard to origin of some potash salts (Braitsch, 1971). Alteration can be important for repository studied in bedded salt because the resulting variations in lithology and mineralogy may not be stratigraphically controlled.

Detailed studies for WIPP determined that salt in the Salado Formation was altered after deposition, including recrystallation of potash salts and clay minerals as well as alteration of gypsum to anhydrite (Powers and others, 1978, p. 7-27 to 7-30; Bodine, 1978). Similarly, detailed studies of salt from the Salina Group in New York indicate that some halite recrystallized in place (Treesh and Friedman, 1973). In both these cases, water released in the alteration of gypsum to anhydrite was suggested as a main contributor to the recrystallization process.

\subsubsection{Stratigraphy and Lithology}

Three main factors are important in discussing the stratigraphy of bedded salt:

1. Order of precipitation of evaporite minerals.

2. Depositional cycles.

3. Environment of deposition. 
These factors determine the vertical successions and lateral facies of salt deposition and can be significant on both large and small scales.

Order of precipitation: As water evaporates and brine is concentrated, minerals are precipitated in the reverse order of their solubility. Accordingly, a typical stratigraphic sequence deposited from increasing concentrations of brine would contain (from bottom to top): clastic sediments, carbonates, gypsum or anhydrite, chlorides (including halite), and the more soluable potash salts (Table 6.2.1-1). This sequence is apparent on a large scale in the Delaware Basin, where the Salado halite overlies the Castile anhydrite (Jones, 1968), and in the A-1 unit of the Salina Group (Matthews and Egleson, 1973). On a smaller scale, evaporites typically contain layered sequences of these minerals in order. Thicknesses of these layers vary significantly, ranging from varve couplets of less than a centimeter described in the Castile Formation (Anderson and others, 1972) to larger cycles with a typical spacing of 1 to 10 meters in the Salado Formation (Jones, 1968).

These sequences can be observed on a large scale in lateral facies, as described by Mear (1962) for the southeastern Permian Basin in Texas. Similarly, Hite (1970) claimed that nearly all marine evaporites have an adjacent and contemporaneous carbonate facies, in reference to carbonate deposition on shelf areas while the evaporites were deposited in the central part of the Paradox Basin.

Depositional Cycles: Cycles in evaporite deposition are thought to be caused by fluctuations in sea level, or perhaps by climate change. These cycles reflect changes over large areas and may be more useful for correlations than lithologic changes alone (Matthews, 1977). The sequence of minerals deposited in the reverse order of their solubility, as described previously, occurs during the decreasing sea level, or increasing aridity, part of the cycle. These deposits typically are well preserved as they are covered with increasingly concentrated brine, in which they are insoluble. However, as the cycle reverses, the deposits may be exposed to dilute brines and redissolved. As a result, the top of each of these depositional cycles in many cases is an unconformity, termed a "corrosion surface." The amount of material that may have been removed above these surfaces is difficult to determine reliably; Hite (1970) estimated dissolution of at least 5 to 10 feet of salt from some of these surfaces in the Paradox Basin.

The layers of fine clastic material that typically overlie the corroion surfaces commonly are called clay, claystone, or shale although they do not consist mainly of clay minerals. In addition to clay, they 
contain fine silt ("rock flour"), mica, anhydrite, and other fine clasts of relatively insoluble minerals. This material has been suggested to be a residue remaining from dissolution of halite (Powers and others, 1978, p 4-33) or may represent very slow clastic sedimentation during the period when evaporites were not being deposited. Typical thicknesses are on the order of a few centimeters or less. The more prominent of these layers can be correlated over large areas and are valuable marker horizons. Where present, corrosion surfaces can be important as a mechanical discontinuity in the salt and as a preferred hydrologic flow path.

Small scale laminations, that are thought to represent annual varves, are characteristic of some evaporite sequences. These have been well studied in the Castile and Salado Formations of west Texas and southeastern New Mexico and found to be continuous over distances of more than $100 \mathrm{~km}$ (Anderson and others, 1972). These studies found that varves in the Castile Formation typically are calcite in anhydrite while those in the Salado Formation are generally anhydrite in halite. Some layers are rich in organic material. Average thicknesses are about 1 to 5 millimeters (Anderson and others, 1972). Similarly, some layers of anhydrite inclusions in halite with average thicknesses of 2 to $8 \mathrm{~cm}$ have been observed in the Salina salt (Treesh and Friedman, 1973). Occurences of finely varved halite has been reported in the Paradox Basin (Hite, 1962) and the Hutchinson Salt in Kansas (Dellwig, 1962).

Unlike the more prominent corrosion surfaces, the fine varves typically are not significant discontinuities in the salt. However, they may be useful correlation features and certainly require consideration in evaluating the mineralogic composition of the salt. Because they are thought to represent annual deposition cycles, they have been used for interpretations that evaporite sequences developed over remarkably short periods of geologic time (Anderson and others, 1972). Although salts have been found to precipitate more rapidly than one would expect for a chemical evaporite (e.g., Ingerson, 1962), such interpretations are considered suspect because of the numerous intraformational unconformaties present and because each varve may not represent a single year.

Environment of Deposition: Depositional environment can have a significant influence on the lithology and stratigraphy of bedded salt sequences, particularly on the associated clastic sediments and on the nature of lateral facies. Major distinctions can be made between deep basin, shallow basin, and sabkha environments. Distinctions in addition to those discussed here also may be made at a greater level of detail. 
Deep basin environments may be characterized by their lack of clastic sediments, as in the Castile Formation (Jones, 1968) and the A-1 cycle of the Salina Group (Matthews and Egleson, 1973). Clastic sediments that are present are typical of the euxinic (i.e., barred basin with restricted circulation and oxygenation) environment, such as the black shales of the Paradox Basin (Peterson and Hite, 1969). The chemical and thermal inertia of the large volume of water in a deep basin also is thought to result in longer depositional cycles. - For example, Matthews and Egleson (1973) interpret the greater thicknesses of the lower cycles in the Salina Group of Michigan to indicate deep basin deposition and the thinner upper cycles to represent deposition in a shallow, nearly filled basin. Petrographically, halite of deep-basin origin is characterized by large, clear cubic crystals, lacking the zoning and brine inclusions that are believed to result from frequent environmental fluctuations (Nurmi and Friedman, 1977).

As the basins fill, and typically decrease in size, the evaporite deposits are characterized by increased content of clastic sediments, as in the Salado Formation (Jones, 1968) and in the B, D, and F units of the Salina Group in Michigan (Matthews and Egleson, 1973). Lateral facies also may become more important, as in the southeastern Permian Basin (Mear, 1962) and the carbonate shelf facies of the Paradox Basin (Hite, 1970). Bottom conditions typically remain anaerobic until a very shallow depth is reached, as indicated by black shale interbeds. organic content may be high in the shallow evaporite basins, much as it is in deep basins.

Evaporite deposition on a sabkha or very shallow shelf typically differs significantly from deposition in basins. These sediments contain relatively large amounts of clastic material and generally lack black shale interbeds as they are well oxygenated. Cycles of transgression and regression can cause the evaporites to be interlayered with continental red beds (sandstone and shale) as in the Palo Duro Basin (Presley, 1979). Extensive evaporite deposits of sabkha origin are believed to result from progradation of the coastal features (Jacka and Franco, 1973). These near shore sediments also typically contain significant amounts of organic material, commonly including algal mats (Treesh and Friedman, 1973; Kinsman, 1969; Nurmi and Friedman, 1977).

\subsubsection{Structure}

In undeformed bedded salt, the most prominent structures are the essentially horizontal sedimentary stratification and the corrosion surfaces, or intraformational unconformities, described previously. As the salt is deposited in a low energy (low velocity of water flow) 
environment, the original bedding typically is flat and has low initial gradients. Additional sedimentary structures that may occur in beds of shallow water origin include ripple marks, cross bedding, and mud cracks in shale interbeds (Dellwig, 1968).

Structural features of particular interest in bedded salt include salt anticlines and breccia pipes, discussed below. Other types of structural anomalies that may result from dissolution or salt deformation also may be important in the salt and overlying beds.

The most important mechanical discontinuities within the halite are the corrosion surfaces described previously. The plasticity of the halite generally is not conducive to fracturing and jointing. However, fracturing can be important in the interbeds of dolomite and anhydrite, as can mud cracks in the shale interbeds. Notable examples include the fracture-controlled solution features in the anhydrite of the Castile Formation (Olive, 1957) and the dolomite aquifers in the Rustler Formation of the Permian Basin (Brokaw and others, 1972).

Salt Anticlines: Salt anticlines are characterized by thickening of the salt beds in the axial part of the fold because of plastic flow of the salt. Salt anticlines are important in the Paradox Basin, where they parallel faulting along the northeast part of the basin (Ohlen and McIntyre, 1965) and at the eastern margin of the Delaware Basin, along the Capitan Reef (Anderson and Powers, 1978). Salt anticlines in the Paradox Basin are being considered as prospective repository sites (Frazier and McPherson, 1980). Salt anticlines are thought to be an early stage in the development of salt domes and the related aspects of salt tectonics have been studied extensively.

The initial local thickening of the salt that can lead to development of a salt anticline may be caused by the shape of the underlying basement, inhomogeniety in the overlying rocks, or some property of the salt itself (Trusheim, 1960). Others have suggested factors such as uneven sediment loading (Loocke, 1978) and down-slope movement of the overlying sediments (Humphries, 1978). Salt anticlines in the Delaware Basin are thought to have been caused by crumpling of the salt beds because of down-dip movement against the Capitan Reef (Powers and others, 1978, p. 4-65).

Salt anticlines are significant as structural features and because they may be associated with hydrologic anomalies. Although the salt may flow plastically, the extensive associated deformation can cause fracturing and faulting in overlying and intercalated beds of other rock types. Hydrologic anomalies encountered in the "ERDA No. 6" hole 
that was drilled as part of a repository siting study in the Delaware Basin included a solution zone near the axis of the fold and a significant pocket of $\mathrm{H}_{2} \mathrm{~S}$ pressurized brine (Anderson and Powers, 1978).

Breccia Pipes: Breccia pipes were recognized as anomalous domal features in the Delaware Basin (Vine, 1960) and have been investigated in some depth for the WIPP program. These features, which also have been termed "domal karst features" (Powers and others, 1978, p. 6-41), typically are more or less circular in plan view, 50 to 500 meters in diameter, and are higher than the surrounding topography. The cores of the breccia pipes contain irregular blocks of rocks from the stratigraphically higher formations in a matrix of clay and sand that appears to be a dissolution residue. Beds in strata adjoining breccia pipes have been found to dip either inward or outward. The central parts of some breccia pipes are collapsed. Breccia pipes are recognized to be dissolution features, although the mechanism whereby they are formed is uncertain. It has been proposed that the breccia pipes result from deep dissolution of the underlying salt and that their positive topographic expression then is caused by dissolution at a slower rate than the surrounding salt beds (Anderson, 1978). However, this theory is not universally accepted and the breccia pipes are not completely understood.

\subsubsection{Hydrology}

Natural salt deposits typically contain only very small amounts of water, on the order of a couple of percent or less, and have very low porosities and permeabilities, such that they are difficult to measure in the laboratory. The main water-bearing zones in bedded salt generally are not productive aquifers and contain only water of poor quality. These typically include fractured dolomite or anhydrite interbeds, such as the Culebra and Magenta dolomites in the Rustler Formation of southeastern New Mexico (Brokaw and others, 1972), claystone partings, and layers of dissolution residues that have been leached of halite. The dissolution residues consist of silt- and clay-size insoluble material similar to that described previously for the claystone partings, and would have low permeability. However, they may be tens to hundreds of feet thick (e.g., Brokaw and others, 1972; Anderson, 1978). Anomalous pockets of brine, some pressurized with $\mathrm{H}_{2} \mathrm{~S}$ gas, also occur in salt and halite crystals contain very small brine inclusions. Any of the groundwater in bedded salt typically is saturated brine, being in solution equilibrium with the salt.

Dissolution is one of the most important aspects of hydrology in bedded salt, and considered a potential hazard to a nuclear waste repository in intensive studies of dissolution in support of repository programs 
(e.g., Bachman, 1974; Anderson, 1978; Powers and others, 1978, Chapter 6; Gustavson, 1979). Three general mechanisms of dissolution have been recognized:

1. Dissolution at the top of the salt beds from water percolating down from the surface or shallow aquifers.

2. Dissolution wedges progressing laterally into the salt beds along permeable zones.

3. Deep dissolution at the base of the salt beds from water in the underlying aquifers.

Dissolution in interbeds also may progress along fracture systems (e.g., Olive, 1957) and may thereby influence salt beds along the same patterns. For dissolution to occur it is necessary for fresh (unsaturated) water to have access to the salt and a means for saturated brine to be transported away. The dissolution process occurs over millions of years, however, making detailed understanding of the mechanisms more difficult. The most valuable information on dissolution therefore is obtained from recognizing residues in the salt sequence and effects of dissolution on the overlying strata.

\subsubsection{Resources}

Important geologic resources that occur in association with bedded salt are potash ores, sulfur, and hydrocarbons, in addition to the halite itself. Gypsum and anhydrite have resource value but are mined economically only at shallow depth. The dolomite associated with bedded salt contains magnesium, although brines and sea water are considered a more important source. United states resources of potassium compounds, salt, gypsum, anhydrite, and magnesium are considered virtually inexhaustible (Smith and others, 1973). Other resources also may occur at a place containing bedded salt but are not characteristic of the evaporite environment and therefore cannot be predicted in this generic analysis.

Potash salts, as discussed previously, are components of normal sea water and are precipitated from concentrated brine following precipitation of halite. It also is proposed that potash salts may form during post depositional alteration of the evaporite deposit (e.g., Goldsmith, 1969). As a result of these factors, potash salts are common in bedded salt sequences. Economically important deposits are in the Delaware Basin of southeastern New Mexico (Jones, 1968) and the Prairie evaporites of Canada (Baar, 1973). Significant potash concentrations also 
are in the Salina Basin of Michigan (Matthews and Egleson, 1973) and the Paradox Basin (Goldsmith, 1969).

Sulfur deposits can develop from post-depositional alteration of the anhydrite and gypsum in an evaporite sequence and therefore can be important in bedded salt. It is notable that the world's largest producer of sulfur by the Frasch method is the Rustler Springs Mine in the evaporite sequence of the southern Permian Basin (Smith, 1978). The Rustler springs deposit is thought to have been formed by a combination of (1) anhydrite and gypsum in the formation, (2) presence of abundant hydrocarbons, and (3) presence of oxygenated groundwater. This is thought to have led to generation of $\mathrm{H}_{2} \mathrm{~S}$ gas and subsequent oxidation to sulfur.

There is at least some hydrocarbon production from most of the marine evaporite basins. In recognition of this association, petroleum geologists have evaluated evaporite geology to determine the relationship between evaporite deposition and the generation and accumulation of hydrocarbons (e.g., Buzzalini, 1969; Fisher, 1977).

It has been suggested that the evaporite environment plays a direct role in the origin of hydrocarbon resources (Peterson and Hite, 1969). In this theory, the barred basins that concentrate ocean salts also serve to concentrate organic material. It is then suggested that the low oxygen content of the basin helps to preserve the organic matter so that it can be converted into hydrocarbons. Accumulation in the Paradox Basin (the area of Peterson and Hite's research) was in the shelf facies carbonates that Hite (1970) proposes to have' a genetic relationship to the evaporites. Although there may be uncertainties regarding the nature of a genetic relationship, reefs commonly occur in association with significant evaporite deposits (e.g., Jones, 1968; Baar, 1973; Droste and Shaver, 1977) and there appears to be ample evidence that organic material is abundant in the evaporite sequence. Accordingly, the depositional environment of marine evaporites appears to be favorable for hydrocarbon resources.

\subsubsection{INFORMATION NEEDS FOR PRECHARACTERIZATION STUDIES IN BEDDED SALT}

The information needed to evaluate whether characterization should be undertaken at a prospective site in bedded salt may be anticipated based on the occurrence and geology of bedded salt and the design concepts for a repository in this medium. Criteria used in previous and ongoing repository siting studies in bedded salt provide additional perspectives on potentially important factors. Pertinent assumptions that may be developed from these background sources are summarized in 
the following introductory paragraphs before describing the information needs in bedded salt.

The general geologic setting of a prospective repository site in bedded salt may be anticipated from the occurrence of salt basins in the continental United States (Pierce and Rich, 1962). The major deposits of bedded salt are in parts of the United States that are tectonically stable, with low levels of seismicity, very low rates of tectonic movements, and no evidence of igneous activity for long periods of geologic time. The salt basins also generally are in the interior of the continent, well above sea level, and in areas of relatively subdued surface topography. These conditions are considered favorable for a repository and likely would be sought by DOE in their site-selection studies. Accordingly, they are assumed to be typical of a prospective site for this analysis. (In making this assumption, it is understood that bedded salt can occur in other geologic settings, and in fact does so in other parts of the world. However, the assumed conditions appear valid to the extent that they are typical of the places in the United States where a repository is likely to be sited.)

The general stratigraphy, lithology, and structure of a prospective site in bedded salt may be assumed from the information summarized in Section 6.2.1. Taking the typical occurrence of bedded salt as a marine sedimentary basin that progressively fills and changes to shelf, sabkha, and continental conditions, we have assumed the typical stratigraphic section in Table 6.2.2-1. Depths and thicknesses are taken arbitrarily. Beds are assumed to be generally flat lying with the possible exceptions of structural anomalies that may be identified in site exploration.

The prospective repository level is assumed to be near the midale of the zone of predominantly halite shown at depths of 1,800 to 3,000 feet. This follows typical design practice in concepts for the repository at WIPP (Powers and others, 1978) and in NWTSR-2 (Ritchie and others, 1979) that place the repository levels at depths of 2,000 to 3,000 feet.

Criteria that have been used in repository siting studies in bedded salt are instructive to the extent that they indicate factors considered important in identifying sites for further study. The criteria used in four previous studies are summarized in Table 6.2.2-2. Factors in these general areas are likely to remain highly important as more specific criteria are developed to identify sites for characterization. 
TABLE $6 \cdot 2 \cdot 2-1$

ASSUMED STRATIGRAPHY OF A

TYPICAL SITE IN BEDDED SALT

Depth Below

Surface

Formation

0-700 feet

Sandstone, conglomerate, and shale; water bearing

$700-1200$

Shale, siltstone, and limestone; locally water bearing in fractured and solutioned limestone, low productivity

$1200-1800$

Evaporite sequences of anhydrite, dolomite, and halite interbedded with sandstone and shale redbeds; locally water bearing with poor water quality and low productivity

$1800-3000$

Predominantly halite with interbeds of anhydrite, dolomite, potash salts, and minor shale.

$3000-3400$

Predominantly anhydrite with interbeds of halite and dolomite.

$3400-3700$

Dolomite and limestone

$3700-4400$

Shale

$4400-6000^{+}$

$6000^{+}$

Sandstone, shale and limestone, interbedded, water bearing under confined conditions

Crystalline basement

$6-13$ 


\subsubsection{Geology}

The general category of geology includes information needs relating to the nature and rate of past and present geologic processes and to the geometry and lithology of the prospective host rock and surrounding materials. These may be summarized as:

- Nature and rates of geologic processes;

- Quaternary climate history

- Quaternary history of surface hydrology

- History and rates of erosion or deposition

- History and rates of dissolution or salt tectonics

- Lithology, stratigraphy, and structure of rocks above the salt;

- Lithology, stratigraphy, and structure of the salt, including depth, thickness and lateral extent of prospective host beds;

- Lithology, stratigraphy, and structure of beds below the salt.

Information needs that are specific to bedded salt generally are those regarding geologic conditions in the evaporite sequence (containing the prospective host rock) and to some extent those in the overlying and underlying formations.

For a prospective site in bedded salt, information regarding surface geology and geologic conditions in the rocks above the evaporite sequence are of particular importance for evaluating possible histories of dissolution or salt tectonics. Additional concerns regarding these conditions are essentially identical to those in other media. As at any prospective repository site, it is important to determine the history of climate fluctuations and surface hydrologic conditions over Quaternary time as expressed by geomorphology and surface geology. Similarly, it will be necessary to determine stratigraphy, lithology, and geologic structure of the formations overlying the salt in order to understand their hydrostratigraphy, evaluate feasibility of shaft construction, and to aid interpretations of geologic history.

Stratigraphy, lithology and structure within the evaporite sequence will be of particular concern for identifying potentially suitable host beds. Formations that are largely bedded salt typically contain interbeds of anhydrite, potash salts, and dolomite as well as shale partings and possible dissolution residues. Shale partings, fractured interbeds, or dissolution residues may be preferred flow paths in the bedded salt and may contain small amounts of water or gas, making their identification an important contribution to the hydrologic analyses, and preliminary analyses of mining factors. The dissolution residues also would provide information on dissolution history. In general, the 
TABLE $6.2 .2-2$

SUMMARY OF CRITERIA USED IN PREVIOUS SCREENING STUDIES FOR REPOSITORIES IN BEDDED SALT

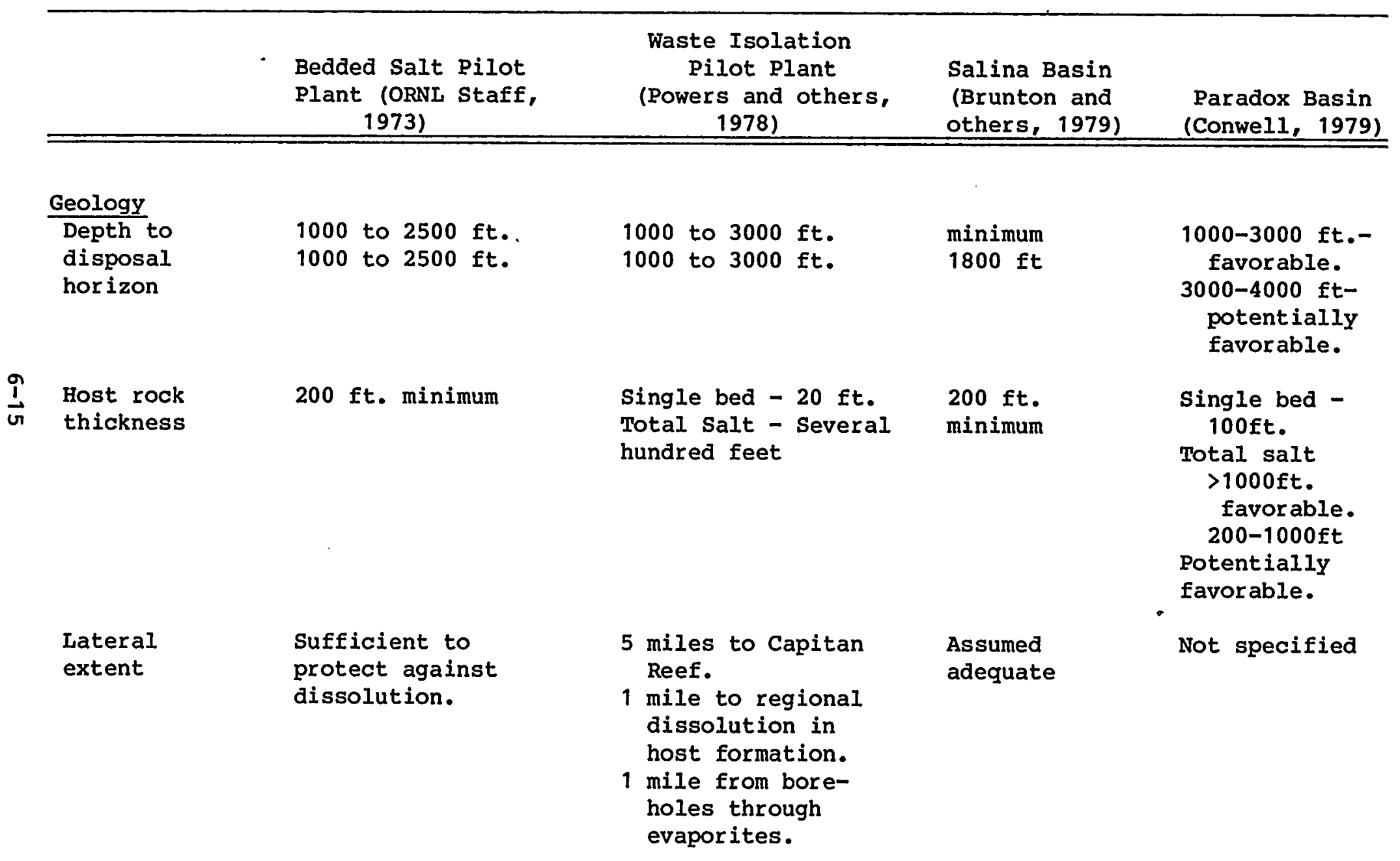


TABLE 6.2-2 (Continued)

\begin{tabular}{|c|c|c|c|c|}
\hline & $\begin{array}{c}\text { Bedded Salt Pilot } \\
\text { Plant (ORNL Staff, } \\
\text { 1973) }\end{array}$ & $\begin{array}{c}\text { Waste Isolation } \\
\text { Pilot Plant } \\
\text { (Powers and others, } \\
\text { 1978) } \\
\end{array}$ & $\begin{array}{l}\text { Salina Basin } \\
\text { (Brunton and } \\
\text { others, 1979) } \\
\end{array}$ & $\begin{array}{c}\text { Paradox Basin } \\
\text { (Conwe11, 1979) } \\
\end{array}$ \\
\hline $\begin{array}{l}\text { Attitude } \\
\text { disposal } \\
\text { horizon }\end{array}$ & $\operatorname{dip}<100 \mathrm{ft} / \mathrm{mile}$ & $<3^{\circ}$ dip & Not specified & Not specified \\
\hline Bydrology & $\begin{array}{l}\text { Minimal ground water and } \\
\text { remote from surface water. }\end{array}$ & $\begin{array}{l}\text { Surface water not } \\
\text { to endanger pene- } \\
\text { trations, salt } \\
\text { assumed free of } \\
\text { ground water. }\end{array}$ & $\begin{array}{l}\text { Criteria not } \\
\text { established } \\
\text { because of } \\
\text { insufficient } \\
\text { data. }\end{array}$ & $\begin{array}{l}\text { Areas in vicin- } \\
\text { ity of ground- } \\
\text { water use or } \\
\text { discharge are } \\
\text { potentially } \\
\text { unfavorable. }\end{array}$ \\
\hline & Avoid dissolution & Avoid dissolution & Not specified & Not specified \\
\hline \multirow[t]{2}{*}{ Geochemistry } & $\begin{array}{l}\text { Formation should be } \\
\text { largely halite; prop- } \\
\text { erties not degraded } \\
\text { by impurities. }\end{array}$ & $\begin{array}{l}\text { Beds of unusual } \\
\text { composition or } \\
\text { containing bound } \\
\text { water not within } \\
20 \text { feet of waste } \\
\text { horizon. }\end{array}$ & $\begin{array}{l}\text { Not considered } \\
\text { applicable in } \\
\text { reconnaissance } \\
\text { screening. }\end{array}$ & Not specified \\
\hline & Less than 28 water. & $\begin{array}{l}\text { Less than } 2.58 \\
\text { water. }\end{array}$ & $\begin{array}{l}\text { Less than } 3 \% \\
\text { brine. }\end{array}$ & Not specified \\
\hline Geomechanics & $\begin{array}{l}\text { Easily drillable } \\
\text { and easily minable. }\end{array}$ & $\begin{array}{l}\text { Clay seams and } \\
\text { structurally weak } \\
\text { zones to be avoided. } \\
\text { No major natural } \\
\text { thermal barriers } \\
\text { within } 20 \text { feet. }\end{array}$ & $\begin{array}{l}\text { Not considered } \\
\text { applicable to } \\
\text { reconnaissance } \\
\text { screening } \\
\text { (State of } \\
\text { stress consid- } \\
\text { ered in depth } \\
\text { limitations). }\end{array}$ & Not specified \\
\hline
\end{tabular}


TABLE 6.2-2 (Continued)

\begin{tabular}{|c|c|c|c|c|}
\hline & $\begin{array}{c}\text { Bedded Salt Pilot } \\
\text { Plant (ORNL Staff, } \\
\text { 1973) }\end{array}$ & $\begin{array}{c}\text { Waste Isolation } \\
\text { Pilot Plant } \\
\text { (Powers and others, } \\
\text { 1978) } \\
\end{array}$ & $\begin{array}{l}\text { Salina Basin } \\
\text { (Brunton and } \\
\text { others, 1979) } \\
\end{array}$ & $\begin{array}{c}\text { Paradox Basin } \\
\text { (Conwell, 1979) } \\
\end{array}$ \\
\hline $\begin{array}{l}\text { Seismicity/ } \\
\text { Tectonics }\end{array}$ & $\begin{array}{l}\text { Avoid tectonic structures. } \\
\text { Avoid diapirism. } \\
\text { Site to have low } \\
\text { historic seismicity. }\end{array}$ & $\begin{array}{l}\text { Avoid major faults } \\
\text { and structural } \\
\text { trends. } \\
\text { Avoid salt anticlines } \\
\text { and diapirs. } \\
\text { Avoid regional uplift } \\
\text { or subsidence. } \\
\text { Avoid igneous activity. } \\
\text { Low seismicity } \\
\text { desirable. }\end{array}$ & $\begin{array}{l}\text { Criteria not } \\
\text { set; entire } \\
\text { study region } \\
\text { generally } \\
\text { stable. }\end{array}$ & $\begin{array}{l}\text { Areas within } \\
5 \text { miles of } \\
\text { faults or } \\
\text { igneous } \\
\text { features } \\
\text { potentially } \\
\text { unfavorable. }\end{array}$ \\
\hline Resources & $\begin{array}{l}\text { Avoid mineral pro- } \\
\text { duction, existing } \\
\text { or potential mining } \\
\text { operations and } \\
\text { boreholes. }\end{array}$ & $\begin{array}{l}1 \text { mile from } \\
\text { existing boreholes } \\
\text { or shafts pene- } \\
\text { trating through } \\
\text { salt, } 2 \text { miles } \\
\text { from existing } \\
\text { mining (future } \\
\text { mining to within } \\
\text { one mile). Avoid } \\
\text { known oil and gas } \\
\text { trends. Avoid } \\
\text { known potash } \\
\text { enclave. }\end{array}$ & $\begin{array}{l}\text { Distribution } \\
\text { of mineral } \\
\text { resources in } \\
\text { study region } \\
\text { too uniform to } \\
\text { permit screen- } \\
\text { ing specifica- } \\
\text { tions. }\end{array}$ & $\begin{array}{l}\text { Areas to have } \\
\text { no identified } \\
\text { conflict with } \\
\text { resources. }\end{array}$ \\
\hline
\end{tabular}


interbeds differ significantly from the halite in their mineralogy, chemical composition, hydrology and mechanical properties such that their distribution and lithology will be critical for identifying potential host beds.

Locations and spacing of shale partings and the associated corrosion surfaces can be important in determining feasiblity of repository development at a prospective site. The corrosion surfaces, being mechanical discontinuities in the salt, can contribute to roof falls and floor heave if they are close to an underground opening. Because the discontinuities associated with the shale partings are independent of their thickness, partings only a few millimeters thick should be identified in the vicinity of prospective host beds.

Precharacterization studies of the entire evaporite sequence to identify potentially suitable host beds would concurrently determine their depth and thickness. More detailed analyses of their stratigraphy, lithology, and structure would be needed in site characterization.

Occurrence of structural features, dissolution, and lateral facies in the evaporite sequence can control the lateral extent of suitable host rock. Although bedded salt generally has much greater lateral extent than is needed for a repository, combinations of potentially adverse features have been found to greatly limit the area available, as in the siting studies for WIPP (Powers and others, 1978, chapter 2). Information regarding these features would be needed in precharacterization.

The structural features of concern include faults and folds, in addition to features unique to bedded salt. Faults are an obvious concern as they may constitute a preferred hydrologic flow path, introduce complexities and uncertainties in the geologic setting, or possibly terminate a prospective host bed. Folds are to be identified because essentially flat-lying bedding is preferred to minimize complexity of geologic interpretation and to facilitate mining operations. Features unique to bedded salt, as described in section 6.2.1, include breccia pipes, salt anticlines and other features indicating flow or dissolution of the salt.

Dissolution progressing laterally along stratigraphically controlled paths can limit lateral extent of suitable host beds, as can significant dissolution progressing from the base of the salt. Salt units typically have some evidence of dissolution in their upper parts and information as to the depth and rate of dissolution would be required to evaluate potential placement of a repository. 
In the absence of structural features or dissolution, extent of potentially suitable host rocks would be determined by lateral facies in the salt. Important information in this regard would include identification of lateral transitions to anhydrite, carbonates, or clastic sediments.

Geologic information from the formations underlying the bedded salt are important, much as in the other bedded media. As discussed in section 6.2 .1 and indicated in Table 6.2.2-1, salt typically occurs in a filling sedimentary basin and is likely to be underlain by anhydrite, carbonate rocks and shale as well as sandstones that may be water bearing. Conditions at a site may differ from this idealized section, particularly in that salt of sabkha origin may be interbedded with sandstone and that carbonate beds may be significant aquifers. Structures in the underlying rocks or features such as reefs or irregular depositional topography may localize deformation in the salt beds or may indicate potential safety problems in mine development. For example, potential problems of gas and brine in beds overlying reefs have been identified in Saskatchewan potash mines (Baar, 1973). Basement rocks typically would be at depths well below the salt beds but irregularites in shallow basement may be a concern.

\subsubsection{Hydrology}

Information needs regarding hydrology at a prospective site in bedded salt include:

- Climate

- Surface hydrology

- Hydrology of ground water above the salt

- Hydrology of possible flow paths within the salt

- Hydrology of ground water below the salt

- Dissolution history and potential

Aside from the concerns with dissolution, these information needs are essentially the same as in any other medium. The most important factors determining the specific information needs at a site would be the number, distribution, and character of the water-bearing units present. 
Information on climate is needed for hydrologic analyses to the extent that it bears on surface hydrology, which in turn may affect groundwater conditions. Climate information for hydrologic studies typically is obtained from meteroogical records and observations. In order to provide an adequate base for extrapolation over the performance period of a repository, additional information on past climates is obtained from the geologic record, as discussed in the section on geology.

Information on surface hydrology is needed as it relates to groundwater hydrology and to inundation potential at a prospective site. For bedded salt, information on surface-water quality and flow may contribute to analyses of dissolution. Specific information on surface hydrology includes rainfall-runoff relationships, flood potentials, possible effects of impoundment failures, stream flow data, and surface-water quality.

Hydrostratigraphy above, within, and below the salt must be determined, including indentification of water-bearing zones and characterization of the hydrologic properties of aquifers and confining zones. Aquifer properties and flow parameters to be determined for each water-bearing zone include:

- Locations and mechanisms of recharge and discharge

- Piezometric heads and gradients

- Porosity, permeability, and related aquifer properties

- Direction and velocity of flow

- Residence time, or age of ground water, at different places along the flow paths

These parameters form a basis for identifying pathways to the accessible environment and for determining travel times for fluids moving in the hydrologic system. Geochemical age dating of the ground water at various places along the flow paths can provide valuable calibrations for these analyses in the low gradient aquifers typical of a prospective repository site in bedded salt.

Beds below the salt are likely to include potential aquifers that would be confined by the low permeability rocks in the evaporite sequence. Information will be needed on these aquifers to determine whether fluids may tend flow upward through the prospective repository level to the accessible environment. This information also may contribute to evaluations of deep dissolution. 
Dissolution is a particular concern in salt as it could significantly affect integrity of the host beds. Information regarding dissolution history largely would be interpreted from the geologic record. Potential for future dissolution would be based on past history combined with analyses of hydrologic conditions at the prospective site.

\subsubsection{Geochemistry}

Information needs in geochemistry include geochemical dating of rocks and water, water chemistry, and geochemical characterization of the various rock types in the geologic setting of the prospective repository. The geochemical dating is done in support of and would be coordinated with the related geologic and hydrologic work.

Water-chemistry information needs include determining $\mathrm{ph}$, $\mathrm{Eh}$, and mineral content of the waters from various sources at and near the prospective site. These analyses would be coordinated with the work in hydrology and would aid understanding of the hydrologic system. similarly, information on the hydrologic system would guide the chemical sampling and testing program.

Information needs regarding rock geochemistry include mineralogy, organic content, alteration, and retardation properties of the various rock types. At the precharacterization stage of investigations in bedded salt, much of this geochemical information would be based on geologic interpretations of lithology and mineralogy. As indicated by the chemical formulas of the typical evaporite minerals (Table 6.2.1-1), there would be significant differences in geochemical conditions at a site according to the relative percentage of the various minerals present. Extensive detailed geochemical analyses of specific materials in the evaporite sequence should follow selection of preferred repository configurations.

\subsubsection{Geomechanics}

Information needs in geomechanics include mechanical and thermal properties of the prospective host rocks under in situ conditions. These are a particular concern in bedded salt because the plasticity of the halite and associated potash salts can cause problems in maintaining stability of underground openings. It also is necessary to determine geomechanical parameters significant for excavating shafts through the overlying materials. Specific factors to be determined for the rocks present include: classification, rock quality, strength, deformation moduli, plasticity, specific heat, thermal conductivity, coefficient of thermal expansion, and potential for thermal alteration. In 
situ geomechanical performance also will depend on factors such as pore pressure and the distribution and character of discontinuities in the rock.

The rock types present in a typical evaporite sequence have markedly different geomechanical properties and the corrosion surfaces form significant discontinuities. Accordingly, some of the most important geomechanical information at the precharacterization stage in bedded salt would be the stratigraphy, lithology, and geologic structure at the prospective site.

\subsubsection{Seismotectonics}

As discussed previously, the significant occurences of bedded salt in the United states generally are in regions that are tectonically stable and have low levels of seismicity. Even so, it would be desirable to establish that seismic/tectonic conditions are favorable at the precharacterization stage. Information needs in this regard include the histories of and potentials for: uplift or subsidence, faulting and other tectonic movements or deformations, igneous activity, and seismicity. Direct information on these factors may be obtained from geodetic surveys and the seismic record. However, much of the pertinent information typically is based on geologic interpretations.

\subsubsection{Resources}

The resource potential and history of exploration and exploitation at a prospective site should be established before commencing characterization. As discussed in section 6.2 .1 , the significant resources typically associated with bedded salt are potash, sulfur, and hydrocarbons. information on the occurrence of potash and sulfur would be obtained in the prospective bedded salt host rock. Information on hydrocarbon resources would be obtained from the deeper stratigraphy, lithology, and geologic structure.

\subsubsection{TECHNIQUE APPLICATIONS TO PRECHARACTERIZATION INFORMATION NEEDS IN BEDDED SALT}

Established techniques of exploration and testing can be used to satisfy the information needs for a prospective repository site in bedded salt. For this discussion, techniques are grouped according to the principal types of information obtained: geology, hydrology, geochemistry, geomechanics, seismotectonics, and resources. However, information obtained in each of the groups typically is applicable to 
needs in the others and in practice there is significant interchange between disciplines. General applications are summarized in Table $6.2 .3-1$.

Application of techniques are considered at three stages of exploration: (1) no drilling at the prospective site, (2) results of previous drilling available for the site, and (3) drilling performed at the site specifically for this work. The types of information available. at each of these stages has been assumed for this discussion, based on typical characteristics of a prospective site in bedded salt.

In the first case, where no drilling has been done at the site, information is available from surface techniques only. In this context, "drilling" is assumed to involve penetrations to about the level of the salt beds and to not include shallow drilling or trenching in support of the surface mapping. It also is assumed that there may be some shallow water wells, penetrating the near-surface aquifers. Existence of water wells to near the depth of the salt is very unlikely because of the typically poor water quality. It is expected that borehole data will be available from the surrounding vicinity, as salt basins typically have been explored for hydrocarbon or mineral resources. These surrounding data will provide a general knowledge of the subsurface stratigraphy and aid interpretations of geophysical data.

Previous drilling in bedded salt typically would have been for hydrocarbon or mineral exploration. Drillers' or geologists' logs are likely to be available for either type of well, but may provide general information only, as the exploration concerns may consider the detailed logs to be propretary and not release them. Core samples are unlikely to be available. The most valuable information from the pre-existing boreholes typically will be the borehole geophysical logs. Based on typical industry practice, it is assumed that self potential, resistivity, natural gamma (gamma ray) and acoustic logs would be available. Mud logs may be available from hydrocarbon exploration wells. It is considered unlikely that the pre-existing boreholes would be in suitable condition for running new logs or for hydrologic testing or monitoring.

In drilling specifically for the exploration program, coring, sampling, and logging would be designed to best obtain the desired information. These would include detailed core logging, availability of core for testing, and using selected borehole geophysical logs. 
TABLE 6.2.3-1 SUMMARY OF TECHNIOUE APPLICATIONS IN BEDDED SALT

\begin{tabular}{|c|c|c|c|c|}
\hline \multirow{2}{*}{\multicolumn{2}{|c|}{ TECHNIOUE }} & STAGE 1 & STAGE 2 & STAGE 3 \\
\hline & & $\begin{array}{l}\text { NO DRILLING SURFACE } \\
\text { EXPLORATION ONLY }\end{array}$ & EXISTING DRILLING & NEW DRILLING \\
\hline \multirow{2}{*}{ REMOTE SENSING } & SATELLITE & G h s r & $\underline{G} \underline{h} \underline{s} \underline{r}$ & $\underline{\underline{G}} \stackrel{\underline{h}}{=} \underline{\underline{s}} \underline{\underline{r}}$ \\
\hline & AIRCRAFT & G h s $r$ & $\underline{\mathbf{G}} \underline{\mathbf{h}} \underline{\mathbf{s}} \underline{\mathbf{r}}$ & $\underline{\underline{G}} \underline{\underline{h}} \underline{\underline{s}} \stackrel{r}{=}$ \\
\hline \multirow{3}{*}{ SURFACE MAPPING } & LANDFORMS & G h s & $\underline{\mathbf{G}} \underline{\mathbf{h}} \underline{\mathbf{s}}$ & $\underline{\underline{G}} \underline{\underline{h}} \underline{\underline{\mathbf{S}}}$ \\
\hline & LITHOLOGY/MATERIALS & $\mathrm{G} \mathrm{hr}$ & $\underline{G} \underline{h} I$ & $\underline{\mathrm{G}} \underline{\underline{\mathrm{h}}} \underline{\underline{\mathrm{r}}}$ \\
\hline & PROCESSES/STRUCTURE & $G$ h $s$ & $\underline{G} \underline{h} \underline{s}$ & $\underline{\mathrm{g}} \underline{\underline{\mathrm{s}}}$ \\
\hline \multirow{4}{*}{$\begin{array}{l}\text { GEOPHYSICAL } \\
\text { LOGGING }\end{array}$} & ELECTRICAL & & $G h \mathbf{c} m \mathbf{r}$ & $\underline{\mathbf{G}} \stackrel{\mathbf{h}}{=} \stackrel{\mathbf{c}}{=} \stackrel{\mathbf{r}}{=}$ \\
\hline & RADIOACTIVE & & $G h \subset m r$ & 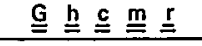 \\
\hline & MECHANICAL & & $G h \subset m r$ & $\underline{\underline{G}} \stackrel{\mathrm{h}}{=} \underline{\underline{c}} \stackrel{\mathrm{m}}{=} \stackrel{\mathrm{r}}{=}$ \\
\hline & ACOUSTICAL & & $G h \subset m r$ & $\underline{\underline{\mathbf{G}}} \stackrel{\mathrm{h}}{=} \underline{\mathbf{c}} \stackrel{\mathrm{m}}{=} \underline{\mathbf{r}}$ \\
\hline \multirow{6}{*}{$\begin{array}{l}\text { GEOPHYSICAL } \\
\text { EXPLORATION }\end{array}$} & GRAVITY & 95 & $\underline{\underline{g}} \underline{\mathbf{s}}$ & $\underline{\underline{g}} \underline{\underline{s}}$ \\
\hline & AUDIO-MAGNETOTELLURICS & & & \\
\hline & SEISMIC REFRACTION & gh & $\underline{\mathrm{g}} \underline{\mathrm{h}}$ & $\stackrel{\mathrm{g}}{=} \mathrm{h}$ \\
\hline & RESISTIVITY & $\mathrm{gh}$ & $\underline{g} \underline{h}$ & $\underline{\underline{g}} \stackrel{\mathrm{h}}{=}$ \\
\hline & MAGNETICS & & & \\
\hline & SEISMIC REFLECTION & Ghs $r$ & $\underline{G} \underline{h} \underline{s} \underline{r}$ & $\underline{\underline{G}} \underline{\underline{h}} \underline{\underline{s}} \underline{\underline{r}}$ \\
\hline \multirow{4}{*}{$\begin{array}{l}\text { GEOMECHANICSI } \\
\text { THERMOMECHANICS }\end{array}$} & ROCK MATERIALLAB TESTS & & $\mathrm{G} \mathrm{h} \mathrm{m}$ & $\underline{\underline{\underline{g}}} \underline{\underline{\underline{h}}} \underline{\underline{m}}$ \\
\hline & ROCK FIELD OBSERVATIONS & . & & \\
\hline & DESIGN LAB TESTS & & M & $\underline{M}$ \\
\hline & DESIGN IN SITU TESTS & & M & $\underline{M}$ \\
\hline \multirow{5}{*}{ GEOCHEMICAL } & $\begin{array}{l}\text { GRAPHICAL' } \\
\text { STATISTIC ANALYSES }\end{array}$ & $\mathrm{C} \mathrm{h}$ & $\underline{\mathbf{c}} \underline{\mathrm{h}}$ & $\underline{\underline{\underline{G}}} \underline{\underline{h}}$ \\
\hline & SAMPLING AND ANALYSES & & & C $h r$ \\
\hline & VIATER-ROCK MODELING & & $\mathrm{Ch}$ & $\underline{\underline{C}} \stackrel{h}{=}$ \\
\hline & STABLE ISOTOPE MODELING & & & C $h$ \\
\hline & GROUNDWATER AGE DATING & & & H c \\
\hline \multirow{6}{*}{ HYDROLOGY } & FLOOD FREQUENCY & H & H & H \\
\hline & RECHARGEIDISCHARGE & $H$ & $\underline{H}$ & $\underline{\underline{\mathrm{H}}}$ \\
\hline & SURFACE WATER CHEMISTRY & $\mathrm{HC}$ & $H C$ & H c \\
\hline & NUMERICAL MODELING & & & H \\
\hline & AQUIFER TESTS & . & & H \\
\hline & TRACER TESTS & & & H \\
\hline \multirow{6}{*}{$\begin{array}{l}\text { SEISMICITY/ } \\
\text { TECTONICS }\end{array}$} & $\begin{array}{l}\text { HISTORICAL } \\
\text { EARTHOUAKE ANALYSIS } \\
\end{array}$ & $\mathrm{sg}$ & $5 \mathrm{~g}$ & $\mathrm{sg}$ \\
\hline & $\begin{array}{l}\text { INSTRUMENTAL } \\
\text { EARTHOUAKE ANALYSIS } \\
\end{array}$ & $S g$ & $5 g$ & $\mathrm{sg}$ \\
\hline & MONITORING NETYORKS & 59 & $S g$ & $S g$ \\
\hline & VELOCITY STUDIES & 59 & S g & $S g$ \\
\hline & FAULT STUDIES & S g & S g & $\mathbf{S} \mathrm{g}$, \\
\hline & $\begin{array}{l}\text { ATTENUATION AND } \\
\text { GROUND MOTION }\end{array}$ & $\mathrm{sg}$ & $\mathrm{Sg}$ & $S g$ \\
\hline \multicolumn{2}{|c|}{ DRILLING/LOGGING } & & & G HCM $M S R$ \\
\hline
\end{tabular}

EXPLANATION

CLASSES OF INFORMATION NEEDS

$G=G E O L O G Y$

$H=$ HYDROLOGY

C = GEOCHEMISTRY

$M=$ GEOMECHANICS/THERMOMECHANICS

$S=$ SEISMICITY/TECTONICS

$R=$ RESOURCES

NOTES:

1. CAPITAL LETTERS INDICATE MOST APPLICABLE TECHNIQUES.

LOWER CASE LETTERS INDICATE LESS APPLICABILITY.

DOUBLE UNDERLINE INDICATES ENHANCEMENT OY NEW DRILLING DATA.

2. LETTERS INDICATE INFORMATION NEEO CLASSES WHOSE TECHNIQUES

OBTAIN DATA THROUGH STAGES OF INVESTIGATION. LETTERS INDICATE

APPLICABILITY WITHIN A STAGE, BUT DO NOT REPRESENT EQUIVALENCE

BETWEEN TECHNIOUE. RESOLUTION, RELIABILITY, AND OTHER EVALUATION 


\subsubsection{Geology}

\subsection{No Drilling at a Site}

The bedded salt and the associated evaporite units at a prospective repository site typically would not be exposed at the surface within several miles of the site. Where they may be exposed, at a considerable distance away, they would be very much altered by weathering. As a result, little direct information on a prospective bedded salt host rock can be obtained without drilling. The techniques that may be used before drilling at a site are remote sensing, surface mapping, and geophysical exploration. These can be applied to some significant information needs at a site.

The information needs relating to geomorphology, Quaternary geology, paleoclimate, history of erosion and deposition, and similar topics can be addressed before drilling is undertaken at a site. These typically utilize techniques in remote sensing and surface mapping (Appendix A), supplemented by shallow drilling and trenching as required. As discussed previously, these information needs are unrelated to the medium involved but instead are determined by the other geologic conditions at a prospective site. Resolution and reliability of these geologic observations and the resulting interpretations also would depend on site conditions, particularly on the amount of information available and the complexity of the geologic record.

Lateral extent of the suitable host rock surrounding a prospective site may be addressed by identifying tectonic features, anomalous structures, or dissolution effects that typically are expressed at the surface. Geophysical techniques, particularly seismic reflection (Appendix $B-6$ ), also may be used to identify such features and to recognize termination of suitable beds by sedimentary facies changes. Reliability and resolution of these determinations could vary significantly, according to local conditions in relation to the nature of the features involved. Thickness and composition of the overburden at a site would be particularly important in determining how reliably features of a given size may be detected.

General information on stratigraphy, lithology, and geologic structure at a prospective site may be extrapolated from off-site boreholes and interpreted from seismic reflection data. Many bedded salt environments are notable for lateral continuity, such as in the Delaware basin (Brokaw and others, 1972), allowing such extrapolations to be made with considerable confidence. Interbeds less than a foot thick typically can be recognized on borehole geophysical logs but beds correlated by seismic reflection generally will be at least a few tens of feet thick (Appendix B-6). 


\subsection{Previous Drilling}

Results of previous drilling at a site in bedded salt can greatly aid evaluations of stratigraphy, lithology, and geologic structure. The typical borehole geophysical logs assumed to be available can be very useful for interpreting stratigraphy in evaporities (e.g., Jones and others, 1960) and can detect interbeds less than a foot thick. Moreover, the data from previous boreholes can greatly increase the reliability and accuracy of geophysical interpretations. In particular, the borehole data would provide depth control for the geophysical interpretations and would confirm lithologic correlations with the seismic stratigraphy. The minimum thickness of a prominent stratigraphic unit that could be mapped confidently through the site area may be reduced from a few tens of feet (based on seismic reflection alone) to a foot or less.

\section{$6 \cdot 2 \cdot 3 \cdot 1 \cdot 3$. New Drilling}

New drilling at a prospective site would allow detailed core logging and selection of the most suitable techniques for borehole geophysical logging (Appendix $\mathrm{C}-1$ ). The combined effect of these techniques is to greatly increase the resolution and reliability of the stratigraphic, lithologic, and structural information. Although the borehole geophysical logs can be interpreted with considerable confidence, direct observation of the core is valuable to confirm lithology and to analyze structural features. Detailed core logging can detect features on the order of 0.01 foot or less. This level of detail is desired in bedded salt because of the importance of thin shale partings for identifying suitable depths for underground openings.

Mud logging and selected geophysical logs run in the new boreholes can be used to provide data for zones that are not cored and to aid or supplement the core logging. Natural gamma logs are particularly useful for confirming depths of the core return. In addition to the basic logs assumed available for the pre-existing holes, logs that may be useful to aid lithology determinations include spectral gamma, density, porosity, and acoustic logs. Silicon and carbon activation logs can be used to identify argillaceous zones in the halite and organic layers, respectively. State-of-the-art tools such as borehole radar and borehole gravity also may be used to aid identification of structural features, brine pockets and other anomalies. As noted previously, standard borehole logs typically can detect layers less than a foot thick. By using combinations of logs under relatively controlled conditions, layers to 0.1 foot may be detected with significant confidence. Resolution and reliability of the radar and gravity tools has not been established. 


\subsubsection{Hyärology}

\subsection{No Drilling At a Site}

Hydrologic techniques that may be used at a site with no drilling are limited to those involving climate, surface hydrology, and hydrology of groundwater at shallow depths, well above the salt. These techniques are independent of the prospective host medium and would be applied at any site as described in Appendix G-1. Resolution and reliability of these techniques also are independent of the host medium and depend on local conditions and factors such as the length and quality of climate and streamflow records.

Without arilling at a site, some information on hydrology in and below the salt may be developed from inference and extrapolation of lithologic and stratigraphic data. However, drilling and aquifer testing are needed to obtain reliable hydrologic data.

\subsection{Previous Drilling}

Previous arilling at a prospective repository site in bedded salt is unlikely to include water wells to the depths of concern and the holes are unlikely to be suitable for hydrologic testing or monitoring at or below the salt level. As a result, the main benefits to the hydrologic studies from the previous drilling would be that hydrostratigraphy could be defined with much greater reliability, using techniques discussed in the preceding section (6.2.3.1).

\subsection{New Drilling}

New drilling at a prospective repository site in bedded salt is needed for application of the hydrologic testing techniques described in Appendix G-1. At this stage of exploration, water samples may be obtained by pumping or bailing, aquifer tests may be performed, and the well may be completed for monitoring water levels in selected aquifers. specific concerns for this work in bedded salt include the difficulties of measuring hydrologic parameters in materials of low permeability and the need to avoid dissolution or other disruption of the salt from injection tests.

In a typical bedded salt environment, even the zones considered to be potential aquifers generally have low transmissivity and contain only small amounts of water. Testing for WIPP (Powers and others, 1978, p.6-31) found that long periods of time were needed to collect samples adequate for water quality testing and that water levels in some 
observation wells required more than 12 months to recover to static conditions. In these conditions, injection tests appear to be potentially most useful. Pump tests would be less desirable because of the small volumes of water available and the long travel times involved may make tracer tests infeasible.

Aquifer parameters can be significantly different for the various zones in a typical bedded salt environment. As the porosity and permeability of the salt itself is "low to virtually none" (Brokaw and others, 1972), the water bearing zones and potential flowpaths to be tested typically are interbeds such as dolomite beds, shale partings, and zones of dissolution residues. Fluid yields from dolomite interbeds tested for WIPP generally ranged from 2.3 to 310 gallons per day (GPD), but results of $8640 \mathrm{GPD}, 5760 \mathrm{GPD}$ and 0.5 gallons in 33 days also were obtained (Table 6.3-4 in Powers and others, 1978). Transmissivities indicated these zones ranged from $10^{-4} \mathrm{ft}^{2} /$ day to $140 \mathrm{ft}^{2} /$ day (Mercer and Orr, 1978). Similar tests of the dissolution residue zone in the salt had yields of 0.5 gallons in 73 days to $75 \mathrm{GPD}$, indicating transmissivities of $10^{-4} \mathrm{ft}^{2} / \mathrm{day}$ to $10^{-1} \mathrm{ft}^{2} / \mathrm{day}$ (sources as above). The ranges of values observed in the tests appear to represent variations in aquifer properties that would be typical of such zones in bedded salt. Accordingly, possible inaccuracies in the aquifer testing techniques would be insignificant in comparison to the natural variability of the potential aquifers in the bedded salt.

Laboratory porosity and permeability tests may be performed on core samples obtained from the new drilling and may contribute to understanding of aquifer properties. As discussed in Appendix G-1, there typically is some uncertainty in these tests because of possible disturbance of the core samples. In bedded salt, however, a more important concern is how representative the samples are of the conditions important in the repository zone. The reliability of these tests therefore must be evaluated on the basis of detailed core logging and comprehensive geologic analyses of conditions at the prospective site.

Techniques for modeling and analysis may be used to evaluate hydrologic conditions at a prospective site, based on the results of the borehole and laboratory testing. Geologic determinations of the site configuration and geochemical data regarding quality and age of the waters in the various zones also contribute to these analyses. Results provide information on hydrologic flow in the prospective repository area, including: locations and mechanisms of recharge and discharge, hydrologic heads and gradients, directions and rates of flow, and travel times through the hydrologic system. 
Reliability and resolution of the modeling and analysis techniques is determined chiefly by how well the geohydrologic system is understood. On a conceptual basis, bedded salt is a simple hydrologic system with generally horizontal and continuous layering. However, the variability of aquifer properties discussed above suggests that these systems may be much more complicated in detail and may be difficult to quantify - accurately, even though conditions may be well within an acceptable range for repository performance. Professional judgement will be very important in these analyses; it would not be valid to merely select the most conservative (i.e., adverse) parameters determined from testing as these appear likely to be more representative of local anomalous conditions than of the overall conditions along potential pathways to the accessible environment.

Dissolution is a particular concern in bedded salt and may be evaluated using techniques of hydrologic analysis combined with interpretations of dissolution history and rates based on geologic techniques. The geologic techniques contributing information regarding dissolution include remote sensing analyses and surface mapping (Appendix A) to recognize surface expressions of dissolution, as well as drilling (Appendix $D-1$ ) and geophysical exploration (Appendix B) to identify the subsurface zones where dissolution has occurred. Hydrologic techniques contribute to these analyses by quantifying transport of fluids through the salt, based on the geohydrologic model. All of these techniques have been applied in dissolution studies of the Permian Basin (Bachman and Johnson, 1973; Swenson, 1974; Anderson, 1978). The resolution and reliability of such analyses is essentially that of the geohydrologic model combined with the level of understanding of the dissolution mechanisms involved. As a result, dissolution potential is likely to be difficult to quantify accurately. However, typical rates of dissolution are such that dissolution potential is likely to be well within an acceptable range for repository performance, even considering the uncertainty involved.

\subsubsection{Geochemistry \\ 6.2.3.3.1 No Drilling}

Before drilling is done at a site, techniques available in geochemistry are limited to testing of surface-water quality and isotope dating of surface samples, supporting the hydrologic and geologic efforts, respectively. At this stage of investigation, geochemical conditions directly relevant to a prospective repository only may be inferred from general information on lithology and stratigraphy. 


\subsection{Previous Drilling}

Previous arilling will provide general information on geochemical conditions at prospective repository depths by interpretation of stratigraphy and lithology from borehole geophysical logs. This general information would be very useful in bedded salt because mineralogy of the associated materials typically varies significantly. However, the geochemical information available at this stage would be of uncertain reliability and would be able to resolve zones approximately corresponding to the general stratigraphic units.

\subsection{New Drilling}

New drilling at a prospective site would allow application of laboratory techniques for geochemical analyses of rock and water samples (Appendix F-1) and would allow geochemical interpretations to be made from selected borehole geophysical logs (Appendix $\mathrm{C}-1$ ). This testing and analysis provides the basis for geochemical description of the prospective repository environment and for age dating of rocks and waters. The specific techniques that may be used are described in Appendix $\mathrm{F}-1$.

Geochemical properties of individual samples can be determined with a high degree of accuracy and reliability. However, the more important question of how well the geochemical environment of the prospective repository can be defined depends on how well the geologic and hydrologic framework is understood in addition to accuracy of testing and density of sampling. These factors cannot be quantified with any confidence on a generic basis.

\subsubsection{Geomechanics}

\subsection{No Drilling At a Site}

Information needs in geomechanics comprise the mechanical and thermal properties of the rocks influencing the repository and description of in situ stress conditions. For a prospective site in bedded salt, drilling is needed to obtain information on host rock characteristics. If the host rock crops out at all, it would be miles from the prospective site and any surface exposures would be very much altered by weathering. Patterns of fractures and joints cannot be extrapolated confidently from surface exposures to the salt beds because mechanical properties of the salt typically are significantly different than those of the overlying rocks. In view of these factors, geomechanical information that may be obtained at a site in bedded salt without 
drilling typically would be limited to: (1) extrapolations of conditions from offsite, (2) general interpretations based on available lithologic, stratigraphic, and structural information, and (3) interpretations of tectonic stresses.

\subsection{Previous Drilling}

Data from previous boreholes at a site could provide useful information in geomechanics by defining lithologic zones with increased accuracy and reliability. There are such significant differences in geomechanical properties between the typical rock types in an evaporite sequence (i.e., halite, anhydrite, dolomite, potash salts, and the shale partings) that the distribution of these rock types is likely to be the most important geomechanical information to be obtained at the precharacterization stage. The reliability and resolution of geomechanics information from previous arilling would depend on the quality of the available geologic information.

\subsection{New Drilling}

New drilling at a prospective site would allow direct determination of geomechanical parameters by use of the techniques described in Appendix E-1. In addition to these tests, detailed core logging and borehole geophysics would be available to better define stratigraphy, lithology, and geologic structure, and particularly to identify the corrosion surfaces that could be a concern for the stability of proposed underground openings. Important parameters to be determined in testing would include: strength, elastic moduli, plasticity, specific heat, coefficients of thermal conductivity and expansion, and potential for thermal alteration of associated argillaceous minerals. Typical values of selected parameters for the rock types typically associated with bedded salt are summarized in Table 6.2.3-2. The wide ranges of values indicated for mechanical parameters likely reflect impurities or mechanical defects in the samples tested. For example, argillaceous zones in halite typically are much weaker than relatively clean beds.

The variation in geomechanical properties between the rock types typically associated with bedded salt is very much greater than the uncertainty in geomechanical measurement techniques. Accordingly, the reliability and resolution of the geomechanical analyses would be determined to a large extent by the quality of the geologic model of the site. 


\subsubsection{Seismotectonics}

Information needs in seismicity and tectonics are resolved in programs that are independant of the potential host medium involved and of the stage of site investigation (as defined by the availability of borehole data). As discussed in section 6.2.2, bedded salt typically is found in parts of the United States that are characterized by tectonic stability and low levels of seismic activity. It would be beneficial to confirm and quantify these conditions before undertaking drilling at a site, although final analyses commonly would be delayed to allow additional time for monitoring of seismicity. Borehole information also would be valuable for applications of the seismologic data to evaluate specific conditions of shaking at the surface and at various depths.

Techniques used to obtain information on seismicity and tectonics include the seismic techniques described in Appendix $\mathrm{H}$ combined with geologic techniques for recognizing the faults and tectonic movements from remote sensing, surface mapping, and subsurface exploration. Reliability and resolution of the interpretations from these techniques cannot be quantified on a generic basis because they depend on complex factors such as length and quality of the local seismic record and level of understanding of the associated geologic setting. In spite of these possible uncertainties, seismic/tectonic conditions at a prospective site in bedded salt are expected to be well within the acceptable range for a repository.

\subsubsection{Resources}

\subsection{No Drilling at a Site}

Before drilling is begun at a site, resource potential may be well known from extrapolation of off-site data and from interpretation of geophysical surveys. Potash salts commonly are found in laterallyextensive beds, such as the "ore zones" in the Delaware Basin (Jones, 1968). These zones typically would be well known from off-site boreholes and may be extrapolated to the site using seismic reflection data. However, in other environments, potash ores occur in irregular bodies developed from post-depositional alteration (e.g., Baar, 1973) and their definition would require detailed site-specific exploration.

In the typical model of a bedded salt environment (Table 6.2.2-1), hydrocarbon resources would be most likely to occur in the sandstone beds below the salt or in reefs developed as lateral facies to the evaporite sequence. In this typical case, hydrocarbon potential could be determined generally before drilling at a prospective site and interpretations could be confirmed and their reliability improved 
TABLE $6.2 .3-2$

MECHANICAL AND THERMAL PROPERTIES OF TYPICAL MATERIALS ASSOCIATED WITH BEDDED SALT

\begin{tabular}{|c|c|c|c|c|c|c|c|}
\hline- & $\begin{array}{r}\text { Density } \\
\left(\mathrm{gm} / \mathrm{cm}^{3}\right) \\
\end{array}$ & $\begin{array}{l}\text { Young 's } \\
\text { Modulus } \\
\text { (E - in } \\
\text { Megabars) }\end{array}$ & $\begin{array}{c}\text { Poisson's } \\
\text { Ratio }\end{array}$ & $\begin{array}{l}\text { Compressive } \\
\text { Strength } \\
\end{array}$ & $\begin{array}{l}\text { Thermal } \\
\text { Expansion }\end{array}$ & $\begin{array}{c}\text { Thermal } \\
\text { Conductivity } \\
10^{-3} \mathrm{Cal} / \mathrm{cm} \mathrm{sec}{ }^{\circ} \mathrm{C} \\
\end{array}$ & $\begin{array}{l}\text { Specific } \\
\text { Heat }^{7} \\
\end{array}$ \\
\hline Halite & $2.16^{1}$ & $\begin{array}{r}.28-.37^{3} \\
.19^{2}\end{array}$ & $.20-.21^{3}$ & $270^{4}-255$ bars ${ }^{2}$ & $2.29^{5}$ & $\begin{array}{c}12.8-17.2^{6} \\
\text { (Single crystals } \\
7.5-16.7^{6} \text { ) }\end{array}$ & 1240 \\
\hline Anhydrite & $2.9^{1}$ & $.72-.74^{3}$ & .30 & $140-6370$ bars $^{4}$ & & $12 \cdot 9-13 \cdot 4^{6}$ & 2600 \\
\hline Gypsum & $2.31^{1}$ & & & & $.58^{5 a}$ & & \\
\hline $\begin{array}{l}\text { Limestone } \\
\text { (Calcite) }\end{array}$ & $2 \cdot 4-2 \cdot 7^{3}$ & $.17-71^{3}$ & $.18-.27^{3}$ & $390-5100$ bars $^{4}$ & $2.9^{5}$ & $4.7-8.0^{6}$ & 2220 \\
\hline Dolomite & $2.83-2.87^{3}$ & $.63-69^{3}$ & $.16-27^{3}$ & $600-8300$ bars $^{4}$ & & $7 \cdot 9-13 \cdot 2^{6}$ & $4080^{7 a}$ \\
\hline Carnalite & $1.60^{1}$ & & & & & & \\
\hline Sylvite & $1.98^{1}$ & & & & $1.94^{5}$ & $11.8-16.6^{6}$ & 1260 \\
\hline Kainite & $2.10^{1}$ & & & & & & \\
\hline
\end{tabular}


TABLE $6 \cdot 2 \cdot 3-2$ (continued)

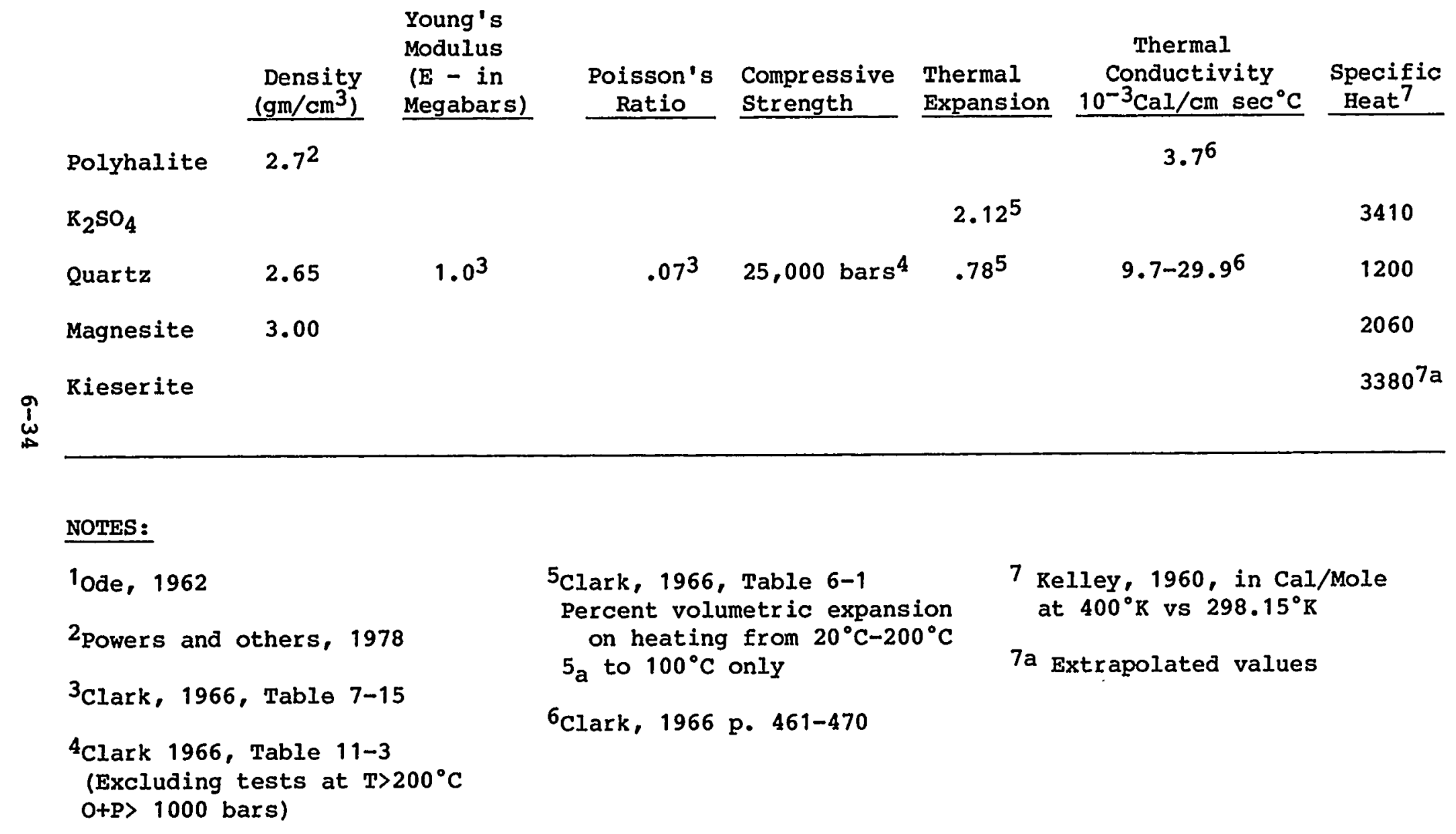


by data from previous and new drilling. Potential reservoir rocks generally would be known from off-site sources and hydrocarbon traps can be identified from reconnaissance (in the context of repository investigations) seismic reflection surveys.

\subsection{Previous Drilling}

Information from previous drilling at a prospective site would improve the resolution and reliability of resource determinations by allowing direct identification of ore zones and refining interpretations of stratigraphy, lithology, and geologic structure. The borehole geophysical logs assumed to be available would be the most valuable information in this regard as they can allow reliable identification of potash salts and evaporite stratigraphy (e.g., Jones and others, 1960). Previous drilling for hydrocarbon exploration typically would penetrate below the salt zone and would provide information at those depths to aid interpretations of hydrocarbon potential.

\subsection{New Drilling}

New drilling at a prospective site would increase the reliability and resolution of resource evaluations by generally improving the confidence in geologic interpretations. It also may be assumed that this new drilling would include holes placed to evaluate any potential resources identified in the site area, as was done for WIPP (Powers and others, 1978, Chapter 8). In view of the expectation that precharacterization exploration of a prospective site would involve a detailed study of general geology, resource potential of the site would be defined with a high level of confidence. It is unlikely that resources of present or potential economic value would be overlooked.

\subsubsection{COST AND TIME ESTIMATES FOR PRECHARACTERIZATION TECHNIQUES}

Cost and time estimates for the techniques that would be used in investigation of a prospective site in bedded salt are summarized in the accompanying Tables $(6.2 .4-1$ to $6.2 .4-7)$. Many of these techniques are essentially similar to those used in other media and for other types of studies and, as a result, cost and time estimates also will not vary. Parameters that are unique to bedded salt are emphasized in the following discussion. 


\begin{abstract}
6.2.4.1 Remote Sensing and Mapping
Costs and times involved in remote sensing analyses and surface geologic mapping are discussed in Appendix $A$ and summarized in Table 6.2.4-1. Although there would be specific objectives in this work for a site in bedded salt, the techniques used would be essentially the same as for sites in other media; cost and time estimates similarly would not differ. The main factors influencing costs and times for the field work would be accessibility and trafficability of terrain at a site and the complexity of geologic conditions. These differ significantly at known occurrences of bedded salt and cannot be accounted for on a generic basis.
\end{abstract}

\title{
6.2.4.2 Drilling and Coring \\ Costs and times for drilling or coring and for geologic logging of cuttings and core are discussed in Appendix $\mathrm{D}-1$. Drilling techniques and equipment used in the petroleum industry are judged most effective for work in bedded salt. Estimated costs and production rates for drilling or coring to typical repository depths are in Table 6.2.4-2. As for other techniques, the validity of these estimates may vary according to site conditions such as terrain, accessibility, and nature of overburden materials. The time, and associated personnel costs, for both remote sensing and geologic mapping would also depend on the complexity of geologic conditions at a particular site, and may vary accordingly.
}

\subsubsection{Borehole Geophysical Logging}

Costs for various borehole geophysical logs are discussed in Appendix C-1 and summarized in Table 6.2.4-3. Per foot costs typically would depend on factors such as mobilization distance, standby time, and calibration requirements, in addition to the total footage logged and the number of tools run concurrently.

Times required for running individual logs depend on trolling speed and setup requirements (i.e., changing probes, calibration, etc.). In general, however, several logs can be run per day and the most extensive logging program at a single well can be completed within a couple of days once the contractor is on the site. These times are nearly insignificant in comparison to the duration of drilling and associated testing. 
COST AND TIME SUMMARY FOR REMOTE SENSING AND MAPPING

Acquiring Imagery or Photography

\section{Approximate \\ Cost Range}

LANDSAT

Enhancement
$\$ 8-150$ per image $(2)$
$\$ 200-1000$ per scene $(3)$

$\$ 8-150$ per image (2)

$\$ 8-150$ per image $(2)$

\section{Delivery} Time (1)

1-4 weeks 4-16 weeks (3)

1-4 weeks

$1-4$ weeks

1-4 weeks

2-6 weeks

1-4 weeks

2-6 weeks
Approximate Area Covered

$$
13,500 \mathrm{mi}^{2}
$$

Stereo Aerial Photography

purchase existing $\$ 3-60$ per frame(2)

New flight $\$ 25-40$ per frame (4)

Low Sun Angle Photography

purchase existing $\$ 3-60$ per frame (2)

New flight

\$25-75 per frame (4)

Radar Imagery

purchase existing $\$ 125$ per strip

New flight

1-3 weeks $100-2500 \mathrm{mi}^{2}$

3-10 weeks per survey design

$\frac{\text { Interpreting Imagery or Photography }}{\text { Cost }}$

Satellite Imagexy

$\$ 1050-1750$

(generally 1:250,000)

Aerial photography $(8)$

e $1: 62,500$

Land forms

Iithology

Geologic Structure

$\$ 70-175$

$\$ 70-175$

$\$ 175-280$

Aerial photography $(8)$

e 1:24,000

$\begin{array}{ll}\text { Land forms } & \$ 175-350 \\ \text { Lithology } & \$ 175-350 \\ \text { Geologic structure } & \$ 280-700\end{array}$

Radar Imagery
(9)

$$
\frac{\text { Time }}{3-5 \text { days }}^{(5)}
$$

Comments

per scene

$1 / 4-1 / 2$ days

$1 / 4-1 / 2$ days

$1 / 2-1$ day

For 100

$\mathrm{mi}^{2}$ area

1/2-1 day

1/2-1 day

3/4-2 days

For 100

$\mathrm{mi}^{2}$ area

(9) 
TABLE $6.2 .4-1$ (cont.)

$\begin{array}{llll}\text { Field Mapping (6) } & \text { Cost } & \text { Time } & \text { Comments } \\ \text { Reconnaissance } & & & \\ 1: 62,500 \text { scale } & \$ 1800 & 3 \text { days } & \\ 1: 24,000 \text { scale } & \$ 3000 & 5 \text { days } & \text { For } 100 \\ & & & \text { mi }^{2} \text { area } \\ \text { Relatively complete mapping } & & \\ 1: 62,500 \text { scale } & \$ 4200 & 7 \text { days } & \\ 1: 24,000 \text { scale } & \$ 6600 & 11 \text { days }\end{array}$

TABLE 6.2.4-1 (cont.) -

NOTES

(1) Delivery times generally do not depend on quantity ordered.

(2) Cost of photos or imagery is determined by size of print ordered, whether in color or black and white, and extra charges for shorter delivery time.

(3) Cost and delivery time for enhancements depends on source and on availability of previous processing for scene desired.

(4) Flight costs in addition to costs of photo reproduction indicated above.

(5) Approximate man-days to complete work; delivery time may be longer. Time required for interpretations can depend on complexity of geologic conditions at a site.

(6) Cost and time estimates assure interpretation of imagery and photography completed previously. Actual times and costs in an area would be influenced by access, trafficability, and complexity.

(7) Obtaining radar imagery from a new flight costs several thoùsand dollars. Actual costs depend on mobilization (radar equipment is not widely available), altitude requirements and other flight parameters.

(8) Estimated times and costs are applicable to all types at $9^{\prime \prime} \mathrm{X}$ 9" stereo aerial photographs, including back and white color, and infra red (black and white or color).

(9) Time and cost for interpreting radar imagery depends on scale and resolution of the imagery, purpose of the interpretations, and other factors. See Appendix A for discussion. 
TABLE $6.2 .4-2$

COST AND TIME SUMMARY FOR

DRILLING \& CORING(1)

\begin{tabular}{|c|c|c|c|c|}
\hline $\begin{array}{c}\text { Type } \\
\text { Equipment }\end{array}$ & $\begin{array}{l}\text { Cost }(2) \\
\text { (per foot) }\end{array}$ & $\begin{array}{l}\frac{\text { illing }}{\text { Production }} \\
\text { Rate } \\
\text { (feet per day) }\end{array}$ & $\begin{array}{l}\text { Cost }(2) \\
\text { (per foot) }\end{array}$ & $\begin{array}{l}\frac{\text { oring }}{\text { Production }} \\
\text { Rate } \\
\text { (feet per day) }\end{array}$ \\
\hline Petroleum & $\$ 55$ & 300 & $\$ 135$ & 120 \\
\hline Mining & $\$ 75$ & 160 & $\$ 150$ & 80 \\
\hline Water Well & $\$ 40$ & 200 & $\$ 135$ & 60 \\
\hline
\end{tabular}

Notes:

(1) Adapted from Appendix D

(2) Includes personnel, supplies, mud, and all other support equipment. 
TABLE $6.2 \cdot 4-3$

COST AND. TIME ESTIMATES FOR BOREHOLE GEOPHYSICAL LOGGING

Techniques

Approximate

Cost Range

Typical Log Package (1)

Borehole Caliper

Focused Resistivity

single-point Resistivity

Spontaneous Potential

Gross-count Gamma Ray

Density

Neutron Porosity

Deviation
$\$ 1300$

to

$\$ 6500(2)$
$1 / 2$ day

Additional Logs (4)

Electrical

Radioactive

$\left.\begin{array}{l}\$ 350-900(5) \\ \$ 300-1000(5) \\ \$ 800-2700^{(5)}\end{array}\right\}$

Acoustic

Time $^{(3)}$

\}

$$
\$ 6500(2)
$$

Specialized logs requiring separate mobilization: (not practical for single hole)
Radar Iog
$\$ 6000(6)$
$1 / 2$ day
Gravity Log
$\$ 4000^{(6)}$
$1 / 2$ day one hour per sonde 
TABLE 6.2.4-3 (cont.) - NOTES

\section{(1) Assumes:}

a. Single 1000-foot hole

b. 400 miles (round trip) travel charge to well site

c. Holes ready to log upon arrival (i.e. no standby time)

d. Logging speed of 50 feet per minute

e. Non-logging (entering hole) at 60 feet per minute

f. Log package combined on two sondes

(2) Low cost for minerals logging contractor; high end cost for oilfield logging contractor. Cost per hole would be reduced if travel charge can be applied to additional holes.

(3) Approximate time on site, not including travel.

(4) Assumed to be added to package described in note (1)

(5) Actual costs will depend on services desired, available combinations in single sondes, and minimum charges imposed by some contractors. Ranges are as in note (2) above.

(6) Estimated cost for single 1000-foot hole logged as part of larger program. Includes interpretation. 


\subsubsection{Geophysical Exploration}

Costs and times for various techniques of geophysical exploration are discussed in Appendix $B$ and summarized in Table 6.2.4-4. Seismic reflection surveys are most applicable in bedded salt while resistivity and seismic refraction also may be used for specific information needs. Airborne magnetic gravity surveys also may be applicable to reconnaissance investigations of specific information needs. Additional techniques, discussed in Appendix B, generally are not applicable in bedded salt and are not included in Table 6.2.4-4.

The ranges of costs and times reflect to a large extent the differences between reconnaissance-level surveys in the early part of an investigation and the detailed, high-resolution surveys needed as precharacterization studies focus on a site. This is particularly evident for seismic reflection surveys, as the lower costs are for reconnaissance surveys to determine general structure and resource potential at moderate depths. The smaller detector spacing and higher resolution needed for reliable investigation at the proposed repository levels would result in corresponding increases in costs and time requirements.

\subsubsection{Geomechanics}

Costs and times for typical laboratory and field techniques in geomechanics are provided in Table 6.2.4-5. Creep testing which is likely to be very important in salt, is not included in this table as it is expected that sufficient data for precharacterization would be obtained from long-duration triaxial compression tests. Additional data on creep testing will be provided in the section on site characterization.

\subsubsection{Geochemistry}

Estimates of costs and times for typical laboratory and analytical techniques in geochemistry are summarized in the tables accompanying Appendix F-1. Costs for obtaining and transporting samples are not included.

\subsubsection{Hydrology}

Costs and times for typical techniques used in hydrologic studies are summarized in Table 6.2.4-6. As discussed previously, these investigations at a prospective site in bedded salt will address several different hydrologic systems, above, within and below the salt. In general, the potential range of costs indicated reflects the differences between testing of shallow, relatively productive aquifers above the salt and work in the deeper, relatively unproductive zones within and below the salt. Costs of drilling and well completion are not included in these estimates. 
TABLE $6 \cdot 2.4-4$

COST AND TIME SUMMARY FOR

GEOPHYSICAL EXPLORATION TECHNIQUES

Technique

Gravity

Seismic Refraction

Resistivity Profile

Resistivity Sounding

Airborne Magnetic

Seismic Reflection

- Typical survey

- High resolution
Approximate Cost Range (1)

$\$ 60-75$ per

station (2)

$\$ 3,000-15,000$

per mile(3)

$\$ 1000$ per station (4)

$\$ 2500$ per

sounding (6)

$\$ 20$ per mile plus mobilization cost (see Appendix B-5)
Typical Production Rates (1)

2 to 4 stations per hour

3 stations per crew per day in field (5)

2 soundings per crew per day in field(5)

2 to 6 week delivery time (depending on equipment availability

Field rate of 100

line miles per month per crew (7)

Field rate of 40 line miles per month per crew (7) 
TABLE 6.2.4-4 (cont.) - NOTES

(1) All estimates assume average to good access, terrain, and weather conditions. Costs and times for all ground-based techniques will be higher in areas of rugged terrain or otherwise difficult access or trafficability.

(2) For 100 to 200 station survey under good field conditions (see Figure 4 in Appendix B-1). Widely spaced stations require increased travel times affecting costs and production rates. Costs for surveys requiring helicopter access could be on the order of $\$ 250$ per station.

(3) Cost and production rate determined by (1) spacing between geophones, (2) number of shots recorded in each layout, and (3) shot size. Single large shots may require several days of preparation, while small surveys may be completed in a few hours. See Appendix B-3 for discussion.

(4) Based on typical survey consisting of six profiles, each $1 \mathrm{~km}$ long. See Table $4 A$ in Appendix B-4.

(5) See Table 5 in Appendix B-4 for estimates of times for additional related activities.

(6) Based on typical soundings with five separate measurements and maximum 300-meter pole separation. See Table 4B in Appendix B-4.

(7) Based on typical land-based crew working on medium-term contract, using dynamite source, 96-trace, 1-millisecond, 12-fold sampling and 50-meter detector spacing. Assumes no adverse conditions of access or trafficability. Data processing adds $\$ 200$ to $\$ 300$ per mile for "typical" survey and $\$ 800$ to $\$ 1200$ per mile for highresolution. Specialized processing would incur additional costs. See Appendix B-6 for discussion. 
COST AND TIME SUMMARY FOR

GEOMECHANICAL TECHNIQUES

Technique

Regional Stress State

Unconfined Compressive strength

Description of discontinuities

Rock Quality Designation

Porosity/Density (3)

water Content (3)

Absorption (3)

Swelling and slake Durability

Sonic Velocity

Uniaxial Compressive Stress

Permeability (6)

Triaxial Compressive Strength

Thermal Conductivity

Borehole Modulus

In Situ Stress State

$$
\begin{array}{lll}
\text { overcoring } & \$ 40,000-\$ 60,000(9) & 5 \text { hours }(10) \\
\text { hydrofracture } & \$ 50,000-\$ 70,000(9) & 1-10 \text { days }(10)
\end{array}
$$

$\$ 14,400$ (estimate)

(2)

$\$ 50$

$\$ 10$

$\$ 50$

$\$ 350-1,250$

$\$ 50-500(4)$

$\$ 250(5)$

$\$ 250-1,000$

$\$ 2,000-10,000(7)$

$\$ 1,000-2,000(8)$

$\$ 10,000-15,000(9)$ (estimate)

(2)
Comments

3 wks per region (estimate) based on literature review

5 minutes(11) per test

1 man month per site

$\begin{array}{ll}2 \text { weeks } & \text { per test } \\ 2 \text { weeks } & \text { per test } \\ 2 \text { weeks } & \text { per test }\end{array}$

2 weeks per test

3 weeks per test

3-6 weeks per test

3 weeks per test

3-6 weeks per test

8 weeks per test

1 week $(10)$ per test

$6-45$ 
TABLE 6.2.4-5 (cont.) - NOTES

(1) Turn-around time for delivery of laboratory results, unless otherwise stated.

(2) Done by well-site geologist in conjnction with normal core logging at no measurable increase in cost or change in drilling rate.

(3) These routine tests may be applicable to rocks associated with bedded salt although not directly applicable to the salt itself.

(4) Higher costs are for tests at elevated temperature and pressure.

(5) Includes measurement of deformation, can obtain strength data only for less than $\$ 50$.

(6) Requires use of special testing fluid to avoid dissolution of salt.

(7) Test program would be designed to meet project needs. Further cost increases would result from requirements for additional measurements or testing at elevated temperature or pressure.

(8) Higher cost for tests at elevated pressure.

(9) Excluding drilling costs.

(10) Actual working time on test.

(11) Field tests using portable point load apparatus or Schmidt Hammer. See page 8 and 9, Appendix E-1. 
TABLE 6.2.4-6

COST AND TIME SUMMARY FOR

HYDROLOGY TECHNIQUES

Technique

Approximate

Approximate

Cost Range

Turn-Around

Time

Comments

Surface Hydrology

Singular Flood Frequency
Regional Flood Frequency
Rainfall-Runoff
100-year flood plain
Flooding from dam failure
Discharge measurements
Field surveys of
recharge/discharge

Surface-water sampling

Borehole Testing (5)

Head measurement
a. Manual
b. Winch
c. Recorder

Drill stem test

Pump test

Injection test (10)

Straddle packer test(10)

Tracer tests

\section{Permeability Tests}

on core sample

Numerical Modeling
$\$ 25-100(6)$

$\$ 100-500(7)$

$$
\begin{gathered}
\$ 300 \\
\$ 5500 \\
\$ 1000-2300 \\
\$ 5400 \\
\$ 1800-3100 \\
\$ 50 \\
\$ 60-100 \\
\$ 50-75
\end{gathered}
$$

1-2 days

2 weeks

2-5 days

2 weeks

4-7 days

1 hour (2)

(3)

(4)

4)

$$
\$ 3000-10,000
$$

(9)

(8)

(9)
(1)

(1)

(1)

(1)

(2)

per square mile (3) per square mile (4)

to $\$ 25,000(11) \quad 2 \mathrm{hr}-7$ days per test to $\$ 25,000(11) \quad 2 \mathrm{hr}-7$ days per test $\$ 200$ or more (12) (12)

$$
\begin{aligned}
& \text { per } \\
& \text { measurement } \\
& \text { per } \\
& \text { measurement } \\
& \text { installa- } \\
& \text { tion of } \\
& \text { recording } \\
& \text { system } \\
& \\
& \text { per test } \\
& \text { per test }
\end{aligned}
$$

$$
\begin{array}{lll}
\$ 250-1000(13) & 3 \text { weeks }(13) & \text { per test } \\
\$ 400-4000(14) & 1-10 \text { days }(14) & \text { per model }
\end{array}
$$


TABLE 6.2.4-6 (cont.) - NOTES

(1) Cost and time for specific analysis, after compiling basic field data.

(2) Cost and time for single field measurement, using simple plywood wier, portable flume, or existing structure. Does not include travel to measurement site.

(3) Assumes 2-man field party working at rate of 10 to 15 square miles per day. Actual costs and rates of progress would vary with field conditions.

(4) Assumes 2-man field party working at rate of 25 to 50 square miles per day, including cost of expendible sampling equipment. Costs for typical water-quality tests are in Table 1 of Appendix G.

(5) Not including arilling or completion costs. See Appendix D.

(6) Manual measurement using tape or probe to about $750^{\prime}$ depth - not including travel to well site.

(7) Measurement at greater depth, requiring winch to handle probe not including travel to well site.

(8) Costs and time requirements for testing vary according to depth, duration of test, and size or type of drilling equipment used. See Appendix G.

(9) Pump test costs depend on equipment in place of a well and duration of the test. Can be done for about $\$ 200$ at existing water-supply well with pump in place. Cost can be thousands of dollars for complex testing systems requiring installation of pump, power supply, and equipment for monitoring water levels.

(10) Must use specially designed test fluid to avoid dissolution of salt.

(11) Cost and time estimate for high-technology testing in tight formation at repository depths. Includes mobilization of specialized equipment and preliminary analyses of results.

(12) For long-duration tests, as may be needed in formations with low permeability, costs are likely to be determined by need for continued monitoring, involving pumping or bailing to detect tracer in deep aquifer. Such tests would cost several thousand dollars.

(13) Does not include cost or time for obtaining core.

(14) Cost and time for numerical analyses only, after basic field and lab data are compiled. 


\subsubsection{Seismotectonics}

Costs and time estimates for seismological monitoring and analyses are summarized in Table 6.2.4-7. Estimates for the related geologic studies to investigate faulting and tectonics are in Table 6.2.4-1.

\subsubsection{CRITERIA FOR EVALUATING DATA ADEQUACY OF PRECHARACTERIZATION STUDIES IN BEDDED SALT}

The information discussed previously on geology of bedded salt (6.2.1), information needs $(6.2 .2)$ and applications of techniques $(6.2 .3)$ can be applied to develop general criteria or guidelines for evaluating the information on exploration and testing expected to be presented in a Site Characterization Report for a prospective repository site in bedded salt. As described in 10CFR60.11 (Federal Register v46, p13681, Feb. 25, 1981) the Site Characterization Report is to include results of the exploration and testing supporting site selection, in addition to description of the planned site characterization work. The discussions in this report emphasize guidelines for evaluating previous exploration; evaluation of the work performed in site characterization is discussed in Section 6.3.

\subsubsection{Geology}

For a prospective site in bedded salt, the general information needs regarding geology and the techniques applied to satisfy them are:

- Overburden lithology/stratigraphy/structure - Remote sensing, surface mapping, drilling and logging, seismic reflection and refraction, resistivity

- Depth to host rock - Drilling and logging, seismic reflection,

- Host rock thickness and lateral extent - Remote sensing, surface mapping, drilling and logging, seismic reflection, resistivity

- Host rock lithology/stratigraphy/structure - drilling and logging, seismic reflection

- Erosion processes - remote sensing, surface mapping 
TABLE $6.2 .4-7$

COST AND TIME SUMMARY FOR

SEISMOTECTONIC TECHNIQUES

Technique

Approximate Cost Range

Time

Comments

Historical Data

$\$ 2,900-5,900$

2 weeks

per basic analysis

Instrumental Data

$\$ 5,800-8,800$

1-2 months

per basic analysis

Fixed Network

Installation

Operation

Portable Network

Crustal Refraction Profile
$\$ 8,000-10,000$

12-28 weeks

$\$ 7,300-14,600$

$\$ 3,250-5 ; 700$

2 days

(to install)

$\$ 2,000-\$ 5,400$ per station

cost per station/year

cost per station/month

per station 
As in any medium, surface geology and geologic processes should be well understood from the precharacterization studies at a site in bedded salt. Information on Quaternary paleoclimates is needed for analyses of the geologic processes and should be developed in the course of this work. Similarly, these surface studies should identify faults or other features (e.g., breccia pipes) that may be expressed at the surface. The investigations should encompass the prospective site and include information from off-site as needed to confidently satisfy the information needs. For a prospective site in bedded salt, surface expressions of dissolution are a particular concern and should be emphasized in this effort.

For the most part, approach and scope of the surface geologic studies will be determined by the conditions at a prospective site and guidelines for their evaluation cannot be provided on a generic basis for bedded salt. Criteria for evaluating the techniques used in surface geology will depend on site conditions. In general, the validity of results from these techniques is determined by the quality of geologic information in relation to the complexity of the geologic record. Factors that should be considered regarding completeness of surface geologic information include: (1) types of geologic materials exposed at the surface, (2) extent and continuity of surface exposures, (3) nature of vegetation and other cover, and (4) seasonal effects on remote sensing data.

Substantial information on subsurface stratigraphy, lithology, and geologic structure is needed to select a prospective site in bedded salt and to confidently plan the characterization program. Data obtained in this regard should include thickness, lateral extent, and lithology of the prospective host rock as well as information on the overlying and underlying materials, as may be needed for hydrology and other analyses. Although preliminary information typically would be available from previous work in the surrounding (off-site) parts of a basin, these investigations require new drilling and logging with seismic reflection surveys to extrapolate information from the borehole locations. Supporting information also may be obtained from other geophysical methods, such as seismic refraction and resistivity.

Important considerations in evaluating information from these techniques include resolution limits of the exploration methods and reliability of correlating beds within the salt zone. Seismic reflection typically has the highest resolution of the available geophysical exploration methods. The actual level of resolution will vary according to the design of the survey and the depth of interest. As discussed in Appendix B, the minimum size of features that can be detected in horizontal and vertical scale depend on the layout of sources and 
receivers and on the frequency of seismic energy used. Moreover, high frequency energy is filtered out as the seismic waves pass through the earth, reducing the effective resolution in the deeper parts of a survey. Survey design and site conditions also determine a depth above which meaningful information cannot be obtained. These limitations in the seismic reflection technique are important to consider in evaluating results of exploration as well as plans for proposed work.

Lateral continuity of beds is a significant concern in evaluating extrapolations of borehole data across a prospective site in bedded salt. Although many sequences of bedded salt are notable for their lateral continuity, facies changes and local anomalies also can be significant in some environments. Even in the same environment, some features, such as corrosion surfaces, may be notably continuous, while others, such as replacement concentrations of potash salts, may be local in occurrence. Lateral variations that indicate dissolution are a particular concern in bedded salt; identification of thinning in salt beds and occurrence of dissolution residues must be stressed. In general, a thorough understanding of the depositional environment and diagenitic history is needed to interpret exploration results with confidence.

\subsubsection{Hydrology}

The general information needs regarding hydrology and the techniques that should be used to determine them are tabulated below:

- Hydrostratigraphy - Drilling and logging, seismic reflection and refraction,resistivity

- Recharge and discharge - Remote sensing, surface mapping, drilling and logging, water sampling and analyses, geochemical modeling

- Aquifer properties - Drilling and logging, aquifer testing, lab testing, modeling

- Heads, gradients, and flow parameters - Drilling and logging, aquifer testing, well monitoring, geochemical testing and analysis, tracer tests, groundwater dating, analysis and modeling

- Dissolution - Remote sensing, surface mapping, drilling and logging, seismic reflection, resistivity, hydrologic analysis and modeling, geochemical testing and analysis 

quency, recharge/discharge, and surface-water chemistry

- (Paleo) climate - Remote sensing, surface mapping

Surface hydrology, as related to both present and past (Quaternary) climate conditions, should be well established by the precharacterization work. As in the case for surface geology, the approach and scope of this work and the criteria for evaluating the techniques used are essentially independent of the prospective host medium but will be determined by the surface conditions at a prospective site. One particular concern for bedded salt is that surface-water quality should be evaluated to identify possible evidence of on-going dissolution.

Investigations of subsurface hydrology prior to site characterization should include determining hydrostratigraphy and identifying preliminary aquifer properties for water-bearing zones and potential flow paths above, within, and below the prospective host rock. Aquifer properties and dynamics of groundwater movement should be determined with considerable confidence, although additional, more detailed analyses will be performed during site characterization.

Applicability of individual techniques and criteria for their evaluation depend on the conditions in each aquifer. Water-bearing zones above and below the salt typically include sandstone or conglomerate beds, such as are addressed commonly in hydrologic work, but also are likely to include carbonate aquifers requiring considerations of fracture flow. Aquifers below the salt typically would be confined while both confined and unconfined zones may be present above the salt. Flowpaths and brine-bearing zones within the salt typically would have low permeabilities and contain only small volumes of fluid. As these zones in salt generally are secondarý features (e.g., dissolution residues or results of fracturing and dissolution in carbonate beds) hydrologic properties are likely to differ significantly from place to place. All these factors require thorough consideration in evaluating information regarding techniques that have been used or are proposed for hydrologic evaluations in bedded salt.

Occurrence of past dissolution may limit thickness and lateral extent of suitable host rock for a prospective site in bedded salt and potential for dissolution hypothetically could influence long-term site performance. Accordingly, precharacterization studies should include identifying dissolution features and evaluating dissolution history. The required analyses integrate results from exploration techniques in surface geology, drilling and logging, geophysical exploration, and hydrology. 
Integrating results from the various exploration techniques is a most important aspect of the dissolution analyses. Aside from identifying saline surface water or ground water, dissolution as a process generally cannot be observed directly and must be interpreted from geologic evidence and hydrologic analyses. Dissolution residue can be recognized in drill core and effects of dissolution can be interpreted from thinning of salt beds. However, geologic interpretations, addressing stratigraphy and thickness variations in beds overlying the salt, are needed to assess the history of dissolution. It is particularly important to distinguish dissolution that has occurred under the present (and prospective) hydrologic regime(s) from that occurring during the cyclic deposition of the evaporite sequence or under previous hydrologic conditions that would not be reproduced in the future.

Numerical analyses of dissolution potential require consideration of fluid quantities and rates of flow into and out of the salt zone. These are independent of the geologic analyses and both methods should be used to provide increased confidence.

\subsubsection{Geochemistry}

The general information needs in geochemistry for a prospective site in bedded salt are listed below along with the techniques that should be used:

- Rock mineralogy, alteration and organic content - Drilling and logging, geochemical sampling and analyses, rock material lab testing

- Retardation properties - Geochemical sampling and analyses

- Water chemistry - Drilling and logging (using selected borehole geophysical $\log$ ), sampling and analysis

Although the general geochemical environment of bedded salt may be well defined from preliminary studies, conditions at a prospective repository level may vary significantly in detail. Because of the mineralogic differences between the various rock types typically associated with bedded salt (Table 6.2.1-1), the relative proportions of these materials in a given zone may greatly affect geochemical conditions. Because of the high solubility of these materials, composition of brines may be expected to reflect these variations in composition of the nearby rocks. In consideration of these factors, geochemical 
findings at the precharacterization stage in bedded salt should be reviewed in the context of their relation to the overall geologic framework.

\subsubsection{Geomechanics}

Information needs in geomechanics and the related techniques for exploration and testing are listed below:

- Rock classification, quality and discontinuities - Drilling and logging, rock materials lab tests

- In situ stresses - Engineering tests (in situ), seismic/tectonic analyses

- Strength, moduli, plasticity - Drilling and logging, velocity logging, seismic refraction, rock materials lab tests, engineering design lab tests

- Pore pressure - Engineering tests (in situ), hydrologic analyses

- Specific heat, thermal conductivity, and thermal expansion Drilling and logging, rock materials lab tests, engineering design lab tests

- Thermal alteration - engineering design lab tests

For evaluation of geomechanics information from a prospective site in bedded salt, it will be most important to consider stratigraphy and lithology of the relevant evaporite zones and presence of corrosion surfaces or other discontinuities. As summarized in Table 6.2.3-2, the materials typically associated with bedded salt have significantly different mechanical and thermal properties. As a result, their distribution and relative proportions will greatly influence the geomechanical conditions at a prospective repository level. The corrosion surfaces are the prominent discontinuities in bedded salt and their distribution also is of importance for geomechanical evaluations. Moreover, the importance of these features generally is unrelated to thickness of the associated clay or shale layer. Detection of these surfaces is facilitated to some extent by their typical lateral continuity, allowing features identified in boreholes to be extrapolated over a larger area. In view of these factors, a most important contribution to geomechanical information at the precharacterization stage is detailed logging of continuous core in the zones of concern. Test results must be evaluated in consideration of the geologic data. 


\subsubsection{Seismotectonics}

Information needs regarding seismotectonics and the applicable techniques are listed below:

- Uplift and subsidence - Remote sensing, surface mapping, seismic reflection, drilling and logging

- Faulting - Remote sensing, surface mapping, seismic reflection, analyses of earthquake history

- Igneous activity - Remote sensing, surface mapping, magnetic surveys

- Earthquakes (history and potential) - Historic seismic record, instrumental seismic record, monitoring networks, analyses of faulting

Investigations of tectonics and seismicity for a prospective site in bedded salt are essentially similar to those in other media or for other types of facilities. Critieria and guidelines for evaluating these types of information are well established in existing NRC Reg Guides and Standard Review plans. However, some particular concerns regarding bedded salt are related to the characteristic geomechanical properties of the salt. As noted in section 6.2.3.1, indications of salt flow, such as salt anticlines or diapirism, are a particular concern. These features are also important in evaluations of seismicity as the associated surface faults may be aseismic or capable or fenerating much smaller earthquakes than typical (i.e., deep-seated) features of equivalent surface expression. In general, it is important to consider that tectonic features below, within, or above a thick layer of bedded salt may reflect significantly different conditions of stress and strain. As a result, surface features may reflect dissolution or salt tectonics rather than basement faulting and, conversely, basement faulting may not be propagated to the surface. These factors may be important considerations in evaluating information on tectonics and seismicity for a prospective site in bedded salt.

\subsubsection{Resources}

Information needs regarding resources and the applicable investigative technique for a prospective site in bedded salt are listed below:

- Mineral resources - Remote sensing, surface mapping, drilling and logging, seismic reflection, geochemical analyses 
- Hydrocarbon resources - Remote sensing, surface mapping, drilling and logging, seismic reflection

- Geothermal resources - Remote sensing, drilling and logging, resistivity, hydrologic analyses, geochemical analyses, seismic/ tectonic analyses.

Resource potential and exploration/production history of a prospective site can be determined by the precharacterization studies and should be well established before undertaking the commitment of time and expense involved in site characterization. Information on resources for a site in bedded salt should be in two categories: (1) resources directly associated with the salt, including halite, anhydrite, gypsum, magnesium, potash, and sulfur, and (2) hydrocarbon resources that may occur in overlying or underlying formations. Resource potentials for the halite and for any associated potash, sulfur or other evaporite minerals should be determined with considerable confidence from the exploration of the evaporites to identify a prospective site. However, evaluations of hydrocarbon potential may require seismic reflection and bore hole information from greater depths, as determined by site conditions. The geologic setting at the site will be an important consideration in evaluating information on all types of resources, including those that are not typical of evaporite environments but occur fortuitously at a particular site.

\subsection{SITE CHARACTERIZATION STUDIES}

\subsubsection{GEOLOGIC FEATURES OF BEDDED SALT IMPORTANT FOR SITE CHARAC- TERIZATION}

General geologic properties of bedded'salt are discussed in section 6.2.1 with emphasis on the factors that may be determined by drilling and geophysical exploration and that would contribute to identifying potentially suitable sites in precharacterization. For site characterization, geologic properties of the bedded salt would be determined in more detail by direct observation and in situ testing in pilot excavations. This work would emphasize hydrology within the salt, geomechanics and geochemistry. Geologic properties of the salt that relate to these topics include:

1. Mineralogy - lithology: Directly affects geochemical composition and can influence geomechanical properties. 
2. Texture (i.e., size and form of grains and distribution of impurities): Influences geomechanical properties and can affect geochemical reactions.

3. Structure: Small scale structures within the salt influence geomechanical performance and can provide hydrologic flow paths.

4. Fluid inclusions: Fluids within the salt are direct concerns for hydrology and geochemistry and can affect geomechanical properties such as response to heating.

Each of these geologic properties is discussed in the following subsections.

\subsubsection{Mineralogy - Lithology}

Mineralogy and lithology of bedded salt typically vary stratigraphically and lateral variations also are common. Both types of variation are important for site characterization.

As discussed in section 6.2.1.1, bedded salt is deposited by precipitation from evaporating seawater. Although the original seawater generally is of a uniform composition, the precipitation is a complex process with salinity and temperature of the fluid determining the minerals that are formed at a given time. Salinity in turn is determined by the history of evaporation and precipitation as well as by the influx of relatively fresh seawater. (For a comprehensive description of the minerals formed under various conditions, refer to Braitsch, 1971.) Salinity and temperature fluctuate over time because of seasonal changes, climate cycles, or random events, causing stratigraphically controlled mineralogic variations in the bedded salt sequence. These are expressed on a larger scale by the interbeds of dolomite, anhydrite, or potash salts and by the argillaceous layers and associated corrosion surfaces discussed in section 6.2.1.2. Layering also occurs on a smaller scale within the salt beds and involves varying concentrations of halite, anhydrite, potash salts, carbonaceous materials, and fine particles of relatively insoluble sediments. The varved sequences in the Delaware Basin (Anderson and others, 1972) and in the Salina Group (Treesh and Friedman, 1973; Nurmi and Friedman, 1977) are examples of this type of layering.

The significance of this fine layering for site characterization stems from its influence on the bulk composition of the salt, causing local variations in mechanical and chemical properties. For example, Baar (1977) notes that joints, faults, and boudinage structures typically 
are found in the more competent beds of an interbedded sequence. However, he also states that the difference in mechanical properties between the various evaporite minerals is insignificant as compared to the importance of the clay partings (in the context of normal mining operations). This potential for joints or small faults may be important for site characterization, as may the differences in thermal properties (Table 6.2.3-2). Because of the differences in chemical composition of the various evaporite minerals (Table 6.2.1-1), fine scale layering can directly affect the overall geochemical composition of the salt and the associated brines.

Lateral variations in mineralogy can be significant in bedded salt of sabkha origin or as a result of secondary alteration. Because of their solubility, the evaporite minerals are particularly susceptible to alteration by fluid moving through the partially consolidated salt. Secondary alteration can cause lateral variations by dissolving minerals at one place and redepositing them at another (e.g., Figure 2-16 in Baar, 1977). The significance of these lateral variations in mineralogy is similar to those of the stratigraphic variations discussed previously.

\subsubsection{Texture}

Texture of the salt includes factors such as form and size of the salt grains and distributions of the impurities. These small scale geologic properties may be significant for geomechanical and geochemical evaluations in site characterization. Grain size has been found to influence mechanical properties of the salt (e.g., Abel, 1969). The mechanical significance of argillaceous material in the salt also depends on whether these impurities are in discrete bands or are distributed along interlocking grain boundaries (Appendix E-2). Grain size also can influence geochemical reactions by affecting the available surface area for such reactions in a mass of salt. For example, sorption processes may be influenced by the accessability of the argillaceous materials along grain boundaries as compared to their being inclusions within halite crystals.

Different textures in bedded salt result from the various conditions of deposition and alteration. For example, zoned, chevron-shaped crystals that commonly are cloudy with fluid inclusions are throught to develop on the bottom of a shallow water body while large, clear crystals are more common from deeper water (Nurmi and Friedman, 1977). Recrystallization typically results in crystals that are notably large and clear, with impurities concentrated along the grain boundaries (Baar, 1977; Treesh and Friedman, 1973). Similarly, pods of abnormally large 
halite crystals and an overlying polyhalite bed observed in detailed logging of the Project Gnome excavations were interpreted to be products of recrystallization (Gard, 1968). Recrystallization also may be accompanied by flow of the salt, disrupting the original sedimentary bedding, as discussed in the following section on structure.

Although the academic questions of relating salt textures to the depositional and alteration history of the salt may seem unrelated to the concerns in site characterization, they can be valuable for interpreting the distributions of minerals, textures, and structures to predict geologic conditions in the parts of the salt that are not accessible for direct observation. Another important application involves systematic description of salt textures over the areas of in situ testing to aid understanding of the test results and evaluate their relation to other field and laboratory tests. Similarly, description of textures over the volume of salt proposed for a repository can be important in using the test results to predict repository performance.

\subsubsection{Structure}

After the large scale structures have been evaluated by the precharacterization work, small scale structures within the salt may be important for site characterization. On a large scale, structure at a prospective repository site in bedded salt would be typified by generally horizontal and uniform stratification, although some sites in salt anticlines also are being considered. The small scale structures of concern in site characterization include sedimentary features and effects of post-depositional alteration.

Primary sedimentary structures typical of bedded salt include local intra-formational unconformities (associated with the corrosion surfaces discussed previously), ripple marked bedding planes, cross bedding, and polygonal mudcracks. Dellwig (1968) also reports shale balls as much as a meter in diameter as inclusions within the salt at Retsof, New York. Any of these features could be significant for evaluating structural conditions in characterization of a site.

Polygonal patterns of vertical dissolution wedges that have been identified underlying corrosion surfaces may be particularly important for site characterization. As described by Richter-Bernburg (1979), the original salt has been removed in vertical wedges over as much as several meters of stratigraphic thickness and the wedges filled by argillaceous sediment and continued salt deposition. These features are interpreted to have been caused by dissolution progressing along 
polygonal muöcrack patterns during freshening cycles in the depositional system. Similar features, although of smaller vertical extent, were observed in the Project Gnome excavations (Gard, 1968).

Volume changes of the evaporite minerals during secondary alteration can cause significant small scale structures in beds that have not been deformed tectonically. Decreases in volume upon dehydration (or conversely increases upon hydration) are particularly notable in evaporites. For example, carnalite undergoes a volume loss of about 508 upon conversion to sylvite (Baar, 1977); and anhydrite swells about 608 when hydrated to gypsum (Klingsberg and Duguid, 1980). The large volume changes accompanying these alterations can cause intraformational faulting, brecciated beds within otherwise undeformed strata, and intrusion of more plastic materials into the resulting voids (Baar, 1977). The corresponding volumetric increases upon hydration cause tight intraformational folding, termed "enterolithic structures" (Hills, 1967).

Because of their high plasticity, halite and the potash salts may develop into tight folds from minor perturbations in beds that otherwise have not undergone significant tectonic deformation. Such

features have been described in laminated salt of the Salina Group in New York (Treesh and Friedman, 1973).

\subsubsection{Fluid Inclusions}

Fluid inclusions in salt may be classified as those occurring within the salt grains and those in larger intercrystalline cavities. Both types may be important for site characterization. Fluid inclusions within salt grains commonly occur in "negative crystals" (small crystal-shaped voids) that are less than about a millimeter in size, although larger cavities also are found. Such inclusions are abundant in some salt beds, giving the crystals a cloudy'appearance, but generally the fluids represent only about one percent of the total salt mass. These inclusions have been found to migrate in a thermal gradient and have received substantial attention in studies for nuclear waste isolation (e.g., Anthony and Cline, 1973; Holdoway, 1973; Claiborne and others, 1980).

Pockets of brine, some of which are pressurized by gas, are found in some salt beds and have been concerns for drilling and mining operations. A notable example is the pressurized brine pocket encountered by the ERDA 6 borehole at a prospective repository site in New Mexico (Powers and others, 1978). Similar pockets are relatively common in European potash mines and have caused several problems in mine safety, but they are rare in other regions and have not been found in the 
Prairie evaporites of Canada (Baar, 1977). The brine in such pockets may have come from infiltration along structural discontinuities (Anderson and Powers, 1978). However, their pressurization and the patterns of flow observed in mines that have encountered such features indicate that the brine pockets generally are not connected to the larger hydrologic system (Baar, 1977).

For site characterization, brine pockets would be a main concern with regard to safe development of the underground workings in bedded salt. It also would be important to establish whether they in fact do have any connection to the hydrologic system outside the salt in order to properly evaluate potential flow paths from a repository. However, it would be most desirable to identify any brine pockets in site characterization and avoid them in the repository layout in order to minimize hazards and uncertainties.

\subsubsection{INFORMATION NEEDS FOR SITE CHARACTERIZATION IN BEDDED SALT}

\subsubsection{General}

The general information needs for a prospective repository in bedded salt have been summarized in Section 6.2.2, with emphasis on the precharacterization studies performed for selecting a potentially suitable site. The information needs specific to site characterization to a large extent are those that require the detailed exploration techniques available at this stage. While many of the techniques used in precharacterization continue to be applicable, the important difference involves excavation of a pilot shaft and development of a test room near the proposed repository level. This allows much more detailed examination and testing of the rocks at depth as well as providing a base for intensive (horizontal or inclined) drilling in the salt without creating a connection between a prospective repository and the accessible environment. As a result, it is possible to obtain a very large amount of detailed geosciences information on the proposed host rock during site characterization. The NWTS program has devoted considerable attention to the needs for field testing in salt at special test facilities as well as at prospective repository sites. Issues identified by the NWTS program as being important for field testing in salt are summarized in Table 6.3.2-1.

Exploration and field testing in site characterization involves very considerable expense and a very significant schedule commitment, beginning with design and construction of the pilot shaft and test room. Because of this commitment, the results of precharacterization must provide a high level of confidence in the ultimate suitability of a candidate site. In general, precharacterization is expected to 
resolve those issues that may be addressed by geologic exploration of the site vicinity rather than by detailed exploration and testing at depth, including: surface geology, surface hydrology, and climate. Tectonics, seismicity, and potential for igneous activity also would be resolved in this manner during precharacterization but are not significant problems at the main occurrences of bedded salt in the continental United States. Similarly, exploration history and resource potential at a site may be determined by investigations that are of a reconnaissance level as compared to the detailed characterization studies and can be resolved in precharacterization.

Following suitable completion of the precharacterization studies, the main issues to be emphasized in site characterization are (1) confirming site suitability with regard to containment and isolation of radionuclides and (2) providing the detailed site specific parameters for design and construction of a repository. In addition, there would be continued exploration and testing to better quantify or increase reliability of information on other topics. Results of the work in site characterization also would be monitored with regard to all the related disciplines to confirm the previous findings of potential site suitability.

The following subsections summarize the information needs specific to characterization of a prospective repository site in bedded salt, under the categories of: geology, hydrology, geochemistry, geomechanics, seismotectonics, and resources. For each category there is a brief description of the information that is assumed to have been obtained from precharacterization. From this basis, the information needs for site characterization are discussed.

\subsubsection{Geology}

The information needs regarding geology at the site characterization level mainly involve obtaining detailed information in the candidate host bed on the geologic conditions that relate to design, construction, and performance of the repository. In addition, the geologic issues summarized in Section 6.2.2.1 are common to both levels of site investigation but would be addressed in greater depth and at finer scale by the intensive work in site characterization. Table 6.3.2-2 lists the geologic issues that would be emphasized in precharacterization and those stressed in site characterization.

Results of the precharacterization work should be adequate to define surface geologic conditions and processes, and to generally describe stratigraphy, lithology, and geologic structure at depth. Surface 
Waste/salt interactions:

- Waste form dissolution and nuclide leaching

- Changes in thermal and mechanical properties of the salt from exposure to the waste

- Storage and release of radiation energy in the salt

Brine migration:

- Brine migration to the waste package, radiolysis, and accelerated corrosion

- Gas generation effects from radiolysis

- Radionuclide transport

- Impact on retrievability

Waste package materials behavior:

- Performance of various waste forms, canister materials, and designs

- Performance of backfill materials

- Canister corrosion

Thermomechanical response:

- Integrity of emplacement holes, rooms, and pillars under anticipated temperature and stress conditions

- Variations in strength, plasticity, thermal response, and permeability of the medium as functions of temperature, stress, and scale

Geohydrology and nuclide transport:

- Fracture healing in the salt

- Nuclide transport in rocks surrounding the salt

Development of site confirmation tests to be performed in situ at selected sites for characterizing geologic conditions and thermal and mechanical properties.

*Adapted from U.S. Department of Energy, 1981 
geology should have been determined as needed to interpret nature and rates of the relevant processes, including: erosion, deposition, previous Quaternary climate and hydrologic conditions, dissolution, and salt tectonics. The subsurface geologic information from precharacterization should include depth, thickness, and lateral extent of salt beds potentially suitable for a repository. Features such as faults, folds, dissolution fronts, or breccia pipes would limit the lateral extent of suitable salt and should have been defined. stratigraphy of the salt zone and of the overlying and underlying units should be known adequately to define existing or potential aquifers and confining units, recognize dissolution residues, and identify strata that may contain potash, sulfur, hydrocarbons, or other resources. Interbeds within the salt, particularly the "clay seams" (those more than about $3 \mathrm{~mm}$ thick, following the classification in Appendix $\mathrm{E}-2$ ) and their associated corrosion surfaces, should be well defined from the precharacterization borehole data.

The detailed and intensive studies at depth during site characterization should provide a more refined description of the lithology and structure within the salt zone proposed for a repository. This should include identifying and quantifying impurities in the salt (such as zones of argillaceous halite), variations in bed thickness, and variations in the bulk composition of any finely varved sections. Clay partings and clay breaks (Appendix E-2) should be defined reliably by this more detailed information.

Lateral variations in mineralogy or texture of the salt can be important for a repository and should be evaluated in site characterization. Although bedded salt commonly is laterally continuous and uniform as deposited (Section 6.2.1.1), such variations may be important in beds of sabkha origin or as a result of post-depositional alteration. Lateral variations would be difficult to evaluate properly from the limited drilling in precharacterization and should be addressed by the more intensive site characterization program.

In addition to the various features discussed here, it would be important to identify any other anomaly or inhomogeniety in the salt at the prospective repository zone. Complete understanding of the geologic conditions in the volume of salt proposed for the repository is needed to evaluate repository" performance from the results of hydrologic, geochemical, and geomechanical testing.

\subsubsection{Hydrology}

The information needs in hydrology that are specific to site characterization in bedded salt relate to fluids and flow paths within the

$$
\text { 6-65 }
$$


Emphasized in Precharacterization:

1. Geologic processes.

2. Lithology, stratigraphy and structure of rocks above and below the salt.

3. Depth and thickness of the salt.

4. Large scale structures (faults, folds, breccia pipes, etc.).

5. Interbeds and clay seams.

Emphasized in Site Characterization:

1. Detailed mineralogy and lithology of the salt.

2. Clay partings and clay breaks.

3. Impurities in the salt.

4. Lateral variations.

5. Smaller scale structures.

6. Texture of the salt.

7. Any other geologic anomalies. 
salt and, possibly, to dissolution. However, the general hydrologic information needs discussed for precharacterization (Section 6.2.2.2) would continue to be addressed by investigations at greater detail and by continued monitoring. The information needs in hydrology that would be emphasized before and during site characterization are summarized in Table $6 \cdot 3 \cdot 2-3$.

Climate history and (present and past) surface hydrology are investigated at the surface and should be resolved before undertaking the detailed subsurface work of site characterization. Hydrology of aquifers above and below the salt also should be generally well known from the precharacterization subsurface work, although continued evaluations to better quantify aquifer properties would be performed concurrently with site characterization. The preliminary studies of dissolution should be adequate to establish that it is not a potential hazard to the site; this would be confirmed and quantified during the site characterization work.

While intact salt typically is dry and impermeable, fluids may occur as inclusions within crystals or in larger brine pockets, and flow paths may exist along interbeds, corrosion surfaces, or other discontinuities. Water also may be associated with the minerals occurring as impurities and interbeds in the salt. The limited drilling in precharacterization should be able to identify widespread discontinuities, such as interbeds or corrosion surfaces, and to recognize the general distribution of impurities and grains containing fluid inclusions where these are stratigraphically controlled. However, the detailed exploration at depth would contribute direct observation (through subsurface mapping) of some potential flow paths to evaluate their nature and variability. The studies in site characterization also should evaluate the presence of fluids and the potential effects of repository construction and thermal loading on their migration or other behavior.

Dissolution is a particular concern in bedded salt and should be evaluated carefully from results of both the precharacterization and characterization programs. It is clear that characterization would not be considered unless there were a high level of confidence that dissolution would not be a hazard to a potential repository at the site. As more detailed and reliable site data on flow paths and fluids within the salt become available, it would be important to quantify and confirm the earlier findings on dissolution. The detailed exploration at depth also should stress attempting to identify any additional evidence of previous dissolution and to evaluate its history. 
TABLE $6 \cdot 3 \cdot 2-3$

HYDROLOGY INFORMATION NEEDS IN BEDDED SALT

Emphasized in Precharacterization:

1. Climate.

2. Surface hydrology.

3. Aquifers above and below the salt.

4. Dissolution.

5. Large brine pockets.

Emphasized in Site Characterization:

1. Fluid-bearing zones and flow paths within the salt.

2. Smaller brine pockets.

3. Brine inclusions within salt grains.

4. Hydrate water in minerals of interbeds or impurities.

5. Quantification of aquifer properties.

6. Quantification of dissolution rates. 


\subsubsection{Geochemistry}

The information needs in geochemistry for characterization of a site in bedded salt are essentially as described in section 6.2.2.3 for precharacterization but with emphasis on describing chemical properties of rocks and fluids at the prospective repository level and analyzing their potential influence on repository performance (Table 6.3.2-4). In addition, it is necessary to establish geochemical properties of rocks and fluids along flow paths to the accessible environment in order to quantify potential for radionuclide transport. Chemical conditions of overburden materials in the areas of shafts and boreholes will be needed to provide design parameters for repository sealing.

The results of precharacterization should be adequate to define the general geochemistry of the site, particularly of the salt and any associated brines, and to establish chemistry of water in the overlying and underlying aquifers. The variations in mineralogy identified from borehole logging should have identified beds or zones that are likely to contribute retardation or to require special consideration in selecting seal materials. The precharacterization dating of rocks and water should have been adequate to establish geologic history of the site and to demonstrate that fluids have long residence times and are well isolated from the accessible environment. It is expected that this level of information would be required to select a site for characterization.

The intensive subsurface work in site characterization should provide a detailed understanding of geochemical variations within the prospective host bed in the salt, including stratigraphically-controlled changes in mineralogy and possible lateral variations resulting from postdepositional alteration. Depending on the specific conditions at a site and the actual level of information obtained from precharacterization, concurrent work would address uncertainties or specific information needs outside the repository zone. In addition to these descriptive aspects of geochemistry, an important part of the site characterization work should involve investigating geochemical reactions relating to repository performance. These include potential reactions of the brines or salt with materials of the cannister, over-pack, waste form, or other engineered features as may influence design or determine performance of engineered barriers. Similarly, it will be important to evaluate effects of the waste on the host medium, such as radiolytic alterations of the brine or salt (e.g., Swyler and others, 1978; Wilems and others, 1980). As in other media, a most important concern would be geochemical reactions relating to radionuclide transport. These include reactions such as retardation, complexing, diffusion, precipitation, and filtration, and would require evaluation in the prospective host bed and elsewhere along possible flow paths to the accessible

$6-69$ 
TABLE $6 \cdot 3 \cdot 2-4$

GEOCHEMISTRY INFORMATION NEEDS IN BEDDED SALT

Emphasized in Precharacterization:

1. Chemistry of salt and interbeds.

2. Brine chemistry.

3. Chemistry of fluids in aquifers.

4. Chemistry of rocks along potential flow paths outside the salt.

5. Preliminary dating of rocks and fluids.

Emphasized in Site Characterization:

1. Detailed chemistry of salt and interbeds.

2. Detailed brine chemistry.

3. Reactions with canisters, wasteforms, and other engineered materials.

4. Radiolysis and hydrolysis of salt and brine.

5. Retardation in salt and associated minerals.

6. Retardation in other minerals along flow paths outside the salt.

7. Complexing and polymerization of radionuclides in repository fluids.

8. Ion exchange and exclusion.

9. Precipitation.

10. Filtration.

11. Dating of rocks and fluids. 
environment. For these evaluations, it is necessary to consider the temperature field resulting from waste emplacement, as the chemical reactions in the brine and salt are greatly influenced by temperature (e.g., stewart and Potter, 1978).

\subsubsection{Geomechanics}

A main objective of site characterization in bedded salt is to determine geomechanical and thermal conditions through in situ testing near the prospective repository level. Geomechanics are a major concern in bedded salt because plastic creep of the halite and the associated potash salts can cause problems in maintaining underground openings for operation of the repository and, particularly, for the retrieval period. Moreover, the creep rate of these materials can be greatly influenced by temperatures over the range expected in a repository (e.g., Bradshaw and others, 1962; Heard, 1972). This makes it important to obtain adequate information on the thermal properties of materials in the repository zone in order to reliably anticipate the temperature field resulting from waste emplacement. It also is important to establish the in situ temperature and stress conditions existing prior to repository development. Geomechanics information needs before and during site characterization for a prospective site in bedded salt are summarized in Table 6.3.2-5.

The precharacterization studies should be adequate to establish that geomechanical conditions are potentially suitable for a repository. They should include identifying interbeds, corrosion surfaces, and other discontinuities in the prospective repository zone. Laboratory testing in precharacterization should be adequate to bound the geomechanical properties of the materials present. The in situ stress and temperature fields also should be reasonably well determined. Geomechanical conditions in the overburden also should be determined by precharacterization, as these must be known to design and excavate the pilot shaft. After these parameters have been bounded and found to be within acceptable ranges by precharacterization, they should be confirmed and quantified in additional detail by continued laboratory and field testing during the site characterization program.

Detailed in situ testing at depth in site characterization should be performed to evaluate response of the salt to the anticipated repository conditions. As discussed in Appendix E-2, this type of large scale, in situ testing is particularly important in bedded salt because of the prevalence of discontinuities and potential for material variations in this bedded media. The information to be determined by such tests includes: distributions of stresses from mechanical and thermal loading, displacements (strains), temperature distributions, plastic 
TABLE $6.3 \cdot 2-5$

GEOMECHANICS INFORMATION NEEDS IN BEDDED SALT

Emphasized in Precharacterication:

1. Temperature field.

2. In situ stress field.

3. Thermal conductivity and specific heat of salt, interbeds, and surrounding rocks.

4. Deformation moduli of salt, interbeds, and surrounding rocks.

5. Preliminary survey of discontinuities and inhomogeneities in the repository zone.

Emphasized in Site Characterization:

1. Thermal expansion of salt, interbeds, and surrounding rocks.

2. Creep properties of salt at anticipated temperatures.

3. Decrepitation and other temperature effects.

4. Radiation effects.

5. Anticipated temperature field.

6. Detailed survey of discontinuities and inhomogeneities in the repository zone. 
creep, and potentials for temperature-induced fracturing or alteration. At the same time, these tests provide a vehicle for evaluating migration of fluid inclusions in the salt under a thermal gradient.

Thermal decrepitation and radiation effects are particular concerns in bedded salt. Previous testing has found that salt can fracture violently upon heating, due to the expansion of fluid inclusions. This phenomenon, termed decrepitation, has been observed at temperatures of $240^{\circ} \mathrm{C}$ to $380^{\circ} \mathrm{C}$ although salt from some sources shows no effects after heating to $400^{\circ} \mathrm{C}$ (Bradshaw and others, 1962). On the other hand, some larger inclusions (more than about $1 \mathrm{~mm}$ ) have been found to decrepitate at temperatures as low as $60^{\circ} \mathrm{C}$ (Roedder and Belkin, 1978). Decrepitation properties have been found to differ according to source of the salt tested and also can vary between samples of salt from a single location. Accordingly, testing would be needed to establish the decrepitation potential of salt at a site and the variations with differences in the fluid inclusions and salt texture over the prospective host beds. This phenomenon can be important for site characterization as it can limit the maximum allowable temperature in the salt.

Effects of radiation on strength and creep properties of the salt have been recognized and, although minor, are considered a potential geomechanical concern for waste isolation. Irradiation at potential repository temperatures has been found to produce defects in the salt crystal lattice by separating the halite into sodium metal and chlorine gas. However, available test results indicate that this process affects much less than one mole percent of the salt (Swyler and others, 1978) and that the resulting effects on mechanical properties are insignificant (Bradshaw and others, 1962).

Analysis of the geomechanical data from site characterization should incorporate results of the detailed geologic investigations in the test zone. Geomechanical responses can be influenced by factors such as distribution of interbeds, corrosion surfaces or other discontinuities, impurities in the salt, grain size, texture, fabric, small-scale structures, or others. Accordingly, information on these factors is needed for proper interpretation and application of the test results.

\subsubsection{Seismotectonics}

The information needs for a prospective site in bedded salt are essentially the same as in other media and are summarized in section 6.2.2.5. It is expected that these conditions would be demonstrated to 
be favorable at a site before it would be selected for characterization. This is particularly true for bedded salt as the main occurrences of this medium within the continental United states are in places that are notable for tectonic stability and low levels of seismic activity. However, seismic monitoring should be continued through the period of site characterization and results should be incorporated into the design basis for the repository facility as appropriate.

\subsubsection{Resources}

Resource potential of a site should be established by precharacterization as it would seem inappropriate to conduct detailed testing at depth and then have a site found unacceptable because of resource conflicts that certainly would have been preexisting. The typical resources found in association with bedded salt (potash, sulfur, and hydrocarbons) occur on a much larger scale than the geologic hazards of concern for a repository (e.g.. faults or breccia pipes). Therefore, the results of precharacterization should be adequate for evaluating resource conflicts that may be present. Resource potential of the site should be verified during site characterization by continued monitoring of the geologic and geochemical exploration results.

\subsubsection{TECHNIQUE APPLICATIONS TO SITE CHARACTERIZATION INFORMATION} NEEDS IN BEDDED SALT

The techniques to be discussed in the specific context of site characterization are those involved in the detailed testing of the host rock and in situ testing at depth. In addition, a significant part of the work during the site characterization program would involve continued application of the techniques used in precharacterization, as discussed in section 6.2.3. Table $6 \cdot 3 \cdot 3-1$ is a summary of the general types of techniques that would be applied to the information needs in site characterization for bedded salt.

There is much less precedent and experience for the work in site characterization than for that in precharacterization. Precharacterization uses techniques that are generally well developed from use in hydrocarbon or resource exploration or common engineering practice. However, only a few programs for mining or other underground construction approach the level of detail and reliability desired for site characterization. For example, a recent summary of measurement techniques relevant to prospective repositories in bedded salt discusses methods that largely are at a conceptual or development level (Mao and 
Ramirez, 1980). There also have been only a few applicable test programs specifically for nuclear waste isolation: Project salt vault in Kansas during 1965 through 1967, and the on-going programs in salt domes at Avery Island, Louisiana and the Asse facility in the Federal Republic of Germany (U.S. Department of Energy, 1981). Of these, only Project Salt vault involved testing with actual radioactive materials in bedded salt. Renewed testing of this type in bedded salt is awaiting development of a test facility at WIPP or elsewhere (Robinson, 1979). It is planned that a site for a Testing and Evaluation Facility (TEF) in salt is to be recommended to DOE during FY 82 (U.S. Department of Energy, 1981, p. 55). Assuming that the site is selected and depending on the results of preliminary work, waste packages may be emplaced for testing by 1990 (Ibid.).

\section{3 .3 .1 Geology}

During site characterization, geologic properties of the prospective bedded salt host rock would be determined in the field from detailed excavation logging, subsurface-based drilling, and subsurface-based geophysical exploration. These would be supported by laboratory analyses of mineralogy and petrology. As noted in section 6.3.2.2, the main objective of these investigations would be evaluating geologic factors relating to design, construction, and performance of the proposed repository.

Excavation logging would be done in considerable detail in the pilot shaft, test room(s), and any exploratory drifts, using techniques common to mining and engineering geology (e.g., Appendix A-2 and Herness, 1977). This logging would emphasize identifying mineralogic, textural, and structural variations in the salt and describing these systematically to aid analyses in geomechanics, geochemistry, and hydrology. Additionally, logging in the pilot shaft would provide significant information regarding the overburden. Direct observation of the excavation surfaces would allow detailed analyses of discontinuities such as clay partings, clay breaks, and any fractures or faults. The contacts between the salt beds may be examined to evaluate features that may influence mechanical behavior of the salt mass, such as corrosion surfaces, ripple marks, or polygonal fracture patterns. Sedimentary features that commonly occur within the salt beds, such as cross bedding or shale balls (Dellwig, 1968) also should be identified for characterization.

Logging in shafts, rooms, or drifts would allow identification of anomalous vertical features that may be missed in boreholes. For example, vertical wedges of argillaceous material or recrystallized 
TABLE 6.3.3-1 SITE CHARACTERIZATION TECHNIQUE APPLICATION

\begin{tabular}{|c|c|c|c|c|c|c|c|c|}
\hline $\begin{array}{l}\text { APPLICATIONS OF TECHNIQUES } \\
\text { TO INFORMATION NEEDS } \\
\text { FOR SITE CHARACTERIZATION } \\
\text { MAJOR CONTRIBUTION } \\
\text { O SUPPORTING CONTRIBUTION }\end{array}$ & 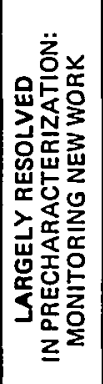 & 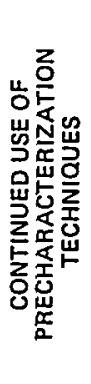 & 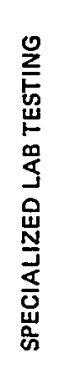 & 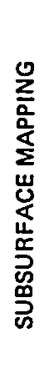 & 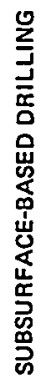 & 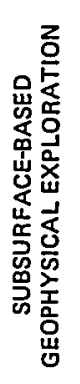 & 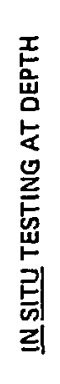 & 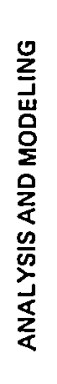 \\
\hline \multicolumn{9}{|l|}{ GEOLOGY } \\
\hline GEOLOGIC PROCESSES & $\bullet$ & o & & & & & & 0 \\
\hline STRATIGRAPHY AND STRUCTURE OF OVERBURDEN & - & 0 & & 0 & & & & \\
\hline DEPTH AND THICKNESS OF SALT & $\bullet$ & 0 & & $\circ$ & 0 & 0 & & \\
\hline INTERBEDS AND CLAY SEAMS & $\bullet$ & 0 & & 0 & o & o & & \\
\hline CLAY PARTINGS AND BREAKS & 0 & 0 & & $\bullet$ & $\circ$ & 0 & & \\
\hline IMPURITIES IN SALT & 0 & $\mathbf{0}$ & & $\bullet$ & 0 & 0 & & \\
\hline LATERAL VARIATIONS & 0 & 0 & & ० & $\bullet$ & 0 & & \\
\hline FAULTS AND FOLDS & 0 & - & & o & 0 & o & & \\
\hline $\begin{array}{l}\text { FRACTURES AND SEDIMENTARY STRUCTURES } \\
\text { IN SALT }\end{array}$ & $\circ$ & 0 & & $\bullet$ & o & o & & \\
\hline TEXTURE OF SALT & 0 & 0 & & $\bullet$ & o & & & \\
\hline \multicolumn{9}{|l|}{ HYOROLOGY } \\
\hline AOUIFERS ABOVE SALT (1) & $\bullet$ & 0 & & 0 & & & & 0 \\
\hline AQUIFERS BELOW SALT (1) & $\bullet$ & o & & & 0 & & & 0 \\
\hline $\begin{array}{l}\text { FLUID BEARING ZONES OR } \\
\text { FLOW PATHS WITHIN SALT (1) }\end{array}$ & O & 0 & & 0 & 0 & 0 & 0 & 0 \\
\hline BRINE POCKETS & 0 & 0 & & & o & $\bullet$ & & \\
\hline & & & & & & & & \\
\hline
\end{tabular}

(1) INFORMATION NEEDS FOR EACH INCLUDE: RECHARGE, OISCHARGE, HEADS, GRADIENTS STORAGE TRANSMISSIVITY. AND OTHERS, AS DISCUSSED IN APPENDIX G. 
TABLE 6.3.3-1 (CONT'D) SITE CHARACTERIZATION TECHNIQUE APPLICATION

\begin{tabular}{|c|c|c|c|c|c|c|c|c|}
\hline $\begin{array}{l}\text { APPLICATIONS OF TECHNIQUES } \\
\text { TO INFORMATION NEEDS } \\
\text { FOR SITE CHARACTERIZATION } \\
\text { O MAJOR CONTRIBUTION } \\
\text { O SUPPORTING CONTRIBUTION }\end{array}$ & 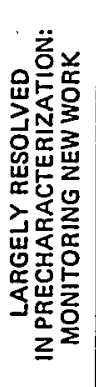 & 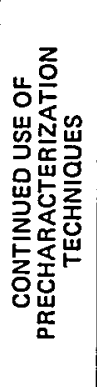 & 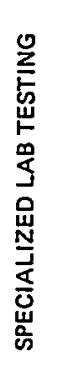 & 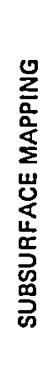 & 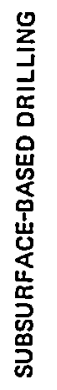 & 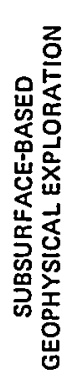 & 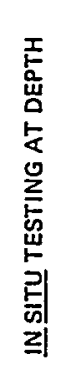 & 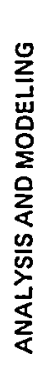 \\
\hline \multicolumn{9}{|l|}{ BRINE INCLUSIONS } \\
\hline IDENTIFICATION & 0 & o & 0 & - & 0 & & & \\
\hline MIGRATION POTENTIAL & & & & & & & 0 & $\bullet$ \\
\hline $\begin{array}{l}\text { HYDRATE WATER IN MINERALS OF INTERBEDS } \\
\text { AND IMPURITIES }\end{array}$ & 0 & ० & $\bullet$ & o & o & & & \\
\hline \multicolumn{9}{|l|}{ DISSOLUTION } \\
\hline EVIOENCE FOR & 0 & o & & $\circ$ & o & 0 & & \\
\hline POTENTIAL RATES & & & & & & & & $\bullet$ \\
\hline \multicolumn{9}{|l|}{ GEOCHEMISTRY } \\
\hline CHEMISTRY OF SALT ANO INTERBEDS & 0 & $\bullet$ & & 0 & ० & 0 & & \\
\hline BRINE CHEMISTRY & 0 & $\bullet$ & & & 0 & & & 0 \\
\hline CHEMISTRY OF FLUIDS IN AOUIFERS & o & $\bullet$ & & & $\mathbf{0}$ & & & 0 \\
\hline CHEMISTRY OF ROCKS ALONG FLOW PATHS & 0 & $\bullet$ & & 0 & 0 & 0 & & \\
\hline REACTIONS WITH CANNISTER AND WASTE FORM & & o & $\bullet$ & & & & 0 & o \\
\hline RADIOLYSIS AND HYDROLYSIS OF SALT AND BRINE & & o & - & & & & 0 & o \\
\hline RETARDATION IN SALT AND ASSOCIATED MATERIAL & 0 & o & $\bullet$ & & & & 0 & 0 \\
\hline $\begin{array}{l}\text { RETARDATION IN OTHER MATERIAL } \\
\text { ALONG FLOW PATHS }\end{array}$ & o & 0 & $\bullet$ & & & & o & o \\
\hline COMPLEXING AND POLYMERIZATION & & & $\bullet$ & & & & & o \\
\hline
\end{tabular}


TABLE 6.3.3-1 (CONT'D) SITE CHARACTERIZATION TECHNIQUE APPLICATION

\begin{tabular}{|c|c|c|c|c|c|c|c|c|}
\hline $\begin{array}{l}\text { APPLICATIONS OF TECHNIQUES } \\
\text { TO INFORMATION NEEDS } \\
\text { FOR SITE CHARACTERIZATION } \\
\text { MAJOR CONTRIBUTION } \\
\text { O SUPPORTING CONTRIBUTION }\end{array}$ & 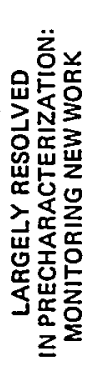 & 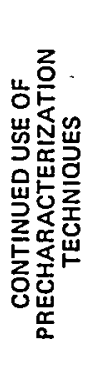 & 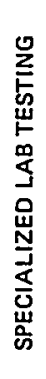 & 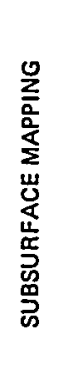 & 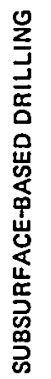 & 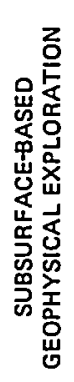 & 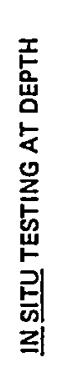 & 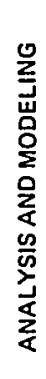 \\
\hline ION EXCHANGE AND EXCLUSION & & & $\bullet$ & & & & & 0 \\
\hline GEOCHEMICAL DATING OF ROCKS AND FLUIOS & $\circ$ & 0 & $\bullet$ & & & & & $\circ$ \\
\hline PAECIPITATION & & & $\bullet$ & & & & & o \\
\hline FILTRATION & & & $\bullet$ & & & & & 0 \\
\hline \multicolumn{9}{|l|}{ GEOMECHANICS } \\
\hline NATURAL TEMPERATURE FIELD & 0 & - & & & 0 & & 0 & 0 \\
\hline IN SITU STRESS & 0 & $\bullet$ & & & & & 0 & 0 \\
\hline $\begin{array}{l}\text { THERMAL CONDUCTIVITY AND SPECIFIC HEAT } \\
\text { OF SALT AND INTERBEDS }\end{array}$ & 0 & $\bullet$ & o & & & & 0 & \\
\hline $\begin{array}{l}\text { THERMAL CONDUCTIVITY AND SPECIFIC HEAT OF } \\
\text { OVERLYING AND UNDERLYING ROCKS }\end{array}$ & 0 & - & $\circ$ & & & & & \\
\hline THERMAL EXPANSION OF SALT AND INTERBEDS & & & - & & & & 0 & \\
\hline \multicolumn{9}{|l|}{$\begin{array}{l}\text { THERMAL EXPANSION OF } \\
\text { OVERLYING AND UNDERLYING ROCKS }\end{array}$} \\
\hline DEFORMATION MODULI OF SALT AND INTERBEDS & o & - & o & & & & - & \\
\hline $\begin{array}{l}\text { DEFORMATION MODULI OF } \\
\text { OVERLYING AND UNDERLYING ROCKS }\end{array}$ & $\circ$ & - & 0 & & & & & \\
\hline $\begin{array}{l}\text { CREEP PROPERTIES OF SALT } \\
\text { (TEMPERATURE DEPENDANT) }\end{array}$ & & & - & & & & - & o \\
\hline \multicolumn{9}{|l|}{ RADIATION EFFECTS } \\
\hline \multicolumn{9}{|l|}{ DECREPITATION OR OTHER TEMPERATURE EFFECTS } \\
\hline $\begin{array}{l}\text { DISCONTINUITIES AND INHOMOGENITIES } \\
\text { IN REPOSITORY ZONE }\end{array}$ & & & & 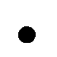 & 0 & o & & \\
\hline
\end{tabular}


TABLE 6.3.3-1 (CONT'D) SITE CHARACTERIZATION TECHNIQUE APPLICATION

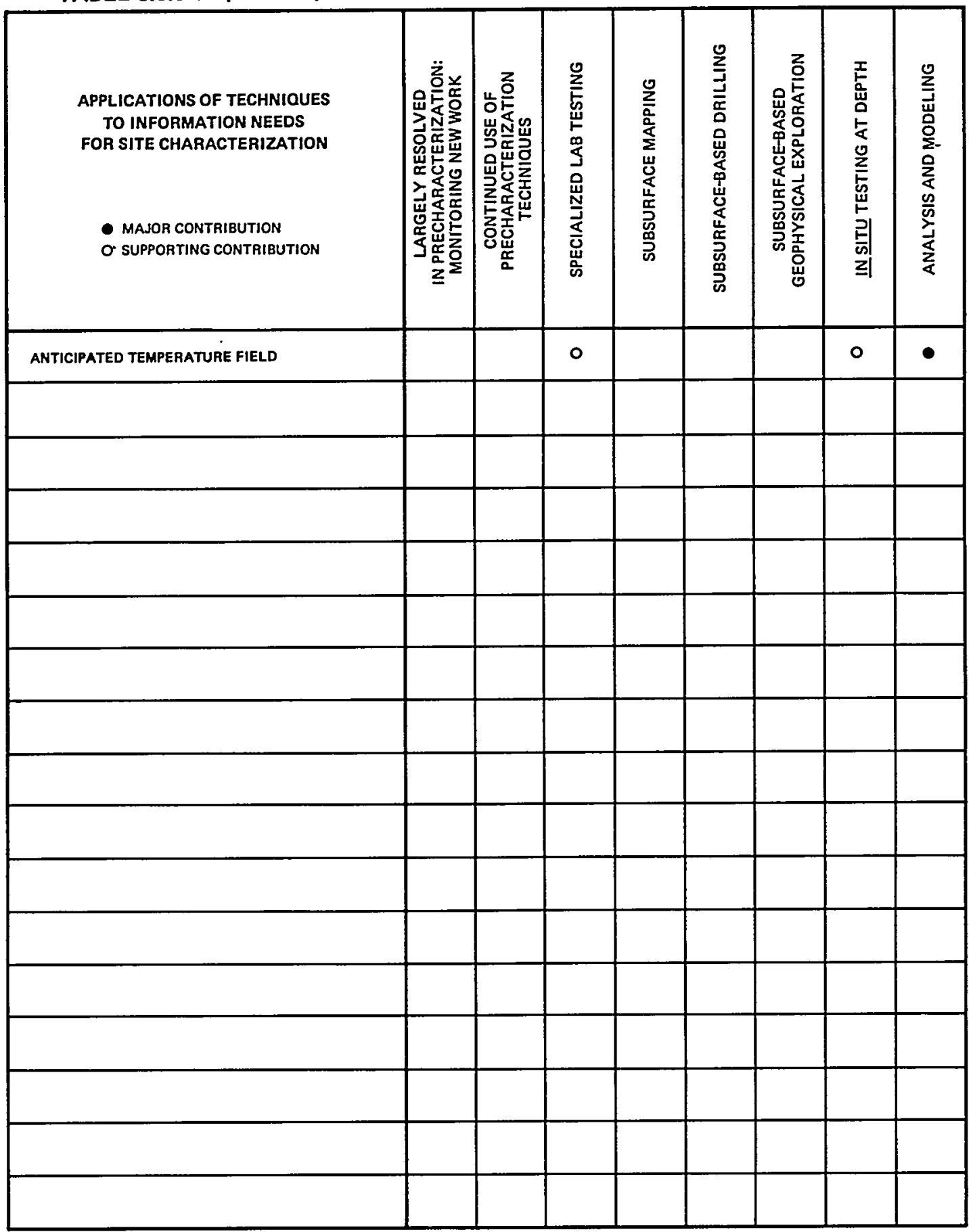


halite have been found in polygonal patterns extending as much as several meters below some corrosion surfaces. They are thought to result from partial dissolution of the salt due to influx of unsaturated brine shortly after original deposition of the affected beds (Richter-Bernberg, 1979). These features would be important for evaluating potential hydrologic flow paths within the salt as well as for geomechanical considerations.

Variations of impurities, texture, grain size, and other small scale features that may occur laterally or stratigraphically within the salt can be evaluated by detailed logging of the test excavations. Geomechanical parameters have been found to be particularly influenced by crystal size (Abel, 1969) and by concentrations of argillaceous material in the salt (Chapter 9 in Powers and others, 1978).

Drilling based from a test room within the salt would allow more intensive exploration of the proposed repository zone than would be feasible from the surface. The conditions and features addressed in excavation logging may be evaluated over a much larger area, although in much less detail, by using horizontal, inclined, or vertical boreholes. Horizontal boreholes would be particularly useful for evaluating lateral changes in mineralogy or other properties. Drilling methods are described in Appendix $D-2$ and logging techniques would be applied essentially as discussed for precharacterization (Section 6.2.3.1).

Techniques for subsurface based geophysical surveys using radar, sonar, or resistivity are applicable for identifying anomalous features within the salt. Features such as faults, fracture zones, brine pockets, lithologic changes, or preexisting boreholes may be identified at significant distances from the pilot shaft, test room(s), or test drift.s by these techniques. Salt is considered particularly well suited for radar applications because its characteristic low moisture content is favorable for propagation of the radar waves and facilitates recognizing features associated with fluids.

Applications of radar in salt have been summarized in the literature by Stewart and Unterberger (1976) and more recently by Unterberger (1979). Resolution and range of this technique are determined by the frequency (and associated wavelength) of the radar signal. The maximum effective range is reduced in salt with greater moisture content or larger amounts of impurities. A high resolution radar system, suitable for detecting small fractures or impurities in salt, has a wavelength of about $3 \mathrm{~cm}$ and an effective range of about 20 meters in dry salt. A low-frequency-long $r$ ange system has a wave length of about 4 meters and is effective to ranges of about 2000 meters in dry salt or about 500 meters in wet salt. The minimum size feature that could be detected by 
this low frequency system would be about two orders of magnitude larger than that detectable by the high resolution radar; other systems would fall between these extremes. For a general indication of the resolution in radar systems, the low frequency radar uses wavelengths about an order of magnitude shorter than those used in high resolution seismic reflection surveys.

Sonar probing systems have been developed for exploration in wet salt where radar penetration is greatly reduced. Using wavelengths of about $19 \mathrm{~cm}$, sonar was found to have ranges of almost 400 meters in dry salt and about 200 meters in wet salt. Features as small as a $10 \mathrm{~cm}$ sandstone bed could be detected (Unterberger, 1979).

Resistivity surveys may be conducted at depth in salt in much the same manner as at the surface. Reliability, resolution, and other aspects of the applicable techniques are discussed in Appendix B-4.

\subsubsection{Hydrology}

Hydrologic techniques used in site characterization include laboratory determinations of permeability and in situ hydrologic tests in the host rock at depth. Special techniques would be required for studying migration of brine inclusions. Sophisticated numerical modeling would be important for evaluating fluid movements and dissolution. Brine pockets, dissolution residues, and discontinuities that may control potential flow paths would be identified by the geologic techniques discussed in section 6.3.3.1. Applications of standard borehole and laboratory hydrologic tests would continue from precharacterization, as discussed in section 6.2.3.2.

Applications of hydrologic techniques in bedded salt pose some unique problems. Because the intact salt is essentially impermeable, flow paths are controlled by discontinuities, such as interbeds or clay partings. As a result, the locations and geometry of the discontinuities present must be considered in applying results of permeability tests to evaluate fluid movement. An additional problem is that permeability testing in salt must use special fluids, such as gasses or saturated brines, because water would dissolve the salt and enlarge existing flow paths or create new openings.

Laboratory testing for WIPP, as an example, used argon, nitrogen, and air to determine permeability of intact polycrystalline halite. These tests found permeability to be less than 0.05 microdarcy (the resolution limit of the apparatus) after an initial consolidation period to close fractures that may have been caused by sampling (Powers and 
others, 1978). Such tests emphasize the virtual impermeability of intact salt and the importance of discontinuities as potential flow paths.

Migration of fluid inclusions is a concern specific to salt and would be evaluated in site characterization. Techniques for evaluating this phenomena have been discussed in the literature (e.g., Anthony and Cline, 1973; Rothfuchs, 1979; Jockwer, 1979) and models for brine migration in salt have been developed (Claiborne and others, 1980). These techniques and models would be applied to quantify conditions of brine migration for the rocks and anticipated temperature field at a prospective site.

A major aspect of the hydrologic work in site characterization involves modeling factors such as fluid movements and dissolution rates. The general hydrologic modeling techniques applicable in bedded salt are similar to those in other media and are discussed in Appendix $G$. Additionally, a model has been specifically designed by Sandia Laboratories to evaluate dissolution in salt while considering the effects of thermal expansion, subsidence, crack formation, and salt creep (Campbell and Cranwell, 1981).

\subsubsection{Geochemistry}

The geochemical techniques used for site characterization in bedded salt would be generally similar to those used in other media. Some techniques that are particularly applicable for site characterization are described in Appendix F-2 and a comprehensive list of available techniques for geochemical work in bedded salt has been compiled by Rnauss and Steinborn (1980). These techniques would be applied to characterize geochemical properties of the salt and associated brines. Results would be used in analyses to aid evaluations of hydrologic isolation and to anticipate performance of the proposed repository.

The descriptive geochemical work will involve applications of standard laboratory techniques to determine in considerable detail the compositions of the brines and rocks at the prospective repository zone. The rocks typically present in association with bedded salt are discussed in section 6.2 .1 .1 and chemical composition of the typical evaporite minerals is in Table 6.2.1-1. Compositions of typical brines from bedded salt environments are summarized in Tables $6 \cdot 3 \cdot 3-2$ and $6 \cdot 3 \cdot 3-3$.

Evaluations of hydrologic isolation use the techniques described in Appendix F-2 to determine sources of water in the repository zone and to estimate how long the fluids have been isolated from the larger hydrologic system. Geochemical evidence that meteoric water is not 


\section{TABLE 6.3.3-2 REPRESENTATIVE FLUID COMMOSITIONS USED FOR WIPP EXPERIMENTATION}

\begin{tabular}{|c|c|c|c|}
\hline Ion & $\begin{array}{l}\text { Brine "A" } \\
\text { (mg/liter) } \\
( \pm 3 \%)\end{array}$ & $\begin{array}{l}\text { Brine "B" } \\
\text { (mg/liter) } \\
( \pm 3 \%)\end{array}$ & $\begin{array}{l}\text { Solution "C" } \\
\text { (mg/liter) } \\
( \pm 3 \%)\end{array}$ \\
\hline $\mathrm{Na}^{+}$ & 42,000 & 115,000 & 100 \\
\hline $\mathrm{K}^{+}$ & 30,000 & 15 & 5 \\
\hline $\mathrm{Mg}^{++}$ & 35,000 & 10 & 200 \\
\hline $\mathrm{Ca}^{++}$ & 600 & 900 & 600 \\
\hline $\mathrm{Fe}^{+++}$ & 2 & 2 & 1 \\
\hline $\mathrm{Sr}_{+}^{++}$ & 5 & 15 & 15 \\
\hline $\mathrm{Li}^{+}$ & 20 & - & - \\
\hline $\mathrm{Rb}^{+}$ & 20 & 1 & 1 \\
\hline $\mathrm{Cs}^{+}$ & 1 & 1 & 1 \\
\hline $\mathrm{Cl}^{-}$ & 190,000 & 175,000 & 200 \\
\hline $\mathrm{SO}_{4}^{--}$ & 3,500 & 3,500 & 1,750 \\
\hline $\mathrm{B}\left(\mathrm{BO}_{3}{ }^{-\cdots}\right)$ & 1,200 & 10 & - \\
\hline $\mathrm{HCO}_{3}=$ & 700 & 10 & 100 \\
\hline $\mathrm{NO}_{3}=$ & - & - & 20 \\
\hline $\mathrm{Br}^{-}$ & 400 & 400 & - \\
\hline $1^{-}$ & 10 & 10 & - \\
\hline pH (adjusted) & 6.5 & $\begin{array}{l}6.5 \\
1.2\end{array}$ & 7.5 \\
\hline & 1.2 & 1.2 & 1.0 \\
\hline
\end{tabular}

\footnotetext{
NOTES: BRINE "A" IS EXPECTED COMPOSITION OF AQUEOUS SOLUTION IN CONTACT WITH THE POTASH DEPOSITS AT WIPP. ARINE "B" IS TYPICAL OF FLUIDS IN CONTACT WITH THE HALITE AT THE REPOBITORY LEVEL. COLUTION "C" is REPRESENTATIVE OF THE SHALLOW GROUNDWATER OVERLYING THE SALT. ADAFTED FROM TABLE 9.3-1 IN POWERS AND OTHERS, 1978
} 


\section{TABLE 6.3.3-3 REPRESENTATIVE COMPOSITIONS OF BRINES FROM}

SOME BEDDED SALT DEPOSITS

\begin{tabular}{|lccr|}
\hline & Michigan & New Mexico & Utah \\
\hline $\mathrm{Na}$ & 28,000 & 44,400 & 18,800 \\
$\mathrm{~K}$ & 9,000 & 30,250 & 5,990 \\
$\mathrm{Ca}$ & 80,000 & 500 & 52,700 \\
$\mathrm{Mg}$ & 16,000 & 62,600 & 39,200 \\
$\mathrm{Sr}$ & 2,000 & --- & 2,000 \\
$\mathrm{Cl}$ & 250,000 & 251,500 & 241,000 \\
$\mathrm{Br}$ & --- & 3,300 & 3,080 \\
$\mathrm{SO}_{4}$ & -- & $395,090^{\mathrm{a}}$ & 4 \\
$\mathrm{TDS}$ & 385,000 & & $366,608^{\mathrm{b}}$ \\
\hline
\end{tabular}

a. INCLUDES: $1170 \mathrm{HCO}_{3}$ AND $840 \mathrm{NO}_{3}$

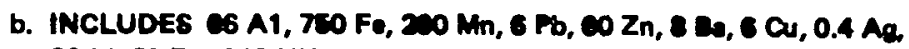
CL Li, $20 \mathrm{Rb}, 240 \mathrm{NH}_{4}, 1,010 \mathrm{HCO}_{3}, 26 \mathrm{~F}, 421,000$ B. DENGITY 1.331

ADAPTEDFROM TAELE 1 IN ETEWART AND POTTER, 1978 
present or that the fluids present have been isolated from the larger hydrologic system for long periods of geologic time can indicate an absence of connections from the proposed repository to the accessible environment.

Geochemical reactions that are important for repository performance include the interactions of the salt and brine with the waste form, canisters, and other engineered materials. These are analysed by use of available models (Addendum to Appendix F-2), incorporating the geochemical characterization of site conditions and the anticipated temperatures, pressures, and rates of fluid movement. Factors of particular concern in bedded salt include corrosion rates of the canister material, leaching rates of the waste form, and reactions influencing transport and retardation of the radionuclides.

\subsubsection{Geomechanics}

Techniques applied to the information needs in geomechanics for characterizing a site in bedded salt comprise laboratory testing, in situ field test programs, and analyses using modeling. Additional information relevant to the work in geomechanics will be obtained from the exploration techniques in subsurface geology (6.3.3.1) used to identify and describe discontinuities and variations in the salt proposed for a repository.

Although some specialized techniques would be used, many applications of laboratory testing in site characterization are similar to those in precharacterization. Appendix E-2 provides specific descriptions of the specialized laboratory techniques and the techniques for in situ geomechanical testing in salt for site characterization. General summaries of the available mechanical and thermal techniques that could be applied in salt have been compiled by IECO (1979). While the tests described are applicable to bedded salt in general, it is important to note that tests of this type involve specially designed programs for individual applications. Accordingly, test programs would be designed for a specific site during or prior to site characterization.

An important part of the work in geomechanics for site characterization is modeling of repository behavior. Applications of selected models are discussed briefly in Appendix E-2. A comprehensive list of computer codes applicable to various aspects of radioactive waste isolation has been prepared by Nuclear Safety Associates (1980). 


\subsubsection{Seismotectonics}

Techniques in seismicity and tectonics for site characterization would largely consist of continuing to monitor the seismograph networks emplaced during precharacterization. The main occurrences of bedded salt in the United States are in areas that are tectonically stable and have low seismicity, and it is expected that any significant questions regarding these topics would be resolved during precharacterization. However, any notable or anomalous events recorded during the characterization period may require additional specific investigations, using the techniques discussed in Appendix $\mathrm{H}$.

\subsubsection{Resources}

Resource evaluations during site characterization should be limited to continued monitoring of the ongoing exploration programs to confirm the findings of precharacterization regarding resource potential. The techniques applied in this work would be identical to those applied in precharacterization, and are discussed in Section 6.2.3.6.

\subsubsection{COST AND TIME ESTIMATES FOR TECHNIQUES IN SITE CHARACTERIZATION}

Estimates for the costs and times that would be required for the techniques used in characterizing a site in bedded salt are summarized in Tables 6.3.4-1 through 6.3.4-6. Additionally, the work in site characterization would involve continued use of the techniques of precharacterization; the cost and time estimates summarized in Tables $6.2 .4-1$ to 6.2.4-7 would remain applicable for these. In evaluating cost and time estimates for site characterization, an important consideration is that many of the tests are specially designed for site conditions and particular information needs. Durations of geomechanical and hydrologic tests, in particular, may be a design factor and can be important in determining costs.

\subsubsection{Geologic Mapping and Supporting Activities}

Typical costs and times for detailed surface mapping, as would be done at a prospective site during characterization, and the supporting work in remote sensing, trenching, and age dating are summarized in Table 6.3.4-1. This work would be performed during site characterization but chiefly would involve validating previous findings, as it would not be reasonable to undertake characterization at a site if there were significant outstanding questions regarding surface geology. For these 
estimates, it is assumed that access and trafficability would not be problems at a site chosen for characterization.

Table 6.3.4-2 summarizes typical costs and times for mapping geologic conditions in the pilot excavations. Costs for the geochemical analyses that may be used in support of this mapping are provided in Appendix F-1. For subsurface mapping done in coordination with the excavation, cost and schedule are likely to be controlled by the need to avoid interference with the excavation process. The actual rate of subsurface mapping would depend to a large extent on the complexity of geologic conditions in the excavations.

\subsubsection{Subsurface Based Drilling and Coring}

Appendix D-2 includes a comprehensive summary of the costs and penetration rates for various techniques used in drilling and coring from pilot excavations. Information applicable to bedded salt is summarized in Table 6.3.4-3, with some revisions to the Appendix D-2 costs for increased compatibility with the costs for other techniques. Costs for mobilization and delays for availability of suitable equipment are not included on the assumption that the site characterization program would be of sufficient magnitude to maintain the required equipment on site for a significant period.

Techniques for geologic logging of the drill return or core, as discussed in Appendices $D-1$ and $E-1$ would continue to apply in site characterization. Geophysical logging techniques discussed in Appendix $C$ also would remain applicable for vertical and near vertical holes; costs generally would be as summarized in Table 6.2.4-3.

\subsubsection{Geophysical Techniques in Site Characterization.}

In general, the geophysical techniques discussed in Appendix B would remain applicable in site characterization and costs would continue to follow the parameters outlined in Table 6.2.4-4. Costs for the techniques used in site characterization for detailed evaluation of near surface engineering parameters and for exploring the salt surrounding the pilot excavations are summarized in Table 6.3.4-4.

As discussed previously, the radar and sonar techniques used for subsurface exploration in geologic media are specially designed systems and therefore can differ significantly in costs and capabilities. Moreover, new techniques are continually under development, making it particularly difficult to forecast costs and capabilities for work that would be performed in future years. 
COST AND TIME SUMMARY FOR SURFACE GEOLOGIC TECHNIQUES

IN SITE CHARACTERIZATION

\begin{tabular}{|c|c|c|}
\hline & $\begin{array}{l}\text { Approximate } \\
\text { Cost }\end{array}$ & $\begin{array}{l}\text { Approximate } \\
\text { Time } \\
\end{array}$ \\
\hline \multicolumn{3}{|l|}{ REMOTE SENSING INTERPRETATION } \\
\hline $\begin{array}{l}1: 4800 \text { photo analysis } \\
\left(100 \text { photos for } 12 \mathrm{mi}^{2} \text { site }\right)\end{array}$ & $\$ 1,750-3,500(1)$ & 5-10 man days \\
\hline \multicolumn{3}{|l|}{$\begin{array}{l}\text { DETAILED SURFACE MAPPING } \\
\text { (for } 12 \mathrm{mi}^{2} \text { site area) }\end{array}$} \\
\hline General Mapping & $\$ 12,000-18,000$ & $\begin{array}{l}20-30 \text { man days } \\
(10-15 \text { field days } \\
\text { for } 2 \text {-man crew) }\end{array}$ \\
\hline Detailed structure analysis(2) & $\$ 6,000$ & $\begin{array}{l}10 \text { man days } \\
\text { (5 field days } \\
\text { for } 2 \text {-man crew) }\end{array}$ \\
\hline \multicolumn{3}{|l|}{ EXCAVATION LOGGING (3) } \\
\hline Reconnaissance & $\$ 1,200 /$ day $^{(4)}$ & $10,000 \mathrm{ft}^{2} / \mathrm{day}(4)$ \\
\hline Detailed logging at $1^{n}=10^{\prime}$ & $\$ 1,200 /$ day (4) & $1,500 \mathrm{ft}^{2} / \mathrm{day}(4)$ \\
\hline
\end{tabular}

NOTES:

(1) Does not include cost of large scale stereographic aerial photos, assumed to be available in site characterization.

(2) Only applicable where bedrock (overlying the salt) is exposed at the surface. Cost and time is in addition to general mapping.

(3) For surface excavations such as exploratory trenches or quarry cuts. Also for natural exposures such as bluffs or stream banks.

(4) Typical production rate and daily cost for 2-man field crew. Rates will vary according to access, difficulty of cleaning off the excavation, and, particularly, complexity of geologic conditions. Mapping of critical relationships at larger scale would require additional time. 
TABLE $6.3 .4-2$

COST AND TIME SUMMARY FOR SUBSURFACE GEOLOGIC MAPPING

IN SITE CHARACTERIZATION (1)

Cost Per Day

Typical Mapping

Rate

Detailed Mapping

$\$ 650.00$

$1200 \mathrm{ft} \mathrm{t}^{2} / \mathrm{day}(3)$

of Shaft or Drift

at $1^{n}=5 \cdot(2)$

NOTES:

(1) Based on Appendix A-2.

(2) Typical scale for geologic mapping in drift 8 feet wide and 8 feet high, after completion of engineering survey and preparation of base maps.

(3) Actual rates depend on complexity of geologic conditions at the place mapped. 
TABLE $6 \cdot 3 \cdot 4-3$

COST AND TIME SUMMARY FOR

SUBSURFACE BASED DRILLING AND CORING

IN SITE CHARACTERIZATION (1)

\begin{tabular}{|c|c|c|c|c|c|}
\hline \multirow{3}{*}{$\begin{array}{l}\text { Hole } \\
\text { Size } \\
\text { (In) }\end{array}$} & \multirow{3}{*}{$\begin{array}{c}\text { Maximum } \\
\text { Depth } \\
\text { (Ft) }\end{array}$} & \multicolumn{2}{|c|}{$\begin{array}{l}\text { Penetration } \\
\text { Rate (2) }\end{array}$} & \multirow[b]{2}{*}{ Cost per } & \multirow[b]{2}{*}{ foot $(5)$} \\
\hline & & & $\mathrm{Hr})$ & & \\
\hline & & Range & Average & Range & Average \\
\hline
\end{tabular}

PERCUSSION DRILLS

Track drill

$2-5 \quad 200 \quad 400-500(3) 450^{(3)} \$ 0.30-0.40^{(6)} \$ 0.35^{(6)}$

Core

Size

CORE DRILLS

Longyear

EHS 38

NQ $(1-7 / 8) \quad 1900 \quad 10-15(4) \quad 12(4)$

$\$ 9-13$

$\$ 11$

Longyear 65

BQ $(1-3 / 8) \quad 500$

$3-5(4) \quad 4^{(4)}$

$\$ 17-27$

$\$ 23$

NOTES:

(1) Adapted from Appendix D-2

(2) Not including move-in or set-up time. Rates calculated for representative drill or core sizes and would differ for other sizes.

(3) At 67\% efficiency.

(4) At 508 efficiency.

(5) Direct operating costs $\times 1.75$ to account for administration, insurance, interest, contractor's profit margin and other typical cost factors. Does not include cost of on-site geologic inspection or subsequent core logging. Does not include allowance for standby time.

(6)

Compressor costs calculated assuming two drills per compressor 
COST AND TIME SUMMARY FOR

GEOPHYSICAL TECHNIQUES

IN SITE CHARACTERIZATION

\begin{tabular}{|c|c|c|}
\hline & $\begin{array}{l}\text { Approximate } \\
\text { Cost } \\
\end{array}$ & $\begin{array}{l}\text { Approximate } \\
\text { Time } \\
\end{array}$ \\
\hline $\begin{array}{l}\text { SEISMIC CROSSHOLE } \\
\text { (typical survey to about } \\
500 \text { feet) }\end{array}$ & $\$ 34,000-39,000(1)$ & 4-5 weeks (2) \\
\hline $\begin{array}{l}\text { DOWNHOLE SEISMIC VELOCITY } \\
\text { (typical survey to about } \\
500 \text { feet) }\end{array}$ & $\$ 7,500-16,000(1)$ & $2-3$ weeks $(2)$ \\
\hline $\begin{array}{l}\text { RADAR OR SONAR } \\
\text { (from pilot excavation) }\end{array}$ & $\$ 5,500(3)$ & 3 days (3) \\
\hline
\end{tabular}

NOTES:

(1) Includes arilling costs.

(2) Turn around time for results from beginning field work. Does not include mobilization.

(3) Typical cost and field time for set of radial probings from single test room. Only a few sources provide radar or sonar services commercially. Both services are available from Rock Probers, Inc. (c/O Dr. R. R. Unterberger, Texas A \& M Univ.). Xadar Corporation, formerly Ensco, Inc. (Springfield, Virginia) provides radar. Typical daily rates are $\$ 1,500$ (Rock Probers, 2 or 3 man crew) to $\$ 1,750$ (Ensco, 2 man crew) for a minimum of three days, not including travel. Following initial setup and calibration numerous probes can be done in a day. Ensco estimates that lateral probes can be done along a tunnel at 1000 to 2000 feet per day. Actual duration of work in pilot excavations would depend on their layout and extent, and on the need to recalibrate radar velocities due to variations in the medium. (J. Fowler, 1981, personal communication, and R. R. Unterberger, 1981, personal communication).

$$
6-91
$$




\subsubsection{Hydrology}

Costs and times for the hydrologic techniques most important in site characterization are sumarized in Table 6.3.4-5, based on the information in Appendix G-2. All of the techniques in Table 6.3.4-5 involve testing programs that vary in cost and duration according to their design, in addition to the properties of the test medium. Costs of drilling and well completion are not included in the estimates for the hydrologic techniques. Additionally, a large part of the work in site characterization would involve continued use of the typical hydrologic techniques discussed for precharacterization. Cost and time estimates in Table 6.2.4-5 would remain applicable.

\subsubsection{Geochemistry}

Cost estimates for typical geochemical analyses are summarized in Appendix F-1. The specific tests and the number of analyses needed would be determined by site conditions and cannot be quantified reliably on a generic basis. The main factors determining turn-around time for results of the geochemical analyses are capabilities of the available laboratories, their work load, and the priority of the specific project. It is expected that most individual analyses for site characterization could be performed within a few weeks but longer times may be required for specialized analyses or for work on large numbers of samples.

\subsubsection{Geomechanics}

The work in geomechanics for site characterization involves specialized laboratory testing and in situ tests designed individually for each program. Representative costs and times are provided in Table 6.3.4-6 but these can differ significantly acording to design of a specific program. In particular, the number of tests required to characterize a site would be determined by the variability of site conditions and the proposed repository layout. Instrumentation is a notable problem for long duration tests and needs to develop new or unique systems could be costly. Additional costs also may result from the needs to protect test equipment from corrosion in the salt. 
COST AND TIME SUMMARY FOR

HYDROLOGIC TECHNIQUES

IN SITE CHARACTERIZATION

\begin{tabular}{lcc}
$\begin{array}{c}\text { Tests and } \\
\text { Analyses }(1)\end{array}$ & $\begin{array}{c}\text { Approximate } \\
\text { Cost Range (2) }\end{array}$ & $\begin{array}{c}\text { Approximate } \\
\text { Turn around } \\
\text { Time (3) }\end{array}$ \\
\hline INJECTION TESTS & $\begin{array}{c}\$ 20,000-50,000 \\
\text { per test }\end{array}$ & $5-15$ days \\
STRADDLE PACKER TESTING & $\begin{array}{c}\$ 10,000-25,000 \\
\text { per test }\end{array}$ & $5-15$ days \\
TRACER TESTS & $\begin{array}{l}\$ 20,000 \text { or more } \\
\text { per test interval }\end{array}$ & $\begin{array}{l}\text { Time until } \\
\text { detection } \\
\text { depends on } \\
\text { site conditions }\end{array}$
\end{tabular}

FLOW SYSTEM MODELING

Without fracture flow

2 dimensional

$\$ 20,000$

2-4 weeks

3 dimensional

$\$ 30,000$

3-6 weeks

With fracture flow

2 dimensional

$\$ 50,000$

5-10 weeks

3 dimensional

$\$ 75,000$

7-15 weeks

NOTES:

(1)

Described in Appendix G

(2) These tests are typically designed for particular site conditions in characterization. Costs are determined by test design and duration.

(3) Times for hydrologic tests are determined by site conditions and may vary significantly. 
TABLE $6.3 .4-6$

COST AND TIME SUMMARY FOR GEOMECHANICS TECHNIQUES

IN SITE CHARACTERIZATION (1)

\section{Tests $(2)$}

HYDROTHERMOMECHANICAL

IN SITU BLOCR TEST

LABORATORY TRIAXIAL CREEP

TESTING (per set of tests)

IN SITU UNIT CELI

SINGLE CANISTER HEATER TEST

(performed along with

unit cell)

LARGE SCALE HEATER TESTS

FLAT JACR CREEP TESTS (program)

LARGE-SCALE LABORATORY TESTS ON $1 \mathrm{~m}^{3}$ BLOCKS using electric heaters and flat jack loading

$$
\begin{gathered}
\text { Approximate } \\
\text { Cost }
\end{gathered}
$$

Approximate Duration (3)

$$
\begin{array}{cc}
\$ 700,000-800,000 & 9-15 \text { months } \\
\$ 10,000-15,000 & 4-8 \text { weeks } \\
\$ 250,000-400,000 & 2-3 \text { years } \\
\$ 200,000 & 2-3 \text { years } \\
& \\
\$ 400,000-600,000(4) & 2-3 \text { years } \\
\$ 300,000(5) & 2-3 \text { years }(6) \\
& \begin{array}{c}
\text { variable } \\
\text { per test } \\
\text { design }
\end{array} \\
\$ 30,000(7) &
\end{array}
$$

NOTES :

(1) Geomechanical testing for site characterization involves test programs designed for particular information needs and site specific conditions. Costs and times will vary according to test design.

(2) Descriptions in Appendix E-2

(3) Costs and times for in situ tests do not include excavation of test room.

(4) Additional tests may be run concurrently at reduced unit cost.

(5) Series of 8 tests. Additional tests at reduced unit cost.

(6) Assumes approximately 1 year per test with staggered schedule.

(7) Cost is indicated for short duration test. Costs for longer duration creep tests would be higher. 


\subsubsection{CRITERIA FOR EVALUATING DATA ADEQUACY OF SITE CHARACTERIZATION STUDIES IN BEDDED SALT}

This section summarizes factors to be considered in evaluating the geosciences information obtained from characterizing a site in bedded salt. It emphasizes the information needs and techniques specific to site characterization; that is, those related to detailed exploration and testing at depth. The criteria presented in section 6.2 .5 for precharacterization remain applicable for (1) the information needs that are essentially resolved in precharacterization to the extent that site characterization is not expected to provide significant new data and (2) applications that chiefly are continuations of similar work in precharacterization. Accordingly, criteria for these applications are not repeated here. No criteria are presented for seismicity/tectonics and resources in this section because information needs and applications in these categories are completely within the classifications discussed above.

The techniques that are applied to each of the information needs for characterizing a site in bedded salt are summarized generally in Table 6.3.3-1 and discussed in section 6.3.3. To the extent that section 6.3.3 indicates appropriate applications of available technigues, it can be useful in evaluating the scope of work planned or performed in characterizing a candidate site. However, the most important parts of site characterization involve programs of testing and exploration that are designed for a specific site. As such, these are not suitable for evaluation solely by generic criteria but instead must be judged on the basis of site conditions. Individual criteria for each prospective site should be developed from the results of precharacterization and from the preliminary findings in site characterization.

\subsubsection{Geology}

General information needs regarding geology that are emphasized in characterization of a prospective repository site in bedded salt, and the techniques applied to them, include:

- Detailed mineralogy and lithology of the salt - subsurface geologic mapping, drilling and logging, subsurface-based geophysical exploration

- Clay partings and clay breaks - subsurface geologic mapping, drilling and logging, subsurface-based geophysical exploration 
Impurities in the salt - subsurface geologic mapping, drilling and logging, subsurface-based geophysical exploration

- Lateral variations - horizontal or inclined drilling and logging from pilot excavations, subsurface-based geophysical exploration

- Smaller scale structures - subsurface geologic mapping, drilling and logging, high resolution subsurface-based geophysical surveys

- Salt texture - subsurface geologic mapping, drilling and logging

Investigations of geology in site characterization chiefly are intended to describe the volume of salt proposed for a repository and to identify variations or anomalies that may influence site suitability or performance of a repository. These geologic investigations largely support the work in hydrology, geochemistry, and geomechanics. The geologic activities in site characterization include detailed subsurface geologic mapping, subsurface based drilling and geophysical exploration, and supporting laboratory analyses. Criteria for the information obtained from this effort are concerned with: (1) capabilities of available exploration techniques and (2) geologic properties of bedded salt that affect the ability to understand conditions at a site.

Capabilities of the available exploration techniques are reflected in the different levels of confidence for geologic information in each part of the subject volume of rock. Excavation logging has very high resolution and reliability but covers only the limited extent of the pilot excavations. Drilling and geophysical exploration must be used to interrogate the salt outside this extent. As discussed in section 6.2.3.1.3, drill core may be logged in great detail and features on the order of $1 \mathrm{~mm}$ or smaller may be detected with confidence. However, because the core provides a smaller sample for examination, interpretations would not be as reliable as in excavation logging. There also may be uncertainties regarding location of borehole data because of hole deviation. The core return from the boreholes also represents only a small part of the total volume of rock, although it provides representative samples over a much larger area than the pilot excavations.

Geophysical techniques are used to interrogate the volume of the salt beds outside the pilot excavations and boreholes. Radar, sonar, and geophysical techniques discussed for precharacterization may be used to identify variations in mineralogy of the salt, interbeds, faults, or anomalies such as brine pockets. In general, the resolution of such techniques and the confidence in interpretations decrease with increasing depth of penetration. For example, as discussed in section 
6.3.3.1, radar systems with lower frequencies and longer wavelengths are effective at greater distances into the salt but cannot resolve the smaller features detected by the high-resolution, low-penetration systems. The resolution and penetration of a radar system is determined by the design of the individual system used and cannot be quantified reliably on a generic basis.

To allow proper evaluation of the geologic interpretations and conclusions presented, the information on geology obtained from site characterization should include: (1) identification of the techniques used to explore each part of the volume of salt proposed for a repository and the surrounding "disturbed zone" (following the definition proposed for 10CFR60), (2) estimates of the resolution and reliability of the data obtained from each part of the volume of rock explored, and (3) sufficient description of each geophysical technique to allow an independent evaluation of its resolution and reliability. Additionally, deviations of horizontal or inclined boreholes should be determined with sufficient accuracy to allow confident interpretation of the borehole data.

Geologic properties of bedded salt and the histories of deposition, diagenesis, and tectonic deformation at a site are important in site characterization as a basis for extrapolating findings from the pilot excavations to other parts of the subject volume of rock that are not accessible for direct observation. (The geologic factors that are important in this regard are discussed in sections 6.2 .1 and 6.3.1) Therefore, in addition to thoroughly describing the lithology, stratigraphy, and geologic structure of a prospective site, the geologic investigations should be adequate to provide a comprehensive and reliable understanding of the deposition and subsequent geologic history of the bedded salt unit proposed for a repository. This information would support interpretation of such factors as stratigraphic control of mineralogy, texture, and fluid content. It also would aid in determining the extent to which properties can be extrapolated beyond the pilot excavations. For example, many occurrences of bedded salt are notable for their lateral continuity, and extrapolations may be made with confidence at a site if such continuity is indicated by comparing findings in the boreholes and pilot shaft.

However, understanding of the depositional facies and post-depositional alterations at a site would be needed to evaluate lateral variations that may be present. Similarly, the history of deformations at a site would aid in evaluating structures such as fracturing in interbeds and possible folding or faulting.

Because the geology of a bedded salt formation is important for its suitability as a host medium, the geologic information obtained from 
site characterization should be evaluated to judge how well it forms a comprehensive model. This model should be consistent with and rationally explain the geologic conditions at and surrounding the prospective site.

\subsubsection{Hydrology}

Techniques applied to the hydrologic information needs for site characterization in bedded salt may be summarized as:

- Fluid-bearing zones and flow paths within the salt - geologic exploration, geochemical techniques, laboratory permeability testing, field injection tests, hydrologic modeling

- Smaller brine pockets - geologic exploration geochemical techniques, hydrologic modeling - Brine inclusions within salt grains - specialized laboratory

- Hydrate water in minerals of interbeds and impurities - geologic exploration, geochemical techniques, specialized laboratory testing

- Quantification of aquifer properties - laboratory permeability tests, field injection, discharge, straddle-packer, and tracer tests, geochemical techniques, flow modeling

- Quantification of dissolution rates - geologic evidence quantification of aquifer properties (above), geochemical evidence, specialized modeling

Some general criteria may be proposed for evaluating the hydrologic work specific to site characterization in bedded salt: the investigations addressing fluids and potential flow paths within the salt. The criteria discussed in section 6.2 .5 .2 would remain applicable for the continued studies of aquifers above and below the salt to confirm or better quantify results of precharacterization.

As discussed in section 6.3.3.2, there are some important considerations in applying hydrologic techniques to bedded salt. Because of the importance of discontinuities as potential flow paths, locations and geometry of these features must be considered in selecting samples for laboratory testing or identifying intervals for field permeability tests. Confining pressures used in laboratory testing should be similar to those at the prospective repository level in order to 
maintain openings of the discontinuities at close to field conditions. Fluids used in the field or laboratory tests should be designed to avoid dissolution of the salt.

The low permeability, long travel times, and other problems in applying typical hydrologic techniques in bedded salt emphasize the importance of integrating results from related work in geology and geochemistry for the hydrologic analyses. The geologic work contributes to hydrology by identifying and describing potential flow paths and by determining the distribution of brine pockets and fluid inclusions. Criteria for evaluating the applicable geologic techniques are in section 6.3.5.1. Geochemistry can allow interpretations of the fluid movement along low permeability flow paths typical of bedded salt, effectively using naturally occurring isotopes as tracers for flow over long periods of geologic time. For example, ratios of $18 \mathrm{O} /{ }^{16} \mathrm{O}$ and $\mathrm{D} / \mathrm{H}$ can be used to determine origin of the water in the salt and the various techniques for dating can aid in determining rates of flow. Criteria for the geochemical techniques are in section 6.3.5.3.

\subsubsection{Geochemistry}

Geochemistry is a most important part of site characterization as it contributes to describing the repository environment, evaluating hydrologic conditions, and predicting performance of the repository under the anticipated conditions of waste emplacement. There are two main aspects of this geochemical work: (1) describing the geochemical properties of the rocks and fluids, mainly by laboratory analyses, and (2) interpreting geochemical reactions, including both the past reactions relating to history of groundwater movement and the potential reactions involved in repository performance. Techniques used to address the information needs in geochemistry for site characterization in bedded salt (Table 6.3.2-4) generally follow those in precharacterization (Section $\mathbf{6 . 2 . 5 . 3}$ ) with the addition of specialized laboratory techniques, as discussed in Appendix F-2. Criteria for evaluating the geochemical results of site characterization are concerned with the interpretations as well as the laboratory analyses.

Procedures for sample collection and for field or laboratory geochemical analyses accompany Appendix F-2. The procedures used in site characterization should generally follow these, although equivalent alternates may be evaluated individually. Applications of these tests to describe the geochemical framework of a site should be guided by the geologic information on the occurrences of minerals within the salt and the overlying and underlying geologic units, as discussed in section 6.2 .5 .3 . 
Criteria for evaluating the geochemical interpretations of groundwater age or histories of geochemical alteration should recognize the complexity of such interpretations and the uncertainties involved. As discussed in Appendix F-2, a single set of stable isotope data normally is subject to several possible interpretations. The results of multiple analyses should be combined to reduce these uncertainties. Interpretations of hydrologic and geologic histories from the geochemical analyses similarly should be evaluated against the other types of evidence available.

Geochemical reactions relating to anticipated performance at a repository would be interpreted from the geochemical framework of the site, as determined by site characterization, and the expected repository conditions. As there is some uncertainty in each of these, criteria for evaluating such interpretations should require consideration of the degree of uncertainty present and the sensitivity of the interpretations to possible variations in each of the input parameters. In this manner, it should be possible to establish confidently that the anticipated reactions are within the desired bounding conditions even though significant numerical uncertainty may exist.

\subsubsection{Geomechanics}

Information needs and the applicable techniques for site characterization in bedded salt are summarized as:

- Thermal expansion - special laboratory testing, HTM in situ tests, field heater tests

- Creep properties - Special laboratory testing, HTM in situ tests, field scale heated flat jack tests

- Thermal and radiation effects - Special laboratory testing

- Temperature field (from waste emplacement) - laboratory tests, field heater tests, geologic information, numerical modeling

- Discontinuities and inhomogenieties - Geologic exploration

The geomechanical program for evaluating response of the salt to anticipated thermal and mechanical stresses is a critical part of site characterization. It incorporates geologic description of the salt beds proposed for a repository, results of laboratory testing, and in situ testing at depth specifically for site characterization. This information then is applied in numerical models to evaluate repository performance. The criteria for the geologic work are in section 6.3.5.1 
and those for the commonly used laboratory testing would be as discussed for precharacterization in Section 6.2.5.4 and Appendix E-1.

Programs of geomechanical testing in salt for site characterization are described in Appendix E-2 and generally represent the level of work that would be required. However, any such testing should be designed for the conditions at a site and should be evaluated on that basis. Notable concerns regarding the design and operation of such tests include stress measurements for in situ testing and loading rates for creep tests, as discussed in Appendix E-2. Instrumentation will require particular attention for tests of long duration because of the potential corrosion problems in the salt. Even aside from corrosion, long term reliability of instrumentation systems may be uncertain and should be evaluated carefully.

Important considerations for analysing test results and modeling repository performance include (1) reliable geologic descriptions of discontinuities and variations in the salt and (2) accurate prediction of temperature conditions. It would be most desirable that any test cells and the actual repository be in a single uniform salt bed. Realistically, however, this is unlikely to be the case. It will be necessary to describe the discontinuities and variations (i.e., grain size, texture, impurities, fluid content, etc.) in a test sample, whether laboratory or in situ, for proper interpretation of the results. Similar information will be needed for the proposed repository interval to apply the test results for evaluating repository performance.

Temperature conditions are a particular concern for predicting creep behavior of the salt. Laboratory testing has indicated that creep rates of halite can change significantly over the temperature range. anticipated in a repository. Because of this sensitivity, evaluations of creep estimates especially should consider the possible variation in temperature conditions.

As discussed previously for the geochemical analyses, the geomechanical evaluations of a prospective repository are based on a number of measurements and interpretations, each having some level of uncertainty. Criteria for evaluating these analyses should require consideration of the uncertainty in each input parameter and the resulting effects on the prediction of repository performance. This sensitivity analysis will be an important part of establishing that the expected repository performance is within the desired bounds. 


\subsection{REFERENCES}

Abel, J. F., 169, Rock Mechanics - Can It Pay Its Way? Northern Ohio Geologic Society, Third Symp. on Salt, Vol. 2, pp. 197-207.

Anderson, R. Y., 1978, Report to Sandia Laboratories on deep dissolution of salt, northern Delaware Basin, New Mexico (Unpublished).

Anderson, R. Y., Dean, W. E. Jr., Kirkland, D. W., and Snider, H. I., 1972, Permian Castile varved evaporite sequence, west Texas and New Mexico: Geol. Soc. Am. Bull., Vol. 83, pp. 59-86.

Anderson, R. Y. and Powers, D. W., 1978, Anticlines in Castile-Salado evaporite sequence, northern Delaware Basin: New Mexico Bureau Mines and Mineral Resources Circ. 159, pp. 79-84.

Anthony, T. R. and Cline, H. E., 1973, Thermomigration of Iiquid Droplets In Salt: Northern Ohio Geologic Society Fourth Symp. on Salt, Vol. 1, pp. 313-321.

Baar, C. A., 1973, Geological problems in Saskatchewan potash mining due to peculiar conditions during deposition of potash beds: Northern Ohio Geologic Society, Fourth Symp. on Salt, Vol. 1, pp. 101-118.

Baar, C. A., 1977, Applied Salt-Rock Mechanics I, The In Situ Behavior of Salt Rocks: Elsevier, Amsterdam.

Bachman, G.O., 1974, Geologic processes and Cenozoic history related to salt dissolution in southeastern New Mexico: U.S. Geol. Survey Open-File Rpt. 74-194.

Bachman, G.O. and Johnson, R. B., 1973, Stability of salt in the Permian Basin of Ransas, Oklahoma, Texas, and New Mexico: U.S. Geol. Survey Open-File Rpt. 4339-4.

Bodine, M. W., Jr., 1978, Clay-mineral assemblages from drill core of Ochoan evaporites, Eddy County: New Mexico Bureau Mines and Mineral Resources Circ. 159, pp. 21-32.

Bradshaw, R. L., Empson, F. M., Boegly, W. J., Jr., Kubota, H., Parker, F. L., and Stuckness, E. G., 1962, Properties of salt important in radioactive waste disposal: Geol. Soc. America Spl. Paper 88, pp. 643-658.

Braitsch, 0., 1971, Salt deposits: Their origin and composition: Springer-Verlag, New York, 297 p. 
Brokaw, A. L., Jones, C. L., Cooley, M. E., and Hays, W. H., 1972, Geology and hydrology of the Carlsbad potash area, Eddy and Lea Counties, New Mexico: U.S. Geol. Survey Open-File Rpt. 4339-1.

Brunton, G. D., Laughon, R. B., and McClain, W. C., 1978, Screening specifications for bedded salt, Salina Basin, New York and Ohio: Y/OWI/TM-54.

Buzzalini, A. D., 1969, Evaporites and petroleum: Introduction: Am. Assoc. Petroleum Geologists Bull. Vol. 53, 775 p.

Campbeli, J. E. and Cranwell, R. M., 1981, DNET: A model for incorporating feedback effects in salt dissolution processes [abs.]: Symposium on uncertainties associated with the regulation of the geologic disposal of high-level radioactive waste, Gatlinburg, Tennessee, March 9-13, 1981 (Sponsored by USCRC and ORNL).

Clairborne, H. C., Rickertson, L. D., and Graham, R. F., 1980, Expected environments in high-level nuclear waste and spent fuel repositories in salt: ORNL/TM-7201.

Clark, S. P., Jr., 1966, Handbook of physical constants: Geol. Soc. Am. Memoir 97.

Conwell, F. R., 1979, Regional geological screening studies for wasterepository siting in the Paradox Basin: ONWI-62, pp. 70-72.

Dellwig, L. F., 1962, Significant features of deposition in the Hutchinson salt, Kansas, and their interpretation: Geol. Soc. Am. Spl. Paper 88, pp. 422-426.

Dellwig, L. F., 1968, Primary sedimentary structures of evaporites, in, Richter-Bernburg, G., ed. 72, Geology of saline deposits: UNESCO Publication in Earth sciences No. 7, pp. 53-58.

DOE, 1980, Statement of position in the matter of proposed rulemaking on the storage and disposal of nuclear waste: PR-50, 51 (44FR $61372)=$ DOE/NE-0007.

Droste, J. B. and Shaver, R. H., 1977, Synchronization of deposition: Silurian reef-bearing rocks on Wabash Platform with cyclic evaporites of Michigan Basin, in, Fisher, J. H., 1977, Reefs and evaporites, concepts and depositional models: Am Assoc. Petroleum Geologists Studies in Geology No. 5, pp. 93-110. 
Empson, F. M., Bradshaw, R. I., McClain, W. C., and Houser, B. L., 1970, Results of the operation of Project Salt Vault: a demonstration of disposal of high level radioactive solids in salt: Northern Ohio Geol. Soc. 3rd Symp. on Salt, Vol. 1, pp. 455-462.

Fisher, J. H., ed, 1977, Reefs and evaporites - concepts and depositional models: Am. Assoc. Petroleum Geologists Studies in Geology No. 5 .

Gard, L. M., Jr., 1968, Geologic studies, Project Gnome, Eddy County New Mexico: U.S. Geol. Survey Prof. Paper 589.

Goldsmith, I. H., 1969, Concentration of potash salts in saline basins: Am. Assoc. Petroleum Geologists Bull., Vol. 53, p. p790-797.

Gustavson, T. C., 1969, Salt dissolution: Texas Bureau Economic Geology Circ. 79-1, pp. 87-95.

Heard, H. D., 1972, Steady-state flow in polycrystalline Halite at pressure of 2 Rilobars: AGU Geophysical Monograph 16, pp. 191-209.

Herness, S. R., 1977, Subsurface representation in mining geology, in, LeRoy, L. W., LeRoy, D. O., and Raeses, J. W., 1977, Subsurface Geology: Colorado School of Mines, Golden, Colorado, pp. 529-539.

Hills, E. S., 1967, Elements of Structural Geology: John Wiley \& Sons, Inc., New York, $68 \mathrm{p}$.

Hite, R. J., 1970, Shelf carbonate sedimentation controlled by salinity in the Paradox Basin, southeast Utah: Northern Ohio Geol. Soc. Third Symp. on Salt, Vol. 1, pp. 48-66.

Holdoway, R. A., 1973, Behavior of fluid inclusions in salt during heating and irradiation: Northern Ohio Geologic Society Fourth Symp. on Salt, Vol. 1, pp. 303-312.

Huh, J. M., Briggs, I. I., and Gill, D., 1977, Depositional environments of pinnacle reefs, Niagara and Salina Groups, northern shelf, Michigan Basin, in, Fisher, J. H., ed., 1977, Reefs and evaporites -- concepts and depositional models: Am. Assoc. Petroleum Geologists Studies in Geology No. 5, pp. 1-22. 
Humphris, C. C., Jr., 1978, Salt movement on continental slope, northern Gulf of Mexico, in, Bouma, A. H., Moore, G. T., and Coleman, J. M., eds., 1978, Framework, facies, and oil-trapping characteristics of the upper continental margin: Am Assoc. Petroleum Geologists Studies in Geology No. 7, pp. 69-86.

IECO (International Engineering Company), 1979, Review of geotechnical measurement techniques for a nuclear waste repository in bedded salt: UCRL 15141.

Ingerson, E., 1962, (Report of) Deposition and geochemistry work sessions: Geol. Soc. Am. Spl. Paper 88, pp. 671-681.

Jacka, A. D. and Franco, L. A., 1973, Deposition and diagenesis of Permian evaporites and associated carbonates and clastics on shelf areas of the Permian Basin: Northern Ohio Geol. Soc. Fourth Symp. on Salt, Vol. 1, pp. 67-90.

Jockwer, J., 1979, Investigation of the migration and release of water within rock salt: Proceedings of US/FRG bilateral workship, waste isolation performance assessment and in situ testing, ONWI-88, pp. 392-396.

Jones, C. L., 1968, Permian Basin potash deposits, southwestern United States, in, Richter-Bernburg, G., ed., 1972, Geology of saline deposits: UNESCO Publication in Earth Sciences No. 7, pp. 191-201.

Jones, C. L., Bowles, C. G., and Bell, K. G., 1960, Experimental drill hole logging in potash deposits of the Carlsbad District, New Mexico: U.S. Geol. Survey Open-File Rpt. 60-84.

Kelley, K.K., 1960, Contributions to the data on theoretical metallurgy: XIII. High-temperature heat-content, heat-capacity, and entropy data for the elements and inorganic compounds: U. S. Bur. Mines Bull. 584 .

King, R. H., 1947, Sedimentation in Permian Castile sea: Am. Assoc. Petroleum Geologists Bull., Vol. 31, pp. 470-477.

Kinsman, D. J. J., 1969, Modes of formation, sedimentary associations, and diagnostic features of shallow-water and supratidal evaporites: Am. Assoc. Petroleum Geologists Bull. Vol. 53, pp. 830-840.

Kirkland, D. W. and Evans, R., 1973, Marine evaporites: Origin, diagenesis, and geochemistry: Dowden, Hutchinson \& Ross, Inc. Stroudsburg, Pa., 248 p. 
Klingsberg, C. and Duguid, J., 1980, Status of technology for isolating high-level radioactive wastes in geologic repositories: DOE/TIC 11207 (Draft).

Knauss, R. G. and Steinborn, T. L., 1980, Review of geochemical measurement techniques for a nuclear waste repository in bedded salt: UCID-18664.

Loocke, J. E., 1978, Growth history of the Hainesville salt dome, Wood County, Texas: Univ. Texas, Austin M.A. thesis.

Mao, N. H. and Ramirez, A. L., 1980, New developments in measurements technology relevant to the studies of deep geological repositories in bedded salt: UCID-18687.

Matthews, R. D., 1977, Evaporite cycles and 1ithofacies in Lucas Formation, Detroit River Group, Devonian, Midland, Michigan, in, Fisher, J. H., ed., 1977, Reefs and evaporites - concepts and depositional models: Am. Assoc. Petroleum Geologists Studies in Geology No. 5, pp. 73-92.

Matthews, R. D., and Egleson, G. C., 1973, Origin and implications of a mid-basin potash facies in the Salina Salt of Michigan: Northern Ohio Geol. Soc. Fourth Symp. on Salt, Vol. 1, pp. 15-34.

Mear, C. E., 1962, Upper Permian sediments in southeastern Permian Basin, Texas: Geol. Soc. Am. Spl. Paper 88, pp. 349-358.

Mercer, J. W. and Orr, B.R., 1978, Geohydrology of the proposed Waste Isolation Pilot Plant, Eddy County, New Mexico: U. S. Geol. Survey Preliminary Report.

NAS/NRC, 1957, Disposal of radioactive wastes on land: National Academy of Sciences - National Research Council Publication 519

Nuclear Safety Associates, 1980, Post-closure monitoring and prediction of long-term repository performance; Section III-G in Document 2 of 4, Statement of Position of the Utility Nuclear Waste Management Group-Edison Electric Institute In the Matter of Proposed Rulemaking on the Storage and Disposal of Nuclear Waste, PR-50-51.

Nurmi, R.D. and Friedman, G.M., 1977, Sedimentology and depositional environments of basin-center evaporites, Iower Salina Group (Upper Silurian), Michigan Basin, in, Fisher, J.H., ed., 1977, Reefs and evaporites -- concepts and depositional models: Am. Assoc. Petroleum Geologists Studies in Geology No. 5, pp. 23-52.

$$
6-106
$$


Ode, H., 1962, Review of mechanical properties of salt relating to salt dome genesis: Geol. Soc. Am. Spl. Paper 88, pp. 543-596.

Ohlen, B.R. and McIntyre, L.B., 1965, stratigraphy and tectonic features of Paradox Basin, Four Corners area: Am. Assoc. Petroleum Geologists Bull, Vol. 49, pp. 2020-2040

Olive, W.W., 1957, Solution-subsidence troughs, Castile Formation of Gypsum Plain, Texas and New Mexico: Geol. Soc. Am. Bull., Vol. 68 , pp. $351-358$

ORNL Staff, 1973, site selection factors for the bedded salt pilot plant: ORNL/TM-4219.

Peterson, J. A. and Hite, R. J., 1969, Pennsylvania evaporite-carbonate cycles and their relation to petroleum occurrence, southern Rocky Mountains: Am. Assoc. Petroleum Geologists Bull., Vol. 53, pp. 884-908.

Pierce, H. W., 1973, Thick evaporites in the Basin and Range Province, Arizona: Northern Ohio Geol. Soc. Fourth Symp. on Salt, Vol. 1, pp. 47-56.

Pierce, W. G. and Rich, E. I., 1962, Summary of rock salt deposits in the United States as possible storage sites for radioactive waste materials: U. S. Geol. Survey Bull. 1148.

Powers, D. W., Lambert, S. J., Shaffer, S. E., Hill, L. R., and Weart, W. D., eds., 1978, Geological characterization report, Waste Isolation Pilot Plant (WIPP) site, southeastern New Mexico: SAND 78-1596.

Presley, M. W., 1979, Upper Permiam evaporites and red beds: Texas Bureau Economic Geology Circ. 79-1, pp. 39-49.

Richter-Bernburg, G., 1979, Aberrant vertical structures in well-bedded halite deposits: Northern Ohio Geologic Society Fifth Symp. on Salt, Vol. 1, pp. 159-166.

Robinson, R. A., 179, U. S. in situ studies in salt: Proceedings of US/FRG bilateral workshop, Waste isolation performance assessment and in situ testing, ONWI-88, pp. 75-82.

Roedder, E. and Belkin, H. E., 1978, Application of studies of fluid inclusions in Permian Salado salt, New Mexico, to problems of siting the Waste Isolation Pilot Plant, in, McCarthy, G. J., ed., 1979, Scientific basis for nucleat waste management: Plenum Press, New York, pp. 313-322. 
Rothfuchs, T., 1979, Asse II in situ brine migration tests: Proceedings US/FRG bilateral workshop, waste isolation performance assessment and in situ testing, ONWI-88, pp. 385-391.

Scruton, P. C., 1953, Deposition of evaporites: Am. Assoc. Petroleum Geologists Bull., Vol. 37, pp. 2498-2512.

Shearman, D. J., 1966, Origin of marine evaporites by diagenesis: Inst. Mining Met. Trans., Vol. 75, pp. 208-215.

Smith, A. R., 1978, sulfur deposits in Ochoan rocks of southeast New Mexico and west Texas: New Mexico Bureau Mines and Mineral Resources Circ. 159, pp. 71-77.

Smith, G. I., Jones, C. I., Culbertson, W. C., Erickson, G. E., and Dyni, J. R., 1973, Evaporites and brines, in, Brobst, D. A. and Pratt, W. D., eds., 1973, United States mineral resources: U. S. Geol. Survey Prof. Paper 820, pp. 197-216.

Stewart, D. B. and Potter, R. W. II, 1978, Application of physical chemistry of fluids in rock salt at elevated temperature and pressure to repositories for radioactive waste, in, McCarthy, G. J., ed., 1979, Scientific basis for nuclear waste management: Plenum Press, New York, pp. 297-311.

Stewart, R. D. and Unterberger, R. R., 1976, Seeing through rock salt with radar: Geophysics, Vol. 41, pp. 123-132.

Swyler, R. J., Klaffky, R. W., and Levy, P. W., 1978, Radiation damage studies on natural and sythetic rock salt for waste disposal applications, in, McCarthy, G. J., ed., 1979, Scientific basis for nuclear waste management: Plenum Press, New York, pp. 349-354.

Treesh, M. I. and Friedman, G. M., 1973, Sabkha deposition of the Salina Group (Upper Silurian) of New York state: Northern Ohio Geol. Soc. Fourth Symp. on Salt, Vol. 1, pp. 35-46.

Trusheim, F., 1960, Mechanism of salt migration in northern Germany: Am. Assoc. Petroleum Geologists Bull., Vol. 44, pp. 1519-1540.

U. S. Department of Energy, 1981, Geologic disposal of radioactive waste: Program plan for field tests in salt: DOE/NWTS-80(2).

Unterberger, R. R., 1979, Radar and sonar probing of salt: Northern Ohio Geological Society Fifth Symp. on Salt, Vol. 1., pp. 423-437. 
Vine, J. D., 1960, Recent domal structures in southeastern New Mexico: Am. Assoc. Petroleum Geologists Bull., Vol. 44, pp. 1519-1540.

Wilems, R. E., Arbital, J., Fowler, J., Mosier, J., Rickertson, I., and Stevens, P., 1980, Retrievability: Technical considerations: ONWI-203. 


\subsection{DOME SALT}

\subsection{PREVIOUS WORK IN DOME SALT}

Salt domes have been known since late in the $18 \mathrm{th}$ century. They occur in different regions of the world including the Gulf of Mexico, Persian Gulf and northern Germany. Since the early 19th century, salt domes have been economically important for petroleum production, mineral production (salt, potash, sulfur, etc.) or a combination of these uses. They have received additional attention in the last few decades for the cavern storage of hydrocarbons and other materials. These interests have generated extensive exploration and geologic research in salt domes.

In 1954, the United States Atomic Energy Commission (AEC) asked the National Academy of Sciences - National Research Council (NAS-NRC) to look at the problem of identifying a suitable repository site in salt. Since 1957 many institutions and many geologists have been involved in the study of the salt domes in relation to the problem of the radioactive waste disposal. Anderson and others (1973) conducted the first assessment of onshore salt domes in the Gulf Coast of the United states with regard to their general potential for waste disposal.

Most of the salt dome studies have been in the Gulf Coast region. More than 500 salt domes are present in the combined offshore and onshore Gulf coast basin. Of these domes, some 263 are located onshore in three principal salt basins in east Texas, northern Louisiana, and southern Mississippi (ONWI, 1981). Of these 263 domes, 148 are considered too deep for HLW storage and 79 exhibited competing uses, leaving 36 domes that met the general considerations of Anderson and others (1973). Extensive studies have also been done to screen information regarding the best site location. In 1978, draft reports were issued by various consultants which summarized the existing data and previous work in the region of interest containing salt domes. These reports formed the basis for a recommendation to DOE that eight domes be investigated further. Based on this recommendation, extensive studies have been undertaken to evaluate those eight salt domes and as a result, ONWI (1981) recommended continuing further studies at the four domes assessed as acceptable in meeting site performance criteria.

Results of these specialized studies are presented in various project reports and provide the basis for several articles in the general literature. Investigations specifically for isolation of radioactive material provides particular information on the requirements for a repository site in dome salt. Significant information on generation, 
tectonic, dissolution, detailed stratigraphy and structure of the salt domes as well as on mechanical properties of salt has also come from these studies. It is anticipated that these investigations will lead to identification of a single candidate dome to be considered for extensive at-depth testing and characterization.

\subsection{PRECHARACTERIZATION STUDIES}

\section{2:1 GEOLOGY OF DOME SALT}

\subsubsection{Origin}

A salt dome is a structure resulting from the migration and accumulation of a salt mass. Thick salt layers, which typically have a uniform thickness during deposition, are deformed under high static pressure in deep evaporitic basins, generally below about 1000 meters depth and develop salt flowage. Trusheim (1960) states that experience with the German salt basins showed that an overburden of about 1000 meters and a thickness of at least 300 meters of salt were necessary to initiate the process of flowage. Similarly, the salt domes in the Gulf coast of the United States appear to have originated below a few thousand meters depth. Small changes in static pressure on the upper surface of the salt sequence cause salt to move from high-pressured areas toward low-pressured areas, and accumulate there as a dome or pillow. Loocke (1978) confirms the migration of salt under uneven overburden weight. Trusheim (1960) states that lateral, fluid-like plastic flow of salt is facilitated if the basement dips at an angle of more than $1^{\circ}$. The initial impulse to movement can be sought in inhomogeneities, either in the basement under the salt, or in the salt itself, or even in the roof of the salt layer. Movement also may be initiated by tectonic stresses.

Salt dome formation and growth are in response to deep burial and essentially buoyant forces (Martinez, 1973); although little, if any, regional strees effects are observed in Gulf Coast domes, evidence for this is found elsewhere, such as Mexico. Sediment weight may have initiated diapirism in favorable areas and propelled the remainder of the salt mass toward these areas (Kupfer, 1973). Diapirism appears to be strongly influenced by burial depth, temperature, stratigraphic and basinal position, original thickness, and purity; in short, the total geologic history (Rupfer, 1973).

Humphris (1978) discusses the possibility of down-slope movement of the overlying sediments to initiate the salt movement in an evaporitic basin. Gussow (1968) hypothesized that heat is critical for the occurrence of salt intrusion, although Ala (1974) shows evidence that 
salt flows may occur at normal ground surface temperature. Obviously, all these theories and interpretations seem to be effective in salt movement, however, some of them may not occur in some places due to the local geologic conditions. Martinez (1973) concludes that there is no unifying theory for the origin of all salt structures.

The thickness of a salt mass below the crown of the forming dome may become many times thicker than the original thickness of the salt bed. The migration of salt toward the dome area causes sinking in highpressured areas and uplifting in low-pressured areas, creating a rim syncline around the dome. Continuous migration of salt causes swelling of the salt pillow or salt dome. The sedimentary rocks over the swelling salt dome will gradually be broken along shearing cracks and give way to piercement by the salt. After breaking the overlying layers, the diapir stage or piercing stage starts and salt commences to migrate vertically through overlying beds. Figure 7.2.1-1 shows the general configuration of the process. $P_{h}$ is the static pressure related to the thickness of overburden (H) at point $A$ and $P_{d}$ is the static pressure related to the thickness of overburden (D) at point $B$. The vector $p$ which is equal to $\left(P_{h}-P_{d}\right)$ has a tendency to push the overlying beds upward and pierce through them, in combination with buoyancy of the salt and tectonic forces. Trushein (1960) states that theoretically it is possible that stresses present in times of regional tectonic unrest might accelerate the flowing movement of the salt. In any case, it is conceivable that all these forces may increase the vector $p$ (Figure 7.2.1-1) to accelerate piercing of the salt through the overlying beds. As is mentioned before, accumulation of salt in the dome area causes tension faults and fractures in the overlying layers. Parker and McDowell (1955) after extensive model tests on this subject, concluded that the overburden becomes arched and fractured by the growth of model domes, and layers above the core of the model domes were arched and broken by normal radial faults. As $P_{d}$ (Figure 7.2.1-1) is reduced by upward movement of the salt, vector p gets constantly larger and exerts more force through the overlying layers.

Various terms have been used to describe the salt bodies resulting from accumulation and diapirism. The accumulations of salt have been called: salt dome, salt pillow, and salt stock. Salt piercing the overlying beds has been called: piercing salt dome, salt dome, diapir, salt diapir, salt intrusion, and salt plug. Following common usage in the United States, all types of accumulated salt including salt pillows, piercing salt and salt plugs will hereafter be called salt domes in this report. 


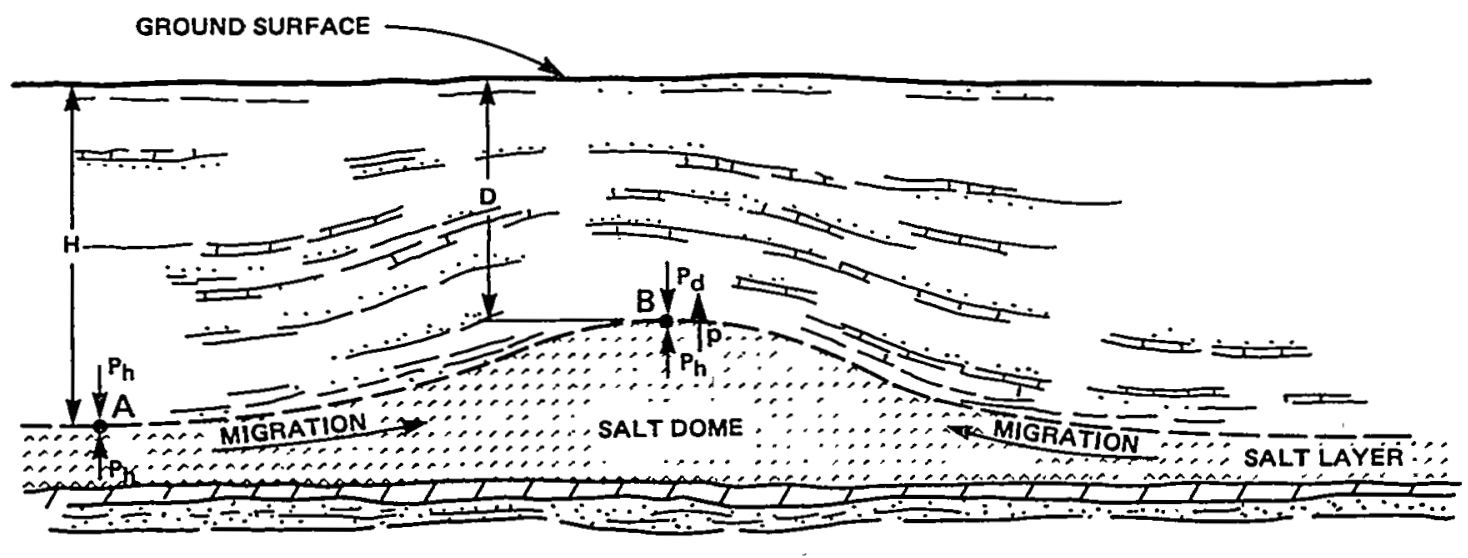

$P_{h}=$ STATIC PRESSURE RELATED TO HEIGHT OF $H$

$P_{h}>P_{d}$

$P_{d}=$ STATIC PRESSURE RELATED TO HEIGHT OF D

$P_{h}-P_{d}=p$

FIGURE 7.2.1-1 GENERALIZED SALT MOVEMENT PROCESS 


\subsubsection{Form of Occurrence}

Trusheim (1960) discusses and demonstrates that no two salt domes are alike. The form of occurrence depends on the volume of the salt mass, piercing force, thickness and hardness of the overburden, tectonics and structures of the regions and probably several other factors.

The geological section of the Lampton dome in Mississippi (Figure 7.2.1-2) depicts the general profile of a salt dome. The dome consists of a salt mass surrounded by geologic formations of the Gulf coast region. The tectonics of the area is influenced by the intrusion of the salt dome. Figure 7.2.1-3 shows a schematic cross section of a typical Gulf Coast salt dome basin. In a more simplified picture, Figure 7.2.1-4 shows the progression of a salt dome upward to the ground surface. Although salt domes in the Gulf Coast are not exposed at the surface, surface exposures do occur in other parts of the world and may be a common stage in the development of the dome. Exposed salt domes can stand a few hundred meters above the ground surface. The Ruh-e-Namak salt dome, north central Iran, has a height of about 400 meters above the ground level. Ala (1974) reports some salt domes rising up to 1200 meters (4000 feet) above the valley floor in the Persian Gulf region. At this stage the height of the exposed salt dome above the ground level produces an extra static pressure which finally equilibrates vector $p$ (Figure 7.2.1-1) and the movement of salt mass comes to a standstill (Figure 7.2.1-4).

Erosion and dissolution of the top of the salt dome may reduce the height of it. In such a case the static pressure of salt raises the salt dome to its previous height in order to keep static equilibrium. Such a salt dome is considered active and there have been various estimates for the rates of movement in active salt domes. Sannemann (1968) concludes that the absolute rate of the horizontal wave-front-like flow of the salt over great distances averages about 0.3 millimeter a year. Trusheim (1960) refers to Lotze (1957) that a relative rise of 1-2 millimeters per year was measured on salt domes of the Caspian depression. Teichmuller (1958) reports the post-diapiric rise of the salt dome of Segeberg, in Holstein (northern Germany) as about two millimeters per year in the last 20,000 years. Recent movements of salt domes in Iraq have reached a rate of 2.4 millimeters per year. Ala (1974) reports that the rate of intrusion is a highly fluctuating quantity, amounting to about 2 millimeters per year in the most actively rising domes.

A salt dome which has no potential for further movement or reactivation, is considered inactive. As mentioned above, the rock layers which overlie salt beds sink and subside around the salt dome due to 


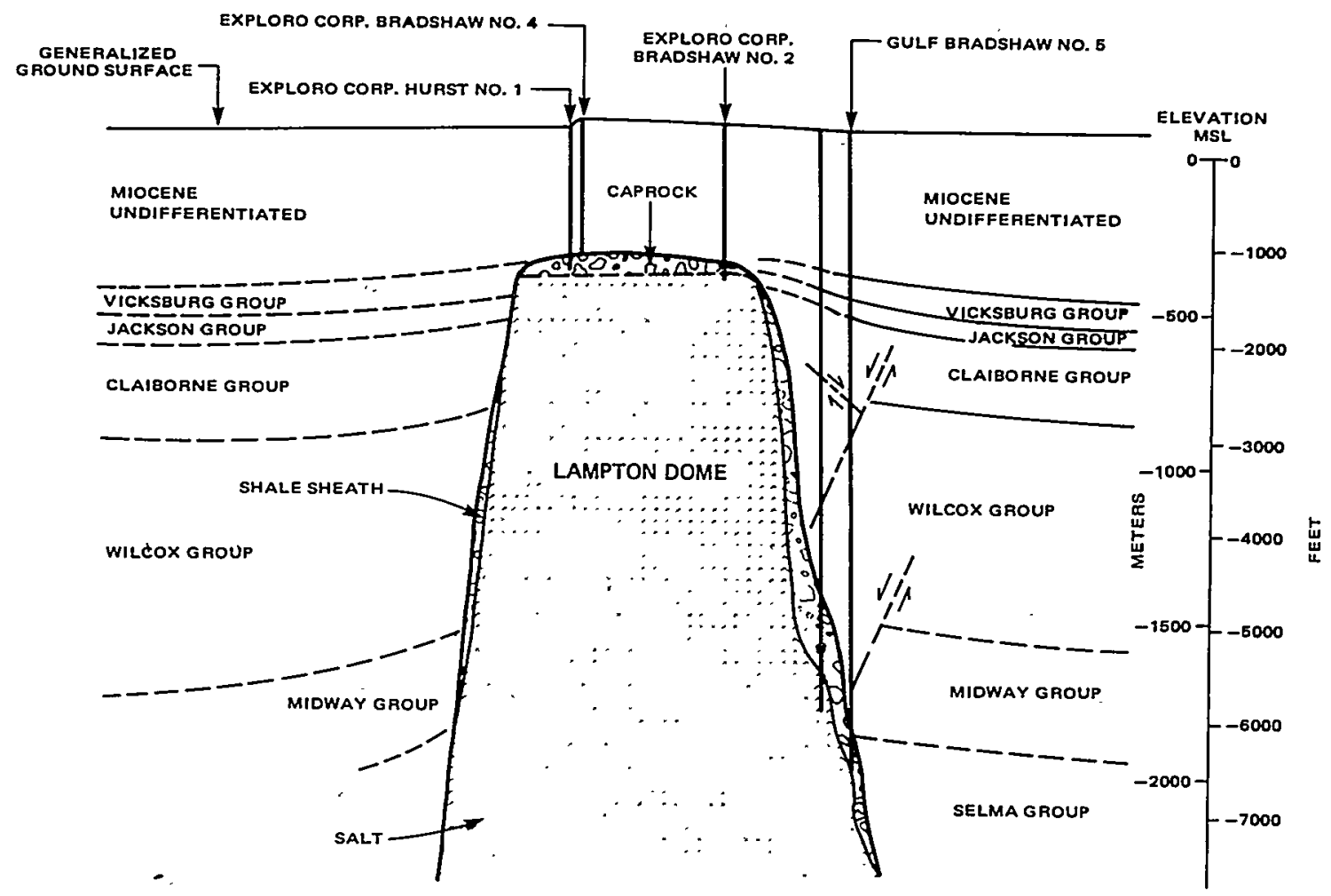

FIGURE 7.2.1-2 LAMPTON DOME GEOLOGIC SECTION (MODIFIED FROM ONWI-109, 1981) 


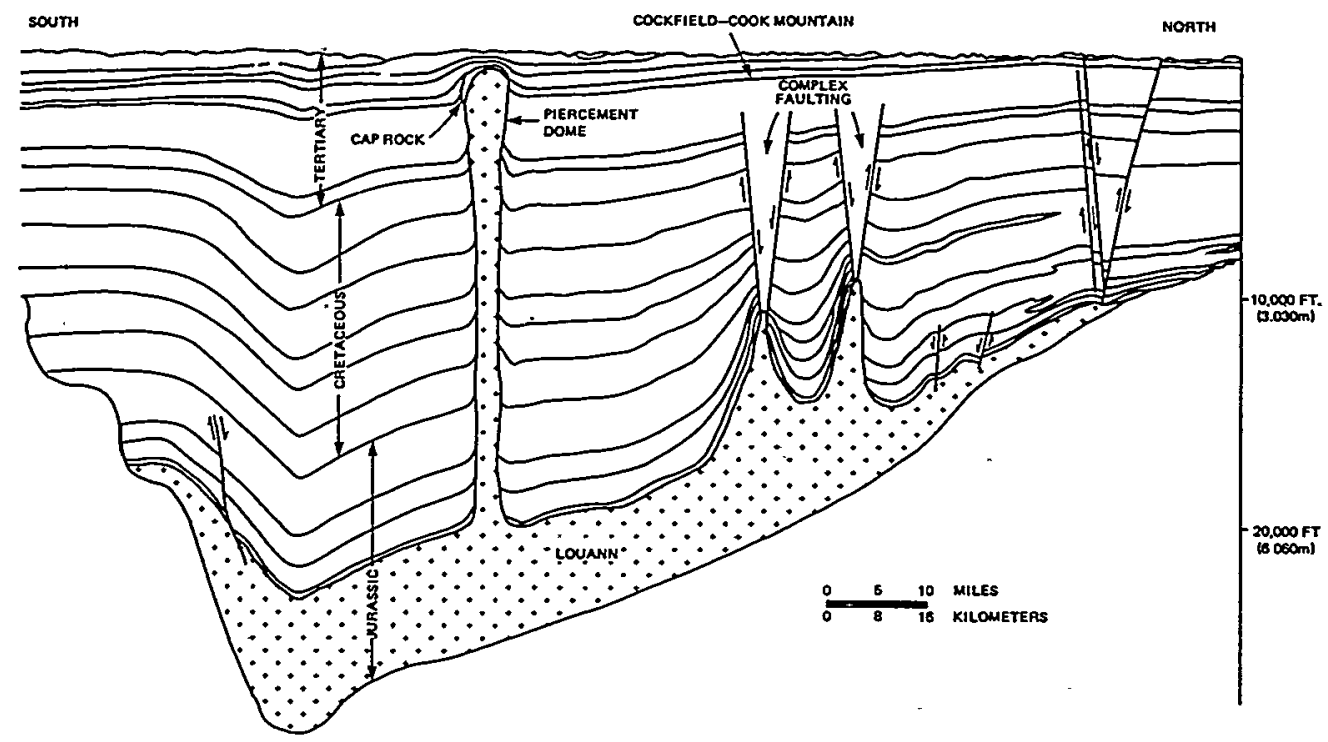

FIGURE 7.2.1-3 SCHEMATIC CROSS SECTION OF TYPICAL GULF COAST SALT DOME BASIN (MODIFIED FROM JOHNSON AND GONZALES, 1076) 


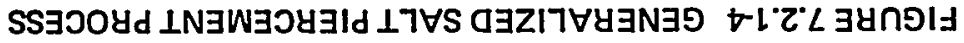

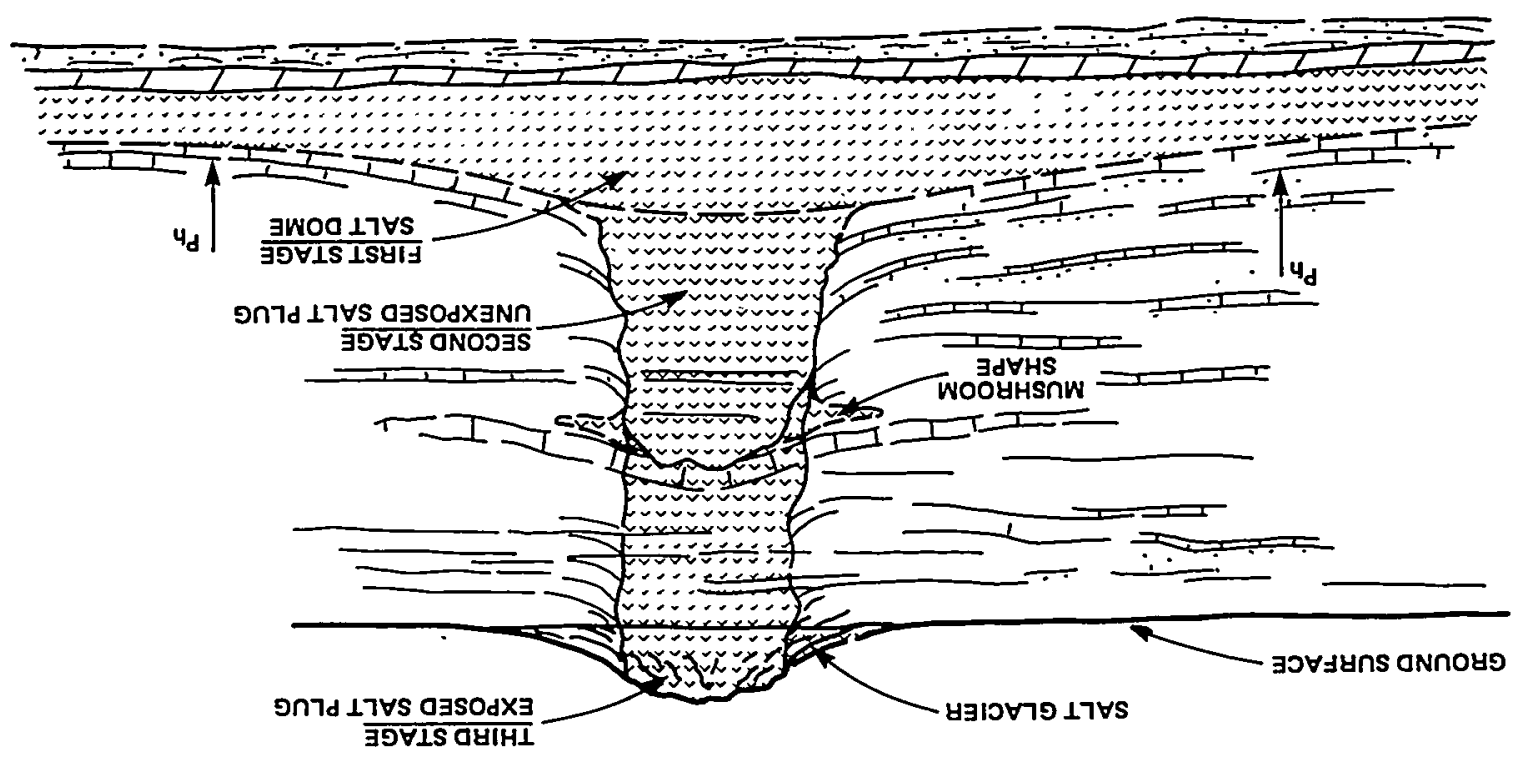


the migration of salt toward the dome area. It has been suggested that when these overlying subsiding layers collapse onto the underlying layers due to the complete consumption of the salt, all migration of the salt toward the dome will cease, and the static pressure of the salt may reduce down to zero. At this stage, it has been proposed that the salt mass becomes inactive. Trusheim (1960) discussing "end of migration" refers to seismic surveying in the northern Germany salt basins which has shown that the Triassic rock layers (above the zechstein salt) in many places directly overlies the pre-saline rock layers in the areas between the salt domes. Gussow (1968, p.51 and Figure 25) shows that in this type of salt dome the movement of salt usually is ceased because the salt supply is exhausted and the overlying beds come to rest on underlying beds.

There are domes which have potential for further movement and reactivation, but for a certain period of time or by some mechanism, they do not move and thus appear inactive. Such conditions may occur when a piercing salt dome encounters higher resistance in the overlying rock layers and ceases vertical movement, but changes in the existing equilibrium may cause the salt mass to move again. Tectonic forces, additional deposition in the basin, a reduction in the overburden resistance, movement into new voids, or any similar mechanism may initiate salt movement again.

Discrimination between the true inactive salt dome and apparently inactive (but potentially capable to move) salt dome requires extensive geologic study. Although it is well known that some salt domes in the Gulf coast basin have been stable for at least the past several million years (ONWI, 1981), the exact mechanism and reasons for cessation of salt movement has not yet been determined, and the true inactive salt domes are not verified.

Nettleton $(1934,1943,1947,1955)$ realized that the distinct gravity minima which are present over salt domes reflect the difference between the specific gravity of salt and that of the intruded strata. He concluded that the fluid-like flow under gravitational forces is the result of the salt's being lighter than the overlying rocks, and that the salt rises by buoyancy. Based on this conclusion every salt dome is expected to reach the ground surface, but in fact, this is not the case. It seems that in this conclusion, the friction forces around the salt dome have been neglected. Trusheim (1960) reports that in the German salt basin, the forces of buoyancy in the accumulated salt mass were not sufficient to cause a break-through. Gussow (1968) summarizes his discussion about salt diapirism by stating that the prime motivating force for all intrusion (including salt intrusion) is the weight differential of the overburden, or geostatic load, supplemented by the 
buoyancy effect caused by a density differential, which may be positive or negative (for salt, it is always positive). Heat is critical, but the driving energy is gravitational potential energy. Buoyancy becomes an effective force only when the height of the intrusion has increased greatly. Buoyancy is not a requirement for intrusion, but it has a modifying effect.

Some salt domes have a mushroom shape caused by the uplifting of the thick competent beds on top of the piercement dome, which causes side rooms to develop. Occupation of these side rooms by lateral movement of salt enlarges the top of the salt dome and makes a mushroom shape. This shape also may develop when the salt dome is exposed at the ground surface where the salt may flow laterally.

Rent (1958) reports that in some of the Iranian salt domes, the salt plug rises more than 600 meters above the valley floor and salt has flowed around pre-existing topography by simple gravity flow, forming a salt glacier. This remarkable phenomenon was first described by Lees (1927), who applied the term "salt glacier" to the occurrence.

To sum up, different types of salt domes with different shapes and sizes occur in different geologic environments. In reality, no two salt domes are alike. Description of a salt dome requires detailed knowledge of local geology and specific site conditions. All the above mentioned descriptions pertain to the salt dome itself, whereas the form of occurrence of salt domes also depends highly on the surrounding geology. The overburden rock formations may consist of different types of lithology and structures. The United States Gulf Coast stratigraphy is well known because of the numerous wells that have been drilled in conjunction with the intensive search for oil. The oldest sediments are continental, and are unconformably overlain by shallow marine clastic rocks, which grade upward into the evaporite sequence. The Louann salt, the most important of these units and the source of salt domes, grades upward into marine sediments characteristic of a shallow marine, deltaic, and fluvial sediments characteristic of transgressiveregressive sequences. Six of these sequences are recognized from the East Texas basin (Kreitler and others, 1980), and this is probably representative of the Gulf Coast Basin as a whole. Marl, clay, chalk, sand, shale and limestone of Cretaceous, Paleocene, and Eocene age with a total thickness of a few thousand meters occur in the sequence.

In contrast, the salt dome region in the northwestern Germany looks rather different. The "mother salt" formation of the German salt stocks is Permian in age (Trusheim, 1960). The cover of the salt formation is formed by Triassic beds consisting of thick clastic and 
carbonate sediments averaging about 1500 meters in total thickness, which are overlain by Jurassic, Cretaceous, and Tertiary rocks.

Salt in the Persian Gulf region is mainly of Infracambrian age. Stocklin, 1968, and James and Wynd (1965) report that the overlying rock sequence consists of sandstone, dolomite and limestone of Paleozoic age; dolomite, limestone and marl of Mesozoic age; and limestone, marl, shale and continental red beds and evaporite of Tertiary age. The total thickness of this rock sequence exceeds 10,000 meters. Ala (1974) reports that more than 200 piercement salt domes are present in southern Iran and in the Persian Gulf region. The domes are famous for their tongue-like projections, known as "salt glaciers", and for their associated igneous, metamorphic, and sedimentary exotic blocks.

These three examples suggest that the geology and structures in the surrounding beds of a salt dome can vary considerably, affecting geology and hydrology of the salt dome.

\subsubsection{Typical Stratigraphy and Lithology}

The salt mass in a salt dome is the result of movement and accumulation of bedded salt into a dome. Like any other sedimentary rock sequence, the typical bedded salt sequences consist of salt layers, thin or thick, pure or impure, white or colorful (reddish, pinkish, greenish, brownish, etc.) depending on the impurities present. Typically, they are also interbedded with other evaporite minerals such as anhydrite (see section 6.2.1). However, these layers lose their original stratification and bedding characteristics after migration to the dome area. In those salt domes which have attained heights of a few thousand meters, the original bedding is no longer apparent. Only different color bands, which are almost always intricately twisted and foliated, reflect the original bedding. In a swelling salt mass, before piercing begins, the original bedding in the accumulated salt materials may be recognizable, but irregularities, disorders and disturbances are so great that measurement regarding geometry of original bedding may be meaningless. Conversely, in a salt dome, we are facing a salt mass which has highly distorted stratification and bedding. Due to the high compressive forces in a salt dome, schistosity also may develop within the salt mass. Structure of salt in a few U. S. Gulf Coast domes has been discussed in detail by Rupfer (1962) and his further research concludes the spine concept of diapirism and occurrences of the boundary shear zones in salt stocks (Rupfer, 1973).

Lithology of the salt mass in the salt dome is rather simple. Throughout most of the salt mass halite is the major component. The halite 
is mainly white, medium hard, fine or coarse grained, highly crushed and intricately tectonized. Essentially no porosity exists in the salt mass of a salt dome. Anhydrite is the minor component in most salt masses, and usually is associated with inclusions of solids, liquids, and gases. These inclusions may be primary, that is deposited along with the salt, or they may be secondary and introduced during the piercement of salt (Rupfer 1979).

Primary inclusions include the more conventional clastic materials deposited as interbeds in the salt sequence, as well as solid materials brought into the basin by dust and sand storms, flash floods or turbidite flows. Primary brines of various compositions, and gases from organic decomposition could also be trapped in the highly impermeable salt. Secondary inclusions typically include the sediments of the external shear zone plastered on the side of the salt mass and later incorporated into it during salt movement. This would include not only clastic materials such as sand and shale, but organic matter and any liquids or gases that penetrated the salt through the shale sheath or cap rock, such as water, petroleum and natural gas (Rupfer 1979).

In some of the salt domes, salt is associated with small or large particles of the surrounding rock formations through which salt has pierced. Meyerhoff and Hatten (1968) report exotic blocks in two salt domes in central Cuba consisting of fragments of eugeosynclinal, median welt, and miogeosynclinal facies. The blocks, mostly dolomite and limestone, commonly range from fragments less than one centimeter in diameter to massive blocks more than 100 meters long.

Sappenfield and Schroeder (1968) report that one of the wells drilled on the Iza diapir structure in northern spain penetrated an interval block of Upper Cretaceous sandstone above Paleocene carbonate rock; the block apparently was incorporated into the diapir. The size of this block ranges between two and five hundred meters thick.

The most famous place for occurrence of the exotic blocks in a salt dome is the Persian Gulf basin. Stocklin (1968) reports that the majority of the salt domes contain highly contorted masses and innumerable blocks of various sedimentary and igneous rocks. They form, together with the salt and gypsum, a very characteristic rock assemblage, the "Hormuz Series" or "Hormuz Formation". Generally, the size of the exotic blocks ranges from a few centimeters to a few tens of meters. Locally much larger blocks have also been found. 


\subsubsection{Structure}

The piercement salt dome is usually in the form of a cylindrical mass of salt, roughly circular or elliptical in plan view, of relatively narrow diameter but often a few thousand meters in depth. Ala (1974) concludes that the circular or oval shapes of the salt domes require minimum energy expenditure to burst through the overlying sedimentary cover. This seems to be true as most (if not all) of the salt domes which pierce through a uniform undisturbed overburden have circular or oval shape, whereas, piercing through a tectonically disturbed rock sequence, salt will pierce along the fault planes or other structures and will take on a specific irregular shape. The top of the salt dome may be flat, mushroomed, tapered or irregular. As was explained in section 7.2.1.2, in a number of domes the upper portions of salt pillars bulge outward (mushroom) and are underlain by sediments. These overhangs may occur within a few thousand feet of the surface (ONWI, 1981).

One of the main features associated with salt domes is the cap rock. It consists of highly tectonized, compressed, and partly brecciated layers of anhydrite. The upper part of it may become hydrated by the influence of the groundwater and occur as gypsum. Cap rock is commonly brecciated or sheared and may contain fragments of adjacent strata, especially in the upper part (ONWI-109). Contreras and Castillon (1968) state that most large salt structures, as well as individual domes, have a cap rock composed mainly of anhydrite and smaller quantities of gypsum. Some domes, however, have no cap rock. Johnson and Gonzales (1978) have shown that in the Gulf Coast salt basin approximately 80 percent of the salt domes have cap rock.

Formation of the cap rock is a complex process and is not completely understood (Gussow, 1968). The most commonly accepted theories are: 1) residual accumulation and secondary alteration, and 2) precipitation in place. However, questions have been raised regarding the ability of these theories to account for observed variation in the cap rock and relationships to the surrounding environment.

Residual accumulation assumes that the cap rock was formed at the top of the salt dome sometime in the past as the salt was dissolved by ground water, leaving less soluble materials (mainly anhydrite) behind. Such anhydrite comprises a small percentage of the original salt mass and is generally believed to have been deposited with the salt from sea water when the salt beds were formed (ONWI, 1981, section 4.4.2). In support of this theory, Gussow (1968) discusses that: "in Iran salt masses are 2000-4000 feet above ground level; a 2000 foot thickness of salt with an anhydrite content of only 3 percent would result in a 
60-foot-thick residual anhydrite layer (or cap rock) after removal of the salt by solution" (Gussow, 1968, p. 49). In this theory a few questions remain unsolved. The anhydrite exposed to water and dissolution will hydrate and become gypsum, while the lower part of the cap rock almost always consists of anhydrite. The theory proposes that every salt dome having cap rock on top had been subject to dissolution. The available information from the Persian Gulf salt domes (Stocklin, 1968) does not confirm it. Walker (1974) opposing the concept, explains that great thicknesses of anhydrite cap rock means that a tremendous thickness of salt would have had to be dissolved in order to accumulate thick residues. Minerals not found in the salt's less soluble residue are contained in cap rock, and their presence cannot always be explained by secondary alteration. It is difficult to account for the large chemical differences between the salt anhydrite and cap rock anhydrite by the residual accumulation theory.

The second theory, precipitation-in-place, assumes that salt brine from deep saline aquifers rose along the salt dome stock and precipitated cap rock on top of the dome when the dome top came into contact with a fresh water aquifer (ONWI, 1981, section 4.4.2). This theory requires the occurrence of very special conditions which is hard to believe have occurred in 80 percent of the Gulf Coast salt domes.

ONWI (1981) also states that the cap rock represents material concentrated when more soluble material was removed. It appears all salt domes containing cap rock have undergone a considerable amount of dissolution in the past. Walker (1974) states that precipitation of anhydrite can result in a thick cap rock, but this process cannot account for the minor minerals included in the cap rock which are similar to those in the salt. Paulson (1977) observing field evidence suggests that some of the cap rock has been brought up along with the developing dome from evaporites originally beneath the salt bed in the evaporite basin. However, it is more likely that the anhydrite commonly found in beds overlying the salt may have been carried upward with the salt movement and formed part of the cap rock.

Besides cap rock on top, the piercing salt dome is surrounded by a gouge zone or shale sheath which consists of highly ground, brecciated, compressed and squeezed materials such as clay, marl, shale, and limestone. This shale sheath is produced by crushing and grinding of rock layers around the salt dome during piercing of the salt. Having a high percentage of clay materials, this gouge or shale sheath is usually impermeable, and normally a few meters thick. 


\subsubsection{Hydrology}

Essentially, a salt deposit has no porosity and a salt mass, accumulated and compressed in a salt dome, typically does not contain any water. However, salt is highly soluble and water penetrating the salt mass causes dissolution. In addition, some halite crystals may contain very small brine inclusions. Generally, any kind of water occurring in a salt dome will typically be saturated brine as it would be in equilibrium with the salt.

Dissolution is probably the most important aspect of hydrology in salt domes. For dissolution to occur it is necessary to have access of fresh or generally unsaturated water to the salt, and a means for accruing saturated brine to be transported away. Such circulating water could enter and exit through a path-way in the cap rock or shale sheath. Generally the cap rock and gouge or shale sheath consist of impermeable materials, and therefore they prevent penetration of water into the salt dome. However, occasionally post emplacement breakage or fracturing of the shale sheath and cap rock may provide avenues for water movement.

Recent investigation in the Gulf Coast region shows that the thickness of cap rocks ranges from a few meters to a few hundred meters. This few hundred meters of gypsum and anhydrite may have aquifer and water circulation in itself. The upper part of the cap rock typically is brecciated and disturbed.

\subsubsection{Resources}

The following minerals have been found in evaporitic basins and they also occur in the salt domes: sodium chloride (halite), sodium sulfate, calcium sulfate (anhydrite and gypsum), magnesium chloride, magnesium sulfate, potassium chloride, potassium sulfate, boracite, and chemical composites of iodine, boron and bromine. Normally, halite is the major component of a salt dome (up to 98 percent of the salt mass), and except potash which sometimes occurs in large, mineable amounts, the above-mentioned minerals occur in a very low percentage. No other types of minerals occur in a salt dome or are associated with salt deposition.

Oil and gas resources have been discovered around many salt domes, especially in the Gulf Coast region, although there are also many salt structures and salt domes in the world that have no petroleum occurrences. Evaporitic deposits are not oil bearing or oil generating materials, but when salt domes occur in a petroliferous province, they 
create favorable structures for oil and gas accumulation. The beds overlying a salt dome take on an anticlinal shape, known as salt-cored anticline, and brittle beds (e.g., carbonate rocks) may become highly fractured and shattered by extensional faulting. This is an ideal situation for the creation of an oil and gas reservoir. Around a salt dome, the rock layers are bent upwards by piercement of the salt. In such a situation, a porous formation such as sandstone becomes a good reservoir for oil and gas.

Another mineral occurring in association with salt domes is sulfur. Gussow (1968) states that many salt domes in the Gulf coast of the United states and Mexico have large deposits of elemental sulfur in association with the cap rock. It is notable that the world's largest producer of sulfur by the Frasch method is the Rustler Springs Mine in the evaporite sequence of the southern Permian Basin (Smith, 1978). Gussow (1968) mentions that Thode, and others $(1951,1953)$ pointed out that sulfur is present only in salt domes that are productive of oil and/or gas and is not present in salt domes that are barren. On the basis of sulfur isotope fractionation studies, Thode was able to prove that the sulfur and the associated limestone are both of biogenic origin and are the result of bacterial reduction of sulfates in the cap rock in the presence of hydrocarbons.

\subsubsection{INFORMATION NEEDS FOR PRECHARACTERIZATION STUDIES IN DOME SALT}

The occurrence and geology of salt domes, and design concepts for a repository in this medium allow a judgement of the types of information needed to evaluate whether characterization should be undertaken at a prospective site. Factors of concern for salt domes also are indicated from the results of previous and ongoing studies for isolation of radioactive materials in this medium. The following introductory paragraphs summarize the assumptions made in assessing information needs for prospective salt dome sites.

The general geologic setting of a prospective site may be assumed to be that of the Gulf Coast region. This is the main occurrence of salt domes in the continental United States (Pierce and Rich, 1962) and is the region being investigated by DOE for siting a repository in this medium (DOE, 1980). In the Gulf Coast region, salt domes penetrate generally flat-lying, moderately consolidated sedimentary rocks with fresh water at relatively shallow depths and saline water below depths of a few hundred feet. 
Following typical design concepts for a repository in a salt dome (e.g., Mattern and others, 1979; ONWI, 1981), the representative site geometry is shown in Figure 7.2.2-1. The repository levels are assumed to be at depths of 1500 to 3000 feet below the surface.

The approach and scope of the DOE evaluations of Gulf Coast salt domes have been reviewed for this analysis. These are considered instructive because they indicate the factors considered important by the consultants to DOE and the efficacy of the exploration and testing methods used. Main issues that have been emphasized in the DOE program have included (Durham, 1979):

- Available space in the salt dome

- Tectonic stability

- Lithology of materials surrounding the salt

- Groundwater transport time from the salt dome to the biosphere.

- Mineral resources

- Movements of the salt dome.

- Effects of flooding

These factors are generally expected to be important in the precharacterization level of work, and will be discussed in the following pages.

\subsubsection{Geology}

The general category of geology includes information needs relating to the nature and rate of past and present geologic processes and to the geometry and lithology of the prospective host rock and the surrounding materials. For a prospective salt dome site these include:

- Nature and rate of processes

- Quaternary climate history

- Quaternary history of surface hydrology

- History and rates of erosion and deposition

- Histories and rates of dissolution and salt tectonics 


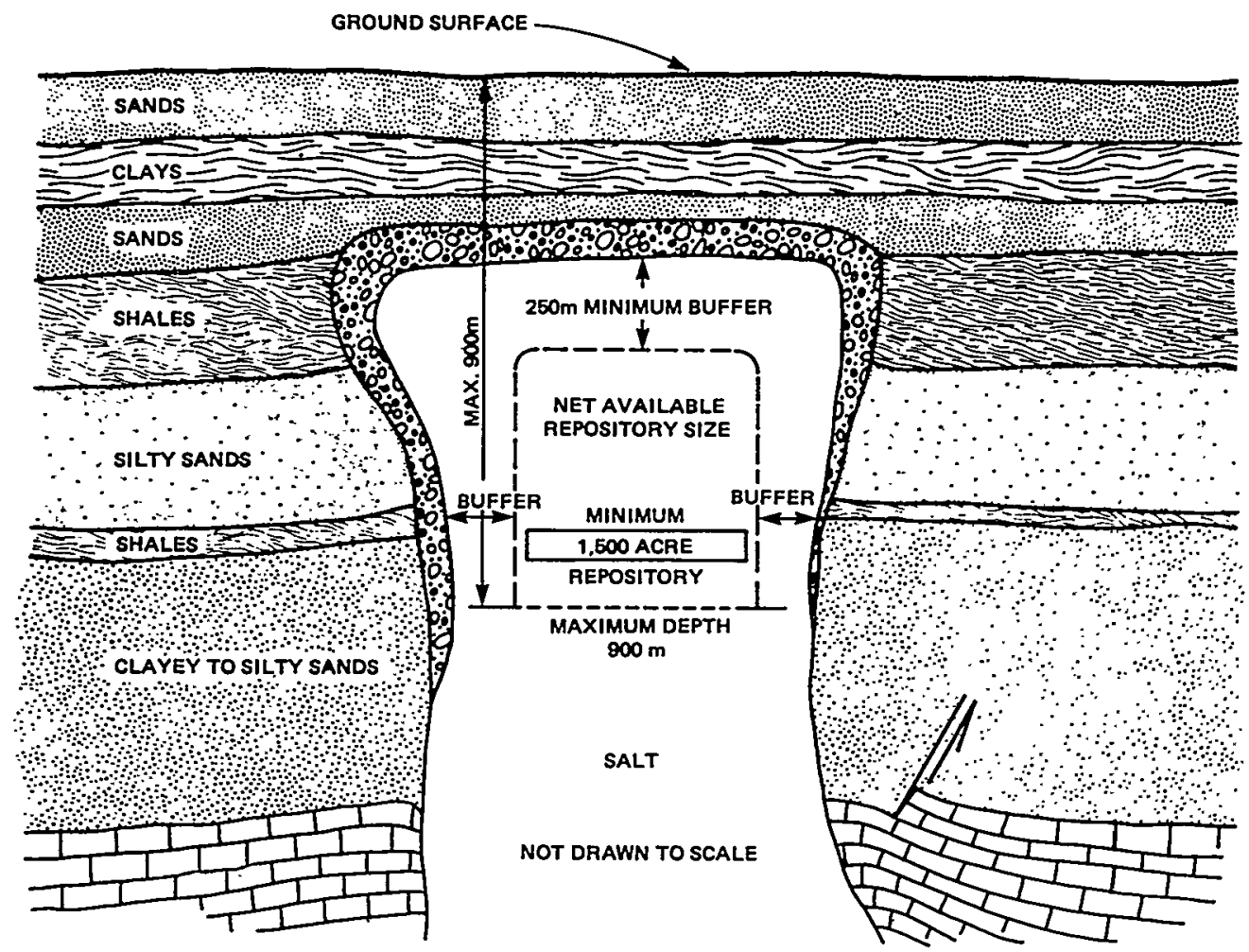

FIGURE 7.2.2-1 CONCEPTUAL SITE GEOMETRY

(FROM ONWI-109, 1981) 

surrounding the salt dome

- Geometry and lithology of the salt dome

$\begin{array}{ll}\circ & \text { Salt mass } \\ \circ & \text { Cap rock } \\ \circ & \text { Shale sheath } \\ \circ & \text { Exotic blocks }\end{array}$

As at any prospective repository site, it is important to determine the history of climate changes and surface hydrologic conditions during Quaternary time, as are expressed by the geomorphology and surface geology. The geology of the beds overlying the host rock typically is important for determining feasibility of shaft construction. However, for a prospective salt dome site, geomorphology and geology of beds above and surrounding the salt are particularly important for evaluating movement history of the dome and history of dissolution. The hydrologic setting of a salt dome also is determined to a large extent by the geology of the overlying and surrounding rocks.

Of special interest is geometry and lithologic characteristics of the salt dome. Information needs include exact geometric shape and size of the salt dome, from top of the dome to at least 900 meters below the ground surface. Referring to Figure 7.2.2-1, a minimum space for the repository and a minimum distance between the edge of the salt dome and the repository are required. Also, a minimum vertical distance between the uppermost level of repository and the cap rock must exist. The geometric studies should result in preparation of accurate subsurface geologic maps, so that geologic cross sections oriented in different directions through the salt dome can be drawn and a three dimensional model of the salt dome can be prepared. This investigation should result in determination of whether or not the salt dome under investigation will provide sufficient space for the repository.

Study of the cap rock is one of the most critical problems. Because a cap rock is the only barrier to dissolution of the upper surface of the dome, having geologic information about the size, extension, thickness, composition and integrity of the cap rock is important. Subsurface geologic mapping should develop this information in detail. Ideal cap rock condition should consist of impermeable materials and generally be free of fracturing. Lithology and petrology of the cap 
rock is also of special interest. Typically, the cap rock consists of materials such as anhydrite, gypsum, marl, clay, and shale. In the event of water penetration, anhydrite absorbs water and swells. This swelling closes the joints and fractures which may occur in the cap rock. Clay particles in marl, shale and claystone also swell by water penetration, and exhibit varying degrees of plasticity. Information needs to investigate cap rock should consider all these items.

As mentioned above, a salt dome is normally surrounded by a shale sheath. Investigation of this shale sheath presents some unique problems and having accurate information concerning thickness, extension, deformation and lithology of this shale sheath is of utmost importance. The shale sheath and cap rock contribute to integrity of the salt dome by isolating it from circulating water in the surrounding formations. Because of their importance, these features should be evaluated to the extent practical prior to site characterization. However, because direct information regarding the shale sheath and cap rock is difficult to obtain from surface-based exploration, detailed information may be obtained chiefly during site characterization.

The chief suitability of dome salt for a HLW repository is that accumulation of halite creates a homogeneous isotropic mass of medium-hard rocks. However, exotic blocks may occur in a salt mass and range from a few centimeters to a few tens of meters in size. Occasionally much larger blocks have also been reported. A salt mass with exotic blocks is no longer homogeneous or isotropic. These exotic blocks may also affect the geomechanical and thermal properties of a salt dome. Therefore, as a part of the information need, investigation of the salt dome should comprise determination of location, size, and geologic characteristics of exotic blocks which may exist in the salt dome. Construction of a repository in an active salt dome may face specific problems. Salt moving under high hydrostatic pressure may disrupt repository facilities and promote radionuclide migration. Information needs should include sufficient evidence to determine salt dome activity.

It also would be desirable to make a preliminary evaluation of internal structures and lithologic variations of the salt in the salt dome, although detailed characterization would be needed to determine these with confidence. Lithologic variations, exotic blocks, and structural features, such as relict bedding, may be detected in boreholes through the salt but the complex structure of a salt dome would preclude extrapolating such features over significant distances.

Geologic information needs to be obtained to a depth below the proposed repository level that would be adequate for (1) determining relationship of the salt dome to the surrounding water-bearing strata, 
evaluating movement history of the salt dome, and (3) evaluating resource potential. As the salt domes typically continue downward for several thousands of feet, there appears to be no need to investigate formations underlying the salt. Basement rocks are usually well below the zone of interest.

\subsubsection{Hydrology}

Information needs regarding hydrology for a prospective salt dome site include:

- Climate

- Surface hydrology

- Hydrology of beds overlying and surrounding the salt

- Hydrologic conditions in the cap rock

- Fluids and flowpaths within the salt

- Dissolution history and potential.

Aside from the specific concerns with cap rock hydrology and dissolution, these information needs are essentially similar to those in other media. Particular information needs for an individual site would depend on the water-bearing units present in the surrounding and overlying rocks.

Information on climate is needed for hydrologic analyses because it bears on surface hydrology, which in turn may affect ground water conditions. Climate information is also an important parameters for defining erosional processes. Climate information for hydrologic studies typically is obtained from meteorological records and observations. In order to provide an adequate basis for extrapolation over the performance period of a repository, additional information on past climates is obtained from the geologic record. Such information will allow projections of future climatic activity.

Information on surface hydrology is needed as it relates to ground water hydrology and to flooding potential at a prospective site. Surface hydrology data will also contribute to characterizing the erosional processes. For salt domes, information on surface-water quality and flow may contribute to analyses of salt dissolution. Specific information on surface hydrology includes rainfall-runoff 
relationships, flood potentials, possible effects of impoundment failures, stream flow data, and surface-water quality.

Hydrostratigraphy of beds above and surrounding the salt dome must be determined, including identification of water-bearing zones and characterization of the hydrologic properties of aquifers and confining zones. Aquifer properties and flow parameters to be determined for each water-bearing zone include:

- Locations and mechanisms of recharge and discharge.

- Piezometric heads and gradients.

- Porosity, permeability, and related aquifer properties.

- Direction and velocity of flow.

- Residence time, or age of ground water, at different places along the flow paths.

These parameters form a basis for identifying pathways to the accessible environment and for determining travel times for fluids moving in the hydrologic system.

Hydrologic conditions in the cap rock are a particular concern for salt domes. Although the caprock typically protects the upper part of the salt from circulating water, fracturing or voids in the cap rock may allow water to circulate in this zone. If water is present in the cap rock, it would be important to determine its circulation properties and relation to possible flow paths in the salt and the aquifers in the surrounding and overlying strata. Also, water content, porosity, permeability, aquifer, and solubility of the cap rock must be considered.

Salt in domes typically is dry and does not contain hydrologic flow paths. However, it would be important to evaluate any applicable data obtained in the precharacterization studies to identify possible dissolution features. The repository should be located so that subsurface salt dissolution does not have an impact on system performance. To investigate this case, existing salt solution features in the salt dome and the possibility of further dissolution in future must be carefully evaluated. A dissolved area in the salt mass is normally filled with brine and is known as a brine pocket. A detailed investigation should be carried out in order to delineate brine pockets or other dissolved areas within the salt dome. This investigation should be concentrated mainly in the areas immediately below the cap rock 
and near the surrounding shale sheath, where most likely brine pockets may occur. Any fluid inclusions of salt mass within the salt dome should also be investigated. This investigation may help to locate possible water flow-paths in the salt dome (if any).

Of special interest is the hydrologic condition of the shale sheath. As mentioned above, a salt dome normally is surrounded by a layer of gouge which consists of brecciated shale, marl, clay and limestone (the major components of the surrounding rock formations). Normally this gouge or shale sheath is impermeable and thick enough (a few meters) to inhibit penetration of the ground water into the salt mass. However, it is possible that under special circumstances this sheath may have been damaged, destroyed and removed. In such a case, circulating ground water around the dome may penetrate inside, dissolve portions of the salt mass or produce brine pockets. Rnowledge of the actual hydrologic conditions of this sheath is needed. Therefore, a very detailed and careful hydrologic study should be carried out in collaboration with aqueous geochemical studies. The purpose of the study would be to check continuity and impermeability of the gouge by looking for any evidence that chemical assemblages of the salt mass may occur in the aquifers and circulating ground water in the geologic formations around the salt dome. The extent of the study area for this purpose would depend on local geological and hydrological conditions.

Future changes in the ground water flow system around the salt dome is also a particular concern for salt domes. As at any prospective repository site, there is potential for future changes in the flow system around the site and these changes may adversely affect the cap rock or shale sheath conditions. This investigation also includes a detailed study concerning future potential climatic changes based on the reflection of the changes and conditions in past climates.

\subsubsection{Geochemistry}

Information needs in geochemistry include geochemical dating of rocks and water, and geochemical characterization of the various rocks and water (surface and subsurface) in the geologic setting of the prospective repository area. The geochemical dating is done in support of and would be coordinated with the related geologic and hydrologic work.

Water-chemistry information needs include determining $\mathrm{pH}, \mathrm{Eh}$, and mineral content of the waters from various sources at and near the prospective site. These analyses would be coordinated with the work in hydrology and would aid understanding of the hydrologic system. Similarly, information on the hydrologic system would guide the chemical sampling and testing program. 
Information needs regarding rock geochemistry include mineralogy, organic content, alteration, and retardation properties of the various rock types present. For a prospective site in a salt dome, these factors should be determined for the cap rock, shale sheath and salt mass. Because of the general homogeniety of dome salt, preliminary geochemical descriptions would be applicable at the precharacterization stage. Similarly, geochemical evaluations of the shale sheath and cap rock would be needed in precharacterization but possibly in more detail because of greater variability in lithology. Additional detailed studies would be needed at the characterization stage of the program.

For geochemical studies, the following items are of special concern:

1 - Brine pockets - After discovery of a brine pocket, precise information is needed on its characteristics, age, integrity, and relationship to surrounding host rock. Geochemistry will complement hydrology in this respect.

2 - Geochemical properties of the salt mass - A detailed chemical analysis of the salt mass in the salt dome is needed to investigate the nature of the impurities within the salt and determine the different types of the chemical assemblages which may exist in the salt mass. This investigation should help correlate chemical properties of the salt inside the salt dome with the chemical properties of groundwater around the salt dome.

3 - Geochemical properties of the ground water around the salt domeAs mentioned above, this information is needed for correlation of geochemical properties of the salt mass (inside the salt dome) with the ground water around the dome. Ground water chemistry may indicate dissolution of the salt mass, cap rock, shale sheath, and alteration of rock formations around the salt dome. Similarly, investigation of the geochemical properties of water occurring in the cap rock is important. This investigation should result in clarifying whether the water within the cap rock is in equilibrium.

\subsubsection{Geomechanics}

Information needs in geomechanics include mechanical and thermal properties of the prospective host rocks under in situ conditions. It also is necessary to determine preliminary geomechanical parameters significant for excavating shafts through the overlying materials.

Specific factors to be determined for the salt and the host rocks include: classification, rock quality, strength, deformation moduli, 
plasticity, specific heat, thermal conductivity, coefficient of thermal expansion, and potential for thermal alteration.

For salt domes, creep behavior of the salt is a particular concern as it may cause problems in maintaining stability of underground openings for the required retrieval periods. For the precharacterization stage of work, dome salt may be considered essentially homogeneous and results of testing may be applied to preliminary engineering analyses. Although lithologic variations and structural discontinuities may be present, detailed subsurface exploration would be needed to determine their distribution.

\subsubsection{Seismotectonics}

As for prospective sites in other media, information regarding tectonics and seismicity should be well established before commencing site characterization.

The prospective repository site shall be located so that ground motion associated with maximum credible earthquake will not have unacceptable impact on system performance. The principal issues are the ability of the repository to withstand tectonic events with little effect on repository integrity.

The main occurrence of salt domes in the United States is in the Gulf Coast region, an area of low historic seismicity and notable tectonic stability. In this region, regional sedimentation ceased during the Tertiary and it is generally accepted that cessation of regional sediment deposition eliminated a motivating force for domal growth and contributed to regional stability. Stabilization of individual domes can be confirmed where appropriate Quaternary deposits exist over the domes. In such cases, lack of deformation would suggest lack of subsequent movement. Studies of Quaternary deposits over the Gulf Coast domes have so far indicated no deformation related to further dome growth. Nevertheless, precise and reliable information is needed to define and monitor seismicity and tectonic activity on a regional scale, as well as individual salt domes.

Faults in the Gulf coast region typically are related to intrusion of the salt domes and to differential consolidation of the thick sequences of sedimentary rocks (e.g., "growth faults"). Although these faults generally are aseismic, they would require evaluation where they may influence a prospective site. 


\subsubsection{Resources}

Studies prior to characterization at a prospective site should establish the history of exploration and resource development, and the presence, or apparent presence, of geologic resources. The resources typically found in association with salt domes are chemicals composed of sodium, potassium, and magnesium occurring as sulfate, chloride, nitrate, borate, iodate, bromide, carbonate and bicarbonate. No other type of mineral resources so far are known in a salt mass. Hydrocarbons are the most important resource associated with the salt domes and typically are found in traps formed by the upturned beds surrounding the dome or in anticlines over the salt domes. Sulfur may occur in the cap rock as an alteration of anhydrite. Evaluation of these potential resource occurrences may require additional geologic studies beyond those for the repository itself. Requirements for evaluation and investigation of these economic resources include types of resources, origin, types of occurrence, economic value and exploitation potential.

\subsubsection{TECHNIQUE APPLICATIONS TO PRECHARACTERIZATION INFORMATION} NEEDS IN DOME SALT

The information needed to determine whether characterization should be undertaken at a prospective salt dome repository site can be addressed using the techniques of exploration and testing described in the accompanying appendices. For this discussion, the techniques are grouped according to the types of information obtained: geology, hydrology, geochemistry, geomechanics, seismotectonics, and resources.

However, in practice there is significant interchange between groups because the information obtained in each group commonly is applicable to the needs of the others. General applications of techniques to the main groups of information needs are summarized in Table 7.2.3-1

Applications of techniques are considered at three stages of exploration: (1) no drilling at the prospective site, (2) results of previous drilling available for the site, and (3). drilling performed at the site specifically for this work. The types of information available at each of these stages has been assumed for this discussion, based on typical characteristics of a prospective site in a salt dome.

In the first case, where no drilling has been done at the site, information is available from surface techniques only. In this context, "drilling" is assumed to involve penetrations to about the level of the repository in salt and does not include shallow drilling or trenching. 
TABLE 7.2.3-1 SUMMARY OF TECHNIOUE APPLICATIONS IN DOME SALT

\begin{tabular}{|c|c|c|c|c|}
\hline \multirow{2}{*}{\multicolumn{2}{|c|}{ TECHNIQUE }} & STAGE 1 & STAGE 2 & STAGE 3 \\
\hline & & $\begin{array}{l}\text { NO ORILLING SURFACE } \\
\text { EXPLORATION ONLY }\end{array}$ & EXISTING DRILLING & NEW DRILLING \\
\hline \multirow{2}{*}{ REMOTE SENSING } & SATELLITE & G H S r & G H S r & G H S r \\
\hline & AIRCRAFT & G H S r & G H S r & G H S r \\
\hline \multirow{3}{*}{ SURFACE MAPPING } & LANDFORAS & G H S r & G H S R & G H $\mathbf{S}$ \\
\hline & LITHOLOGYJMATERIALS & $G H \subset m R$ & G $H \subset m s R$ & G $H \subset m s R$ \\
\hline & PROCESSESISTRUCTURE & G H S R & G $H S R$ & G H S R \\
\hline \multirow{4}{*}{$\begin{array}{l}\text { GEOPHYSICAL } \\
\text { LOGGING }\end{array}$} & ELECTRICAL & & g H & G H \\
\hline & RADIOACTIVE & & gr & G H R \\
\hline & MECHANICAL & & $\mathbf{g}$ & $\mathbf{G}$ \\
\hline & ACOUSTICAL & & $\mathbf{g}$ & G $M$ \\
\hline \multirow{6}{*}{$\begin{array}{l}\text { GEOPHYSICAL } \\
\text { EXPLORATION }\end{array}$} & GRAVITY ' & $\mathbf{G S}$ & $\mathbf{G} \mathbf{S}$ & $\mathbf{G} \mathbf{S}$ \\
\hline & AUDIO-MAGNETOTELLURICS & $\mathbf{g} \mathbf{h}$ & g h & g h \\
\hline & SEISMIC REFRACTION & gh & g h & $\mathrm{gh}$ \\
\hline & RESISTIVITY & G $\mathrm{H}$ & G $\mathrm{H}$ & GH \\
\hline & MAGNETICS & $9 \mathrm{Sr}$ & g S r & g S r \\
\hline & SEISMIC REFLECTION & G 5 R & G $5 \mathbf{R}$ & G s $R$ \\
\hline \multirow{4}{*}{$\begin{array}{l}\text { GEOMECHANICS/ } \\
\text { THERMOMECHANICS }\end{array}$} & ROCK MATERIALLAG TESTS & G $H \subset M$ & $\underline{G} \underline{\mathbf{H}} \underline{\mathrm{C}} \mathrm{M} \mathrm{S}$ & $\underline{\mathrm{G}} \underline{\underline{\underline{H}}} \underline{\underline{\mathrm{C}}} \stackrel{\mathrm{M}}{\mathrm{S}} \mathrm{R}$ \\
\hline & ROCK FIELD OBSERVATIONS & $G H C M s r$ & G $H C M S r$ & $\underline{G} \underline{H} \mathrm{C} M S R$ \\
\hline & DESIGN LAB TESTS & & m & $M$ \\
\hline & DESIGN IN SITU TESTS & & & $M$ \\
\hline \multirow{5}{*}{ GEOCHEMICAL } & $\begin{array}{l}\text { GAAPHICALL } \\
\text { STATISTIC ANALYSES }\end{array}$ & & & \\
\hline & SAMPLING AND ANALYSES & g $H C R$ & g H C R & g H C R \\
\hline & VIATER-ROCK MODELING & & h $c$ & H C \\
\hline & STABLE ISOTOPE MODELING & & h c & H C \\
\hline & GROUNDWATER AGE DATING & h $\mathrm{C}$ & hc & H C \\
\hline \multirow{6}{*}{ HYOROLOGY } & FLOOD FREQUENCY & H & H & $\mathrm{H}$ \\
\hline & RECHARGE/DISCHARGE & $\mathrm{H}$ & H & $\mathrm{H}$ \\
\hline & SURFACE WATER CHEMISTRY & H C $\mathrm{R}$ & H C R & H C R \\
\hline & NUMERICAL MOOELING & $\mathbf{h}$ & $\mathbf{h}$ & h \\
\hline & AQUIFER TESTS & & H C m & $H C M$ \\
\hline & TRACER TESTS & & H & $\mathrm{H}$ \\
\hline \multirow{6}{*}{$\begin{array}{l}\text { SEISMICITYI } \\
\text { TECTONICS }\end{array}$} & $\begin{array}{l}\text { HISTORICAL } \\
\text { EARTHUUAKE ANALYSIS }\end{array}$ & g S & g $s$ & g S \\
\hline & $\begin{array}{l}\text { INSTRUMENTAL } \\
\text { EARTHOUAKE ANALYSIS }\end{array}$ & g S & g S & gS \\
\hline & MONITORING NETWORKS & g $\mathbf{S}$ & g S & $9 s$ \\
\hline & VELOCITY STUDIES & 95 & g S & $9 S$ \\
\hline & FAULT STUDIES & $\mathbf{G} \mathbf{S}$ & $\mathbf{G} \mathbf{S}$ & $\mathbf{G} \mathbf{S}$ \\
\hline & $\begin{array}{l}\text { ATTENUATION AND } \\
\text { GROUND MOTION } \\
\end{array}$ & gs & $9 \mathrm{~s}$ & g S \\
\hline \multicolumn{2}{|c|}{ DRILLING/LOGGING } & & & $G H C M R$ \\
\hline
\end{tabular}

EXPLANATION

CLASSES OF INFORMATION NEEDS

G = GEOLOGY
H = HYOROLOGY
C = GEOCHEMISTRY
$M=$ GEOMECHANICS/THERMOMECHANICS
S = SEISMICITY/TECTONICS
R $=$ RESOURCES

NOTES:

1. CAPITAL LETTERS INDICATE MOST APPLICABLE TECHNIQUES.

LOWER CASE LETIERS INDICATE LESS APPLICABILYY. DOUBLE UNDERLINE INDICATES ENHANCEMENT BY NEW DRILLING DATA.

2. LETTERS INDICATE INFORMATION NEED CLASSES WHOSE TECHNIQUES OBTAIN DATA THROUGH STAGES OF INVESTIGATION. LETTERS INDICATE BETWEEN TECHNIOUE RESOLUTION AEUABILTTY AND OTHER EVALUATION FACTORS ARE DISCUSSED IN TEXT. 
Previous drilling at salt domes typically would have been for hydrocarbon or mineral exploration. Drillers' or geologists' logs are likely to be available for either type of well, but may be considered proprietary by exploration companies. Core samples are unlikely to be available because of proprietary considerations. The most valuable information from the pre-existing boreholes typically will be the borehole geophysical logs. Based on typical industry practice, it is assumed that self potential, resistivity, natural gamma (gross count gamma ray) and acoustic logs would be available. Mud logs may be available from hydrocarbon exploration wells. It is considered unlikely that the pre-existing boreholes would be in suitable condition for running new logs or for hydrologic testing or monitoring. Well plug records may also be of value.

In drilling specifically for the exploration program, coring, sampling, and logging would be designed to best obtain the desired information. These would include detailed core loging, availability of core for testing, and using selected borehole geophysical logs.

\subsubsection{Geology}

\subsection{No Drilling at a Site}

Salt domes that are likely to be considered for repository sites are generally not exposed at the surface and, if they are, the exposed salt is unlikely to be representative of conditions at depth. As a result, arilling is needed to obtain direct information on the prospective host rock in a salt dome. However, some techniques can be used without drilling to obtain significant information about the site.

The information needs relating to geomorphology, Quaternary geology, paleoclimate, history of erosion and deposition, and similar topics can be addressed before drilling is undertaken at a site. These typically utilize techniques in remote sensing and surface mapping (Appendix $A$ ), supplemented by shallow drilling and trenching as available. As discussed previously, these information needs are unrelated to the medium involved but instead are determined by other geologic conditions at a prospective site. Resolution and reliability of these geologic observations and the resulting interpretations also would depend on site conditions, particularly on the amount of information available and the complexity of the geologic record.

Lateral extent of the suitable host rock in a salt dome commonly would be controlled by the dimensions of the dome. These typically are determined best by seismic reflection profiling, supplemented by gravity and specialized seismic refraction surveys (Appendix $B$ ). 
However, these techniques are unlikely to detect internal structures in the salt body. The shallow-penetration, high-resolution seismic reflection methods that would be best to define boundaries in the upper part of a salt dome also would provide significant information on the stratigraphy and structure of the surrounding and overlying beds. In the Gulf Coast region, beds in the shallow subsurface commonly extend over large areas and their general properties may be well known from previous work in off-site locations.

\subsection{Previous Drilling}

Results of previous drilling at a site in a salt dome can be very useful for evaluations of stratigraphy, lithology, and geologic structure of the rocks penetrated. Borehole geophysical logs that may be available can be very useful for interpreting stratigraphy and 1ithology in sedimentary rocks and for recognizing distinctions between the various evaporite minerals, such as the contact between the anhydrite in the cap rock and the halite in the salt body. Moreover, borehole geophysical logs can determine depth to the top of salt or other interfaces within less than a foot and provide important calibrations for interpretation of seismic reflection data or other geophysical surveys. Applications of the available geophysical logs are discussed in Appendix C.

\subsection{New Drilling}

New drilling at a prospective site would allow detailed core logging and selection of the most suitable borehole geophysical logging techniques. The combined effect of these techniques is to greatly increase the resolution and reliability of the stratigraphic, lithologic, and structural information. Although the borehole geophysical logs can be interpreted with considerable confidence, direct observation of the core is valuable to confirm lithology and to analyze structural features. Detailed core logging can detect features on the order of 0.01 foot or less. However, although features of this scale may be important in the salt at the prospective repository level, they could not be extrapolated beyond the borehole with any confidence because of the complex structure typically in a salt dome.

Mud logging and selected geophysical logs run in the new boreholes can be used to provide data for zones that are not cored and to aid or supplement the core logging. These logs can be particularly useful for confirming depths of the core return. In addition to the basic logs available for the pre-existing holes, special logs that may be useful include spectral gamma, density, porosity, and acoustic logs to aid 
Iithology determinations. Silicon and carbon activation logs can be used to identify argillaceous zones in the salt or caprock and organic layers, respectively. State-of-the-art tools such as borehole radar and borehole gravity also may be used to aid identification of structural features, brine pockets, and other anomalies. The Ultra Long Spacing Electrical Log is a specialized tool that can be useful in detecting the boundary of a salt dome at some distance from the borehole (Appendix $\mathrm{C}-1$ ) .

Resolution and reliability of standard borehole geophysical tools is well established, as discussed in Appendix $c-1$. The radar, gravity, and Ultra Long Spacing tools have received less use and attention and consequently their performance characteristics are not as well known. However, the main consideration regarding reliability of borehole data for a prospective site in a salt dome is the uncertainty in extrapolating features beyond the borehole. As has been emphasized in these discussions, the internal structure of a salt dome is very complex and typically cannot be resolved by geophysical techniques. Beds immediately surrounding a salt dome also are likely to be folded, faulted, and tilted from the effects of the salt intrusion. As a result, interpretations of borehole data can be significantly less reliable than the results obtained from logging at each hole.

All these techniques should help to understand more about geometry of salt dome, conditions of cap rock and shale sheath, and existence of exotic blocks. Regarding geometry of salt dome, high resolution geophysical seismic reflection and gravity methods will provide information within the limit of needed accuracy. The high contrast between the wave-velocity in salt and in the hard rock formation around a salt dome makes seismic reflection method a reliable and applicable method to determine geometry of a salt dome. Similarly, the big difference in specific gravity between salt and surrounding rock formation makes geophysical gravity surveys a reliable and applicable method. Uncertainties may range from a few meters to about 100 meters depending on the distances between detectors and depth of interest.

Borehole logging methods claim to detect geometry of a salt dome from the surrounding borehole, but the reliability and resolution of these methods are not considered high.

The cap rock condition should be investigated by EX or NX drilling with special attention to the information needs for cap rock. Except for the shape and thickness of cap rock that may be detected by high resolution seismic reflection methods, other characteristics of cap rock should be investigated by drilling. Although the safety of cap rock necessitates minimum penetration, drilling into the cap rock is 
inevitable. Drill logs and continuous core will provide information on the physical and chemical characteristics of cap rock.

There is no direct way to measure thickness and lithology of the shale sheath around a salt dome except by drilling and coring. Geophysical methods are not able to define these measurements accurately. The integrity and safety of a repository highly depends on shale sheath conditions. Drilling through a shale sheath may affect the impermeability of the shale sheath. Hydrology and geochemistry studies may be able to indicate current shale sheath permeability conditions.

If the presence of exotic blocks is suspected, directional drillholes may be designed in order to penetrate these blocks. Once penetrated, additional drilling incorporated with some of the borehole logging methods could be used to define exact shape, size and lithology of the block. Applicability and reliability of directional drilling for discovering exotic blocks in salt dome are considered high. Resolution depends on the number of directional drillholes and spacing or angle of drilling.

\subsubsection{Hydrology}

\subsection{No Drilling at a Site}

Hydrologic techniques that may be used at a site with no drilling are limited to those involving climate, surface hydrology, and hydrology of ground water at shallow depths, well above the salt. These techniques are independent of the prospective host medium and would be applied at any site as described in Appendix G-1. Resolution and reliability of these techniques also are independent of the host medium and depend on local conditions and on factors such as the length and quality of climate and stream-flow records.

Some information on the hydrology in beds above and surrounding a salt dome may be obtained before drilling at a site by using extrapolations from off-site investigations. However, such data would be of questionable reliability.

\subsection{Previous Drilling}

Previous drilling at a prospective repository site in a dome is unlikely to include water wells to the depths of concern and the holes are unlikely to be suitable for hydrologic testing or monitoring at or near the repository level. As a result, the main benefits to the hydrologic studies from the previous drilling would be that hydro- 
stratigraphy could be defined with much greater reliability, using techniques discussed in section 7.2.3.1.2.

An additional benefit is that saline plumes may be identified in electric logs of wells adjacent to the salt dome, thereby providing information on possible hydrologic connections between the salt and surrounding aquifers.

\subsection{New Drilling}

New drilling at a prospective repository site in a salt dome would allow application of the techniques for hydrologic testing described in Appendix G-1. Drilling new boreholes under controlled conditions would allow water samples to be obtained, aquifer tests to be performed, and wells to be completed for monitoring water levels at selected zones. Particular concerns for this work in a salt dome include hydrology of the cap rock and the relationships of the salt to water-bearing units in the surrounding sediments. Water contents, porosity, permeability, aquifers and circulating water in the cap rock, as well as solubility of the cap rock must be investigated. Aquifer tests, ground water age dating, tracer test and chemical laboratory tests on cap rock cores should be performed in order to determine hydrological conditions of the cap rock. Applicability, resolution and reliability of these techniques are highly dependent on the local geologic conditions. Without drilling into cap rock, little information about hydrological conditions of the cap rock would be attainable. A drilling program for geologic investigation of cap rock should also include hydrologic and geochemical investigations of cap rock.

Hydrological investigations of the shale sheath around the salt dome is one of the most critical problems. The investigation should indicate whether or not the shale sheath is impermeable and will protect the salt mass from dissolution. In this regard, little information will be available during the first stage (no drilling). During the second stage, limited information may be obtained depending on the existing drill pattern and the depth of the existing boreholes. The main information will be obtained during the third stage. For the safety of the repository, drilling through the shale sheath is not recommended. Instead, hydrology and chemical analysis of the ground water around the salt dome should be used to determine if any flow-paths exist in the shale sheath. All aquifers around the salt dome to a certain depth below the lowest level of the repository should be investigated. The flow direction, chemical property of water, and the age of water in each aquifer should be determined. Parallel to these studies, detailed chemical properties of salt in the dome, especially its associated chemicals such as potassium, magnesium, iodine, bromine and boron is 
needed. A comparison between mineral assemblages of ground water around the dome and mineral assemblages of salt within the dome may indicate dissolution of salt through a flow-path in shale sheath.

Hydrologic investigations of brine pockets in the salt mass are also an important task. The size of pockets may vary considerably and may be randomly located within the dome. However, previous studies have indicated brine pockets. tend to concentrate near the cap rock and sheath areas. Hydrological techniques will provide important parameters to determine flow-paths, brine equilibrium, and age.

Uncertainties that have been recognized in preliminary hydrologic investigations of prospective salt dome sites have included the relationship of cap rock to permeable beds surrounding the dome (Smith, 1977) and mechanisms for transport of water into the interior of a salt body (Martinez and Thoms, 1977). Resolving these uncertainties requires continued detailed hydrologic and geologic investigations.

Dissolution is a particular concern in bedded and dome salt and may be evaluated using techniques of hydrologic analysis combined with interpretations of dissolution history and rates based on geologic techniques. The geologic techniques contributing information regarding dissolution include remote sensing analyses and surface mapping to recognize surface expressions of dissolution as well as drilling and geophysical exploration to identify the subsurface zones where dissolution has occurred. One of the techniques used for evaluating dissolution in salt domes has been identification of saline plumes in the surrounding aquifers (Hoda and Barlow, 1977). However, analyses of these data requires detailed information on dynamics of the hydrologic system in order to determine whether the saline ground water represents recent or ancient dissolution. Other approaches have employed detailed petrologic studies of the cap rock (Martinez and Rovik, 1977).

\subsubsection{Geochemistry}

\subsection{No Drilling at a site}

Before drilling is done at a site, techniques available in geochemistry are limited to testing of surface-water quality and isotope dating of surface samples, supporting the hydrologic and geologic efforts, respectively. At this stage of investigation, geochemical conditions directly relevant to a prospective repository may only be inferred from information on lithology and stratigraphy. 


\subsection{Previous Drilling}

Borehole geophysical logs that are available from previous drilling can provide preliminary information on geochemical properties of the salt, overburden and surrounding area. However, because previous drilling may not have been sufficiently controlled for a waste isolation project, the results may be of uncertain reliability and typically would have coarse resolution.

\subsection{New Drilling}

New drilling at the prospective salt dome would allow collection of water and rock samples for testing with the laboratory techniques described in Appendix $\mathrm{F}-1$. Use of selected borehole geophysical logs under controlled conditions also would allow more reliable interpretations of geochemical conditions. This testing and analysis should provide the information needed to evaluate specific dome conditions to the extent required for precharacterization. Among these conditions are brine pockets, salt and the ground water system around the salt dome.

As mentioned previously, investigation of the brine pockets essentially is a hydrological problem, however geochemistry contributes significant information to the study. The same contribution applies also to the ground water study in cap rock and in the geologic formations around the dome. In both cases, hydrology should be accompanied by geochemistry.

Reliability of the information obtained at this stage would be controlled by the reliability with which distribution of geologic materials can be quantified in the environment of a salt dome. In particular, distributions of geologic materials in the cap rock and the salt body are likely. to be complex and difficult to quantify in detail. It may be similarly difficult to evaluate fluids in the cap rock and to determine their chemical equilibrium with the associated lithologic units. Resolution of these questions is likely to require detailed exploration and testing in the site characterization stage of the work. 


\subsubsection{Geomechanics}

\subsection{No Drilling at a Site}

For a prospective site in a salt dome, drilling is needed to obtain information on mechanical and thermal properties of the host rock. Geomechanical information that may be obtained at such a site without drilling would be limited to general interpretations of tectonic stresses and interpretations based on lithology.

\subsection{Previous Drilling}

Data from previous boreholes at a site may provide preliminary information on geomechanical properties of the salt, cap rock, and the overlying beds. This information at best would be limited to geologic descriptions of the materials present, allowing interpretations of their geomechanical properties. In addition, extrapolations from the borehole locations to the prospective repository site may be questionable because the distributions of lithology and structure in the caprock and salt may be difficult to predict.

\subsection{New Drilling}

New drilling at a prospective site would allow direct determination of geomechanical parameters by use of the testing techniques described in Appendix E-1. Detailed core logging in new boreholes and use of selected borehole geophysical logs also would allow more reliable interpretations of lithology and structure. In general, testing would determine parameters including: strength, elastic moduli, specific heat, coefficients of thermal conductivity and expansion, and potential for thermal alteration. Plasticity of the salt-would be a particular concern as it would determine long-term stability of underground openings. However, it is expected that testing in precharacterization would provide preliminary data only and that plastic behavior of the salt would be evaluated in detail during the site characterization program.

There are significant differences between the geomechanical properties of halite and those of the other minerals that may occur as inclusions or impurities in the salt. Cap rock materials may have similar variations. Typical values are summarized in Table 7.2.3-2 However, it is unlikely that compositional variations in the salt could be defined in detail at the precharacterization stage of the program and, in general, the material in the salt body is almost entirely halite. In view of these factors, results of preliminary geomechanical

$$
7-35
$$


testing may reasonably be applied for engineering analyses at the precharacterization stage with the understanding that variations in detail may be determined during the later characterization.

\subsubsection{Seismotectonics}

The general information needs in seismicity and tectonics are resolved in programs that are independent of the prospective host medium at a site and of the degree to which the host medium has been explored by drilling. The techniques that are used in this work are described in Appendix $\mathrm{H}$ and would be supplemented by geologic studies to evaluate faulting and tectonic movements. History and rates of salt tectonics would be evaluated by these geologic techniques, as has been done in previous studies for DOE (e.g., Kumar 1977; Guevara and Giles, 1979).

A specific problem that is of concern is reactivation of an apparently inactive salt dome through tectonic movement. As mentioned before, such a movement could endanger long-term stability of underground openings. Geologic studies and tectonic framework of the region should indicate the potential of such movement.

Interpretations of tectonics and seismicity depend on information from a variety of geologic, geophysical, and seismologic techniques. As a result, their reliability and resolution cannot be quantified on a generic basis. However, tectonic conditions in the region of the main occurrence of salt domes in the United States are notably stable and generally appear to be well within an acceptable range for a prospective repository.

\subsubsection{Resources}

\subsection{No Drilling at a Site}

Information on resources at a prospective site in a salt dome may be obtained from exploration and development history of the surrounding vicinity before drilling is commenced at the site. In particular, hydrocarbon resources may be evaluated by identification of potential production zones from existing information in the surrounding area and recognizing possible traps from analyses of seismic reflection data. The reliability of these analyses would depend on the availability of data in the surrounding vicinity. 
TABLE $7 \cdot 2 \cdot 3-2$

MECHANICAL AND THERMAL PROPERTIES OF TYPICAL MATERIALS ASSOCIATED WITH DOME SALT

\begin{tabular}{|c|c|c|c|c|c|c|c|}
\hline & $\begin{array}{l}\text { Density } \\
\left(\mathrm{gm} / \mathrm{cm}^{3}\right)\end{array}$ & $\begin{array}{l}\text { Young 's } \\
\text { Modulus } \\
\text { (E - in } \\
\text { Megabars) }\end{array}$ & $\begin{array}{l}\text { Poisson's } \\
\text { Ratio }\end{array}$ & $\begin{array}{l}\text { Compressive } \\
\text { Strength }\end{array}$ & $\begin{array}{l}\text { Thermal } \\
\text { Expansion }\end{array}$ & $\begin{array}{l}\text { Thermal } \\
\text { Conductivity } \\
10^{-3} \mathrm{Cal} / \mathrm{Sp} \\
\mathrm{cm} \sec ^{\circ} \mathrm{C}\end{array}$ & $\begin{array}{r}\text { Specific } \\
\text { Heat }\end{array}$ \\
\hline Halite & $2.16^{1}$ & $\begin{array}{r}.28-.37^{3} \\
.19^{2}\end{array}$ & $.20-.21^{3}$ & $270^{4}-255$ bars & $2.29^{5}$ & $\begin{array}{c}12.8-17.2^{6} \\
\text { (Single crystals) } \\
7.5-16.7^{6}\end{array}$ & 5) 1240 \\
\hline Anhydrite & 2.91 & $.72-.74^{3}$ & .2953 & $140-6370$ bars $^{4}$ & & $12.9-13.4^{6}$ & 2600 \\
\hline Gypsum & 2.311 & & & & $.58^{5 a}$ & & \\
\hline $\begin{array}{l}\text { Limestone } \\
\text { (Calcite) }\end{array}$ & $2.4-2.7^{3}$ & $.17-71^{3}$ & $.18-.27^{3}$ & $390-5100$ bars $^{4}$ & $2.9^{5}$ & $4.7-80^{6}$ & 2220 \\
\hline Dolomite & $2.83-2.87^{3}$ & $.63-69^{3}$ & $.16-27^{3}$ & $600-8300$ bars 4 & & $7.9-13.2^{6}$ & $40807 a$ \\
\hline Carnalite & $1.60^{1}$ & & & & & & \\
\hline Sylvite & $1.98^{1}$ & & & & $1.94^{5}$ & $11.8-16.6^{6}$ & 1260 \\
\hline Kainite & $2.10^{1}$ & & & & & & \\
\hline
\end{tabular}


TABLE 7.2.3-2 (continued)

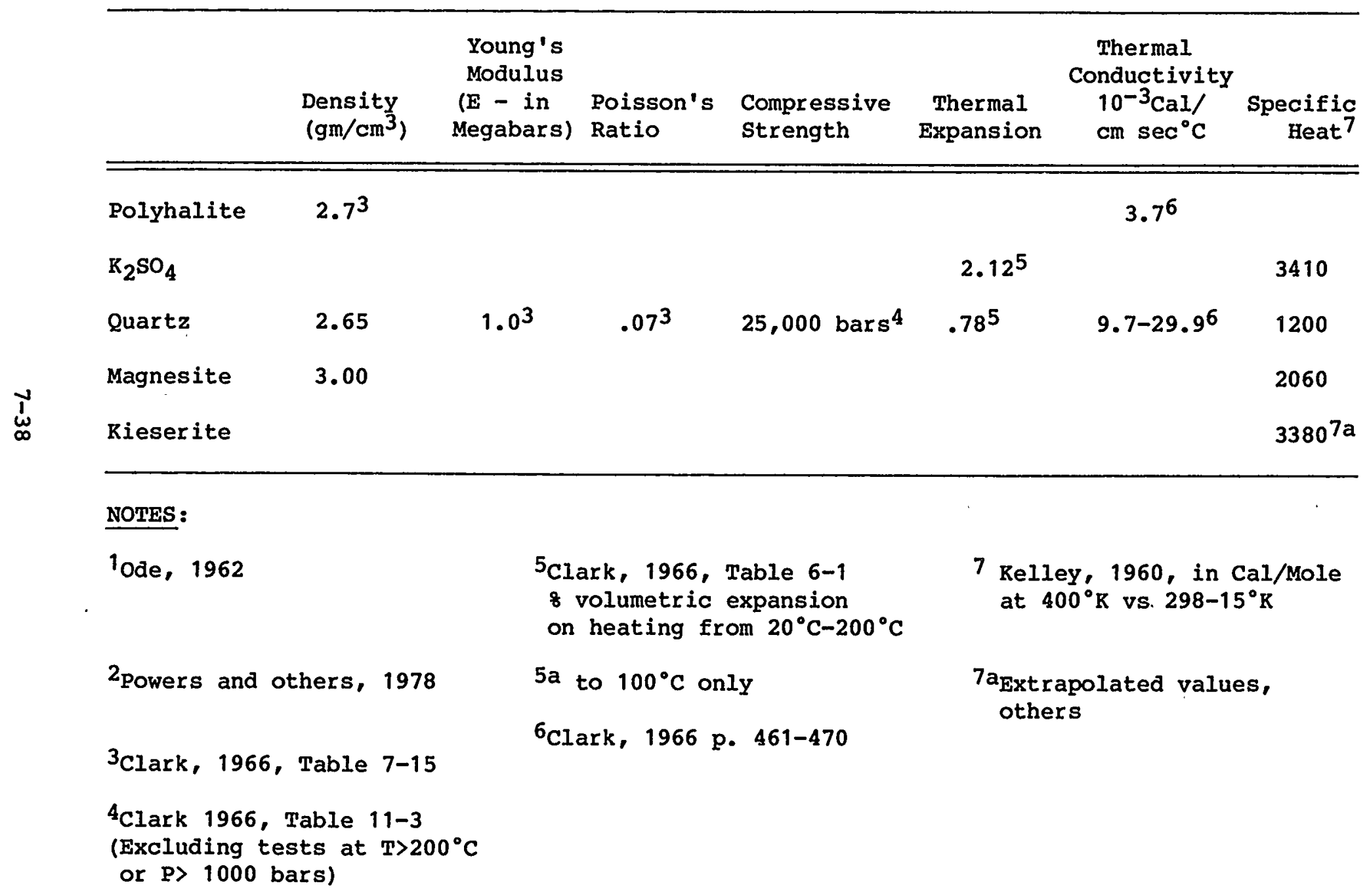




\subsection{Previous Drilling}

Previous drilling at a salt dome likely would have been exploration for hydrocarbon or mineral resources and thus would provide additional information on resources. Previous hydrocarbon exploration could be particularly useful as it would be likely to provide information at depths where the hydrocarbons may be found. Previous drilling in the salt or in the cap rock for potash or sulfur also could provide significant lithologic information that would aid evaluation of these resources.

\subsection{New Drilling}

New drilling at a site would provide reliable, relatively detailed information on lithology and structure, contributing to resource evaluations. In the event that particular concerns regarding resources are identified, additional boreholes may be planned to address them specifically. At this stage of exploration, the standard geologic and geochemical techniques for resource evaluation may be employed to resolve any resource issues to an adequate level of confidence.

\subsubsection{COST AND TIME ESTIMATES FOR PRECHARACTERIZATION TECENIQUES}

Cost and time estimates for the techniques that would be used in investigation of a prospective site in dome salt are summarized in the accompanying Tables (7.2.4-1 to 7.2.4-7). Many of these techniques are essentially similar to those used in other media and for other types of studies and, as a result, cost and time estimates also will not vary. However, specific problems concerning salt domes may affect and vary cost and time of some techniques. In general, the higher range of costs would be appropriate for program with higher resolution and accuracy requirements.

The following discussion is directed toward cost and time of each technique, and those specific problems related to salt domes will respectively be discussed.

\subsubsection{Remote Sensing and Mapping}

Costs and times for typical remote sensing and surface mapping techniques are summarized in Table 7.2.4-1. The cost of surface mapping in regard to the dome salt may become higher, as a high resolution in Quaternary mapping is expected, especially for mapping faults related

$$
\text { 7-39 }
$$


TABLE $7.2 .4-1$

COST AND TIME SUMMARY FOR

REMOTE SENSING AND MAPPING

Acquiring Imagery or Photography

LANDSAT

Enhancement

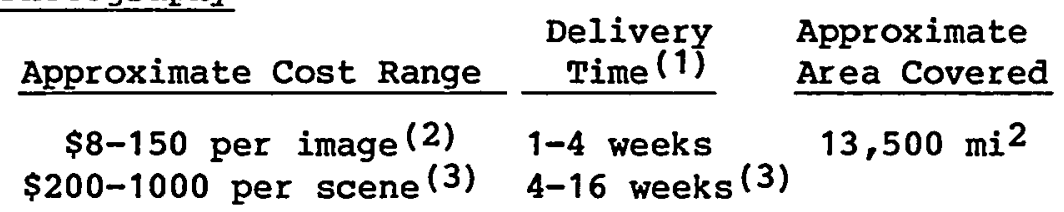

SRYLAB

Multispectral

\$8-150 per image (2) 1-4 weeks

$2,000 \mathrm{mi}^{2}$

Earth Terrain

$\$ 8-150$ per image $(2) \quad 1-4$ weeks

$4,600 \mathrm{mi}^{2}$

Stereo Aerial Photography

$\begin{array}{lrlr}\text { Purchase existing } & \$ 3-60 \text { per frame (2) } & 1-4 \text { weeks } & 3-80 \mathrm{mi}^{2} \\ \text { New flight } & \$ 25-40 \text { per frame (4) } & 2-6 \text { weeks } & \end{array}$

Low Sun Angle Photography

Purchase existing

New flight

$\$ 3-60$ per frame (2) 1-4 weeks

$3-12 \mathrm{mi}^{2}$

Radar Imagery

$\begin{array}{llll}\text { Purchase existing } & \$ 125 \text { per strip } & 1-3 \text { weeks } & 100-2500 \mathrm{mi}^{2} \\ \text { New flight } & & 3-10 \text { weeks } & \text { Per survey }\end{array}$

\$25-75 per frame (4) 2-6 weeks

design

\section{Interpreting Imagery or Photography}

\begin{tabular}{|c|c|c|c|}
\hline & Cost & Time (5) & Comments \\
\hline $\begin{array}{l}\text { Satellite Imagery } \\
\text { (generally @ } 1: 250,000)\end{array}$ & $\$ 1050-1750$ & 3-5 days & per scene \\
\hline \multicolumn{4}{|l|}{$\begin{array}{l}\text { Aerial photography }(8) \\
\text { e } 1: 62,500\end{array}$} \\
\hline $\begin{array}{l}\text { Land forms } \\
\text { Lithology } \\
\text { Geologic structure }\end{array}$ & $\begin{array}{r}\$ 70-175 \\
\$ 70-175 \\
\$ 175-280\end{array}$ & $\begin{array}{l}1 / 4-1 / 2 \text { days } \\
1 / 4-1 / 2 \text { days } \\
1 / 2-1 \text { day }\end{array}$ & $\begin{array}{ll}\text { For } & 100 \\
\mathrm{mi}^{2} & \text { area }\end{array}$ \\
\hline \multicolumn{4}{|l|}{$\begin{array}{l}\text { Aerial photography }(8) \\
\text { e } 1: 24,000\end{array}$} \\
\hline $\begin{array}{l}\text { Land forms } \\
\text { Lithology } \\
\text { Geologic structure }\end{array}$ & $\begin{array}{l}\$ 175-350 \\
\$ 175-350 \\
\$ 280-700\end{array}$ & $\begin{array}{l}1 / 2-1 \text { day } \\
1 / 2-1 \text { day } \\
3 / 4-2 \text { days }\end{array}$ & $\begin{array}{ll}\text { For } & 100 \\
\mathrm{mi}^{2} & \text { area }\end{array}$ \\
\hline Radar Imagery & (9) & (9) & \\
\hline
\end{tabular}


TABLE 7.2.4-1 (cont.)

Field Mapping (6)

Reconnaissance
$1: 62,500$ scale
$1: 24,000$ scale

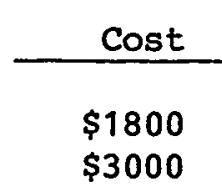

Relatively complete mapping

$$
1: 62,500 \text { scale }
$$$$
1: 24,000 \text { scale }
$$

$\$ 3000$

$\$ 4200$

$\$ 6600$

\begin{tabular}{rll} 
Time $(5)$ & & Comments \\
\cline { 3 - 3 } 3 days & & $\begin{array}{l}\text { For } 100 \\
\mathrm{mi}^{2} \text { area }\end{array}$ \\
& & \\
7 days & & For 100 \\
11 days & & $\mathrm{mi}^{2}$ area
\end{tabular}

NOTES

(1) Delivery times generally do not depend on quantity ordered.

(2) Cost of photos or imagery is determined by size of print ordered, whether in color or black and white, and extra charges for shorter delivery time.

(3) Cost and delivery time for enhancements depends on source and on availability of previous processing for scene desired.

(4) Flight costs in addition to costs of photo reproduction indicated above.

(5) Approximate man-days to complete work; delivery time may be longer. Time required for interpretations can depend on complexity of geologic conditions at a site.

(6) Cost and time estimates assume interpretation of imagery and photography completed previously. Actual times and costs in an area would be influenced by access, trafficability, and complexity.

(7) Obtaining radar imagery from a new flight costs several thousand dollars. Actual costs depend on mobilization (radar equipment is not widely available), altitude requirements, and other flight parameters.

(8) Estimated times and costs are applicable to all $9^{n} \times 9^{n}$ stereo aerial photographs: black and white, color and infrared (both black and white and color).

(9) Time and cost for interpreting radar imagery depends on resolution and scale of the imagery, purpose of the interpretation, and other factors. See Appendix A for discussion.

$$
\text { 7-41 }
$$


to the salt movement. Also local ground surface conditions for mapping which may affect transportation, mobilization, accommodation, etc., should also be considered. All these factors may raise the cost and increase the time.

\subsubsection{Drilling and Coring}

Costs and times for typical drilling and coring techniques in salt are summarized in table 7.2.4-2. It consists of the following items: petroleum, mining, and water well drilling and coring.

The salt section must be cored with salt saturated mud systems and good solids removal equipment must be employed. Directional drilling will cost higher and require more time.

\subsubsection{Borehole Geophysical Logging}

Costs and times for typical geophysical borehole logging techniques are summarized in table 7.2.4-3. These methods will be used in exploring a salt dome and the local geologic and geographic conditions will determine the most useful method to be used.

Table 7.2.4-3 provides only the costs and times involved in field operation and obtaining the geophysical data. Interpretation of the results and processing of the field data, by whatever method or instrument, will cost extra money and time.

\subsubsection{Geophysical Exploration}

Costs and times for typical geophysical exploration techniques used in salt dome exploration are summarized in Table 7.2.4-4. Depending on local geologic conditions, including burial depth of the salt dome, distances between sounding locations and recording stations will change and consequently the total cost is highly related to the local condition.

Table 7.2.4-4 provides only the costs and times involved in field operation and obtaining the geophysical data. Interpretation of the results and processing of the field data, by whatever means, methods and instrument, will cost extra money and some time which have to be considered. 
TABLE $7 \cdot 2 \cdot 4-2$

COST AND TIME SUMMARY

DRILLING \& CORING (1)

\begin{tabular}{|c|c|c|c|c|}
\hline \multirow[b]{2}{*}{$\begin{array}{l}\text { Type } \\
\text { Equipment }\end{array}$} & \multicolumn{2}{|c|}{ Drilling } & \multicolumn{2}{|c|}{ Coring } \\
\hline & $\begin{array}{l}\text { Cost }(2) \\
\text { (per foot) }\end{array}$ & $\begin{array}{l}\text { Production } \\
\text { Rate } \\
\text { (feet per day) }\end{array}$ & $\begin{array}{l}\text { Cost }(2) \\
\text { (per foot) }\end{array}$ & $\begin{array}{l}\text { Production } \\
\text { Rate } \\
\text { (feet per day) }\end{array}$ \\
\hline Petroleum & $\$ 32$ & 500 & $\$ 135$ & 120 \\
\hline Mining & $\$ 60$ & 200 & $\$ 150$ & 80 \\
\hline Water Well & $\$ 40$ & 200 & $\$ 135$ & 60 \\
\hline
\end{tabular}

Notes :

(1) Adapted from Appendix D

(2) Includes personnel, supplies, mud, and all other support equipment. 
TABLE $7.2 .4-3$

COST AND TIME ESTIMATES FOR

BOREHOLE GEOPHYSICAL LOGGING

Techniques

Approximate

Cost Range

Time (3)

Typical Log Package (1)

Borehole Caliper

Focused Resistivity

Single-point Resistivity

Spontaneous Potential

Gross-count Gamma Ray

Density

Neutron Porosity

Deviation
$\$ 1300$

to

$\$ 6500(2)$

$1 / 2$ day

Add approximately

one hour per sonde

Specialized logs requiring separate mobilization: (not practical for single hole)

Radar Log

$\$ 6000(6)$

$1 / 2$ day

Gravity Log

$\$ 4000(6)$

1/2 day 
TABLE 7.2.4-3 (cont.) - NOTES

(1) Assumes:

a. Single 1000-foot hole

b. 400 miles (round trip) travel charge to well site

c. Holes ready to log upon arrival (i.e. no standby time)

d. Logging speed of 50 feet per minute

e. Non-logging (entering hole) at 60 feet per minute

f. Log package combined on two sondes

(2) Low cost for minerals logging contractor; high end cost for oilfield logging contractor. Cost per hole would be reduced if travel charge can be applied to additional holes.

(3) Approximate time on site, not including travel.

(4) Assumed to be added to package described in note (1)

(5) Actual costs will depend on services desired, available combinations in single sondes, and minimum charges imposed by some contractors. Ranges are as in note (2) above.

(6) Estimated cost for single 1000-foot hole logged as part of larger program. Includes interpretation. 


\subsubsection{Geomechanics}

Costs and times for typical geomechanical techniques are summarized in Table 7.2.4-5.

\subsubsection{Geochemistry}

Costs and times for typical geochemical techniques are summarized in Appendix $\mathrm{F}-1$.

\subsubsection{Hydrology}

Costs and times for typical hydrological techniques used in salt dome studies are summarized in Table 7.2.4-6. Depending on the local geologic condition and the burial depth of the salt dome, costs may rise and the time may increase proportionally.

\subsubsection{Seismotectonics}

Costs and times estimates for typical seismological techniques used for seismological monitoring and analyses are summarized in Table 7.2.4-7 Monitoring ground motions resulting from salt movement is a principal task in these studies.

\subsubsection{CRITERIA FOR EVALUATING DATA ADEQUACY OF PRECHARACTERIZATION STUDIES IN DOME SALT}

The previously discussed information on geology of dome salt (Section 7.2.1), information needs (Section 7.2.2), and applications of techniques (Section 7.2.3) can be used to develop general criteria or guidelines for evaluating the information on exploration and testing likely to be presented in a site Characterization Report for a prospective repository site in dome salt. Such a report would include results of the previous exploration and testing used to select the site (precharacterization) and descriptions of the planned exploration effort for site characterization. The discussions in this chapter emphasize guidelines for evaluating the adequacy of precharacterization study. Evaluation of the work performed for site characterization will be addressed in Section 7.3. Following the organization of the preceeding chapters, these criteria are grouped according to disciplines: geology, hydrology, geochemistry, geomechanics, seismotectonics, and resources. 
TABLE 7.2.4-4

COST AND TIME SUMMARY FOR

GEOPHYSICAI EXPLORATION TECHNIQUES

Technique

Gravity

Audio-Magnetotelluric

Seismic Refraction

Resistivity Profile

Resistivity Sounding

Airborne Magnetic

Ground Magnetic

Seismic reflection

-Typical survey

-High resolution
Approximate Cost (1)

$\$ 60-75$ per

station (2)

$\$ 900$ per station

$\$ 3,000-15,000$

per mile (3)

$\$ 1000$ per station (4)

$\$ 2500$ per

$\$ 20$ per mile plus mobilization cost (see Appendix B-5)

(7)

$\$ 4,000$ per line mile ${ }^{(8)}$

per crew ${ }^{(8)}$

$\$ 10,000$ per line mile(8)
Field rate at 100 line miles

per month

2 to 4 stations per hour

2 stations per crew per day

(3)

3 stations per crew per day in field (5)

2 soundings per crew per day in field(5)

2 to 6 week delivery (depending on equipment availability)

(7)

Field rate of

40 line miles

per month

per crew ${ }^{(8)}$ 
TABLE 7.2.4-4 - NOTES

(1) All estimates assume average to good access, terrain, and weather conditions. Costs and times for all ground-based techniques will be higher in areas of rugged terrain or otherwise difficult access or trafficability.

(2) For 100 to 200 station survey under good field conditions (see Figure 4 in Appendix B-1). Widely spaced stations require increased travel times, affecting costs and production rates. Costs for surveys requiring helicopter access could be on the order of $\$ 250$ per station.

(3) Cost and production rate determined by (1) spacing between geophones, (2) number of shots recorded in each layout, and (3) shot size. Single large shots may require several days of preparation, while small surveys may be completed in a few hours. See Appendix B-3 for discussion.

(4) Based on typical survey consisting of six profiles, each $1 \mathrm{~km}$ long. See Table $4 \mathrm{~A}$ in Appendix B-4.

(5) See Table 5 in Appendix B-4 for estimates of times for additional related activities.

(6) Based on typical soundings with five separate measurements and maximum 300-meter pole separation. See Table 4B in Appendix $\mathrm{B}-4$.

(7) When run along with gravity survey, ground magnetic measurements may be done at additional cost of ábout $\$ 400$ per day, representing one man and magnetometer rental. Survey would cover area at approximately same rate as the gravity survey (discussed above) although measurements may be taken at more stations.

(8) Based on typical land-based crew working on medium-term contract, using dynamite source, 96-trace, 1-millisecond, 12-fold sampling and 50-meter detector spacing. Assumes no adverse conditions of access or trafficability. Data processing adds $\$ 200$ to $\$ 300$ per mile for typical survey and $\$ 800$ to $\$ 1200$ per mile for highresolution. Specialized processing would incur additional costs. See Appendix B-6 for discussion. 
COST AND TIME SUMMARY FOR

GEOMECHANICAL TECHNIQUES

Technique

Regional Stress State

Unconfined Compressive strength

Description of discontinuities

Rock Quality

Designation

Porosity/Density (3)

Water Content (3)

Absorption (3)

Swelling and slake Durability

Sonic Velocity

Uniaxial Compressive stress

Permeability (6)

Triaxial Compressive Strength

Thermal conductivity

Borehole Modulus

In Situ Stress State
Approximate

Cost Range

$\$ 4,440$

(estimate)

$\$ 25-300$

$\$ 14,400$

(estimate)

(2)

$\$ 50$

$\$ 10$

$\$ 50$

$\$ 350-1,250$

$\$ 50-500(4)$

$$
\$ 250(5)
$$

$\$ 1000-1,500$

$\$ 2,000-10,000(7)$

$\$ 1,000-2,000(8)$

$\$ 10,000-15,000(9)$
Approximate

Turn-Arounà Time (1)

Comments

$$
\begin{array}{cc}
3 \text { wks } & \text { per region - } \\
\text { (estimate) } & \begin{array}{l}
\text { based on liter- } \\
\text { ature review }
\end{array}
\end{array}
$$

5 minutes(11) per test

1 man month

per site

(estimate)

(2)

2 weeks

per test

2 weeks

per test

2 weeks

per test

2 weeks

per test

3 weeks

per test

3-6 weeks

per test

3 weeks

per test

3-6 weeks

per test

8 weeks

per test

1 week (10)

per test
$\$ 40,000-\$ 60,000(9)$
$\$ 50,000-\$ 70,000(9)$
overcoring
5 hours (10)
per test
hydrofracture
1-10 days $(10)$
per test 
TABLE 7.2.4-5 (cont.) - NOTES

(1) Turn-around time for delivery of laboratory results, unless otherwise stated.

(2) Done by well-site geologist in conjnction with normal core logging at no measurable increase in cost or change in drilling rate.

(3) These routine tests may be applicable to rocks associated with bedded salt although not directly applicable to the salt itself.

(4) Higher costs are for tests at elevated temperature and pressure.

(5) Includes measurement of deformation, can obtain strength data only for less than $\$ 50$.

(6) Requires use of special testing fluid to avoid dissolution of salt.

(7) Test program would be designed to meet project needs. Further cost increases would result from requirements for additional measurements or testing at elevated temperature or pressure.

(8) Higher cost for tests at elevated pressure.

(9) Excluding drilling costs.

(10) Actual working time on test.

(11) Field tests using portable point load apparatus or Schmidt Hammer. See page 8 and 9, Appendix E-1. 
TABLE $7.2 .4-6$

COST AND TIME SUMMARY FOR

HYDROLOGY TECHNIQUES

Technique

Surface Hydrology

Singular Flood Frequency

Regional Flood Frequency

Rainfal1-Runoff

100-year flood plain

Flooding from dam failure

Discharge measurements

Field surveys of

recharge/discharge

Surface-water sampling

Borehole Testing (5)

Head measurement

a. Manual

b. Winch

c. Recorder

Drill stem test

Pump test

Injection test (10)

Straddle packer test $(10)$

Tracer tests

Permeability Tests

on core samples

Numerical Modeling
Approximate

Approximate Turn-Around

Cost Range
Comments
1-2 days

2 weeks

2-5 days

2 weeks

4-7 days

1 hour (2)

(3)

(4)

$\$ 50-75$
(1)

(1)

(1)

(1)

(2)

per square

mile (3)

per square mile(4)
(8)

(9)

to $\$ 25,000(11) \quad 2 \mathrm{hr}-7$ days per test to $\$ 25,000(11) 2 \mathrm{hr}-7$ days per test $\$ 200$ or more $(12)$ (12)

$\begin{array}{lll}\$ 250-1000(13) & 3 \text { weeks }(13) & \text { per test } \\ \$ 400-4000(14) & 1-10 \text { days }(14) & \text { per model }\end{array}$

7-51 
TABLE 7.2.4-6 (cont.) - NOTES

(1) Cost and time for specific analysis, after compiling basic field data.

(2) Cost and time for single field measurement, using simple plywood wier, portable flume, or existing structure. Does not include travel to measurement site.

(3) Assumes 2-man field party working at rate of 10 to 15 square miles per day. Actual costs and rates of progress would vary with field conditions.

(4) Assumes 2-man field party working at rate of 25 to 50 square miles per day, including cost of expendible sampling equipment. Costs for typical water-quality tests are in Table 1 of Appendix G.

(5) Not including drilling or completion costs. See Appendix D.

(6) Manual measurement using tape or probe to about $750^{\prime}$ depth - not including travel to well site.

(7) Measurement at greater depth, requiring winch to handle probe not including travel to well site.

(8) Cost and time requirements for testing vary according to depth, duration of test, and size or type of drilling equipment used. See Appendix G.

(9) Pump test costs depend on equipment in place of a well and duration of the test. Can be done for about $\$ 200$ at existing water-supply well with pump in place. Cost can be thousands of dollars for complex testing systems requiring installation of pump, power supply, and equipment for monitoring water levels.

(10) Must use specially designed test fluid to avoid dissolution.

(11) Cost and time estimate for high-technology testing in tight formation at repository depths. Includes mobilization of specialized equipment and preliminary analyses of results.

(12) For long-duration tests, as may be needed in formations with low permeability, costs are likely to be determined by need for continued monitoring, involving pumping or bailing to detect tracer in deep aquifer. Such tests could cost several thousand dollars.

(13) Does not include cost or time for obtaining core.

(14) Cost and time for numerical analyses only, after basic field and lab data are compiled. 
TABLE $7.2 .4-7$

COST AND TIME SUMMARY FOR SEISMOTECTONIC TECHNIQUES

Technique

Aproximate

Cost Range

Time

Comments

Historical Data

$\$ 2,900-5,900$

2 weeks

per basic analysis

Instrumental Data

$\$ 5,800-8,800$

1-2 months

per basic analysis

Fixed Network

Installation

$\$ 8,000-10,000$

12-28 weeks

per station

Operation

$\$ 7,300-14,600$

$--$

cost per station/year

Portable Network

$\$ 3,250-5,700$

2 days

cost per

(to install)

station/month

Crustal Refraction

$\$ 2,000-5,400$

1-4 weeks

per station 


\subsubsection{Geology}

The minimum information required to adequately characterize a dome salt medium for a waste repository site, and the most generally applicable techniques for gathering these data are presented below.

- Ground surface erosional and depositional processes - remote sensing, surface mapping

- Lithology, stratigraphy and structure of overburden - drilling and geophysical logging, seismic reflection

- Geometry of the salt dome - seismic reflection, drilling and logging, geophysical gravity survey

- Cap rock conditions - drilling and logging, geochemical sampling and lab tests, ground water age dating, tracer test

- Depth to cap rock - seismic reflection, electrical resistivity, drilling and coring

- Exotic blocks survey - directional drilling and coring, geochemical lab tests

As in any medium, surface geology and geologic processes around and above the salt dome should be well understood. Information on Quaternary paleoclimates is needed for analyses of the geologic processes. The investigations should encompass the salt dome and the surrounding areas. For a prospective salt dome site, Quaternary tectonics and surface expression of the recent movement of the salt dome are of special concern.

Accurate determination of the salt dome conditions regarding geometry, depth to cap rock, cap rock lithology and structure, and exotic blocks within the salt dome, are strongly dependent on the accuracy of the data obtained from the applicable exploration techniques. Criteria for evaluating these techniques will also depend on the site conditions. In general, the validity of results from these techniques is determined by the quality of geologic information obtained.

The specific problems related to salt may occur during drilling in dome salt. The possibility of using air drilling in salt may have to be considered. Also, for investigation of the exotic blocks directional drilling may be required. Coring in directional drilling within the salt dome needs special attention. Geophysical logging operations for determination of the salt dome geometry also needs special attention. 


\subsubsection{Hydrology}

The necessary data and applicable techniques to adequately characterize the needs of hydrology should include the following:

- Surface hydrology - flood frequency, geochemistry, surface mapping

- Brine pockets condition - drilling and logging, borehole logging, geochemistry lab tests, tracer tests brine age dating

- Cap rock condition - drilling and coring, geochemical lab tests, tracer tests, water age dating

- Gouge or shale sheath condition (hydrology around the salt dome) - drilling and borehole logging, tracer tests, geochemical rock and water lab tests, ground water age dating, aquifer testing

- Future ground water flow system (hydrology around the salt dome) - drilling and logging, aquifer testing, ground water age dating, tracer tests, geochemical and chemical lab tests

- Climate - remote sensing, surface mapping

Surface hydrology, as related to both present and past (Quaternary) climate conditions, should be well understood. Similarly subsurface hydrology should be well established by the pre-characterization investigations. The approach and scope of these works and the criteria for evaluating the techniques used are essentially independent of the prospective host medium, and will be determined by the surface and subsurface conditions at the prospective site. Applicability of individual techniques and criteria for their evaluation depend on the site conditions. The results of both the surface and subsurface hydrology studies are used in meeting the needs of the hydrology discipline and to provide data that may be required to fill needs of other disciplines.

The specific problems related to dome salt may occur during investigation of the cap rock and shale sheath conditions. Accurate drilling and hydrologic planning should be done for this investigation. Hydrologic studies must be coordinated with geochemical analyses in order to understand the relationship of the ground water to the surrounding rock materials. 


\subsubsection{Geochemistry}

The minimum data and most applicable techniques to adequately characterize the needs of geochemistry must include the following:

- Brine pocket condition - geochemical lab tests, brine age dating, tracer tests, drilling and logging, borehole logging

- Salt mass condition - geochemical lab tests, drilling and coring

- Cap rock condition - drilling and coring, geochemical lab tests, chemical lab tests (rock and water), tracer tests, water age dating

- Ground water geochemistry - drilling, geochemical lab tests, water age dating

Some of these needs are closely related to those of the hydrology and resource disciplines. The exploration program should provide for integration of geochemical data with other disciplines.

The specific problems related to dome salt may occur in investigation and determination of exact chemical assemblages occurring in the different parts of the salt mass. Comparison between these assemblages and the geochemistry of the ground water around the dome is one of the very important tasks in this study.

\subsubsection{Geomechanics}

Adequate characterization of the geomechanical and thermal properties of a host rock requires the measurement of certain parameters. The minimum parameters required and the best techniques to measure them fall into the two categories shown below:

\section{Geomechanical Parameters}

- Rock classification, quality and discontinuities - laboratory testing

- $\quad$ Strength - laboratory testing

- Moduli - laboratory testing 
- In-situ stresses - in situ testing

- Pore pressure - in situ testing

\section{Thermal Parameters}

- Specific heat - laboratory testing

- Conductivity; - laboratory testing

- Coefficient of thermal expansion - laboratory testing

- Thermal alteration - laboratory testing

The actual laboratory techniques for measuring these parameters vary. The important criteria are that the aforementioned parameters be measured.

Actually, the host rock consists of approximately 98 percent halite, and this is the expected composition of the rock at the repository level. Only small variations in geomechanical properties of the salt in the salt dome are expected from the impurities in the salt. However, there are possibilities that exotic blocks may occur with in the salt dome.

Besides salt itself, geomechanical properties of the exotic blocks may have to be investigated also. Specific problems may occur in collecting good rock samples from coring the salt. Mud drilling and air drilling both have problems to provide good reliable core for geomechanical investigation. In addition, due to the intricate foliation and disturbances of the salt mass resulting from piercement, the results of geomechanical laboratory tests may differ from in situ testing results.

\subsubsection{Seismotectonics}

Because of the temporal nature of tectonic movement and seismic activity it is very difficult to define the level of data which will be 
"adequate" to satisfy the information needs. At a minimum, however, a study should include the items discussed below.

- Uplift and subsidence - surface mapping, fault studies

- Faulting - remote sensing, monitor networks, fault studies, surface mapping, seismic reflection

- Igneous activity - monitor networks, gravity surveys

- Seismic activity - monitor networks, historical seismic analysis, instrumental seismic analysis (includes fault plane solutions)

- Natural stress variations - in situ testing

With the exception of testing for natural stress variations, none of the techniques above are real "hands on" tests, and are therefore subject to errors of interpretation.

Investigations of seismicity and tectonics for a prospective site in dome salt are essentially similar to those in other media. Criteria and guidelines for evaluating these types of information for other critical nuclear facilities are well established in existing NRC Reg. Guides and Standard Review Plans. However, some particular concerns regarding dome salt are related to the plasticity of salt and salt movement. In evaluation of seismicity of the region, small faults related to salt movement and capable of generating much smaller earthquakes than typical (i.e., deep-seated) features should be given high consideration.

\subsubsection{Resources}

The necessary data and most applicable techniques to adequately characterize the needs of the resource discipline should generally include the following:

- Mineral resources - surface mapping, petrography, geophysical exploration remote sensing, drilling and logging, geochemical analyses

- Hydrocarbon resources - surface mapping, geophysical exploration, remote sensing, drilling and logging geochemical analyses 
Geothermal resources - surface mapping, geophysical exploration, remote sensing, drilling and logging, geochemical analysis, temperature gradient

- Water resources - surface mapping, geophysical exploration, remote sensing, drilling and logging, geochemical analyses

Information on resources for a site in dome salt should be in two categories: 1) resources directly associated with salt in the salt dome, including halite, potash, and similar evaporitic chemicals, and 2) sulfur and hydrocarbon resources which may occur around the salt mass of the salt dome, as well as water and other resources in the surrounding area.

Resource potential within the salt dome should be determined with considerable confidence from the hydrologic and geochemical investigations of salt dome. However, evaluations of hydrocarbon, sulfur and water resources around the dome may require special techniques, as determined by site conditions. The geologic setting at the site will be an important consideration in evaluating information on all types of resources, including those that are not typical of evaporite environments but occur fortuitously at a particular site.

\subsection{SITE CHARACTERIZATION STUDIES}

\subsubsection{GEOLOGIC FEATURES OF DOME SALT IMPORTANT FOR SITE CHARACTER-} IZATION

A salt dome is a large salt mass intruded through a thick overburden and approaching the ground surface. Salt dome geology was previously described in Section 7.2.1, with emphasis on the factors that need to be assessed to identify a potentially suitable site in the precharacterization phase. This short review will concentrate mainly on those geologic properties of a salt dome which need to be determined in more detail by direct observation and in situ testing in the pilot shaft and test room(s) during site characterization.

Four principal elements of a salt dome can be distinguished and are illustrated on Figure 7.3.1-1. These elements are: 1) the salt mass, 2) cap rock, 3) shale sheath, and 4) overburden and surrounding area. For site characterization, the important geologic properties related to each element are discussed in the following subsections. 


\subsubsection{Salt Mass}

A salt mass typically is over 98 percent halite with a cylindrical shape, roughly circular or elliptical plan view and often a few thousand meters in depth. Some salt domes in the Gulf coast region have diameters of a few kilometers.

A salt mass is the result of the accumulation of salt that was originally deposited as bedded salt, but those stratigraphic and lateral variations which may occur in bedded salt usually do not occur in dome salt. The mineralogy and lithology of the salt mass may vary slightly from place to place, with anhydrite and gypsum being the main impurities. The salt texture, including grain size and form, and impurities distribution may also vary slightly, but the variation is usually so small that the salt mass is generally considered homogeneous. This variation may be significant for geomechanical and geochemical evaluation during site characterization. Grain size has been found to influence mechanical properties of the salt (e.g., Abel, 1969), and could influence geochemical reactions by altering the available surface area in the salt mass. Sorption processes may be influenced by impurity accessibility along grain boundaries rather than occurring as inclusions within halite crystals. Recrystallization typically produces crystals that are notably large and clear, with impurities concentrated along the grain boundaries (Baar, 1977; Treesh and Friedman, 1974), and may be accompanied by salt flow.

As mentioned previously, the salt mass has no specific structure as it is the result of the gathering, accumulation, compression and squeezing of salt, but this compression and squeezing may produce schistosity, cleavages and foliation of the original bedding. These small scale structures within the salt mass may be important for site characterization.

Another topic of concern during site characterization is liquid and gaseous (fluid) inclusions within the salt grains and in larger intercrystalline cavities. Both types may be important for site characterization. Fluid inclusions along crystal boundaries commonly occur in the form of "negative crystals" or small crystal-shaped voids (Hanson and Carter, 1980) that are less than a millimeter in size, although larger cavities also are found. These inclusions migrate in a thermal gradient and have received substantial attention in studies for nuclear waste isolation (e.g., Anthony and Cline, 1974; Holdoway, 1974; Claiborne and others, 1980).

Gas inclusions within salt grains and along shear zones are common and their accumulation under high pressure occasionally causes blowouts which are a relatively well known phenomenon in room and pillar mines 


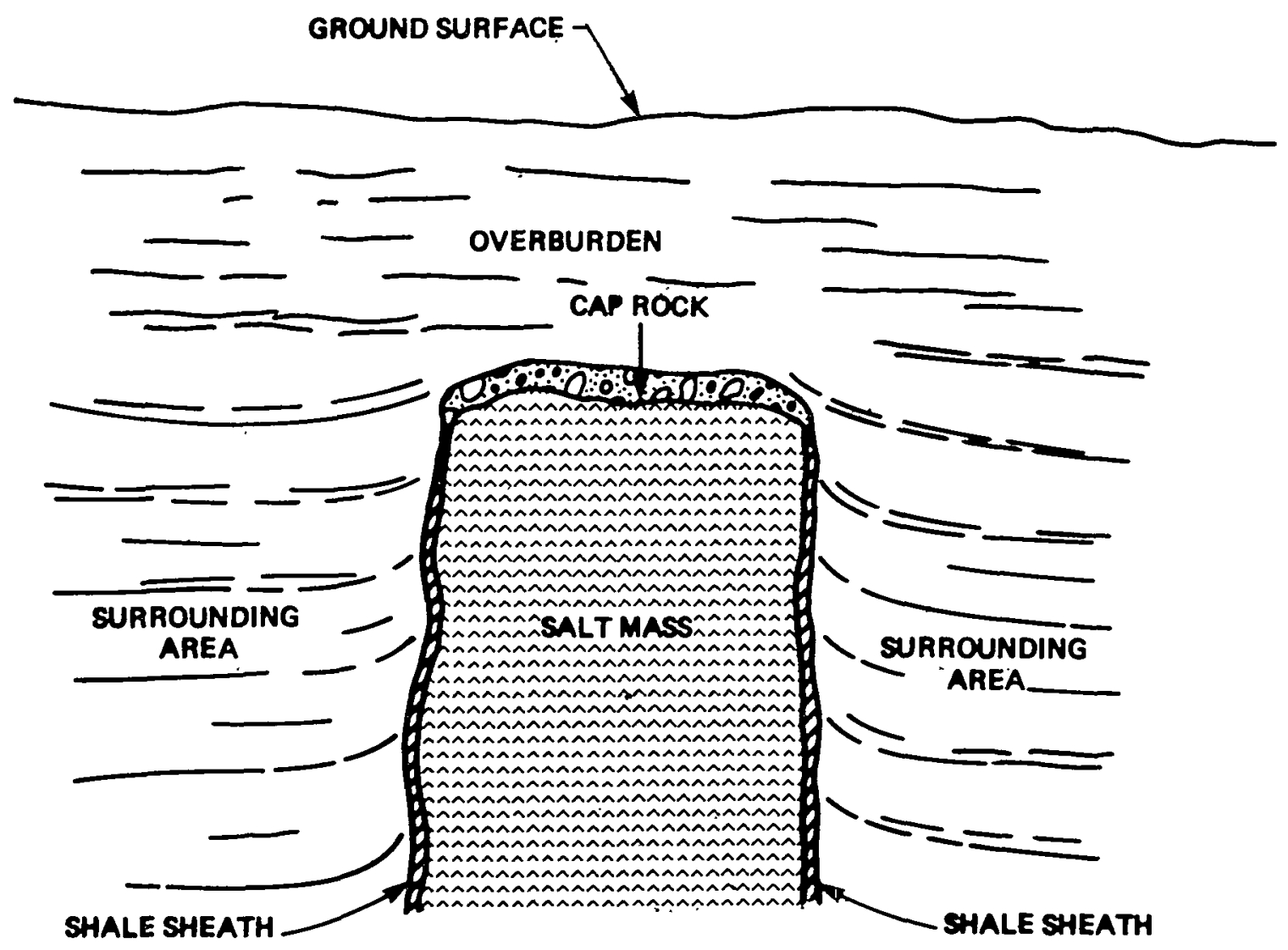

FOUR PRINCIPAL ELEMENTS OF A SALT DOME:

1. SALT MASS

2. CAP ROCK

3. SHALE SHEATH

4. OVERBURDEN AND SURROUNDING AREA

FIGUAE 7:3.1-1 GEOMETRY OF A SALT DOME

$$
7-61
$$


of U.S. Gulf Coast salt domes (Cameron, 1949; Belchic, 1960; Hoy and O'Neil, 1960; Hoy and others, 1962; Obert and Duval1, 1967; Kupfer, 1976; Martinez and others, 1977), and potash mines (Obert and Duvall, 1967; Hoy and others, 1962). All of these authors noted the presence of gas in association with blowouts in salt. In fact, blowouts are sometimes referred to as "gas outbursts", particularly by investigators with previous experience in coal mining (Obert and Duvall, 1967). Thoms and Martinez (1979) state that the dominating energy source for blowouts in the U.S. Gulf Coast salt domes is entrapped gas. Most detailed observations on gas inclusions and rock burst or blowouts in rock salt have been done in the Gulf coast area winnfield salt mine, through the previously cited works of Cameron (1949) and data generated by Project Cowboy, carried out by the Atomic Energy Commission from December, 1959, to March, 1960. The gas most frequently encountered in this mine was $\mathrm{CO}_{2}$ (Cameron, 1949; Belchic, 1960), although $\mathrm{H}_{2} \mathrm{~S}$ reportedly was also encountered at one location (Thoms and Martinez, 1979). The character of gas in blowouts generally varies between salt deposits and even between sites within one salt dome. Hoy and others (1962) reported the results of a gas analysis of some Winnfield crackle salt and noted the main constituent to be $\mathrm{CO}_{2}$ (46.98) with lesser amount of $\mathrm{H}_{2} \mathrm{O}(17.38), \mathrm{N}_{2}(18.48)$ and other gases: $\mathrm{CO}(4.88), \mathrm{O}_{2}$ (4.48), $\mathrm{SO}_{2}(3.78), \mathrm{H}_{2}(1.88), \mathrm{CH}_{4}(1.58), \mathrm{A}(0.48), \mathrm{S}_{2} \mathrm{H}_{2}(0.48)$, other hydrocarbons $(0.48)$. They also noted that methane gas had been reported in potash mine blowouts. Obert and Duvall (1967, p.609) state: "The gas in evaporite deposits include carbon dioxide, nitrogen, and methane. In some instances, the methane content is high enough for the product to be explosive."

Blowouts depicted schematically in a "feature" map of the winnfield salt mine occurred near the edges of the dome (Cameron, 1949; Belchic, 1960; Hoy and others, 1962), although gas and moisture were generally distributed in lesser amounts throughout the dome. The more frequent occurrence of blowouts near the edge of the dome can be attributed to several possibilities such as entrapment of gas producing materials into the shale sheath or high gas content in original salt beds now forming the periphery of the salt mass. Thoms and Martinez (1979) state that it must be emphasized at this point that the frequency and magnitude of blowouts in U.S. Gulf Coast salt domes depend strongly upon the character of the individual domes, i.e., the history of reported numbers and magnitudes of blowouts varies widely between domes. Furthermore, as previously noted, certain zones within domes are blowout prone, whereas others are not.

Brine pockets in some of the Gulf Coast salt mines also cause leakage problems, which may relate to the geologic or operating situation. Martinez and others (1976) state that a tour of Avery Island mine disclosed the serious nature of brine seeps which are inferred to be 
connected to the ground-water system. Martinez (1975) has reported the observations of mine managers from Canada, to the effect that some leaks are a result of trapped water and decline with time. Some Gulf Coast salt mines are dry, while others have a leakage problem. The Grand Saline salt mine in Texas is a dry mine and occasional leaks are the result of water, introduced into the mine by routine operation (Martinez and others, 1976).

Brine pockets would be a major concern during site characterization to insure safe development of underground workings. It is important to establish whether these brine pockets connect to the hydrologic system outside the salt dome, in order to properly evaluate potential flow paths from a repository. Further, it is most desirable to identify these brine pockets in site characterization and avoid them in the repository layout to minimize hazards and uncertainties.

Ground motion in a salt dome area is generally related to the regional tectonics and seismicity, and occasionally to salt movement. For site characterization, ground motions related to the salt movement is of major concern. Upward movement of salt initiates ground motion which results in uplifting of the overburden, tilting of surficial strata, small scale faulting and shear zones, topographic changes, and interruption of the hydrologic system. The area uplifted by salt movement could be reduced by erosion and visible topographic changes may not exist after a period of time. The magnitude and intensity of these ground motions may be too small to be noticed on a human time scale, but the long term movement during geologic periods makes it important. Salt movement is not a constant process, but starts and stops under the influence of prevailing geologic conditions.

\subsubsection{Cap Rock}

Cap rock occurs on top of the salt mass, ranging in thickness from a few meters to a few hundred meters, and typically consists of anhydrite in the lower part and gypsum in the upper part, although some Gulf Coast salt domes have no cap rock (Johnson and Gonzales, 1978). The cap rock is typically highly tectonized, compressed, and brecciated in the upper part, but generally prevents water penetration from the overburden into the salt mass. During site characterization the main geologic investigation should focus on the basal part of the cap rock, where anhydrite is in contact with salt. A hypothesis has been advanced that the presence of a well-cemented basal anhydrite would constitute evidence of a cessation of salt dissolution at that point and possibly evidence of hydrologic stability (Martinez and others, 1976). 


\subsubsection{Shale Sheath}

The salt mass is usually surrounded by a few meter thick gouge zone or shale sheath which consists of finely ground, brecciated and compressed materials such as clay, marl, shale, and limestone, produced by crushing and grinding of rock layers around the salt dome during piercing of the salt. Because of a high clay material percentage, this sheath is usually impermeable and prevents water penetration from the surrounding area into the salt mass.

Shale sheath mineralogy and lithology depends on the surrounding rock formations. The sheath is a very fine grained, compact mylonite composed of rock fragments from the surrounding layers which have been pulled off by the upwelling salt. Consequently, mineralogy and 1ithology of the shale sheath typically varies vertically with the surrounding rock.

Rock formations external to the shale sheath are fixed, whereas the salt rocks on the inside are slowly piercing upward under intense hydrostatic pressure. This relative movement of one side of the sheath against the other, under very high pressure, creates a classic shear zone, with shear cleavage. Recrystallization of the rock fragments occasionally may occur. Thickness of this shale sheath varies laterally and vertically.

\subsubsection{Overburden and Surrounding Area}

Geologic properties of the overburden would be determined in more detail by direct observation and in situ testing in the pilot shaft. As noted previously, geology of the overburden is unrelated to the geology of the salt mass, but the form of occurrence and integrity or deterioration of a salt dome depends on geology of the overburden and the surrounding area. Generally the rock formations around a salt dome were laid down in the same depositional basin as the salt, but formations were structurally affected by salt piercing, resulting in a series of uplifted rock layers around the dome periphery, which later may become reservoirs for oil and gas. Like any rock sequence, the formations around and over the salt dome are interbedded impermeable and permeable layers, producing an environment for ground water aquifers at different levels, some of which may contact the salt mass and locally cause dissolution. In such a case a saline water plume occurs around the dome, extending laterally towards the flow direction. widely spaced tension fractures in the cap rock and overburden, resulting from piercement of the salt, may also provide an avenue for the water of the overlying aquifers to penetrate the dome and cause dissolution. 


\subsubsection{INFORMATION NEEDS FOR SITE CHARACTERIZATION IN DOME SALT}

The information needs specific to site characterization in dome salt are essentially similar to those already used in precharacterization, except that much more detailed investigation is required. There are also new items which relate to the location of site and in situ testing at depth. Continuation of some previous operations, such as monitoring seismicity, is also a part of the information needs during site characterization. Excavation of pilot shaft and test room(s) also requires special additional studies during this period.

It is expected that precharacterization studies will resolve those issues which are not related to the depository condition at depth, such as surface geology and hydrology, climate, seismicity, tectonics, and igneous activity. The issues, related to subsurface conditions, need detailed investigation during site characterization. Igneous activity is not a significant factor for Gulf Coast salt domes. Resource potential at a site should be investigated during precharacterization studies.

The following subsections summarize the information needs specific to site characterization of a prospective repository site in dome salt, under the categories of: geology, hydrology, geochemistry, geomechanics, seismotectonics, and resources. Each category has a brief description of information assumed to have been obtained from precharacterization and the information needs for site characterization are discussed from this basis.

\subsubsection{Geology}

The information needs regarding geology of a salt dome at the site characterization level mainly involve obtaining detailed information on the geologic conditions in the candidate salt dome, as they relate to design, construction, and performance of the repository. The geologic issues summarized in section 7.2.2.1 are common to both. levels of site investigation but would be addressed in greater depth and at a finer scale by the intensive work in site characterization.

Precharacterization geologic results should be adequate to define surface geologic conditions and processes. They also should generally describe geometry, depth, size and structural condition of the candidate salt dome, as well as stratigraphy, lithology, and geologic structures of the overburden and the surrounding subsurface rock sequences. Surface geology should have been determined as needed to interpret 
nature and rates of the relevant processes, including: erosion, deposition, previous Quaternary climate, surface hydrologic conditions, seismotectonics and salt tectonics. The subsurface geologic information from precharacterization studies should include depth, size, shape, salt activity and structural condition of the potentially suitable salt dome. Features such as exotic blocks, dissolution and reactivation potential of salt which may adversely affect suitability of the site, should have been defined.

The detailed and intensive subsurface geologic studies during site characterization should refine the description of the geologic conditions in the principal elements of a salt dome repository (Figure 7.3.1-1), i.e., the salt mass, cap rock, shale sheath. Table 7.3.2-1 lists the geologic needs that would be emphasized in precharacterization and those stressed in site characterization.

\subsubsection{Hydrology}

In general, hydrologic information needs previously discussed in the precharacterization phase (Section 7.2.2.2) will be the same for site characterization, but addressed by investigations in greater detail and by continued monitoring. Some items such as climate history (present and past) and surface hydrology are investigated at the surface and should be resolved before undertaking more detailed subsurface work of site characterization.

The hydrologic information needs specific to salt dome site characterization relate to fluids and flow paths within the salt mass, cap rock and shale sheath. More precise information about overburden and surrounding area hydrology would help refine precharacterization models. Table 7.3.2-2 lists the hydrologic needs that would be emphasized in precharacterization and those stressed in site characterization.

Surface hydrology and flooding models should be refined and verified during the site characterization phase.

During site characterization, research on dissolution of salt in a candidate salt dome should focus on detailed hydrological studies regarding aquifer salinity and saline plumes around the dome. The studies should assess the volume of salt dissolved as a function of time under actual conditions to evaluate the hydrologic stability, or instability, of the salt dome. Unfortunately a good definition for hydrologic stability (of a salt dome) has not been established. Smith, Jr. (1977) reports that estimates of the rate of salt dissolution from a few domes in northeast Texas which are associated with saline plumes, 
TABLE $7 \cdot 3 \cdot 2-1$

GEOLOGY INFORMATION NEEDS IN DOME SALT

Emphasized in Precharacterization:

1. Geologic processes.

2. Lithology, stratigraphy and structure of rocks overlying and surrounding the salt dome.

3. Geometry and lithology of the salt dome.

Emphasized in site Characterization:

1. Needs related to the salt mass:

- mineralogy and textural variation

- isotropic condition

- exotic blocks

- cleavage and schistosity

- collapse and caving potential, structural condition

- impurities in the salt

2. Needs related to the cap rock:

- detailed lithology, stratigraphy and mineralogy

- structure (folds, faults)

- fractures

- cleavage and schistosity

3. Needs related to the shale sheath:

- detailed lithology

- mineralogy and textural variation

- geometry (thickness, extension) 
TABLE $7 \cdot 3 \cdot 2-2$

HYDROLOGY INFORMATION NEEDS IN DOME SALT

Emphasized in Precharacterization:

1. Climate.

2. Surface hydrology.

3. Aquifers above and around the salt.

4. Dissolution.

5. Large brine pockets.

Emphasized in Site Characterization:

1. Needs related to the salt mass:

- brine pocket locations

- brine inclusion characteristics

- brine age

- relation between different brine pockets

- capillary movement

- dissolution processes and rates

2. Needs related to the cap rock:

- water age

- fracture permeability

- dissolution and voids

3. Needs related to the shale sheath:

- detailed porosity and permeability

- flow path 
indicate that less than 30 meters of salt will be removed from the upper surfaces of a dome in 250,000 years. This data indicates that even apparently unstable domes may be sufficiently stable to serve as waste disposal sites.

\subsubsection{Geochemistry}

Geochemistry information needs for site characterization are essentially as described in Section 7.2.2.3 for precharacterization but will emphasize rock and fluid chemical properties at the prospective repository level, and their influence on repository performance. The results of precharacterization studies should adequately define the general geochemistry of the site, particularly of the salt mass and associated brine pockets, as well as establish the water chemistry in the overburden and the surrounding aquifers. Mineralogic study of the overburden rock sequences should have identified rock layers or zones that may contribute to retardation or require special consideration in selecting seal materials. Precharacterization dating of water and rocks should be adequate to document the geologic history of the site, and demonstrate that fluids have long residence times and are well isolated from the accessible environment.

Site characterization studies should provide a detailed understanding of the geochemical properties of the salt mass, cap rock and shale sheath. Intensive subsurface work should also provide information regarding rock and water geochemical properties in the overburden and the surrounding area to quantify radionuclide transport potential to the accessible environment. Chemical conditions in the areas of shafts and boreholes must be evaluated to provide design parameters for repository sealing. An important part of site characterization will involve investigation of geochemical reactions relating to repository performance, including potential reactions of the brines or salt with waste or engineering materials which may influence design or determine performance of engineered barriers. The studies include effect of heat and water on reactions and rates, sorption property of salt and its impurities under dry and wet conditions, nuclide solubility in water approaching waste, and radionuclide migration. Similarly, the effects of the waste on the host medium, such as radiolytic alterations of the salt or brine should be carefully evaluated. As in other media, a most important concern would be geochemical reactions relating to radionuclide transport, including reactions such as retardation, diffusion, precipitation, and filtration, which must be evaluated in the prospective host rock and along possible flow paths to the accessible environment. For these evaluations, it is necessary to consider the temperature field resulting from waste emplacement, as chemical reactions are greatly influenced by temperature. 
TABLE $7 \cdot 3 \cdot 2-3$

GEOCHEMISTRY INFORMATION NEEDS IN DOME SALT

Emphasized in Precharacterization:

1. Chemistry of salt mass.

2. Brine chemistry.

3. Chemistry of fluids in aquifers around the dome.

4. Chemistry of rocks along potential flow paths outside the salt dome.

5. Preliminary dating of rocks and fluids.

\section{Emphasized in Site Characterization:}

1. Detailed chemistry of salt mass.

2. Detailed brine chemistry.

3. Reactions with canisters, wasteforms, and other engineered materials.

4. Radiolysis and hydrolysis of salt and brine.

5. Retardation in salt and associated minerals.

6. Retardation in other minerals along flow paths outside the salt dome.

7. Complexing and polymerization of radionuclides in repository fluids.

8. Ion exchange and exclusion.

9. Precipitation.

10. Filtration.

11. Dating of rocks and fluids. 
Detailed geochemical property of gas inclusions is needed for :valuation and investigation of bursting potential of the salt mass. Chemical properties of salt mass impurities should also be investigated, because of possible special reactions with -.. ?. Table 7.3.2-3 shows the geochemical needs that would be emphas 12 in precharacterization and those stressed in site characterization

\subsubsection{Geomechanics}

The precharacterization studies should be adequate to establish that geomechanical conditions are potentially suitable for a repository. The studies would include an evaluation of deformation and creep behavior, stress fields, radionuclide sorption, plasticity, drillability, waste/salt reactions, specific heat and thermal behavior. The studies should also include the geomechanical studies of the cap rock and overburden, for design and excavation of the pilot shaft. Parameters found to be within acceptable ranges by precharacterization studies should be verified and quantified in detail by continued study and testing during the site characterization program.

Construction design, radionuclide migration and thermal performance evaluation of a repository requires reliable information on geomechanical and thermal properties of the salt mass. A main objective of site characterization in a salt dome is in situ testing of the geomechanical and thermal properties of salt, as defined by U.S. Department of Energy (1981) near the prospective repository level. Geomechanics are a major concern in rock salt because plastic creep, spallation and fracture behavior of salt may induce problems in maintaining underground openings during repository operation and, more importantly, for retrieval. It is also important to obtain adequate thermal property information on salt and its impurities. Because the creep rate of these materials can be greatly influenced by temperatures in the range expected in a repository (e.g., Heard, 1972), the temperature field resulting from waste emplacement should reliably be anticipated. It is also important to establish the in situ temperature and stress conditions in the salt dome prior to repository development, and properties such as thermal expansion, cooling contraction, thermal diffusivity, heat transfer coefficient and emissivity of salt must be verified.

The response of the salt to the anticipated repository conditions should be evaluated by performing detailed in situ testing at depth. According to U.S. Department of Energy (1981) these field tests can be categorized as follows: 


\section{Very-Near-Field (10's of feet), including:}

- Waste/salt interaction

- Borehole backfill behavior

- Brine migration

- Gas generation and migration

- Retrievability

Near-Field (100's of feet), including:

- Thermomechanical-hydrological response

- Backfill of repository rooms

- Canister placement geometry

Far-Field (1000's of feet), including:

- Thermal response

- Geohydrology and nuclide mass transport.

These tests should determine stress distributions from mechanical and thermal loading, displacements (strains), temperature distributions, plastic creep, and potential for temperature-induced fracturing, radiolysis, and alteration. At the same time, these tests provide a vehicle for evaluating migration of fluid inclusions in the salt under a thermal gradient. Geomechanical response of rock salt during blowouts by gas should also be determined. Table 7.2.2-4 lists the geomechanical needs that would be emphasized in precharacterization and those stressed in site characterization.

\subsubsection{Seismotectonics}

Tectonic and seismicity information needs of a prospective site are essentially the same as in other media and are summarized in section 7.2.2.5. It is expected that these conditions would be demonstrated to be favorable at a site before it would be selected for characterization. The main occurrences of salt domes within the United States are in areas that are notable for tectonic stability and low levels of seismic activity, but seismic monitoring should be continued during site characterization and results incorporated into the design basis for the repository facility as appropriate. 


\subsubsection{Resources}

As mentioned in section 7.2.2.6 of this report, studies prior to characterization at a prospective site should establish the history of exploration and resource development, and the presence, or apparent presence, of resources. Consequently, during site characterization information needs are limited to verifying the presence or absence of resources at the repository.

\subsubsection{TECHNIQUE APPLICATIONS TO SITE CHARACTERIZATION INFORMATION NEEDS IN DOME SALT}

Generally, site characterization studies are those involved in the detailed testing of the host rock and in situ testing at depth. As mentioned before, precharacterization studies at a nominated site are expected to resolve those issues that may be addressed without the detailed exploration and testing at depth, including surface geology, surface hydrology, climate, tectonics, seismicity and resource potential. Most techniques used in precharacterization continue to be applicable in site characterization and will not be discussed further here. Table 7.3.3.1 summarizes applicability of the new techniques to the information needs in site characterization.

In some cases, the applicable techniques for site characterization are less developed than those for precharacterization, and there is less precedent and experience. Precharacterization techniques are generaliy well developed from use in oil, gas or resource exploration or common engineering practice. However, few mining or underground construction programs approach the level of detail and reliability necessary for site characterization, and even fewer tests have specifically been done for waste isolation in salt domes, including those tests at Avery Island, and Asse II in West Germany (U.S. Department of Energy).

The following subsections summarize specific techniques applicable in site characterization related to geology, hydrology, geochemistry, geomechanics, seismotectonics and resources which are described in detail in Appendices $\mathrm{A}-\mathrm{H}$.

\subsubsection{Geology}

The main objective of geologic investigations of a candidate salt dome is evaluation of geologic factors relating to design, construction and performance of the proposed repository. During this period, geologic properties of the prospective salt dome would be determined in the 
TABLE $7 \cdot 3 \cdot 2-4$

GEOMECHANICS INFORMATION NEEDS IN DOME SALT

Emphasized in Precharacterization:

1. Temperature field.

2. In situ stress field.

3. Thermal conductivity and specific heat of salt, and surrounding rocks.

4. Deformation moduli of salt and surrounding rocks.

5. Preliminary survey of discontinuities and inhomogeneities in the repository zone.

Emphasized in Site Characterization:

1. Thermal expansion of salt and surrounding rocks.

2. Creep properties of salt at anticipated temperatures.

3. Decrepitation and other temperature effects.

4. Radiation effects.

5. Anticipated temperature field.

6. Detailed survey of discontinuities and inhomogeneities in the repository zone.

7. Waste/salt interaction.

8. Brine migration by thermal gradient.

9. Gas generation and migration.

10. Retrievability.

11. Borehole backfill behavior.

12. Backfill of repository rooms.

13. Canister placement geometry. 
field from detailed subsurface mapping and subsurface-based drilling and geophysical exploration, supported by laboratory analysis of mineralogy and petrology.

The principal part of the operation is the excavation of a pilot shaft through the overburden and the upper buffer zone, and development of a test room near the proposed repository level. Subsurface mapping would be done in considerable detail in the pilot shaft, test room(s), and any exploratory drifts, using techniques common to mining and engineering geology (e.g., Herness, 1977). This mapping would emphasize identifying mineralogic, textural, and structural variations, as well as impurities and exotic blocks in the salt mass, and systematically describing those parameters which aid geomechanical, geochemical, and hydrologic analyses. Moreover, mapping of the pilot shaft would provide significant information regarding the overburden and the cap rock. Direct observation of excavation surfaces would allow detailed analyses of fractures, faults, stratigraphic changes and lithologic properties of the overburden and the cap rock. The salt mass/cap rock contact should be critically examined to evaluate the dissolution processes. Direct observation of intricate foliation, fractures, cleavage and schistosity in the salt mass will provide valuable information for repository design. Mapping of shafts, rooms, and drifts would allow evaluation of collapse and caving potential of the salt mass around the pillars, roof and floor of the excavated $\operatorname{room}(s)$.

Internal variation of impurities, texture, grain size, and other small scale features can be evaluated by detailed mapping of the test excavations. Geomechanical parameters have been found to be particularly influenced by crystal size (Abel, 1969) and impurity concentrations in the salt (Power and others, 1978).

The conditions and features addressed in subsurface mapping may be evaluated over a much larger area, although in much less detail, by using horizontal, inclined, and vertical boreholes. Drilling boreholes from the test room or drifts would allow more intensive exploration of the proposed repository site than would be feasible from the ground surface, without connecting the repository with the biosphere, and be particularly useful in evaluating spatial changes in lithology and impurities as well as intercepting brine pockets and exotic blocks.

Geologic features of a salt mass can also be explored by radar and sonar performed from boreholes in underground excavations. Radar logging can be utilized in three ways: 1) single borehole logging; 2) crosshole logging; and 3) probing from underground excavations. Dry salt is an ideal medium for radar transmission, and large pene- 
TABLE 7.3.3-1 SITE CHARACTERIZATION TECHNIQUE APPLICATION

\begin{tabular}{|c|c|c|c|c|c|c|c|c|}
\hline $\begin{array}{l}\text { APPLICATIONS OF TECHNIQUES } \\
\text { TO INFORMATION NEEDS } \\
\text { FOR SITE CHARACTERIZATION } \\
\text { O MAJOR CONTRIBUTION } \\
\text { O SUPPORTING CONTRIBUTION }\end{array}$ & 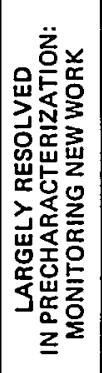 & 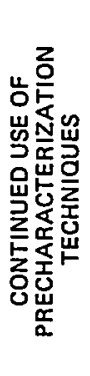 & 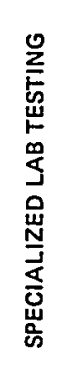 & 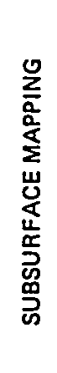 & 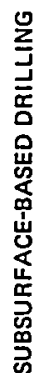 & 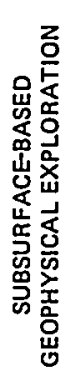 & 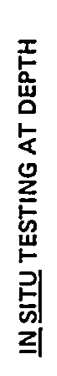 & 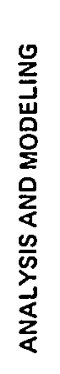 \\
\hline GEOLOGY & & & & & & & & \\
\hline DEPTH & $\bullet$ & 0 & & & & & & \\
\hline GEOMETAY & - & 0 & & o & & & & \\
\hline LITHOLOGY, PETROGRAPHY, MINERALOGY & - & 0 & 0 & 0 & 0 & & & \\
\hline CLEAVAGE AND SCHISTOSITY & o & 0 & & $\bullet$ & 0 & & & \\
\hline STRUCTURAL CONDITION & $\circ$ & 0 & & $\bullet$ & & & & \\
\hline EXOTIC BLOCKS, ISOTROPIC CONDITIONS & 0 & 0 & & o & - & & & \\
\hline GEOMETAY OF CAP ROCK & $\bullet$ & 0 & & ० & & & & \\
\hline LITHOLOGY OF CAP ROCK & - & 0 & o & 0 & & & & \\
\hline STRUCTURAL CONDITION OF CAP ROCK. & $\bullet$ & 0 & & o & & & & \\
\hline SHALE SHEATH EXISTENCE & $\bullet$ & o & & & o & $\circ$ & & \\
\hline $\begin{array}{l}\text { SHALE SHEATH LITHOLOGY, PETROGRAPHY, } \\
\text { MINERALOGY }\end{array}$ & 0 & - & 0 & & 0 & & & \\
\hline SHALE SHEATH EXTENSION AND THICKNESS & 0 & 0 & & & $\bullet$ & - & & \\
\hline STRATIGRAPHY, LITHOLOGY OF OVERBURDEN & $\bullet$ & $\circ$ & 0 & 0 & & & & \\
\hline OVERBURDEN PETROGRAPHY & $\bullet$ & 0 & 0 & o & & & & \\
\hline OVERBURDEN PALEONTOLOGY & $\bullet$ & o & 0 & 0 & & & & \\
\hline OVERBURDEN STRUCTURE, FRACTURES & $\bullet$ & o & & 0 & & & & \\
\hline
\end{tabular}


TABLE 7.3.3-1 (CONT'D) SITE CHARACTERIZATION TECHNIQUE APPLICATION

\begin{tabular}{|c|c|c|c|c|c|c|c|c|}
\hline $\begin{array}{l}\text { APPLICATIONS OF TECHNIQUES } \\
\text { TO INFORMATION NEEDS } \\
\text { FOR SITE CHARACTERIZATION } \\
\text { O MAJOR CONTRIBUTION } \\
\text { O SUPPORTING CONTRIBUTION }\end{array}$ & 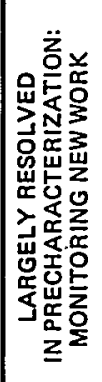 & 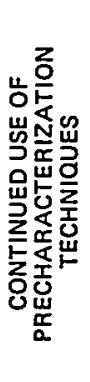 & 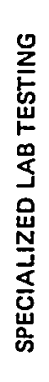 & 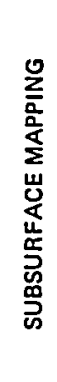 & 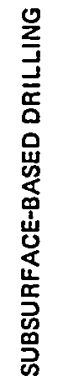 & 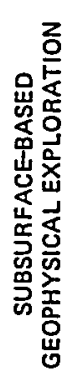 & 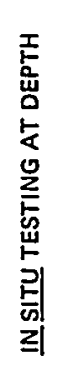 & 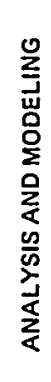 \\
\hline OVEREURDEN THICKNESS & - & $\circ$ & & 0 & & & & \\
\hline \multicolumn{9}{|l|}{ HYDROLOGY } \\
\hline BRINE POCKETS & 0 & $\bullet$ & & $\bullet$ & 0 & 0 & & \\
\hline FLUID INCLUSIONS & o & o & o & - & 0 & & 0 & $\bullet$ \\
\hline DISSOLUTION AND RATES & $\bullet$ & 0 & o & 0 & 0 & 0 & 0 & 0 \\
\hline FLOW PATH, TRAVEL TIME IN SALT & 0 & o & & $\bullet$ & $\circ$ & $\circ$ & o & 0 \\
\hline POROSITY, PERMEABILITY OF SALT & - & 0 & 0 & 0 & & 0 & 0 & \\
\hline CAP ROCK AOUIFERS & $\bullet$ & 0 & & 0 & & $\mathbf{0}$ & & \\
\hline CAP ROCK PERMEABILITY AND POROSITY & $\bullet$ & 0 & o & 0 & & 0 & 0 & \\
\hline CAP ROCK DISSOLUTION AND VOIDS & $\bullet$ & 0 & 0 & 0 & & 0 & 0 & \\
\hline SHALE SHEATH FLOW PATH & $\bullet$ & 0 & 0 & 0 & & 0 & & \\
\hline SHALE SHEATH POROSITY AND PERMEABILITY & 0 & 0 & 0 & & $\bullet$ & & & - \\
\hline OVERBURDEN AOUIFERS & $\bullet$ & 0 & o & 0 & & & & \\
\hline OVËRBURDEN POROSITY ANO PERMEABILITY & $\bullet$ & 0 & o & 0 & & & & \\
\hline OVERBURDEN GROUNDWATER CIRCULATION & $\bullet$ & 0 & 0 & o & & & & \\
\hline OVERBURDEN WATER'S AGE & $\bullet$ & 0 & 0 & 0 & & & & \\
\hline & & & & & & & & \\
\hline
\end{tabular}


TABLE 7.3.3-1 (CONT'D) SITE CHARACTERIZATION TECHNIQUE APPLICATION

\begin{tabular}{|c|c|c|c|c|c|c|c|c|}
\hline $\begin{array}{l}\text { APPLICATIONS OF TECHNIQUES } \\
\text { TO INFORMATION NEEDS } \\
\text { FOR SITE CHARACTERIZATION } \\
\text { MAJOR CONTRIBUTION } \\
\text { O SUPPORTING CONTRIBUTION }\end{array}$ & 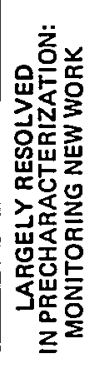 & 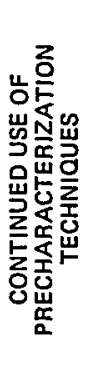 & 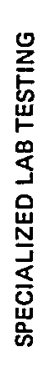 & 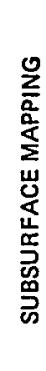 & 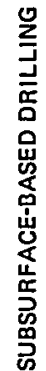 & 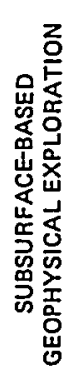 & 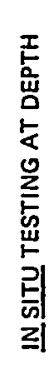 & 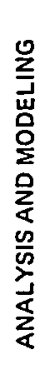 \\
\hline \multicolumn{9}{|l|}{ GEOCHEMISTRY } \\
\hline GEOCHEMICAL PROPERTY OF SALT & - & 0 & 0 & 0 & $\circ$ & & $\circ$ & \\
\hline GEOCHEMICAL PROPERTY OF CAP ROCK & $\bullet$ & o & 0 & 0 & & & 0 & \\
\hline GEOCHEMICAL PFOPERTY OF SHALE SHEATH & $\circ$ & $\bullet$ & 0 & & $\circ$ & & & \\
\hline GEOCHEMICAL PROPERTY OF OVERBURDEN & - & o & 0 & 0 & & & 0 & \\
\hline CHEMISTRY OF BAINE & 0 & - & 0 & 0 & 0 & & 0 & \\
\hline CHEMISTRY OF FLUID INCLUSIONS & 0 & - & 0 & 0 & o & & 0 & \\
\hline PLUG LONGEVITY & 0 & $\bullet$ & 0 & 0 & & & 0 & \\
\hline WATER RESIDENCE TIME & $\bullet$ & 0 & 0 & & & & & \\
\hline HOST ROCKNASTE REACTION & o & 0 & & & & & $\bullet$ & 0 \\
\hline \multicolumn{9}{|l|}{ GEOMECHANICS } \\
\hline GEOMECHANIC GEHAVIOR OF SALT & $\circ$ & & & $\circ$ & $\circ$ & & $\bullet$ & 0 \\
\hline GEOMECHANIC BEHAVIOR OF CAP ROCK & $\bullet$ & & 0 & o & & & o & 0 \\
\hline GEOMECHANIC BEHAVIOR OF OVERBURDEN & $\bullet$ & 0 & & 0 & & & 0 & \\
\hline $\begin{array}{l}\text { PHYSICAL AND MECHANICAL BEHAVIOR OF } \\
\text { SALT UNDER THERMAL LOADING }\end{array}$ & $\circ$ & & & & & & - & o \\
\hline $\begin{array}{l}\text { MIGRATION OF FLUID INCLUSIONS UNDER } \\
\text { A THERMAL GRADIENT }\end{array}$ & $\circ$ & & 0 & & & & $\bullet$ & 0 \\
\hline & - & & & & & & & \\
\hline
\end{tabular}


TABLE 7.3.3-1 (CONT'D) SITE CHARACTERIZATION TECHNIQUE APPLICATION

\begin{tabular}{|c|c|c|c|c|c|c|c|c|}
\hline $\begin{array}{l}\text { APPLICATIONS OF TECHNIQUES } \\
\text { TO INFORMATION NEEDS } \\
\text { FOR SITE CHARACTERIZATION } \\
\text { - MANOR CONTRIBUTION } \\
\text { O SUPPORTING CONTRIBUTION }\end{array}$ & 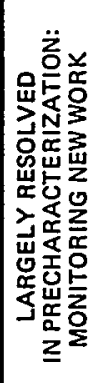 & 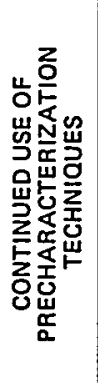 & 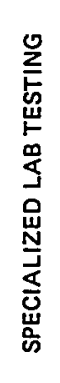 & 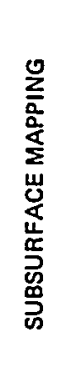 & 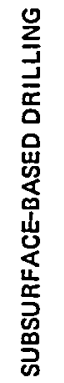 & 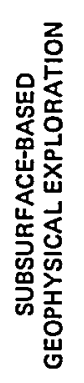 & 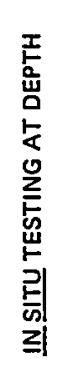 & 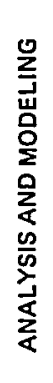 \\
\hline \multicolumn{9}{|l|}{ TECTONIC AND SEISMICITY } \\
\hline SEISMIC ACTIVITY & $\bullet$ & $\circ$ & & & & & & ० \\
\hline ROTATIONAL MOVEMENT & $\circ$ & - & & & & & & o \\
\hline HORIZONTAL MOVEMENT & ? & $\bullet$ & & & & & & $\circ$ \\
\hline VERTICAL MOVEMENT & $\circ$ & $\bullet$ & & & & & & 0 \\
\hline ACOUSTIC EMISSION & o & - & & & & & & o \\
\hline RESOURCES & - & o & o & $\circ$ & o & $\circ$ & & \\
\hline & & & & & & & & \\
\hline & & & & & & & & \\
\hline & & & & & & & & \\
\hline & & & & & & & & \\
\hline & & & & & & & & \\
\hline & & & & & & & & \\
\hline & & & & & & & & \\
\hline & & & & & & & & \\
\hline & & & & & & & & \\
\hline & & & & & & & & \\
\hline
\end{tabular}


tration distances are attainable (Stewart and Unterberger, 1976). A microwave high resolution CW-FM radar system at $4300 \mathrm{MHz}$ gives excellent resolution and can detect small (about $1 \mathrm{~cm}$ ) fractures at ranges from one to 30 meters in salt. A $440 \mathrm{MHz}$ radar system has a longer detection range, about 300 meters in dry salt, but has less resolving power. A $230 \mathrm{MHz}$ radar system obtains greater ranges (over $400 \mathrm{~m})$ and is useful in detecting and mapping the top and flanks of a salt dome. A low frequency ( $30 \mathrm{MHz}$ ) radar system has also been found useful to probe extremely long ranges (up to $2000 \mathrm{~m}$ ) for large discontinuities in the salt such as brine cavities or salt dome flanks (Unterberger, 1979). With radar logging all significant brine pockets and exotic blocks of the salt mass to repository depth should be detectable. Unterberger (1979) states that a sonar system has been developed using $24 \mathrm{kHz}$ sound pulses, and probing ranges of 400 meters in dry salt have been obtained. Resistivity surveys may be conducted at depth in salt in much the same manner as at the surface. Reliability, resolution, and other aspects of the applicable techniques are discussed in Appendix B-2.

\subsubsection{Hydrology}

Suitability of a salt mass for a waste repository is based on the fact that the salt mass, accumulated and compressed in the salt dome, typically does not contain any water and is dry. Therefore, a salt dome for site characterization has no aquifer, no water content, and no hydrology. However, salt is highly soluble and any water penetrating the salt mass causes dissolution which highly affects integrity of the repository. Consequently the necessary hydrologic studies in the salt mass are limited to exploring for brine pockets and dissolution, and evaluating brine migration, travel time and flow paths. The techniques applicable to this investigation are essentially the same as discussed in precharacterization.

As explained previously, the salt mass in the salt dome is typically isotropic, but permeability may vary slightly from place to place and should be investigated. Permeability testing in salt poses a unique problem in that water would dissolve the salt and create new flow paths. Permeability testing at WIPP, using argon, nitrogen, and air, established the gas permeability of polycrystalline halite to be less than 0.05 microdarcy (the resolution limit of the test apparatus) after an initial consolidation period at 2000 to 5000 psi to close fractures that may have been caused by sampling (Powers and others, 1978). Samples at appropriate intervals within the salt mass may be obtained for similar laboratory testing during site characterization. The most applicable field technique for such testing typically would 
be injection tests (Appendix G-2) using a saturated brine to avoid dissolution.

Despite the extremely low permeability (almost nonexistent) of salt, fluid inclusions are typically associated with salt grains, and primary brine of various composition, and gases from organic decomposition could be trapped in the highly impermeable salt (Kupfer, 1979). Fluid inclusion migration due to heat, radiation or other mechanisms is a concern specific to salt and would-be evaluated during site characterization. Based on the observations to date, fluid migration will not be expected to have a major impact on repository integrity (Shefelbine and Raines, 1980). Techniques for evaluating this phenomena have been discussed in the literature (e.g., Anthony and Cline, 1974; Rothfuchs, 1979; Jockwer, 1979) and models for brine migration in salt have been developed (Claiborne and others, 1980). These techniques and models would be applied to quantify conditions of brine migration for the rocks and anticipated temperature field at a prospective site.

During site characterization, the hydrologic studies related to cap rock, shale sheath, overburden and the surrounding area are essentially the same as the precharacterization studies but in more detail, and would involve continued application of the techniques used in precharacterization.

\subsubsection{Geochemistry}

Geochemical techniques for site characterization include laboratory determination of the geochemical properties of the salt mass and in situ investigation and sampling of brines, and brine or gas inclusions. The techniques used in site characterization for the cap rock, shale sheath, overburden and the surrounding area are essentially the same as precharacterization and are described in Section 7.2.3.3. Excavation of the pilot shafts, test room(s), and exploratory drifts provide an opportunity to perform a systematic sampling and testing to evaluate the spatial chemical variation of the salt mass.

In general, the geochemical techniques will be applied in two areas: descriptive geochemistry and evaluations of geochemical reactions. The descriptive geochemistry will involve application of standard laboratory techniques to determine detailed compositions of the salt, impurities, brines and fluid inclusions at the prospective repository zone, and includes techniques to determine $\mathrm{Eh}$ and $\mathrm{pH}$ of brines and fluid inclusions. Evaluations of geochemical reactions would be based on the descriptive geochemical information and the anticipated thermal and fluid-flow conditions in the repository, as determined from results of the geomechanical and hydrologic work. Among the geochemical water- 
rock reaction models, the reaction path models may help to understand brine and gas migration, and data requirements for optimum use of the above models includes accurate field analyses of $\mathrm{Eh}, \mathrm{DO}, \mathrm{pH}$, and temperature.

Chemistry of fluid inclusions (brine, gas) includes their age and origin as described in Appendix F-2. Primary, pseudosecondary and secondary inclusions should be discriminated. Isotopic analyses of fluid inclusions in salt dome may indicate that the water in these inclusions is chiefly of meteoric origin. Stable isotope data and modeling may also help to understand history and evolution of the groundwater around or within the salt dome, from precipitation in the recharge zone to the point of sampling. The question which requires resolution is whether the salinity of the water is due to dissolution of salt by meteoric water, or is the groundwater of more residual or connate origin.

According to Appendices $F-1$ and F-2, several methods of age dating have been developed using stable isotopes of oxygen, hydrogen, carbon, and sulfur. These methods also help to understand the origin of the inclusions, brine, and groundwater within and around the salt domes. The nature, effectiveness, resolution and reliability of the geochemical tests are discussed in Appendices $\mathrm{F}-1$ and $\mathrm{F}-2$.

\subsubsection{Geomechanics}

Applicable techniques for these information needs include laboratory testing, in situ test programs, and numerical modeling. The isotropy and geometry of the salt mass, investigated during precharacterization, will provide a base for selecting the geomechanical techniques applicable to site characterization. These techniques would essentially be the same as used in precharacterization, except that excavation of the pilot shaft and test room(s) will provide access for in situ geomechanical testing during site characterization. Appropriate in situ tests include field heater and flatjack loading (field scale) tests. The laboratory testing techniques during site characterization has the advantage of using larger and oriented blocks of rock salt, excavated from the test room(s), for creep and other relevant tests. The laboratory testing techniques would also consider the salt behavior during blowouts, as well as possible gas and brine migration towards the heat source.

An important part of the work in geomechanics during site characterization is modeling of repository behavior both at normal and elevated temperatures. 


\subsubsection{Seismotectonics}

Site characterization techniques for seismicity and tectonics would largely consist of continued monitoring of the seismograph networks emplaced during precharacterization. The techniques for characterization and precharacterization studies are essentially the same, except for some differences in detail such as resolution. Although most salt domes within the U.S. occur in areas that are noted for tectonic stability and low levels of seismic activity, salt movement is a major concern and determination of site-specific levels of seismic activity related to the salt movement may be beyond the precharacterization network threshold and seismograph detectability. Therefore, higher resolution seismological techniques (microseismic networks) should be employed during site characterization. However, salt movement may cause small scale disturbances at the ground surface such as distortion, rotation, fracturing, faulting, uplifting and subsidence, and detection of these events typically is not possible, even by a microseismograph.

Investigation of small scale surface disturbances by direct field measurement of geodetic changes will be needed to document salt movement. This type of investigation is typically more accurate, reliable and of higher resolution than results obtained by a microseismograph. Huggett (1977) reports that the most accurate way to measure salt movement and its resultant displacements would be the complementary use of a multiwavelength distance measuring (MWDM) instrument and a two-fluid tiltmeter. The MWDM instrument is capable of making consecutive distance determinations with a standard deviation from the mean as small as 4 parts in $10^{8}$ with a long-term stability and precision of better than 1 part in $10^{7}$ over distances up to $15 \mathrm{~km}$. The two-fluid tiltmeter is designed to measure relative vertical movement between two distant piers, and can measure vertical displacement over long baselines to a precision of about $10^{-5}$, and regional tilt to a precision of about 10-8. Huggett (1977) also proposes that numerical modeling of salt dome movement should continue and eventually take on the role of the chief aid in interpretation of data obtained from dome monitoring systems. Thoms (1975) and Martinez and others (1979) propose a system of instrumentation consisting of tiltmeter, strainmeter, extensometer, laser ranging, multiwavelength distance measuring (MWDM), precise leveling and microseismic monitoring. Any notable or anomalous seismic events recorded during site characterization may require additional specific investigation, using the techniques discussed in Appendix $\mathrm{H}$. 


\subsubsection{Resources}

Resource evaluations during site characterization is essentially limited to continued monitoring of ongoing exploration programs to verify the resource potential of the area already explored during precharacterization. The techniques applied in this work would be identical to those applied in the precharacterization period, and are discussed in section 7.2.3.6.

\subsubsection{COST AND TIME ESTIMATES FOR TECHNIQUES IN SITE CHARACTERIZATION}

Estimates for the costs and times that would be required for the techniques used in characterizing a site in dome salt are summarized in Tables 7.3.4-1 through 7.3.4-7. Additionally, the work during site characterization would involve continued use of the techniques used in precharacterization. The cost and time estimates summarized in Tables 7.2.4-1 to 7.2.4-7 would remain applicable for these techniques. In evaluating cost and time estimates for site characterization, an important consideration is that many of the tests are specially designed for site conditions and particular information needs. Durations of geomechanical and hydrologic tests, in particular, may be a design factor and can be important in determining costs.

\subsubsection{Geologic Mapping and Supporting Activities}

Typical costs and times for detailed surface mapping, as would be done at a prospective site during characterization, and the supporting work in remote sensing, trenching, and age dating are summarized in Table 7.3.4-1. This work would be performed during site characterization but chiefly would involve validating previous findings. It would not be reasonable to undertake characterization at a site if there were significant outstanding questions regarding surface geology. For these estimates, it is assumed that access and trafficability would not be problems at a site chosen for characterization.

Table 7.3.4-2 summarizes typical costs and times for mapping geologic conditions in the pilot excavations. Costs for the geochemical analyses that may be used in support of this mapping are provided in Appendix F-2. For subsurface mapping done in coordination with the excavation, cost and schedule are likely to be controlled by the need to avoid interference with the excavation process. 


\subsubsection{Subsurface Based Drilling and Coring}

Appendix D-2 includes a comprehensive summary of the costs and penetration rates for various techniques used in drilling and coring from pilot excavations. Information applicable to dome salt is summarized in Table 7.3.4-3, with some revisions to the Appendix D-2 costs for increased compatibility with the costs for other techniques. Costs for mobilization and delays for availability of suitable equipment are not included on the assumption that the site characterization program should be of sufficient magnitude to maintain the required equipment of site for a significant period.

Techniques for geologic logging of the drill return or core, as discussed in Appendices $\mathrm{D}-1$ and $\mathrm{E}-1$ would continue to apply in site characterization. Geophysical logging techniques discussed in Appendix C also would remain applicable for vertical and near vertical hole; costs generally would be as summarized in Table 7.2.4-3.

\subsubsection{Geophysical Techniques in Site Characterization}

In general, the geophysical techniques discussed in Appendix B would remain applicable in site characterization and costs would continue to follow the parameters outlined in Table 7.2.4-4. Lists for the techniques used in site characterization for detailed evaluation of near surface engineering parameters and for exploring the salt surrounding the pilot excavations are summarized in Table 7.3.4-4. As discussed previously, the radar and sonar techniques used for subsurface exploration in geologic media are specially designed systems and therefore can differ significantly in costs and capabilities. Moreover, new techniques are continually under development, making it difficult to forecast costs and capabilities for work that would be performed in future years.

\subsubsection{Hydrology}

Costs and times for the hydrologic techniques most important in site characterization are summarized in Table 7.3.4-5, based on the information in Appendix G-2. All of the techniques in Table 7.3.4-5 involve testing programs that vary in cost and duration according to their design, in addition to the properties of the test medium. Costs of drilling and well completion are not included in the estimates for the hydrologic techniques. 
COST AND TIME SUMMARY FOR SURFACE GEOLOGIC TECHNIQUES

IN SITE CHARACTERIZATION

Approximate

Cost

REMOTE SENSING INTERPRETATION

$1: 4800$. photo analysis

( 100 photos for $12 \mathrm{mi}^{2}$ site)

DETAILED SURFACE MAPPING

(for $12 \mathrm{mi}^{2}$ site area)

General Mapping

$\$ 1,750-3,500(1)$

5-10 man days
Approximate

Time

$$
\begin{gathered}
\$ 12,000-18,000 \quad \begin{array}{c}
20-30 \text { man days } \\
(10-15 \text { field days } \\
\text { for } 2-\text { man crew })
\end{array}
\end{gathered}
$$

EXCAVATION LOGGING (2)

Reconnaissance

Detailed logging at $1^{n}=10^{\prime}$

$$
\begin{array}{ll}
\$ 1,200 / \text { day (3) } & 10,000 \mathrm{ft}^{2} / \text { day (3) } \\
\$ 1,200 / \text { day (3) } & 1,500 \mathrm{ft}^{2} / \text { day (3) }
\end{array}
$$

\section{NOTES :}

(1)

Does not include cost of large scale stereographic aerial photos, assumed to be available in site characterization.

(2)

For surface excavations such as exploratory trenches or quarry cuts. Also for natural exposures such as bluffs or stream banks.

Typical production rate and daily cost for 2-man field crew. Rates will vary according to access, difficulty of cleaning off the excavation, and, particularly, complexity of geologic conditions. Mapping of critical relationships at larger scale would require additional time. 
TABLE $7 \cdot 3 \cdot 4-2$

COST AND TIME SUMMARY FOR SUBSURFACE GEOLOGIC MAPPING IN SITE CHARACTERIZATION (1)

Cost Per Day

Typical Mapping Rate

Detailed Mapping $\$ 650.00$

$600 \mathrm{ft}^{2} / \mathrm{day}(3)$ at $1^{n}=5,(2)$

NOTES :

(1) Based on Appendix A-2.

(2) Typical scale for geologic mapping in drift 8 feet wide and 8 feet high, after completion of engineering survey and preparation of base maps.

(3) Actual rates depend on complexity of geologic conditions at the place mapped. 
TABLE $7.3 .4-3$

COST AND TIME SUMMARY FOR

SUBSURFACE BASED DRILIING AND CORING

IN SITE CHARACTERIZATION (1)

\begin{tabular}{lcc} 
Penetration \\
Hole Maximum & Rate(2) \\
Size Depth & (Ft/Hr) & Cost per foot (5) \\
(In) (Ft) & Range Average & Range \\
\hline
\end{tabular}

PERCUSSION DRILLS

Track drill

$2-5 \quad 200 \quad 400-500(3)$

$450(3)$

$\$ 0.30-0.40(6)$

$\$ 0.35^{(6)}$

Core

Size

CORE DRILLS

Longyear HQ $(2-1 / 2) 1200$

EHS 38 NO $(1-7 / 8) 1900$

$10-15^{(4)} 12^{(4)} \quad \$ 9-13$

$\$ 11$

Longyear 65

BQ $(1-3 / 8) \quad 500$

$3-5(4)$

$4(4)$

$\$ 17-27$

$\$ 23$

NOTES:

(1) Adapted from Appendix D-2

(2) Not including move-in or set-up time. Rates calculated for representative drill or core sizes and would differ for other sizes.

(3) At 678 efficiency.

(4) At $50 \%$ efficiency.

(5) Direct operating costs $\times 1.75$ to account for administration, insurance, interest, contractor's profit margin and other typical cost factors. Does not include cost of on-site geologic inspection or subsequent core logging. Does not include allowance for standby time.

(6) Compressor costs calculated assuming two drills per compressor 


\subsubsection{Geochemistry}

Cost estimates for typical geochemical analyses are summarized in Appendix F-1. The specific tests and the number of analyses needed would be determined by site conditions and cannot be quantified reliably on a generic basis. The main factors determining turn around time for results of the geochemical analyses are capabilities of the available laboratories, their work load, and the priority of the specific project. It is expected that most individual analyses for site characterization could be performed within a few weeks but longer times may be required for specialized analyses or for work on large numbers of samples.

\subsubsection{Geomechanics}

The work in geomechanics for site characterization involves specialized laboratory testing and in situ tests designed individually for each program. Representative costs and times are provided in Table 7.3.4-6 but these can differ significantly according to design of a specific program. In particular, the number of tests required to characterize a site would be determined by the variability of site conditions and the proposed repository layout. Instrumentation is a notable problem for long duration tests and needs to develop new or unique systems could be costly. Additional costs also may result from the needs to protect test equipment from corrosion in the salt.

\subsubsection{Seismotectonics}

In general the seismotectonic monitoring networks discussed in section 7.2.3.5 and described in Appendix $\mathrm{H}$ would remain applicable in site characterzation, and costs and time summary is shown in Table 7.2.4-7. In addition, precise instrumentation is needed to monitor salt movement during site characterization, cost and time of which are provided in Table 7.3.4-7. Additional cost and extension of time may result from the specific climatic condition.

\subsubsection{CRITERIA FOR EVALUATING DATA ADEQUACY OF SITE CHARACTERIZATION STUDIES IN DOME SALT}

This section discusses criteria (guidelines) which may be used by the NRC to assess the adequacy of the exploration and testing done for characterization of a high level nuclear waste repository site in a salt dome. It is expected that the data obtained during site characterization will be adequate to fulfill the information needs and be of sufficient resolution and reliability. 
COST AND TIME SUMMARY FOR

GEOPHYSICAI TECHNIQUES

IN SITE CHARACTERIZATION

Approximate

Cost

SEISMIC CROSSHOLE

(typical survey to about

500 feet)

DOWNHOLE SEISMIC VELOCITY

(typical survey to about

500 feet)
$\$ 34,000-39,000(1)$

4-5 weeks (2)
Approximate

Time

2-3 weeks (2)

RADAR OR SONAR

(from pilot excavation)

$\$ 5,500(3)$

3 days $(3)$

\section{NOTES:}

(1) Includes drilling costs.

(2) Turn around time for results from beginning field work. Does not include mobilization.

(3)

Typical cost and field time for set of radial probings from single test room. Only a few sources provide radar or sonar services commercially. Both services are available from Rock Probers, Inc. (c/o Dr. R. R. Unterberger, Texas A \& M Univ.). Xadar Corporation, formerly Ensco, Inc. (Springfield, Virginia) provides radar. Typical daily rates are $\$ 1,500$ (Rock Probers, 2 or 3 man crew) to $\$ 1,750$ (Ensco, 2 man crew) for a minimum of three days, not including travel. Following initial setup and calibration numerous probes can be done in a day. Ensco estimates that lateral probes can be done along a tunnel at 1000 to 2000 feet per day. Actual duration of work in pilot excavations would depend on their layout and extent, and on the need to recalibrate radar velocities due to variations in the medium. (J. Fowler, 1981, personal communication, and R. R. Unterberger, 1981, personal communication). 
TABLE $7.3 .4-5$

COST AND TIME SUMMARY FOR

HYDROLOGIC TECHNIQUES

IN SITE CHARACTERIZATION

\begin{tabular}{lcc}
$\begin{array}{c}\text { Tests and } \\
\text { Analyses }(1)\end{array}$ & $\begin{array}{c}\text { Approximate } \\
\text { Cost Range (2) }\end{array}$ & $\begin{array}{c}\text { Approximate } \\
\text { Turn around } \\
\text { Time }(3)\end{array}$ \\
\hline INJECTION TESTS & $\begin{array}{c}\$ 20,000-50,000 \\
\text { per test } \\
\text { STRADDLE PACKER TESTING }\end{array}$ & $5-15$ days \\
TRACER TESTS & $\begin{array}{c}\$ 10,00-25,000 \\
\text { per test } \\
\$ 20,000 \text { or more } \\
\text { per test interval }\end{array}$ & $\begin{array}{l}\text { Time until } \\
\text { detection } \\
\text { depends on } \\
\text { site conditions }\end{array}$ \\
& &
\end{tabular}

FLOW SYSTEM MODELING

Without fracture flow

2 dimensional

$\$ 20,000$

2-4 weeks

3 dimensional

$\$ 30,000$

3-6 weeks

With fracture flow

2 dimensional

$\$ 50,000$

5-10 weeks

3 dimensional

$\$ 75,000$

7-15 weeks

\section{NOTES :}

(1) Described in Appendix G

(2) These tests are typically designed for particular site conditions in characterization. Costs are determined by test design and duration.

(3) Times for hydrologic tests are determined by site conditions and may vary significantly. 
COST AND TIME SUMMARY FOR

GEOMECHANICS TECHNIQUES

IN SITE CHARACTERIZATION (1)

Tests $^{(2)}$

HYDROTHERMOMECHANICAL

IN SITU BLOCR TEST

\section{LABORATORY TRIAXIAL CREEP} TESTING (per set of tests)

IN SITU UNIT CELL

SINGLE CANISTER HEATER TEST (performed along with unit cell)

LARGE SCALE HEATER TESTS

FLAT JACR CREEP TESTS

(in situ program)

LARGE-SCALE LABORATORY TESTS

ON $1 \mathrm{~m}^{3}$ BLOCKS

using electric heaters

and flat jack loading
Approximate Cost (3)
Approximate

Duration (3)

$$
\$ 700,000-800,000 \quad 9-15 \text { months }
$$

$$
\begin{array}{cc}
\$ 10,000-15,000 & 4-8 \text { weeks } \\
\$ 250,000-400,000 & 2-3 \text { years } \\
\$ 200,000 & 2-3 \text { years }
\end{array}
$$

$$
\begin{array}{ll}
\$ 400,000-600,000(4) & 2-3 \text { years } \\
\$ 300,000(5) & 2-3 \text { years }^{(6)}
\end{array}
$$

$\$ 30,000(7)$

variable
per test
design

NOTES:

(1) Geomechanical testing for site characterization involves test programs designed for particular information needs and site specific conditions. Costs and times will vary according to test design.

(2) Descriptions in Appendix E-2

(3) Costs and times for in situ tests do not include excavation of test room.

(4) Additional tests may be run concurrently at reduced unit cost.

(5) Series of 8 tests. Additional tests at reduced unit cost.

(6) Assumes approximately 1 year per test with staggered schedule.

(7) Cost is indicated for short duration test. Costs for longer duration creep tests would be higher. 
TABLE $7.3 .4-7$

COST AND TIME SUMMARY FOR

SEISMOTECTONIC TECHNIQUES

IN SITE CHARACTERIZATION (1)

Tests

PRECISE LEVELING

MONITORING NETWORK (2)

Installation (3)

Operation(4)

Approximate
Cost

$\$ 350 / \mathrm{km}$

$\$ 15,000$

$\$ 6,500$
Approximate

Duration

3 to $3.5 \mathrm{~km} /$ day

about 1 month

2 weeks

NOTES:

(1) Data from ERTEC AIRBORNE SYSTEMS, personal communication (1981).

(2) Monitoring network will consist of about 16 triangulation points in $100 \mathrm{sq} . \mathrm{km}$.

(3) Installation cost is one time only and does not include costs of instruments.

(4) Operation cost is for one time monitoring and should periodically be repeated. It consists of multiwavelength distance measuring (MWDM), laser ranging, and includes tiltmeter, strainmeter or extensometer instrumentation. Theodolite, such as wild T3, may be used to measure angles within 0.1 of a second. 
The following criteria to evaluate data adequacy are based on the geologic description of salt dome (Section 7.3.1), information needs (Section 7.3.2) and application of techniques (Section 7.3.3) during site characterization. The criteria are generally the same as for precharacterization although some differences in detail occur.

Because the pilot shaft, test room(s), and exploratory drifts would provide in situ testing and exploration opportunities during site characterization, additional information needs and new techniques may be involved.

The following subsections will only describe criteria related to the exploration and testing techniques which will generally be appropriate to fulfill the additional information needs of each major technical discipline (i.e., geology, hydrology, geochemistry, geomechanics, seismotectonics, and resources) during site characterization. Criteria related to the information needs previously discussed in precharacterization will not be repeated. Limitations or problems which may exist in applying the various techniques to the information needs during site characterization will be described.

\subsubsection{Geology}

The specific geologic information needs for site characterization in a salt dome and the techniques applied to satisfy them are:

- Geometry of dome flanks - drilling and coring, geophysical radar measurement, mechanical acoustic (sonar) measurements

- Lithology of salt - subsurface mapping, in situ observation and testing in the pilot shaft and test room, $\overline{d r} \overline{i l l i n g}$ and coring, laboratory tests

- Lithology of cap rock - drilling and coring and laboratory tests, in situ observation and testing in the pilot shaft

- Lithology of shale sheath - directional drilling and coring, borehole logging

- Mineralogy and textural variation of salt - in situ observation in the pilot shaft and test room(s), sampling and laboratory tests, drilling and coring and laboratory tests 
- Mineralogy and textural variation of cap rock - in situ observation in the pilot shaft, sampling and laboratory tests, drilling and coring and laboratory tests

- Mineralogy and Textural variation of shale sheath - directional drilling and laboratory tests

- Structural condition of salt - in situ observation and subsurface geologic mapping in the pilot shaft and test room(s), drilling and oriented coring

- Collapse and caving potential of salt - in situ observation and subsurface geologic mapping in the pilot shaft and test $\operatorname{room}(s)$

- Cleavage and schistosity of salt - in situ observation, subsurface geologic mapping in the pilot shaft and test room(s), drilling and coring

- Cleavage and schistosity of the cap rock - in situ observation and excavation logging in the pilot shaft, drilling and coring

- Isotropic condition of salt - in situ observation in the pilot shaft and test room(s), driling/coring and laboratory tests

- Exotic blocks - arilling and coring, radar measurements, mechanical, acoustic (sonar) measurements

- Stratigraphy of cap rock - in situ observation and excavation logging in the pilot shaft, drilling and coring

- Fractures of cap rock - in situ observation in the pilot shaft, drilling and coring

- Existence and extension of shale sheath - directional drilling and coring, borehole logging

- Thickness of the shale sheath - directional drilling and coring, borehole logging

Applicability of the above-mentioned techniques in detailed geologic investigation of the salt dome is highly dependent on local conditions. For instance, in moist salt, radar waves are attenuated and the range of probing is reduced drastically, so application of radar techniques depends on the hydrological condition of the salt dome. The applicability of some of the techniques also depends on integration of data

$$
\text { 7-95 }
$$


from other techniques. For instance, the applicability of the radar and sonar systems to evaluate the shale sheath depends on the thickness and the hydrological condition of the shale sheath.

Resolution and reliability of the aforementioned techniques also depends on operators, instruments and working conditions. The actual level of resolution in subsurface geologic mapping will vary according to the design of the survey, depth of interest, and geologist's experience. The resolution and reliability of the laboratory tests depends on the laboratory equipment, test method, and actual sample condition.

As discussed in Appendix B-2, the minimum size of features that can be detected by radar, sonar, or other geophysical technique depends on the layout of the energy source and receivers, and frequency of energy used.

Drilling and coring is one of the principal tools for site characterization, but the resolution and reliability of this technique can be affected by geologic and hydrologic conditions of the section drilled. Length and diameter of core barrels and minimum curvature radius are the principle elements in designing a directional drilling test program. The resolution in oriented coring may vary considerably depending on rock type and the equipment used. Horizontal, inclined, vertical, and directional drilling is expected to be done from the test room(s) and the exploratory drifts.

\subsubsection{Hydrology}

The specific hydrologic information needs for site characterization in a salt dome and the techniques applied to satisfy them are:

- Brine pockets in salt - electric logs, radar and sonar measurements, drilling

- Brine inclusion in salt - in situ sampling in the pilot shaft and test room(s), drilling and coring, laboratory tests

- Brine age in salt - sampling and laboratory tests (age dating)

- Relation between different brine pockets in salt - tracer tests, age dating, water-rock reaction, stable isotope tests

- Capillary movement or migration of fluids in salt - sampling and laboratory tests 
Dissolution process and rates in salt - aquifer tests around the dome; numerical modeling for salinity, drilling, borehole logging, tracer tests

$\circ$ Age of water in the cap rock - age dating, laboratory tests

Fracture permeability of the cap rock - in situ observation in the pilot shaft and sampling, laboratory tests on hand samples and cores

- Dissolution and voids in the cap rock - in situ oservation in the pilot shaft, water quality sampling and testing

- Detailed porosity and permeability of the shale sheath - drilling and coring, laboratory tests

- Flow path in the shale sheath - water quality sampling and testing around the dome, numerical modeling for salinity

Many of the above-mentioned hydrologic information needs are similar to those already discussed in precharacterization except that a much higher degree of precision and accuracy in the information is required. In some cases, the basic techniques used to solve a similar problem in two different elements of a salt dome may be different. For instance, the techniques used to understand flow paths in the shale sheath are different from those applied to understand flow paths in the cap rock. Therefore, the information needs and the applicable techniques related to each principal element of the salt dome have separately been discussed.

Applicability of some techniques is conditional and depends on: 1) the local geologic condition, and 2) applicability of other techniques on the other information needs. For instance, permeability and porosity testing in the shale sheath would depend on the possibility of coring the shale sheath.

For site characterization, the hydrologic research should be focused on understanding the problems which are important for the design and performance of the repository, and any adverse effects of the existing hydrologic condition on the repository should be studied. 


\subsubsection{Geochemistry}

The specific geochemical information needs for site characterization in a salt dome and the techniques applied to satisfy them are:

- Geochemical properties of salt mass, regarding retardation, diffusion, precipitation and filtration, and variation with temperature - in situ tests, laboratory tests

- Geochemical properties of cap rock, regarding retardation, diffusion, precipitation and filtration, and variation with temperature - in situ tests, laboratory tests

- Geochemical properties of shale sheath, regarding retardation, diffusion, precipitation, and filtration, and variation with temperature - laboratory tests

Geochemical properties of rock units in the overburden and the surrounding area regarding retardation, diffusion, precipitation, and filtration, and variation with temperature - in situ tests, drilling, coring

- Chemistry of brine (in the salt mass) - in situ tests, laboratory tests

- Chemistry of brine inclusions - in situ sampling, laboratory tests

- Chemistry of gas inclusions - in situ sampling, laboratory tests

- Geochemical reactions between rocks and sealing materials in boreholes and shafts regarding plug longevity - rock sampling and laboratory tests

- Salt/canister geochemical reaction - in situ testing, laboratory testing

- Brine/canister geochemical reaction - in situ testing, laboratory testing

- Salt/overpack geochemical reaction - laboratory testing

- Brine/overpack geochemical reaction - laboratory testing

- Salt/waste geochemical reaction - laboratory testing

- Brine/waste geochemical reaction - laboratory testing 
The laboratory tests on salt should consider both dry and wet conditions, and the presence of gas inclusions which might change the salt mass properties during different laboratory tests. Correct sampling of salt, brine, brine and gas inclusion, and other materials is critical.

Whenever a similar test is performed in both laboratory and field (in situ), the laboratory/field test comparison (ratio) should be recorded, to estimate in situ test results based on laboratory tests. This technique particularly applies to quantifying radionuclide transport potential along a cap rock or overburden (other than shafts) flow path.

Many laboratory tests are simple chemical tests, but some, such as measurement of retardation, diffusion, precipitation, filtration and similar tests, require complex chemical and physical tests (Appendix F-2). Similarly in situ testing consists of a combination of special chemical, geochemical, geomechanical and physical tests, dictated by geological conditions of site.

It should be noted that the results of a geochemical research typically consists of two parts: description and evaluation of reactions. As described in Appendix F-2, reliability and resolution of the technique depends on how much descriptive work has been involved in that technique.

\subsubsection{Geomechanics}

During site characterization, the topic of concern is a determination of in situ responses of the salt mass within the salt dome to thermal and mechanical stresses. In this regard, the specific information needs and the techniques applied to satisfy them are:

- Creep behavior

- Deformation, displacement

- Stress field from mechanical loading

- Plasticity

- Spalling and fracturing

- Specific heat

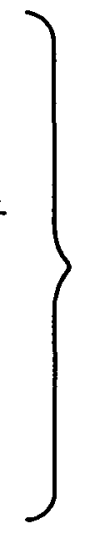

Flatjack loading (field

scale test) with regard

to variable temperature,

laboratory tests 


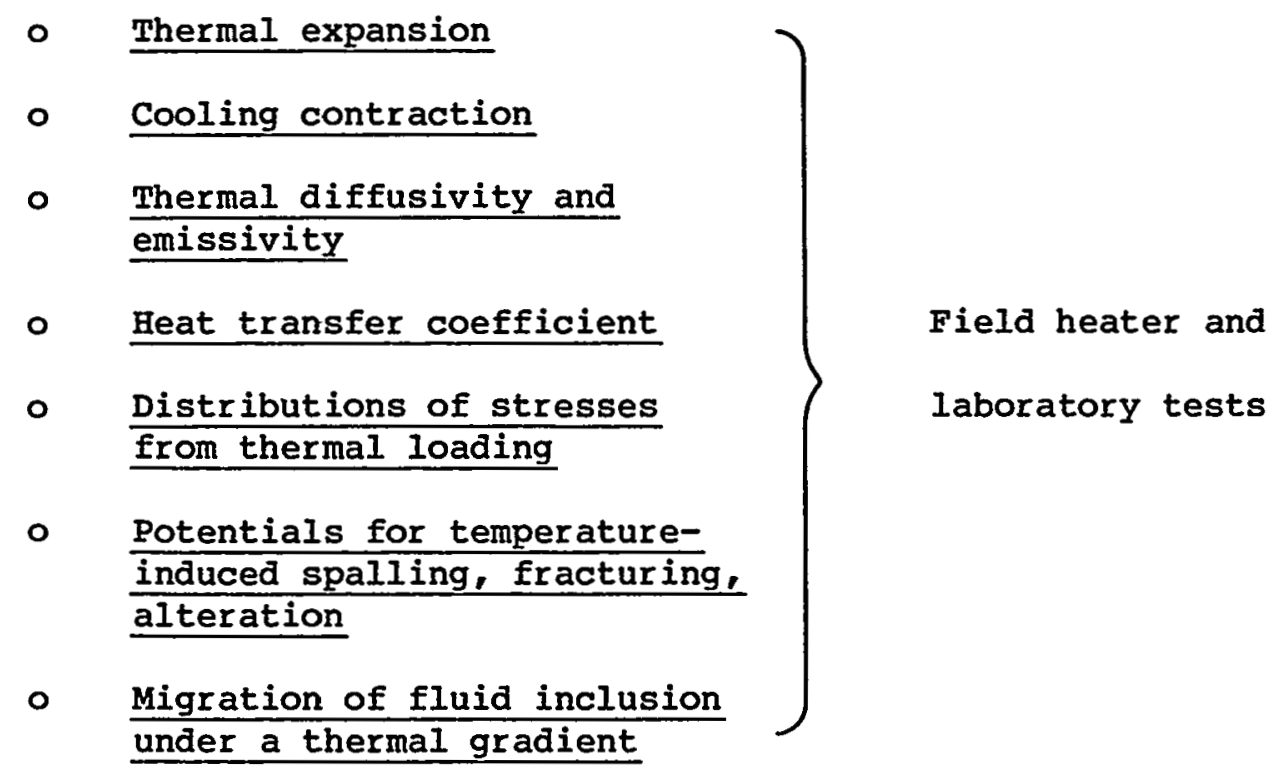

In situ tests on some of these items should include both normal and heated conditions. Although precharacterizaiton studies included most (if not all) of these parameters, these tests were done on cores in the laboratory. However, because the thermal and geomechanical behavior of salt depends to some extent on impurities, which vary from place to place within the salt dome, an in situ test is necessary. As previously noted, whenever a single test could be performed in both laboratory and field (in situ), the laboratory/field test ratio should be recorded.

The geomechanical and thermal properties of salt from the pilot shaft and test room(s) may not accurately represent salt properties in other parts of the salt dome, and consequently a series of boreholes (horizontal, inclined, vertical and directional) should be drilled from the test room. The laboratory/field test ratio would help to estimate the results of the in situ tests in those boreholes.

\subsubsection{Seismotectonics}

Criteria related to seismotectonics are described in the precharacterization section of this report. Information needs relative to salt movement and the techniques appropriate for resolving them are listed below.

- Rotational movement of the ground surface - tiltmeter instrumentation, triangulation network 
- Horizontal movements - laser ranging, multiwave length distance measuring (MWDM), triangulation network

- Vertical movements - precise leveling, strainmeter or extensometer instrumentation

- Active fracturing in salt (acoustic emission) - microseismic monitoring

This instrumentation should detect small movements of salt. Meanwhile monitoring of seismograph networks emplaced during precharacterization will continue.

\subsection{REFERENCES}

Abel, J.F., 1969, Rock mechanics - Can it pay its way? Northern Ohio Geologic Society, Third Symp. on Salt, Vol. 2, pp. 197-207.

Ala, M. A., 1974, - Salt Diapirism in Southern Iran - Am. Assoc. Pet. Geol. Bull., Vol. 58, no. 9, pp. 1758-1770.

Anderson, R. E., D. H. Eargle, and R. O. Davis. 1973. . Geologic and Hydrologic Summary of Salt Domes in Gulf Coast Region of Texas, Louisiana, Mississippi and Alabama, U.S. Geological Survey. Open-File Report 4339-2, U.S. Geological Survey.

Anthony, T.R. and Cline, H.E., 1973, Thermomigration of liquid droplets in salt: Northern Ohio Geologic Society Fourth symp. on Salt, Vol. 1, pp. 313-321.

Baar, C.A., 1977, Applied salt-rock mechanics $I$, the in situ behavior of salt rocks: Elsevier, Amsterdam.

Belchic, Harriet C., 1960, The Winnfield Salt Dome, Winn Parish, Louisiana, Guide Book, 1960 Spring Field Trip, Shreveport Geological society.

Cameron, Harriet, 1949, The Winnfield Louisiana Salt Dome, M.S. Thesis, Louisiana State University.

Claiborne, H.C., Rickertson, L.D., and Graham, R.F., 1980, Expected environments in high-level nuclear waste and spent fuel repositories in salt: Oak Ridge National Laboratory, Report No. ORNL/ TM-7201. 
Clark, S. P., Jr., 1966, Handbook of physical constants: Geol. Soc. Am. Memoir 97.

Contreras, H., and M. Castillon, 1968 - Morphology and origin of salt domes of Isthmus of Tehuantepec, in J. Braunstein and G. D. O'Brien, eds., Diapirism and diapirs: Am. Assoc. of Pet. Geol. Memoir 8, pp. 244-260.

DOE, 1980, Statement of position in the matter of proposed rule-making on the storage and disposal of nuclear waste: PR-50,51 (44FR61372) : DOE/NE-0007

Durham, C. O., Jr., 1979, A review of salt-dome evaluations: ONWI-62, pp. 77-78.

Guevara, E. H. and Giles, A. B., 1979, Upper Cretaceous - Lower Eocene strata, Haineville, Keechi, and Oakwood salt domes, east Texas: Transactions - Gulf Coast Assoc. of Geol.

Gussow, W. C., 1968, Salt diapirism: importance of temperature and energy source of emplacement, in J. Braunstein and G. D. O'Brien, eds., Diapirism and diapirs: Am. Assoc. of Pet. Geol. Memoir 8, pp. 16-52.

Hansen, F.D. and Carter, N.L., 1980, Creep of rock salt at elevated temperature, RE/SPEC., 21st U.S. Symp. on Rock Mech., Univ. of Missouri at Rolla.

Heard, H.C., 1972, Steady-state flow in polycrystalline halite at pressure of 2 kilobars: AGU Geophysical Monograph 16, pp. 191209.

Herness, S.K., 1977, Subsurface representation in mining geology, in, LeRoy, L.W., LeRoy, D.O., and Raese, J.W., eds., Subsurface geology: Colorado School of Mines, Golden, Colorado, pp. 529-539.

Hoda, B. and Barlow, R. A., 1977, Geohydrologic studies of Mississippi salt domes, in, Martinez, J. D., Thoms, R. L., Smith, C. G., Jr., Kolb, C. R., Newchurch, E. J., and Wilcox, R. E., eds., An Investigation of the utility of Gulf coast salt domes for the storage or disposal of radioactive wastes: Office of Nuclear Waste Isolation, Report No. Y/OWI/SUB-4112/37, pp. 129-155.

Holdoway, K.A., 1973, Behavior of fluid inclusions in salt during heating and irradiation: Northern Ohio Geologic Society Fourth Symp. on Salt, Vol. 1, pp. 303-312. 
Hoy, R.B. and O'Neill, Jr., B.J., 1960, Investigation of on-site inspection techniques for high explosive tests in a salt dome, Final Report, Project Cowboy, winnfield, Louisiana. Stanford Research Institute report for U.S. Atomic Energy Commission. SRI Project No. SU-2993.

Hoy, R.B., Foose, R.M. and O'Neill, Jr., B.J. 1962, Structure of Winnfield Salt Dome, Winn Parish, Louisiana, Am. Assoc. Pet. Geol. Bull. $46(8)$, pp. 1444-1459.

Humphris, C. C., Jr., 1978, Salt movement on continental slope, northern Gulf of Mexico, in, Bouma, A. H., Moore, G. T., and Coleman, J. M., eds., 1978, Framework, facies and oil-trapping characteristics of the upper continental margin: Am Assoc. Pet. Geol. Studies in Geology No. 7, pp. 69-86.

Huggett, G.R., 1977, High precision measurement of horizontal and vertical movement over salt domes; in Martinez, J.D. and Thoms, R.L., ed., Salt-dome utilization and environmental considerations, a symposium, Institute for Environmental Studies, Louisiana State University, Baton Rouge, Louisiana, pp. 352-365.

James, G. A., and J. G. Wynd, 1965 - Stratigraphic nomenclature of Iranian Oil Consortium Agreement Area: American Association of Petroleum Geologists Bulletin, Vol. 49, pp. 2182-2245.

Jockwer, N., 1979, Investigation of the migration and release of water within rock salt: Proceedings of US/FRG Bilateral Workshop, Waste Isolation Performance Assessment and In Situ Testing, ONWI-88, pp. 392-396.

Johnson, Kenneth S. and Serge Gonzales, 1978, Salt deposits in the United states and regional geologic characteristics important for storage of radioactive waste: Office of Nuclear Waste Isolation Report No. Y/OWI/SUB-7414/1.

Kelley, R. K., 1960, Contributions to the data on theoretical metallurgy: XIII. High-temperature heat-content, heat-capacity, and entropy data for the elements and inorganic compounds: U.S. Bur. Mines Bull. 584 .

Kent, P. E., 1958, Recent studies of south Persian salt plugs: Am. Assoc. of Pet. Geol. Bull., Vol. 42, no. 12, pp. 2951-2972.

Kreitler, C. W., Agagu, O. K., Basciano, J. M., Collins, E. W., Dix, O., Dutton, S. P., Fogg, G. E., Giles, Guevara, E. H., Harris, D. W., Holiday, D. K., McGowen, M K., Pass, D., and Wood, D. H., 1980, Geology and geohydrology of the East Texas Basin: Texas Bureau of Economic Geology, Geological Circular No. 8012.

$$
7-103
$$


Rumar, M. B., 1977, Growth rates of saltdomes of the north Louisiana salt basin, in, Martinez, J.D., Thomas, R.L., Smith, C.G., Jr., Kolb, C.R., Newchurch, E.J. and Wilcox, R.E., eds., An Investigation of the utility of gulf coast salt domes for the storage or disposal of radioactive. wastes: Office of Nuclear Waste Isolation, Report No. Y/OWI/SUB-4112/37, pp. 225-270.

Kupfer, D.H., 1962, Structure of salt in Gulf Coast domes, in Bersticker, A.G., ed., (First) Symposium on Salt. Northern ohio Geological Society, Inc., Cleveland, Ohio, pp. 104-123.

Rupfer, D.H., 1973, Boundary Shear zones in Salt Stocks, in Fourth Symposium on Salt, Vol. 1, Coogan, A.H., ed: Northern Ohio Geological Society, Inc., Cleveland, Ohio, pp. 215-225:

Kupfer, D.H., 1976, Time and rates of salt movement in north Louisiana, in Martinez, J.D. and Thoms, R.L.; ed., Salt-dome utilization and environmental considerations, a symposium, Institute for Environmental Studies, Louisiana State University, Baton Rouge, Louisiana, pp. 145-170.

Kupfer, D.H., 1979, Problems associated with anomalous zones in Louisiana Salt Stocks, USA, in Coogan, Alan H. and Hauber, Lukas (eds.) Fifth Symposium on Salt, Vol. 1, The Northern Ohio Geological Society, Inc., pp. 119-134.

Lees, G. M., 1927, Salzgletscher in Persien: Vien, Mitt. Geol. Gesell., Vol. 20, pp. 29-34.

Loocke, J. E., 1978, Growth history of the Hainesville salt dome, Wood County, Texas: Univ. Texas, Austin, M.A. thesis.

Lotze, F., 1957, Steinsalz and Kalisalze, Pt. I, 466 p., Gebruder Borntraeger, Berlin

Martinez, J.D., 1973, Tectonic Behavior of Evaporites, in Fourth Symposium on Salt, Vol. 1, Coogan, A.H., ed.: Northern Ohio Geological Society, Inc., Cleveland, Ohio, pp. 155-168.

Martinez, J.D., 1975, Hydrologic stability studies--A perspective, in Martinez, J.D., Kupfer, D.H., Thoms, R.L., Smith, C.G., Jr. and Kolb, C., eds. An investigation of the utility of Gulf Coast salt domes for the storage or disposal of radioactive wastes: Oak Ridge National Laboratory, Report No. ORNL-SUB-4112-10, pp. 111-118. 
Martinez, J.D. and others, 1976, An Investigation of the utility of Gulf Coast salt domes for the storage or disposal of radioactive wastes: Oak Ridge National Laboratory, Report ORNL-SUB4112-25, pp. 317-320.

Martinez, J.D. and Thoms, R.I., 1977, Hydrologic isolation of mined openings in salt domes in Martinez, J.D., Thoms, R.I., Smith, C.G. Jr., Kolb, C.R., Newchurch, E.J. and Wilcox, R.E., eds., An Investigation of the utility of gulf coast salt domes for the storage or disposal of radioactive wastes: Office of Waste Isolation, Report Y/OWI/SUB-4112/37, pp. 161-204.

Martinez, J.D. and others, 1979, An Investigation of the utility of gulf coast salt domes for the storage or disposal of radioactive wastes: Institute for Environmental Studies, Louisiana State University, ES11-02500-A-1, 572 p.

Martinez, J. D. and Rovik, J. E., 1977, Caprock studies, in, Martinez, J.D., Thoms, R.L., Smith, C.G. Jr., Kolb, C.R., Newchurch, E.J. and Wilcox, R.E., eds., An Investigation of the utility of gulf coast salt domes for the storage or disposal of radioactive wastes: Office of Waste Isolation, Report Y/OWI/SUB-4112/37, pp. 157-160.

Mattern, J. C., Pervich, M. P., Weigand, F. I., and Wrenshall, R. B., 1979, Description of an NWTS facility for reprocessing waste in domed salt: ONWI-62, pp. 215-218.

Meyerhoff, A. A., and C. W. Hatten, 1968 - Diapiric structures in Central Cuba, in J. Braunstein and G.D. O'Brien, eds., Diapirism and diapirs: $\mathrm{Am}$. Assoc. of Pet. Geol. Memoir 8, pp. 315-357.

Nettleton, L. L., 1934, Fluid mechanics of salt domes: Am. Assoc. Petroleum Geologists Bull., Vol. 17, pp. 1175-1204.

Nettleton, L. L., 1943, Recent experimental and geophysical evidence of mechanics of salt-dome formation: Am. Assoc. Pet. Geol. Bull., Vol. 27, pp. 51-63.

, 1955, History of concepts of Gulf Coast salt dome formation: Am. Assoc. Petroleum Geologists Bull., Vol. 39, pp. 23732383.

and Elkins, T. A., 1947, Geologic models made from granular materials: Am. Geophys, Union Trans., Vol. 28, pp. 451-466.

Obert, L., and Duvall, W.I., 1967, Rock mechanics and the design of structures in rock, John wiley \& Sons, Inc., pp. 582-610. 
Ode, H., 1962, Review of mechanical properties of salt relating to salt dome genesis: Geol. Soc. Am. Spl. Paper 88, pp. 543-596.

ONWI, 1981, Evaluation of area studies of the U.S. Gulf Coast Salt dome basins: Draft technical report, March 31, 1981, ONWI-109.

Parker, T. J., and A. N. McDowell, 1955 - Model Studies of Salt-Dome Tectonics.- Am. Assoc. of Pet. Geol. Bull., Vol. 39, no. 12, pp. 2384-2470.

Paulson, O. I., Jr., 1977, "Sub-salt origin of salt dome caprock", Transactions of the Gulf Coast Association Geological Society, Vol. 27, pp. 134-138.

Pierce, W. G. and Rich, E. I., 1962, Summary of rock salt deposits in the United States as possible storage sites for radioactive waste materials: U.S. Geol. Survey Bull. 1148.

Powers, D. W., Lambert, S. J., Shaffer, S-E, Hill, L. R., and Weart, W. D. , eds, 1978, Geological characterization report, Waste Isolation Pilot Plant (WIPP) site, southeastern New Mexico: SAND 78-1596.

Rothfuchs, T., 1979, Asse II in situ brine migration tests: Proceedings US/FRG bilateral workshop, waste isolation performance assessment and in situ testing, ONWI-88, pp. 385-391.

Sannemann, D., 1968 - Salt-stock families in northwestern Germany, in J. Braunstein and G. D. O'Brien, eds., Diapirism and diapirs: Am. Assoc. of Pet. Geol., Memoir 8, pp. 261-274.

Sappenfield, L. W., and Schroeder, E. R., 1968 - Iza, an unusual diapir in northern Spain, in J. Braunstein and D. G. O'Brien, eds., Diapirism and Diapirs: Am. Assoc. of Pet. Geol., Memoir 8, pp. 293-300

Shefelbine, H.C. and Raines, G.E., 1980, Fluid migration studies in salt, in Proceedings of the 1980 national waste terminal storage program information meeting: U.S. Department of Energy, Office of Nuclear Waste Isolation, pp. 358-361.

Smith, C.G., Jr., 1976, Hyarologic stability of salt domes, in Proceedings of a symposium held at Louisiana State University, Martinez, J.D. and Thoms, R.I., eds.: The Institute for Environmental Studies, Louisiana State University, pp. 188-198.

Smith, A. R., 1978, Sulfur deposits in Ochoan rocks of southwest New Mexico and west Texas: New Mexico Bureau Mines and Mineral Resources Circ. 159, pp. 71-77. 
Stewart, R.D. and Unterberger, R.R., 1976, Seeing through rock salt with radar: Geophysics, Vol. 41, pp. 123-132.

Stocklin, J., 1968, Salt deposits of the Middle East: Geol. Soc. Am. Special Paper 88, pp. 158-181.

Teichmuller, R., 1958, Das Oberflachenbild des Salzdomes von segeberg in Holstein, Zeits. Deutsh. Geol. Ges., Vol. 98, pp. 7-29.

Thoms, R.L., 1975, Instrumentation for monitoring dome movement, in Martinez, J.D., Kupfer, D.H., Thoms, R.L., Smith, C.G., Rolb, C.R. eds., An investigation of the utility of Gulf Coast salt domes for the storage or disposal of radioactive wastes: Oak Ridge National Laboratory, Report No. ORNL-SUB-4112-10.

Thoms, R.I. and Martinez, J.D., 1979 - Blowouts in domal salt, in Coogan, A. H. and Hauber, L., eds., Fifth Symposium on Salt, Vol. 1, The Northern Ohio Geological Society, Inc., pp. 405-411.

Tresh, M.I. and Friedman, G.M., 1973, Sabkha deposition of the Salina Group (Upper Silurian) of New York state: Northern Ohio Geological Society Fourth Symp. on Salt, Vol. 1, pp. 35-46.

Trusheim, F., 1960, Mechanism of salt migration in northern Germany. American Association of Petroleum Geologists Bulletin, Vol. 44, no. 9, pp. 1519-1540.

U.S. Department of Energy, 1981, Geologic disposal of radioactive waste: Program plan for field tests in salt: DOE/NWTS-80(2).

Unterberger, R.R., 1979, Radar and sonar probing of salt: Northern Ohio Geological Society Fifty Symp. on salt, Vol. 1, pp. 423-437.

Walker, C. W., 1974, Nature and origin of caprock overlying Gulf Coast salt domes, in Fourth Symposium on Salt, Volume One, Coogan, A. H., ed.: Northern Ohio Geological Society, Inc., Cleveland, Ohio, pp. $\overline{169-195 . ~}$ 


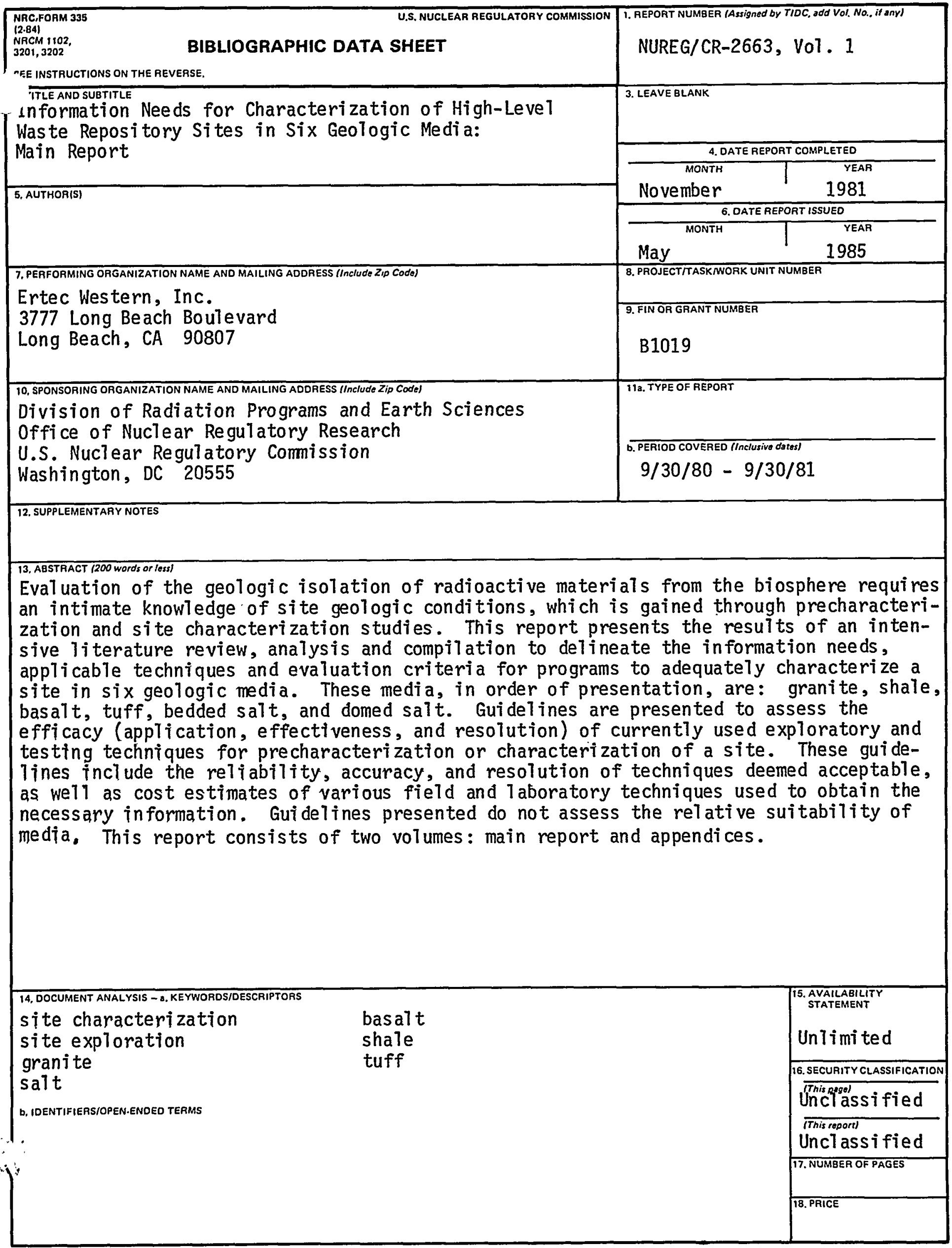

